\title{
SIMPLIFIED METHOD OF ANALYSIS FOR ADJACENT PRECAST "DECK FREE" CONCRETE BOX BEAMS USED IN ACCELERATED BRIDGE CONSTRUCTION
}

\author{
by \\ Masrra Jajjawi \\ B.Eng, Ryerson University, Canada, 2014
}

A Thesis

Presented to Ryerson University

In partial fulfillment of the

Requirement for the degree of

Master of Applied Science

In the program of

Civil Engineering

Toronto, Ontario, Canada, 2016

CMasrra Jajjawi 2016 


\section{AUTHOR'S DECLARATION}

I hereby declare that I am the sole author of this thesis. This is a true copy of the thesis, including any required final revisions, as accepted by my examiners.

I authorize Ryerson University to lend this document to other institutions or individuals for the purpose of scholarly research.

I further authorize Ryerson University to reproduce the document by photocopying or by other means, in total or part, at the request of other institutions or individuals for the purpose of scholarly research.

I understand that my thesis may be made electronically available to the public 


\author{
Simplified Method of Analysis of Adjacent Precast "Deck Free" Concrete Box Beams used \\ in Accelerated Bridge Construction \\ By \\ Masrra Jajjawi \\ Master of Applied Science \\ Department of Civil Engineering - Ryerson University \\ Toronto, Ontario, Canada, 2016
}

\begin{abstract}
The prefabricated bridge is common method in construction since it provides controlled environmental conditions and long-term durability. These adjacent precast box beams are placed side by side with $15 \mathrm{~mm}$ gaps, the top flanges connected with longitudinal shear keys poured onsite to assist in truckload distribution. Since the concrete-filled joints provide transverse shear rigidity, the load transferred from one beam to another takes place through transverse shear. A parametric study is conducted to investigate the accuracy of simplified analysis method in CHBDC for shear-connected beams to the adjacent box beams. A 3D finite-element was conducted on a wide range of box beams to obtain their magnification factors for moment and shear when subjected to truck loading. The obtained results were correlated with CHBDC and a more reliable simplified equations for distribution factors was developed. Special attention was given to the limitations of CHBDC simplified method and how it can be revised to include the adjacent box-beam.
\end{abstract}




\section{ACKNOWLEDGEMENTS}

I would like to take this opportunity to first and foremost thank God for being my strength and guide through this study.

I would like to express my gratitude to my supervisor Dr. Khaled Sennah for his great support and valuable input during my research. Dr. Sennah has been a tremendous mentor for me, his advice on both research as well as on my future career has been precious. His help and guidance is greatly appreciated.

A special thanks to my parents for being supportive of my education, words cannot express how grateful I am for all the sacrifices that they've made on my behalf their prayer for me was what sustained me thus far. Furthermore, I would like to express appreciation to my beloved fiancé who spent sleepless nights and was always my support and encouragement during this study.

The financial support from Natural Science and Engineering Research Council of Canada (NSERC), as well as Ryerson University, is greatly appreciated. 


\section{DEDICATED TO MY FAMILY}




\section{TABLE OF CONTENTS}

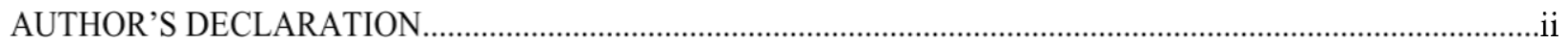

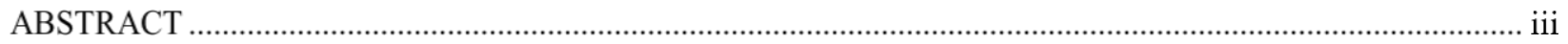

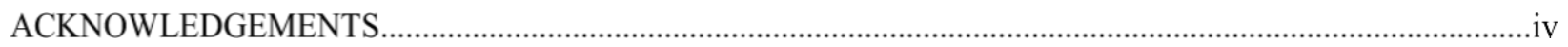

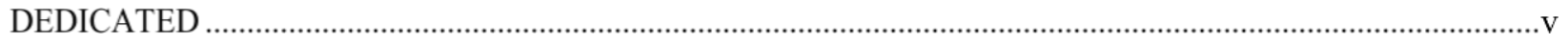

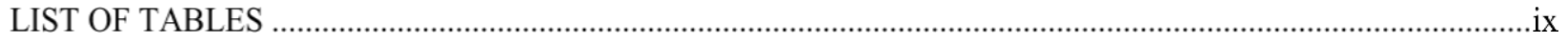

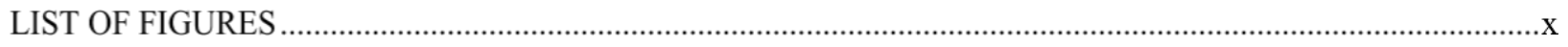

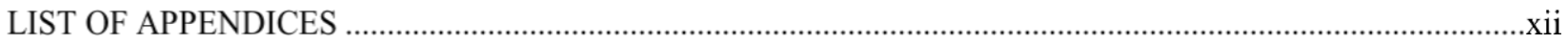

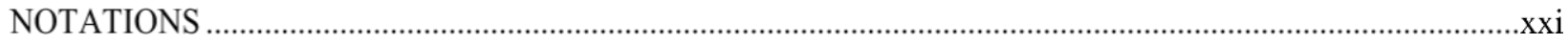

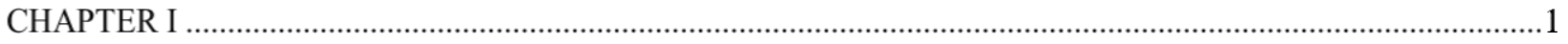

1. INTRODUCTION

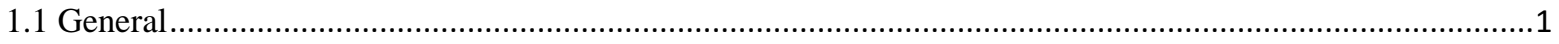

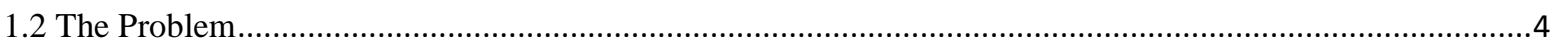

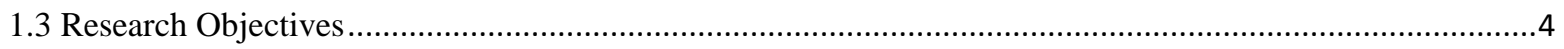

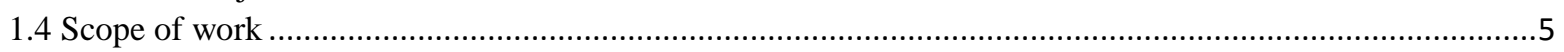

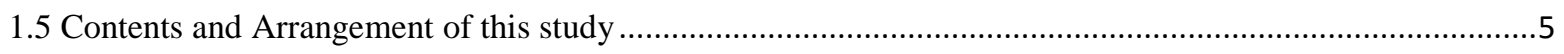

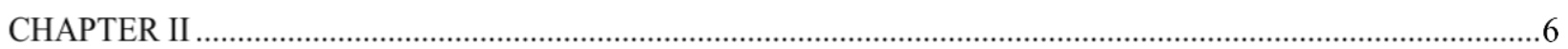

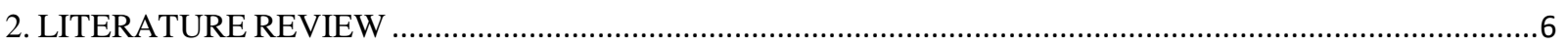

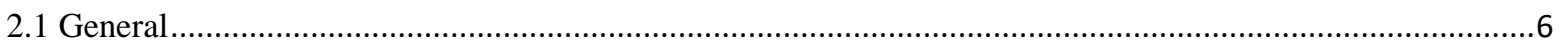

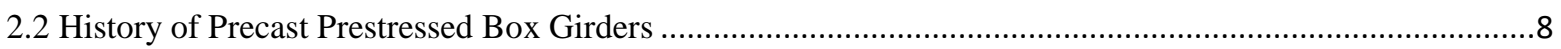

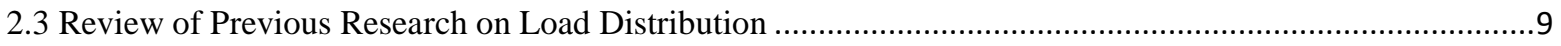

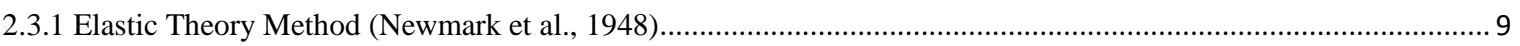

2.3.2 Orthotropic Plate Analogy (Bakht et al., 1979) ………………................................................................. 9

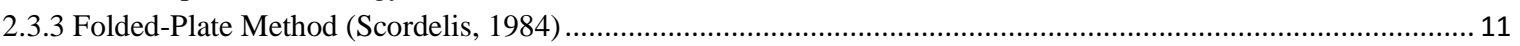

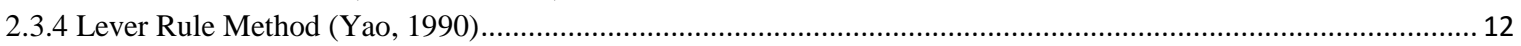

2.3.5 Hinged Joint Method for T-Shaped Girder Bridge (Yao, 1990) ……………………….................................... 12

2.3.6 Fixed Joint Girder Method (Yao, 1990) ................................................................................................ 13

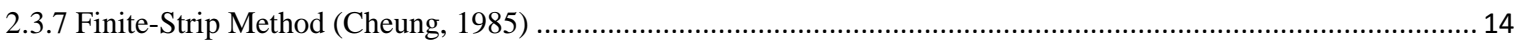

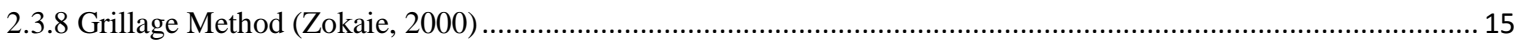

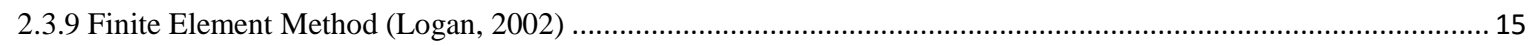

2.3.10 Experimental and Theoretical Studies ……....................................................................................... 17

2.3.11 Bridge Load Evaluation (Alberta Transportation, 2015) ……….................................................................. 18

2.4 Review of Previous Research on Transverse Shear …........................................................................19

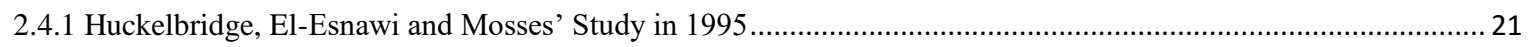

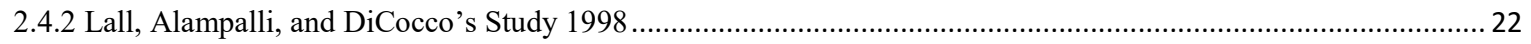

2.4.3 Transverse shear simplified method of analysis (Bakht et al., 2001).................................................................. 22

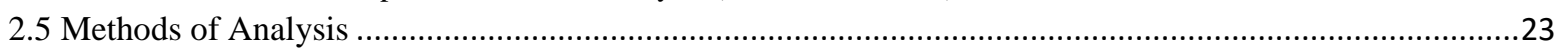

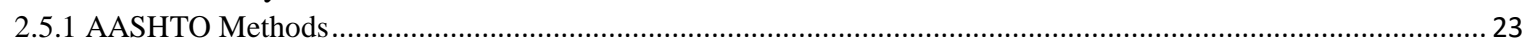

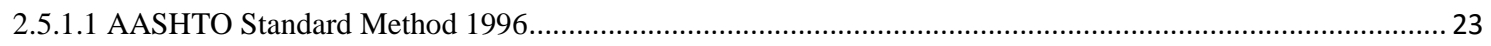

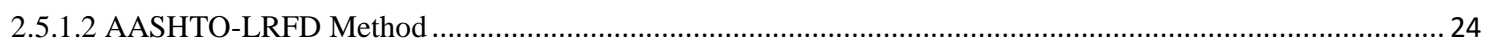

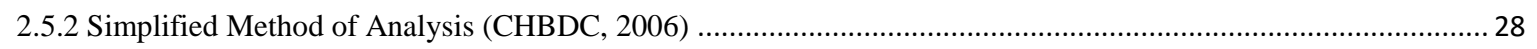

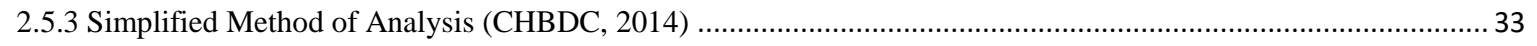




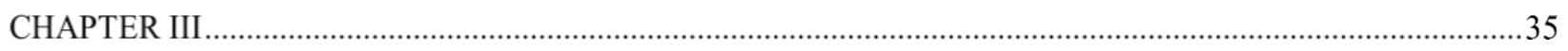

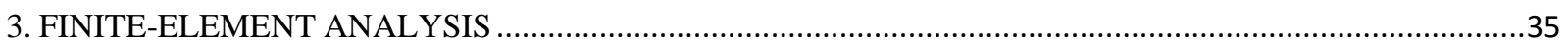

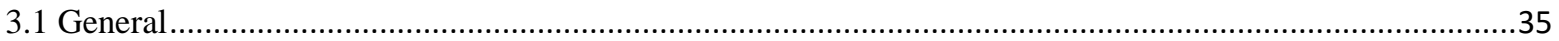

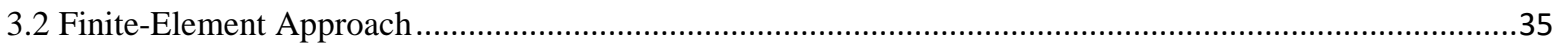

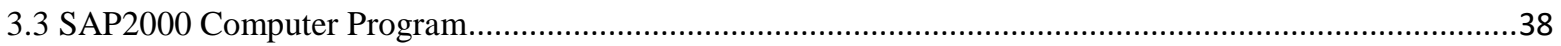

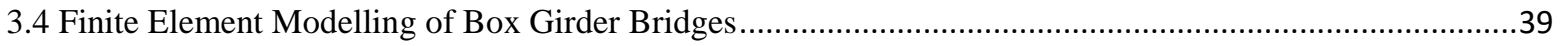

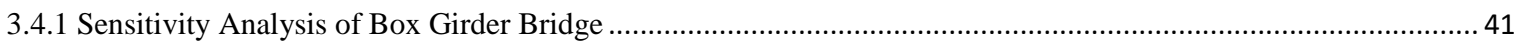

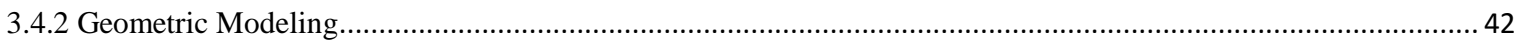

3.4.2.1 Modeling of Webs, Flanges, Connection joints, and End Diaphragms ....................................................... 42

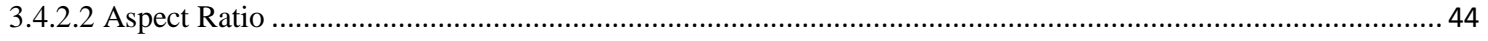

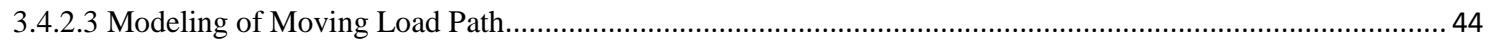

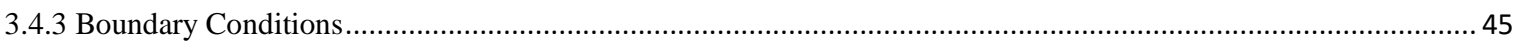

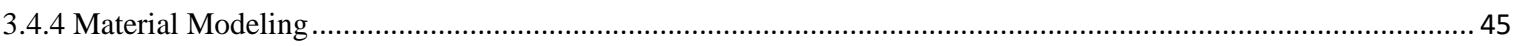

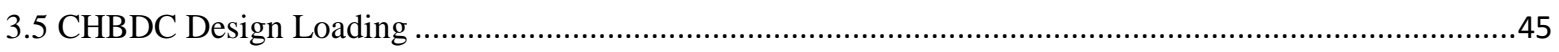

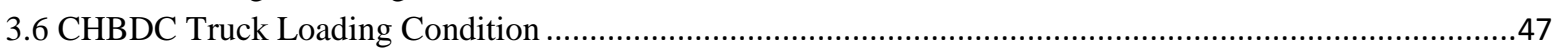

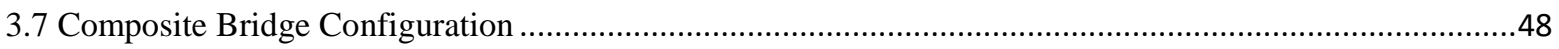

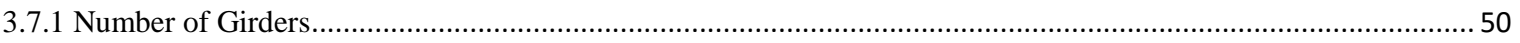

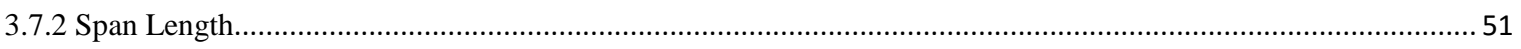

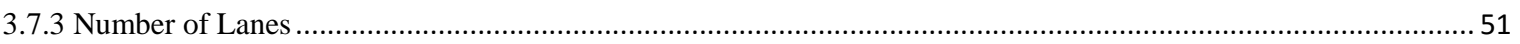

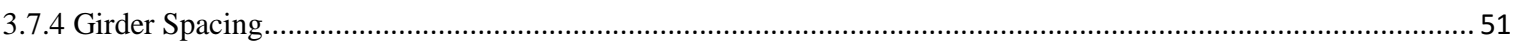

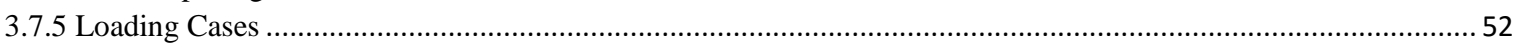

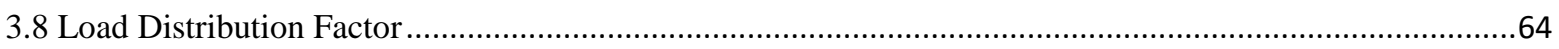

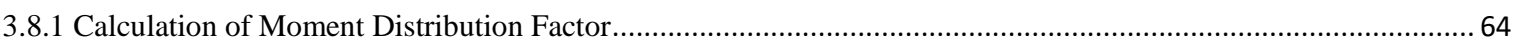

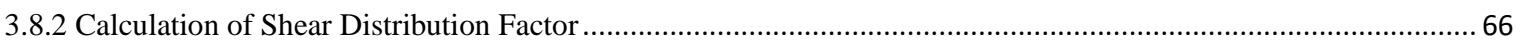

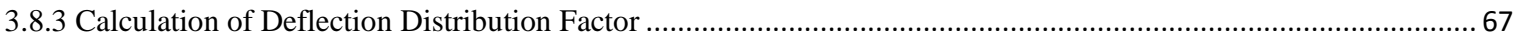

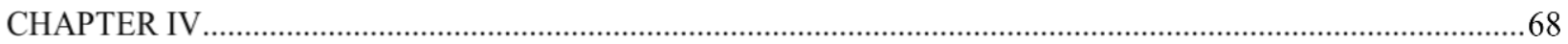

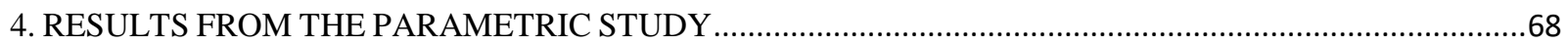

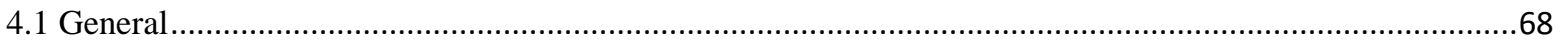

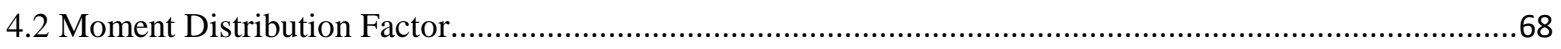

4.2.1 Effect of Number of Girders on Moment Distribution Factors........................................................................ 69

4.2.2 Effect of Span Length on Moment Distribution Factors................................................................................ 70

4.2.3 Effect of Number of Design Lanes on Moment Distribution Factors .................................................................. 70

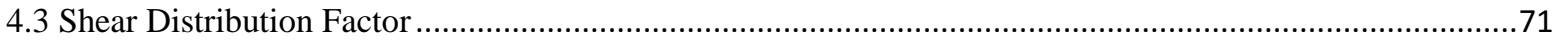

4.3.1 Effect of Number of Girders on Shear Distribution Factors ........................................................................... 71

4.3.2 Effect of Span Length on Shear Distribution Factors ................................................................................. 72

4.3.3 Effect of Number of Design Lanes on Shear Distribution Factors ................................................................ 73

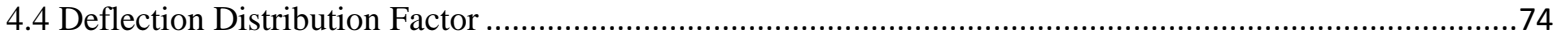

4.4.1 Effect of Number of Girders on Deflection Distribution Factors ................................................................ 74

4.4.2 Effect of Span Length on Deflection Distribution Factors …………………………....................................... 75

4.4.3 Effect of Number of Design Lanes on Deflection Distribution Factors.............................................................76

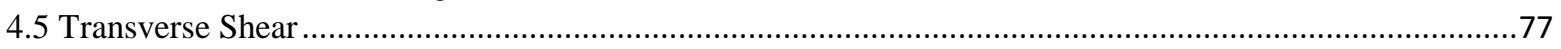

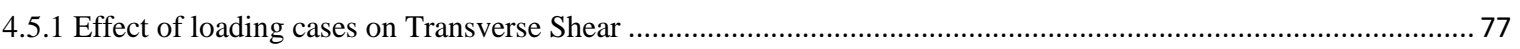

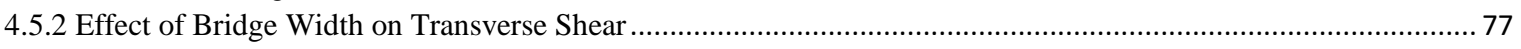

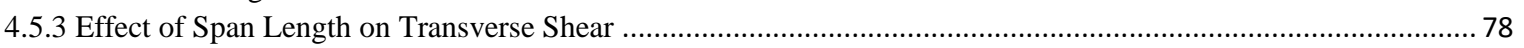

4.6 Development of New Load Distribution Factor Equations ....................................................................79

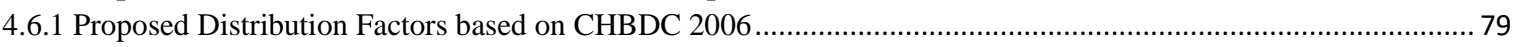

4.6.2 Load Distribution Factors Conversion from CHBDC 2006 to CHBDC 2014 …………………………............... 82

4.6.3 Comparison between FEA Results and CHBDC 2014 Simplified Method for Shear Connected Bridges .............. 82

4.6.4 Comparison between FEA Results and AASHTO-LRFD 2012 Equations .......................................................... 82

4.6.5 Comparison between FEA Results and Alberta Manual 2015 Equations ......................................................... 83

4.6.6 Proposed Distribution Factors based on CHBDC 2014 ………………….................................................. 83 


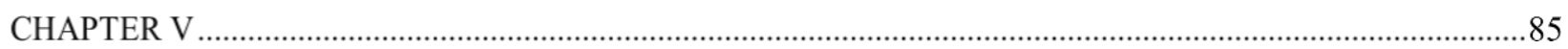

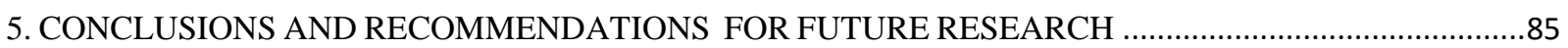

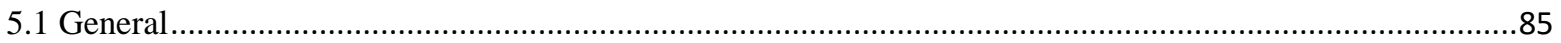

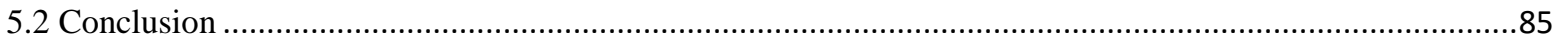

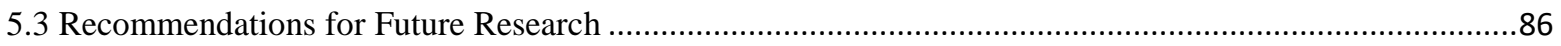

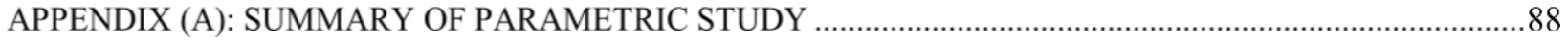

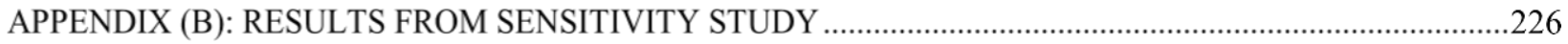

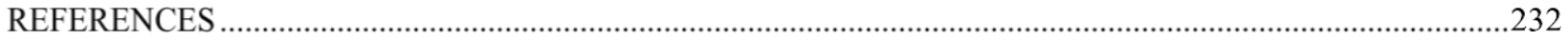




\section{LIST OF TABLES}

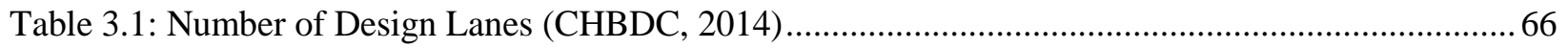

Table 3.2: Modification Factors for Multilane Loading (CHBDC, 2014) .............................................. 66

Table 4.1: Proposed Equations for deck-free precast box girder bridges (CHBDC, 2006) ......................81

Table 4.2: Proposed Equations for deck-free precast box girder bridges (CHBDC, 2014) ...................... 84 


\section{LIST OF FIGURES}

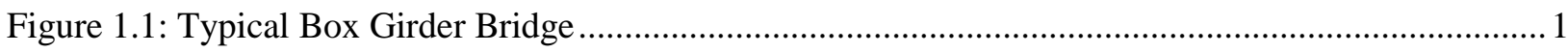

Figure 1.2: Deck free precast adjacent box girder in Sucker Creek Bridge (Source: V-Rod Canada Inc.) ..2

Figure 1.3: Cross-section of Sucker Creek Bridge (Source: V-Rod Canada Inc.) ................................... 2

Figure 1.4: View of the Closure-Strip between the top portion of two adjacent box girders and shear key details (Source: V-Rod Canada Inc.)................................................................................

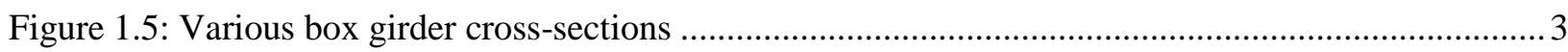

Figure 2.1: Adjacent box girder bridges in various practice ............................................................. 6

Figure 2.2: Real structure and Orthotropic plate analogy …............................................................... 11

Figure 2.3: Free body diagram of Lever rule method (Yao, 1990) ….................................................. 12

Figure 2.4: Free body diagram for hinged T-shaped girder bridges (Yao, 1990) .................................. 13

Figure 2.5: Free body diagram of fixed joint girder bridges (Yao, 1990)................................................. 14

Figure 2.6: Partial depth (left) and full depth (right) shear key ............................................................ 19

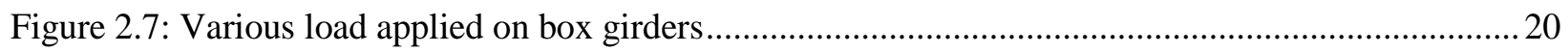

Figure 2.8: Deflection shape of connected and unconnected box girder ..............................................20

Figure 2.9: Values of $\mathrm{k}$ for calculating transverse vertical shear in shear connected beam bridges

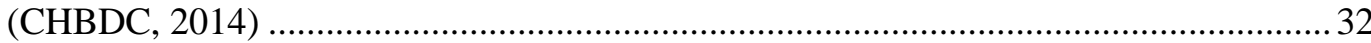

Figure 3.1: Four node quadrilateral shell element (SAP2000) ............................................................ 40

Figure 3.2: Shell element stresses, internal forces and moment at global and local coordinate (SAP2000)

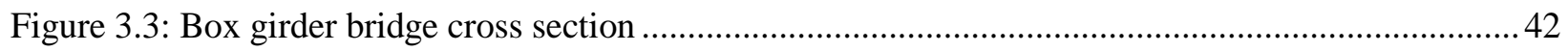

Figure 3.4: Finite-element section of shell elements for bridge cross section .........................................4 43

Figure 3.5: View of 3D model of box girder bridges (13 Box Girder, 20m Span) .................................43

Figure 3.6: Top and bottom view of box girder bridges (13 Box Girder, 20m Span) ............................. 44

Figure 3.7: CL-W-ONT (a) Truck loading, (b) Lane Loading (CHBDC, 2014) ......................................46

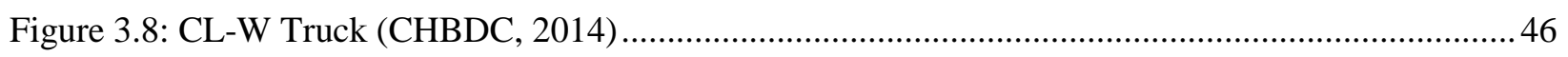

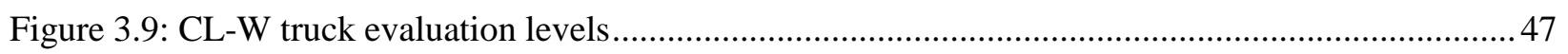

Figure 3.10: Box girder sizes (Pre-Con Manual, 2004) .......................................................................49

Figure 3.11: Box girder section details (Pre-Con Manual, 2004) ...........................................................49

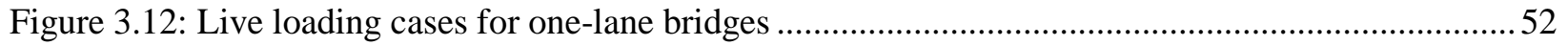

Figure 3.13: Live loading cases for two-lane bridges .......................................................................53

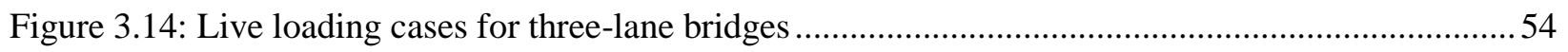

Figure 3.15: Live loading cases for three-lane bridges (Continue) ......................................................5 


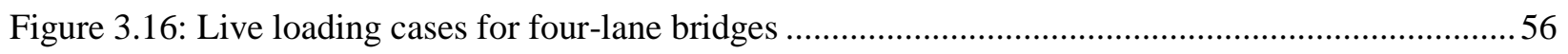

Figure 3.17: Live loading cases for four-lane bridges (Continue) .........................................................57

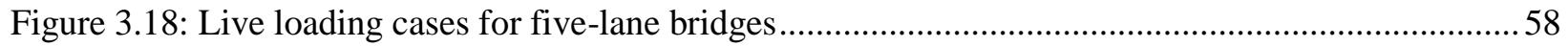

Figure 3.19: Live loading cases for five-lane bridges (Continue) …......................................................59

Figure 3.20: Live loading cases for five-lane bridges (Continue) ..........................................................6 60

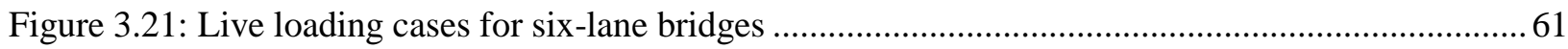

Figure 3.22: Live loading cases for six-lane bridges (Continue) ........................................................62

Figure 3.23: Live loading cases for six-lane bridges (Continue) ..........................................................63

Figure 3.24: Live loading cases for six-lane bridges (Continue) ........................................................... 64 


\section{LIST OF APPENDICES}

Figure A. 1: Effect of number of girders on moment distribution factor (B700, one-lane, 10m span) ......89

Figure A. 2: Effect of number of girders on moment distribution factor (B800, one-lane, 20m span) ...... 89

Figure A. 3: Effect of number of girders on moment distribution factor (B1000, one-lane, 32m span) ....90

Figure A. 4: Effect of number of girders on moment distribution factor (B700, two-lane, 10m span) ...... 90

Figure A. 5: Effect of number of girders on moment distribution factor (B700, two-lane, 13m span) ......91

Figure A. 6: Effect of number of girders on moment distribution factor (B700, three-lane, 10m span) .... 91

Figure A. 7: Effect of number of girders on moment distribution factor (B700, three-lane, 13m span) ....92

Figure A. 8: Effect of number of girders on moment distribution factor (B700, four-lane, 10m span) .....92

Figure A. 9: Effect of number of girders on moment distribution factor (B700, four-lane, 13m span) .....93

Figure A. 10: Effect of number of girders on moment distribution factor (B700, five-lane, 10m span) ....93

Figure A. 11: Effect of number of girders on moment distribution factor (B800, five-lane, 20m span) ....94

Figure A. 12: Effect of number of girders on moment distribution factor (B1000, five-lane, 32m span) .. 94

Figure A. 13: Effect of number of girders on moment distribution factor (B700, six-lane, 10m span) ..... 95

Figure A. 14: Effect of number of girders on moment distribution factor (B800, six-lane, 20m span) .....95

Figure A. 15: Effect of number of girders on moment distribution factor (B1000, six-lane, 32m span)....96

Figure A. 16: Effect of span length on moment distribution factor (one-lane, 4 girders)........................96

Figure A. 17: Effect of span length on moment distribution factor (one-lane, 5 girders).........................97

Figure A. 18: Effect of span length on moment distribution factor (two-lane, 6 girders) ........................ 97

Figure A. 19: Effect of span length on moment distribution factor (two-lane, 7 girders) .........................98

Figure A. 20: Effect of span length on moment distribution factor (two-lane, 8 girders) ....................... 98

Figure A. 21: Effect of span length on moment distribution factor (three-lane, 9 girders) ...................... 99

Figure A. 22: Effect of span length on moment distribution factor (three-lane, 10 girders) .................... 99

Figure A. 23: Effect of span length on moment distribution factor (three-lane, 11 girders) ................... 100

Figure A. 24: Effect of span length on moment distribution factor (four-lane, 12 girders) ..................... 100

Figure A. 25: Effect of span length on moment distribution factor (four-lane, 13 girders).................... 101

Figure A. 26: Effect of span length on moment distribution factor (four-lane, 14 girders).................... 101

Figure A. 27: Effect of span length on moment distribution factor (five-lane, 15 girders) .................... 102

Figure A. 28: Effect of span length on moment distribution factor (five-lane, 16 girders) ..................... 102

Figure A. 29: Effect of span length on moment distribution factor (five-lane, 17 girders) ..................... 103

Figure A. 30: Effect of span length on moment distribution factor (six-lane, 18 girders) ....................... 103

Figure A. 31: Effect of span length on moment distribution factor (six-lane, 19 girders)....................... 104 
Figure A. 32: Effect of span length on moment distribution factor (six-lane, 20 girders)...................... 104

Figure A. 33: Effect of number of lanes on moment distribution factor (B700, 10m Span) .................. 105

Figure A. 34: Effect of number of lanes on moment distribution factor (B700, 13m Span) .................. 105

Figure A. 35: Effect of number of lanes on moment distribution factor (B800, 20m Span) .................. 106

Figure A. 36: Effect of number of lanes on moment distribution factor (B1000, 32m Span) ................ 106

Figure A. 37: Effect of number of girders on shear distribution factor (B700, one-lane, 10m Span) ...... 107

Figure A. 38: Effect of number of girders on shear distribution factor (B800, one-lane, 20m Span) ...... 107

Figure A. 39: Effect of number of girders on shear distribution factor (B1000, one-lane, 32m Span) .... 108

Figure A. 40: Effect of number of girders on shear distribution factor (B700, two-lane, 10m Span) ...... 108

Figure A. 41: Effect of number of girders on shear distribution factor (B700, two-lane, 13m Span) ...... 109

Figure A. 42: Effect of number of girders on shear distribution factor (B700, three-lane, 10m Span) .... 109

Figure A. 43: Effect of number of girders on shear distribution factor (B700, three-lane, 13m Span) .... 110

Figure A. 44: Effect of number of girders on shear distribution factor (B700, four-lane, 10m Span) ..... 110

Figure A. 45: Effect of number of girders on shear distribution factor (B700, four-lane, 13m Span) ..... 111

Figure A. 46: Effect of number of girders on shear distribution factor (B700, five-lane, 10m Span) ...... 111

Figure A. 47: Effect of number of girders on shear distribution factor (B800, five-lane, 20m Span) ...... 112

Figure A. 48: Effect of number of girders on shear distribution factor (B1000, five-lane, 32m Span) .... 112

Figure A. 49: Effect of number of girders on shear distribution factor (B700, six-lane, 10m Span) ....... 113

Figure A. 50: Effect of number of girders on shear distribution factor (B800, six-lane, 20m Span) ....... 113

Figure A. 51: Effect of number of girders on shear distribution factor (B1000, six-lane, 32m Span) ..... 114

Figure A. 52: Effect of span length on shear distribution factor (one-lane, 4 girders) ........................... 114

Figure A. 53: Effect of span length on shear distribution factor (one-lane, 5 girders) ......................... 115

Figure A. 54: Effect of span length on shear distribution factor (two-lane, 6 girders) .......................... 115

Figure A. 55: Effect of span length on shear distribution factor (two-lane, 7 girders) ...........................116

Figure A. 56: Effect of span length on shear distribution factor (two-lane, 8 girders) ........................... 116

Figure A. 57: Effect of span length on shear distribution factor (three-lane, 9 girders) ......................... 117

Figure A. 58: Effect of span length on shear distribution factor (three-lane, 10 girders) ........................ 117

Figure A. 59: Effect of span length on shear distribution factor (three-lane, 11 girders) ....................... 118

Figure A. 60: Effect of span length on shear distribution factor (four-lane, 12 girders) ........................ 118

Figure A. 61: Effect of span length on shear distribution factor (four-lane, 13 girders) ....................... 119

Figure A. 62: Effect of span length on shear distribution factor (four-lane, 14 girders) ........................ 119

Figure A. 63: Effect of span length on shear distribution factor (five-lane, 15 girders) ........................ 120

Figure A. 64: Effect of span length on shear distribution factor (five-lane, 16 girders) ......................... 120 
Figure A. 65: Effect of span length on shear distribution factor (five-lane, 17 girders)..... 121

Figure A. 66: Effect of span length on shear distribution factor (six-lane, 18 girders) 121

Figure A. 67: Effect of span length on shear distribution factor (six-lane, 19 girders) 122

Figure A. 68: Effect of span length on shear distribution factor (six-lane, 20 girders) 122

Figure A. 69: Effect of number of lanes on shear distribution factor (B700, 10m span) 123

Figure A. 70: Effect of number of lanes on shear distribution factor (B700, 13m span) 123

Figure A. 71: Effect of number of lanes on shear distribution factor (B800, 20m span) 124

Figure A. 72: Effect of number of lanes on shear distribution factor (B1000, 32m span) 124

Figure A. 73: Effect of number of girders on deflection distribution factor (B700, one-lane, 10m span) 125 Figure A. 74: Effect of number of girders on deflection distribution factor (B800, one-lane, 20m span) 125 Figure A. 75: Effect of number of girders on deflection distribution factor (B1000, one-lane, 32m span)

Figure A. 76: Effect of number of girders on deflection distribution factor (B700, two-lane, 10m span) 126

Figure A. 77: Effect of number of girders on deflection distribution factor (B700, two-lane, 13m span) 127 Figure A. 78: Effect of number of girders on deflection distribution factor (B700, three-lane, 10m span)

Figure A. 79: Effect of number of girders on deflection distribution factor (B700, three-lane, 13m span)

Figure A. 80: Effect of number of girders on deflection distribution factor (B700, four-lane, 10m span)

Figure A. 81: Effect of number of girders on deflection distribution factor (B700, four-lane, 13m span) 129

Figure A. 82: Effect of number of girders on deflection distribution factor (B700, five-lane, 10m span)129 Figure A. 83: Effect of number of girders on deflection distribution factor (B800, five-lane, 20m span)130 Figure A. 84: Effect of number of girders on deflection distribution factor (B1000, five-lane, 32m span)

Figure A. 85: Effect of number of girders on deflection distribution factor (B700, six-lane, 10m span). 131 Figure A. 86: Effect of number of girders on deflection distribution factor (B800, six-lane, 20m span). 131 Figure A. 87: Effect of number of girders on deflection distribution factor (B1000, six-lane, 32m span)

Figure A. 88: Effect of span length on deflection distribution factor (one-lane, 4 girders) ..................... 132

Figure A. 89: Effect of span length on deflection distribution factor (one-lane, 5 girders).................... 133

Figure A. 90: Effect of span length on deflection distribution factor (two-lane, 6 girders)..................... 133

Figure A. 91: Effect of span length on deflection distribution factor (two-lane, 7 girders)..................... 134

Figure A. 92: Effect of span length on deflection distribution factor (one-lane, 8 girders) ..................... 134 
Figure A. 93: Effect of span length on deflection distribution factor (three-lane, 9 girders)................... 135

Figure A. 94: Effect of span length on deflection distribution factor (three-lane, 10 girders)................. 135

Figure A. 95: Effect of span length on deflection distribution factor (three-lane, 11 girders)................. 136

Figure A. 96: Effect of span length on deflection distribution factor (four-lane, 12 girders) .................. 136

Figure A. 97: Effect of span length on deflection distribution factor (four-lane, 13 girders) .................. 137

Figure A. 98: Effect of span length on deflection distribution factor (four-lane, 14 girders) .................. 137

Figure A. 99: Effect of span length on deflection distribution factor (five-lane, 15 girders) .................. 138

Figure A. 100: Effect of span length on deflection distribution factor (five-lane, 16 girders) ................ 138

Figure A. 101: Effect of span length on deflection distribution factor (five-lane, 17 girders) ................ 139

Figure A. 102: Effect of span length on deflection distribution factor (six-lane, 18 girders) .................. 139

Figure A. 103: Effect of span length on deflection distribution factor (six-lane, 19 girders) .................. 140

Figure A. 104: Effect of span length on deflection distribution factor (six-lane, 20 girders) .................. 140

Figure A. 105: Effect of number of lanes on deflection distribution factor (B700, 10 girders) .............. 141

Figure A. 106: Effect of number of lanes on deflection distribution factor (B700, 13 girders) .............. 141

Figure A. 107: Effect of number of lanes on deflection distribution factor (B800, 20 girders) .............. 142

Figure A. 108: Effect of number of lanes on deflection distribution factor (B1000, 32 girders) ............. 142

Figure A. 109: Effect of loading cases on transverse shear (one-lane, 10m span) …............................ 143

Figure A. 110: Effect of loading cases on transverse shear (one-lane, 20m span) ............................... 143

Figure A. 111: Effect of loading cases on transverse shear (one-lane, 32m span) ................................ 144

Figure A. 112: Effect of loading cases on transverse shear (two-lane, 10m span) ................................ 144

Figure A. 113: Effect of loading cases on transverse shear (two-lane, 13m span) ................................ 145

Figure A. 114: Effect of loading cases on transverse shear (three-lane, 10m span) ............................. 145

Figure A. 115: Effect of loading cases on transverse shear (three-lane, 13m span) .............................. 146

Figure A. 116: Effect of loading cases on transverse shear (four-lane, 10m span) .............................. 146

Figure A. 117: Effect of loading cases on transverse shear (four-lane, 13m span) ................................ 147

Figure A. 118: Effect of loading cases on transverse shear (five-lane, 10m span) .............................. 147

Figure A. 119: Effect of loading cases on transverse shear (five-lane, 20m span) ............................... 148

Figure A. 120: Effect of loading cases on transverse shear (five-lane, 32m span) ............................... 148

Figure A. 121: Effect of loading cases on transverse shear (six-lane, 10m span) ................................. 149

Figure A. 122: Effect of loading cases on transverse shear (six-lane, 20m span) ................................. 149

Figure A. 123: Effect of loading cases on transverse shear (six-lane, 32m span) ................................ 150

Figure A. 124: Effect of bridge width on transverse shear (5 girders, 16 girders, and 20 girders) ........... 150

Figure A. 125: Effect of bridge width on transverse shear ( 7 girders, 10 girders, and 13 girders)...........151 
Figure A. 126: Effect of span length on transverse shear (one-lane, five-lanes, and six-lanes)

Figure A. 127: Effect of span length on transverse shear (two-lane, three-lanes, and four-lanes) 152

Figure A. 128: Comparison between the FEA results from the current study and those from Khan 2010 study (two-lane, Fm at ULS).

Figure A. 129: Comparison between the FEA results from the current study and those from Khan 2010 study (three-lane, Fm at ULS).

Figure A. 130: Comparison between the FEA results from the current study and those from Khan 2010 study (four-lane, Fm at ULS)

Figure A. 131: Comparison between the FEA results from the current study and those from Khan 2010 study (two-lane, Fm at FLS)

Figure A. 132: Comparison between the FEA results from the current study and those from Khan 2010 study (three-lane, Fm at FLS) .....

Figure A. 133: Comparison between the FEA results from the current study and those from Khan 2010 study (two-lane, Fm at FLS)

Figure A. 134: Comparison between the FEA results from the current study and those from Khan 2010 study (two-lane, Fv at ULS)

Figure A. 135: Comparison between the FEA results from the current study and those from Khan 2010

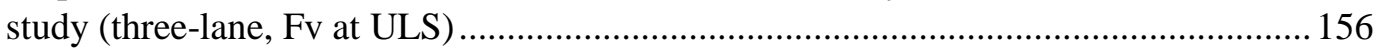

Figure A. 136: Comparison between the FEA results from the current study and those from Khan 2010

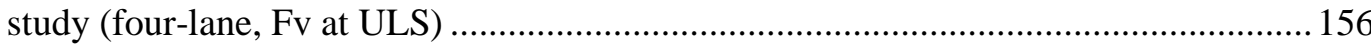

Figure A. 137: Comparison between the FEA results from the current study and those from Khan 2010 study (two-lane, Fv at FLS).

Figure A. 138: Comparison between the FEA results from the current study and those from Khan 2010

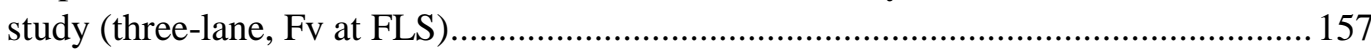

Figure A. 139: Comparison between the FEA results from the current study and those from Khan 2010

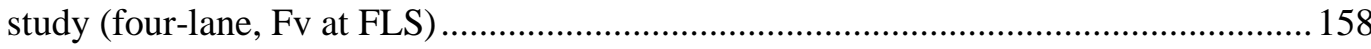

Figure A. 140: Comparison between the FEA results from the current study and those from Khan 2010 study (two-lane, Fd at FLS). 158

Figure A. 141: Comparison between the FEA results from the current study and those from Khan 2010 study (three-lane, Fd at FLS).

Figure A. 142: Comparison between the FEA results from the current study and those from Khan 2010 study (four-lane, Fd at FLS)

Figure A. 143: Correlation between the FEA results and those from the proposed equations for box girder bridges at ULS design for moment (Based on CHBDC 2006) ..................................... 160

Figure A. 144: Correlation between the FEA results and those from the proposed equations for box girder bridges at FLS design for moment (Based on CHBDC 2006).

Figure A. 145: Correlation between the FEA results and those from the proposed equations for box girder bridges at ULS design for shear (Based on CHBDC 2006) 
Figure A. 146: Correlation between the FEA results and those from the proposed equations for box girder bridges at FLS design for shear (Based on CHBDC 2006)...

Figure A. 147: Correlation between the FEA results and those from the proposed equations for box girder bridges at FLS design for deflection (Based on CHBDC 2006) 162

Figure A. 148: Comparison between the FEA results and those from CHBDC for box girder bridges at ULS design for moment (Based on CHBDC 2014) 162

Figure A. 149: Comparison between the FEA results and those from CHBDC for box girder bridges at FLS design for moment (Based on CHBDC 2014).

Figure A. 150: Comparison between the FEA results and those from CHBDC for box girder bridges at ULS design for shear (Based on CHBDC 2014)

Figure A. 151: Comparison between the FEA results and those from CHBDC for box girder bridges at FLS design for shear (Based on CHBDC 2014)

Figure A. 152: Comparison between the FEA results and those from AASHTO-LRFD 2012 for box girder bridges at ULS design for moment....

Figure A. 153: Comparison between the FEA results and those from AASHTO-LRFD 2012 for box girder bridges at FLS design for moment..

Figure A. 154: Comparison between the FEA results and those from AASHTO-LRFD 2012 for box girder bridges at ULS design for shear.

Figure A. 155: Comparison between the FEA results and those from AASHTO-LRFD 2012 for box girder bridges at FLS design for shear

Figure A. 156: Comparison between the FEA results and those from Alberta Bridge Load Manual 2015 for box girder bridges at ULS design for moment

Figure A. 157: Comparison between the FEA results and those from Alberta Bridge Load Manual 2015 for box girder bridges at FLS design for moment....

Figure A. 158: Comparison between the FEA results and those from Alberta Bridge Load Manual 2015 for box girder bridges at ULS design for shear

Figure A. 159: Comparison between the FEA results and those from Alberta Bridge Load Manual 2015 for box girder bridges at FLS design for shear. 168

Figure A. 160: Correlation between the FEA results and those from the proposed equations for box girder bridges at ULS design for moment (Based on CHBDC 2014) 168

Figure A. 161: Correlation between the FEA results and those from the proposed equations for box girder bridges at FLS design for moment (Based on CHBDC 2014). 169

Figure A. 162: Correlation between the FEA results and those from the proposed equations for box girder bridges at ULS design for shear (Based on CHBDC 2014). 169

Figure A. 163: Correlation between the FEA results and those from the proposed equations for box girder bridges at FLS design for shear (Based on CHBDC 2014). 170

Table A. 1: One-Lane Bridge Moment Distribution Factors (Fm) at Serviceability, Ultimate and Fatigue Limit States 
Table A. 2: One-Lane Bridge Shear Distribution Factors (Fv) at Serviceability, Ultimate and Fatigue

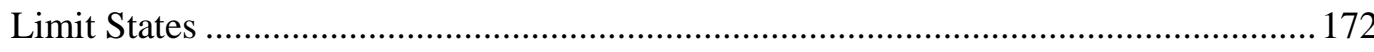

Table A. 3: One-Lane Bridge Deflection Distribution Factors (Fd) at Fatigue Limit States................... 173

Table A. 4: Two-Lane Bridge Moment Distribution Factors (Fm) at Serviceability, Ultimate and Fatigue

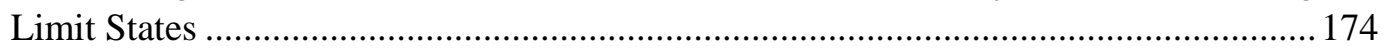

Table A. 5: Two-Lane Bridge Shear Distribution Factors (Fv) at Serviceability, Ultimate and Fatigue

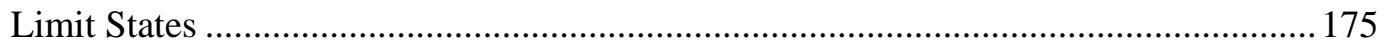

Table A. 6: Two-Lane Bridge Deflection Distribution Factors (Fd) at Fatigue Limit States .................. 176

Table A. 7: Three-Lane Bridge Moment Distribution Factors (Fm) at Serviceability, Ultimate and Fatigue

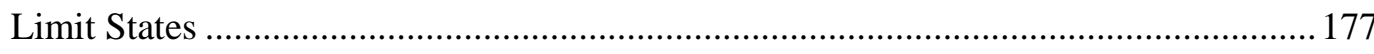

Table A. 8: Three-Lane Bridge Shear Distribution Factors (Fv) at Serviceability, Ultimate and Fatigue

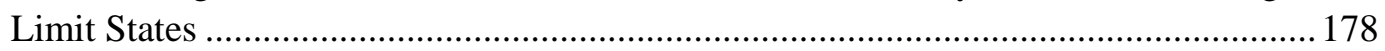

Table A. 9: Three-Lane Bridge Deflection Distribution Factors (Fd) at Fatigue Limit States ................ 179

Table A. 10: Four-Lane Bridge Moment Distribution Factors (Fm) at Serviceability, Ultimate and Fatigue

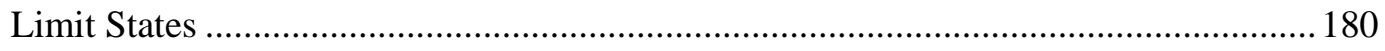

Table A. 11: Four-Lane Bridge Shear Distribution Factors $(F v)$ at Serviceability, Ultimate and Fatigue

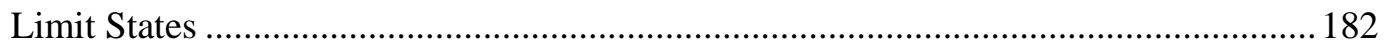

Table A. 12: Four-Lane Bridge Deflection Distribution Factors (Fd) at Fatigue Limit States................ 184

Table A. 13: Five-Lane Bridge Moment Distribution Factors (Fm) at Serviceability, Ultimate and Fatigue

Limit States

Table A. 14: Five-Lane Bridge Shear Distribution Factors (Fv) at Serviceability, Ultimate and Fatigue

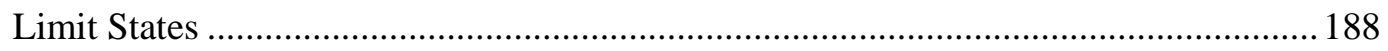

Table A. 15: Five-Lane Bridge Deflection Distribution Factors (Fd) at Fatigue Limit States ................ 191

Table A. 16: Six-Lane Bridge Moment Distribution Factors (Fm) at Serviceability, Ultimate and Fatigue Limit States

Table A. 17: Five-Lane Bridge Shear Distribution Factors (Fv) at Serviceability, Ultimate and Fatigue

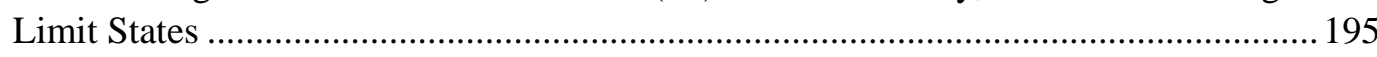

Table A. 18: Six-Lane Bridge Deflection Distribution Factors (Fd) at Fatigue Limit States .................. 198

Table A. 19: One-Lane Bridge Transverse Shear (Vy) at Serviceability, Ultimate and Fatigue Limit States

Table A. 20: Two-Lane Bridge Transverse Shear (Vy) at Serviceability, Ultimate and Fatigue Limit States

Table A. 21: Three-Lane Bridge Transverse Shear (Vy) at Serviceability, Ultimate and Fatigue Limit

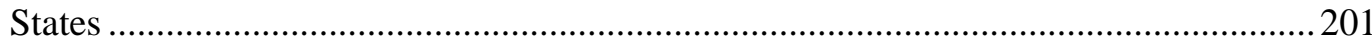

Table A. 22: Four-Lane Bridge Transverse Shear (Vy) at Serviceability, Ultimate and Fatigue Limit States .202 
Table A. 23: Five-Lane Bridge Transverse Shear (Vy) at Serviceability, Ultimate and Fatigue Limit States .204

Table A. 24: Six-Lane Bridge Transverse Shear (Vy) at Serviceability, Ultimate and Fatigue Limit States

Table A. 25: One-Lane Bridge Moment Distribution Factors Comparison at ULS for CHBDC 2014, Alberta 2015, and AASHTO 2012 .................................................................... 210

Table A. 26: One-Lane Bridge Moment Distribution Factors Comparison at FLS for CHBDC 2014,

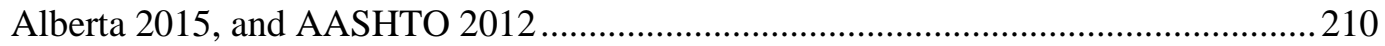

Table A. 27: One-Lane Bridge Shear Distribution Factors Comparison at ULS for CHBDC 2014, Alberta 2015, and AASHTO 2012 ….......................................................................... 210

Table A. 28: One-Lane Bridge Shear Distribution Factors Comparison at FLS for CHBDC 2014, Alberta

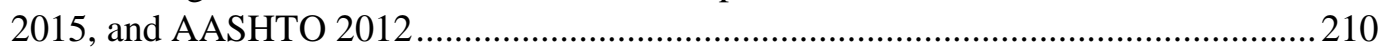

Table A. 29: Two-Lane Bridge Moment Distribution Factors Comparison at ULS for CHBDC 2014, Alberta 2015, and AASHTO 2012 …...................................................................... 211

Table A. 30: Two-Lane Bridge Moment Distribution Factors Comparison at FLS for CHBDC 2014, Alberta 2015, and AASHTO 2012. 212

Table A. 31: Two-Lane Bridge Shear Distribution Factors Comparison at ULS for CHBDC 2014, Alberta 2015, and AASHTO 2012 213

Table A. 32: Two-Lane Bridge Shear Distribution Factors Comparison at FLS for CHBDC 2014, Alberta 2015, and AASHTO 2012 214

Table A. 33: Three-Lane Bridge Moment Distribution Factors Comparison at ULS for CHBDC 2014, Alberta 2015, and AASHTO 2012

Table A. 34: Three-Lane Bridge Moment Distribution Factors Comparison at FLS for CHBDC 2014,

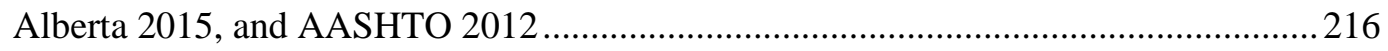

Table A. 35: Three-Lane Bridge Shear Distribution Factors Comparison at ULS for CHBDC 2014, Alberta 2015, and AASHTO 2012

Table A. 36: Three-Lane Bridge Shear Distribution Factors Comparison at FLS for CHBDC 2014, Alberta 2015, and AASHTO 2012.

Table A. 37: Four-Lane Bridge Moment Distribution Factors Comparison at ULS for CHBDC 2014, Alberta 2015, and AASHTO 2012.

Table A. 38: Four-Lane Bridge Moment Distribution Factors Comparison at FLS for CHBDC 2014, Alberta 2015, and AASHTO 2012. 220

Table A. 39: Four-Lane Bridge Shear Distribution Factors Comparison at ULS for CHBDC 2014, Alberta 2015, and AASHTO 2012 221

Table A. 40: Four-Lane Bridge Shear Distribution Factors Comparison at FLS for CHBDC 2014, Alberta 2015, and AASHTO 2012 222

Table A. 41: Five-Lane Bridge Moment Distribution Factors Comparison at ULS for CHBDC 2014, Alberta 2015, and AASHTO 2012. 223 
Table A. 42: Five-Lane Bridge Moment Distribution Factors Comparison at FLS for CHBDC 2014,

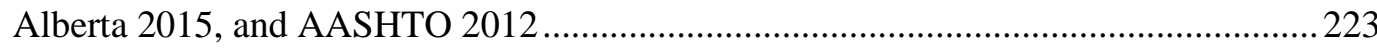

Table A. 43: Five-Lane Bridge Shear Distribution Factors Comparison at ULS for CHBDC 2014, Alberta

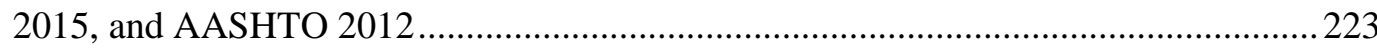

Table A. 44: Five-Lane Bridge Shear Distribution Factors Comparison at FLS for CHBDC 2014, Alberta 2015, and AASHTO 2012

Table A. 45: Six-Lane Bridge Moment Distribution Factors Comparison at ULS for CHBDC 2014,

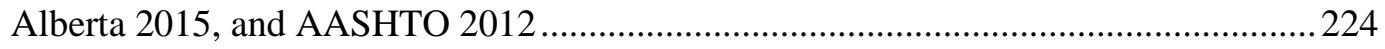

Table A. 46: Six-Lane Bridge Moment Distribution Factors Comparison at FLS for CHBDC 2014,

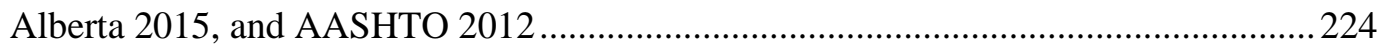

Table A. 47: Six-Lane Bridge Shear Distribution Factors Comparison at ULS for CHBDC 2014, Alberta

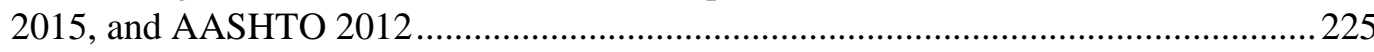

Table A. 48: Six-Lane Bridge Shear Distribution Factors Comparison at FLS for CHBDC 2014, Alberta

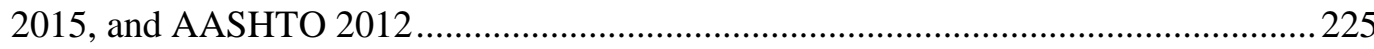

Figure B.1: Comparison between five different types of connections at top flanges for moment distribution factor .227

Figure B.2: Comparison between five different types of connections at top and bottom flanges for moment distribution factor.

Figure B.3: Comparison between five different types of connections at top flanges for shear distribution factor..... 228

Figure B.4: Comparison between five different types of connections at top and bottom flanges for shear distribution factor .. 228

Figure B.5: Comparison between five different types of connections at top flanges for deflection distribution factor

Figure B.6: Comparison between five different types of connections at top and bottom flanges for deflection distribution factor 229

Figure B.7: Comparison between three different connection locations for moment distribution factor... 230

Figure B.8: Comparison between three different connection locations for shear distribution factor .......230

Figure B.9: Comparison between three different connection locations for deflection distribution factor 231 


\section{NOTATIONS}
A
B
$\mathrm{C}_{\mathrm{e}}$
$\mathrm{C}_{\mathrm{f}}$
$\mathrm{D}_{\mathrm{X}}$
$\mathrm{D}_{\mathrm{xy}}$
$\mathrm{D}_{\mathrm{T}}$
$\mathrm{E}_{\mathrm{c}}$
$\mathrm{e}_{\mathrm{g}}$
F
$\mathrm{F}_{\mathrm{m}}$
$\mathrm{F}_{\mathrm{S}}$
$\mathrm{F}_{\mathrm{T}}$
$\mathrm{F}_{\mathrm{V}}$
$\mathrm{f}_{\mathrm{c}}^{\prime}$
g
$\mathrm{I}_{\mathrm{t}}$
$\mathrm{Kg}$
$\mathrm{k}$
L
$\mathrm{M}_{\mathrm{g} \text { avg }}$
$\mathrm{M}_{\mathrm{T}}$
$\mathrm{N}$
n
Cross-sectional area of beam
Width of the bridge
Correction factor for vehicle edge distance obtained from tables
Correction factor obtained from tables
Total bending stiffness
Total torsional stiffness
Truck load distribution width
Modulus of elasticity of concrete
Distance between the center of gravity of the basic beam and deck
The width dimension that characterizes the load distribution for the bridge
An amplification factor for the transverse variation in maximum longitudinal moment
Skew effect
Truck load fraction
An amplification factor for the transverse variation in maximum longitudinal shear
Compressive strength of concrete
Wheel load distribution factor
Moment of inertia of box girder
Longitudinal stiffness parameter
Applicable value obtained from figure
Span length
Average moment per girder
Longitudinal moment generated by one lane of CL-W loading
The number of longitudinal girders
The number of design lanes 


\begin{tabular}{|c|c|}
\hline $\mathrm{R}_{\mathrm{L}}$ & Modification factor for multilane loading \\
\hline S & Centre-to-centre girder spacing \\
\hline$t_{s}$ & Concrete slab thickness \\
\hline $\mathrm{V}_{\mathrm{T}}$ & Longitudinal shear generated by one lane of CL-W loading \\
\hline$V_{g}$ avg & Average shear per girder \\
\hline $\mathrm{W}_{\mathrm{e}}$ & The width of the design lane \\
\hline $\mathrm{W}$ & Heaviest axel load of the design vehicle \\
\hline$Y_{b}$ & Distance from neutral axis to bottom flange \\
\hline$\gamma_{\mathrm{c}}$ & Weight density \\
\hline$v$ & Poisson's ratio \\
\hline EI & Bridge cross-section divided by the width of the bridge \\
\hline$\gamma_{\mathrm{c}}$ & Truck load modification factor for slab on girder bridges \\
\hline$\lambda$ & Lane width parameter \\
\hline$\mu$ & Lane width modification factor \\
\hline$\gamma_{\mathrm{e}}$ & Truck load modification factor for exterior girder for slab on girder bridges \\
\hline$[\mathrm{P}]$ & Nodal load vector \\
\hline$[\mathrm{K}]$ & Global stiffness matrix \\
\hline$[\mathrm{U}]$ & Nodal displacement vector \\
\hline$v(x, y)$ & Internal displacement vector of the element \\
\hline$[\varnothing(\mathrm{x}, \mathrm{y})]$ & Displacement function matrix \\
\hline$[\alpha]$ & Generalized coordinates matrix \\
\hline$[\mathrm{B}(\mathrm{x}, \mathrm{y})]$ & Strain-displacement matrix \\
\hline$[\varepsilon(\mathrm{x}, \mathrm{y})]$ & Strain matrix \\
\hline$[\mathrm{D}]$ & Constitutive matrix or the elasticity matrix \\
\hline $\mathrm{W}_{\mathrm{E}}$ & External virtual work \\
\hline
\end{tabular}




\begin{tabular}{|c|c|}
\hline $\mathrm{W}_{\mathrm{I}}$ & Internal virtual work \\
\hline$\left[\mathrm{u}^{\prime}\right]$ & Vector of virtual displacement \\
\hline$\left[\mathrm{k}^{\prime}\right]$ & Element stiffness matrix \\
\hline$\left(\mathrm{F}_{\mathrm{d}}\right)_{\mathrm{FAT}}$ & Deflection distribution factor for fatigue loading \\
\hline$\left(\mathrm{F}_{\mathrm{m}}\right)_{\mathrm{FL}}$ & Moment distribution factor for fully loaded lanes \\
\hline$\left(\mathrm{F}_{\mathrm{m}}\right)_{\mathrm{PL}}$ & Moment distribution factor for partially loaded lanes \\
\hline$\left(\mathrm{F}_{\mathrm{m}}\right)_{\mathrm{FAT}}$ & Moment distribution factor for fatigue loading \\
\hline$\left(\mathrm{F}_{\mathrm{v}}\right)_{\mathrm{FL}}$ & Shear distribution factor for fully loaded lanes \\
\hline$\left(F_{v}\right)_{P L}$ & Shear distribution factor for partially loaded lanes \\
\hline$\left(\mathrm{F}_{\mathrm{V}}\right)_{\mathrm{FAT}}$ & Shear distribution factor for fatigue loading \\
\hline$\left(\mathrm{R}_{\mathrm{FE}}\right)_{\mathrm{FL}}$ & Maximum reaction at box girder supports from FEM for fully loaded lanes \\
\hline$\left(\mathrm{R}_{\mathrm{FE}}\right)_{\mathrm{PL}}$ & Maximum reaction at box girder supports from FEM for partially loaded lanes \\
\hline$\left(\mathrm{R}_{\mathrm{FE} .}\right)_{\mathrm{FAT}}$ & Maximum reaction at box girder supports from FEM for fatigue loading \\
\hline$\left(\mathrm{R}_{\text {straigth }}\right)_{\text {truck }}$ & Maximum shear force for straight simply supported girder under single truck loading \\
\hline$\left(\sigma_{\mathrm{FE}}\right)_{\mathrm{FL}}$ & Maximum average flexural stress at bottom flange from FEM for fully loaded lanes \\
\hline$\left(\sigma_{\mathrm{FE}}\right)_{\mathrm{PL}}$ & Maximum average flexural stress at bottom flange from FEM partially loaded lanes \\
\hline$\left(\sigma_{\mathrm{FE} .}\right)_{\mathrm{FAT}}$ & Maximum average flexural stress at bottom flange from FEM for fatigue loading \\
\hline$\left(\sigma_{\text {straigth }}\right)_{\text {truck }}$ & Maximum flexural stresses for straight simply supported girder a single truck loading \\
\hline$\left(\Delta_{\text {straigth }}\right)_{\text {truck }}$ & Mid-span deflection from straight simply supported girder under single truck loading \\
\hline$\left(\Delta_{\mathrm{FE}}\right)_{\mathrm{FAT}}$ & Maximum average deflection at bottom flange from FEM for fatigue loading \\
\hline
\end{tabular}




\section{CHAPTER I \\ 1. INTRODUCTION}

\subsection{General}

Precast prestressed concrete bridges are forms of accelerated bridge construction that uses innovative planning, design, materials, and construction methods in a safe and cost-effective manner to reduce the onsite construction time. Bridges built with precast, prestressed concrete box beams were first introduced in 1950s and are a common and economical solution for short to medium span bridges in North America since they provide controlled environmental conditions, improves safety, quality, and long-term durability as well as have high torsional resistant and insignificant torsional warping effect compared to other types of bridges (El-tawil \& Okeil, 2002). Today, about two-thirds of North America's bridges are box girders and in most of them box beams are placed adjacent to each other shown in Figure 1.1.

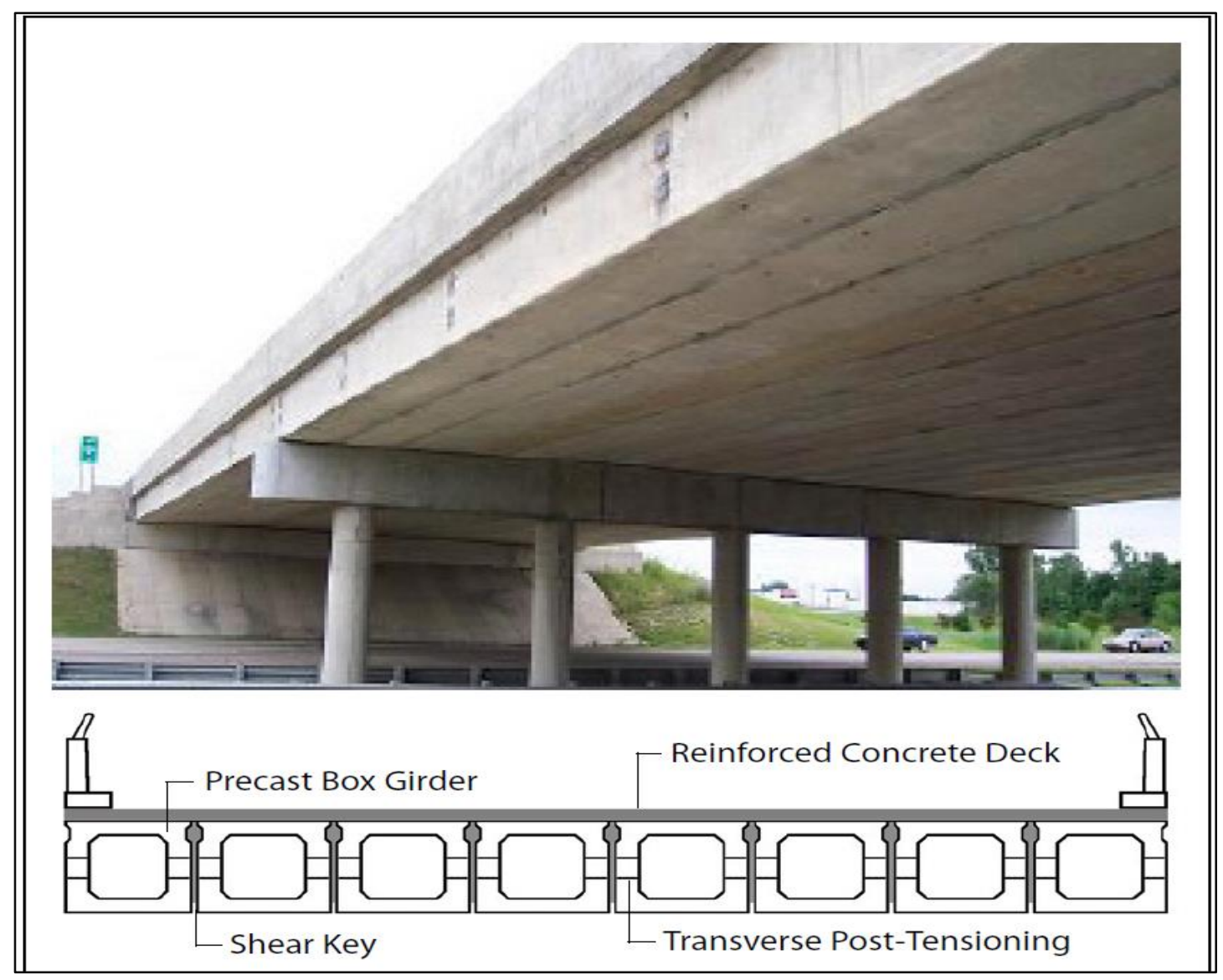

Figure 1.1: Typical Box Girder Bridge 
The precast prestressed concrete box girders are cast in a controlled environment at the fabrication shop and then shipped to the site. The box beams are then installed adjacent to each other with about $15 \mathrm{~mm}$ gaps; this system requires a closure strip to be poured on site between the adjacent box beams to provide a continuous system for live load distribution. Thus, the adjacent precast top flanges are connected with longitudinal shear keys poured on-site with transverse ties, partialdepth or full depth keyways to assist in truck load distribution among beams. The main advantage of using the adjacent box beam bridges with longitudinal shear keys is to eliminate concrete deck formation and use a thick top flange of box beams as a final bridge deck surface to reduce cracks and water leakage to the sides and bottom of the beam thus eliminate severe damage and deterioration of the structure (Khan, 2010). Figure 1.2 through Figure 1.4 show on the applications of deck-free adjacent box girder in Sucker Creek Bridge, County Road 41, built in Ontario in 2006.

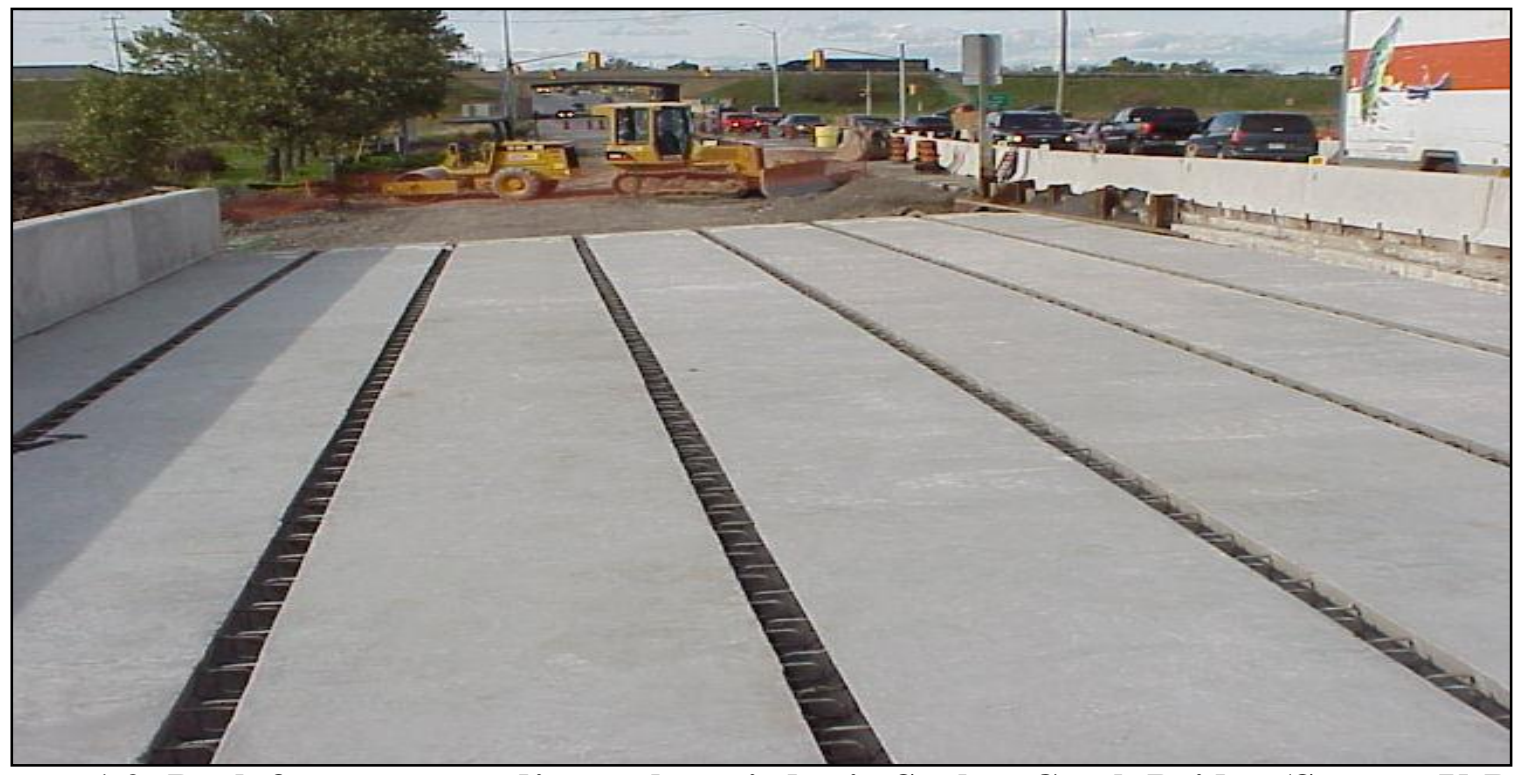

Figure 1.2: Deck free precast adjacent box girder in Sucker Creek Bridge (Source: V-Rod Canada Inc.)

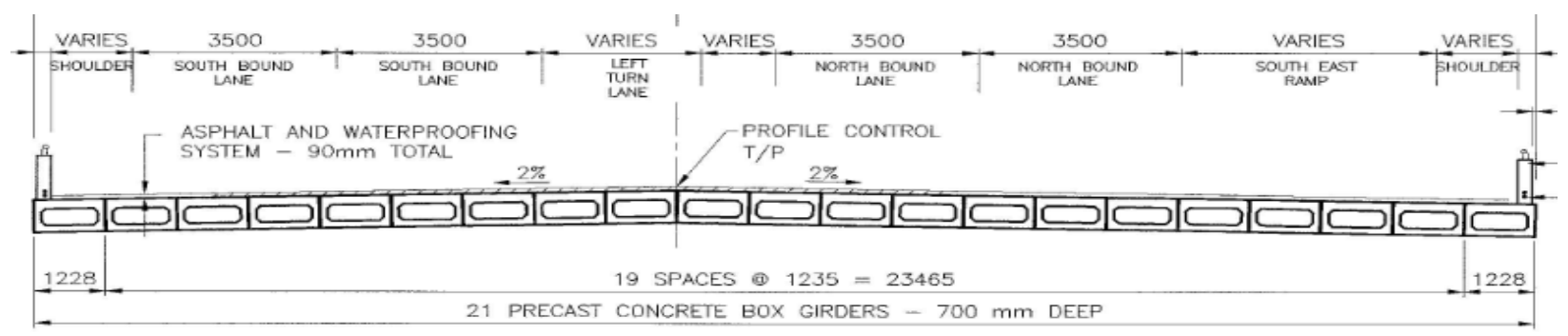

Figure 1.3: Cross-section of Sucker Creek Bridge (Source: V-Rod Canada Inc.) 

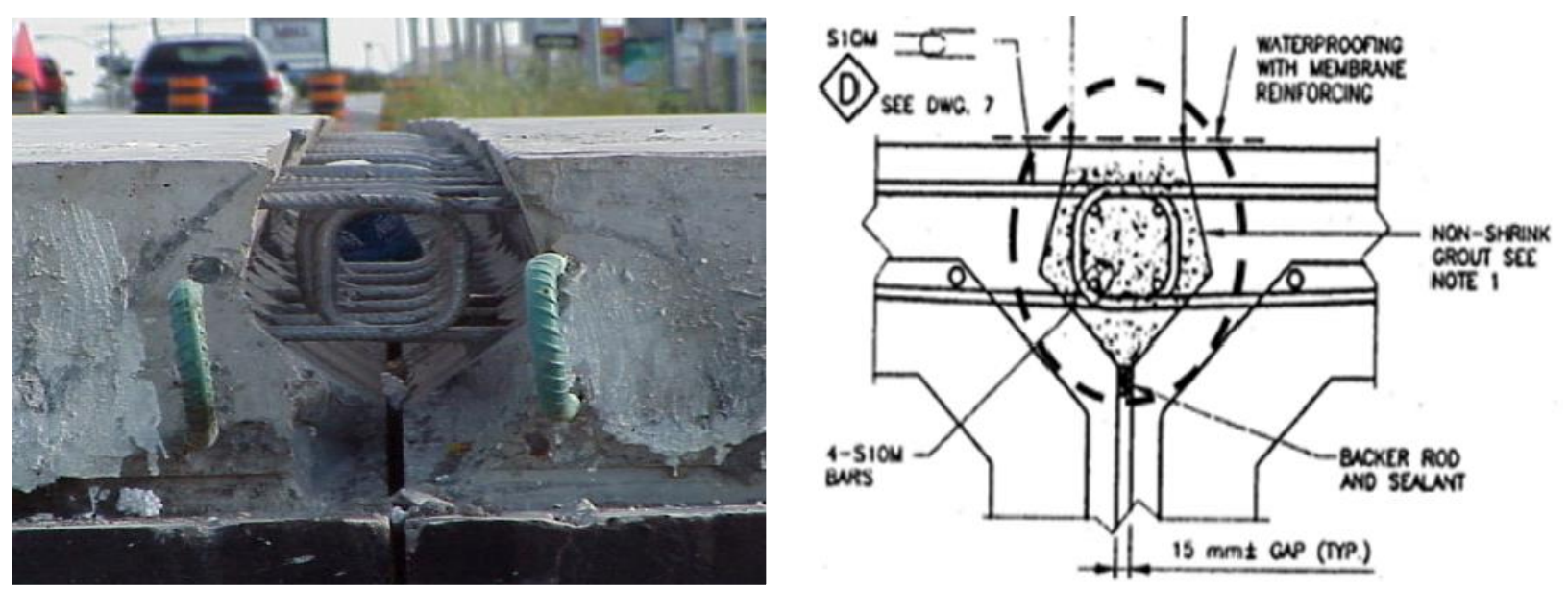

Figure 1.4: View of the Closure-Strip between the top portion of two adjacent box girders and shear key details (Source: V-Rod Canada Inc.)

Due to the increase demand of designing this type of bridges, the need for improved and accurate equations increased. In practice, highway bridges should be designed based on applicable standards such as the Canadian Highway Bridge Design Code (CHBDC, 2014) and AASHTOLRFD Bridge Design Specifications (AASHTO, 2012). Figure 1.5 depicts types of box girder bridges referred to in AASHTO-LRFD Specifications and CHBDC. The bridge under investigation falls within these types of tosionally-stiff cross-sections. This research's main focus is on the applicability of the simplified analysis method specified in CHBDC on adjacent precast prestressed box beam bridges by conducting a 3D finite element analysis to evaluate their moment, shear, and deflection distribution factors as well as transverse shear between adjacent box beams.

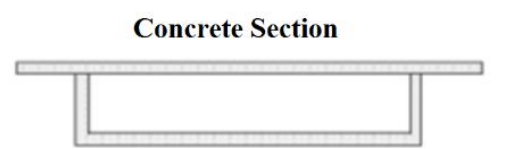

a) Types of Single-box girders

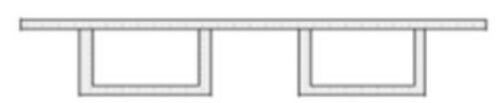

b) Types of Multiple box girders

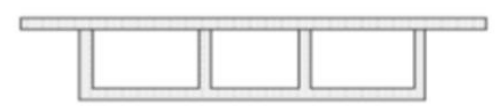

c) Types of Cellular girders
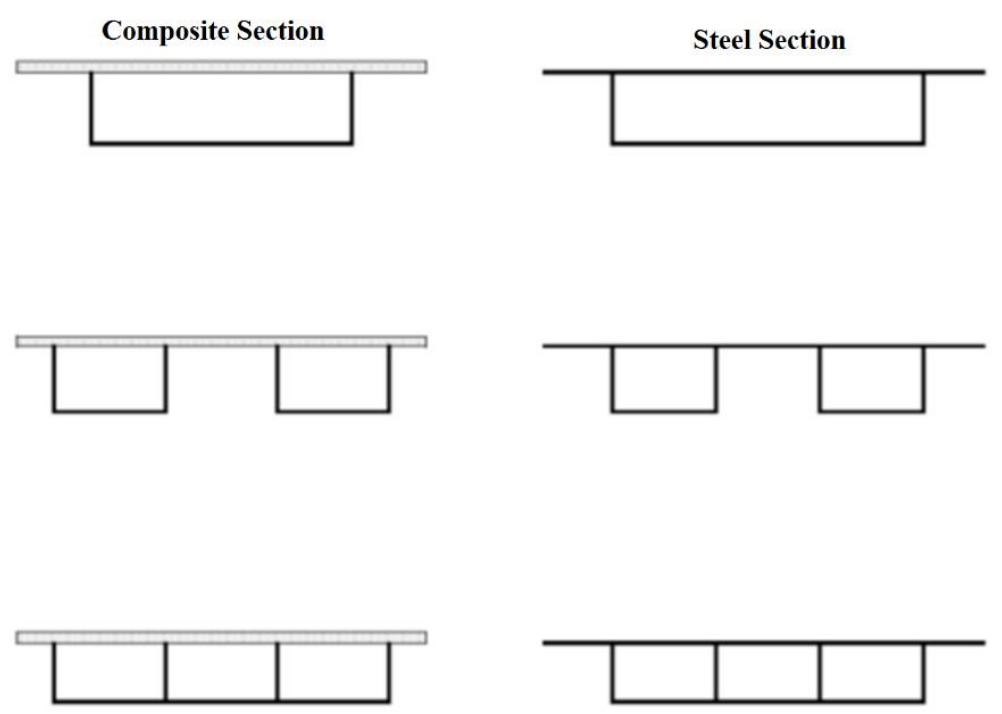

Figure 1.5: Various box girder cross-sections 


\subsection{The Problem}

This research was divided into two parts. The part was related to the shear connected beam, since the concrete-filled joints provide transverse shear rigidity, the load transferred from one beam to another takes place mainly through transverse shear, Vy, across the shear key. As per CHBDC, the maximum intensity of transverse vertical shear was assumed to occur when there is only one design vehicle in the outer lane in a shear-connected box-beam bridge cross-section. To examine whether multi-lane loading would affect the magnitude of shear transfer from one side-by-side beams, a parametric study was conducted, using the finite-element modelling, on selected bridge configurations subjected to different truck loading conditions.

The second part in this research was related to truck load distribution among beams in deck-free adjacent box beam bridges. The literature review shows that the empirical equations developed for box beam bridges by Khan (2010) are applicable only to number of design lanes between 2 and 4 , and bridge spans greater than or equal $16 \mathrm{~m}$. As a result, a more precise expressions of load distribution factors for bridges with greater scope of applicability is required.

A 3D finite element modelling, using SAP2000 software, was conducted on a wide range of adjacent box beams to obtain their moment and shear distribution factors when subjected to CHBDC truck loading conditions. Span length of 10 and $13 \mathrm{~m}$, as well as number of design lanes of 1,5 and 6 , were considered in this study. The obtained results were correlated with those available in CHBDC. A set of simplified equations for the moment and shear distribution factors for the studied bridge configuration was developed.

\subsection{Research Objectives}

The main objectives of this research are to:

1. Conduct a parametric study, using the 3D finite element modelling, to investigate the accuracy of the simplified method of analysis specified in CHBDC for shear-connected beams to the adjacent precast box beams with longitudinal joints that can transfer vertical shear between adjacent box beams.

2. Conduct a parametric study, using the $3 \mathrm{D}$ finite-element modelling on a wide range of adjacent box beam configurations to obtain their moment, shear, and deflection distribution factors when subjected to CHBDC truck loading conditions, followed by correlating them with those available in CHBDC. 
3. Develop set of simplified equations for the moment, shear, and deflection distribution factors for the studied bridge configuration.

\subsection{Scope of work}

The scope of this research includes conducting a literature review of previous research work, textbooks, and design codes of practice related to shear-connected beams and load distribution factors. Also, it includes conducting a sensitivity study, using a 3D finite-element modelling to investigate the effect of number of finite element in the web and flanges of box beams as well as the effect of different types of joint elements between the precast box beams for better representation of the shear key in the modelling. Then, a 3D finite-element modeling of deck-free adjacent box beam bridges was developed to conduct a parametric study to investigate different key parameters affecting load distribution factors and transverse shear transfer between beams using different CHBDC truck loading conditions. The studied parameters included span length, number of beams, number of design lanes, and truck loading conditions. Then, correlation between the obtained results with those available in CHBDC was conducted to examine the level of accuracy of the code design values. Finally, a set of more reliable empirical equations for moment, shear, and deflection distribution factors for the studied bridge configurations was developed.

\subsection{Contents and Arrangement of this study}

In this Thesis, Chapter I is an introductory chapter that demonstrate the research problem and its objectives. Chapter II contains the literature review of load distribution factors and transverse shear concept as well as review of previous work. Chapter III describes the finite-element method and "SAP2000" software used in the analysis, modeling, bridge configurations, loading cases, and the methodology to predict the load distribution factors and transvers shear values. Chapter IV presents the results of the parametric study performed on the box girder bridge, and propose empirical equations for load distribution factors. Chapter $\mathbf{V}$ summarizes the finding of this research, outlines conclusions and provides recommendation for future research. 


\section{CHAPTER II \\ 2. LITERATURE REVIEW}

\subsection{General}

A current practice in designing adjacent box girder bridges includes various practices in the design and detailing of transverse connecting systems. Figure 2.1 (a) shows a non-composite adjacent "deck-free" box girder on which truck loading is applied directly to the top flange of the adjacent boxes. This system depends mainly on the grouted shear key to provide the shear transfer mechanism between adjacent boxes. Figure 2.1 (b) shows a composite cast-in place reinforced concrete slab on top of the box girders. This system uses shear connectors projecting from the top flange of the precast box girder and embedded in the cast-in-place slab, leading to composite superstructure system. Figure 2.1 (c) shows a typical transverse connection made between the adjacent boxes using a post-tensioning tie or a threaded rod. This transverse connection system can be used in conjunction with the composite or non-composite systems to prevent differential deflection (Hanna, 2008).

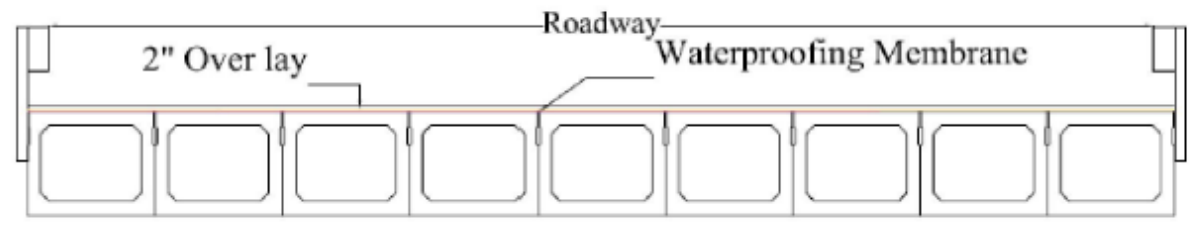

(a)

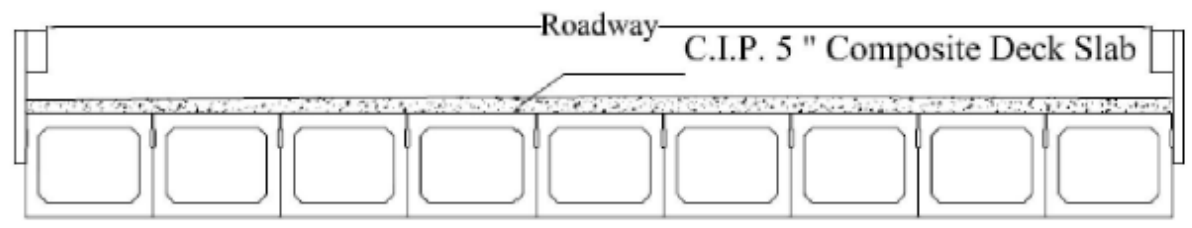

(b)

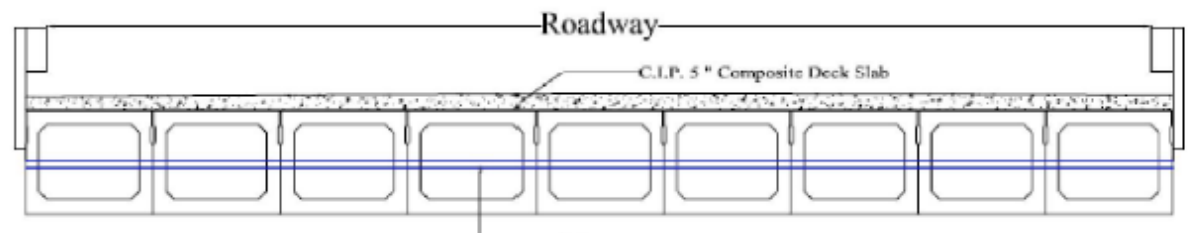

Post-Tensioned Tie or Thread Bar

(c)

Figure 2.1: Adjacent box girder bridges in various practice 
In terms of design analysis, bridges are subjected to different types of loading. Therefore, their structural response to these loads is important for design. One of the main and most important loading analysis is live load analysis since it is a complicated task, given the three-dimensional behavior of the structures and associated assumption in modelling. In the evaluation of live load carried by each box girder, the design values for moment, shear, and deflection depends on the location and number of moving trucks, boundary conditions and cross-section properties of the bridge. These values also vary with the variation of girder span length, width of the bridge, number of girders and loading cases. To simplify the design process, the Canadian Highway Bridge Design Code (CHBDC, 2014) and AASHTO-LRFD Specification (AASHTO, 2012) can be used since they consider the longitudinal and transverse effects of wheel load as uncoupled phenomena by simplifying the design of a two-dimensional bridges to a single beam subjected to single truck loading. The resulting moment, shear, and deflection force are then modified by multiplying them by a factor which is usually referred to as live load distribution factor to account for the two dimensional effects of a bridge superstructure in distribution the truck loading among girders. Therefore, using the code in designing such a bridges will minimize the time and effort spent in design. However, if the design conditions for a bridge with complex configuration did not meet with code conditions, a qualified structural analysis software is recommended in analysis in order to accurately analyze the structure under live load conditions.

According to previous research work on distribution factors for straight bridges, different methodologies have been implemented in practice based on level of bridge lateral rigidity. These methods of analysis include lever rule method, eccentric compression method, Grillage analogy method, finite-element method, orthotropic plate analogy, AASHTO Standard (1996), AASHTOLRFD and CHBDC simplified method. Based on research, the most popular and accurate method of analysis is finite-element method.

The literature review conducted is as follows:

- History of precast prestressed box girders

- Review of previous research on load distribution

- Review of previous research on transverse shear

- Simplified method of analysis 


\subsection{History of Precast Prestressed Box Girders}

The history of implementing prestressed concrete started in 1872 where engineer P.H. Jackson, San Francisco, California, exposed the concept by tightening concrete blocks for floor slabs. In 1888, German Engineer C.E.W Doehring obtained a patent for prestressed concrete slab using metal wires. All these attempts were unsuccessful, because the prestressing force was lost due to shrinkage and creep of concrete. In 1927, the French engineer E. Fressynet (1879-1962) explained the effectiveness of prestressing using high-strength steel to control prestress losses.

According to Miller et al. (1999), the use of prestressed concrete adjacent box beams started in about 1950 for bridges with span lengths of 9 to $32 \mathrm{~m}$, and these box beams are widely used today for these span lengths. The beam design evolved from an open channel design to a box girder design. In the open channel design, shear keys in the top flange were used to transfer the load between adjacent beams. When the load is transferred this way, torsion occurs in the section and, hence, a bottom flange is needed to convert the open section into a torsionally-stiff closed section. Macioce et al. (2007) reported that adjacent box beam bridges constructed of non-composite prestressed concrete with an asphalt wearing surface were developed during the interstate construction period to provide a shallow superstructure, rapid uncomplicated construction, and low initial costs. In many circumstances, this bridge type was used on low-volume roads.

Precast prestressed box beams are fabricated under controlled environment in fabrication shop to improve safety, quality, and long-term durability. Strands are then placed after the reinforcing steel, and then pre-tensioned by using jacks from outside the form. Hold-down points at defined locations are used to allow bending the strands from bottom layers at the middle of the girder to the upper surface at both ends. There are different types of prefabricated girders but the most commonly used for bridges in Canada is CPCI box girder types. These box girders are available in four different sections based on span length (i.e. B700, B800, B900 and B1000). They have constant dimensions of $1220 \mathrm{~mm}$ width top and bottom flanges with thickness of $140 \mathrm{~mm}$, and 125 $\mathrm{mm}$ thick webs, while their depth varies from $700 \mathrm{~mm}$ to $1000 \mathrm{~m}$. (Pre-Con, 2004). 


\subsection{Review of Previous Research on Load Distribution}

The following section describe various structural analysis methods for load distribution factors specified by CHBDC and AASHTO Specifications for straight box girder bridges. These methods can be used when the design conditions doesn't meet with the code conditions.

\subsubsection{Elastic Theory Method (Newmark et al., 1948)}

In 1948, Newmark et al. developed an analytical procedure for determining shear and moment due to live load for both composite and non-composite bridges. A number of bridges was analyzed using simplified assumptions based on elastic theory by recommending the following relationship for the transverse distribution of total longitudinal moment at a cross section in multi-girder bridges and presenting the result of their work in a series of tables containing the fixed-end moment, distribution factors, and the carryover factors for both non-composite and composite slab on-girder bridges.

$$
\begin{aligned}
& M_{G}=D_{f} M_{T} \\
& D_{f}=\frac{S}{K}
\end{aligned}
$$

Where,

$\mathrm{M}_{\mathrm{G}}$ : The design moment of a given girder due to the live load;

$\mathrm{M}_{\mathrm{T}}$ : The maximum moment of the same girder due to a single design truck;

$\mathrm{D}_{\mathrm{f}}:$ The distribution factor;

S : The girder spacing; and

$\mathrm{K}:$ Constant. Newmark et al. suggested K of 1.676.

The 1996 version of AASHTO standard (AASHTO, 1996) uses the same formula for girder spacing up to $1.829 \mathrm{~m}$ in order to determine the design moment for each girder in composite bridges. Experimental research work was carried out by Newmark et al. at the University of Illinois to verify the above equations (Newmark et al., 1948).

\subsubsection{Orthotropic Plate Analogy (Bakht et al., 1979)}

In 1979, Bakht et al. used the concept of orthotropic plate to develop a simplified method to calculate the design live load longitudinal moment as shown in Figure 2.2. They conducted an 
extensive parametric study that led to the fact that the distribution factor of truck loading among girders in bridge cross-section is related to a torsional and a flexural parameter, which are functions of geometry and material properties of the bridge. These parameters are given by:

$$
\begin{aligned}
& \alpha=\frac{D_{x y}+D_{y x}+D_{1}+D_{2}}{2\left(D_{x} D_{y}\right)^{0.5}} \\
& \theta=\frac{b}{2 L}\left(\frac{D_{x}}{D_{y}}\right)^{0.25}
\end{aligned}
$$

Where,

b : The bridge width; and

$\mathrm{L}:$ The span length and the various rigidities are given by:

$$
\begin{aligned}
& D_{x}=\frac{E_{G} I_{G}}{S}+\frac{E_{c} I^{3}}{12} \\
& D_{y}=\frac{E_{c} I^{3}}{12\left(1-v_{c}^{2}\right)} \\
& D_{x y}=\frac{G_{G} J_{G}}{S}+\frac{G_{c} t^{3}}{6} \\
& D_{y x}=\frac{G_{c} t^{3}}{6} \\
& D_{1}=D_{2}=v_{c} D_{y}
\end{aligned}
$$

On which,

$\mathrm{E}_{\mathrm{c}}$ : The young's modulus;

$\mathrm{G}_{\mathrm{c}}$ : The shear modulus;

$\mathrm{v}_{\mathrm{c}}$, The Poisson's ratio;

$\mathrm{t}:$ The concrete slab thickness;

S : The girder spacing;

$I_{G}$ : The flexural moment of inertia of the girder cross section; and $\mathrm{J}_{\mathrm{G}}$ : The torsional moment of inertia of the girder cross section. 
In the above equations, the subscript $G$ refers to girder and $c$ refers to the concrete slab. This method gives better results than the AASHTO recommendations that assume the girder spacing $S$ is the only parameter that affects load distribution in slab-on-girder bridges. This method formed the basis of the 1991 version of the OHBDC (1991).
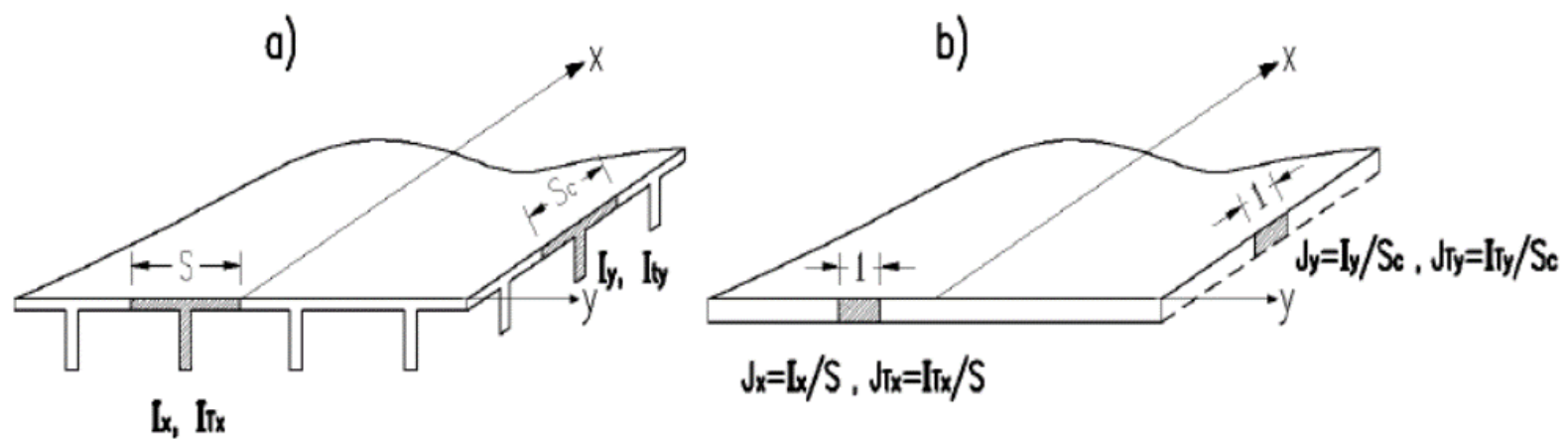
a) Real Structure
b) Analogized Equivalent
Orthotropic Plate

Figure 2.2: Real structure and Orthotropic plate analogy

\subsubsection{Folded-Plate Method (Scordelis, 1984)}

In 1964, DeFries and Scordelis applied the folded-plate method in the structural analysis of general plate structures. This method is suitable for linear elastic analysis of box-girder bridges by means of the elastic theory and by modeling the multiple-spine box-girder bridge as a folded system by considering both ends simply-supported by infinite stiff diaphragms in their planes and unified the longitudinal plate element along their longitudinal edge at joints. The folded-plate method is suitable for simply-supported box-girder bridges with no intermediate diaphragm. In 1966, Scordelis and Gerasimenko, studied the behaviour of two reinforced-concrete folded-plate models for a structure under load used by Evans and Rockey (1975). Later this method has been applied to analyze box girders by using an ordinary folded-plate analysis. In 1994, Sitaram et al. compared the results obtained from the folded plate method and the finite-element modelling using quadratic shell elements. In 1984, Scordelis developed a Berkeley Computer Program, incorporating the folded-plate method, for simply-supported straight or curved and single-span or continuous bridges with single or multi cell box girder. In 1984, Batla et al, applied this method to straight 
folded plate type structures. The folded plate method was restricted to be used for bridges with line-support condition as specified in the Canadian Highway Bridge Design Code.

\subsubsection{Lever Rule Method (Yao, 1990)}

Lever rule is one of the most commonly used methods for calculation of distribution factors and it is very accurate for two girder bridges. In this method, the deck between the girders is assumed to acts as a simply-supported beam or cantilever beam, as shown in Figure 2.3. In this case, the load on each girder is taken as the reaction of the wheel loads. Lever rule can also be used for shear distribution near support, since the load would pass to the pier or abutment mostly through the adjacent two girders. Lever rule can also give very good results when the bridge transverse stiffness is relatively flexible. However, the results would usually be slightly conservative for the interior girders and not conservative for the exterior girders.

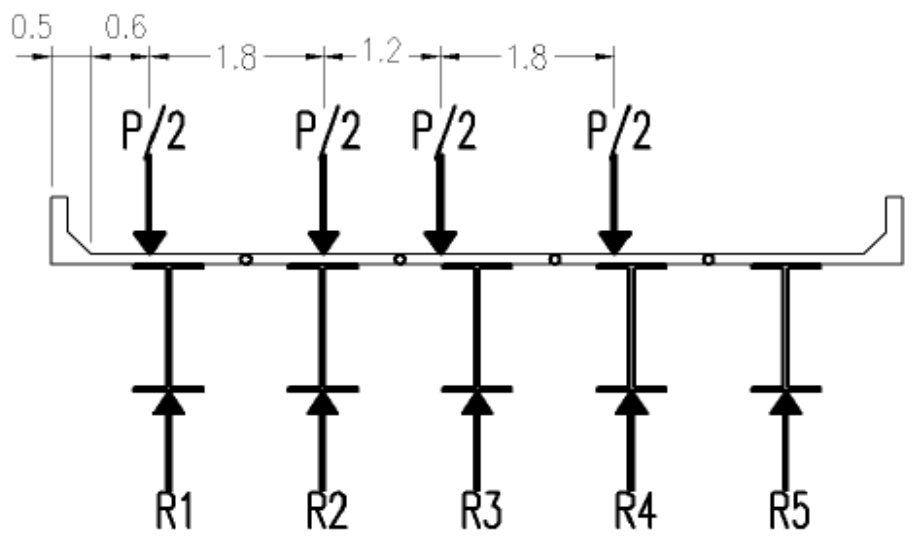

Figure 2.3: Free body diagram of Lever rule method (Yao, 1990)

\subsubsection{Hinged Joint Method for T-Shaped Girder Bridge (Yao, 1990)}

According to Yao (1990), the hinged joint method can be used for small span concrete T-shaped girder bridges without intermediate diaphragms. Figure 2.4 demonstrate the free-body diagrams of unit length section at bridge middle span of the hinged T-shaped girder bridge under unit sinusoidal load. The deflection of the T-shaped girder flanges must be considered, as shown in Figure 2.4. When the cantilever length is within $0.80 \mathrm{~m}$ and the span length is greater than $10 \mathrm{~m}$, the tables for calculating transverse influence line values for hinged-slab bridges can be used for hinged girder bridges. For better accuracy, detailed calculation is required for bridges beyond this range. 
a)

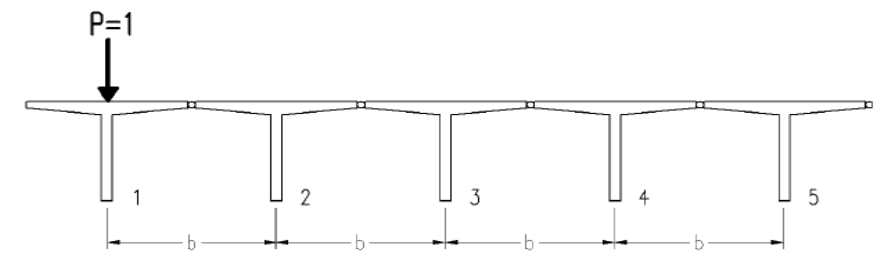

b)
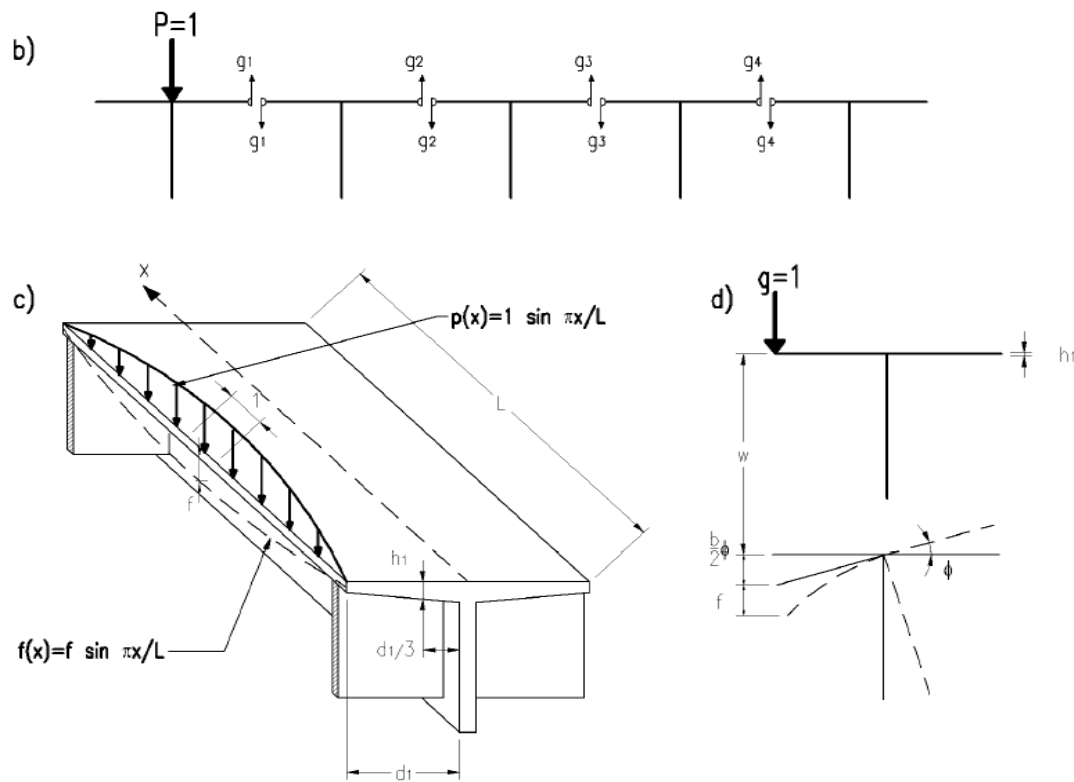

Figure 2.4: Free body diagram for hinged T-shaped girder bridges (Yao, 1990)

\subsubsection{Fixed Joint Girder Method (Yao, 1990)}

In case when the lateral connection between girders is stiffer, the joint can be considered as a fixed joint. In addition to the shear force at the joint, moment must also be considered, as shown in Figure 2.5. For $n$-girder bridge, a $2(n-1)$ order of indeterminate problem is to be solved to obtain the shear and moment at each joint. However, only shearing force $g_{i}$ is considered for calculating distribution factor. Once $g_{i}$ is known, the same procedure as in hinged joint method can be followed to obtain the transverse influence line as well as the distribution factors. 
a)

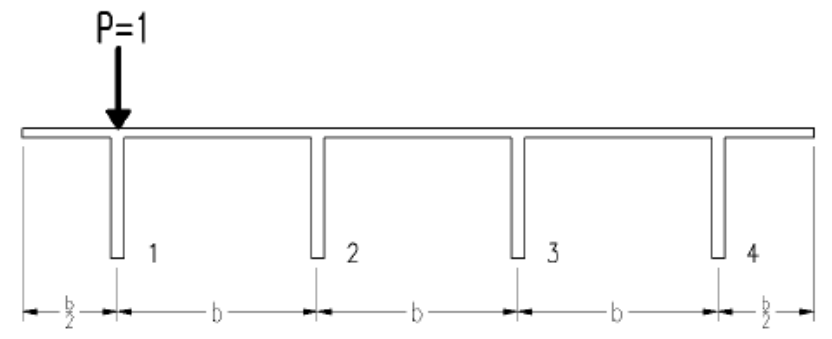

b)

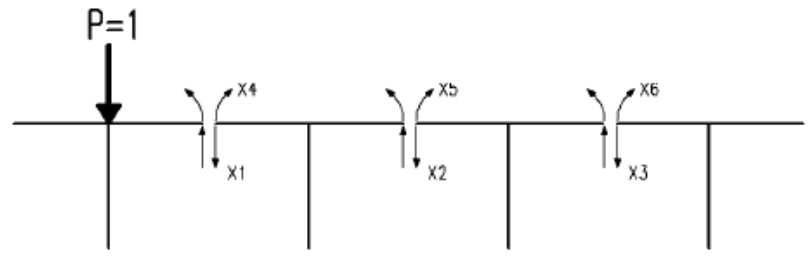

c)

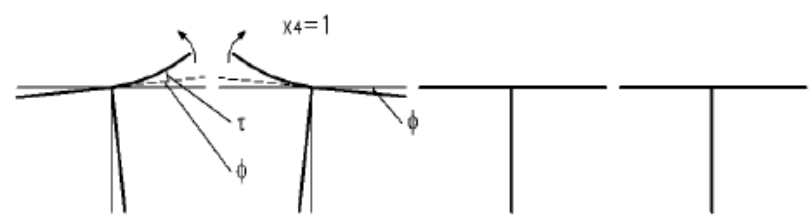

Figure 2.5: Free body diagram of fixed joint girder bridges (Yao, 1990)

\subsubsection{Finite-Strip Method (Cheung, 1985)}

The finite-strip method is a shift method between the folded-plate and finite-element methods. This method were used in the analysis of circularly and orthotropic curved plate elements for which direct application of the theory of elasticity becomes excessively concerned and considered as a prevailing technique. The methodology is to divide the bridge into narrow longitudinal number of strips in circumferential direction to the other end. It considers the bending, warping and membrane distortional effect in the finite strip. The finite-strip and finite-element methods are different in the assumption of displacement interpolation functions. In finite-strip method, the displacement functions for the resulting finite-strip are assumed as changeable mixture for longitudinally and are polynomials in the transverse direction. In 1970, Cheung et al. used the finite-strip method to analyze simply-supported slab and girder bridges. In 1978, Cheung and Chan adopted this method to analyze straight multi-spine and multi-cell box girder bridges to define the effective width of the compression flanges. In 1979, Cheung and Chan introduced the finite-strip method to analyze box girders with deep or inclined girders and slab bridges with or without concentric beams. In 1985, Arzumi et al. studied the behaviour of curved composite box girders with different cross-section geometry. In 1982, Cheung et al. applied the finite-strip method by using strips with curvilinear coordinate system and variable width to analyze the behaviour of the 
webs of continuous box-girder bridges. In 1990, Cheung et al. used the finite-strip method to investigate the improvement of two types of longitudinal shape functions for better accuracy. In 1990, Abdullah and Abdul-Razzak applied the finite-strip method to prestressed box-girder bridges. In 1994, Cheung et al. used a combination of the boundary element method and finitestrip method to analyze composite slab-on-girder and slab-on-box girder bridges and the results was very accurate in local bending moment results due to moving load. Canadian Highway Bridges Design Code restricts the use of this method to single and multi-span bridges having interior supports equivalent to line supports.

\subsubsection{Grillage Method (Zokaie, 2000)}

In 1975, Hambly and Pennells applied the grillage analogy method to cellular deck bridges which modeled as a grid assembly to evaluate the stiffness parameters for grillage analysis. In 1982, Cheung et al. used the finite-element to establish the authority of grillage analogy method and the orthotropic plate method to calculate the longitudinal moment and transverse shear in multi-spine box girder. Results show that accuracy can be achieved if the numbers of spines is not less than three. In 1984, Evans and Shanmugam established a new technique to model the torsional stiffness of closed cells by means of an equivalent I-beam torsion stiffness. In 1997, Razqpur et al. used this method to analyze straight and curved bridges by modelling each segment with three nodal and six degrees of freedom each. In 2000, Zokaie carried out extensive analysis using the grillage and finite-element methods to verify and evaluate the formulas, developed earlier (Zokaie et al., 1991). In the finite element model, shell element was used to represent the deck slab and frame element was used to represent the precast girders. In his study, Zokaie calibrated the developed formulas for moment and shear distribution factors to the interior and the exterior girders for bridges designed for one traffic lane and for bridges designed for two or more traffic lanes. He concluded that the results from the formulas previously provided in 1991 were within $5 \%$ of the results from the finite-element analysis in the study he performed in the year 2000.

\subsubsection{Finite Element Method (Logan, 2002)}

The finite-element method (FEM) has been widely used in many complex engineering applications and became conventional techniques for box girder bridges. The main idea of FEM is discretizing the structure into small division or elements; these elements are connected together through nodal points. The results of any FEM is based on simultaneous algebraic equations rather than requiring analytical solution which is usually not obtainable due to the complexity of geometries, loading 
and material properties. The origin of the modern FEM was back to early 1900s when some researchers approximated and modeled elastic continua using discrete equivalent elastic bars. In 1941, Hrenikoff presented a solution of elasticity problems using "frame work method". In 1966, Roll and Aneja tested two types of bridge models made of simply-supported box beam, both straight and curved in plan, to examine the accuracy of the finite-element modelling. In 1970, Sargious used the finite-element method to calculate the principal stresses and to obtain the stresses of two equal-spans continues prestressed concrete beams. In 1972, Sisodiya et al. used shell elements and new displacement function to derive the in-plane stiffness for variable depth of boxgirder bridges. In 1973, Yuki et al. used the method to Analyze suspension bridges for better accuracy. In 1974, Bazant and Numeiri used it to analyse straight or curved single-cell girders with or without the presence of initial stress. In 1975, Fam and Turkstra used it in the analysis of boxgirder bridges with orthogonal boundaries and arbitrary combination of straight and curved sections. In 1975, Moffat and Dowling suggested methods of simplifying the codes practice by the rules of shear lag. In 1979, Sargious et al. developed the monographs to determine the consequential forces and critical stresses due to external loads and prestressed forces at different locations of box-girder bridges. In 1981, Ghali et al. used the finite-element method to analyze box-girder bridges and compared the results used in design of these types of bridges by the classical beam theories. In 1982, Owens et al. described new techniques for the fabrication of small-scale models of welded steel. In 1984, Kostem suggested how the final stresses and deformation check the designs for beam-slab type superstructures by the finite-element method. In 1984, Hays Jr. developed a description of load distribution factor program application to find maximum distribution factors by the finite-element method across bridge cross-section. In 1985, Ishac and Graves Smith examined the transverse moment in single-span and single-cell concrete box girder in simple bridge design. In 1990, Chan et al. analyzed a three composite box girder over one or two year period by calculating the thermal stresses using the finite-element technique. In 1995, Tarhini et al. used the finite-element method to analyze box girder bridges and compared results with the published wheel load distribution formula. In1995, Galuta and Cheung formulated a combination of the finite-element and boundary element methods (BEM-FEM) and explained its effective application to box girder bridge analysis. In 2001, Sennah and Kennedy discussed the design of straight and curved box-girder bridges, the current design, bracing effects, and load distribution and construction issues. In 2003, Samaan et al. investigated the simply-supported 
straight and curved multiple-spine box-girder bridges, using finite-element methods. They investigated the effect of key parameters in the structural response of such bridges, including span length, number of box girder, and number of lanes and presence of internal and external bracing between box girders. In 2003, Zhang et al. determined the dynamic impact factors for straight composite concrete-steel cellular bridges under AASHTO loading conditions. In 2006, Razaqpur et al. used the finite-element method to evaluate 50 composite I-girder bridge configurations for moment distribution factors. In 2008, Vasseghi et al. developed the design concept for continuous link slabs as a joint less bridge and investigated the bridge response using the finite-element method for straight and skew bridge. In 2010, Khan investigated the load distribution factors for deck free adjacent precast prestressed box girder bridges using finite-element method. Researchers consider FEM as attractive and effective method in solving linear and non-linear static and dynamic problems. This method was recommended by the CHBDC for the analysis of box-girder bridges.

\subsubsection{Experimental and Theoretical Studies}

There were few experimental and theoretical studies conducted in the past to examine the structural response of composite and non-composite bridges. In 1997, Sennah and Kennedy used finite element method to analyzed 120 simply-supported multi-cell bridges considering parameters such as span-to-depth ratio, number of lanes, bridge aspect ratio. They verified the theoretical results by correlating them with the experimental findings obtained from testing few 1/12 linear-scale simply-supported bridge models. In 1998, Miller et al. examined experimentally the effects of the sequence of construction the deck slab on the response of laboratory-scale bridge model. In 2002, Samaan et al. investigated the orientation of bridge bearing in composite box-girder bridges after verifying the three-dimensional finite element model using experimental findings obtained from testing few laboratory scale composite concrete slab-over steel box-girder bridges. In 2003, Androus utilized the finite-element ABAQUS software to investigate the structural behaviour of straight and curved composite box-girder bridges under CHBDC truck loading conditions. He built and tested to-collapse four twin-box girder bridge models to verify the finite element results. In 2007, Samaan et al. experimentally conducted a study on two-span continuous curved composite bridge models to evaluate their frequencies and correlate the results with those obtained from the finite-element modeling. In 2007, Suksawang and Nassif proposed new load distribution factors based on experimental testing of actual box girders of different types, including steel spread box 
girders and prestressed bridges and the results from the finite element modelling. In 2010, Khan conducted a parametric study using finite element modeling to investigate the moment, shear and deflection load distributions factors for adjacent precast prestressed concrete box-girder bridge. Then, he developed a set of simplified equations for moment, shear, and deflection distribution factors.

\subsubsection{Bridge Load Evaluation (Alberta Transportation, 2015)}

According to Alberta Bridge Load Evaluation Manual (2015), the lateral distribution of live load between shear-connected girders shall be in no case less than the following limit:

$$
\geq \frac{1.05 n R_{L}}{N}
$$

Where,

$\mathrm{n}:$ The number of design lanes;

$\mathrm{R}_{\mathrm{L}}$ : Modification factor for multilane loading; and

$\mathrm{N}:$ The number of longitudinal girders.

The lateral distribution of live load moment between shear connected girders shall be taken as the following:

$$
=\frac{\mathrm{S}}{\mathrm{D}} \mathrm{x} \text { live load moment due to a single truck }
$$

Where,

$S:$ The girder width $(\mathrm{m})$;

$\mathrm{D}=3.5+1.65\left(1-\frac{\mathrm{C}}{3}\right)^{2}$;

$\mathrm{C}=\mathrm{K}\left(\frac{10}{\mathrm{~L}}\right) \leq 3$;

$\mathrm{L}:$ The bridge span length(m);

$\mathrm{K}=\sqrt{\frac{\mathrm{I}}{\mathrm{J}}} ;$

I : Moment of inertia $\left(\mathrm{mm}^{4}\right)$; and

$\mathrm{J}:$ Torsional constant $\left(\mathrm{mm}^{4}\right)$. 
The lateral distribution of live load shear between shear-connected girders shall be taken as the following:

$$
=\frac{\mathrm{S}}{\mathrm{D}} \mathrm{x} \text { live load shear due to a single truck }
$$

Where,

(a) For the truck axle at the girder location where the shear is being determined:

$$
\begin{aligned}
& \frac{S}{D}=0.5 \text { if } S \leq 1.2 \mathrm{~m} ; \\
& \frac{S}{D}=\text { the greater of } 0.5 \text { and } 0.9\left(1-\frac{0.6}{S}\right) \text { if } 1.2 \mathrm{~m}<S \leq 1.8 \mathrm{~m} ; \\
& \frac{S}{D}=0.9\left(1.5-\frac{1.5}{S}\right) \text { if } 1.8 \mathrm{~m}<\mathrm{S} \leq 3.0 \mathrm{~m} ;
\end{aligned}
$$

(b) For all other truck axles;

$\frac{\mathrm{S}}{\mathrm{D}}$ Is calculated in the same manner as for live load moment

\subsection{Review of Previous Research on Transverse Shear}

The longitudinal connection between adjacent box beams bridges is provided by grouted keyways forming the shear keys of partial depth or full depth as shown in Figure 2.6. Various load types can be applied on box girder, namely: lateral load, vertical load, and tension as shown in Figure 2.7. The main function of the keys is to provide vertical shear load transfer between adjacent beam elements and eliminate differential movement between the adjacent box beams as shown Figure 2.8.
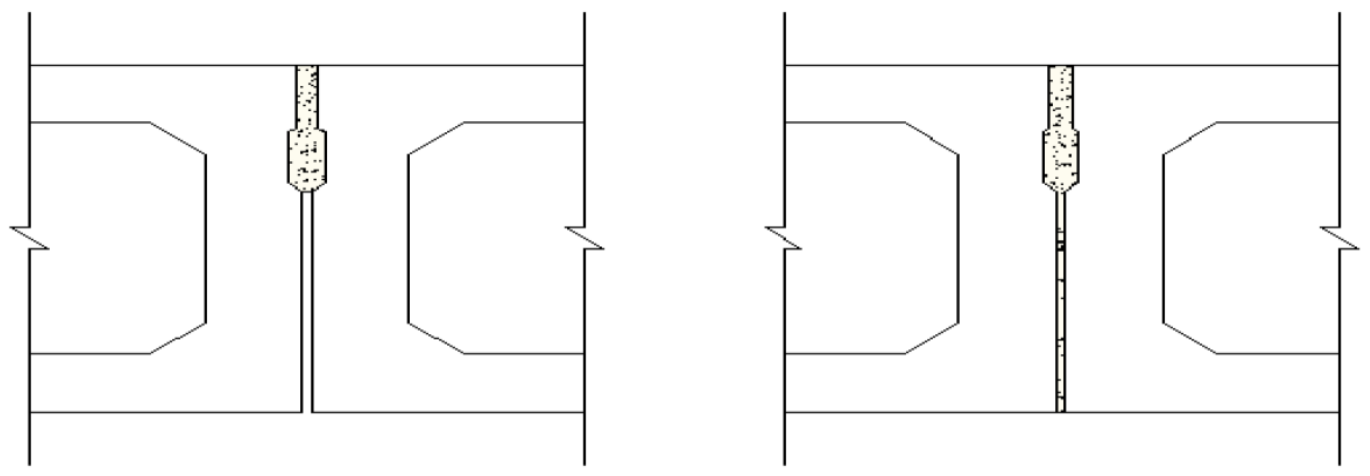

Figure 2.6: Partial depth (left) and full depth (right) shear key 


\section{Lateral (Horizontal) Shear

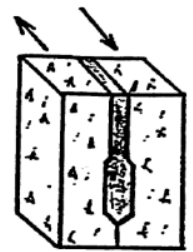

\section{Vertical Shear}

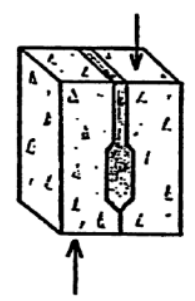

Tension

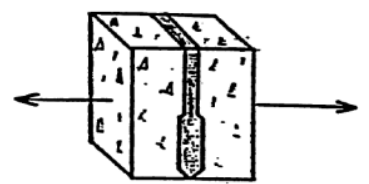

Figure 2.7: Various load applied on box girders

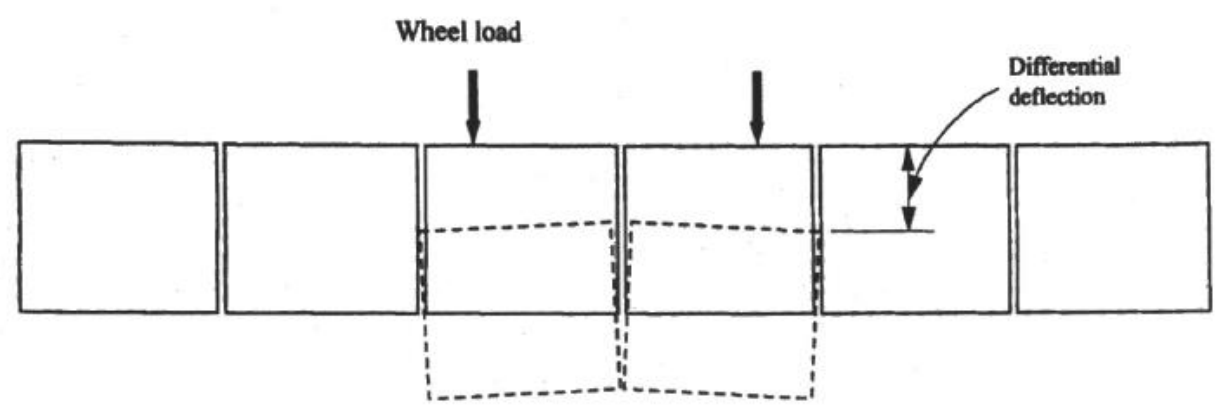

(a) Deflected shape of unconnected boxes

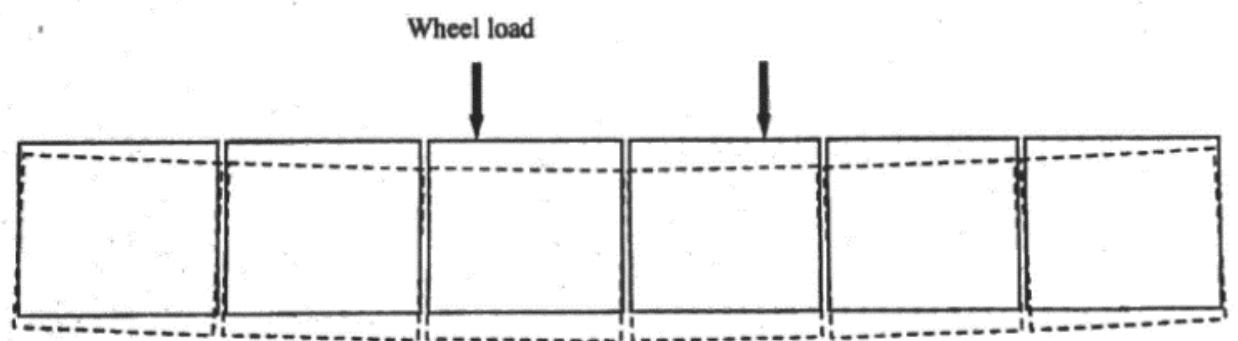

(b) Deflected shape of fully connected boxes

Figure 2.8: Deflection shape of connected and unconnected box girder 
The major weakness of this type of bridges is the shear transfer mechanism between adjacent beams. Failure of shear key results in irregular live load distribution, excessively stressing the internal girders, formation of longitudinal, partial, or full depth cracks, increased relative displacement between beams, and risk of accelerated concrete deterioration as a result of seepage of water and de-icing materials through the cracks. Through literature review, few references were found regarding the performance of shear key. The larger configuration of shear key used in segmental bridge construction joints has received considerably more attention (Kaneko et al., 1993a, b), as posttensioned girder end joints were used in precast building construction. Few researchers (among them: Annamalai and Brown, 1990). Bakht et al. (1983), Cheung et al. (1982), and Zokaie et al. (1991) discussed load distribution factors appropriate for box girder bridges, but did not address shear key performance clearly. Stanton and Mattlock (1986) examined shear keys in open-section multi beam bridges, which have a behavior considerably different from box girders. Young and Huckelbridge (1993) suggested modeling techniques for box girder bridges,

including shear key parameters, but did not quantitatively address the implications of shear key failure. Aside from instances of shear-key/waterproofing failures, as described, prestressed concrete box girder bridges have generally proven to be durable, reliable, and cost-effective structures. An elaborate research program (Huckelbridge et al. 1995) was undertaken in order to quantify the in-situ performance of grouted shear keys in box girder bridges and to observe qualitatively the correlation between shear key performance and problems associated with joint leakage/corrosion. Bakht and Mufti (2001) developed simplified method for only wide single-lane bridges.

\subsubsection{Huckelbridge, El-Esnawi and Mosses' Study in 1995}

In 1995, Huckelbridge et al. conducted a field and laboratory test to study the shear key failure in prestressed adjacent box girder bridges. The tests consisted of monitoring the shear keys from below the bridge as a dump truck with a typical axle weight of $85 \mathrm{kN}$ passed over the bridge in normal direction of travel. Relative displacement between the girders were measured with special transducers for multiple trucks travelling. The data showed relative displacements across some of the joints indicative of fractured shear key. In 1997, Huckelbridge and El-Esnawi created a finiteelement analysis of a three-dimensional bridge model. The analysis showed that the top flange and webs behave as a portal frame. Under wheel load, the top corners moved inward and create tensile stresses in the shear key grout. Further finite-element analysis indicated that moving the shear key 
to the neutral axis and not grouting the throat would element these large tensile strains. After FEA was conducted, the researchers performed tests using hydraulic actuator to simulate a truck wheel passing over the centre of the box girder. Three laboratory tests were performed on the current shear key and the neutral axis shear key using three different grout materials, namely: non-shrink grout, magnesium-phosphate grout, and an epoxy grout. For the non-shrink and magnesiumphosphate grouts, shear key failures were observed as the grout deboned from the girder at an average load of $45 \mathrm{kN}$. While for the epoxy grout, the shear key failure was observed as the concrete in girder failed at an average load of $105 \mathrm{kN}$. The laboratory test confirmed that the neutral axis keyway and the epoxy keyway resist cracking much better than the current design.

\subsubsection{Lall, Alampalli, and DiCocco's Study 1998}

A study was published on the performance of shear key in New York State by Lall et al. in 1998. The study indicated that adjacent box beams in New York State before 1992 were connected through a traditional grouted shear key designed to transfer shear force between individual beam units. The keyway extended to a depth of about $300 \mathrm{~mm}$ from the top of the beam. Longitudinal cracks began appearing in the concrete overlays immediately after construction. Over time, cracks developed over nearly all shear keys. Researchers indicated that $54 \%$ of box beam bridges built between 1985 and 1990 had developed longitudinal cracks over the shear keys. In 1992, a design change was made to increase the depth of the shear key to almost the full depth of the precast unit. A change to the transverse tie requirements was also made. In 1996's survey of 91 bridges built from 1992 through early 1996 found that $23 \%$ of the bridges had shear key related longitudinal cracking compared with $54 \%$ for the previous inspection. Analysis of the data by age of structure at time of inspection showed that the new full-depth shear-key system reduced the percentage of decks with cracks by about $50 \%$.

\subsubsection{Transverse shear simplified method of analysis (Bakht et al., 2001)}

In 1983, Bakht et al. developed a simplified method of analysis for determining transverse shear intensity in the shear keys of multi beam bridges due to the AASHTO and Ontario highway bridge design vehicles. This method is based on orthotropic-plate theory and only applicable to right single span bridges. The analysis shows that the maximum intensity of transverse shear induced adjacent to a single vehicle when placed as near to the free edge of the bridge. 
Bakht et al. (2001) developed a simplified method of analyzing articulated plates for transverse shear forces in shear keys due to truck loads, in which the centre-to-centre distance between the two lines of wheels was assumed to be $1.2 \mathrm{~m}$. They developed their simplified method for only wide single-lane bridges (with a width of $5.5 \mathrm{~m}$ ) on the ground that the values of transverse shears thus determined are on the safe-side for narrower bridges. It was found that the maximum intensity of transverse shear is induced when the vehicle is placed as close to a longitudinal free edge of the bridge, and the transverse shear intensity is investigated between the other longitudinal edge of the bridge and the closer line of wheels. Similar to longitudinal shear intensity, the orthotropic-plate method of the compute program PLATO does not give the maximum intensity of transverse shear, Vy, at the edge of a rectangular patch load; Bakht et al. (2001) have also made the same observation. The locations of critical longitudinal sections were determined for $\mathrm{Vy}$ for each design truck. As expected, the location of the critical section depended upon the distance between the lines of wheels, and not upon the proportions of wheel load distribution along with the corresponding transverse positions of the trucks. In the case of design trucks with unequal sharing of wheel loads, the heavier loads were placed near the critical section.

\subsection{Methods of Analysis}

\subsubsection{AASHTO Methods}

In bridge design, AASHTO introduced empirical methods which are more convenient to use than analytical and numerical methods to define the live load distribution across the bridge. AASHTO expresses the distribution factor as the ratio of the moment or shear obtained from the bridge system to the moment or shear obtained from a single girder loaded by one truck wheel line (AASHTO Standard, 1996) or the axle loads (AASHTO-LRFD, 2012). The AASHTO Standard Specifications and AASHTO-LRFD Specifications define the live load differently. For instance, the live load in the Standard specifications consists of an HS 20 truck or a lane load. While, the live load in the LRFD specifications consists of an HS 20 truck in conjunction with a lane load.

\subsubsection{AASHTO Standard Method 1996}

In 1996, AASHTO Standard specifications used the AASHTO simplified formula for distribution factors based on a research done in the 1940s by Newmark et al. (1948). AASHTO procedure is used to calculate the maximum bending moment based on a single line of wheel loads from the HS20 design truck or lane loading. The calculated bending moment is then multiplied by the load 
distribution factor $(S / 5.5)$ or $(S / D)$, where $S$ is the girder spacing in feet and $D$ is a constant depend on the bridge girder type. This method is applicable to straight and right (non-skewed) bridges only. It was proved to be accurate when girder spacing was near $1.8 \mathrm{~m}$ and span length was about $18 \mathrm{~m}$ (Zokaie, 2000). However, these formulas are not conservative for medium or long span bridges.

\subsubsection{AASHTO-LRFD Method}

The specifications defined in Load and Resistance Factor Design, LRFD Design specifications were adopted (AASHTO, 2012). This code introduced another load distribution factors based on a comprehensive research project, National Cooperation Highway Research Program (NCHRP) 12-26 which was entitled "Distribution of Live Loads on Highway Bridges" and initiated in 1985, thus the guide specification for Distribution of Loads for Highway Bridges (AASHTO, 1994) was found. This guide recommends the use of simplified formulas, simplified computer analysis, and/or detailed finite-element analysis (FEA) in calculating the actual distribution of loads in highway bridges. The new formulas were more complicated than those recommended by the Standard Specifications for Highway Bridges (AASHTO 1996), but their use is associated with a greater degree of accuracy (Munir, 1997). For example, the lateral load distribution factor for bending moment in interior girders of concrete slab on steel girder bridge superstructure is:

$$
\mathrm{g}=0.15+(\mathrm{S} / 3)^{0.6}(\mathrm{~S} / \mathrm{L})^{0.2}\left(\mathrm{Kg} / 12 \mathrm{Lt}_{\mathrm{s}}^{3}\right)^{0.1}
$$

Where,

$\mathrm{g}:$ Wheel load distribution factor;

$\mathrm{S}:$ Girder spacing in feet, $\left(3.5^{\prime}<\mathrm{S}<16^{\prime}\right)$;

$\mathrm{L}:$ Span length of the beam in feet $\left(20^{\prime}<\mathrm{L}<200^{\prime}\right)$;

$\mathrm{t}_{\mathrm{s}}$ : Concrete slab thickness in inches $\left(4.5^{\prime \prime}<\mathrm{t}<12^{\prime \prime}\right)$;

$\mathrm{Kg}$ : Longitudinal stiffness parameter $\mathrm{n}\left(\mathrm{I}+\mathrm{Ae}_{\mathrm{g}}^{2}\right)$;

$\mathrm{n}$ : Modular ratio between beam and deck material;

I : Moment of inertia of beam $\left(\mathrm{in}^{4}\right)$;

A : Cross-sectional area of beam $\left(\mathrm{in}^{2}\right)$; and 
$e_{g}$ : Distance between the center of gravity of the basic beam and deck (in).

AASHTO-LRFD Specifications become highly attractive for bridge engineers because of its inducement allowing the better and more economical use of materials. The rationality of LRFD and its many advantages over the Allowable Stress Design method, ASD, are indicative that the design philosophy will downgrade ASD to the background in the next few years (Salmon and Johnson, 1996). Research results were first adopted by AASHTO Standards in 1994 and were then officially adopted by AASHTO-LRFD in 1998. More parameters, such as girder spacing, bridge length, slab thickness, girder longitudinal stiffness, and skew effect were considered in the developed formulas which earned them sound accuracy. AASHTO-LRFD formulas were evaluated by Shahawy and Huang (2001), their evaluation showed a good agreement with test results for bridges with two or more loaded design lanes, provided that girder spacing and overhang deck did not exceed $2.4 \mathrm{~m}$ and $0.9 \mathrm{~m}$, respectively. Outside of these ranges, the error could be as much as up to $30 \%$. For one loaded design lane, the relative error was less than $10 \%$ for interior girders and could be as high as $100 \%$ and as low as $-30 \%$ for exterior girders. Shahawy and Huang presented modification factors for the AASHTO-LRFD formulas and the results of the modified formulas showed good agreement with their test results.

The AASHTO LRFD Bridge Design Specifications (2012) specify equations for simplified method of analysis to determine the flexural moment and shear force in concrete beams used in multibeam decks due to live load for one design lane and two or more design lanes using distribution factors. The AASHTO LRFD specifies different equations for concrete beams sufficiently connected to act as a unit or connected enough to prevent relative vertical displacement. The AASHTO LRFD distribution factor equations used for concrete beams used in mutibeam decks are as follows:

For longitudinal bending moment distribution factor for girders sufficiently connected to act as one unit:

- Moment distribution factor for interior beam:

1) One design lane loaded:

$$
\mathrm{g}_{\text {interior }}=\mathrm{k}\left(\frac{\mathrm{b}}{33.3 \mathrm{~L}}\right)^{0.5}\left(\frac{\mathrm{I}}{\mathrm{J}}\right)^{0.25}
$$

2) Two or more design lanes loaded: 


$$
\mathrm{g}_{\text {interior }}=\mathrm{k}\left(\frac{\mathrm{b}}{305}\right)^{0.6}\left(\frac{\mathrm{b}}{12.0 \mathrm{~L}}\right)^{0.2}\left(\frac{\mathrm{I}}{\mathrm{J}}\right)^{0.06}
$$

Where,

$\mathrm{k}=2.5\left(\mathrm{~N}_{\mathrm{b}}\right)^{-0.2} \geq 1.5$

b : Beam Width $35 \leq \mathrm{b} \leq 60$ (in. );

$\mathrm{L}:$ Span Length $20 \leq \mathrm{L} \leq 120(\mathrm{ft})$

$\mathrm{N}_{\mathrm{b}}$ : Number of Beams $5 \leq \mathrm{N}_{\mathrm{b}} \leq 20$;

I : Moment of inertia of beam $\left(\mathrm{in}^{4}\right)$;

J : St. Venant's torsional inertia $\left(\mathrm{in}^{4}\right)$;

Simplified value $\frac{\mathrm{I}}{\mathrm{J}}=0.54\left(\frac{\mathrm{d}}{\mathrm{b}}\right)+0.16$; and

$\mathrm{d}$ : Depth of beam (in.).

- Moment distribution factor for exterior beam:

1) One design lane loaded:

$$
\begin{aligned}
& \mathrm{g}=\mathrm{e}_{\text {interior }} \\
& \mathrm{e}=1.125+\frac{\mathrm{d}_{\mathrm{e}}}{30} \geq 1.0
\end{aligned}
$$

2) Two or more design lanes loaded:

$$
\begin{aligned}
& \mathrm{g}=\mathrm{e} \mathrm{g}_{\text {interior }} \\
& \mathrm{e}=1.04+\frac{\mathrm{d}_{\mathrm{e}}}{25} \geq 1.0
\end{aligned}
$$

Where,

ginterior : Interior distribution factor

e : Correction factor; and

$\mathrm{d}_{\mathrm{e}}$ : Horizontal distance from the centerline of the exterior web of the exterior beam at deck level to the interior edge of curb or traffic barrier $\mathrm{d}_{\mathrm{e}} \leq 2.0(\mathrm{ft})$;

For the shear distribution factor for girders sufficiently connected to act as one unit: 
- Shear distribution factor for interior beam:

1) One design lane loaded:

$$
\mathrm{g}_{\text {interior }}=\left(\frac{\mathrm{b}}{130 \mathrm{~L}}\right)^{0.15}\left(\frac{\mathrm{I}}{\mathrm{J}}\right)^{0.05}
$$

2) Two or more design lanes loaded:

$$
\mathrm{g}_{\text {interior }}=\left(\frac{\mathrm{b}}{156}\right)^{0.4}\left(\frac{\mathrm{b}}{12.0 \mathrm{~L}}\right)^{0.1}\left(\frac{\mathrm{I}}{\mathrm{J}}\right)^{0.05}\left(\frac{b}{48}\right)
$$

Where,

$\frac{\mathrm{b}}{48} \geq 1.0$

$\mathrm{b}:$ Beam Width $35 \leq \mathrm{b} \leq 60$ (in. );

$\mathrm{L}$ : Span Length $20 \leq \mathrm{L} \leq 120(\mathrm{ft})$;

$\mathrm{N}_{\mathrm{b}}$ : Number of Beams $5 \leq \mathrm{N}_{\mathrm{b}} \leq 20$;

I : Moment of inertia of beam 40,000 $\leq \mathrm{I} \leq 610,000\left(\mathrm{in}^{4}\right)$;

$\mathrm{J}$ : St. Venant's torsional inertia 25,000 $\leq \mathrm{J} \leq 610,000\left(\right.$ in $\left.^{4}\right)$;

Simplified value $\frac{\mathrm{I}}{\mathrm{J}}=0.54\left(\frac{\mathrm{d}}{\mathrm{b}}\right)+0.16$; and

$\mathrm{d}$ : Depth of beam (in.).

- Shear distribution factor for exterior beam:

1) One design lane loaded:

$$
\begin{aligned}
& \mathrm{g}=\mathrm{e}_{\text {interior }} \\
& \mathrm{e}=1.25+\frac{\mathrm{d}_{\mathrm{e}}}{20} \geq 1.0
\end{aligned}
$$

2) Two or more design lanes loaded:

$$
\begin{aligned}
& \mathrm{g}=\mathrm{e} \mathrm{g}_{\text {interior }}\left(\frac{48}{b}\right) \\
& \mathrm{e}=1+\left(\frac{d_{e}+\frac{b}{12}-2.0}{40}\right)^{0.5} \geq 1.0
\end{aligned}
$$


Where,

$\mathrm{g}_{\text {interior }}$ : Interior distribution factor;

e : Correction factor;

$\mathrm{d}_{\mathrm{e}}$ : Horizontal distance from the centerline of the exterior web of the exterior beam at deck level to the interior edge of curb or traffic barrier $\mathrm{d}_{\mathrm{e}} \leq 2.0(\mathrm{ft})$; and

b : Beam Width $35 \leq \mathrm{b} \leq 60$ (in.).

\subsubsection{Simplified Method of Analysis (CHBDC, 2006)}

The Canadian Highway Bridge Design Code (CHBDC, 2006), and the 1991 version of the Ontario Highway Bridge Design Code (OHBDC, 1991), specifies simplified method of analysis for live load using load distribution factors for slab-on-girder bridges. The simplified method of analysis for the live load was developed based on the results from bridge analysis using grillage, semicontinuum and finite-element methods for which the idealized structure was essentially an orthotropic plate. There are conditions and limitations for the use of simplified method of analysis, which are specified in the CHBDC. Shear-connected beam bridges are analyzed by the methods applicable to shallow superstructure provided that continuity of transverse flexural rigidity across the cross-section is present. If not, analysis for longitudinal moments and shears is by the same method as for multi-spine box girders.

In 2003, Androus applied the CHBDC truck loading to examine the behavior and load distribution characteristics of straight and curved composite multiple box-girder bridges. His experimental tests proved that the presence of external cross bracing ensured better distribution of the stresses under ultimate loading conditions. Results from his work showed that bridge curvature is the most critical parameter that influences the design of girders and bracing members in box bridges. Also, the study showed that bending stress distribution factors decrease with the increase in number of box girders. On the other hand, the bending stress distribution factors for the outer and inner girders increase with increase in the span length of the bridge. In 2005, Hassan used CHBDC truck load to investigate the shear distribution in straight and curved composite multiple box-girder bridges by using the finite-element modeling. It was observed that the bridge span length slightly affects the shear distribution factor of straight bridges. However, its effect significantly increases with 
increase in bridge curvature. On the other hand, the shear distribution factor is significantly affected by the change in number of boxes.

The Canadian Highway Bridge Design Code (CHBDC, 2006) specifies equations for the simplified method of analysis to determine the longitudinal bending moments and vertical shear in slab-on-girder bridges due to live load for ultimate, serviceability and fatigue limit states using load distribution factors. The CHBDC distribution factor equations used for slab on prestressed girders are as follows:

The longitudinal bending moment per girder, $M_{g}$ for ultimate and serviceability limit states:

$$
M_{g}=F_{m} M_{g} \text { avg }
$$

Where,

$\mathrm{M}_{\mathrm{g} \text { avg }}$ : Average moment per girder; and

$\mathrm{F}_{\mathrm{m}}$ : An amplification factor for the transverse variation in maximum longitudinal moment intensity (Distribution Factor).

$$
\begin{aligned}
& M_{g \text { avg }}=\frac{n M_{T} R_{L}}{N} \\
& F_{m}=\frac{S ~ N}{F\left(1+\frac{\mu C_{f}}{100}\right)} \geq 1.05 \\
& \mu=\frac{W_{e}-3.3}{0.6} \leq 1.0
\end{aligned}
$$

Where,

$\mathrm{M}_{\mathrm{T}}$ : The maximum moment per design lane;

$\mathrm{n}$ : The number of design lanes;

$\mathrm{R}_{\mathrm{L}}$ : Modification factor for multilane loading;

$\mathrm{N}$ : The number of longitudinal girders;

$\mathrm{S}:$ Centre-to-centre girder spacing $(\mathrm{m})$;

$\mathrm{W}_{\mathrm{e}}$ : The width of the design lane $(\mathrm{m})$;

$\mathrm{C}_{\mathrm{f}}$ : Correction factor obtained from tables; and 
F : The width dimension that characterizes the load distribution for the bridge.

The longitudinal bending moment per girder, $\mathrm{M}_{\mathrm{g}}$ for Fatigue Limit State:

$$
M_{g}=F_{m} M_{g} \text { avg }
$$

Where,

$\mathrm{M}_{\mathrm{g} \text { avg }}$ : Average moment per girder; and

$\mathrm{F}_{\mathrm{m}}$ : An amplification factor for the transverse variation in maximum longitudinal moment intensity (Distribution Factor).

$$
\begin{aligned}
& M_{g \text { avg }}=\frac{M_{T}}{N} \\
& F_{m}=\frac{S ~ N}{F\left(1+\frac{\mu C_{f}}{100}+\frac{C_{e}}{100}\right)} \geq 1.05 \\
& \mu=\frac{W_{e}-3.3}{0.6} \leq 1.0
\end{aligned}
$$

Where,

$\mathrm{M}_{\mathrm{T}}$ : The maximum moment per design lane;

$\mathrm{n}$ : The number of design lanes;

$\mathrm{R}_{\mathrm{L}}$ : Modification factor for multilane loading;

$\mathrm{N}$ : The number of longitudinal girders;

$\mathrm{S}:$ Centre-to-centre girder spacing $(\mathrm{m})$;

$\mathrm{W}_{\mathrm{e}}$ : The width of the design lane $(\mathrm{m})$;

$\mathrm{C}_{\mathrm{f}}$ : Correction factor obtained from tables;

$\mathrm{C}_{\mathrm{e}}$ : Correction factor for vehicle edge distance obtained from tables; and

F : The width dimension that characterizes the load distribution for the bridge.

The longitudinal vertical shear per girder, $V_{\mathrm{g}}$ for ultimate, serviceability and fatigue limit states:

$$
\mathrm{V}_{\mathrm{g}}=\mathrm{F}_{\mathrm{v}} \mathrm{V}_{\mathrm{g} \text { avg }}
$$

Where, 
$V_{g \text { avg }}$ : Average shear per girder; and

$\mathrm{F}_{\mathrm{v}}$ : An amplification factor for the transverse variation in maximum longitudinal vertical shear intensity (Distribution Factor).

$$
\begin{aligned}
& V_{g \text { avg }}=\frac{n V_{T} R_{L}}{N} \\
& F_{V}=\frac{S N}{F}
\end{aligned}
$$

Where,

$\mathrm{V}_{\mathrm{T}}$ : The maximum vertical shear per design lane;

$\mathrm{n}:$ The number of design lanes;

$\mathrm{R}_{\mathrm{L}}:$ Modification factor for multilane loading;

$\mathrm{N}$ : The number of longitudinal girders;

$\mathrm{S}:$ Centre-to-centre girder spacing $(\mathrm{m})$; and

F : The width dimension that characterizes the load distribution for the bridge.

The Canadian Highway Bridge Design Code (CHBDC, 2006) specifies equations for transverse vertical shear in shear connected beam bridges to determine the maximum intensity of transverse shear. In the CHBDC, it was assumed the maximum transverse vertical shear to occur when there is only one design vehicle on the bridge

The CHBDC simplified method for shear connected beam bridges used for slab on prestressed girders are as follows:

$$
\mathrm{V}_{\mathrm{y}}=\mathrm{kW}
$$

Where,

$\mathrm{k}$ : Applicable value obtained from Figure 2.9; and

$\mathrm{W}:$ Heaviest axel load of the design vehicle $(\mathrm{kN})$.

$$
\begin{aligned}
& \beta=\pi\left[\frac{\mathrm{B}}{\mathrm{L}}\right]\left[\frac{\mathrm{D}_{\mathrm{x}}}{\mathrm{D}_{\mathrm{xy}}}\right]^{0.5} \\
& \mathrm{D}_{\mathrm{x}}=\frac{\mathrm{EI}}{\mathrm{P}_{\mathrm{x}}}
\end{aligned}
$$




$$
D_{x y}=G \frac{4 A_{o}^{2}}{P_{x} \sum \frac{d s}{n_{g t}}}
$$

Where,

B : Width of the bridge;

L : Span length;

$\mathrm{D}_{\mathrm{x}}$ : Total bending stiffness;

$\mathrm{D}_{\mathrm{xy}}:$ Total torsional stiffness; and

EI : Bridge cross-section divided by the width of the bridge.

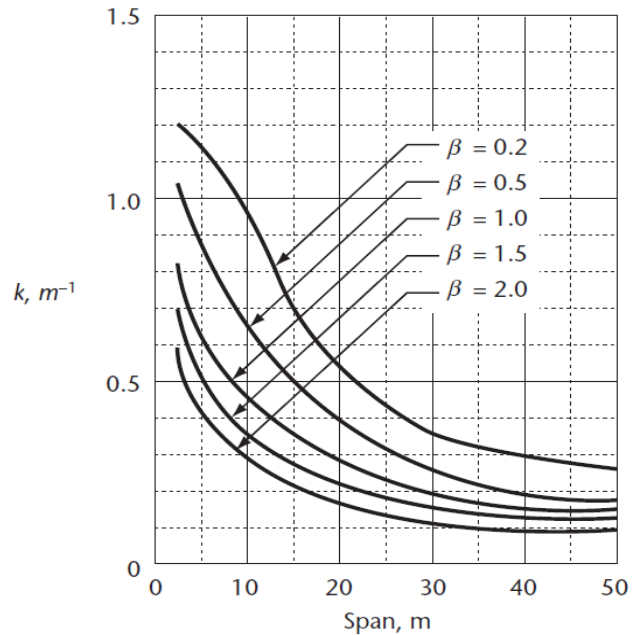

(a) $B=7.5 \mathrm{~m}$

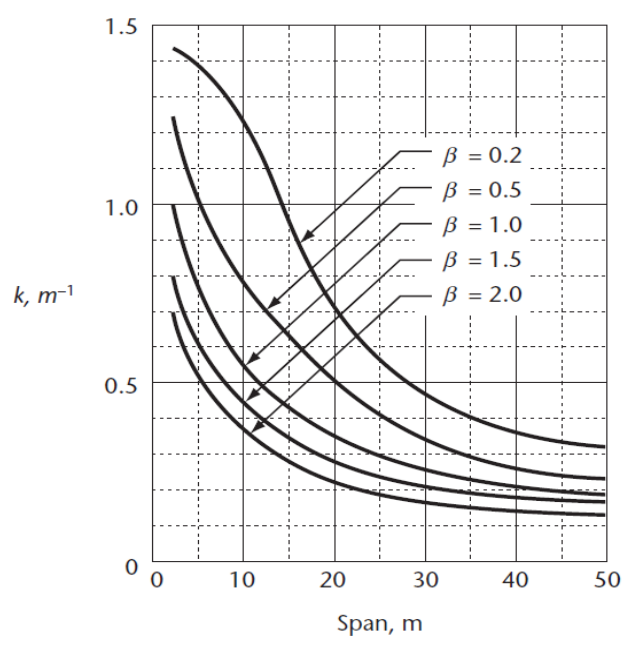

(b) $B=10.0 \mathrm{~m}$

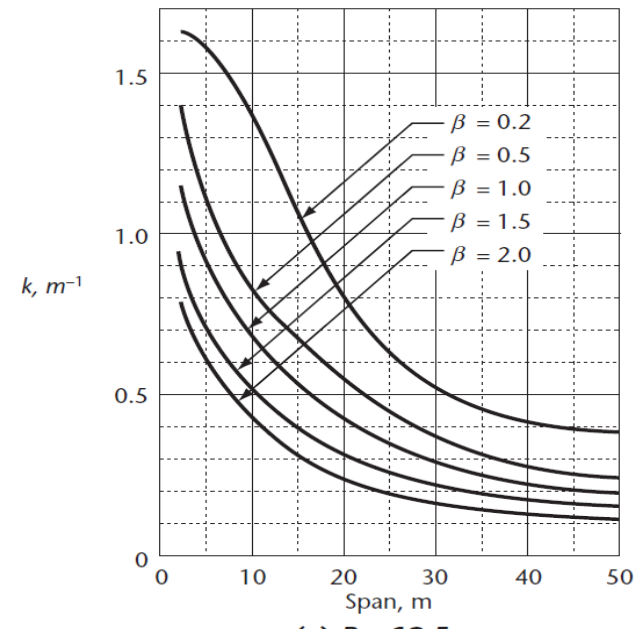

(c) $B=12.5 \mathrm{~m}$

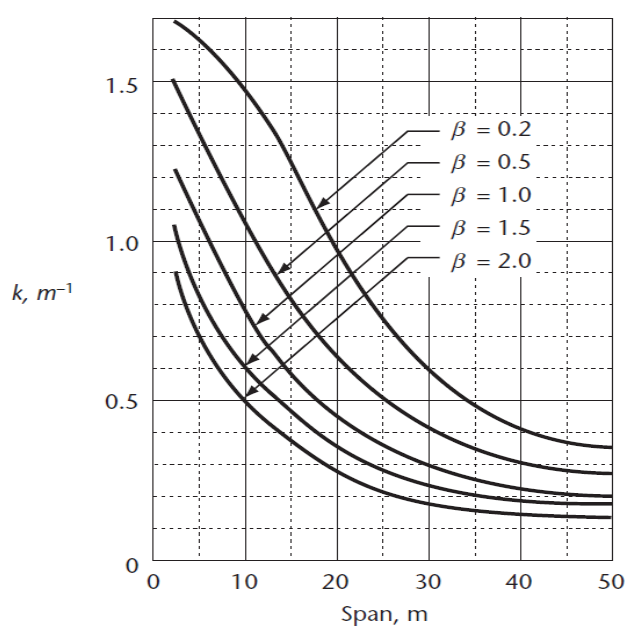

(d) $B=15.0 \mathrm{~m}$

Figure 2.9: Values of $k$ for calculating transverse vertical shear in shear connected beam bridges (CHBDC, 2014) 


\subsubsection{Simplified Method of Analysis (CHBDC, 2014)}

The new version of the Canadian Highway Bridge Design Code (CHBDC, 2014), specifies a developed simplified method of analysis for live load using load distribution factors for slab-ongirder bridges as follows:

The longitudinal moment per girder $\mathrm{M}_{\mathrm{L}}$ and the longitudinal shear per girder $\mathrm{V}_{\mathrm{L}}$, for ultimate and serviceability limit states:

$$
\begin{aligned}
& \mathrm{M}_{\mathrm{L}}=\mathrm{F}_{\mathrm{T}} \mathrm{F}_{\mathrm{S}} \mathrm{M}_{\mathrm{T}} \\
& \mathrm{V}_{\mathrm{L}}=\mathrm{F}_{\mathrm{T}} \mathrm{F}_{\mathrm{S}} \mathrm{V}_{\mathrm{T}}
\end{aligned}
$$

Where,

$\mathrm{M}_{\mathrm{T}}$ : Longitudinal moment generated by one lane of CL-W loading;

$\mathrm{V}_{\mathrm{T}}$ : Longitudinal shear generated by one lane of CL-W loading;

$\mathrm{F}_{\mathrm{T}}:$ Truck load fraction; and

$\mathrm{F}_{\mathrm{S}}:$ Skew effect.

$$
\begin{aligned}
& \mathrm{F}_{\mathrm{T}}=\frac{\mathrm{s}}{\mathrm{D}_{\mathrm{T}} \gamma_{\mathrm{c}}(1+\mu \lambda)} \geq 1.05 \frac{\mathrm{n} \mathrm{R}_{\mathrm{L}}}{\mathrm{N}} \\
& \mu=\frac{\mathrm{w}_{\mathrm{e}}-3.3}{0.6} \leq 1.0
\end{aligned}
$$

Where,

$\mathrm{D}_{\mathrm{T}}:$ Truck load distribution width $(\mathrm{m})$;

$\gamma_{c}$ : Truck load modification factor for slab on girder bridges;

$\lambda:$ Lane width parameter;

$\mu$ : Lane width modification factor;

$\mathrm{n}$ : The number of design lanes;

$\mathrm{R}_{\mathrm{L}}$ : Modification factor for multilane loading;

$\mathrm{N}$ : Number of longitudinal girders;

$\mathrm{S}:$ Centre-to-centre girder $\operatorname{spacing}(\mathrm{m})$; and 
$\mathrm{W}_{\mathrm{e}}$ : Width of the design lane $(\mathrm{m})$.

The longitudinal moment per girder $\mathrm{M}_{\mathrm{L}}$ and longitudinal shear per girder $\mathrm{V}_{\mathrm{L}}$, for fatigue limit states:

$$
\begin{aligned}
& \mathrm{M}_{\mathrm{L}}=\mathrm{F}_{\mathrm{T}} \mathrm{F}_{\mathrm{S}} \mathrm{M}_{\mathrm{T}} \\
& \mathrm{V}_{\mathrm{L}}=\mathrm{F}_{\mathrm{T}} \mathrm{F}_{\mathrm{S}} \mathrm{V}_{\mathrm{T}}
\end{aligned}
$$

Where,

$\mathrm{M}_{\mathrm{T}}$ : Longitudinal moment generated by one lane of CL-W loading;

$\mathrm{V}_{\mathrm{T}}$ : Longitudinal shear generated by one lane of CL-W loading;

$\mathrm{F}_{\mathrm{T}}:$ Truck load fraction; and

$\mathrm{F}_{\mathrm{S}}:$ Skew effect.

$$
\begin{aligned}
& \mathrm{F}_{\mathrm{T}}=\frac{\mathrm{s}}{\mathrm{D}_{\mathrm{T}} \gamma_{\mathrm{c}}\left(1+\mu \lambda+\gamma_{\mathrm{e}}\right)} \geq 1.05 \frac{1}{\mathrm{~N}} \\
& \mu=\frac{\mathrm{W}_{\mathrm{e}}-3.3}{0.6} \leq 1.0
\end{aligned}
$$

Where,

$\mathrm{D}_{\mathrm{T}}:$ Truck load distribution width(m);

$\gamma_{c}:$ Truck load modification factor for slab on girder bridges;

$\gamma_{\mathrm{e}}$ : Truck load modification factor for exterior girder for slab on girder bridges;

$\lambda:$ Lane width parameter;

$\mu$ : Lane width modification factor;

$\mathrm{N}$ : Number of longitudinal girders; and

$\mathrm{W}_{\mathrm{e}}$ : Width of the design lane $(\mathrm{m})$. 


\section{CHAPTER III \\ 3. FINITE-ELEMENT ANALYSIS}

\subsection{General}

According to the literature review, finite-element analysis is considered as the most powerful method of analysis to any complex project nowadays. It deals with problems that have arbitrary arrangements of structural elements, material properties, and boundary conditions. To date, finite element method (FEM) has proven to give the most reliable results when compared to experimental findings; thus the designers and code writers hugely encouraged the use of FEM in the analysis and design of different engineering structure. In finite-element modeling the structure divided into discrete elements connected together by nodal points. A typical finite-element has a stiffness matrix relating the nodal vector displacement to nodal applied forces and can be expressed as functions of properties or geometries of elements. There are three types of functions elements, namely: (i) one dimensional element called linear element, (ii) two-dimensional element such as plane and triangular element and (iii) three-dimensional solid element. In order to model and analyze any structural shape and to generate a finite-element meshing, SAP2000 software (Computers, 2015) is one of the best user-friendly computer software available for such an analysis. SAP2000 software's element library includes six elements with carrying degrees of freedom, namely: 2D Plane element, 3D frame element, 3D shell element, 3D solid element, 2D Asoild element, and 3D Nlink element that will be discussed later in this section.

In this study, a developed finite-element model, using SAP2000 software version 17, was used to perform extensive parametric study on the structural behavior of adjacent precast, prestressed concrete box girder bridges due to CHBDC truck loading conditions.

\subsection{Finite-Element Approach}

The finite-element method can be used to solve any complicated problems in the field of structural engineering and mathematical physics. The methodology used in the finite element method of analysis starts in discretization a model by dividing it into an equivalent system of smaller bodies or units called finite-elements interconnected at points called nodes common to two or more elements and/or boundary lines and/or surfaces and then an equation formulated combining all the elements to obtain solution for one whole body. Thus, the smaller the meshing element size, the more accurate the results. For the purpose of simplifying the formulation of the element equations, 
matrix methods are implemented. Matrix methods are considered as an important tool used to structure the program of the finite-element method to facilitate their computation process in highspeed computers.

In general, there are two approaches related to the finite-element, namely: (i) force or flexibility method, and (ii) displacement or stiffness method. Literature review showed that for computational purposes, the latter method is more desirable because its formulation is simpler for most structural analysis problems. Moreover, an enormous majority of general-purpose finite-element programs have incorporated the displacement formulation for solving structure problems.

In the modelling process, selecting the most appropriate element type to model the most closely model to the actual physical behaviour is very important. An equation is then formulated combining all the elements to obtain a solution for one whole body. Using a displacement formulation, the stiffness matrix of each element is derived and the global stiffness matrix of the entire structure can be formulated by the direct stiffness method. This global stiffness matrix, along with the given displacement boundary conditions and applied loads is then solved, thus the displacements and stresses for the entire system are determined.

The global stiffness matrix represents the nodal force displacement relationships and is expressed in a matrix equation form as follows:

$$
[\mathrm{P}]=[\mathrm{K}][\mathrm{U}]
$$

Where,

[P] : Nodal load vector;

[K] : Global stiffness matrix; and

[U] : Nodal displacement vector.

The steps for deriving the above equations can be summarized as follows:

(a) $v(x, y)=[\varnothing(x, y)][\alpha]$

Where,

$\mathrm{v}(\mathrm{x}, \mathrm{y}):$ Internal displacement vector of the element;

$[\varnothing(\mathrm{x}, \mathrm{y})]$ : Displacement function matrix; and 
$[\alpha]$ : Generalized coordinates matrix.

(b) $[\mathrm{U}]=[\mathrm{A}][\alpha] \quad$ Then, $[\alpha]=[\mathrm{A}]^{-1}[\mathrm{U}]$

Where,

[A] : The transformation matrix from local to global coordinated.

(c) $[\varepsilon(\mathrm{x}, \mathrm{y})]=[\mathrm{B}(\mathrm{x}, \mathrm{y})][\alpha]=[\mathrm{B}(\mathrm{x}, \mathrm{y})][\mathrm{A}]^{-1}[\mathrm{U}]$

Where,

$[\mathrm{B}(\mathrm{x}, \mathrm{y})]$ : Strain-displacement matrix; and

$[\varepsilon(\mathrm{x}, \mathrm{y})]:$ Strain matrix.

(d) $[\varepsilon(\mathrm{x}, \mathrm{y})]=[\mathrm{B}(\mathrm{x}, \mathrm{y})][\alpha]=[\mathrm{B}(\mathrm{x}, \mathrm{y})][\mathrm{A}]^{-1}[\mathrm{U}]$

Where,

[D] : Constitutive matrix or the elasticity matrix

From the principle of minimization of the local potential energy, the total external work is equal to $\frac{1}{2}[\mathrm{U}]^{\mathrm{T}}[\mathrm{P}]$, the

(e) $\mathrm{I}-\mathrm{W}_{\mathrm{E}}=\left[\mathrm{U}^{\prime}\right]^{\mathrm{T}}[\mathrm{P}]$

$$
\begin{gathered}
\text { II- } \mathrm{W}_{\mathrm{I}}=\int[\varepsilon]^{\mathrm{T}}[\sigma]=\left[\mathrm{u}^{\prime}\right]^{\mathrm{T}}[\mathrm{A}]^{-1}\left[\mathrm{k}^{\prime}\right][\mathrm{A}]^{-1}[\mathrm{U}] \\
{\left[\mathrm{k}^{\prime}\right]=\int[\mathrm{B}(\mathrm{x}, \mathrm{y})]^{\mathrm{T}}[\mathrm{D}][\mathrm{B}(\mathrm{x}, \mathrm{y})]}
\end{gathered}
$$

Where,

$\mathrm{W}_{\mathrm{E}}$ : External virtual work;

$\mathrm{W}_{\mathrm{I}}$ : Internal virtual work;

$\left[\mathrm{u}^{\prime}\right]$ : Vector of virtual displacement; and

$\left[\mathrm{k}^{\prime}\right]$ : Element stiffness matrix.

(f) From the principle of virtual work, $\mathrm{W}_{\mathrm{E}}=\mathrm{W}_{\mathrm{I}}$. By taking one element of virtual nodal displacement vector $\left[\mathrm{u}^{\prime}\right]$ equal to unity successfully, the solution becomes:

$[\mathrm{P}]=[\mathrm{K}][\mathrm{U}]$ 
Where $[\mathrm{K}]=\sum\left[\mathrm{k}^{\prime}\right]$, so the global structural stiffness matrix is assemblage of the element stiffness $\operatorname{matrix}\left[\mathrm{k}^{\prime}\right]$.

(g) The solution of the resulting system of equations yields the values of nodal displacement $[\mathrm{U}]$ and the internal forces for each element can be obtained from equation

In the finite-element modeling, linear and non-linear problems can be solved. In the case of a linear (elastic) structural problem, loads are first applied on a model and the solution is obtained directly. In a non-linear case, the analysis follows a different numerical method to obtain a solution.

\subsection{SAP2000 Computer Program}

SAP2000 software (CSI, 2015) is one of the most popular software used since 1980's to model finite-element of complicated structures and to estimate structural response due to various applied load. This software is used worldwide since its very powerful in analyze and solve determinate and indeterminate structure, static or dynamic problems, linear or non-linear types of structure utilizing both geometric and material properties. SAP2000 finite-element library consists of six elements:

1. Frame Element: is a two-node three-dimensional element, which includes the effect of biaxial bending, tension, axial deformation, and biaxial shear deformation.

2. Shell Element: is a three or four-node three-dimensional element, which combines separate membrane and plate-bending behaviour, it allows using pure membrane, pure plate, or full shell behaviour.

- The membrane behaviour includes translational in-plane stiffness components and rotational stiffness component in the direction normal to the plane of the element.

- The plate bending behaviour includes two-way, out of plane, plate rotational stiffness components and translational stiffness component in the direction normal to the plane of the element.

3. Plane Element: is a three- to nine-node two-dimensional element, which contributes stiffness only in two translational degrees of freedom at each of its connected joints. Plane element is used for modeling thin plane stress structures and long plane strain structures. 
4. Solid Element: is an eight-node three-dimensional element, which includes nine optional incompatible bending nodes. The solid element contributes stiffness in all three translational degrees of freedom at each of its connected joints.

5. Asolid Element: is a three- to nine-node two-dimensional element, which contributes stiffness only in the two translational degrees of freedom at each of its connected joints. It is used for modeling axisymmetric structures under axisymmetric loading.

6. Nllink Element: is a one joint grounded spring or two joint link which is composed of six separate springs, one of each of the six deformational degrees of freedom. It is used for modeling linear or nonlinear structural behaviour. The nonlinear behaviour is used only for the time-history analysis.

In addition, subsets of these elements with varying degrees of freedom are available in the form of truss, frame, membrane, beam, strain, gap, and hook elements.

Thus, SAP2000 software is extensive in analyzing the structures in both two dimensional and three dimensional format. It has the advantage of drawing windows of different planes and navigates for live multiple models and for complex modes. It is very effective in controlling complex geometries and easy to describe the concrete or steel shapes or fix modulus of elasticity for any materials particularly for composite construction.

\subsection{Finite Element Modelling of Box Girder Bridges}

In this research, SAP2000 software was used to analyze box girder bridges and to determine its structural response, a three dimensional (3D) finite element model was created using shell elements to determine load distribution factors and transverse shear under CHBDC truck loading.

Figure 3.1 shows a schematic diagram of the four-node quadrilateral shell element considered in this study, while Figure 3.2 shows shell element stresses, internal forces and moment at global and local coordinates as shown in SAP2000 software manual. In this research, the deck-free adjacent box beam bridge was divided into five major components as follows: top flange, bottom flange, webs, connection joints and end diaphragms, on which shell elements were incorporated to develop the finite-element model. A sensitivity study was conducted to investigate the effect of number of finite elements in the web and flanges of the box beams as well as the type of connecting elements between boxes as explained in the following sub-section. 


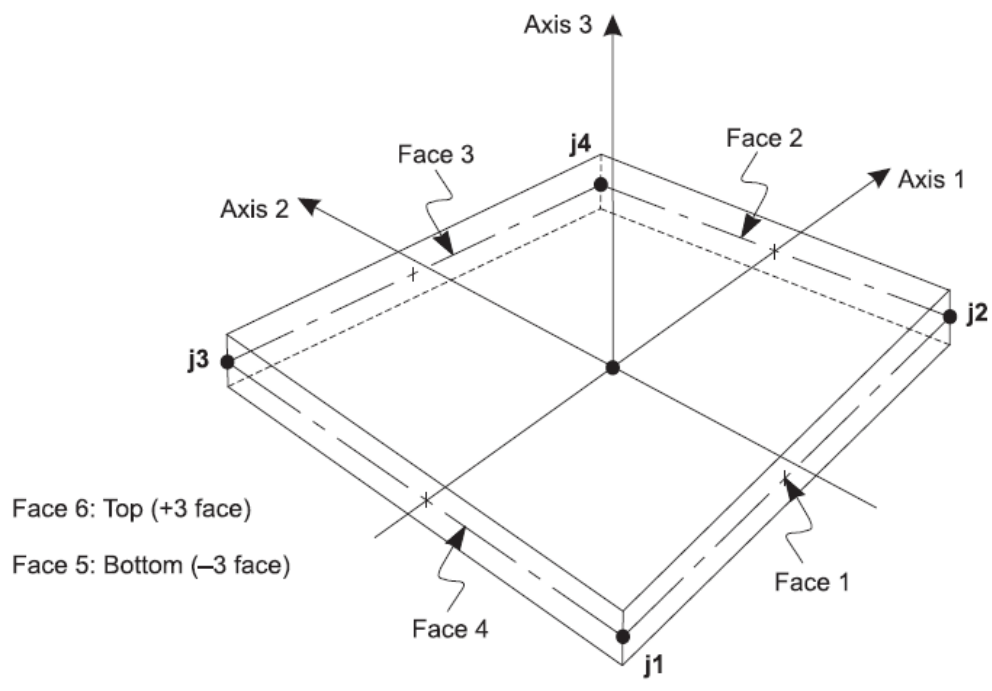

Figure 3.1: Four node quadrilateral shell element (SAP2000)

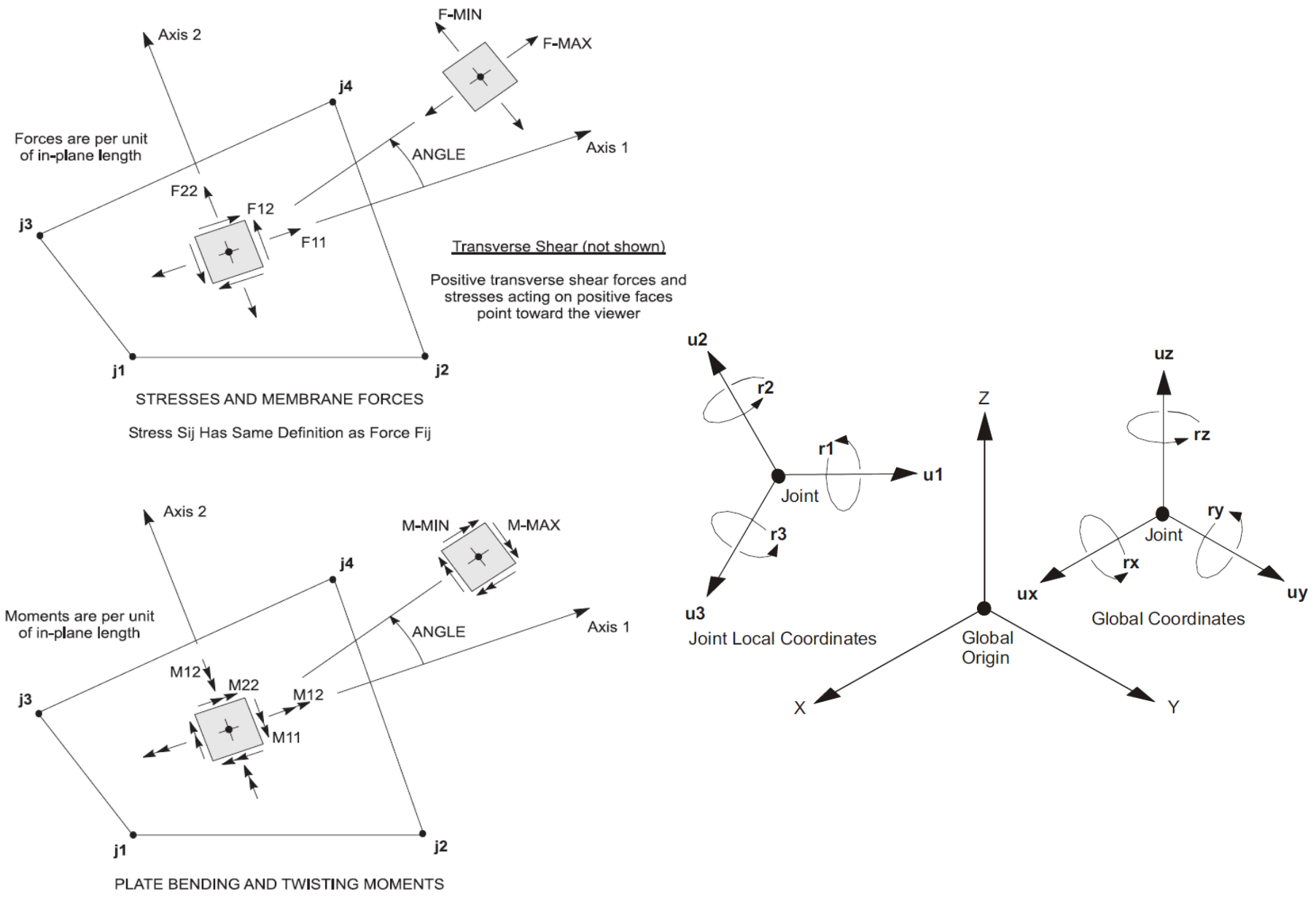

Figure 3.2: Shell element stresses, internal forces and moment at global and local coordinate (SAP2000) 


\subsubsection{Sensitivity Analysis of Box Girder Bridge}

A case of sensitivity study has been carried out to investigate the accuracy of the results from the finite element analysis. In this study, various numbers of elements, in the longitudinal, vertical and transverse directions of the bridge model, have been considered. The various number and types of boundary conditions were used to find the accurate results. The level of accuracy of the developed FEA model was examined against results from simple-beam analysis for a uniform superimposed loading of $10 \mathrm{kN} / \mathrm{m}$. Three main straining actions were considered for comparison, namely: maximum bending moments at mid-span, maximum deflection at mid-span and support reaction. A bridge prototype of 13 adjacent box beams and $20 \mathrm{~m}$ span length was modeled and analyzed using SAP2000 software under CHBDC truck loading. In this model, five different element types of joints between box beams were considered, namely: (1) shell element of thickness $225 \mathrm{~mm}$, (2) frame element of width $257 \mathrm{~mm}$ and depth $200 \mathrm{~mm}$, (3) frame element with hinge element from one side and fixed end from the other side, (4) rigid link as specified in SAP2000 software, and (5) link with fixed displacement as specified in SAP2000 software. Each connection element was examined at three critical locations, namely: (i) connection between the top flanges only, (ii) connection between the top and bottom flanges, and (iii) cellular bridge with combined webs and no joints. It has been observed that using these different connecting elements will not cause significant difference in moment, shear, and deflection distribution factors as shown in Figure B.1 to Figure B.6. However, using shell element connection provides the smallest distribution factor. In addition, it has been observed that using different connection locations in modelling shows the top flange connection providing more conservative values than those obtained when the top and bottom flanges are connected or when using cellular section, as shown in Figure B.7 to Figure B.9. The analysis was conducted to determine load distribution factors for moment, shear and deflection. This sensitivity study has been carried out to investigate the accuracy of the results

from finite-element analysis and verified with previously developed equations by Khan (2010) for adjacent box girder bridges. The results indicate that the proposed finite-element models for this parametric study provides accurate and reliable model. 


\subsubsection{Geometric Modeling}

In this study, the geometry of bridge superstructure is achieved by the appropriate selection of the number of elements representing the webs, bottom flange, top flange, and end diaphragms. The geometric nonlinearity was not considered in this study. A box girder bridge cross-section considered in this study is shown in Figure 3.3.
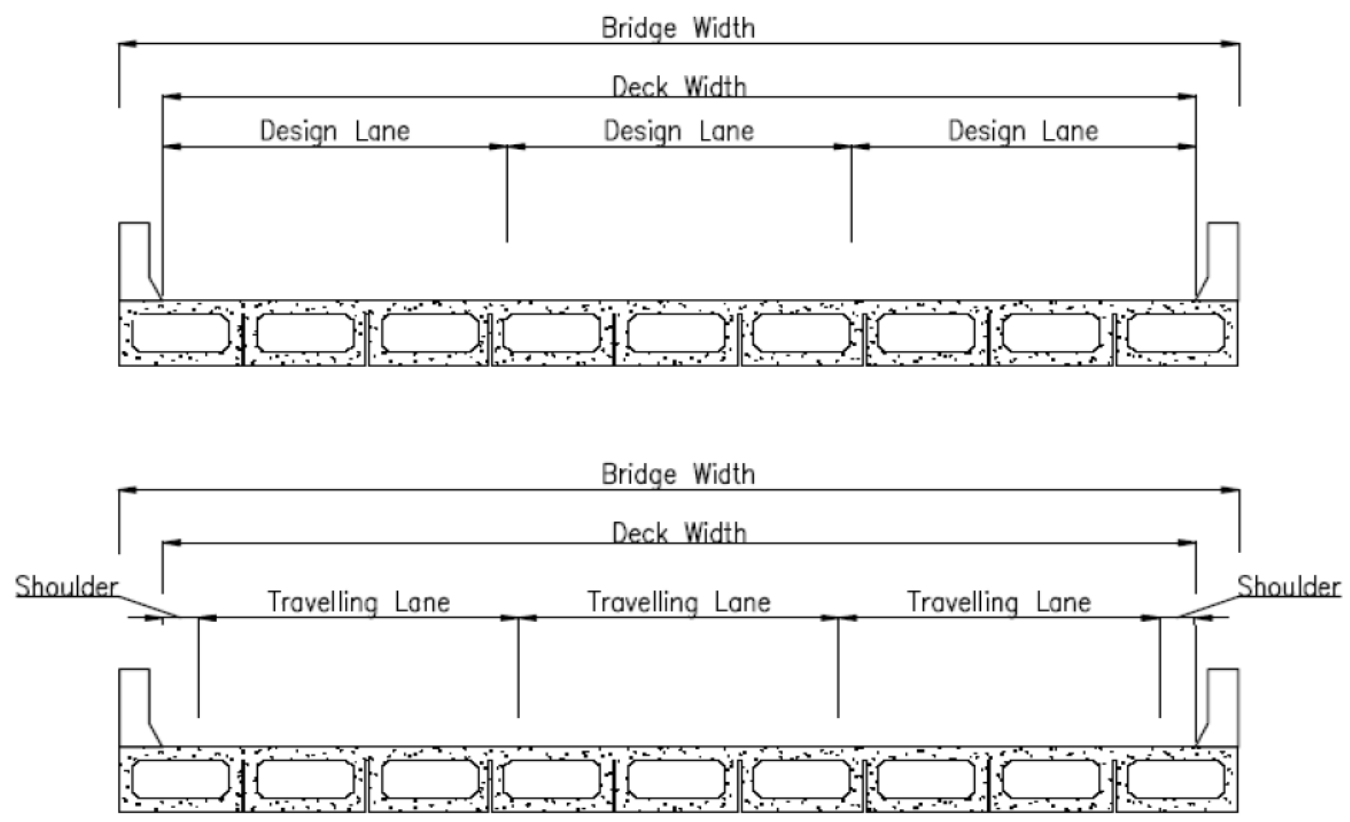

Figure 3.3: Box girder bridge cross section

\subsubsection{Modeling of Webs, Flanges, Connection joints, and End Diaphragms}

To model and analyze box girder bridges, a three-dimensional finite-element model was adopted using SAP2000 software. Shell element was chosen from SAP2000 library to model the bridge components; web, top flange, bottom flange, connecting joints, and end diaphragms. The shell element has four corner nodes with six degrees of freedom at each node that are three displacements (U1, U2, U3) and three rotations $(\varphi 1, \varphi 2, \varphi 3)$ as shown in Figure 3.1 Figure 3.2. Four horizontal shell elements were used to model top and bottom flanges while three vertical shell elements were used to model the webs and one horizontal shell element was used to for connection joints as shown in Figure 3.4. 


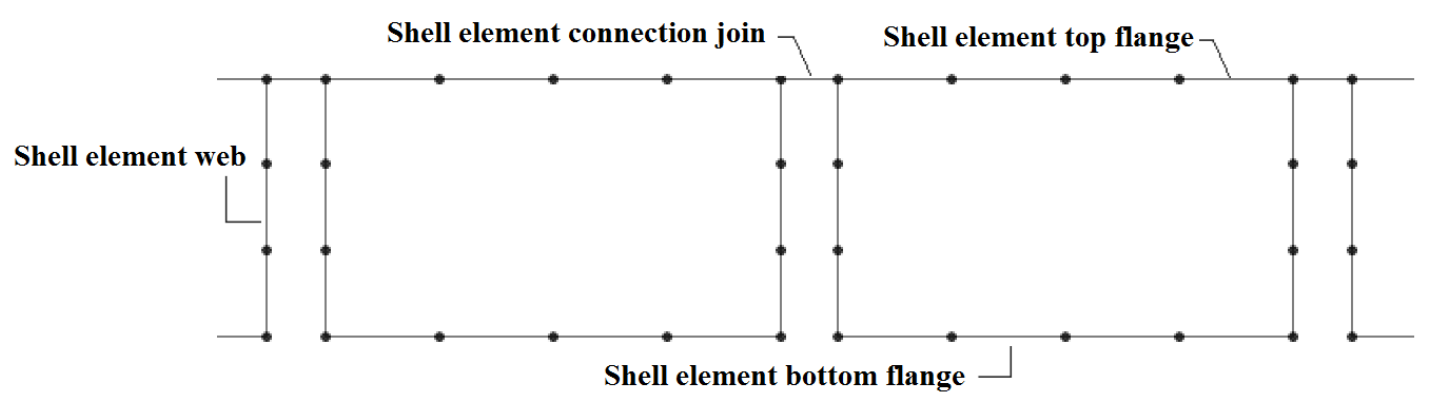

Figure 3.4: Finite-element section of shell elements for bridge cross section

The shell element thickness of these components was taken as those specified in the Pre-Con manual, while the thickness of the top flange, as well as the connecting joint, was taken as $225 \mathrm{~mm}$. End diaphragms between the webs of each box, over the support lines, were modeled with thickness of $300 \mathrm{~mm}$. No intermediate diaphragms were used along the bridge span between supports. In the longitudinal direction of the bridge, number of elements depends on the length of bridge. Figure 3.5 and Figure 3.6.

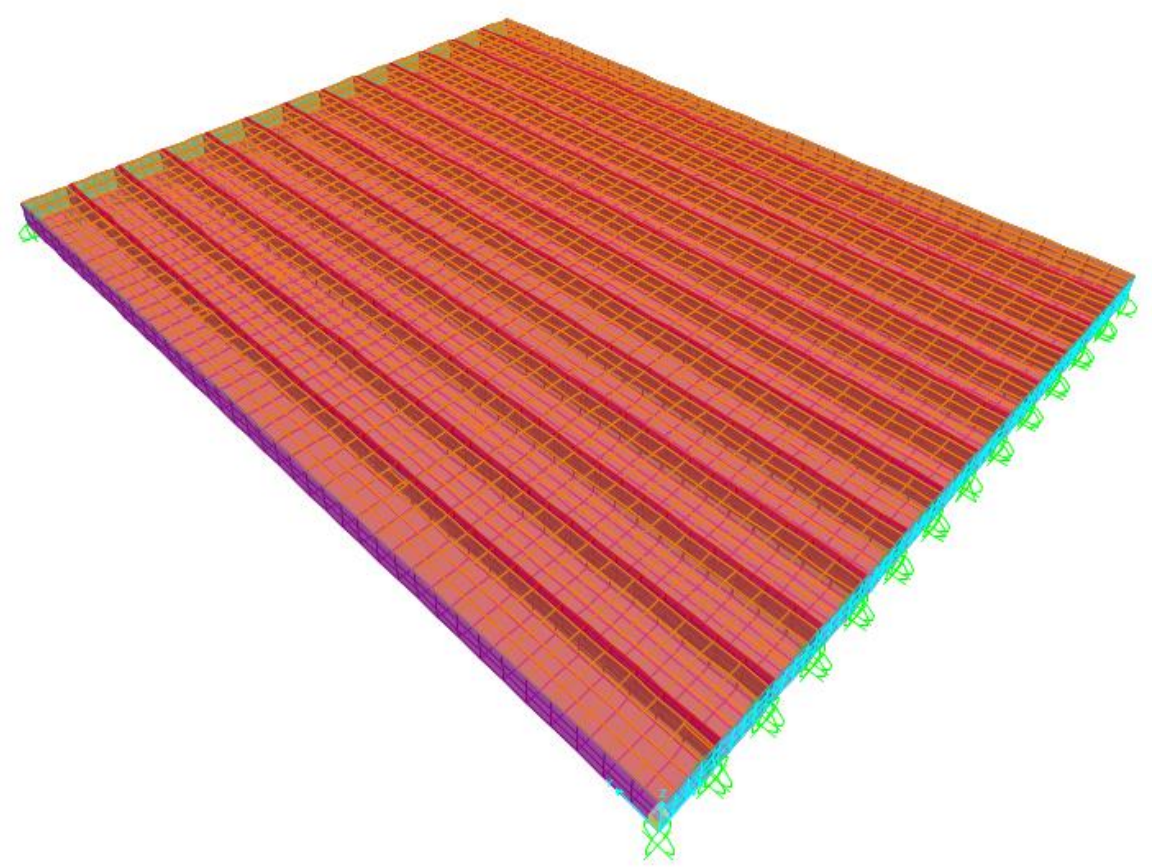

Figure 3.5: View of 3D model of box girder bridges (13 Box Girder, 20m Span) 

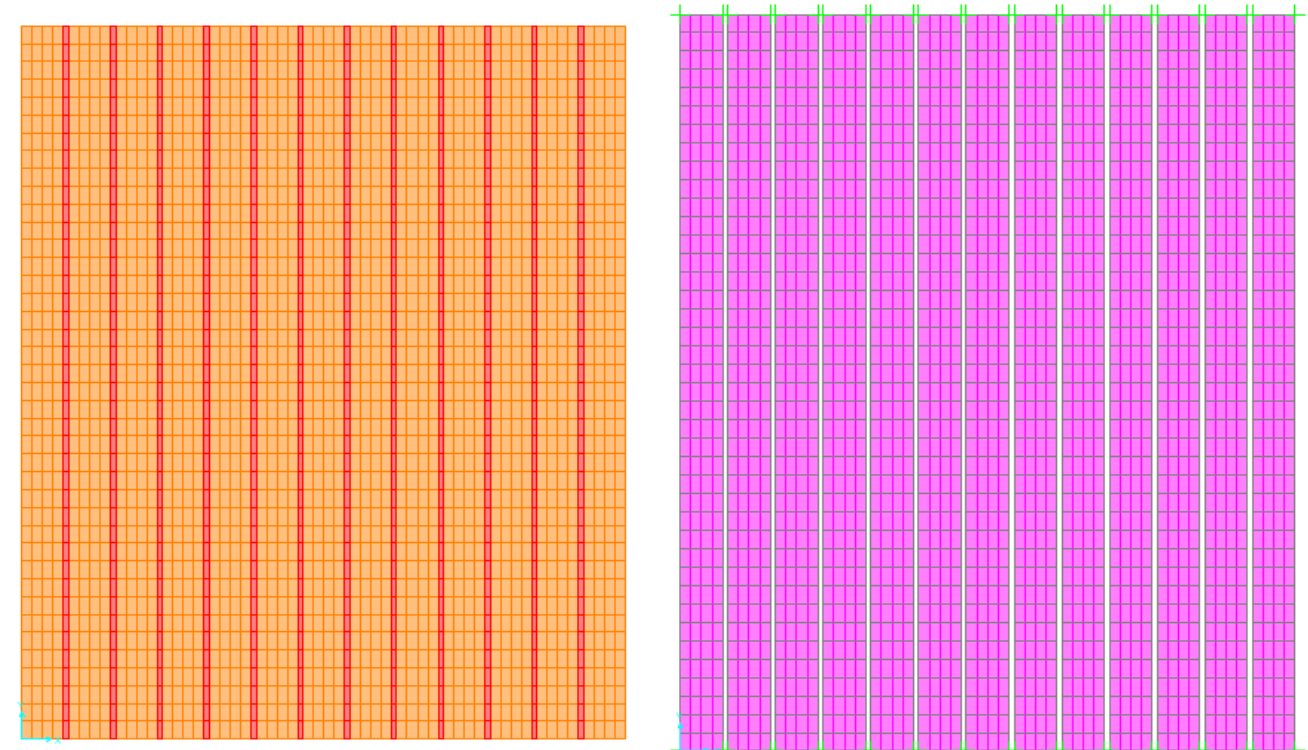

Figure 3.6: Top and bottom view of box girder bridges (13 Box Girder, 20m Span)

\subsubsection{Aspect Ratio}

Element aspect ratio is known as the ratio of the longest to the shortest dimension of a quadrilateral element. According to Logan (2002), the aspect ratio should not be greater than 4 to minimize the percentage of error. As a result, the maximum aspect ratio in this study was below 2.5 by maintaining the length of the shell elements in the direction of a bridge as $500 \mathrm{~mm}$.

\subsubsection{Modeling of Moving Load Path}

In order to analyze different loading cases using moving load path, a Bridge Modeller in CSiBridge software has been used. CSiBridge and SAP2000 have a complete compatibility since the Bridge Modeller supplements SAP2000 releases through version 14, and has since extend into CSiBridge. The software shifts a group of loads, previously defined as static loads, along a defined path and provides the extreme straining action at each node. Therefore, Frame elements are provided in the longitudinal direction at the top of the shell elements in specific locations based on multiple loading cases for the paths of moving load. These frame elements are modeled with a very small dimensions so they do not affect the finite-element model of the structure. A standard CHBDC truck loading at different evaluation levels are previously defined in CSiBridge software used to define the moving loads on frame elements and to provide the maximum bending moments, shear force, and deflection results from the software moving load runs. 


\subsubsection{Boundary Conditions}

The boundary conditions used in this parametric study were chosen carefully to maintain structure's stability as well as temperature-free superstructure. Roller supports were used at the lower nodes of the web ends to restrain vertical movement at the supporting lines. In addition, the lower node of the middle interior web of at a supporting line was restrained to prevent longitudinal and lateral displacements. While the lower node of the same interior web at the other supporting line was restrained to prevent lateral displacement.

\subsubsection{Material Modeling}

Materials and their properties are chosen based on CHBDC and common material used in Ontario. These materials were defined in SAP2000 software to provide suitable properties for elements. Material properties are considered linear elastic and isotropic for this study. The required material properties for SAP2000 software are as follows:

- Compressive strength of concrete $\left(\mathrm{f}_{\mathrm{c}}^{\prime}\right)$ was considered $35 \mathrm{MPa}$

- The weight density $\left(\gamma_{c}\right)$ for normal prestressed concrete was considered $24 \mathrm{kN} / \mathrm{m}^{3}$

- The modulus of elasticity of concrete $\left(\mathrm{E}_{\mathrm{c}}\right)$ was calculated from the following equation.

$$
\begin{aligned}
& \mathrm{E}_{\mathrm{c}}=\left(3000 \sqrt{\mathrm{f}_{\mathrm{c}}^{\prime}}+6900\right)\left(\frac{\gamma_{\mathrm{c}}}{2300}\right)^{1.5} \\
& \mathrm{E}_{\mathrm{c}}=28,000 \mathrm{MPa}
\end{aligned}
$$

- Poisson's ratio $(v)$ for elastic strain of concrete was taken as 0.2

\subsection{CHBDC Design Loading}

In Canada, live load for any bridge design is calculated based on Canadian trucks CL-W or Ontario trucks CL-W-ONT (W represents the gross load of truck which is equal to $625 \mathrm{kN}$ ). In this study, Ontario trucks has been considered since this research has been done in Ontario. According to CHBDC (2014), two types of loading is identified, namely: truck loading and lane loading as shown in Figure 3.7. The CL-625-ONT truck loading is an idealized five-axle truck with dynamic load allowance, while the CL-625-ONT lane loading consist of truck loading with each axle load reduced to $80 \%$ of its original value and superimposed within a uniformly distributed load of 9 $\mathrm{kN} / \mathrm{m}$ with no consideration for dynamic load allowance over $3.0 \mathrm{~m}$ width that represents the clearance envelope for each truck as shown in Figure 3.8. 
(a)

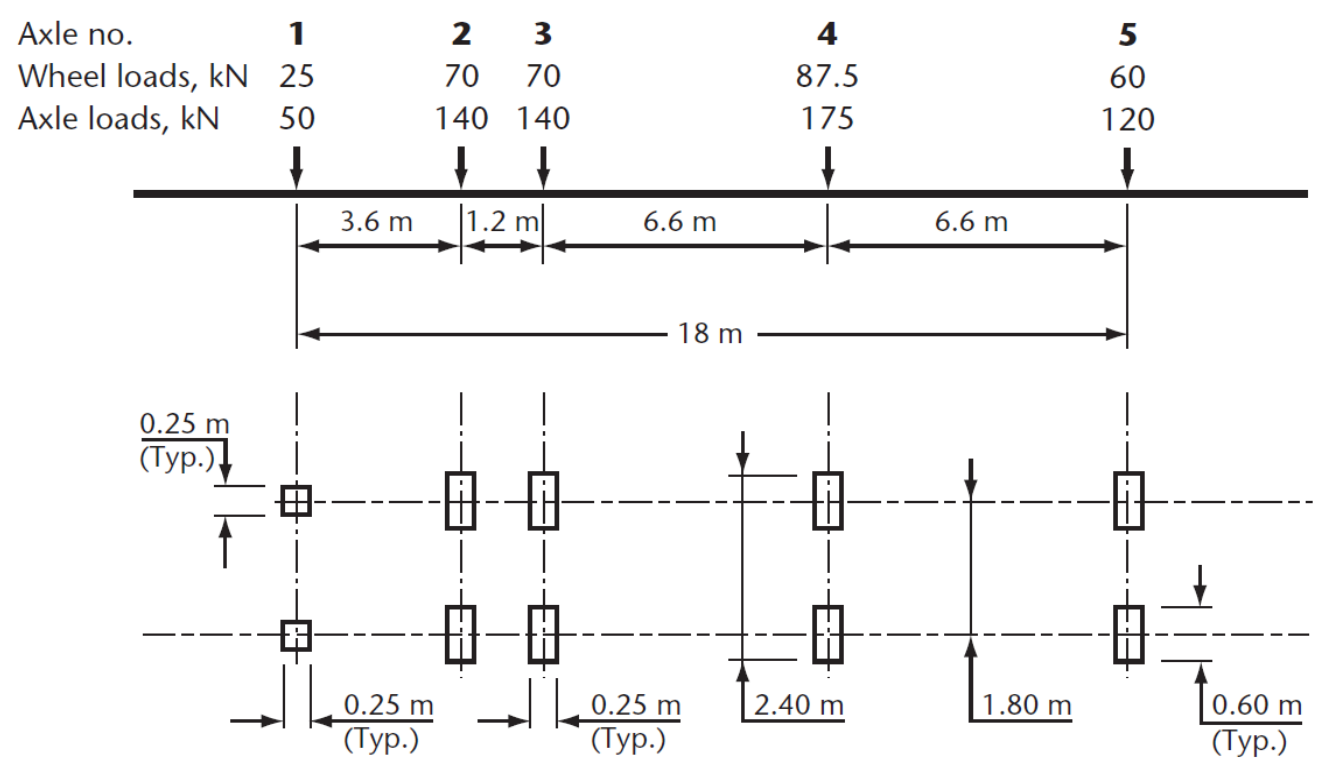

(b)

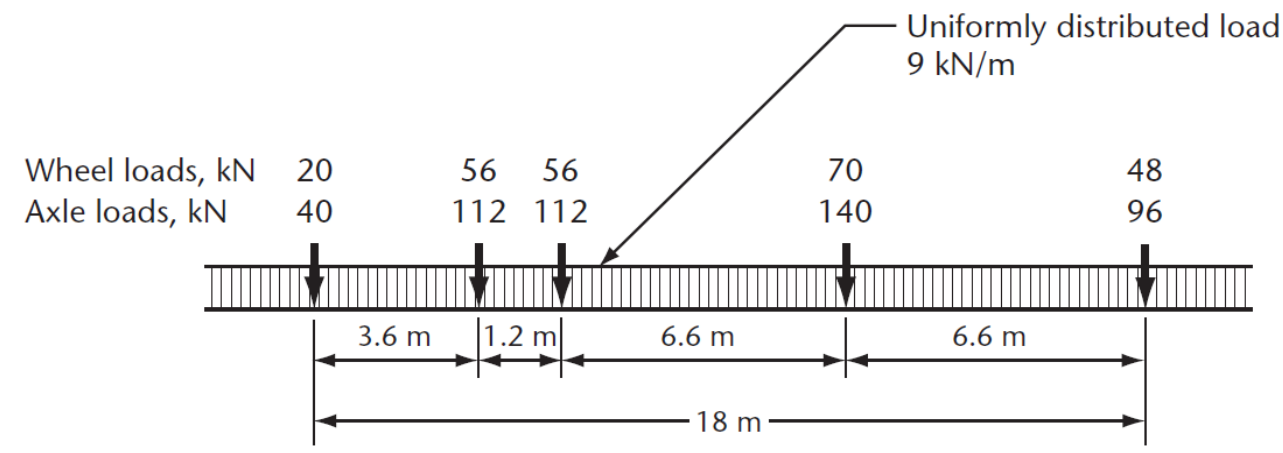

Figure 3.7: CL-W-ONT (a) Truck loading, (b) Lane Loading (CHBDC, 2014)

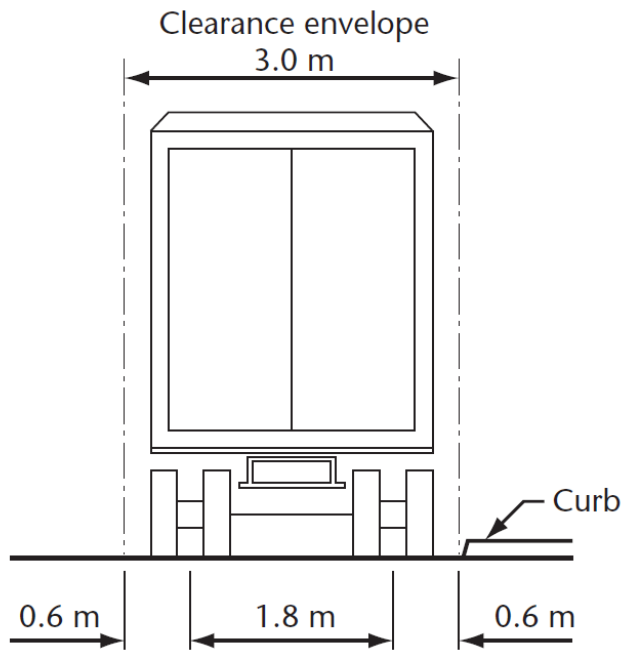

Figure 3.8: CL-W Truck (CHBDC, 2014) 
CHBDC specifies three evaluation levels based on span length to produce the maximum bending moment and shear force. Thus, the span length greater than $18 \mathrm{~m}$, level 1 with five axel loading is considered in design, while span length greater than $12 \mathrm{~m}$ but less than $18 \mathrm{~m}$ level 2 with four axel loading is considered in design. Furthermore, span length less than $12 \mathrm{~m}$, level 3 with three axel loading is considered in design as shown in Figure 3.9. In this study, the maximum bending moment was achieved by using level 3 for $10 \mathrm{~m}$ and $13 \mathrm{~m}$ span length, level 2 for $20 \mathrm{~m}$ span length and level 1 was used for $32 \mathrm{~m}$ span length. On the other hand, the maximum shear force was achieved by using level 3 for $10 \mathrm{~m}$ span length, level 2 for $13 \mathrm{~m}$ and $20 \mathrm{~m}$ span length, and level 1 for $32 \mathrm{~m}$ span length. It should be noted that, loading on the bridge prototypes was applied in such a way to produce maximum reaction force and longitudinal flexural stresses.

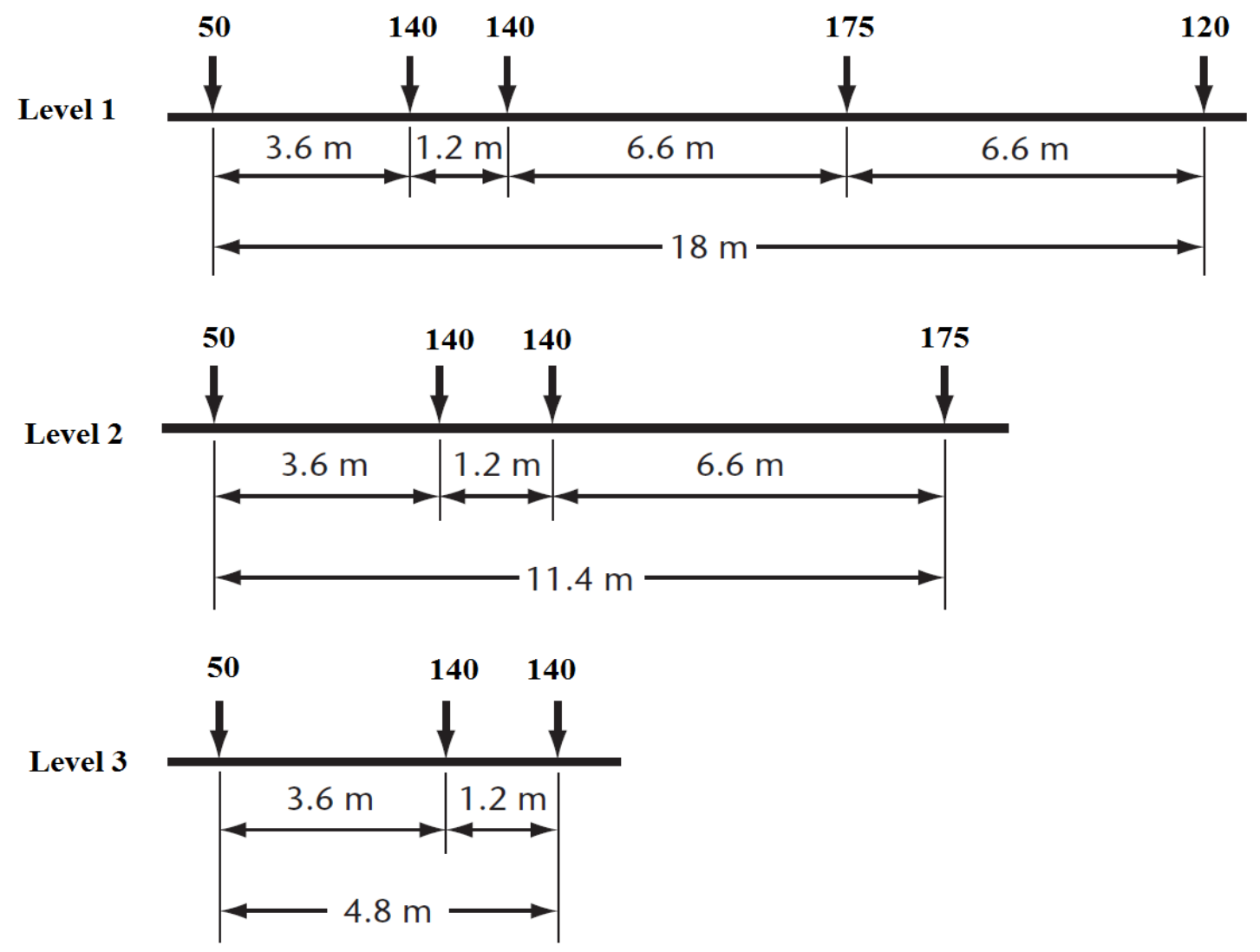

Figure 3.9: CL-W truck evaluation levels

\subsection{CHBDC Truck Loading Condition}

Through the sensitivity study, it was observed that the CL-625-ONT truck loading is governing the extreme design values thus the CL-625-ONT lane loading was not considered. Based on CHBDC (2014), the design on the bridge is characterized by three limit states: 
- Ultimate Limit State (ULS): which involve failure due to rupture, overturning, sliding, and other instability.

- Serviceability Limit State (SLS): which involve the effect of vibration, deflection, and cracking on the usability of the structure.

- Fatigue Limit State (FLS): which involve the effect of fatigue on the strength of the structure.

For fatigue analysis, an equivalent static load is specified in the CHBDC. Only one truck, CL-625ONT Truck, is placed at the centre of one travelling lane. The lane load is not considered for the fatigue limit state. CHBDC states that for longitudinal bending moments and associated deflections for Fatigue Limit State and superstructure vibration, the vehicle edge distance (the distance from the centre of the outer wheel load to the edge of the bridge) shall not be greater than $3.0 \mathrm{~m}$

In this study, loading conditions considered include truck loading cases for each of the three limit stats of design mentioned above to evaluate the moment, shear, and deflection distribution factors. The different loading configuration are represented by: one-lane, two-lanes, three-lanes, fourlanes, five-lanes, and six-lane bridges.

\subsection{Composite Bridge Configuration}

In this study, two hundred and sixty concrete box girder bridge prototypes were considered for the finite element analysis. The size and dimensions of the box girder listed below were taken according to Pre-con Manual as shown in Figure 3.10 and Figure 3.11.

- Deck slab (top flange) thickness: $225 \mathrm{~mm}$

- The bottom flange thickness: $140 \mathrm{~mm}$

- The girder web thickness: $125 \mathrm{~mm}$

- The Diaphragm thickness: $300 \mathrm{~mm}$

- The connection joints thickness $225 \mathrm{~mm}$ and width140 mm. The later represents a $15 \mathrm{~mm}$ gap between boxes and half the web thickness on each side. 


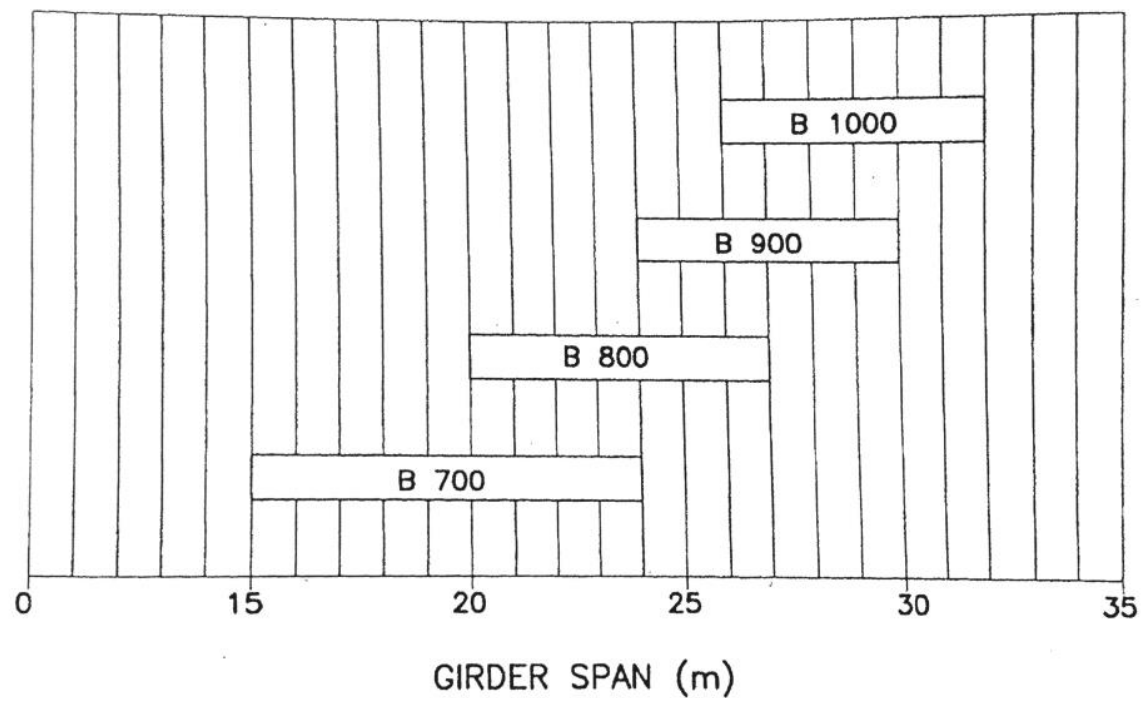

Figure 3.10: Box girder sizes (Pre-Con Manual, 2004)

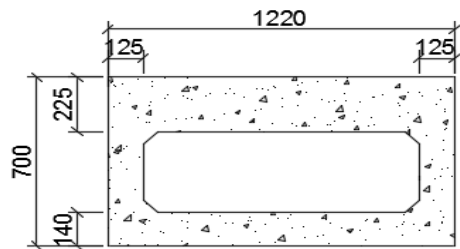

B 700

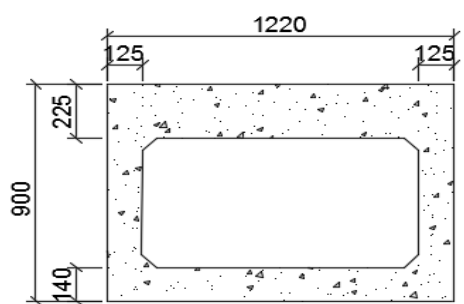

B 900
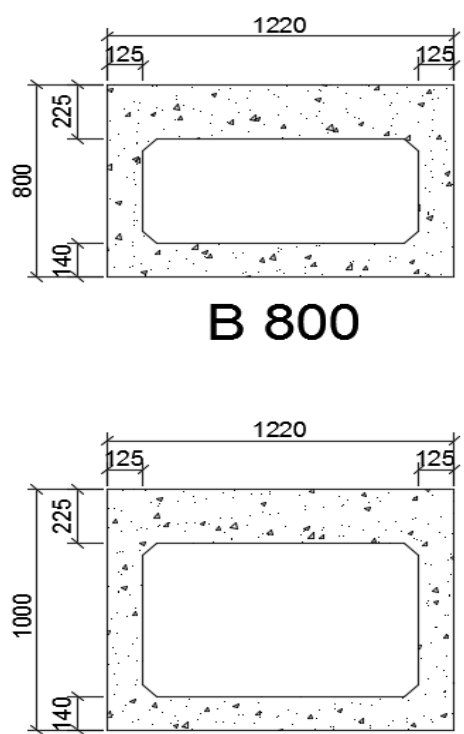

B 1000

Figure 3.11: Box girder section details (Pre-Con Manual, 2004)

Four main box girder bridge configurations were used to model the bridge and analyze the structural response. These configuration are number of girders $(\mathrm{N})$, span length (L), number of lanes (n), and girder spacing $(\mathrm{S})$. The subsection below summarize each configuration: 


\subsubsection{Number of Girders}

Precast prestressed box girders have been used to form the cross-section of the bridge. According to Pre-Con manual, these beams are of variable height based on the span length and fixed width of $1.22 \mathrm{~m}$ with $15 \mathrm{~mm}$ gap between boxes which lead to a total width of $1.235 \mathrm{~m}$. Thus, bridge width is based on box width and increase with increasing number of girders. It should be noted that, the deck width is calculated based on the bridge width minus $1.0 \mathrm{~m}$, taking into account barrier wall on each side of the bridge. As a result, changing bridge width and number of girders have similar effect on the structural response. The bridge width and number of girder for different design lanes used in this study were as follows:

\section{- Bridge cross-section with one design lanes:}

a) Bridge width $=4.926 \mathrm{~m}$, deck width $=3.926 \mathrm{~m}$ and number of box girders $=4$

b) Bridge width $=6.160 \mathrm{~m}$, deck width $=5.160 \mathrm{~m}$ and number of box girders $=5$

\section{- Bridge cross-section with two design lanes:}

a) Bridge width $=7.395 \mathrm{~m}$, deck width $=6.395 \mathrm{~m}$ and number of box girders $=6$

b) Bridge width $=8.630 \mathrm{~m}$, deck width $=7.630 \mathrm{~m}$ and number of box girders $=7$

c) Bridge width $=9.865 \mathrm{~m}$, deck width $=8.865 \mathrm{~m}$ and number of box girders $=8$

\section{- Bridge cross-section with three design lanes:}

a) Bridge width $=11.101 \mathrm{~m}$, deck width $=10.101 \mathrm{~m}$ and number of box girders $=9$

b) Bridge width $=12.336 \mathrm{~m}$, deck width $=11.336 \mathrm{~m}$ and number of box girders $=10$

c) Bridge width $=13.571 \mathrm{~m}$, deck width $=12.571 \mathrm{~m}$ and number of box girders $=11$

\section{- Bridge cross-section with four design lanes:}

a) Bridge width $=14.806 \mathrm{~m}$, deck width $=13.806 \mathrm{~m}$ and number of box girders $=12$

b) Bridge width $=16.041 \mathrm{~m}$, deck width $=15.041 \mathrm{~m}$ and number of box girders $=13$

c) Bridge width $=17.276 \mathrm{~m}$, deck width $=16.276 \mathrm{~m}$ and number of box girders $=14$

- Bridge cross-section with five design lanes:

a) Bridge width $=18.510 \mathrm{~m}$, deck width $=17.510 \mathrm{~m}$ and number of box girders $=15$ 
b) Bridge width $=19.745 \mathrm{~m}$, deck width $=18.745 \mathrm{~m}$ and number of box girders $=16$

c) Bridge width $=20.980 \mathrm{~m}$, deck width $=19.980 \mathrm{~m}$ and number of box girders $=17$

\section{- Bridge cross-section with six design lanes:}

a) Bridge width $=22.216 \mathrm{~m}$, deck width $=21.215 \mathrm{~m}$ and number of box girders $=18$

b) Bridge width $=23.450 \mathrm{~m}$, deck width $=22.450 \mathrm{~m}$ and number of box girders $=19$

c) Bridge width $=24.685 \mathrm{~m}$, deck width $=23.685 \mathrm{~m}$ and number of box girders $=20$

\subsubsection{Span Length}

Four different span lengths were considered in this study to examine the effect of span length on the structural response for moment, shear and deflection distribution factors. According to PreCon manual, the box girder size increase with increasing the span length to maintain realistic flexural stiffness. Therefore, three different box girder sizes along with four different span lengths were considered in this study as follows:

- B700 Box girder for $10 \mathrm{~m}$ and $13 \mathrm{~m}$ spans;

- B800 Box girder for 2 0m spans; and

- B1000 Box girder for $32 \mathrm{~m}$ spans

\subsubsection{Number of Lanes}

In this study, six different design lanes were considered in evaluating moment, shear, and deflection distribution factors of the box girder bridge, namely, 1, 2, 3, 4, 5, and 6. According to CHBDC 2014, the deck width selection depends mainly on the number of design lanes. Thus, the change in design lane will affect the bridge width as well as implied in the parameter $\mu$ in Equation (2.44)

\subsubsection{Girder Spacing}

Box beams are placed adjacent to each other in this study with a constant gap of $15 \mathrm{~mm}$. Thus, adding the box girder width of $1.22 \mathrm{~m}$ to the constant gap will provide a centre to centre spacing of $1.235 \mathrm{~m}$ for all the bridge models. Because of the constant box girder spacing, the effect of the girder spacing was not considered in this study. 


\subsubsection{Loading Cases}

Different loading cases for CHBDC truck loading were considered in the analysis to obtain the maximum effect on each girder. The loading cases considered are for ultimate limit state (ULS), severability limit state (SLS), which can be divided into two group; namely: fully loaded lanes and partially loaded lanes, and fatigue limit state (FLS) as stated previously. Figure 3.12 to Figure 3.24 show the different loading cases considered in this study based on different design lanes. It should be noted that the maximum distribution factors in this study were the greatest values occurred in all girders under the different loading cases. As such, the current study does not differentiate between exterior girder and interior girder as used to be in CHBDC simplified method of analysis.
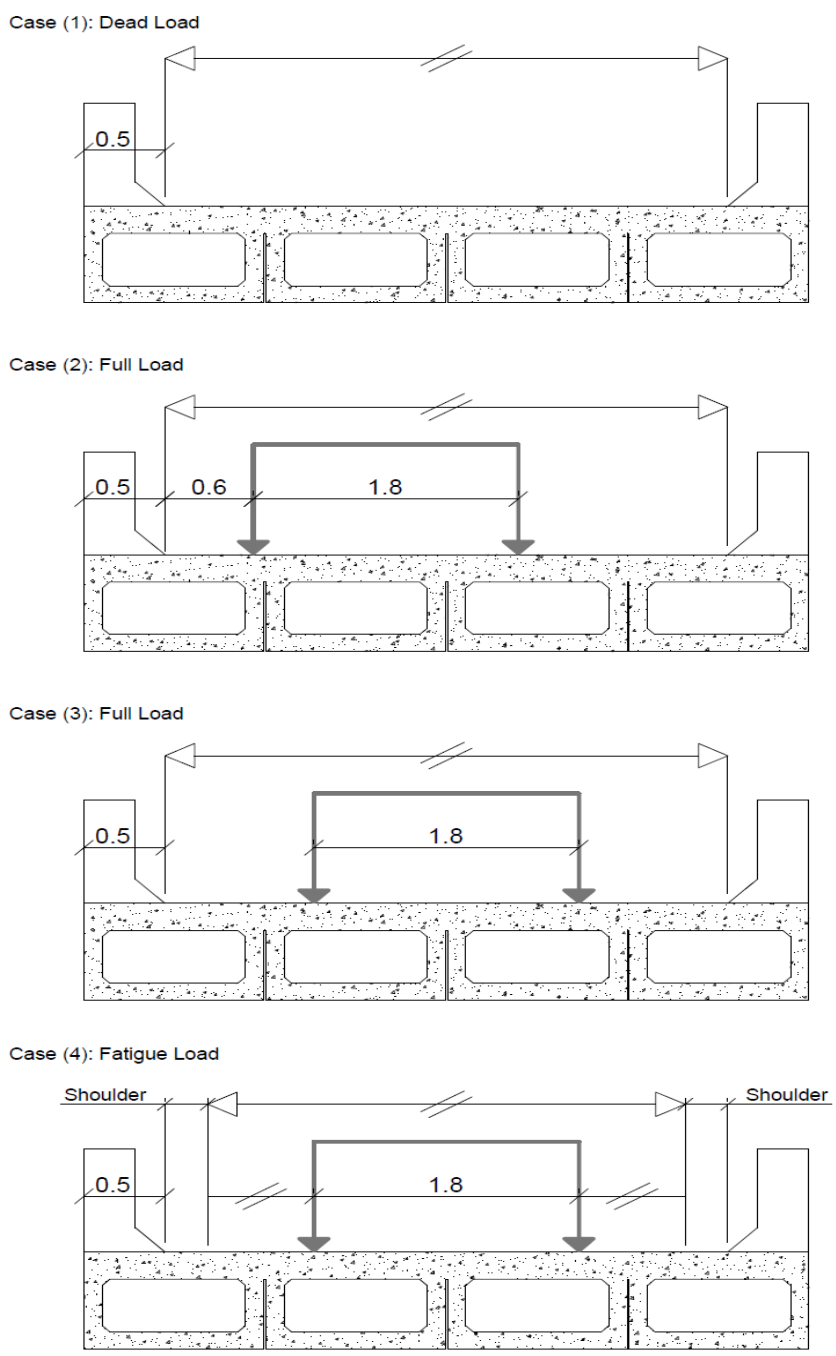

Figure 3.12: Live loading cases for one-lane bridges 

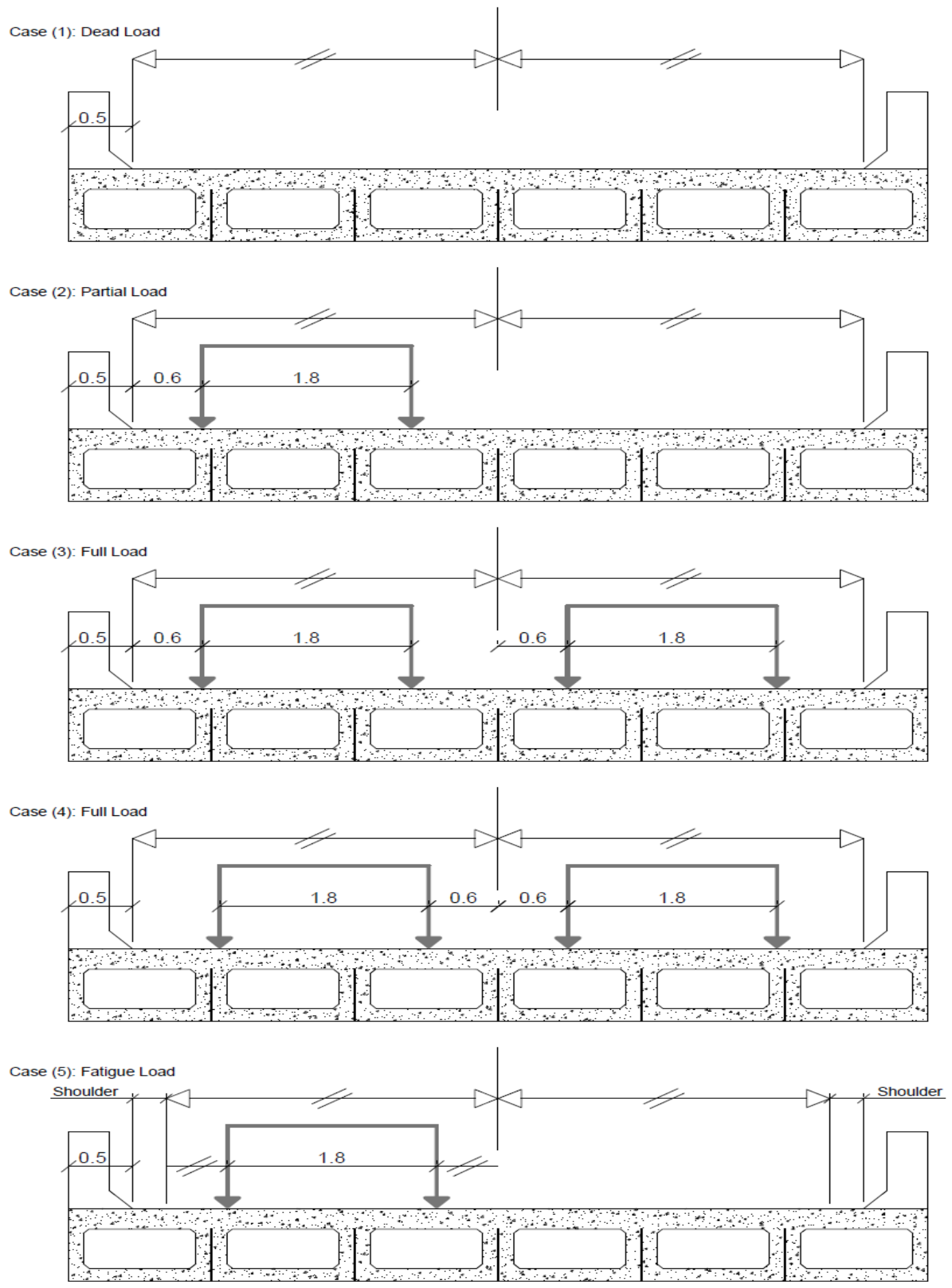

Figure 3.13: Live loading cases for two-lane bridges 

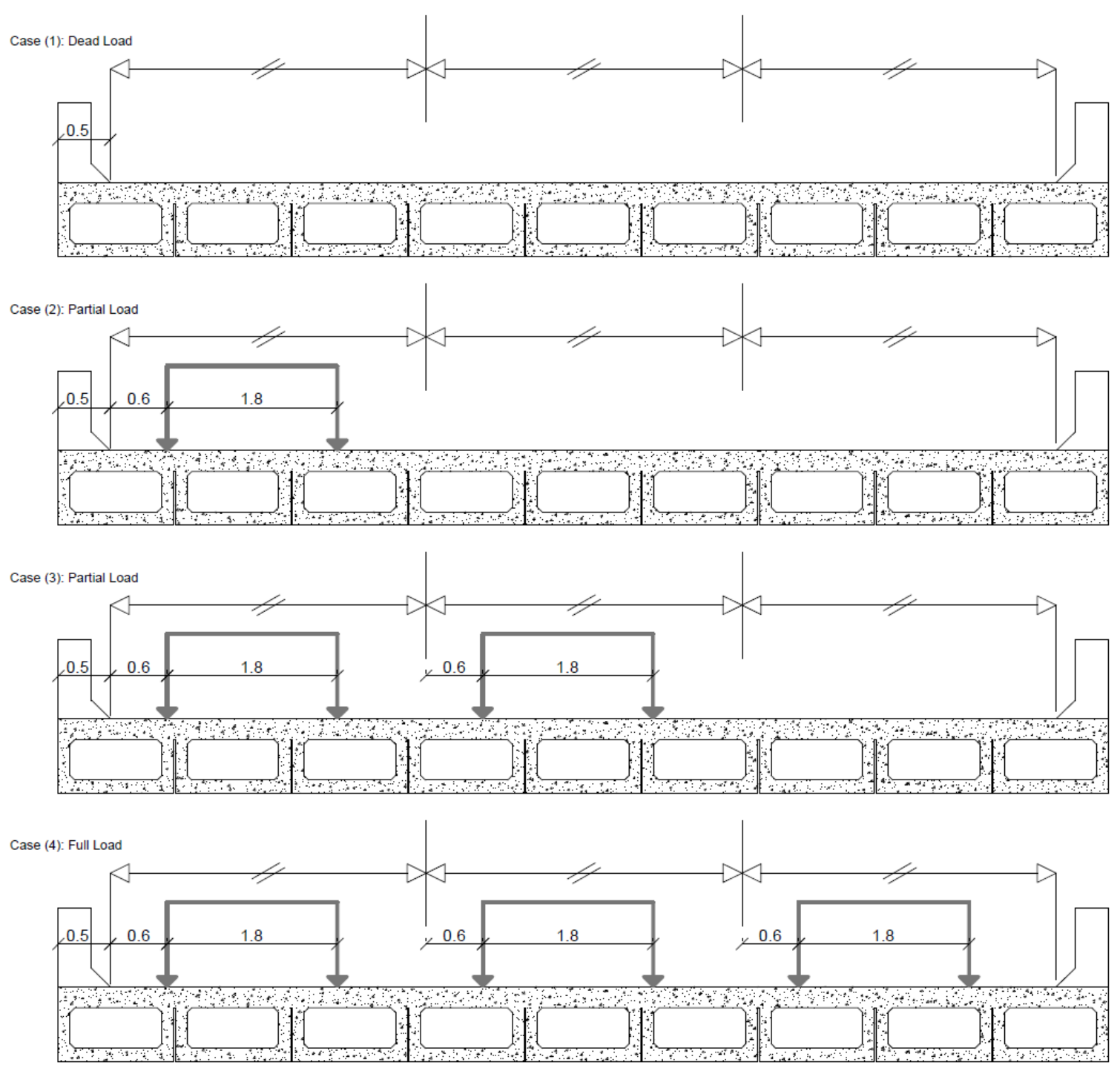

Figure 3.14: Live loading cases for three-lane bridges 

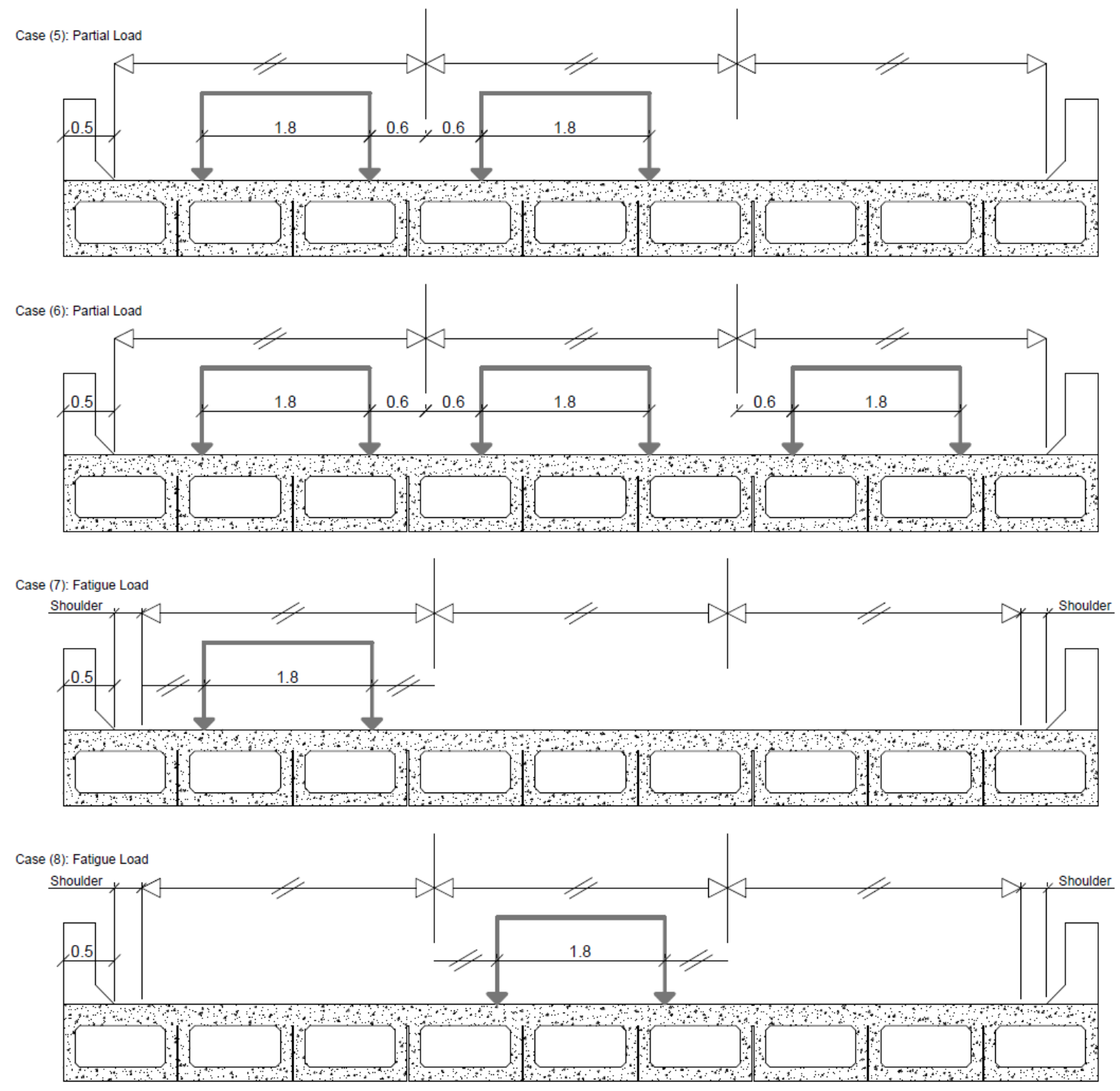

Figure 3.15: Live loading cases for three-lane bridges (Continue) 

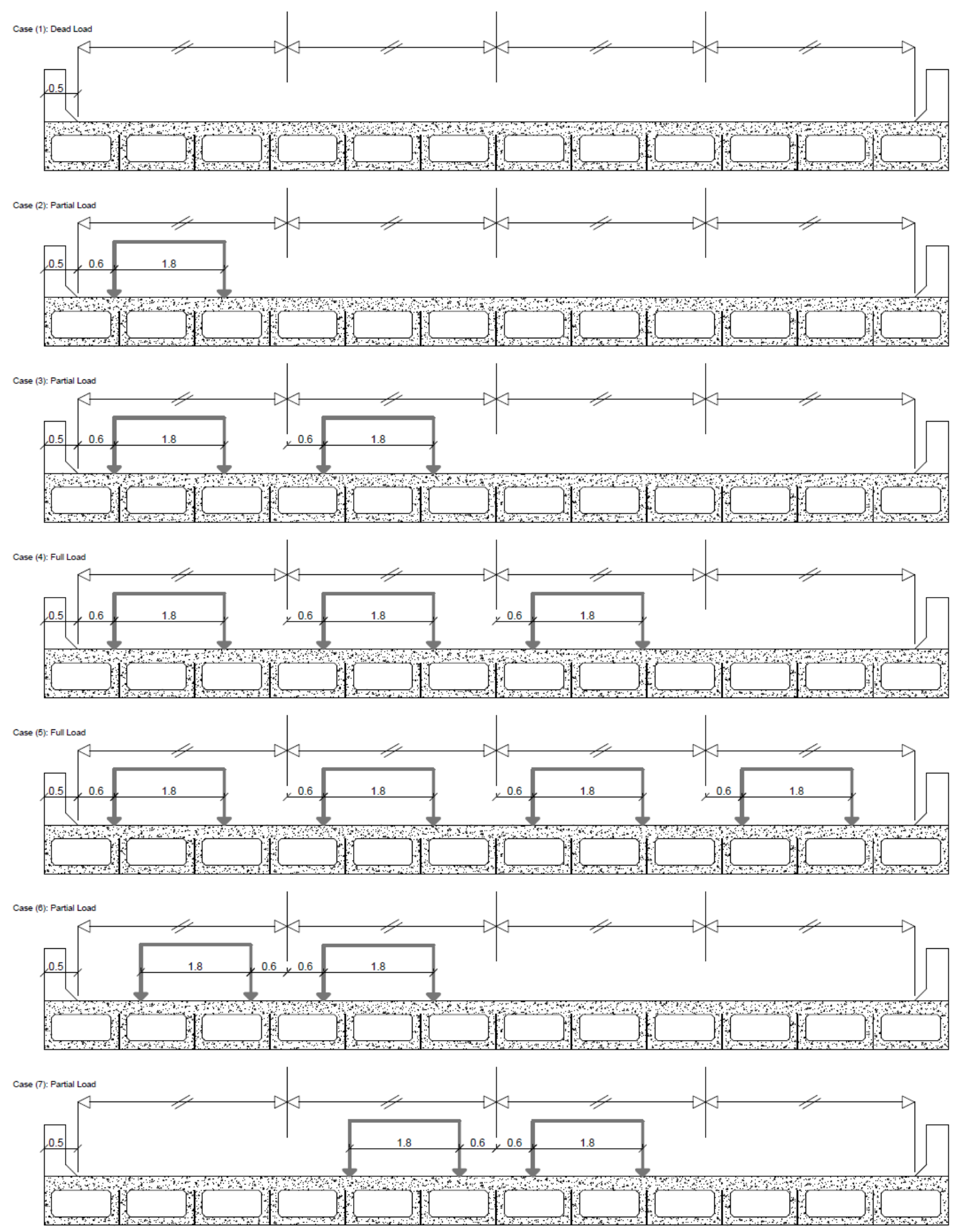

Figure 3.16: Live loading cases for four-lane bridges 

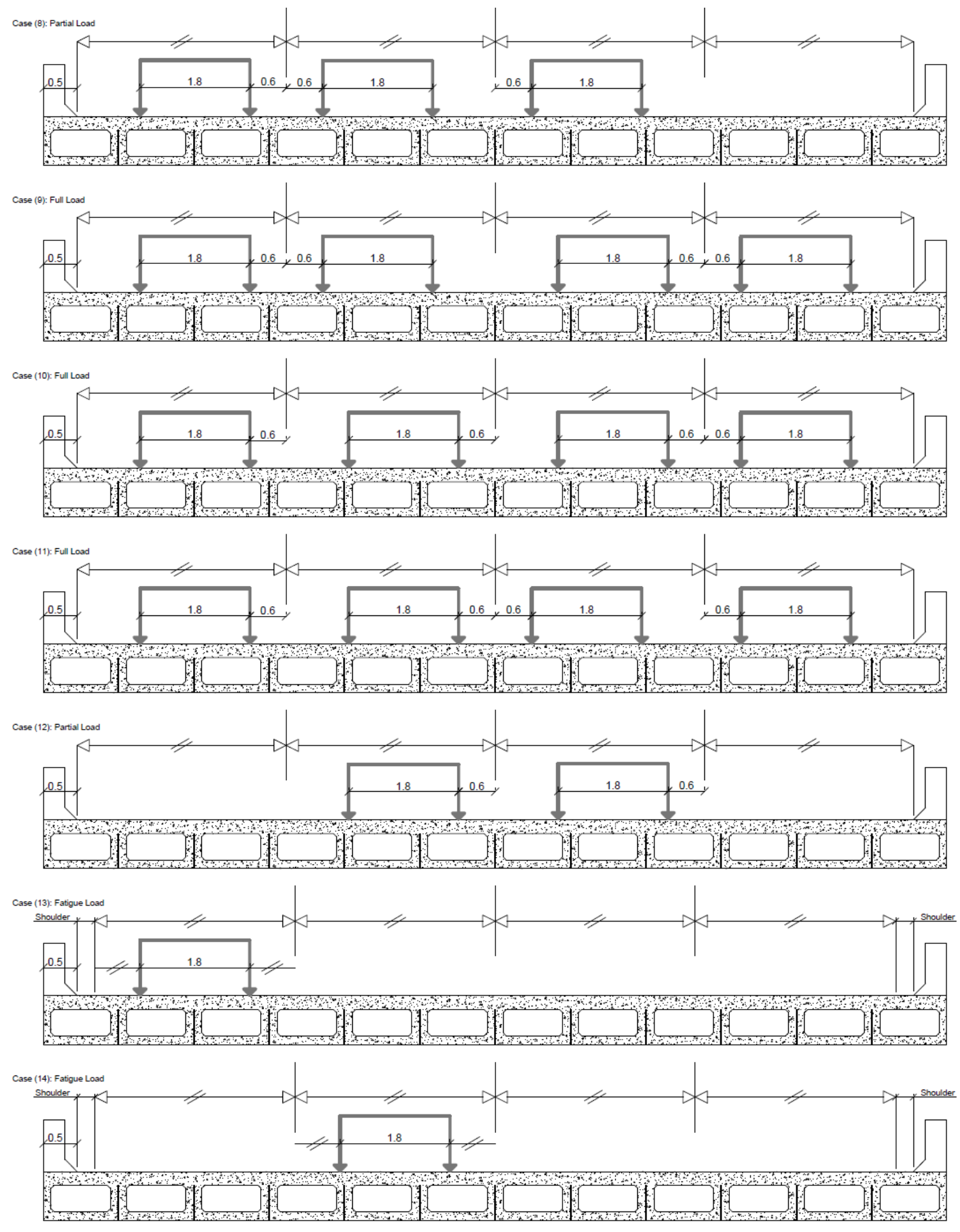

Figure 3.17: Live loading cases for four-lane bridges (Continue) 

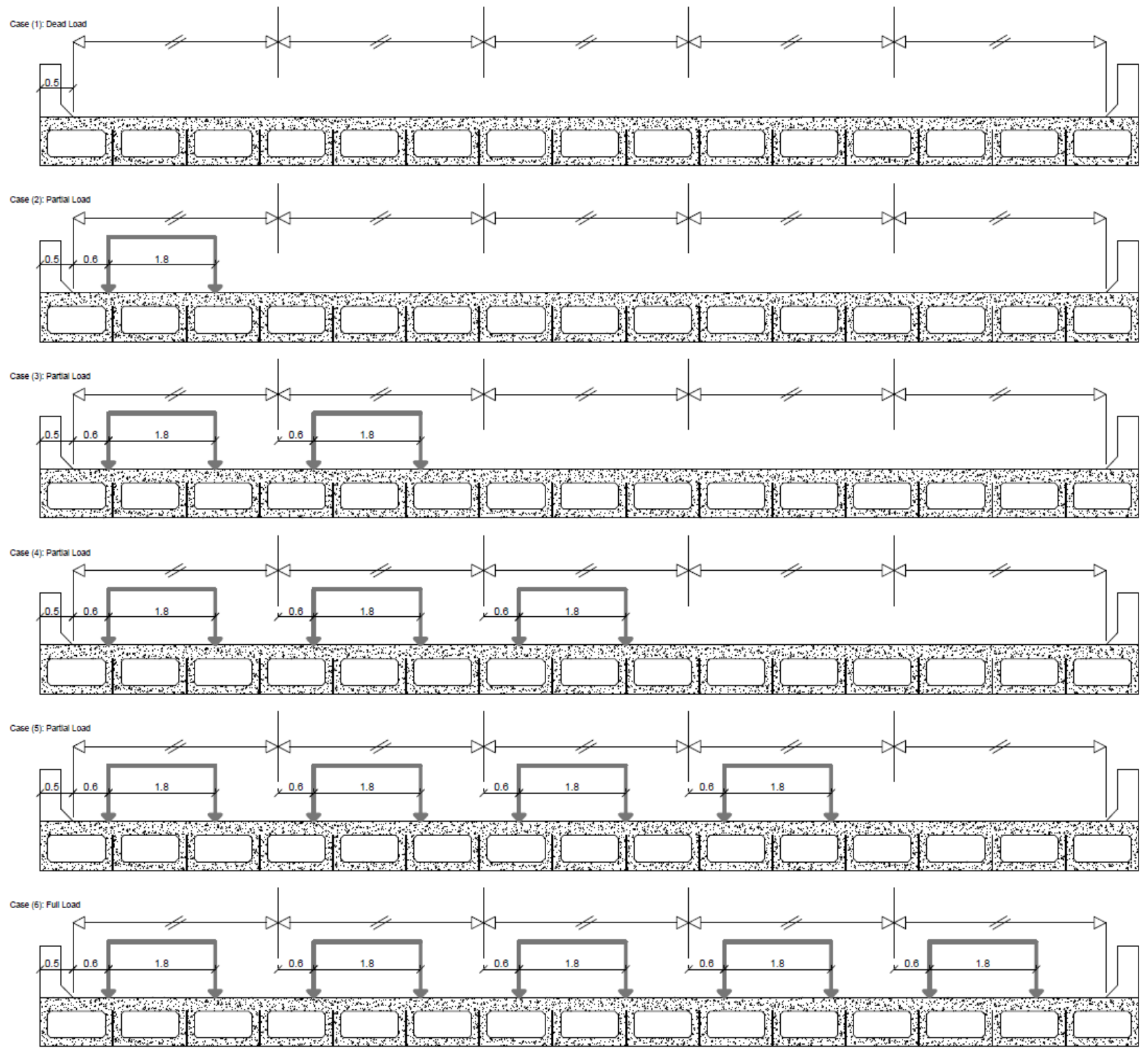

Figure 3.18: Live loading cases for five-lane bridges 

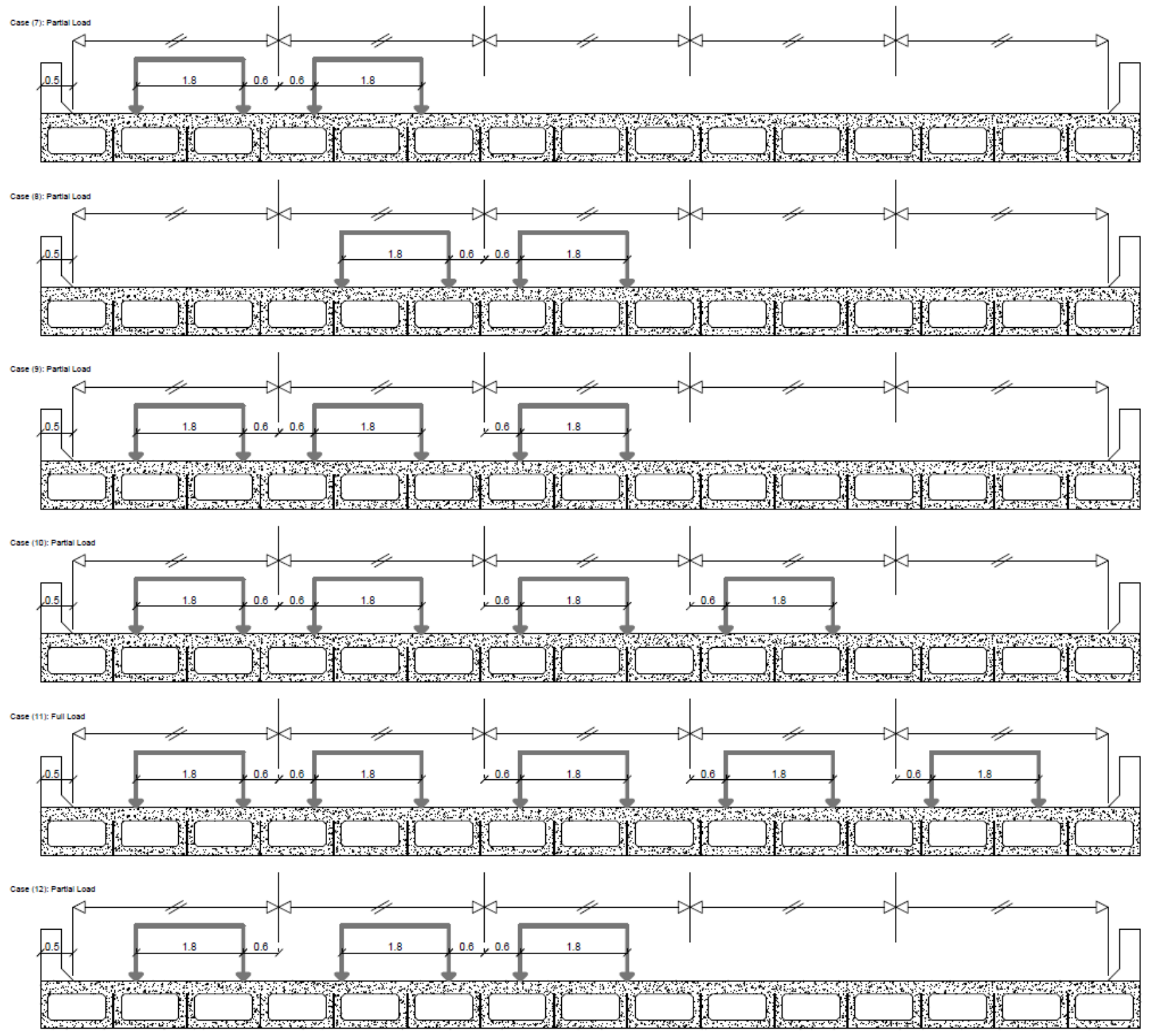

Figure 3.19: Live loading cases for five-lane bridges (Continue) 

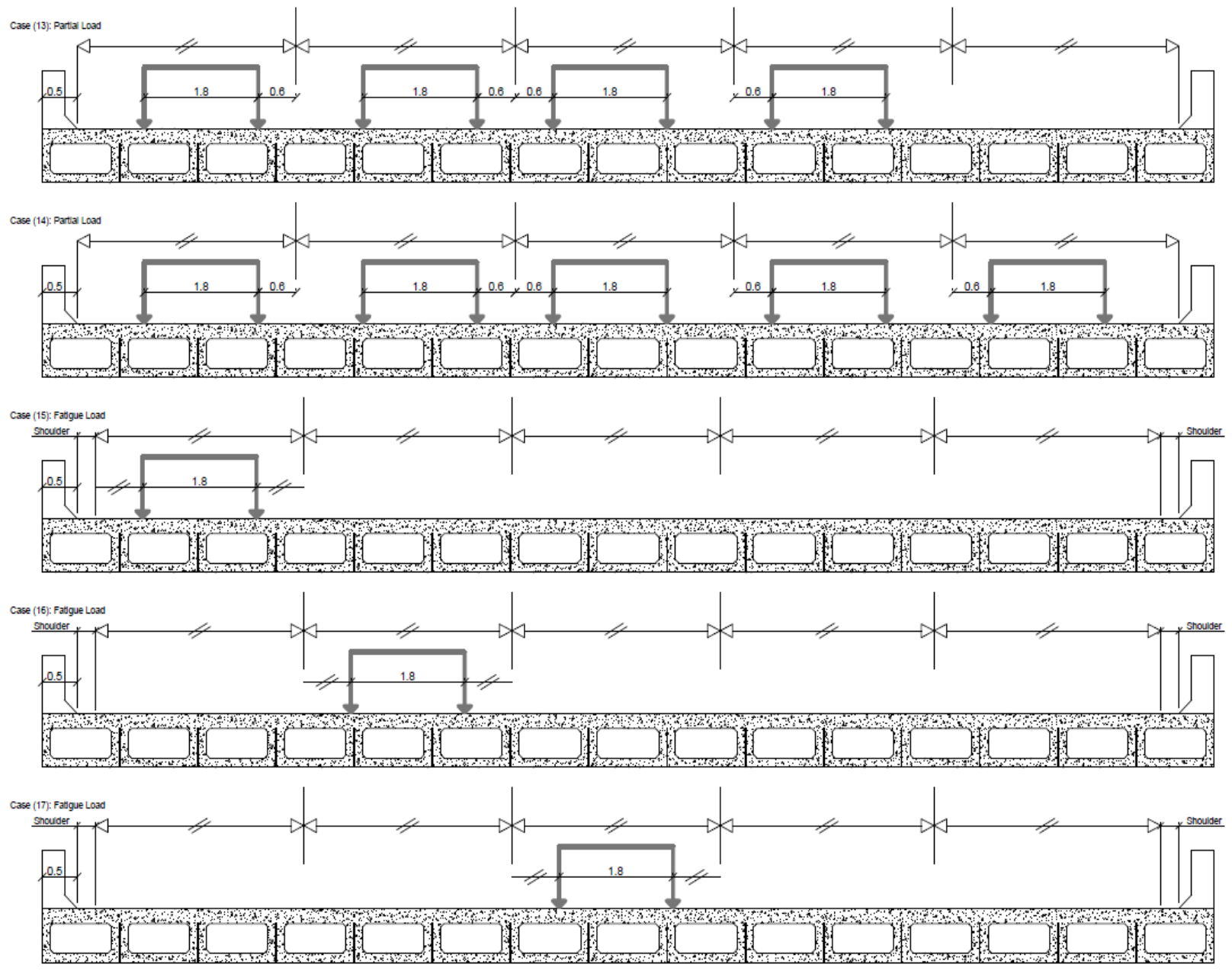

Figure 3.20: Live loading cases for five-lane bridges (Continue) 

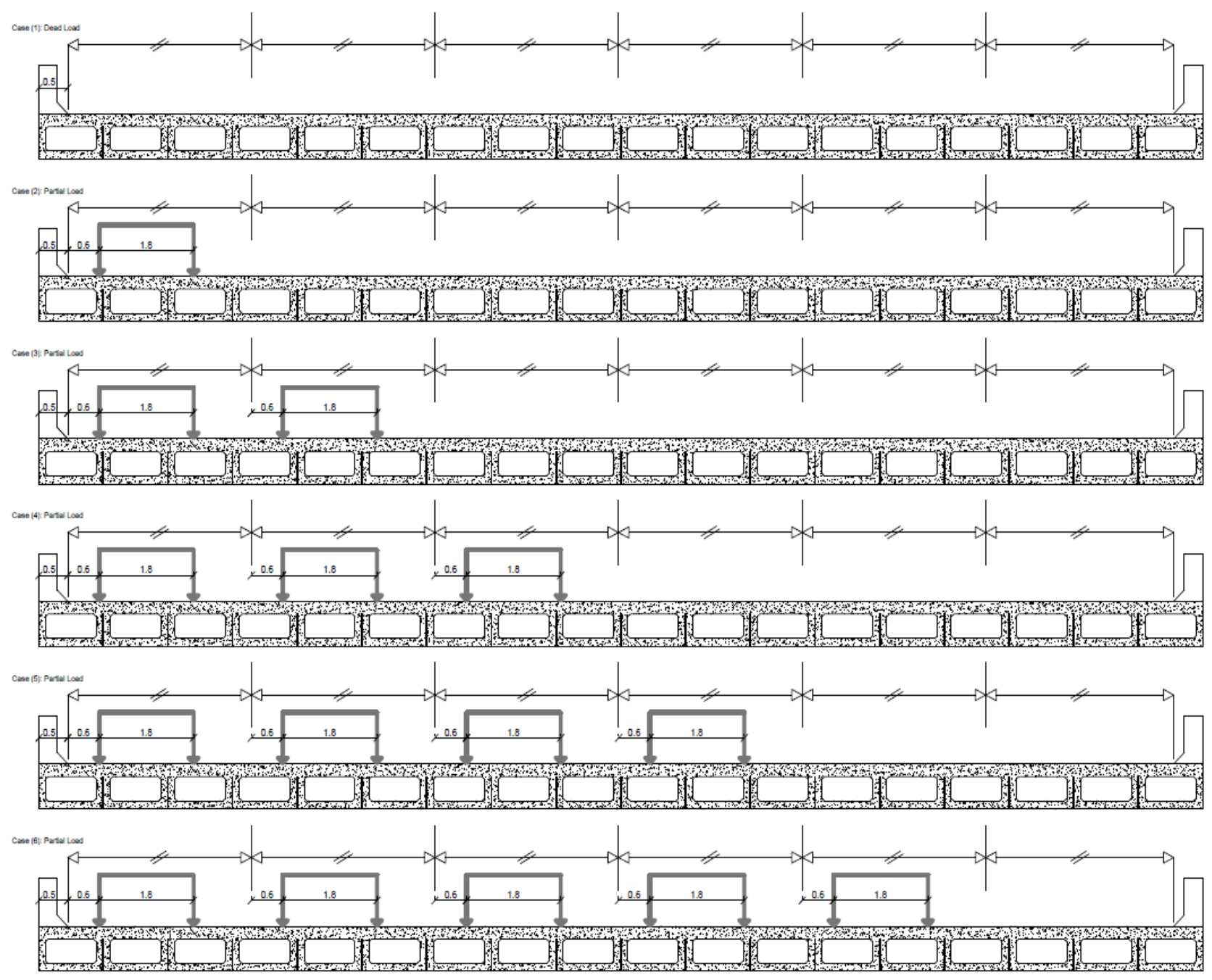

Figure 3.21: Live loading cases for six-lane bridges 

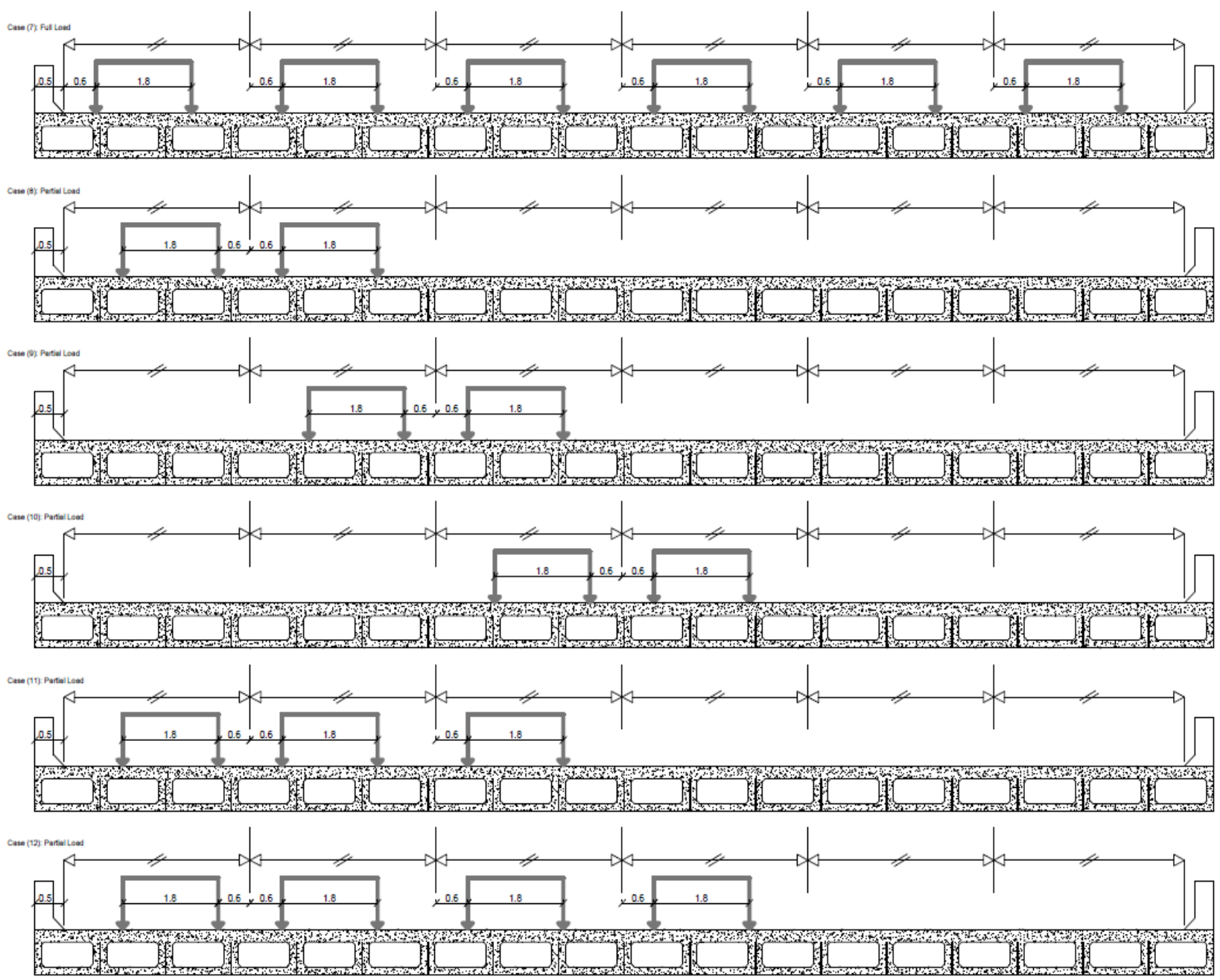

Figure 3.22: Live loading cases for six-lane bridges (Continue) 

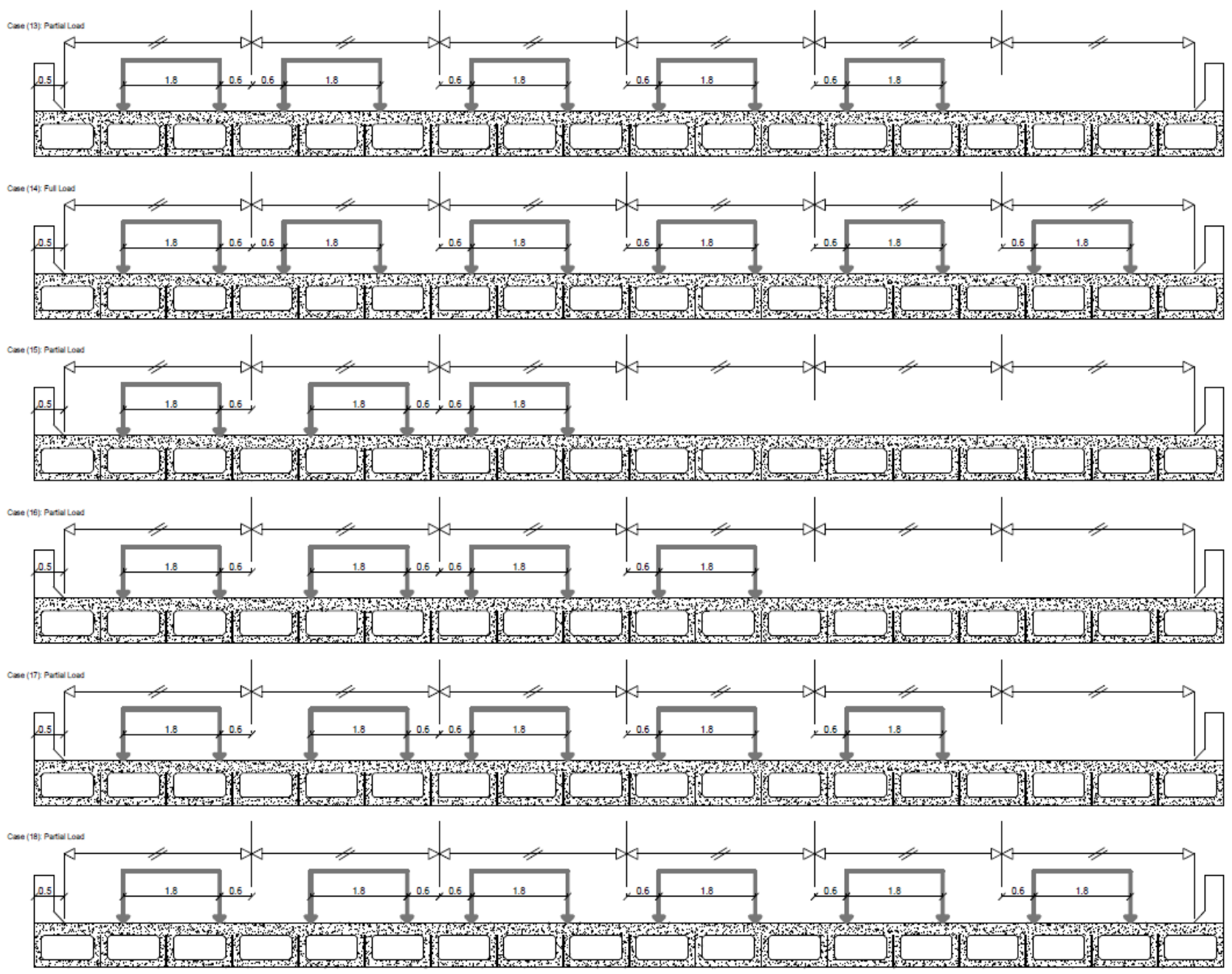

Figure 3.23: Live loading cases for six-lane bridges (Continue) 

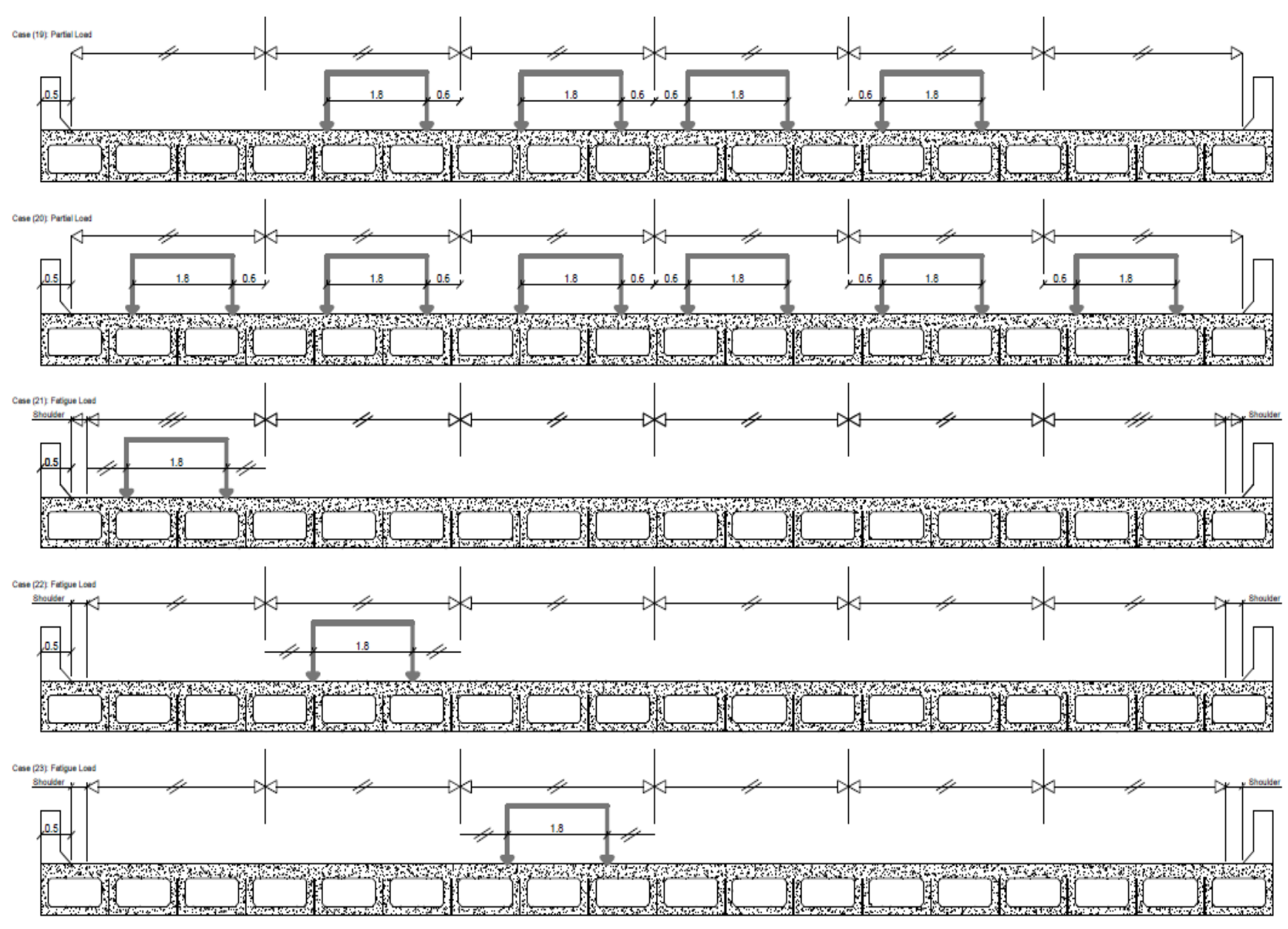

Figure 3.24: Live loading cases for six-lane bridges (Continue)

\subsection{Load Distribution Factor}

\subsubsection{Calculation of Moment Distribution Factor}

The moment distribution factor $\left(\mathrm{F}_{\mathrm{m}}\right)$ for adjacent box girder was determined using the ratio between flexural stresses obtained from finite-element modelling for different loading cases and that calculated from a straight simply supported girder under single truck loading condition.

The longitudinal flexural stresses $\left(\left(\sigma_{\text {straigth }}\right)_{\text {truck }}\right)$ for straight simply supported beam due to a single CHBDC truck loading were calculated using the following equation:

$$
\left(\sigma_{\text {straigth }}\right)_{\text {truck }}=\frac{\mathrm{M}_{\mathrm{T}} \mathrm{Y}_{\mathrm{b}}}{\mathrm{I}_{\mathrm{t}}}
$$


Where,

$\mathrm{M}_{\mathrm{T}}$ : Mid-span moment for a straight simply supported girder;

$\mathrm{Y}_{\mathrm{b}}$ : Distance from neutral axis to bottom flange; and

$I_{t}:$ Moment of inertia of box girder.

Then, a finite-element model was developed using SAP2000 software under different loading cases include fully-loaded lanes, partially loaded lanes, and fatigue loading conditions. Once the model was developed, the max flexural stresses were obtained along the bottom flange for each loading case. Consequently, the moment distribution factors were calculated as follows:

$$
\begin{aligned}
& \left(\mathrm{F}_{\mathrm{m}}\right)_{\mathrm{FL}}=\frac{\left(\sigma_{\mathrm{FE}}\right)_{\mathrm{FL}} * \mathrm{~N}}{\left(\sigma_{\text {straight }}\right)_{\text {truck }} * \mathrm{n}} \\
& \left(\mathrm{F}_{\mathrm{m}}\right)_{\mathrm{PL}}=\frac{\left(\sigma_{\mathrm{FE} .}\right)_{\mathrm{PL}} * \mathrm{~N} * \mathrm{R}_{\mathrm{L}}^{\prime}}{\left(\sigma_{\text {straight }}\right)_{\text {truck }} * \mathrm{n} * \mathrm{R}_{\mathrm{L}}} \\
& \left(\mathrm{F}_{\mathrm{m}}\right)_{\mathrm{FAT}}=\frac{\left(\sigma_{\mathrm{FE} .}\right)_{\mathrm{FAT}} * \mathrm{~N}}{\left(\sigma_{\text {straight }}\right)_{\text {truck }}}
\end{aligned}
$$

Where,

$\left(\mathrm{F}_{\mathrm{m}}\right)_{\mathrm{FL}}$ : Moment distribution factor for fully loaded lanes;

$\left(\mathrm{F}_{\mathrm{m}}\right)_{\mathrm{PL}}$ : Moment distribution factor for partially loaded lanes;

$\left(\mathrm{F}_{\mathrm{m}}\right)_{\mathrm{FAT}}$ : Moment distribution factor for fatigue loading;

$\left(\sigma_{\mathrm{FE} .}\right)_{\mathrm{FL}}:$ Maximum average flexural stress at bottom flange from FEM for fully loaded lanes;

$\left(\sigma_{\mathrm{FE} .}\right)_{\mathrm{PL}}$ : Maximum average flexural stress at bottom flange from FEM for partially loaded lanes;

$\left(\sigma_{\mathrm{FE} .}\right)_{\mathrm{FAT}}$ : Maximum average flexural stress at bottom flange from FEM for fatigue loading;

$\mathrm{N}$ : Number of concrete box girders;

$\mathrm{n}$ : Number of design lanes, Table 3.1;

$\mathrm{R}_{\mathrm{L}}^{\prime}$ : Multi-lane factor based on number of loaded lanes, Table 3.2; and

$\mathrm{R}_{\mathrm{L}}$ : Multi-lane factor based on number of design lanes, Table 3.2. 
Table 3.1: Number of Design Lanes (CHBDC, 2014)

\begin{tabular}{ll}
\hline Deck width, $\mathbf{W}_{\mathbf{c}}, \mathbf{m}$ & Number of lanes, $\mathbf{n}$ \\
\hline 6.0 m or less & 1 \\
Over $6.0 \mathrm{~m}$ to $10.0 \mathrm{~m}$ incl. & 2 \\
Over $10.0 \mathrm{~m}$ to $13.5 \mathrm{~m}$ incl. & 2 or 3 \\
Over $13.5 \mathrm{~m}$ to $17.0 \mathrm{~m}$ incl. & 4 \\
Over $17.0 \mathrm{~m}$ to $20.5 \mathrm{~m}$ incl. & 5 \\
Over $20.5 \mathrm{~m}$ to $24.0 \mathrm{~m}$ incl. & 6 \\
Over $24.0 \mathrm{~m}$ to $27.5 \mathrm{~m}$ incl. & 7 \\
Over $27.5 \mathrm{~m}$ & 8 \\
\hline
\end{tabular}

Table 3.2: Modification Factors for Multilane Loading (CHBDC, 2014)

\begin{tabular}{ll}
\hline Number of loaded design lanes & Modification factor, $\mathbf{R}_{\mathbf{L}}$ \\
\hline 1 & 1.00 \\
2 & 0.90 \\
3 & 0.80 \\
4 & 0.70 \\
5 & 0.60 \\
6 or more & 0.55 \\
\hline
\end{tabular}

\subsubsection{Calculation of Shear Distribution Factor}

The shear distribution factor $\left(\mathrm{F}_{\mathrm{v}}\right)$ for adjacent box girder was determined using the ratio between the maximum girder support reaction obtained from finite-element modeling $\left(\mathrm{R}_{\mathrm{FE}}\right)$ for different loading cases and that calculated from a straight simply supported girder under single truck loading condition $\left(\left(\mathrm{R}_{\text {straigth }}\right)_{\text {truck }}\right)$. The shear distribution factors were calculated as follows:

$$
\begin{aligned}
& \left(\mathrm{F}_{\mathrm{V}}\right)_{\mathrm{FL}}=\frac{\left(\mathrm{R}_{\mathrm{FE}}\right)_{\mathrm{FL}} * \mathrm{~N}}{\left(\mathrm{R}_{\text {straight }}\right)_{\text {truck }} * \mathrm{n}} \\
& \left(\mathrm{F}_{\mathrm{V}}\right)_{\mathrm{PL}}=\frac{\left(\mathrm{R}_{\mathrm{FE}}\right)_{\mathrm{PL}} * \mathrm{~N} * \mathrm{R}_{\mathrm{L}}^{\prime}}{\left(\mathrm{R}_{\text {straight }}\right)_{\text {truck }} * \mathrm{R}_{\mathrm{L}}} \\
& \left(\mathrm{F}_{\mathrm{V}}\right)_{\mathrm{FAT}}=\frac{\left(\mathrm{R}_{\mathrm{FE}}\right)_{\mathrm{FAT}} * \mathrm{~N}}{\left(\mathrm{R}_{\text {straight }}\right)_{\text {truck }}}
\end{aligned}
$$

Where,

$\left(\mathrm{F}_{\mathrm{v}}\right)_{\mathrm{FL}}:$ Shear distribution factor for fully loaded lanes;

$\left(\mathrm{F}_{\mathrm{v}}\right)_{\mathrm{PL}}$ : Shear distribution factor for partially loaded lanes;

$\left(\mathrm{F}_{\mathrm{v}}\right)_{\mathrm{FAT}}$ : Shear distribution factor for fatigue loading; 
$\left(\mathrm{R}_{\mathrm{FE} .}\right)_{\mathrm{FL}}$ : Maximum reaction at box girder supports from FEM for fully loaded lanes;

$\left(\mathrm{R}_{\mathrm{FE} .}\right)_{\mathrm{PL}}$ : Maximum reaction at box girder supports from FEM for partially loaded lanes;

$\left(\mathrm{R}_{\mathrm{FE} .}\right)_{\mathrm{FAT}}$ : Maximum reaction at box girder supports from FEM for fatigue loading;

$\mathrm{N}$ : Number of concrete box girders;

$\mathrm{n}$ : Number of design lanes;

$\mathrm{R}_{\mathrm{L}}^{\prime}$ : Multi-lane factor based on number of loaded lanes; and

$\mathrm{R}_{\mathrm{L}}$ : Multi-lane factor based on number of design lanes.

\subsubsection{Calculation of Deflection Distribution Factor}

The deflection distribution factor $\left(F_{d}\right)$ for adjacent box girder was determined using the ratio between the maximum live load deflection $\left(\Delta_{\mathrm{FE}}\right.$. $)$ for fatigue limit state obtained from finiteelement modelling and that calculated from a straight simply supported girder under single truck loading condition $\left(\left(\Delta_{\text {straigth }}\right)_{\text {truck }}\right)$. The maximum deflection at the bottom flange was identified from the average vertical displacements for the three nodal joints adjacent to the chosen section. The distribution factors for deflection were calculated as follows:

$$
\left(\mathrm{F}_{\mathrm{d}}\right)_{\mathrm{FAT}}=\frac{\left(\Delta_{\mathrm{FE}}\right)_{\mathrm{FAT}_{\mathrm{T}} * \mathrm{~N}}}{\left(\Delta_{\text {straight }}\right)_{\text {truck }}}
$$

Where,

$\left(\mathrm{F}_{\mathrm{d}}\right)_{\mathrm{FAT}}$ : Deflection distribution factor for fatigue loading;

$\left(\Delta_{\mathrm{FE} .}\right)_{\mathrm{FAT}}:$ Maximum average deflection at bottom flange from FEM for fatigue loading; and $\mathrm{N}$ : Number of concrete box girders. 


\section{CHAPTER IV \\ 4. RESULTS FROM THE PARAMETRIC STUDY}

\subsection{General}

The structural response of the box girder bridges was evaluated using finite-element modeling. A practical-design-oriented parametric study was conducted on 260 simply-supported straight adjacent precast box girder bridge prototypes to investigate the moment, shear and deflection distribution factors at the ultimate, serviceability and fatigue limit states, in addition to the transverse shear between box beams at ultimate limit state. The bridges were analyzed using SAP2000 software to evaluate their structural response when subjected to Canadian Highway Bridge Design truck loading, CHBDC truck CL-625-ONT. The key parameters considered in this study include number of girders $(N)$, girder spacing $(S)$, girder size (I, $Y_{n}, \ldots$ etc.), span length (L), number of design lanes (n), and truck loading conditions. Table A. 1 through Table A. 18 summarizes the moment and shear distribution factors for the studied bridges bases on $\mathrm{F}_{\mathrm{m}}$ and $\mathrm{Fv}$ formula available in CHBDC of 2006.

A comparison between the obtained results from finite-element modeling and corresponding factors from the simplified method of analysis in the CHBDC for slab-on-girder bridges was conducted. Based on the results generated from the parametric study, new equations for moment, shear, and deflection distribution factors were developed. The developed equations were then correlated with the FEA values to stand on the level of accuracy. It should be noted that the results obtained from finite-element modeling for moment, shear, and deflection distribution factors were based on CHBDC 2006 equations. However in the process of generating new equations, all the obtained values from finite-element modeling has been converted to match the new equation format in CHBDC 2014.

\subsection{Moment Distribution Factor}

Through the finite-element analysis of the box girder bridges, the moment distribution factor $\left(\mathrm{F}_{\mathrm{m}}\right)$ was calculated for each loading case at ultimate limit state (ULS) and fatigue limit state (FLS) using Equations (3.12), (3.13), and (3.14) for fully-loaded lanes, partially-loaded lanes, and fatigue loading case, respectively. The maximum calculated $\mathrm{F}_{\mathrm{m}}$ at the ULS and FLS was then used for the comparison of results and equation development. 
Appendix A summarizes the moment distribution factors for ULS and FLS designs along with the loading case from which the maximum values were obtained. The following subsections present the effect of each parameter on the moment distribution factor. In addition, correlations of the FEM results with CHBDC and proposed equation values are presented.

\subsubsection{Effect of Number of Girders on Moment Distribution Factors}

Figure A. 1 to Figure A. 15 present the relationship between the number of girders and moment distribution factor $\left(F_{m}\right)$ for ULS, SLS and FLS designs. To be able to analyze the results, Figure A. 7 of three-lane, 13-m span, bridge is taken here as an example. In this figure, it can be observed that $F_{m}$ increased by $10.86 \%$ when increasing number of girders from 9 to 11 for ULS and SLS design. While $\mathrm{F}_{\mathrm{m}}$ increased by $8.45 \%$ when increasing number of girders from 9 to 11 for FLS design. Similar trend was observed in other bridge configurations. It should be noted that the change in bridge width and corresponding number of girders is implied in the parameter $\mu$ in the CHBDC simplified method. Similar trend obtained for other bridge geometries. It can be summarized that, with increasing number of girders the moment distribution factor increases.

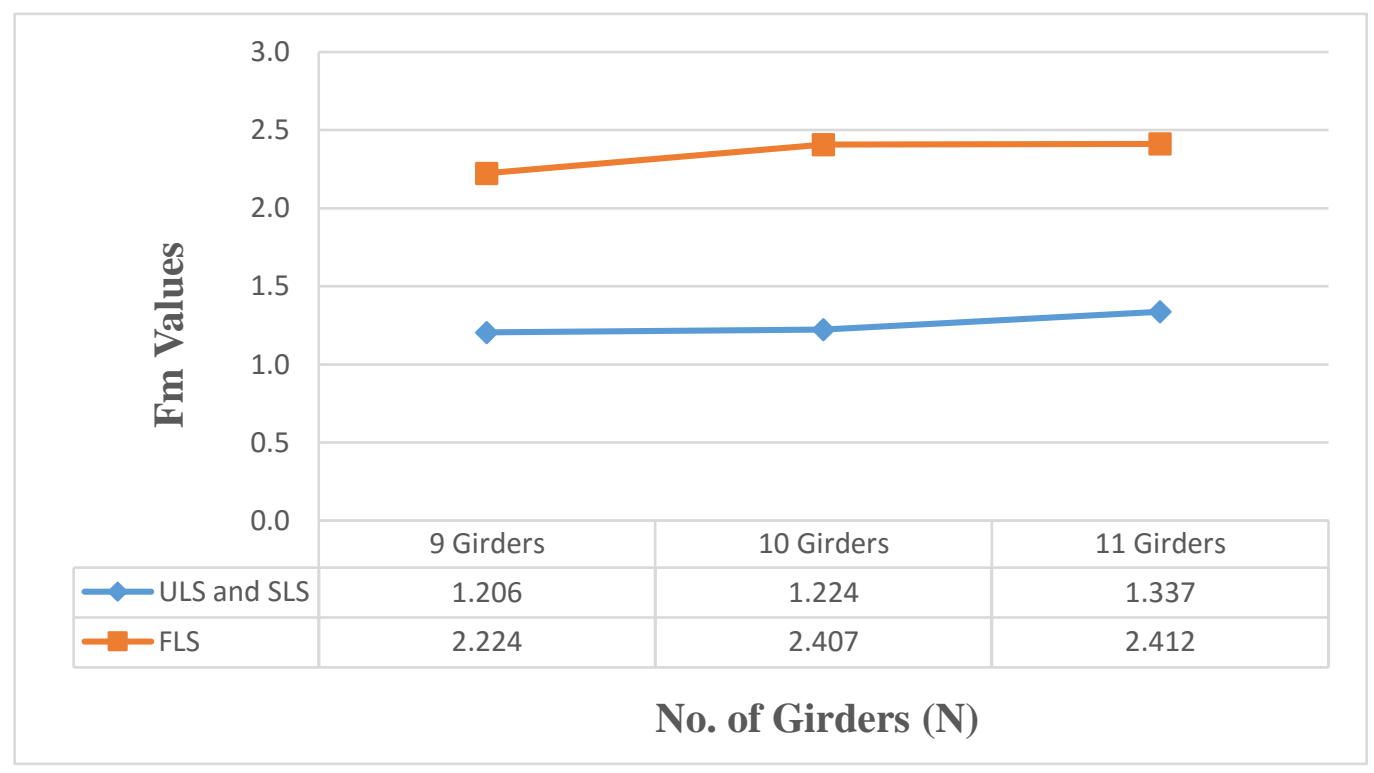

Figure A. 7: Effect of number of girders on moment distribution factor (B700, three-lane, $13 m$ span) 


\subsubsection{Effect of Span Length on Moment Distribution Factors}

Figure A. 16 to Figure A. 32 shows the relationship between the change in span length and moment distribution factor $\left(\mathrm{F}_{\mathrm{m}}\right)$ for ULS, SLS and FLS designs. To explain the trend, Figure A. 27 of fivelane bridge made of 15 girders was taken here as an example. In this figure, it can be observed that $\mathrm{F}_{\mathrm{m}}$ changes from 1.730 to 1.201 (a decrease of $30.6 \%$ ) when increasing span length from 10 to 32 for ULS and SLS design. Similarly, $F_{m}$ decrease from 4.320 to 2.185 when increasing span length from 10 to 32 for FLS design (decrease of a 49.4\%). It should be noted that the change in bridge width and corresponding span length is implied in the parameter $F$ and $\mathrm{C}_{\mathrm{f}}$ in the CHBDC simplified method. Similar trend obtained for other bridge geometries. It can be summarized that, with increasing span length, the moment distribution factor decreases.

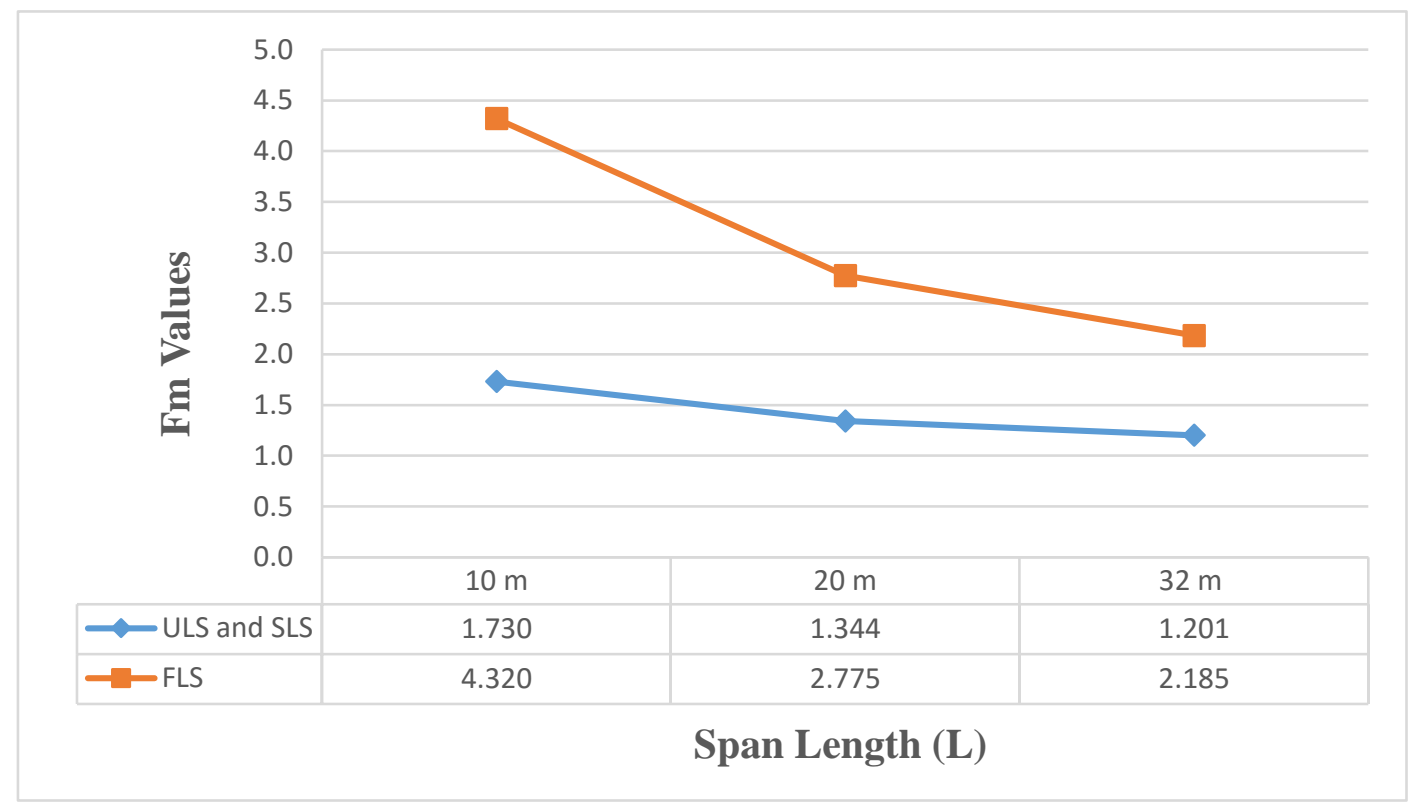

Figure A. 27: Effect of span length on moment distribution factor (five-lane, 15 girders)

\subsubsection{Effect of Number of Design Lanes on Moment Distribution Factors}

Figure A. 33 to Figure A. 36 depicts the relationship between the change in number of design lanes and moment distribution factor $\left(F_{m}\right)$ for ULS, SLS, and FLS designs. It can be observed that the change in number of design lanes has an insignificant effect on $\mathrm{F}_{\mathrm{m}}$ values at ULS, while it have significant effect at the FLS design. To explain the trend, Figure A. 33 for 10-m span bridge, that was studied for one to six design lanes, is taken here as an example. In this figure, it can be observed that $\mathrm{F}_{\mathrm{m}}$ changes from 1.455 to 1.922 when changing the number of design lanes from one to six for ULS and SLS design. On the other hand, $F_{m}$ increase from 1.398 to 5.492 when 
changing the number of design lanes from one to six for FLS design which considered a huge increase. This may be attributed to the fact that only one truck is considered at most eccentric location in the travelling lane. Similar trend obtained for other bridge geometries. It can be summarized that, increasing number of design lanes increases the moment distribution factor.

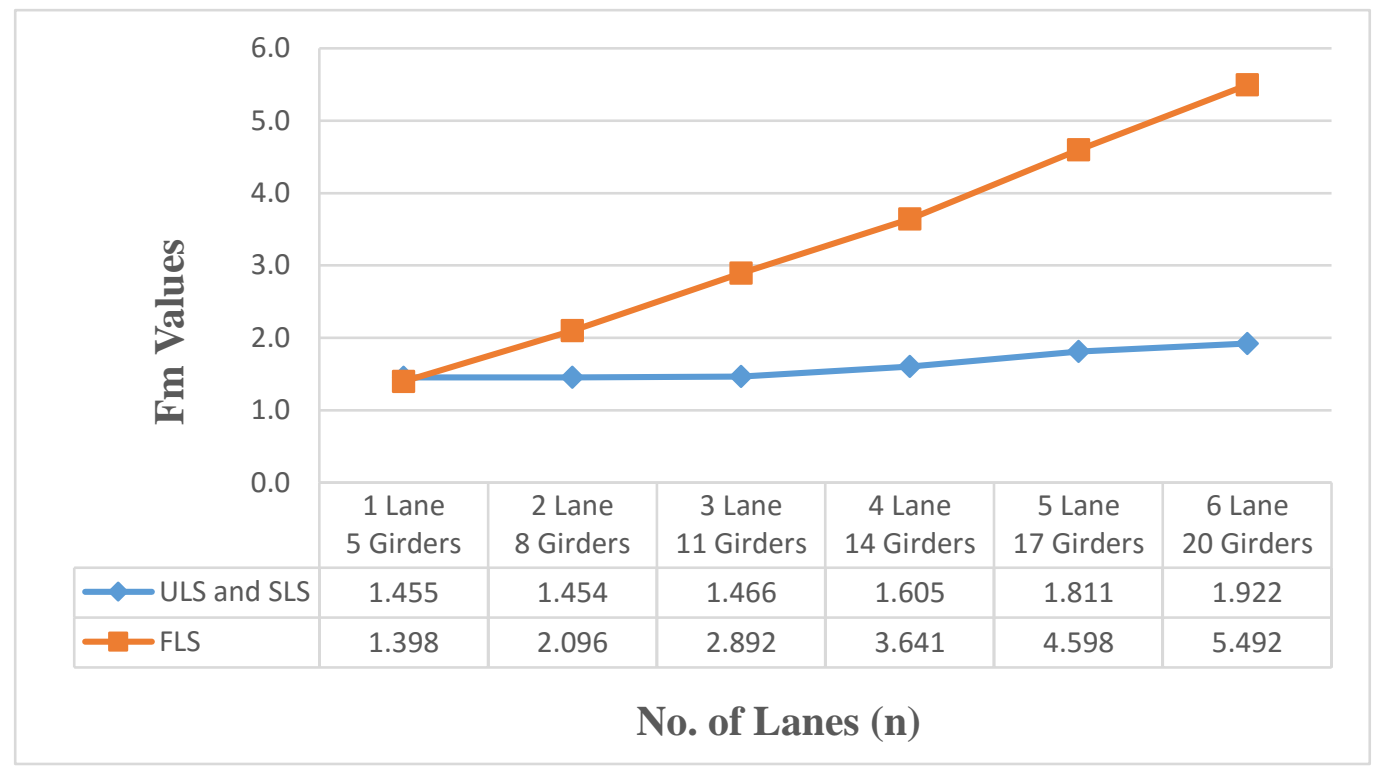

Figure A. 33: Effect of number of lanes on moment distribution factor (B700, 10m Span)

\subsection{Shear Distribution Factor}

In finite element analysis of the box girder bridge, the shear distribution factor $\left(\mathrm{F}_{\mathrm{v}}\right)$ was calculated for each loading case at ultimate limit state (ULS) and fatigue limit state (FLS) using Equations (3.15), (3.16), and (3.17) for fully-loaded lanes, partially-loaded lanes, and fatigue loading case, respectively. The maximum calculated $\mathrm{F}_{\mathrm{v}}$ at the ULS and FLS was then used for the comparison of results and development of equations. Appendix A summarizes the shear distribution factors for ULS and FLS designs along with the loading case from which the maximum values were obtained. The following subsections present the effect of each parameter on the shear distribution factor.

\subsubsection{Effect of Number of Girders on Shear Distribution Factors}

Figure A. 37 to Figure A. 51 present the relationship between the number of girders and shear distribution factor $\left(\mathrm{F}_{\mathrm{v}}\right)$ for ULS, SLS, and FLS designs. To explain the trend, Figure A. 43 for three-lane, 13-m span, bridge is taken here as an example. This figure shows that $\mathrm{F}_{\mathrm{V}}$ increased by $22.3 \%$ when increasing number of girders from 9 to 11 for ULS and SLS design. While $\mathrm{F}_{V}$ increased by $19 \%$ when increasing number of girders from 9 to 9 for FLS design. Similar trend 
obtained for other bridge geometries. It can be summarized that with increasing number of girders the shear distribution factor increases.

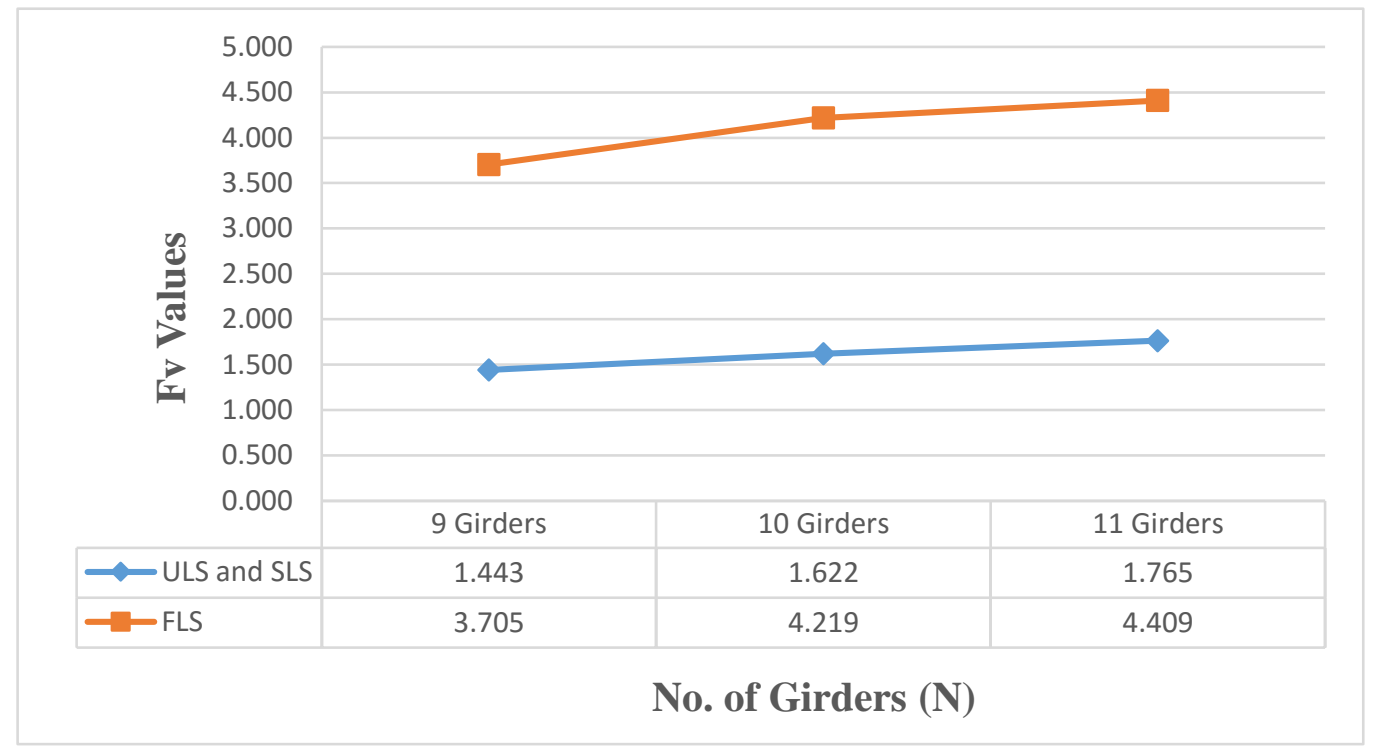

Figure A. 43: Effect of number of girders on shear distribution factor (B700, three-lane, 13m Span)

\subsubsection{Effect of Span Length on Shear Distribution Factors}

Figure A. 52 to Figure A. 68 present the relationship between the change in span length and shear distribution factor $\left(\mathrm{F}_{\mathrm{v}}\right)$ for ULS, SLS and FLS designs. To explain the trend, Figure A. 63 for fivelane bridge made of 15 girders is taken here as an example. In this figure, it can be observed that $\mathrm{F}_{\mathrm{v}}$ changed from 1.904 to 1.447 (a decrease of 24\%) when increasing span length from 10 to 32 for ULS and SLS design. Similarly, $\mathrm{F}_{v}$ decreases from 6.108 to 4.348 when increasing span length from 10 to 32 for FLS design (a decrease of 28.8\%). Similar trend obtained for other bridge geometries with only few cases for $10 \mathrm{~m}$ and $13 \mathrm{~m}$ span length were the values slightly increase or stay the same when increasing span length. It can be summarized that, with increasing span length the shear distribution factor generally decreases. 


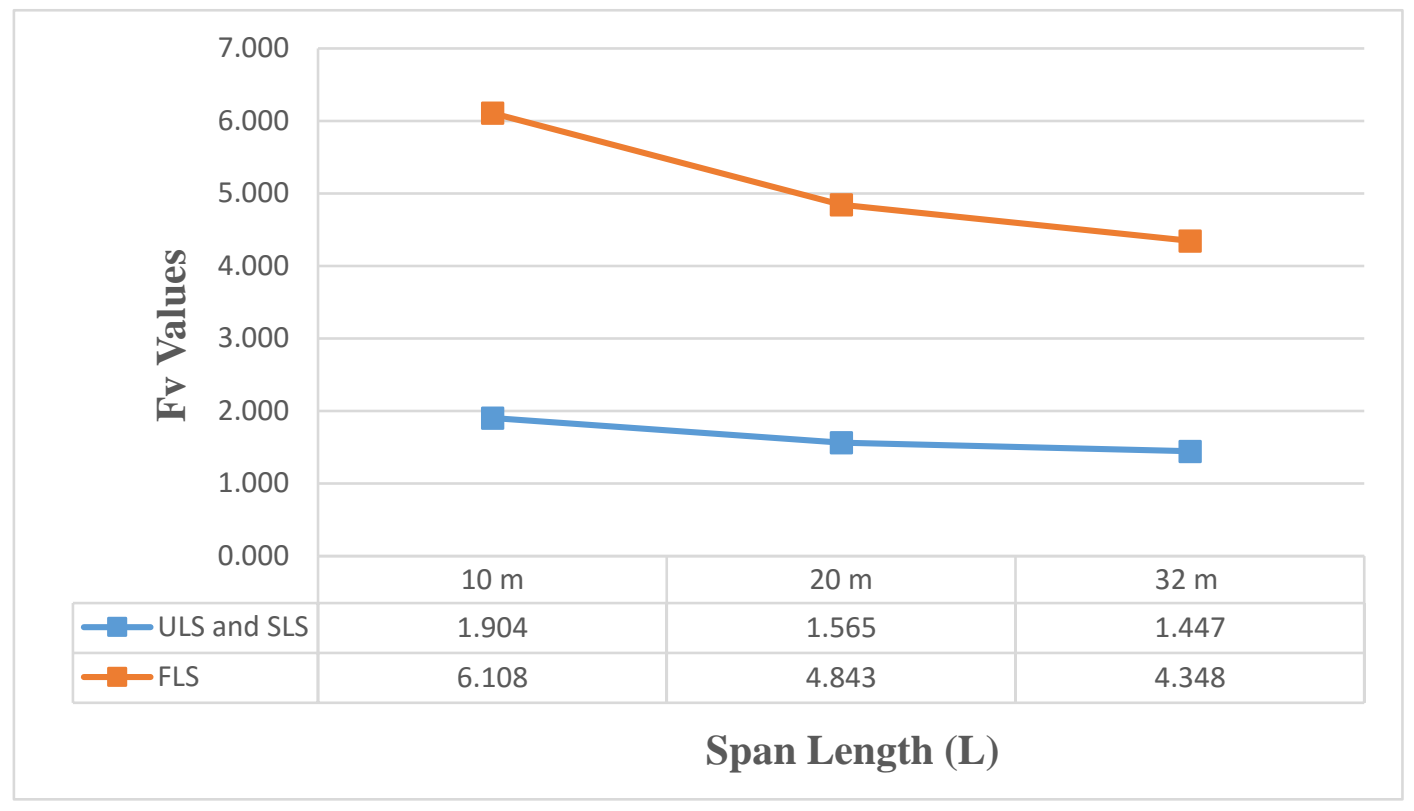

Figure A. 63: Effect of span length on shear distribution factor (five-lane, 15 girders)

\subsubsection{Effect of Number of Design Lanes on Shear Distribution Factors}

Figure A. 69 to Figure A. 72 depicts the relationship between the change in number of design lanes and shear distribution factor $\left(\mathrm{F}_{v}\right)$ for ULS, SLS and FLS designs. A similar trend for shear distribution factors and moment distribution factors was observed when studying the effect of number of design lanes. As an example, Figure A. 69 for 10-m span bridge that was studied for one to six design lanes. The figure shows that $\mathrm{F}_{\mathrm{v}}$ changed from 1.894 to 2.329 when changing the number of design lanes from one to six for ULS and SLS design. On the other hand, $\mathrm{F}_{\mathrm{v}}$ increases from 1.676 to 7.959 when changing the number of design lanes from one to six for FLS design. Similar trend obtained for other bridge geometries. It can be summarized that, increasing number of design lanes increases the shear distribution factor. 


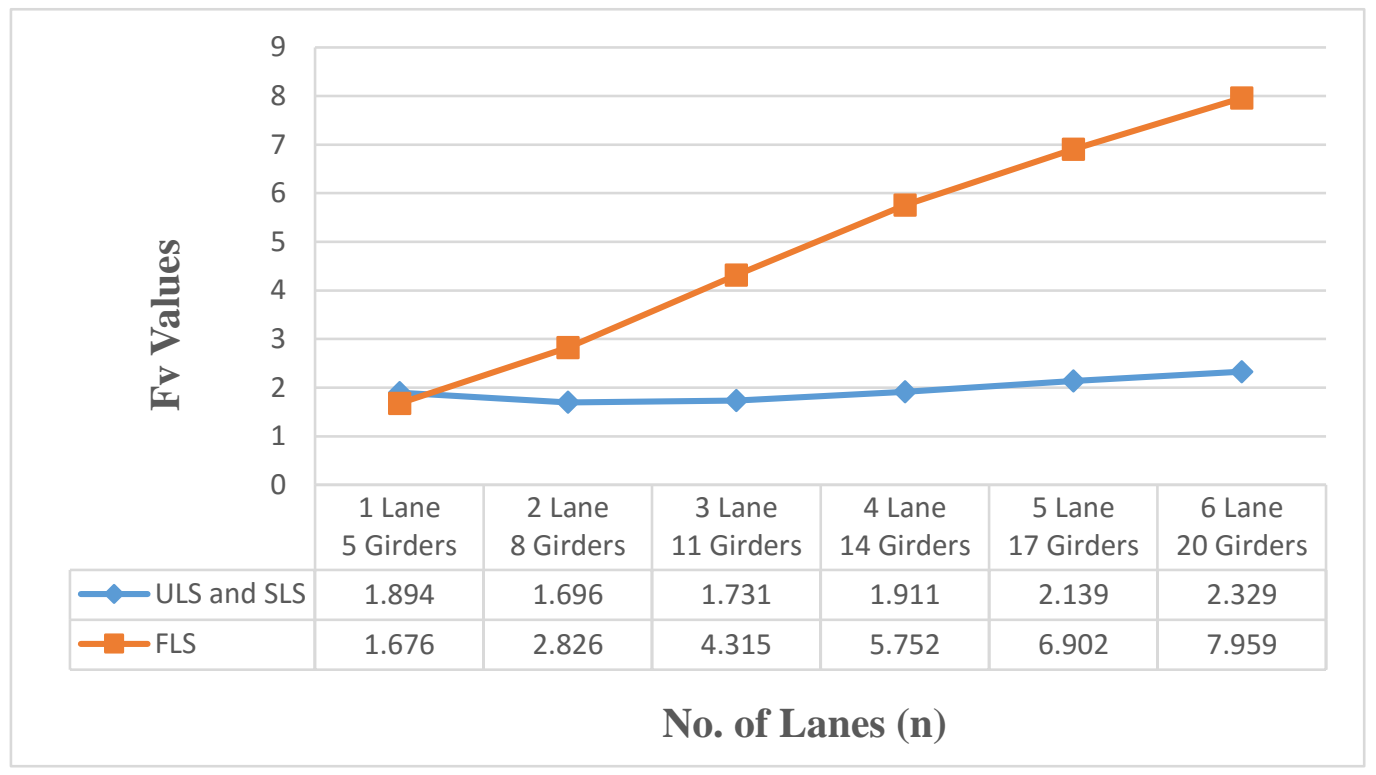

Figure A. 69: Effect of number of lanes on shear distribution factor (B700, 10m span)

\subsection{Deflection Distribution Factor}

The deflection distribution factors were calculated based on fatigue limit state loading case only as specified in CHBDC. Through the finite-element analysis for the box girder bridge, the deflection distribution factor $\left(\mathrm{F}_{\mathrm{d}}\right)$ was calculated for each loading case at fatigue limit state (FLS) using Equation (3.18). The maximum calculated $F_{d}$ at the FLS was then used for the results comparison and equations development.

Appendix A summarizes the deflection distribution factors for FLS design along with the loading case from which the maximum values were obtained. The following subsections present the effect of each parameter on the deflection distribution factor.

\subsubsection{Effect of Number of Girders on Deflection Distribution Factors}

Figure A. 73 to Figure A. 87 shows the relationship between the number of girders and deflection distribution factor $\left(F_{d}\right)$ for FLS design. As an example, Figure A.79 of three-lane 13m span bridge was taken here to explain the trend. From the figure, it can observed that $\mathrm{F}_{\mathrm{d}}$ increased by $9 \%$ when increasing number of girders from 9 to 10 for FLS design, while it slightly increases (about $0.1 \%$ ) when increasing number of girders from 10 to 11. However, when comparing the percentage increase in deflection distribution factor with moment and shear distribution factor, it can be 
observed that the rate of changing values with increase number of girder is less than that for moment and shear.

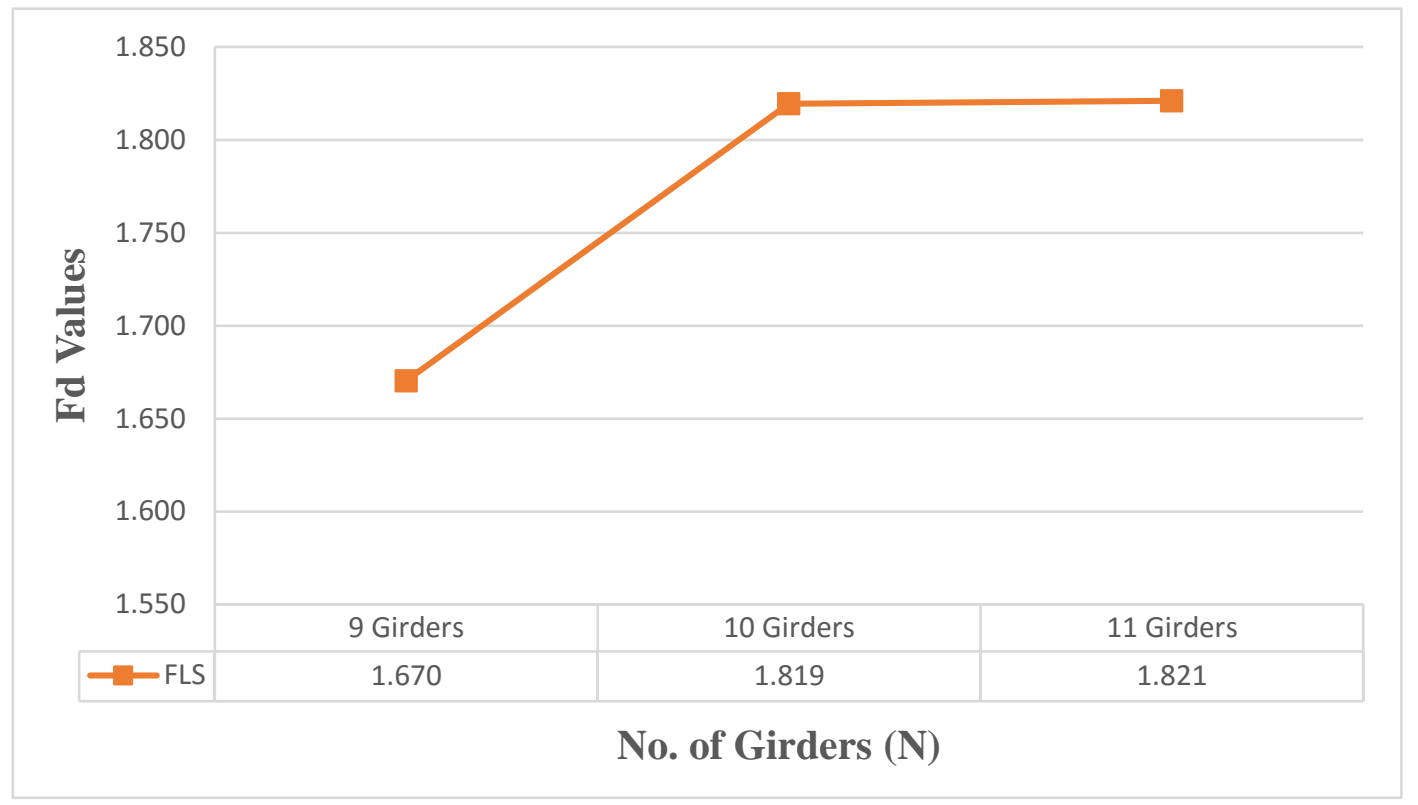

Figure A. 79: Effect of number of girders on deflection distribution factor (B700, threelane, 13m span)

\subsubsection{Effect of Span Length on Deflection Distribution Factors}

Figure A. 88 to Figure A. 104 present the relationship between the change in span length and deflection distribution factor $\left(\mathrm{F}_{\mathrm{d}}\right)$ for ULS, SLS, and FLS designs. To explain the trend, Figure A. 99 for five-lane bridge made of 15 girders is taken here as an example. In this figure, it can be observed that $\mathrm{F}_{\mathrm{d}}$ changes from 3.335 to 1.669 (a decrease of 50\%) when increasing span length from 10 to 32 for FLS design. Similar trend was observed for other bridge geometries. It can be summarized that with increasing span length, the deflection distribution factor decreases. 


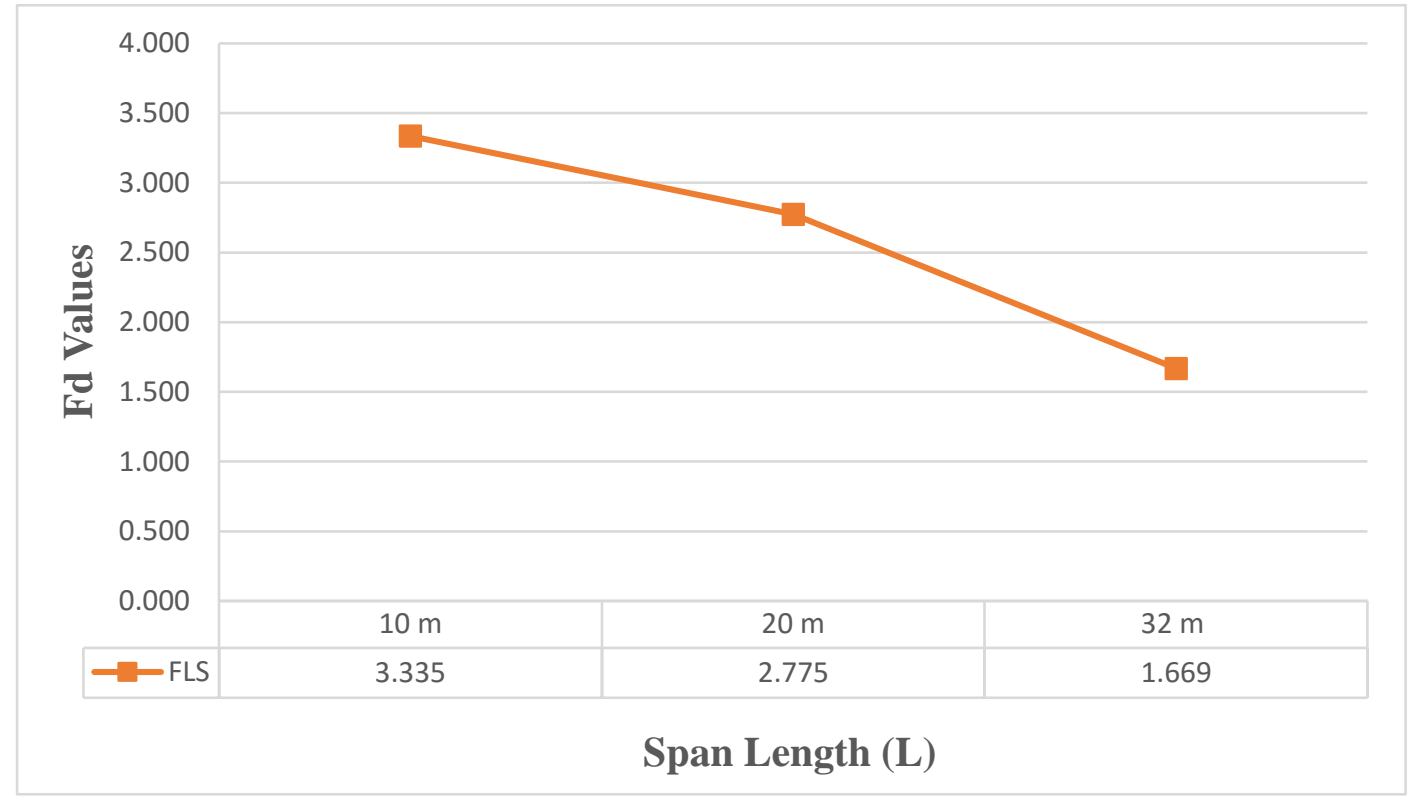

Figure A. 99: Effect of span length on deflection distribution factor (five-lane, 15 girders)

\subsubsection{Effect of Number of Design Lanes on Deflection Distribution Factors}

Figure A. 105 to Figure A. 108 depict the relationship between the change in number of design lanes and deflection distribution factor $\left(\mathrm{F}_{d}\right)$ for FLS design. As an example, Figure A. 105 for 10$\mathrm{m}$ span bridge that was studied for one to six design lanes shows that $\mathrm{F}_{\mathrm{d}}$ increased from 1.179 to 4.045 when changing the number of design lanes from one to six for FLS design. Similar trend was observed for other bridge geometries. It can be summarized that increasing number of design lanes increases the deflection distribution factor.

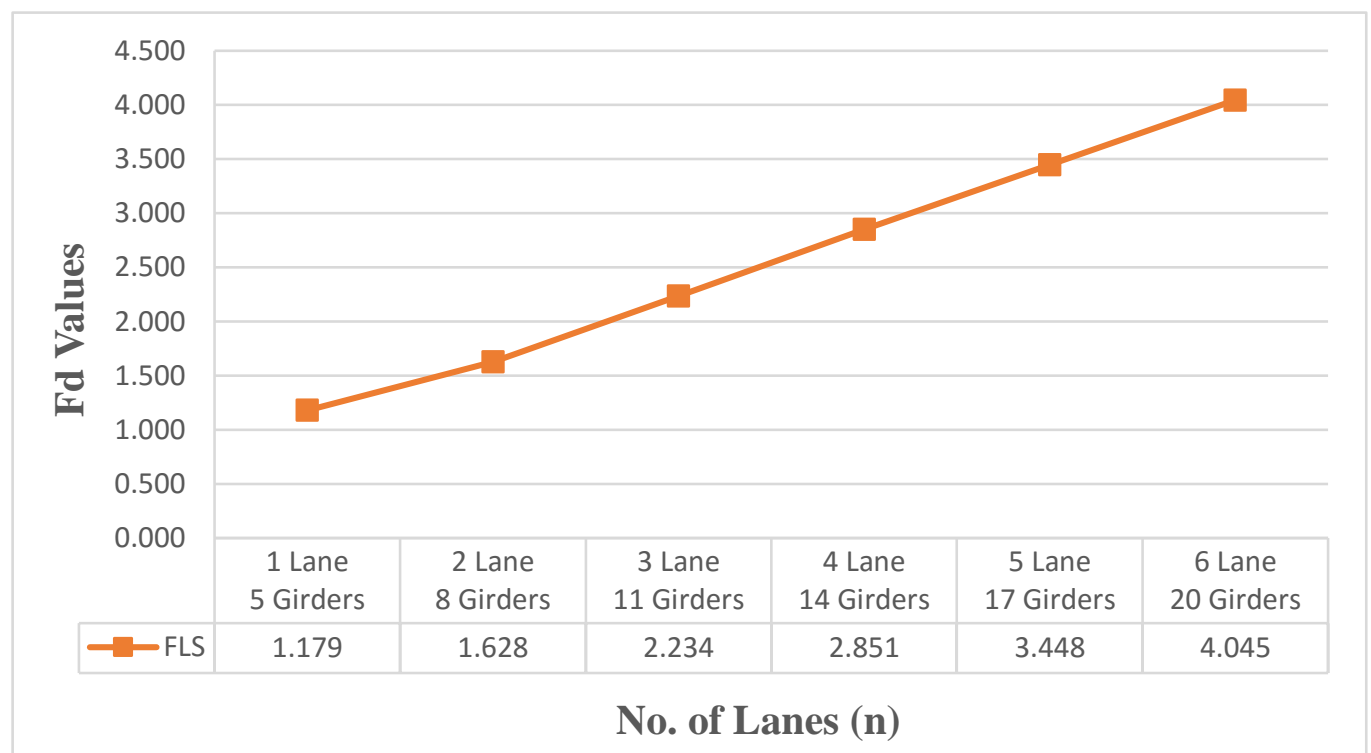

Figure A. 105: Effect of number of lanes on deflection distribution factor (B700, 10 girders) 


\subsection{Transverse Shear}

Through the finite element analysis of the box girder bridge, the vertical transverse shear $\left(V_{y}\right)$ results were obtained for different loading cases at ultimate limit state (ULS) and fatigue limit state (FLS). These values were correlated with those available in the CHBDC. Table A. 19 through Table A. 24 summarises the vertical transverse shear for ULS and FLS along with the loading case from which the maximum values were obtained. The following subsections present the effect of each parameter on the vertical transverse shear.

\subsubsection{Effect of loading cases on Transverse Shear}

Figure A. 109 to Figure A. 123 shows the relationship between different loading cases and transverse shear $\left(\mathrm{V}_{\mathrm{y}}\right)$ for ULS designs. The results from the finite-element analysis show that the maximum intensity of transverse vertical shear occurs mostly when eccentric trucks placed on the bridge at ultimate limit state. However, in some cases when the truck path fall adjacent or within the connection joints, $V_{\mathrm{y}}$ values increase due to local effects of wheel load at the joints between the box beams. For instance, most of the results obtained from the analysis of one to four lane were stable with slight variation when the truck load placed near the connection joints. However, the loading case results for five lanes and six lanes had higher variation in $V_{y}$ values due to the truck path was adjacent or within the joints between box beams. Thus, these values were not considered in the comparison between transverse shear and the variation in bridge width and span length.

\subsubsection{Effect of Bridge Width on Transverse Shear}

Figure A. 124 to Figure A. 125 present the relationship between the bridge width and transverse shear $\left(\mathrm{V}_{\mathrm{y}}\right)$ at ULS and SLS designs. It can be observed that with increasing the number of girder, which means increasing the bridge width, the vertical transverse shear increase. To explain the trend, Figure A. 124 is taken as an example herein. This figure shows that by increasing the number of girders from 5 to 20 girder the transverse shear force at the joint between box beams increases from 56.94 to 84.18 (an increase by $47.8 \%$ ). It can be summarized that, with increasing bridge width, the transverse shear force at the joint increases. 


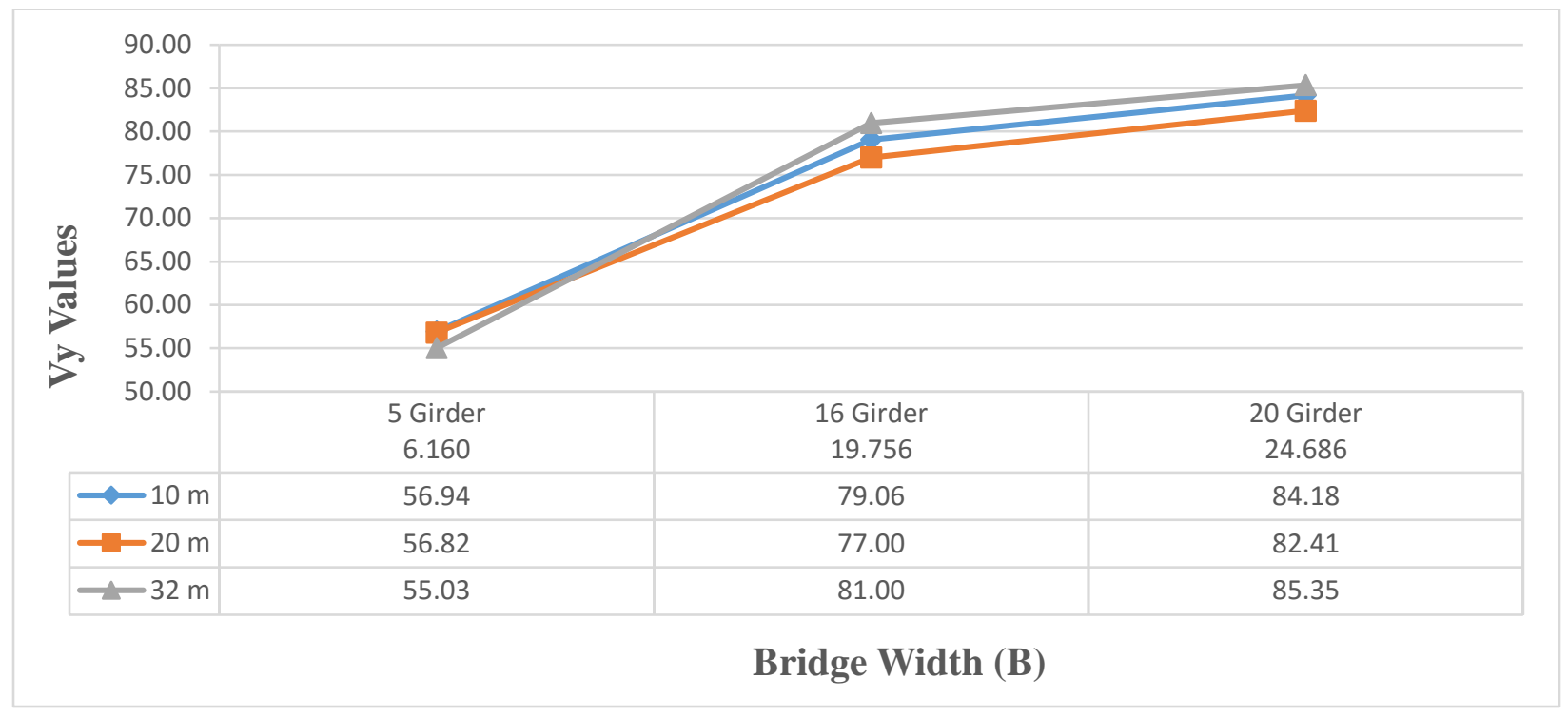

Figure A. 124: Effect of bridge width on transverse shear (5 girders, 16 girders, and 20 girders)

\subsubsection{Effect of Span Length on Transverse Shear}

Figure A. 126 to Figure A. 127 show the relationship between the span length and transverse shear $\left(V_{y}\right)$ at ULS design. It can be observed that with increasing the span length, the vertical transverse shear force at the joint slightly changes so that its effect can be considered insignificant. To explain the trend, Figure A. 126 can be taken as an example herein. This figure shows that by increasing the span length from 10 to $32 \mathrm{~m}$, the transverse shear decreases from 56.94 to 55.03 (a decrease by $3.35 \%$ ). In general, one may observe that loading bridge cross-section with only one truck loaded eccentrically would not provide the most critical value of the design transverse shear force at the joint. In addition, FEA results showed local effects of the wheel load at or close to the joint, leading to unrealistically high shear forces at the joint. So, it is recommended to extend this research to include patch loading rather than wheel loading when analysing bridges for this purpose. Also, it is recommended to use the PLATO software for the analysis of such bridges using the orthotropic plate theory for consistency in results. 


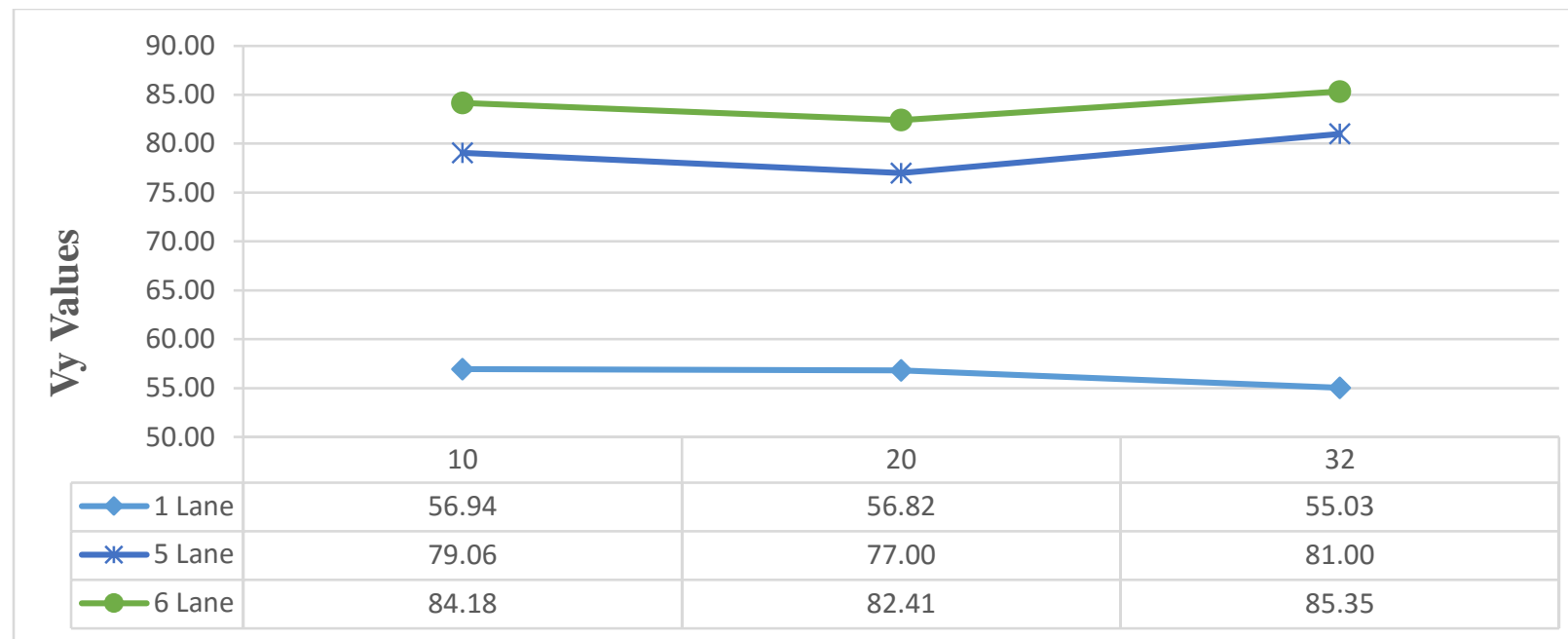

Span Length (L)

Figure A. 126: Effect of span length on transverse shear (one-lane, five-lanes, six-lanes)

\subsection{Development of New Load Distribution Factor Equations}

The parametric study generated database for moment, shear, and deflection distribution factors. This database has been used to develop a more reliable and economical expressions for the moment, shear and deflection distribution factors using a statistical package for curve fit in Microsoft Excel. The following sections present these equations along with their correlations with the finite-element analysis results toward confidence in their use in practice. It should be noted that, the proposed equations were generated according to both CHBDC 2006 and CHBDC 2014.

\subsubsection{Proposed Distribution Factors based on CHBDC 2006}

CHBDC 2006 specifies the following equations for the moment, shear, and deflection distribution factors at ULS, SLS and FLS, as discussed in Chapter 2:

$$
\begin{array}{ll}
\mathrm{F}_{\mathrm{m}}=\frac{\mathrm{S} \mathrm{N}}{\mathrm{F}\left(1+\frac{\mu \mathrm{C}_{\mathrm{f}}}{100}\right)} \geq 1.05 & \text { (ULS) } \\
\mathrm{F}_{\mathrm{m}, \mathrm{d}}=\frac{\mathrm{S} \mathrm{N}}{\mathrm{F}\left(1+\frac{\mu \mathrm{C}_{\mathrm{f}}}{100}\right)} \geq 1.05 & \text { (FLS and SLS2) } \\
\mathrm{F}_{\mathrm{v}}=\frac{\mathrm{S} \mathrm{N}}{\mathrm{F}} & \text { (ULS and FLS) }
\end{array}
$$

The expressions $\mathrm{F}$ and $\mathrm{C}_{\mathrm{f}}$ in the equation were developed as a function of $\mathrm{L}$ as shown below:

$$
\mathrm{F}=\mathrm{a}+\mathrm{bL}
$$




$$
\mathrm{C}_{\mathrm{f}}=\mathrm{c}+\mathrm{dL}
$$

The data generated from the parametric study was used to developed new the parameters $\mathrm{F}$ and $\mathrm{C}_{\mathrm{f}}$ for the deck-free precast box girder bridges. A linear function was assumed for both parameters and provides good accuracy. Table 4.1 summarize the developed parameters in a similar format as CHDBC simplified method of analysis specified in 2006 version. These equations were developed with a condition that the resulting values underestimates the response by a maximum of $5 \%$.

Khan (2010) proposed empirical equations for distribution factor for deck-free box girder bridges. His equations were based on 2 to 4 design lanes for bridges of spans ranging from 16 to $32 \mathrm{~m}$. Figure A. 128 to Figure A. 142 show the correlation between the results obtained from the developed equations in the current study and those obtained from Khan's proposed equations; all equations are listed in Table 4.1 from the two studies. By inspection of these figures, it can be observed that the moment, shear and deflection values from Khan's work were underestimated in some cases. On the other hand, Figure A. 143 to Figure A. 147 show the correlation between the finite-element analysis results and those resulting from the developed equations in the current study at the ULS, SLS and FLS designs. Good agreement between the FEA results and the new developed equations was observed. So, designers can use the proposed equations with confidence. 
Table 4.1: Proposed Equations for deck-free precast box girder bridges (CHBDC, 2006)

\begin{tabular}{|c|c|c|c|c|c|}
\hline \multicolumn{6}{|c|}{ Proposed Moment Distribution Factors $\left(F_{m}\right)$ at Ultimate Limit State } \\
\hline No. of design lanes & Value of $\mathbf{F}$ & Value of $\mathrm{C}_{\mathrm{f}}$ & \multirow{7}{*}{$\begin{array}{l}\text { Proposed Equations } \\
\text { Khan (2010) }\end{array}$} & Value of $\mathbf{F}$ & Value of $\mathrm{C}_{\mathrm{f}}$ \\
\hline 1 & $2.5+0.13 \mathrm{~L}$ & $12-1.34 \mathrm{~L}$ & & & \\
\hline 2 & $5.25+0.07 \mathrm{~L}$ & $14.8+0.37 \mathrm{~L}$ & & $6.15+0.04 \mathrm{~L}$ & $19+0.04 \mathrm{~L}$ \\
\hline 3 & $7.68+0.09 \mathrm{~L}$ & $10.75+0.28 \mathrm{~L}$ & & $9.0+0.04 \mathrm{~L}$ & $13.5+0.15 \mathrm{~L}$ \\
\hline 4 & $7.60+0.22 \mathrm{~L}$ & $17.88-0.11 \mathrm{~L}$ & & $10.7+0.09 \mathrm{~L}$ & \\
\hline 5 & $7.44+0.27 \mathrm{~L}$ & $22.60-0.51 \mathrm{~L}$ & & & \\
\hline 6 & $7.42+0.34 \mathrm{~L}$ & $28.9-0.84 \mathrm{~L}$ & & & \\
\hline \multicolumn{6}{|c|}{ Proposed Moment Distribution Factors $\left(F_{m}\right)$ at Fatigue Limit State } \\
\hline No. of design lanes & Value of $F$ & Value of $C_{f}$ & \multirow{7}{*}{$\begin{array}{l}\text { Proposed Equations } \\
\text { Khan (2010) }\end{array}$} & Value of $F$ & Value of $C_{f}$ \\
\hline 1 & $2.70+0.12 \mathrm{~L}$ & $12.7-1.3 \mathrm{~L}$ & & & \\
\hline 2 & $2.15+0.18 \mathrm{~L}$ & $17.92-0.04 \mathrm{~L}$ & & $5.55+0.05 \mathrm{~L}$ & $11+0.25 \mathrm{~L}$ \\
\hline 3 & $0.94+0.28 \mathrm{~L}$ & $29.94-0.88 \mathrm{~L}$ & & $5.5+0.09$ & $7.4+0.37 \mathrm{~L}$ \\
\hline 4 & $0.37+0.39 L$ & $16.27-0.75 \mathrm{~L}$ & & $5.6+0.15 \mathrm{~L}$ & $2.3+0.25 \mathrm{~L}$ \\
\hline 5 & $1.70+0.23 \mathrm{~L}$ & $20.73-0.56 \mathrm{~L}$ & & & \\
\hline 6 & $1.80+0.22 \mathrm{~L}$ & $21.56-0.52 \mathrm{~L}$ & & & \\
\hline \multicolumn{6}{|c|}{ Proposed Shear Distribution Factors $\left(F_{v}\right)$ at Ultimate Limit State } \\
\hline No. of design lanes & Value of $F$ & Value of $\mathrm{C}_{\mathrm{f}}$ & \multirow{7}{*}{$\begin{array}{l}\text { Proposed Equations } \\
\text { Khan (2010) }\end{array}$} & Value of $F$ & Value of $C_{f}$ \\
\hline 1 & $2.75+0.04 \mathrm{~L}$ & 0 & & & \\
\hline 2 & $5.11+0.05 \mathrm{~L}$ & 0 & & $5.20+0.04 \mathrm{~L}$ & 0 \\
\hline 3 & $7.17+0.05 \mathrm{~L}$ & 0 & & $7.13+0.05 \mathrm{~L}$ & 0 \\
\hline 4 & $8.16+0.08 \mathrm{~L}$ & 0 & & $8.60+0.05 \mathrm{~L}$ & 0 \\
\hline 5 & $8.40+0.15 \mathrm{~L}$ & 0 & & & \\
\hline 6 & $9.16+0.17 \mathrm{~L}$ & 0 & & & \\
\hline \multicolumn{6}{|c|}{ Proposed Shear Distribution Factors $\left(F_{v}\right)$ at Fatigue Limit State } \\
\hline No. of design lanes & Value of $F$ & Value of $C_{f}$ & \multirow{7}{*}{$\begin{array}{l}\text { Proposed Equations } \\
\text { Khan }(2010)\end{array}$} & Value of $F$ & Value of $C_{f}$ \\
\hline 1 & $3.15+0.03 \mathrm{~L}$ & 0 & & & \\
\hline 2 & $2.26+0.08 \mathrm{~L}$ & 0 & & $2.5+0.07 \mathrm{~L}$ & 0 \\
\hline 3 & $1.98+0.09 \mathrm{~L}$ & 0 & & $2.55+0.07 \mathrm{~L}$ & 0 \\
\hline 4 & $1.84+0.10 \mathrm{~L}$ & 0 & & $2.3+0.08 \mathrm{~L}$ & 0 \\
\hline 5 & $2.45+0.06 \mathrm{~L}$ & 0 & & & \\
\hline 6 & $2.48+0.06 \mathrm{~L}$ & 0 & & & \\
\hline \multicolumn{6}{|c|}{ Proposed Deflection Distribution Factors $\left(F_{d}\right)$ at Fatigue Limit State } \\
\hline No. of design lanes & Value of $F$ & Value of $C_{f}$ & \multirow{7}{*}{$\begin{array}{l}\text { Proposed Equations } \\
\text { Khan (2010) }\end{array}$} & Value of $\mathbf{F}$ & Value of $C_{f}$ \\
\hline 1 & $3.9+0.014 \mathrm{~L}$ & $6.6+0.4 \mathrm{~L}$ & & & \\
\hline 2 & $4.30+0.10 \mathrm{~L}$ & $16.6+0.25 \mathrm{~L}$ & & $5.85+0.04 \mathrm{~L}$ & 19.7 \\
\hline 3 & $3.15+0.22 \mathrm{~L}$ & $19.79-0.12 \mathrm{~L}$ & & $5.3+0.12 \mathrm{~L}$ & $28-0.4 \mathrm{~L}$ \\
\hline 4 & $2.30+0.30 \mathrm{~L}$ & $25.39-0.62 \mathrm{~L}$ & & $5+0.16 \mathrm{~L}$ & $25-0.25 \mathrm{~L}$ \\
\hline 5 & $3.83+0.15 \mathrm{~L}$ & $0.96 \mathrm{~L}$ & & & \\
\hline 6 & $3.83+0.13 \mathrm{~L}$ & $1.2 \mathrm{~L}$ & & & \\
\hline
\end{tabular}




\subsubsection{Load Distribution Factors Conversion from CHBDC 2006 to CHBDC 2014}

The load distribution factors were converted from CHBDC 2006 to CHBDC 2014 and the new equations were developed based on CHBDC 2014. By inspection, it can be observed that $\mathrm{F}_{\mathrm{T}}$ equals $\mathrm{F}_{\mathrm{m}}$ times $\mathrm{nRL} / \mathrm{N}$ for ULS and times $1 / \mathrm{N}$ for FLS and SLS2.

$$
\begin{array}{ll}
\mathrm{F}_{\mathrm{T}}=\mathrm{F}_{\mathrm{m}(2006)} \cdot \frac{\mathrm{n} \mathrm{R}}{\mathrm{N}} \geq 1.05 \frac{\mathrm{nR}_{\mathrm{L}}}{\mathrm{N}} & \text { (ULS for moment) } \\
\mathrm{F}_{\mathrm{T}}=\mathrm{F}_{\mathrm{m}(2006)} \cdot \frac{1}{\mathrm{~N}} \geq 1.05 \frac{1}{\mathrm{~N}} & \text { (FLS for moment) } \\
\mathrm{F}_{\mathrm{T}}=\mathrm{F}_{\mathrm{v}(2006)} \cdot \frac{\mathrm{n} \mathrm{R} \mathrm{L}}{\mathrm{N}} \geq 1.05 \frac{\mathrm{n} \mathrm{R}_{\mathrm{L}}}{\mathrm{N}} & \text { (ULS for shear) } \\
\mathrm{F}_{\mathrm{T}}=\mathrm{F}_{\mathrm{v}(2006)} \cdot \frac{1}{\mathrm{~N}} \geq 1.05 \frac{1}{\mathrm{~N}} & \text { (FLS for shear) }
\end{array}
$$

\subsubsection{Comparison between FEA Results and CHBDC 2014 Simplified Method for Shear Connected Bridges}

The Canadian Highway Bridge Design Code specifies equations for calculating the moment shear and deflection distribution factors for shear connected bridges. It should be noted that CHBDC specifies the deflection distribution values for such bridges can be taken as those for moment values for simplicity. Figure A. 148 to Figure A. 151 present correlation between the results from the current study for deck-free precast box girders and those obtained from the CHDBC simplified method for shear connected bridges. By inspection of these figures, it can be observed that the results obtained based on the CHBDC 2014 equations for shear connected bridges are underestimated in some cases and overestimated for others compared to those obtained from FEA results of the deck-free precast box girder bridges. Due to these discrepancies in correlation, it was decided to develop new empirical expressions for the studied bridge geometries to provide bridge engineers and code writers of more economical and reliable simplified method of analysis.

\subsubsection{Comparison between FEA Results and AASHTO-LRFD 2012 Equations}

The AASHTO-LRFD Bridge Design Specifications specify load distribution factors equations for box girder bridges as discussed in chapter 2. Figure A. 152 to Figure A. 155 show the correlation between the results from the current study for deck-free precast box girders and those obtained from AASHTO-LRFD for moment and shear distribution factors at ULS. It can be observed that AASHTO-LRFD overestimates the load distribution factors by a significant margin. Appendix A 
list the AASHTO distribution factors for the studied bridge along with values obtained from finite element analysis.

\subsubsection{Comparison between FEA Results and Alberta Manual 2015 Equations}

The Alberta Bridge load Manual specify load distribution factors equations for box girder bridges as discussed in chapter 2. Figure A. 156 to Figure A. 159 show the correlation between the results from the current study for deck-free precast box girders and those obtained from Alberta Bridge Manual for moment and shear distribution factors at ULS. It can be observed that Alberta Bridge Manual underestimate the load distribution factors in many cases by a significant margin. Appendix A list the Alberta Bridge Manual distribution factors for the studied bridge along with values obtained from finite element analysis.

\subsubsection{Proposed Distribution Factors based on CHBDC 2014}

CHBDC 2014 specifies the following equations for the moment, shear, and deflection distribution factors at ULS, SLS and FLS, as discussed in Chapter 2:

$$
\begin{aligned}
& \mathrm{F}_{\mathrm{T}}=\frac{\mathrm{S}}{\mathrm{D}_{\mathrm{T}} \gamma_{\mathrm{c}}(1+\mu \lambda)} \geq 1.05 \frac{\mathrm{n} \mathrm{R}_{\mathrm{L}}}{\mathrm{N}} \quad(\text { ULS and SLS }) \\
& \mathrm{F}_{\mathrm{T}}=\frac{\mathrm{S}}{\mathrm{D}_{\mathrm{T}} \gamma_{\mathrm{c}}\left(1+\mu \lambda+\gamma_{\mathrm{e}}\right)} \geq 1.05 \frac{1}{\mathrm{~N}} \quad(\mathrm{FLS})
\end{aligned}
$$

According to the CHBDC 2014, $\gamma_{c}$ shall be 1.0 and $\gamma_{e}$ shall be 0.0 for shear-connected bridges.

The converted data from the parametric study was used to developed new the parameters $\beta$ and $\lambda$ for the deck-free precast box girder bridges. A linear function was assumed for both parameters and provides good accuracy. Table 4.2 summarize the developed parameters in a similar format as CHDBC simplified method of analysis specified in 2014 version taking into account various numbers of design lanes. These equations were developed with a condition that the resulting values underestimates the response by a maximum of 5\%. Figure A. 160 to Figure A. 163 show the correlation between the finite-element analysis results and those resulting from the developed equations in the current study at the ULS, SLS and FLS designs. Good agreement between the FEA results and the new developed equations. Thus, designers can use the proposed equations with confidence. 
Table 4.2: Proposed Equations for deck-free precast box girder bridges (CHBDC, 2014)

\begin{tabular}{|c|c|c|c|c|}
\hline Condition & Load Effect & $\mathbf{n}$ & $\mathbf{D}_{\mathrm{T}}$ & $\lambda$ \\
\hline \multirow[t]{6}{*}{ ULS and SLS } & \multirow[t]{3}{*}{ Moment } & 1 & $1.37+1.25 n+3.02 \beta$ & $0.17-7.31 / \mathrm{L}$ \\
\hline & & 2,3 , and 4 & $3.24+0.47 n-0.36 \beta$ & $0.28-0.68 / \mathrm{L}$ \\
\hline & & $>4$ & $3.63+0.34 n-0.31 \beta$ & $0.18+0.91 / \mathrm{L}$ \\
\hline & \multirow[t]{3}{*}{ Shear } & 1 & $1.52+1.40 n+1.11 \beta$ & $0.28-6.56 / \mathrm{L}$ \\
\hline & & 2,3 , and 4 & $3.17+0.14 n-0.15 \beta$ & $0.07-0.26 / \mathrm{L}$ \\
\hline & & $>4$ & $3.66+0.20 n-0.23 \beta$ & $0.02+0.90 / \mathrm{L}$ \\
\hline \multirow[t]{6}{*}{ FLS } & \multirow[t]{3}{*}{ Moment } & 1 & $1.28+1.14 n+3.46 \beta$ & $0.16-7.42 / \mathrm{L}$ \\
\hline & & 2,3, and 4 & $3.62+1.42 n-1.11 \beta$ & $0.40-1.70 / \mathrm{L}$ \\
\hline & & $>4$ & $4.09+0.69 n-0.60 \beta$ & $0.35-0.09 / \mathrm{L}$ \\
\hline & \multirow[t]{3}{*}{ Shear } & 1 & $1.13+0.99 n+3.49 \beta$ & $0.13-7.39 / \mathrm{L}$ \\
\hline & & 2,3, and 4 & $3.25+0.29 n-0.37 \beta$ & $0.16-1.36 / \mathrm{L}$ \\
\hline & & $>4$ & $3.28+0.23 n-0.22 \beta$ & $0.11-0.11 / \mathrm{L}$ \\
\hline
\end{tabular}




\section{CHAPTER V \\ 5. CONCLUSIONS AND RECOMMENDATIONS FOR FUTURE RESEARCH}

\subsection{General}

Deck-free precast adjacent box beams has been widely used nowadays in accelerated bridge construction. As a result, there is a need to develop empirical equations for moment and shear distribution factors among box beams. Therefore, a practical-design-oriented parametric study was conducted, using the finite-element software SAP2000, to investigate the structural response of simply-supported deck-free precast box girder bridges when subjected to CHBDC truck loading. The key parameters considered in this study included span length, number of design lanes, number of girders, and loading conditions. The following section summarizes the research findings and recommendations for future research.

\subsection{Conclusion}

According to the results obtained from the parametric study, the following conclusions are drawn:

- The key parameters that play a significant role on the load distribution factors are bridge span length, number of girders, number of design lanes and loading condition.

- Load distribution factors generally decrease with increase in span length.

- Load distribution factors increase significantly when increasing number of lanes for FLS design when compared with ULS load distribution factors which slightly increase with increasing number of lanes.

- Deflection distribution factors are generally smaller than the corresponding moment distribution factors for a typical bridge configuration.

- CHBDC 2014 equations for moment, shear and deflection distribution factors significantly overestimate the structural response in some bridge configurations and significantly underestimate it on other bridge configurations. Similar conclusion is reached for the AASHTO-LRFD 2012 load distribution factor equations as well as Alberta Bridge Manual 2015 equations.

- Based on the databased generated from the parametric study, a set of empirical expression for moment, shear and deflection distribution factors at ULS, SLS and FLS designs were developed with great accuracy for simply-supported deck-free adjacent box girder bridges 
- The proposed expressions can be used with confidence to design new economical and reliable bridges since an excellent correlation was obtained between the developed equations and the finite-element analysis.

- Loading bridge cross-section with only one truck loaded eccentrically would not provide the most critical value of the design transverse shear force at the joint. In this case, mulilane loading produces vertical shear force, $\mathrm{V}_{\mathrm{y}}$, at the joint between adjacent box beams compared to that obtained for only one loaded lane. In addition, FEA results showed local effects of the wheel load at or close to the joint, leading to unrealistically high shear forces at the joint. So, it is recommended to extend this research to include patch loading rather than wheel loading when analysing bridges for this purpose. Also, it is recommended to use the PLATO software for the analysis of such bridges using the orthotropic plate theory for consistency in results.

\subsection{Recommendations for Future Research}

Through this study, it is recommended that further research efforts be directed towards the following:

- Effect of integral abutment bridge system on $F_{m}, F_{v}$, and $V_{y}$.

- Apply the same research work on modular composite concrete slab over twin-steel girder system, with either moment-transferring joint or shear-transferring joint between the prefabricated twin-girder bridge systems. Effectiveness of this system as compared to fully-braced slab-on-steel girder system and double-tee girder system should be studied.

- Comprehensive study on the $\mathrm{F}_{\mathrm{m}}, \mathrm{F}_{\mathrm{v}}$, and $\mathrm{V}_{\mathrm{y}}$ in concrete box girder bridges in the form of multiple U-shape box girders and concrete cellular bridge system. This analysis is to be conducted for skew and straight bridges.

- Load distribution in composite concrete deck slab over steel multiple spines in skew alignment.

- Revisit equivalent long and transverse flexural and torsional stiffness of bridge superstructure in straight, curved and skew alignments.

- Analysis of deck-free adjacent box beams using orthotropic plate theory to determine the vertical shear force at the joints between beams due to multilane loading. 
- Examine the effect of geometric and material nonlinearity of the adjacent box beams in load distribution factor at ultimate limit state. 


\section{APPENDIX (A): Summary of Parametric Study}




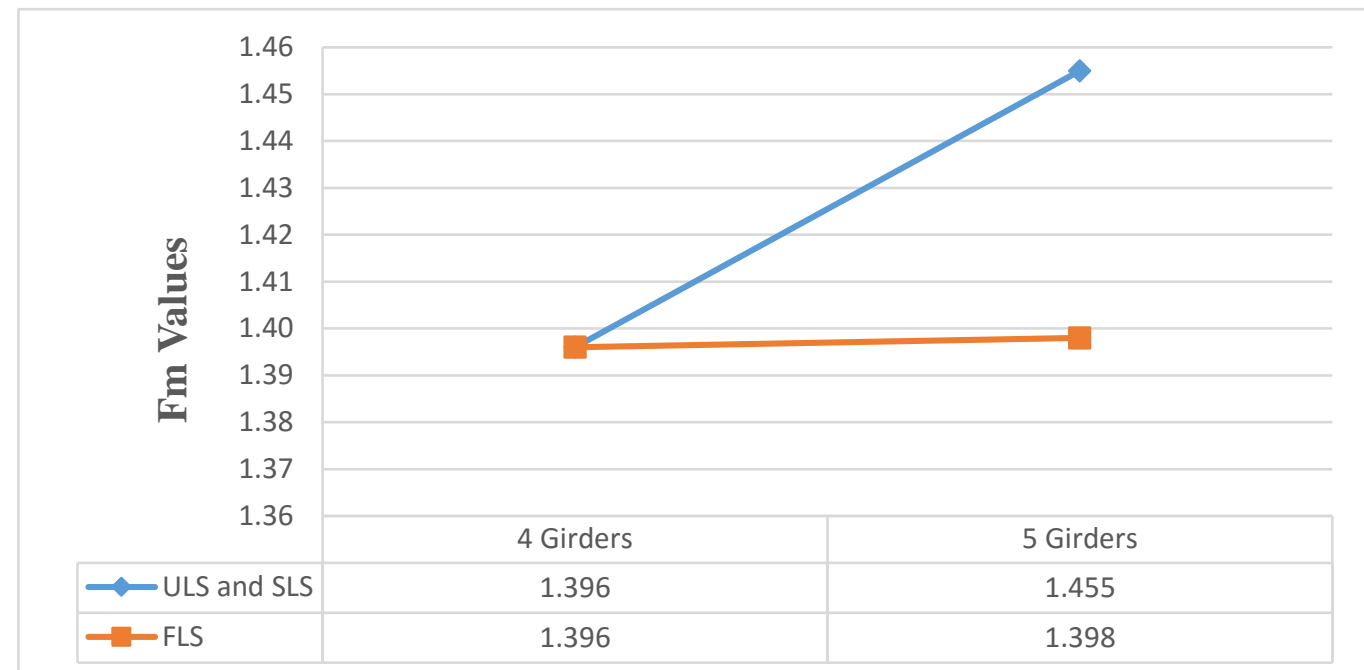

No. of Girders (N)

Figure A. 1: Effect of number of girders on moment distribution factor (B700, one-lane, 10m span)

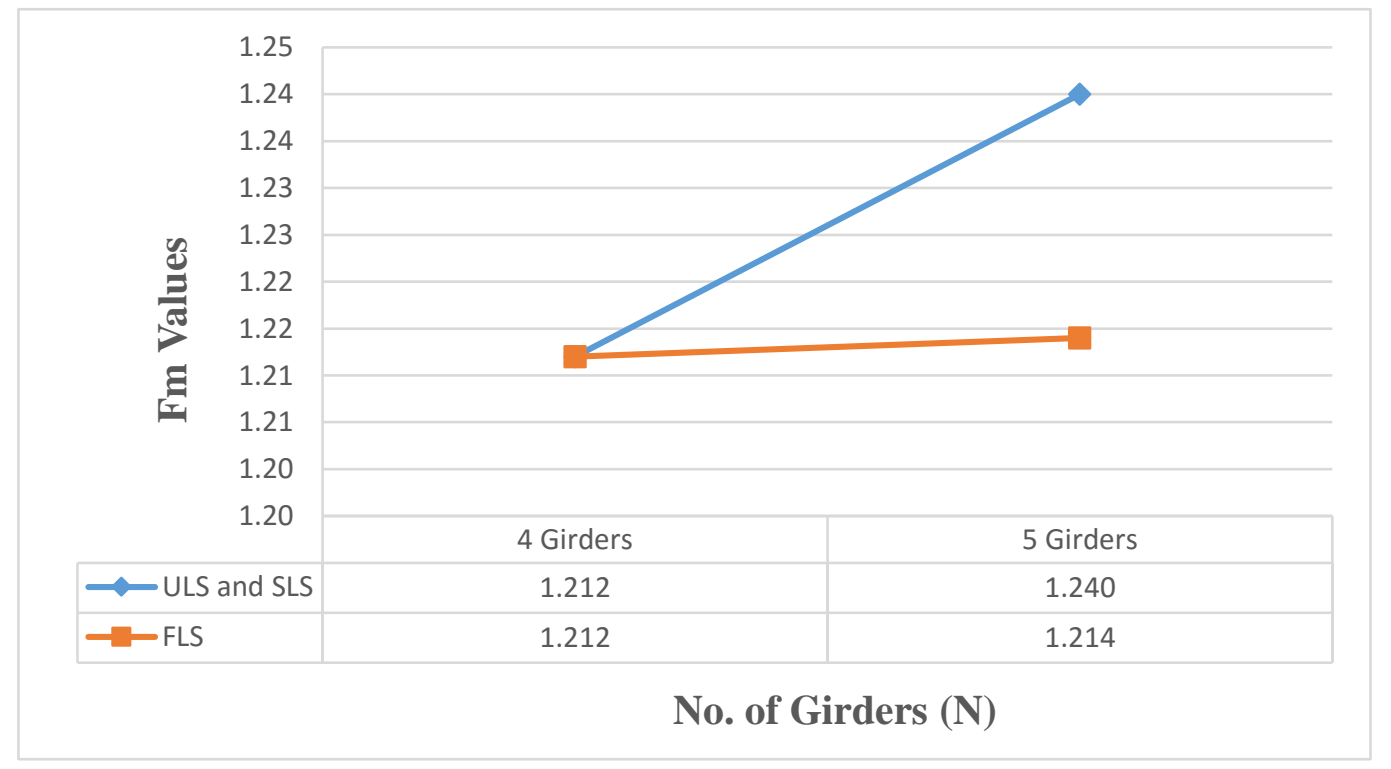

Figure A. 2: Effect of number of girders on moment distribution factor (B800, one-lane, 20m span) 


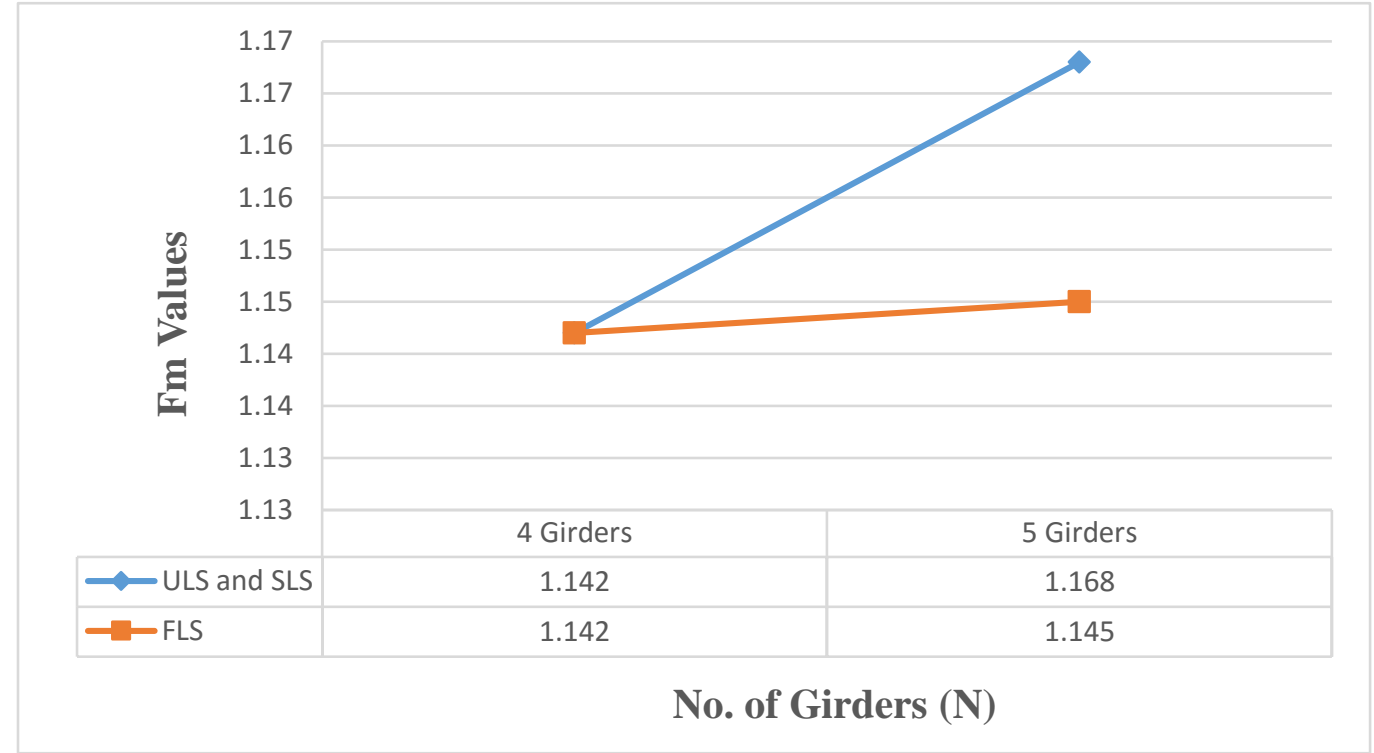

Figure A. 3: Effect of number of girders on moment distribution factor (B1000, one-lane, 32m span)

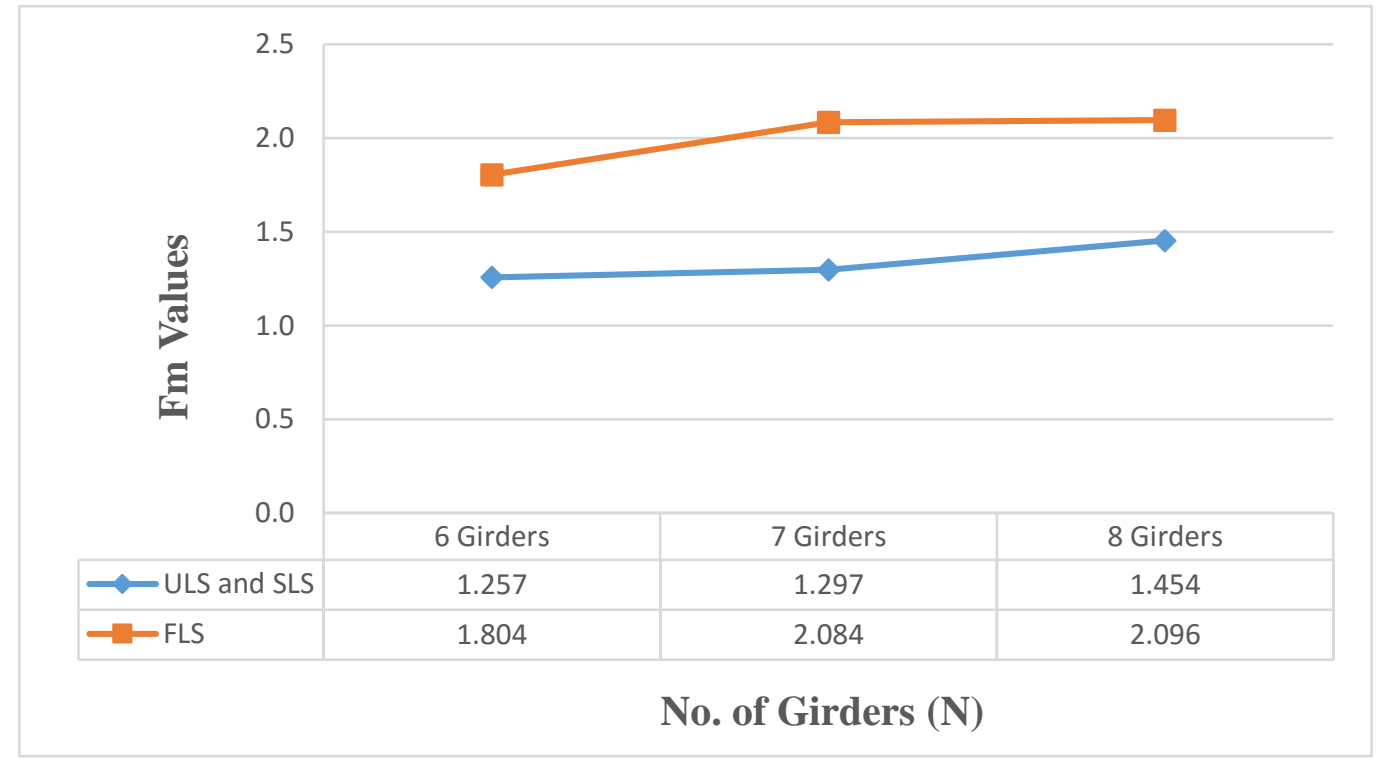

Figure A. 4: Effect of number of girders on moment distribution factor (B700, two-lane, 10m span) 


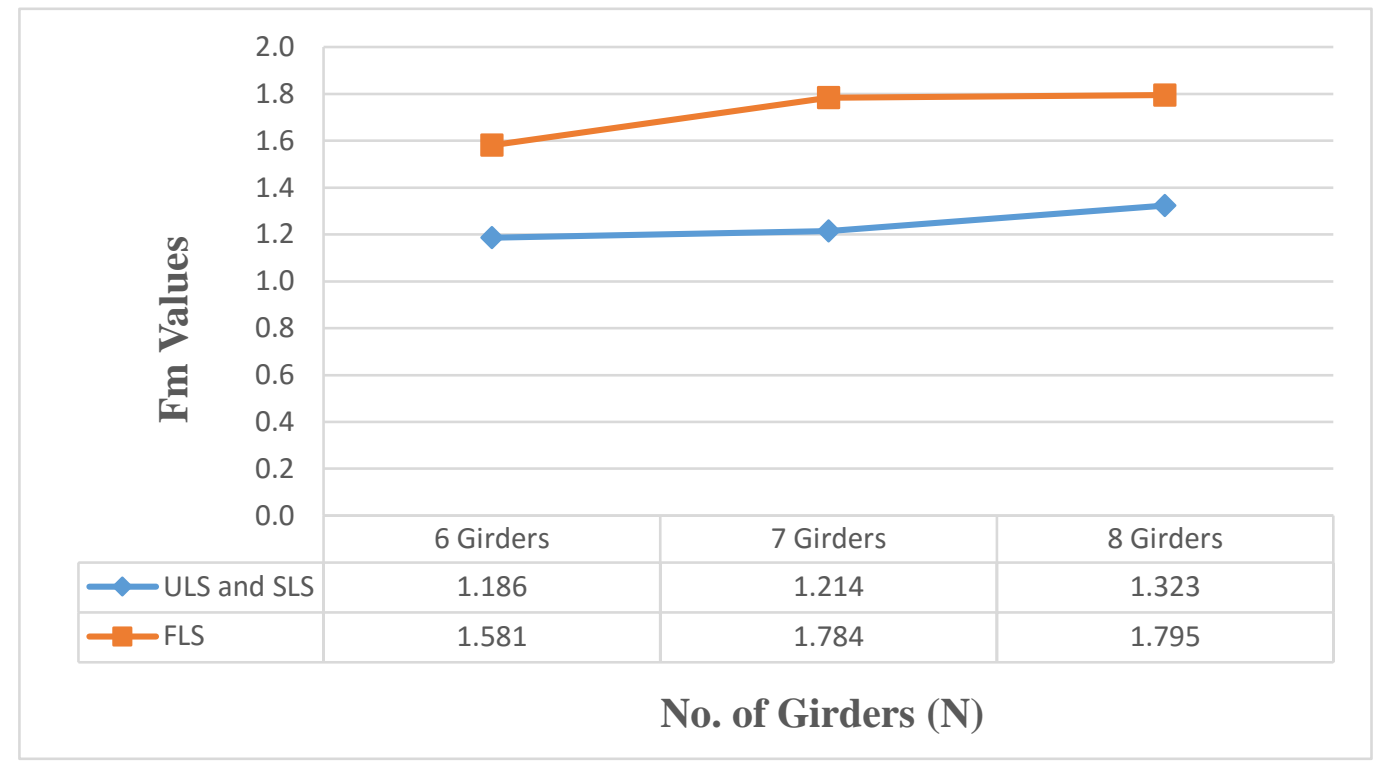

Figure A. 5: Effect of number of girders on moment distribution factor (B700, two-lane, 13m span)

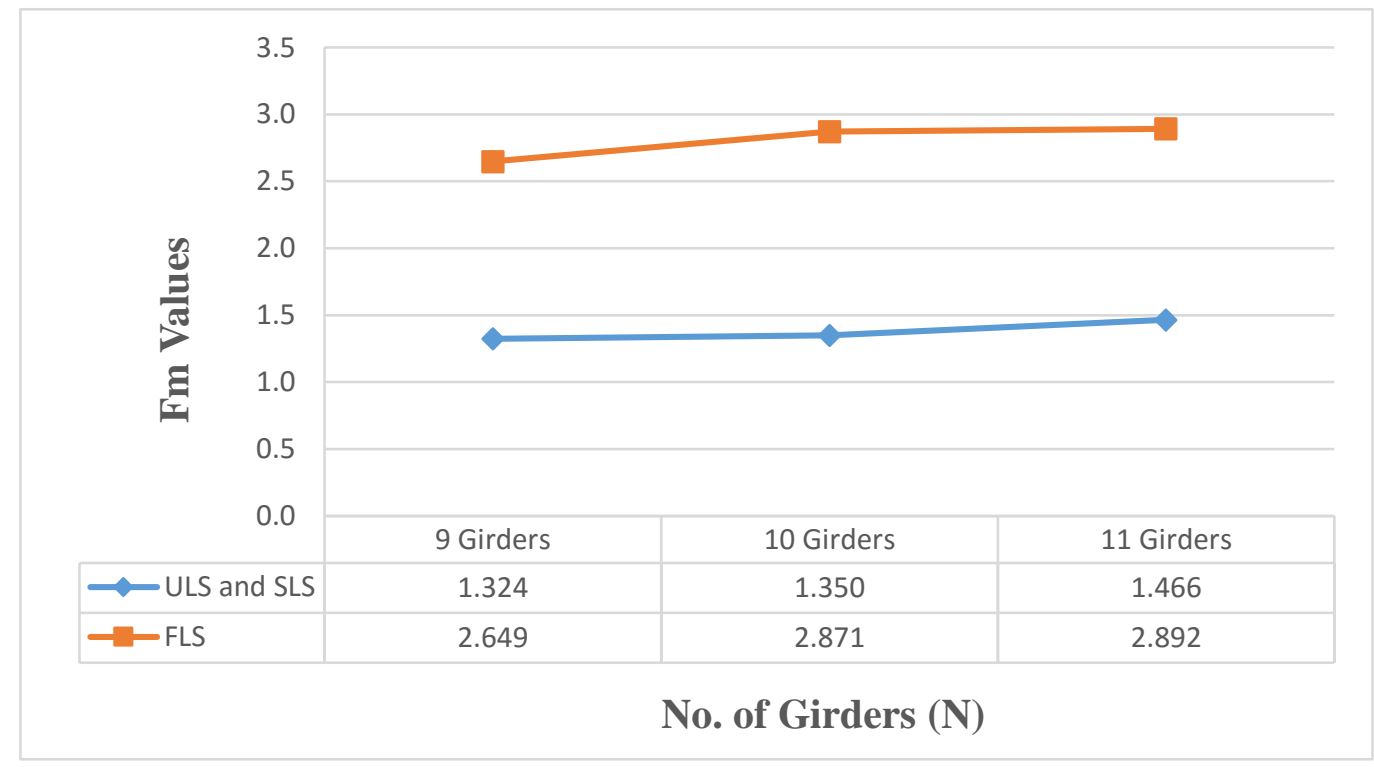

Figure A. 6: Effect of number of girders on moment distribution factor (B700, three-lane, 10m span) 


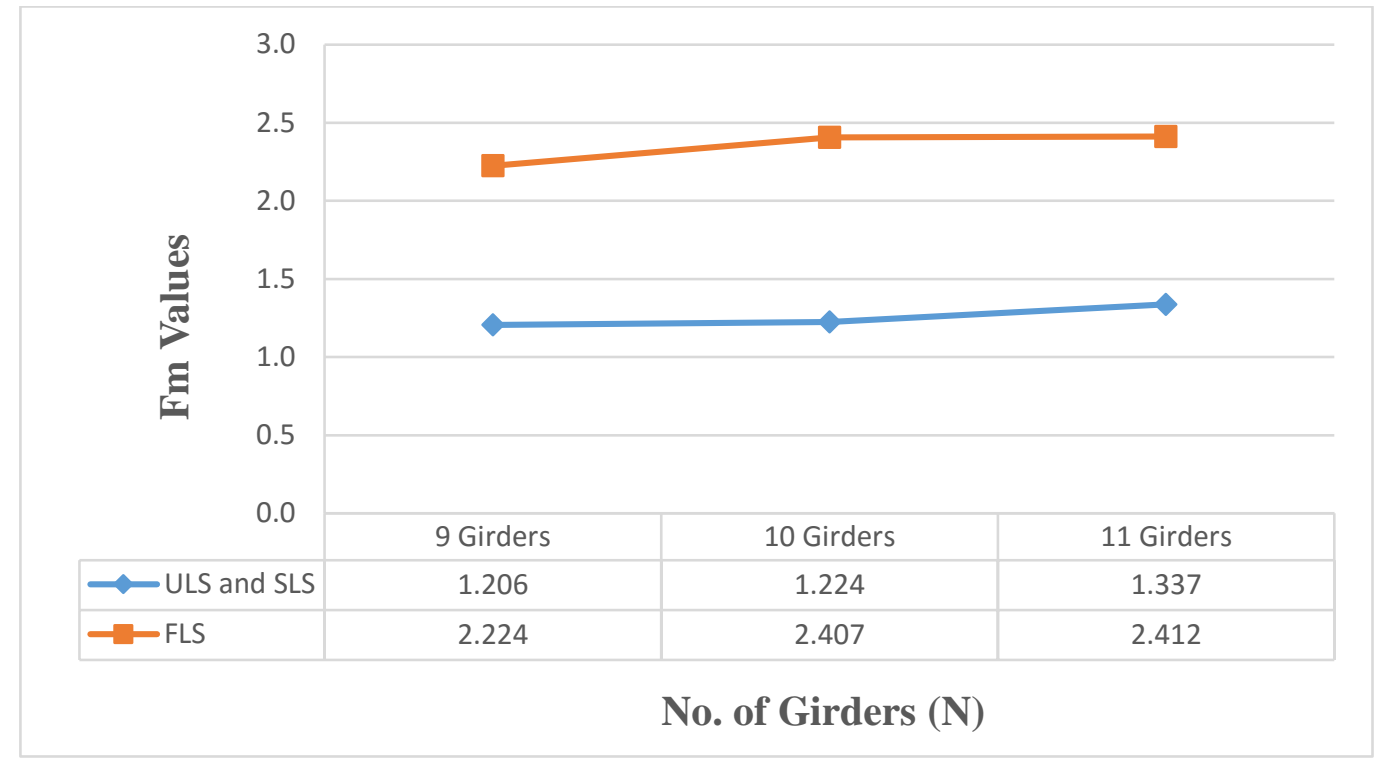

Figure A. 7: Effect of number of girders on moment distribution factor (B700, three-lane, 13m span)

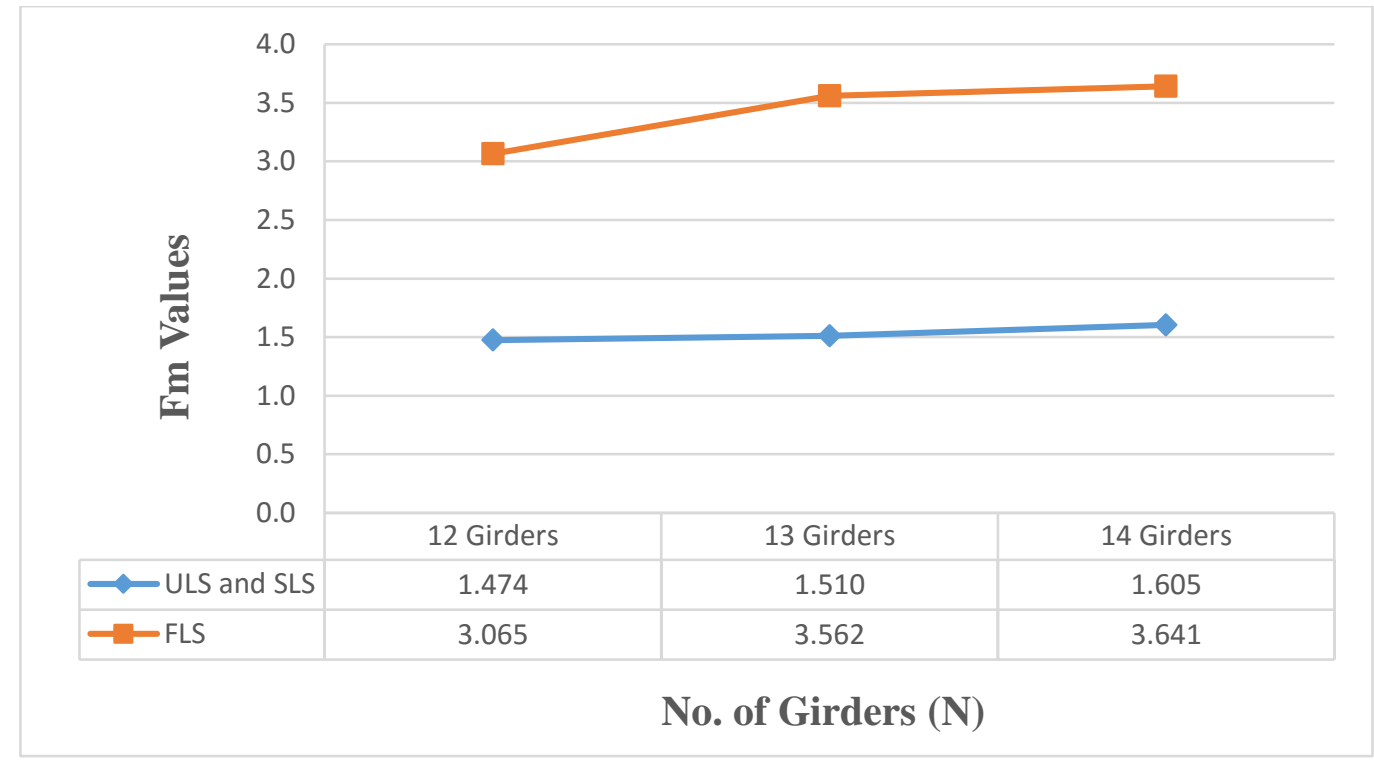

Figure A. 8: Effect of number of girders on moment distribution factor (B700, four-lane, 10m span) 


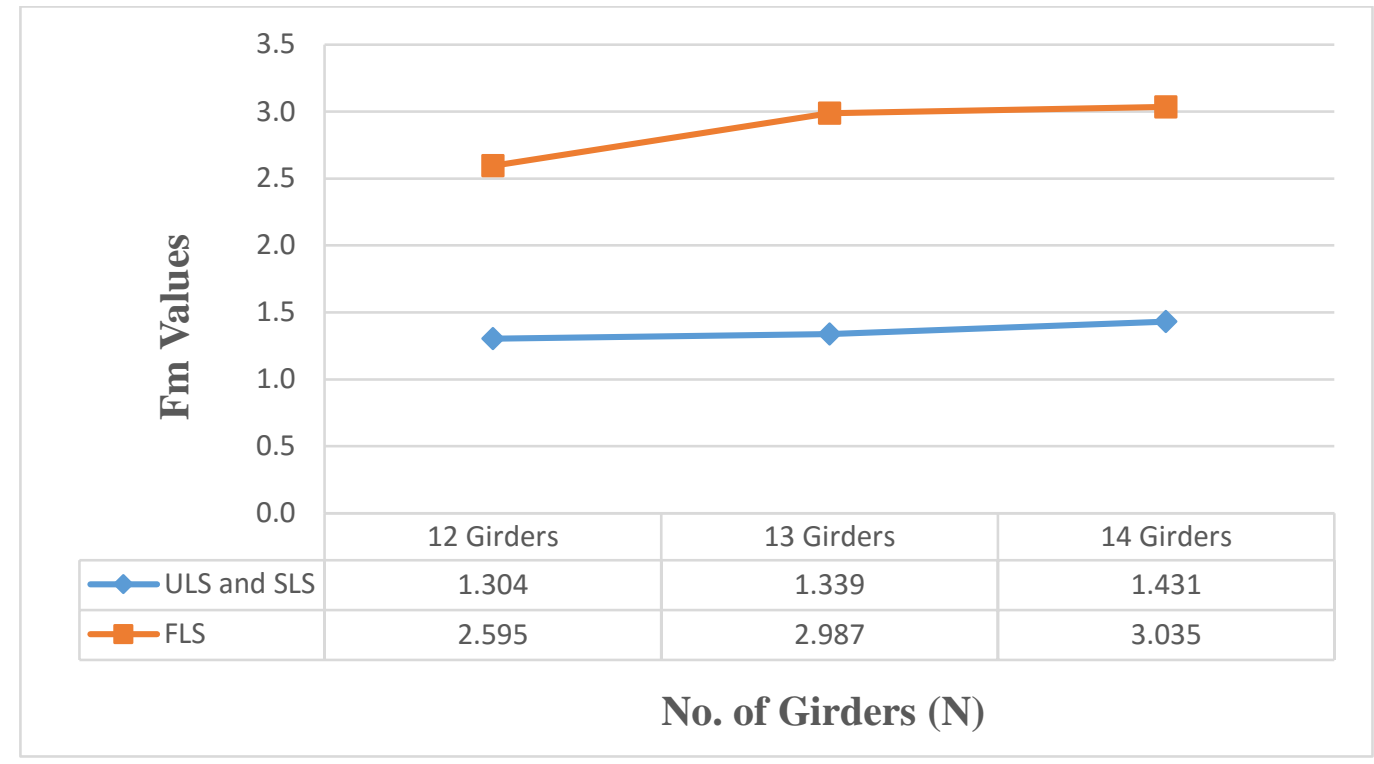

Figure A. 9: Effect of number of girders on moment distribution factor (B700, four-lane, 13m span)

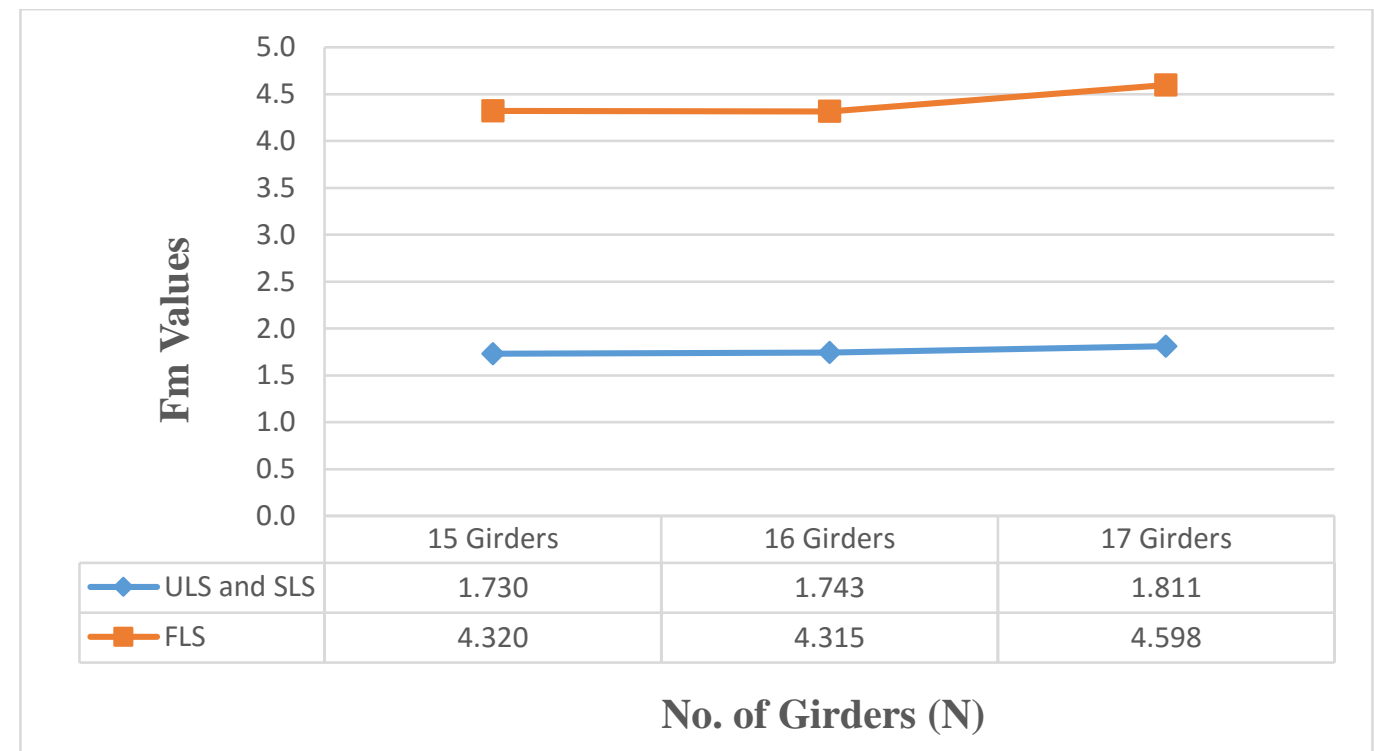

Figure A. 10: Effect of number of girders on moment distribution factor (B700, five-lane, 10m span) 


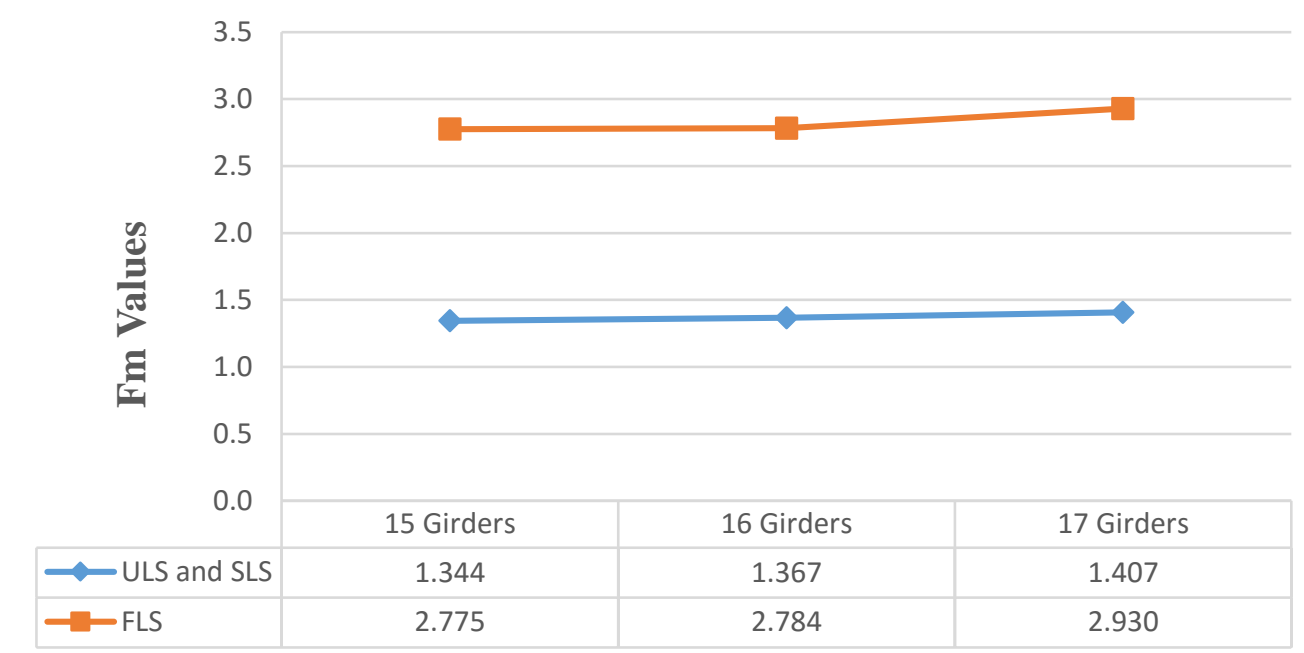

No. of Girders (N)

Figure A. 11: Effect of number of girders on moment distribution factor (B800, five-lane, 20m span)

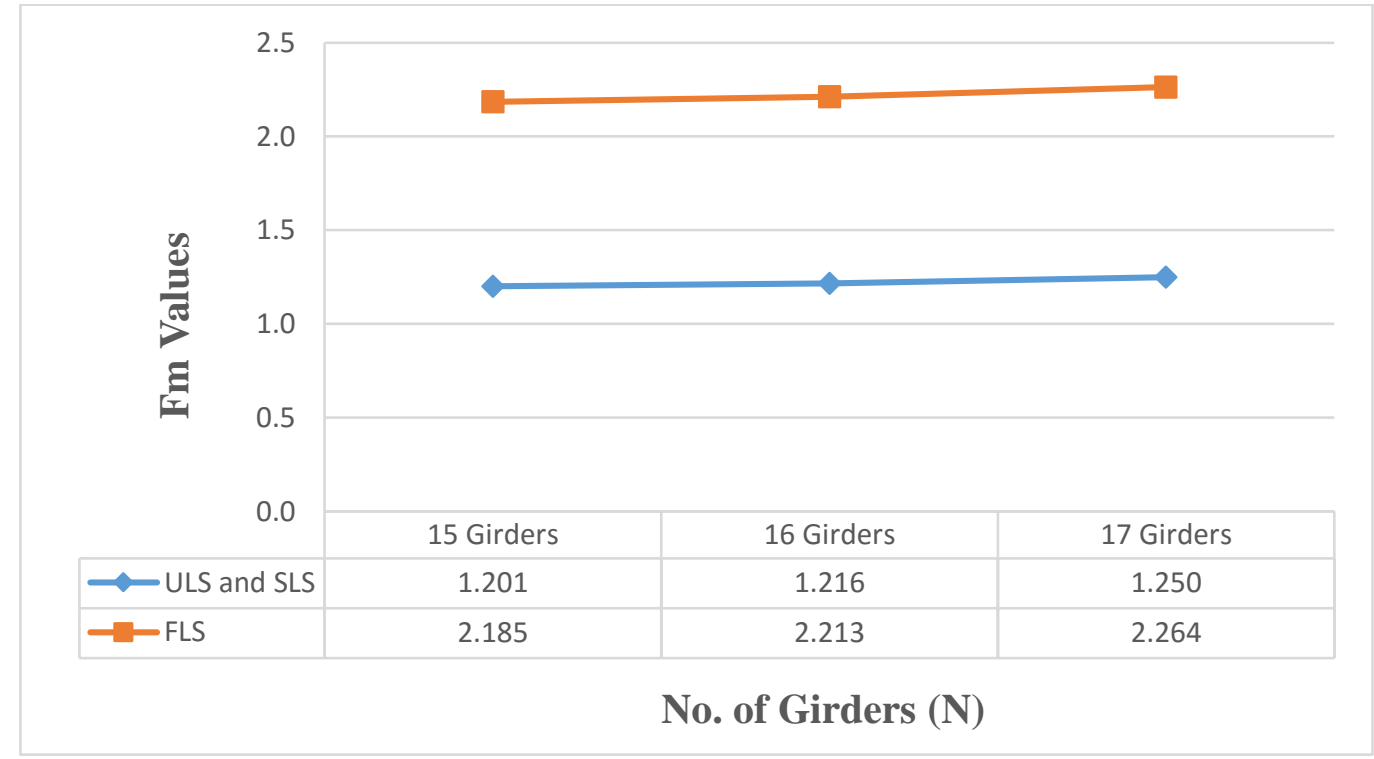

Figure A. 12: Effect of number of girders on moment distribution factor (B1000, five-lane, 32m span) 


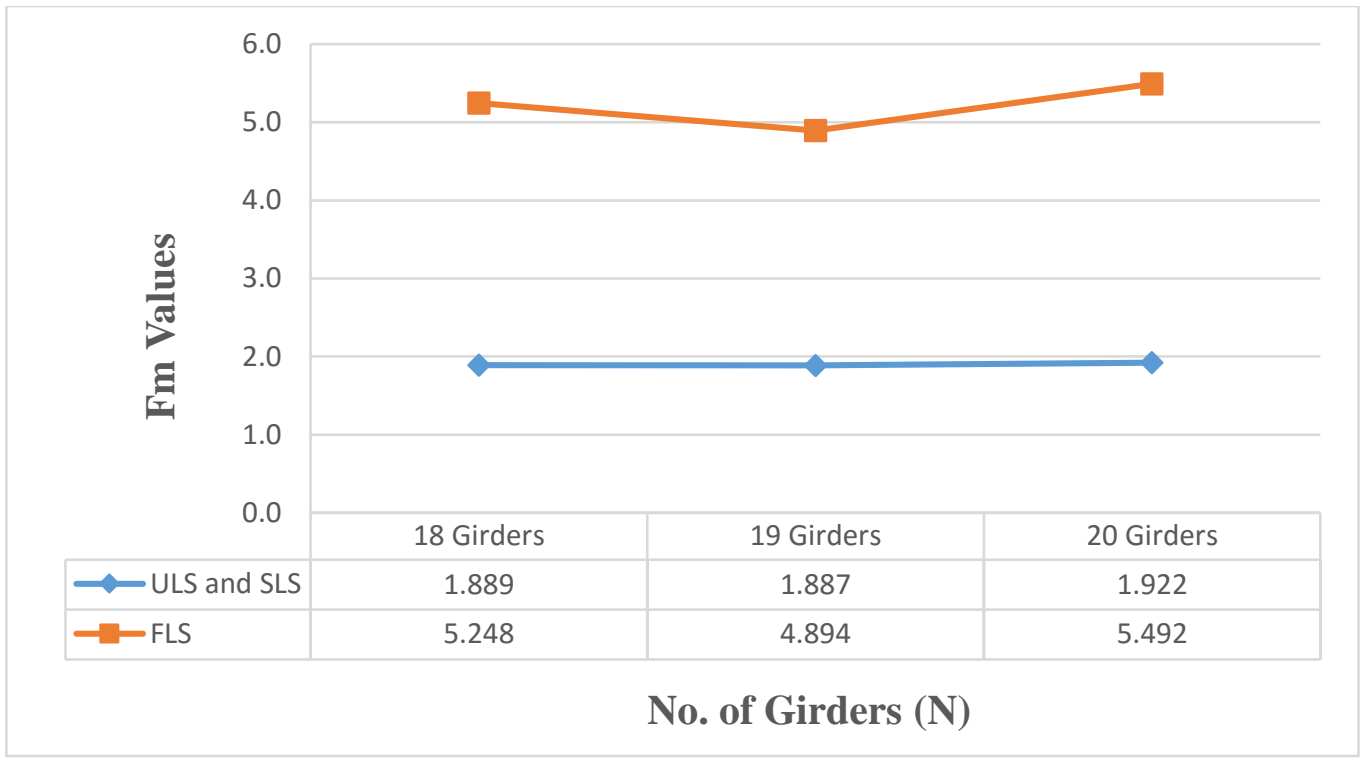

Figure A. 13: Effect of number of girders on moment distribution factor (B700, six-lane, 10m span)

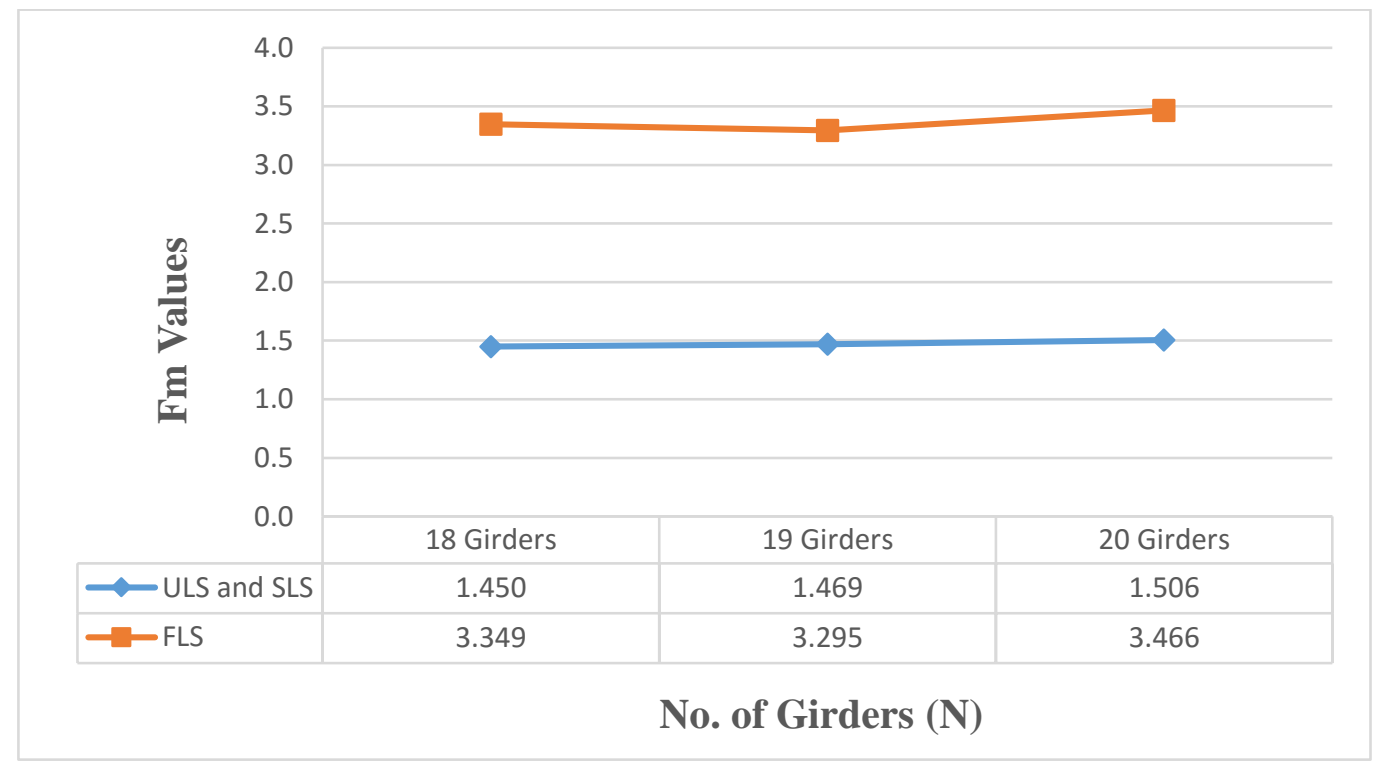

Figure A. 14: Effect of number of girders on moment distribution factor (B800, six-lane, 20m span) 


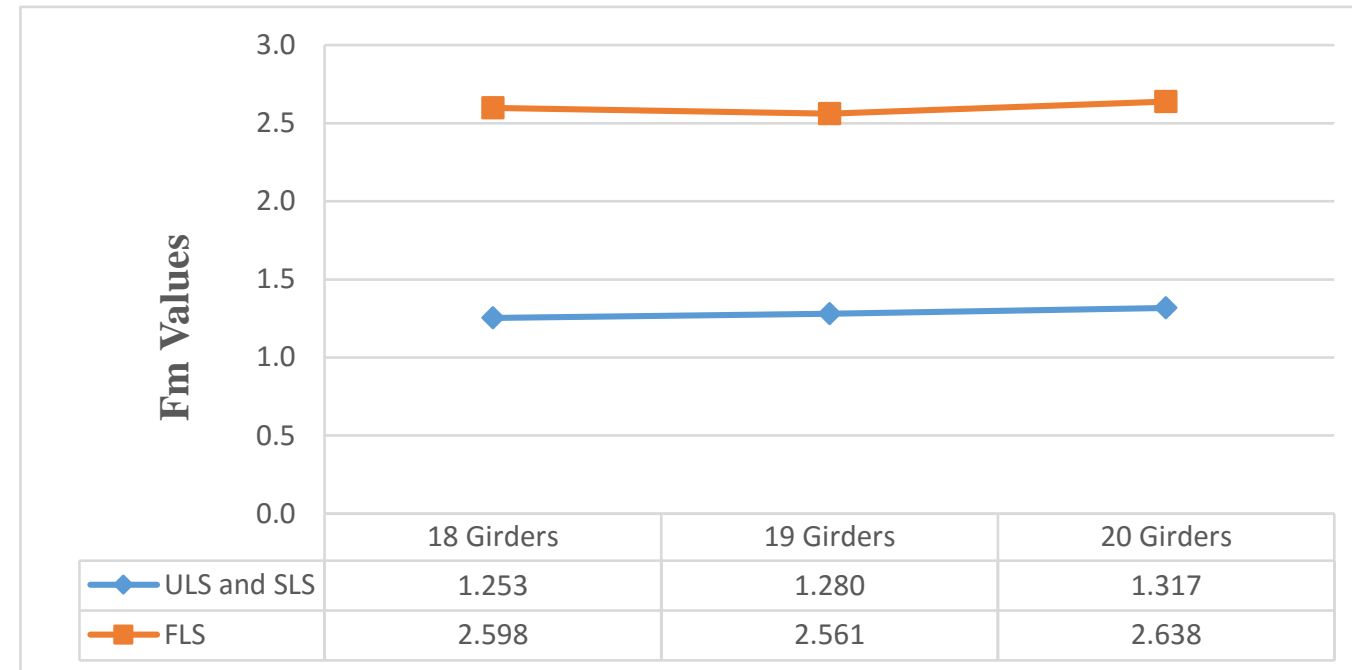

No. of Girders (N)

Figure A. 15: Effect of number of girders on moment distribution factor (B1000, six-lane, 32m span)

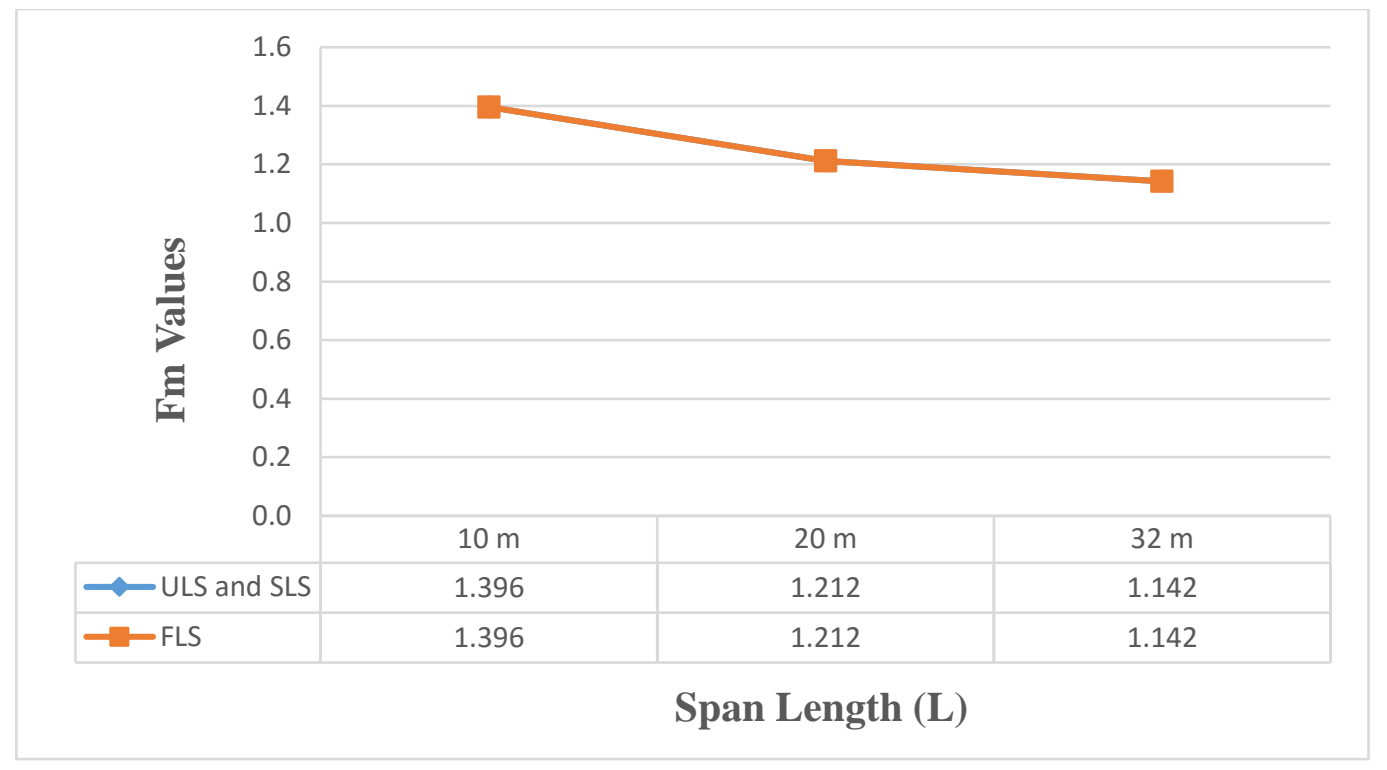

Figure A. 16: Effect of span length on moment distribution factor (one-lane, 4 girders) 


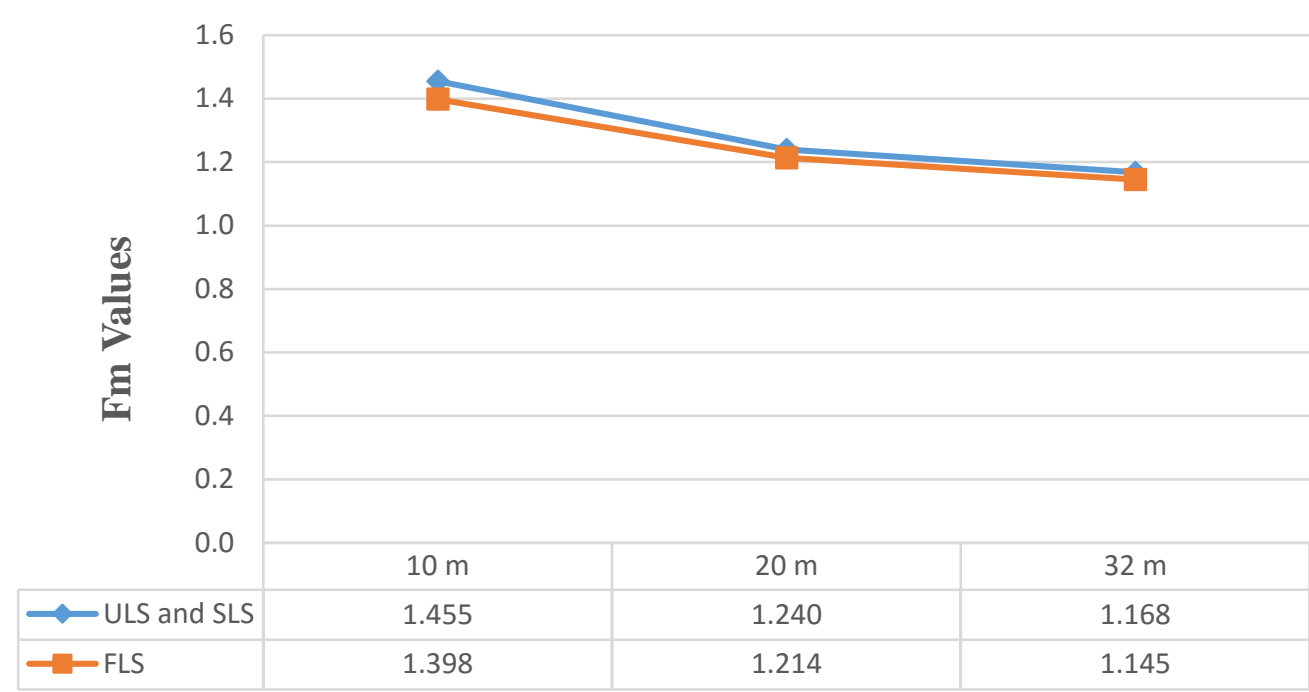

Span Length (L)

Figure A. 17: Effect of span length on moment distribution factor (one-lane, 5 girders)

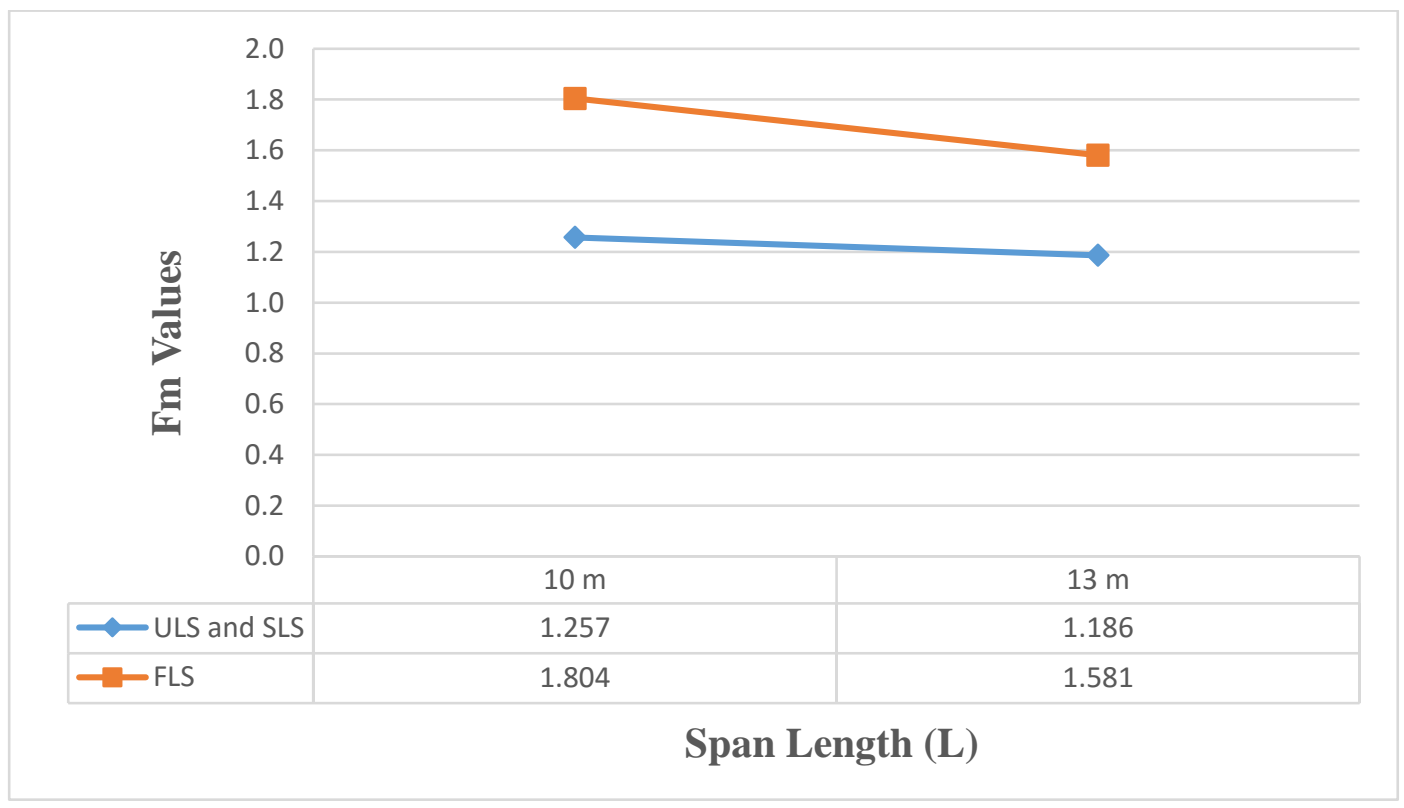

Figure A. 18: Effect of span length on moment distribution factor (two-lane, 6 girders) 


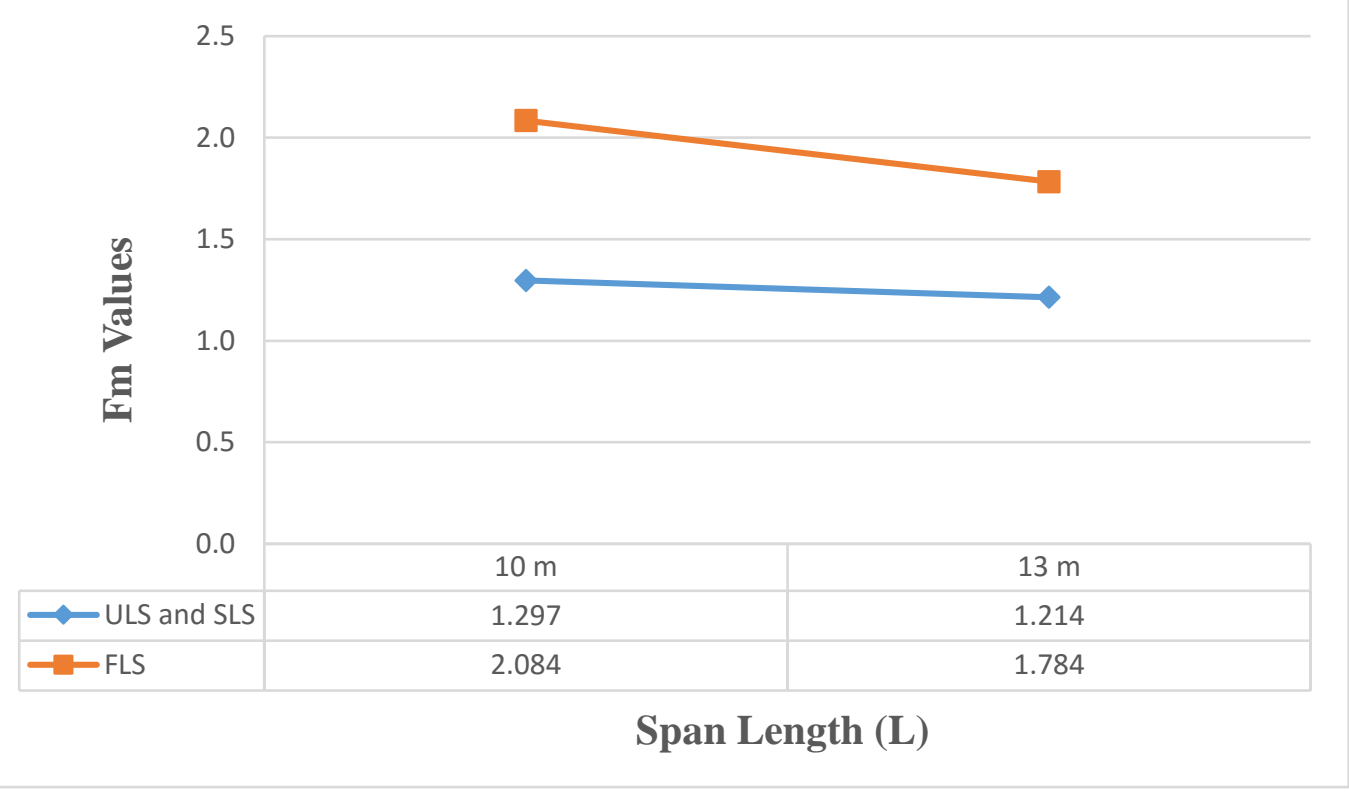

Figure A. 19: Effect of span length on moment distribution factor (two-lane, 7 girders)

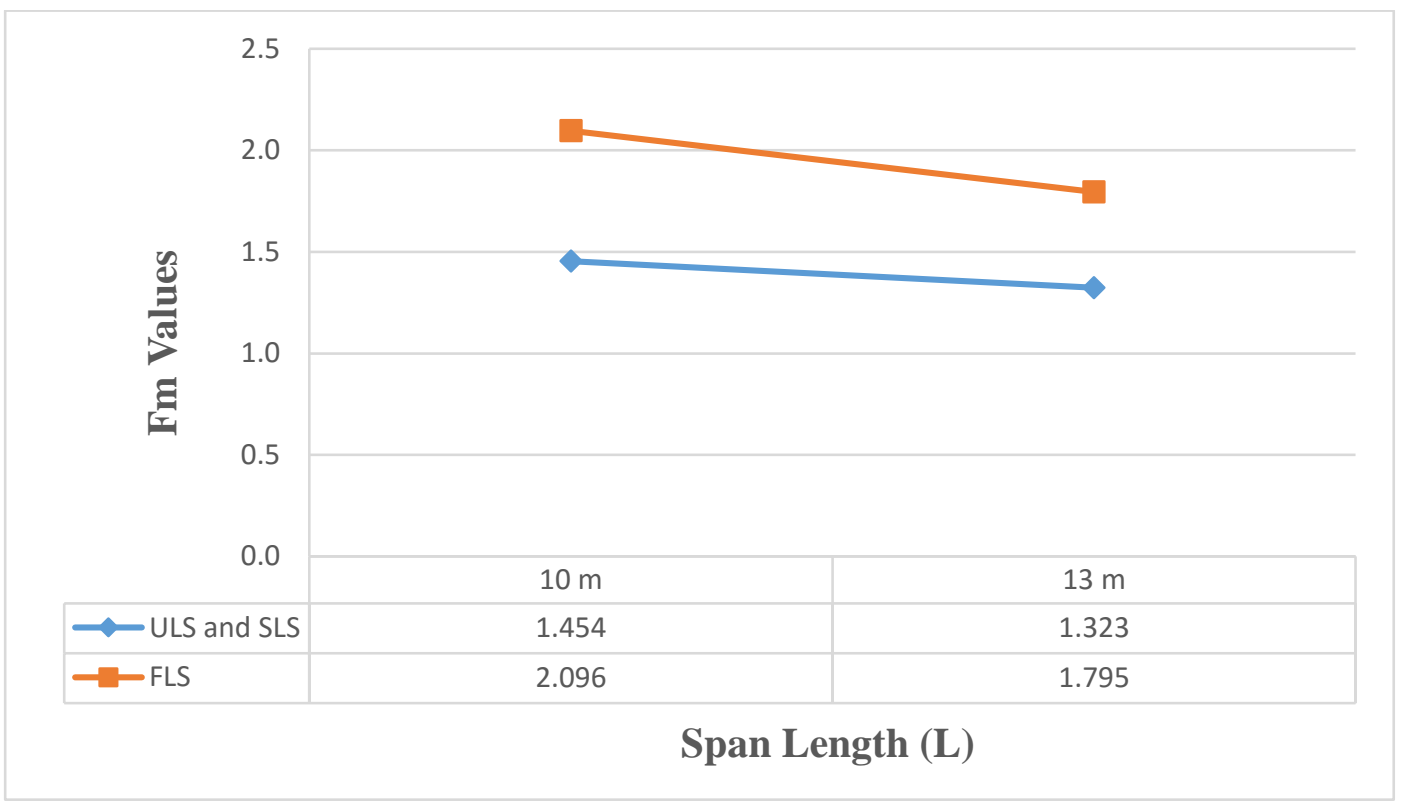

Figure A. 20: Effect of span length on moment distribution factor (two-lane, 8 girders) 


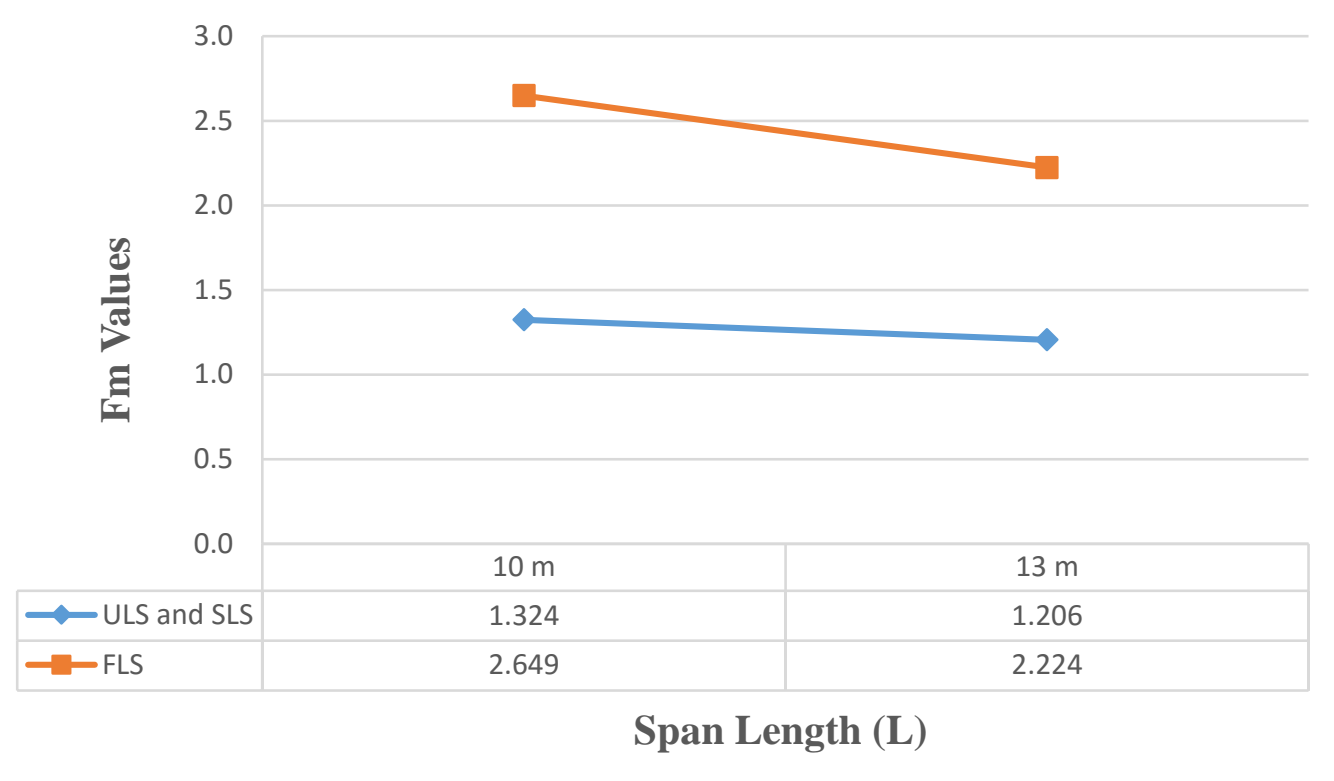

Figure A. 21: Effect of span length on moment distribution factor (three-lane, 9 girders)

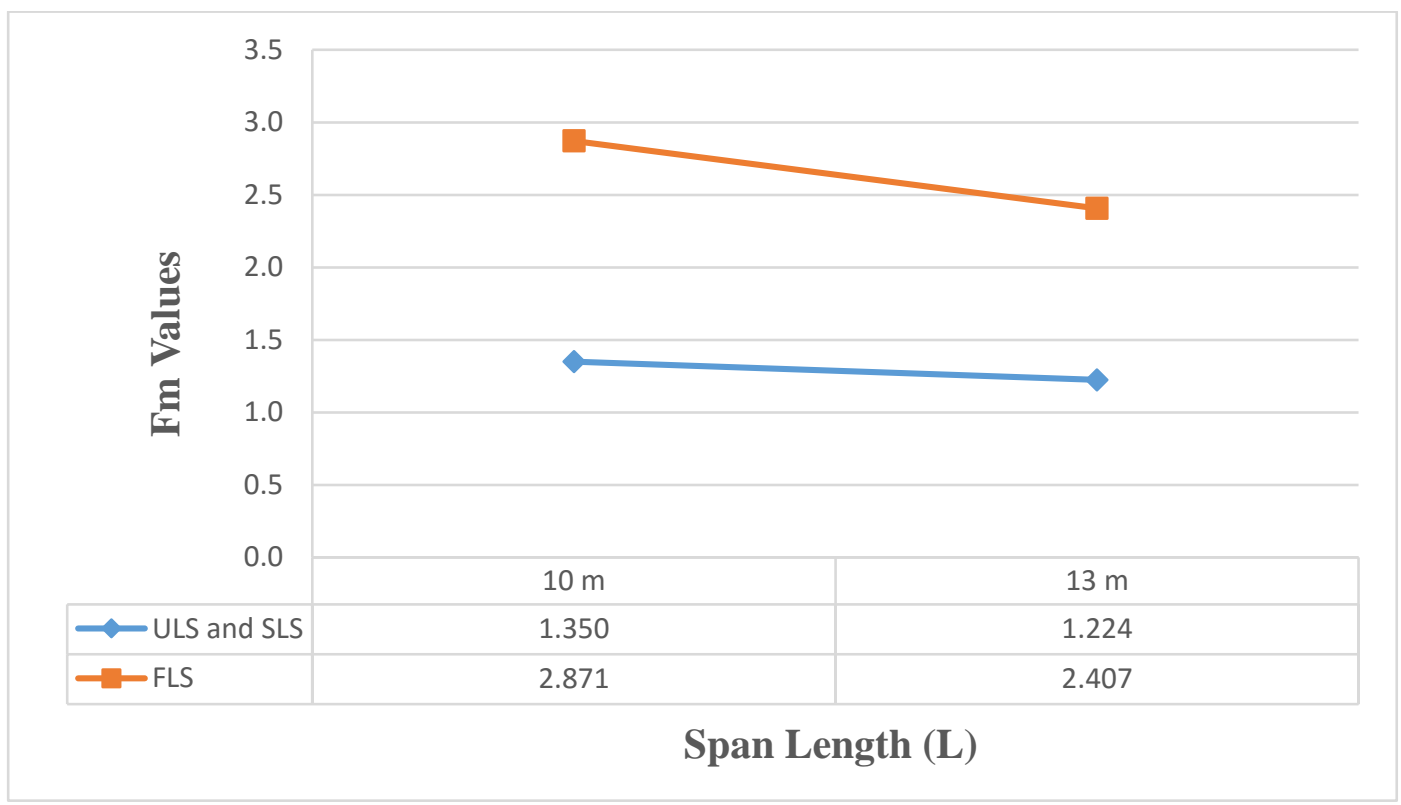

Figure A. 22: Effect of span length on moment distribution factor (three-lane, 10 girders) 


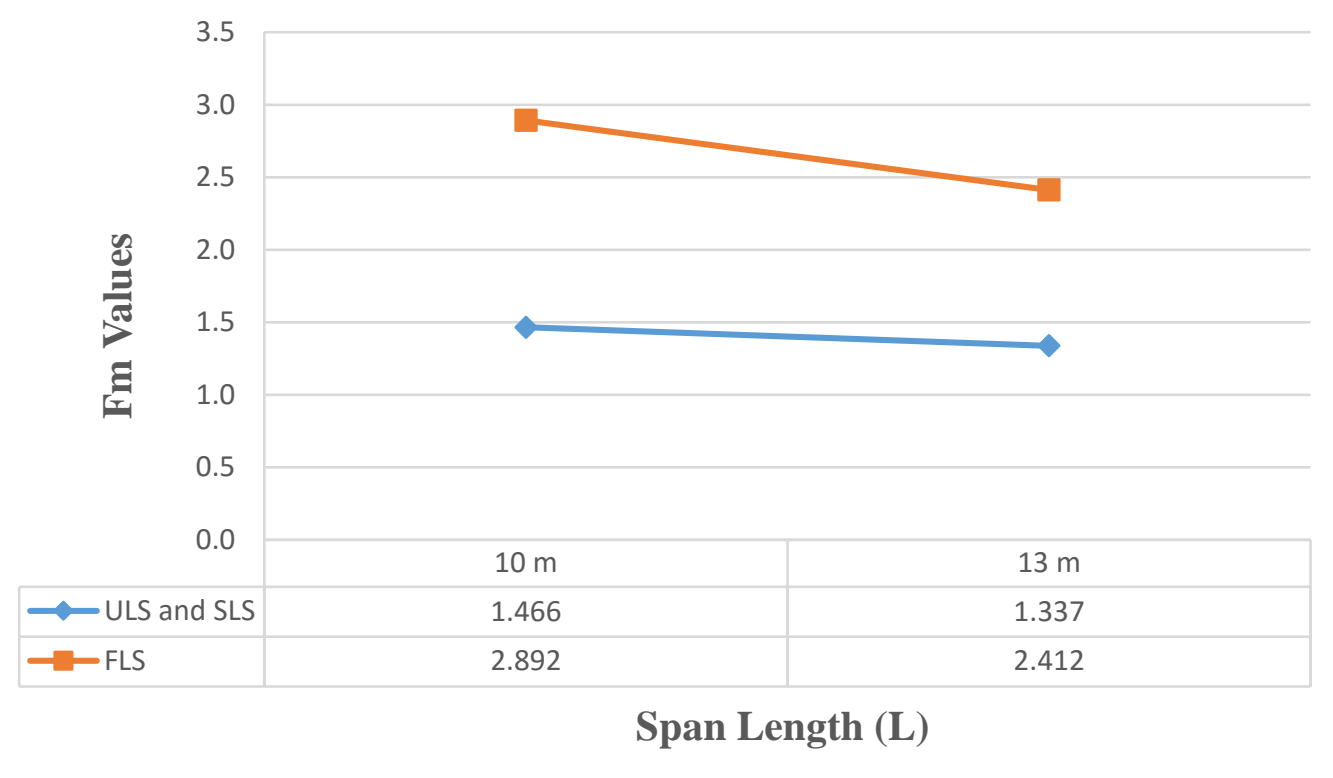

Figure A. 23: Effect of span length on moment distribution factor (three-lane, 11 girders)

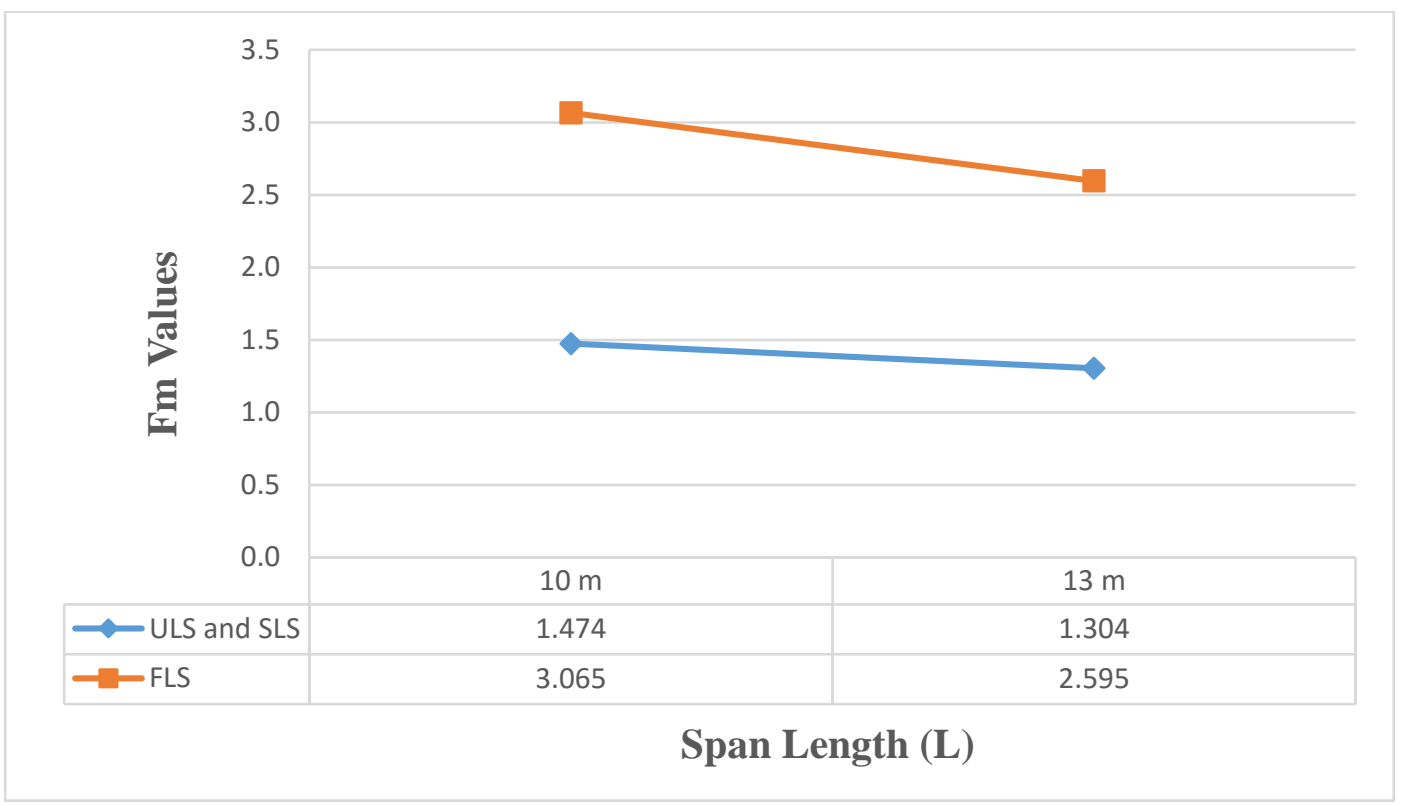

Figure A. 24: Effect of span length on moment distribution factor (four-lane, 12 girders) 


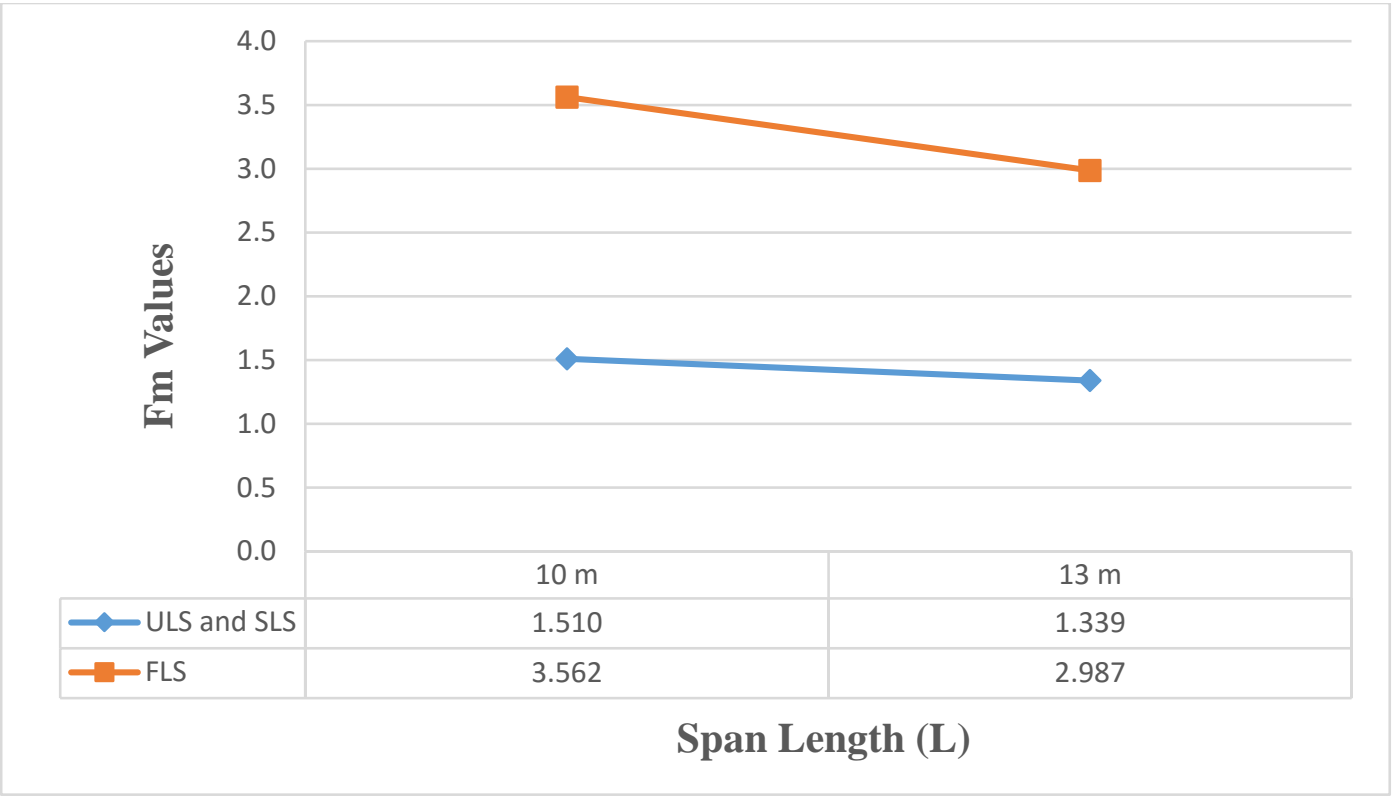

Figure A. 25: Effect of span length on moment distribution factor (four-lane, 13 girders)

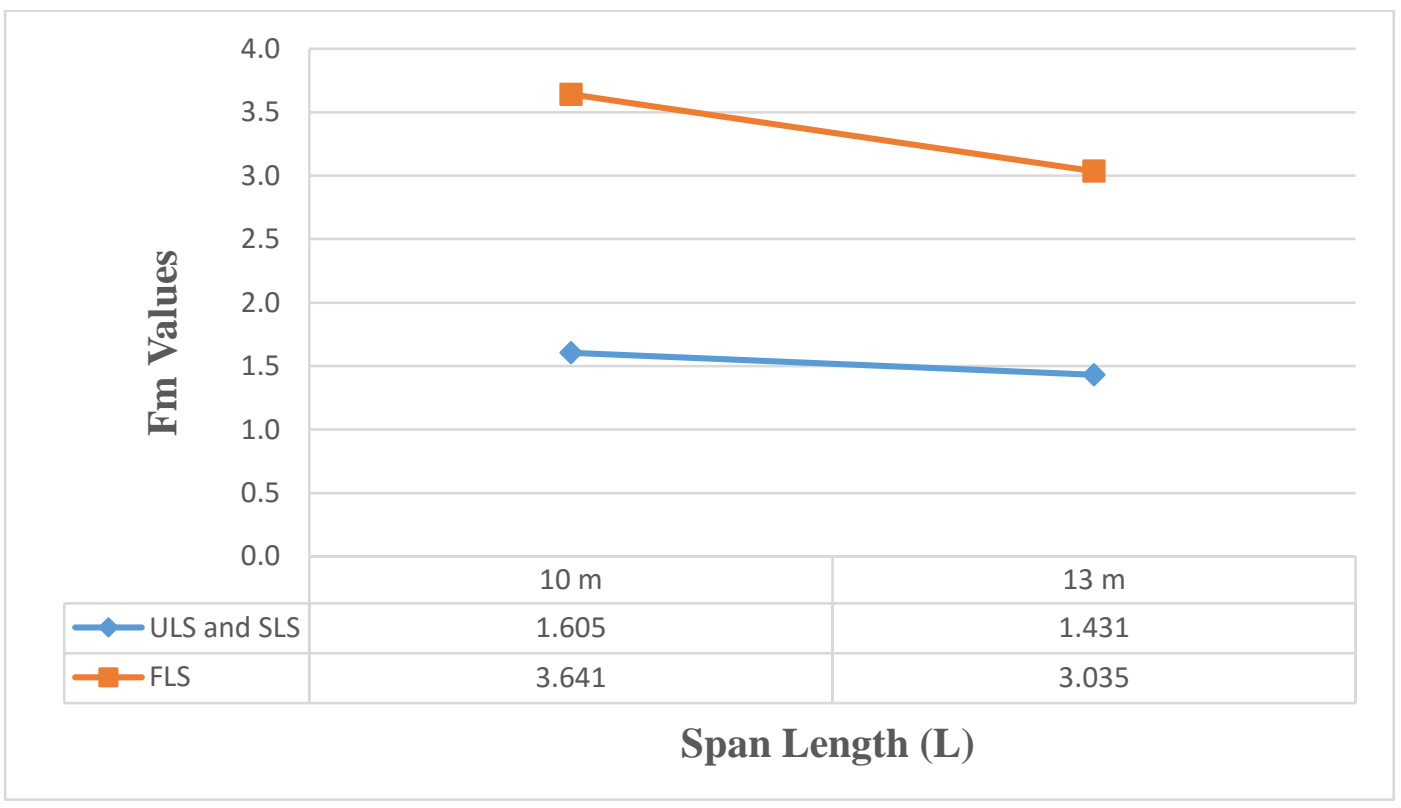

Figure A. 26: Effect of span length on moment distribution factor (four-lane, 14 girders) 


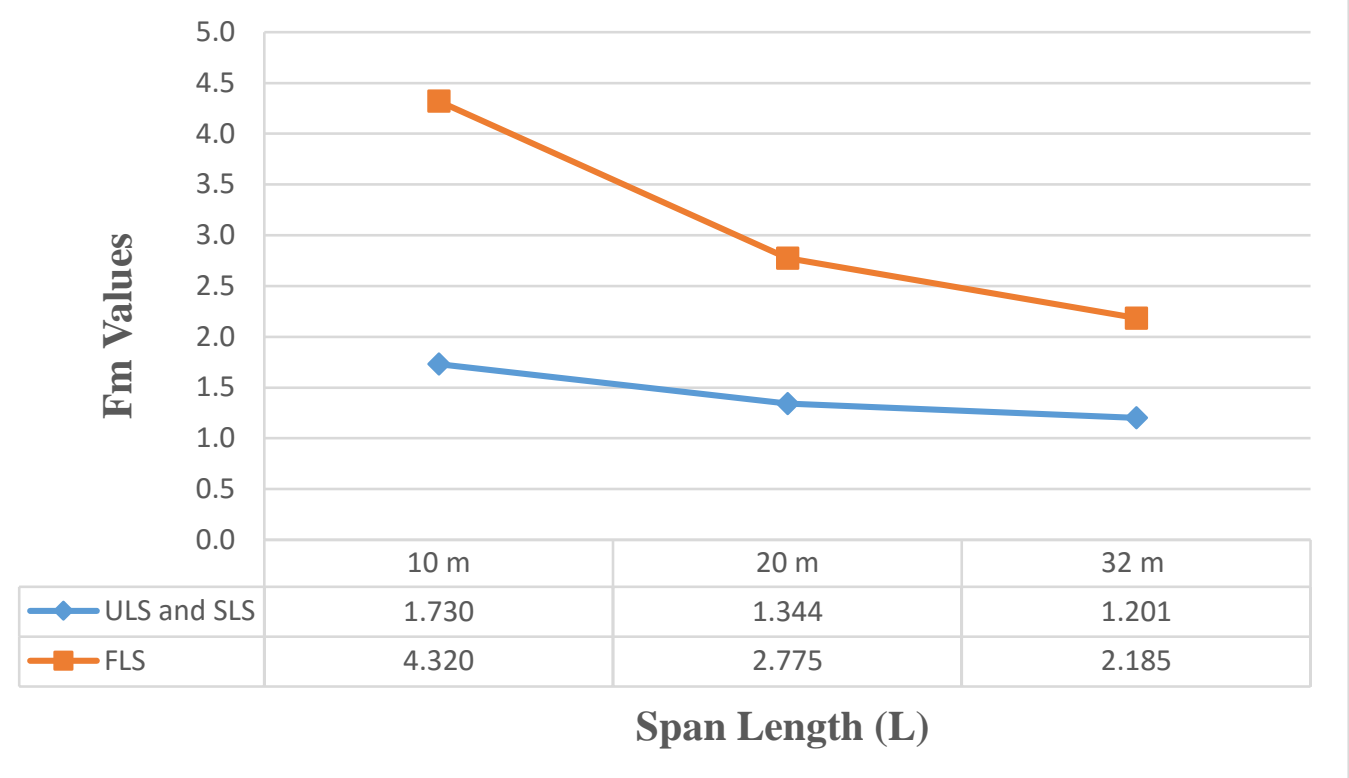

Figure A. 27: Effect of span length on moment distribution factor (five-lane, 15 girders)

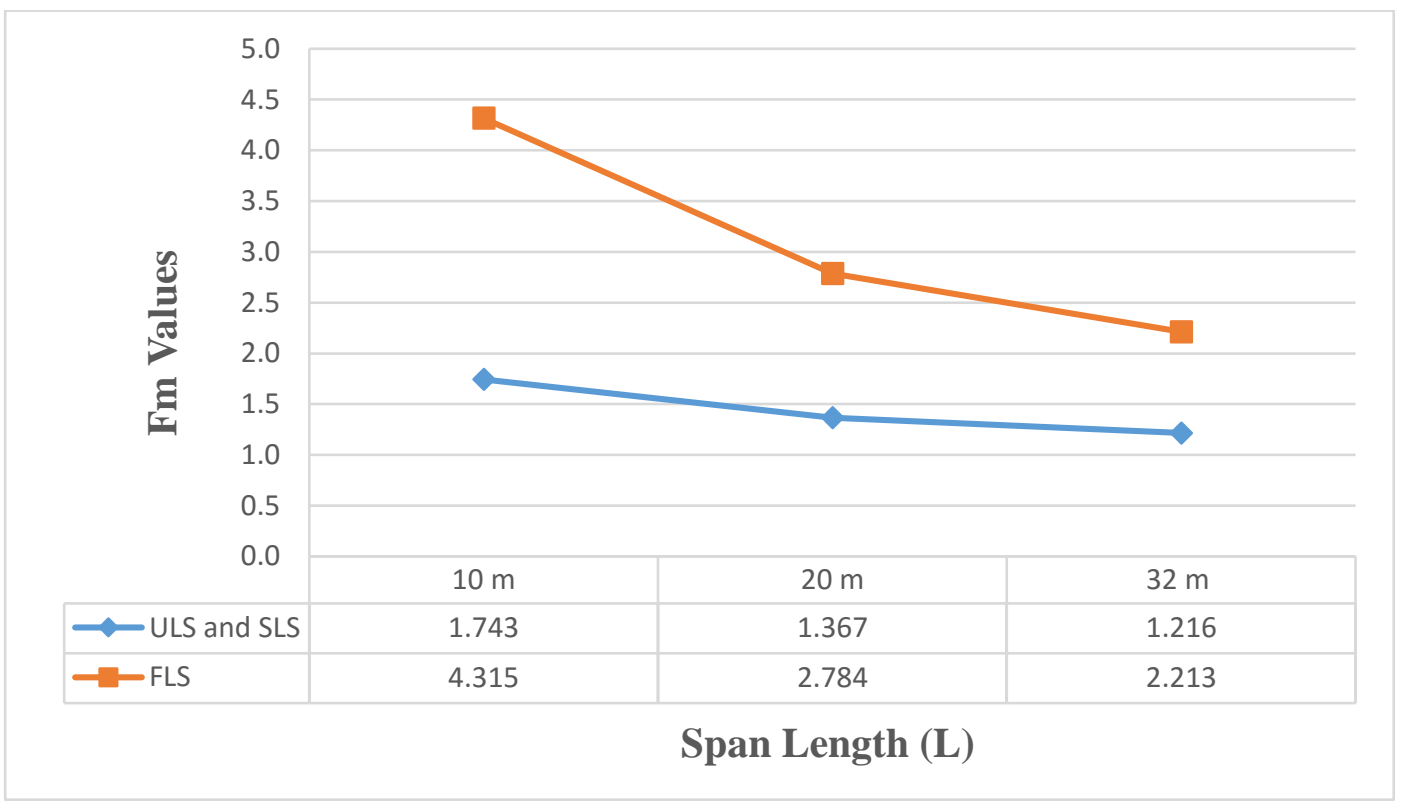

Figure A. 28: Effect of span length on moment distribution factor (five-lane, 16 girders) 


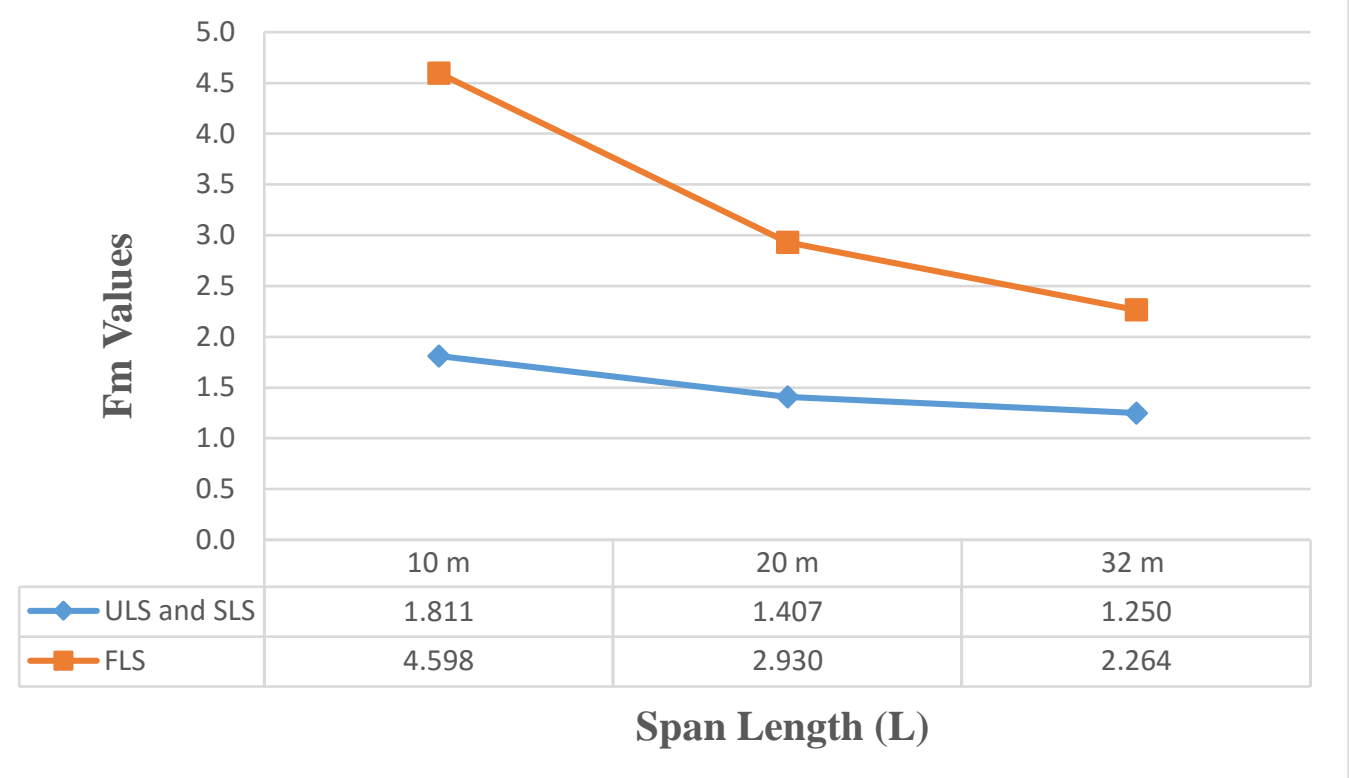

Figure A. 29: Effect of span length on moment distribution factor (five-lane, 17 girders)

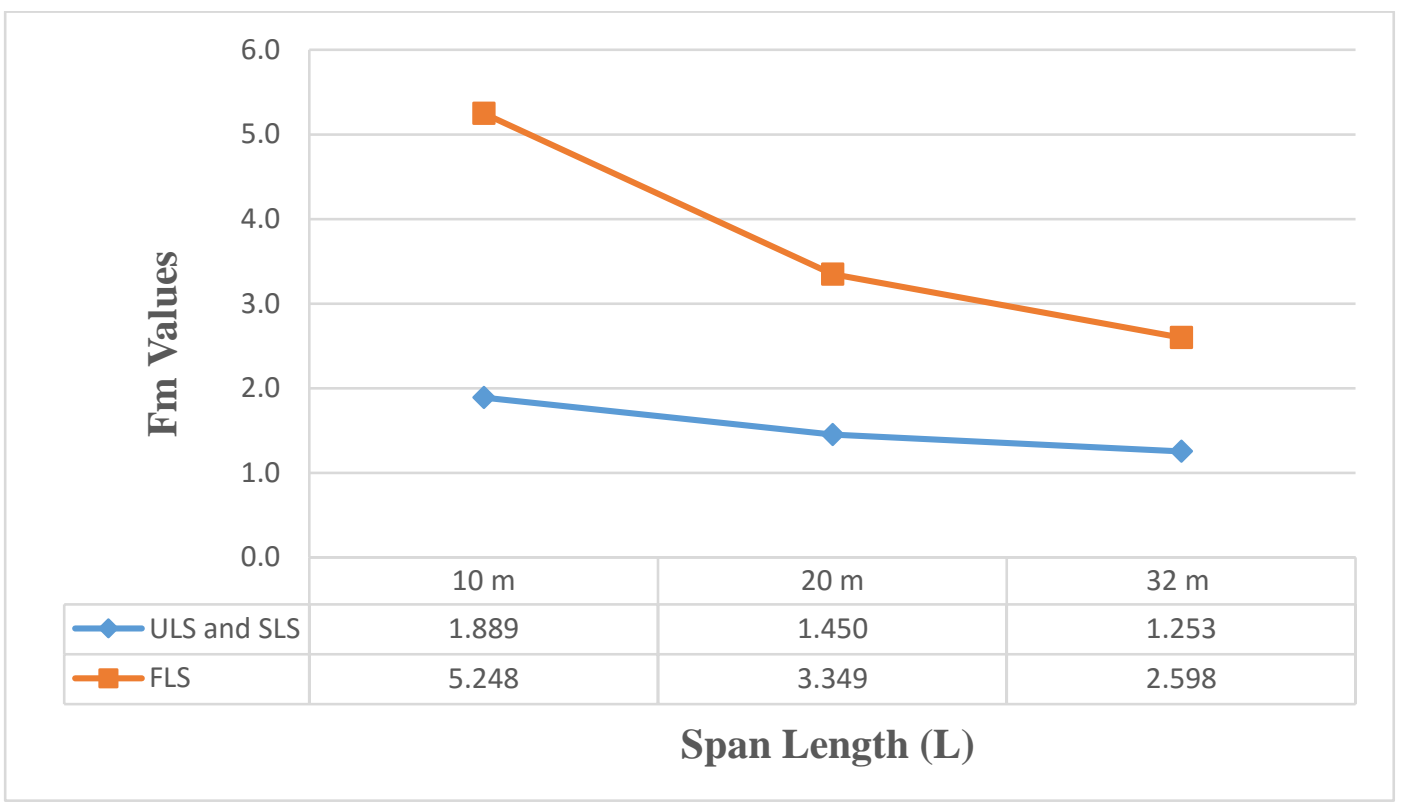

Figure A. 30: Effect of span length on moment distribution factor (six-lane, 18 girders) 


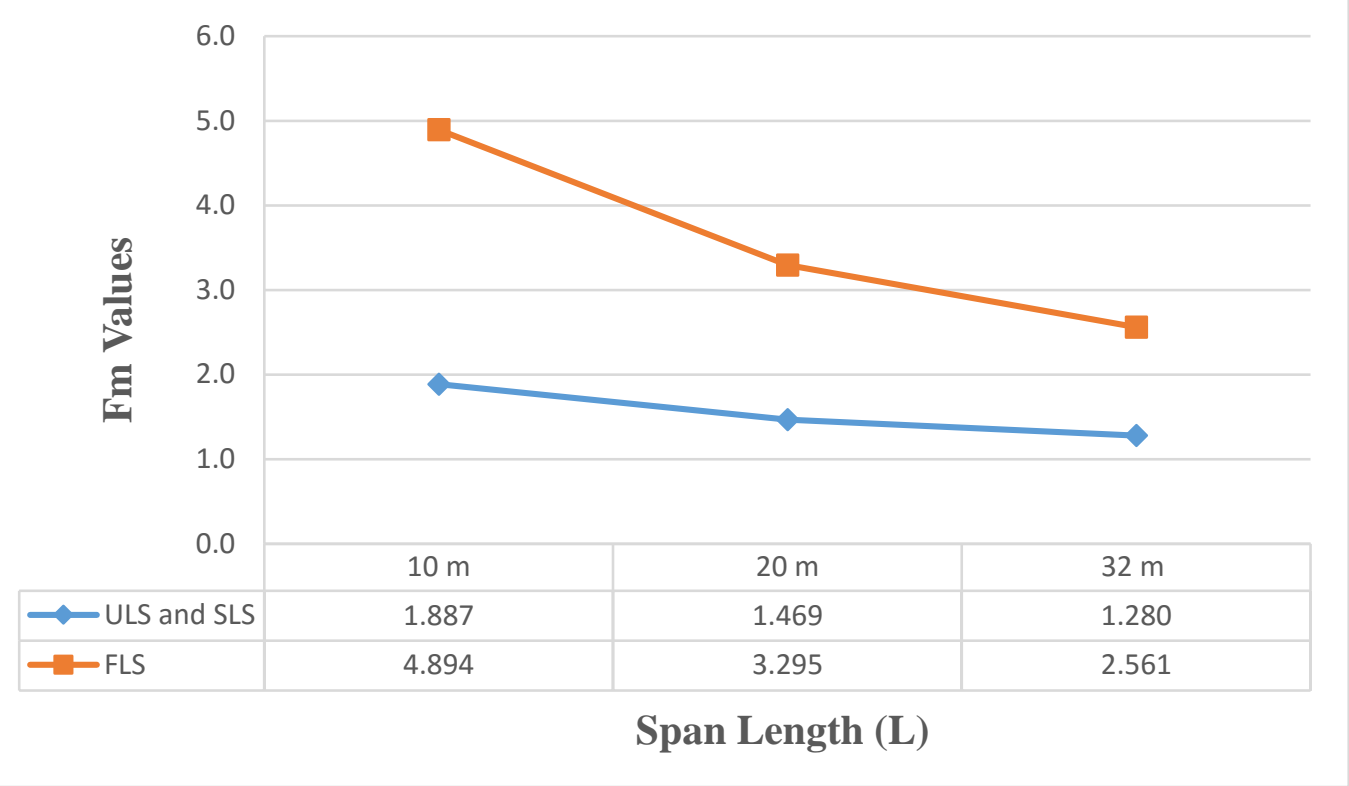

Figure A. 31: Effect of span length on moment distribution factor (six-lane, 19 girders)

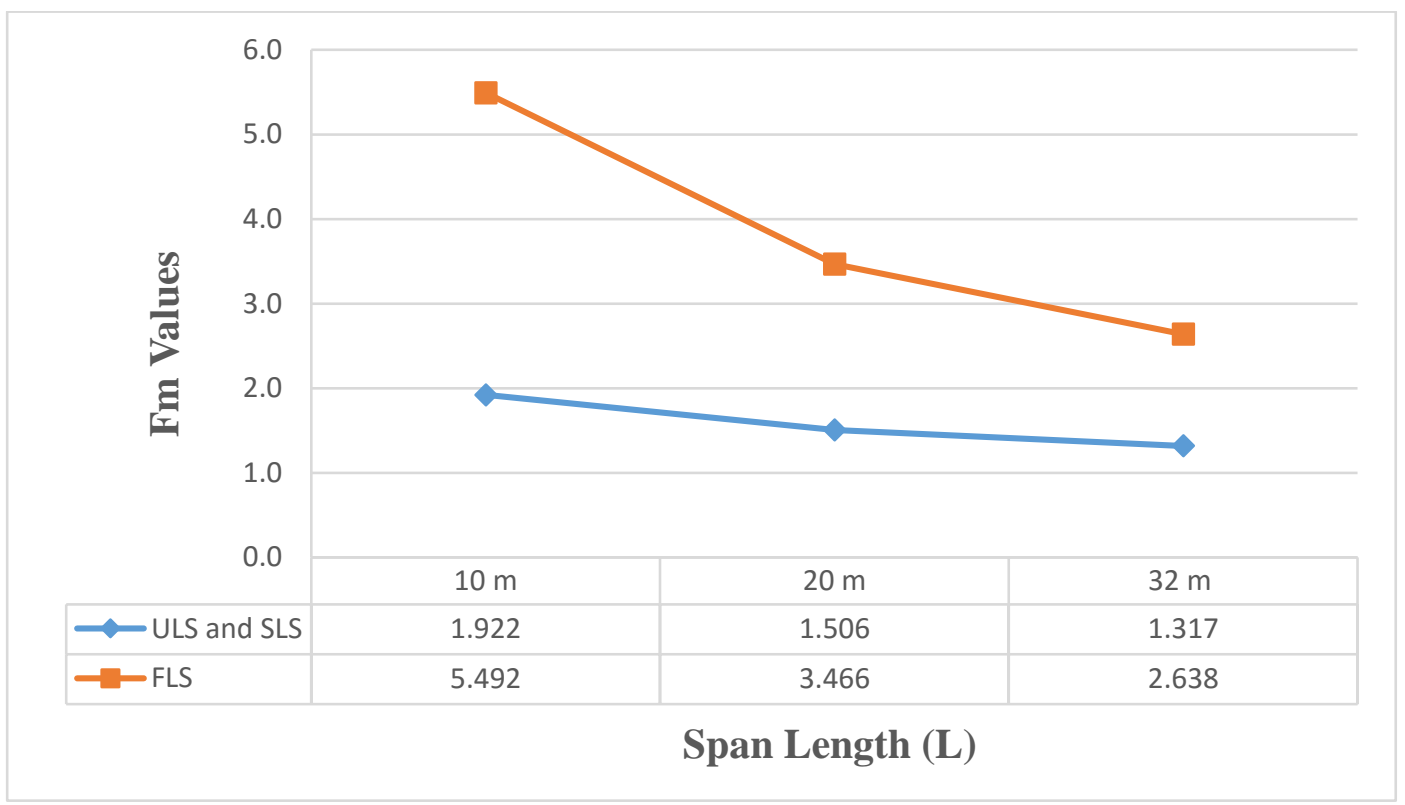

Figure A. 32: Effect of span length on moment distribution factor (six-lane, 20 girders) 


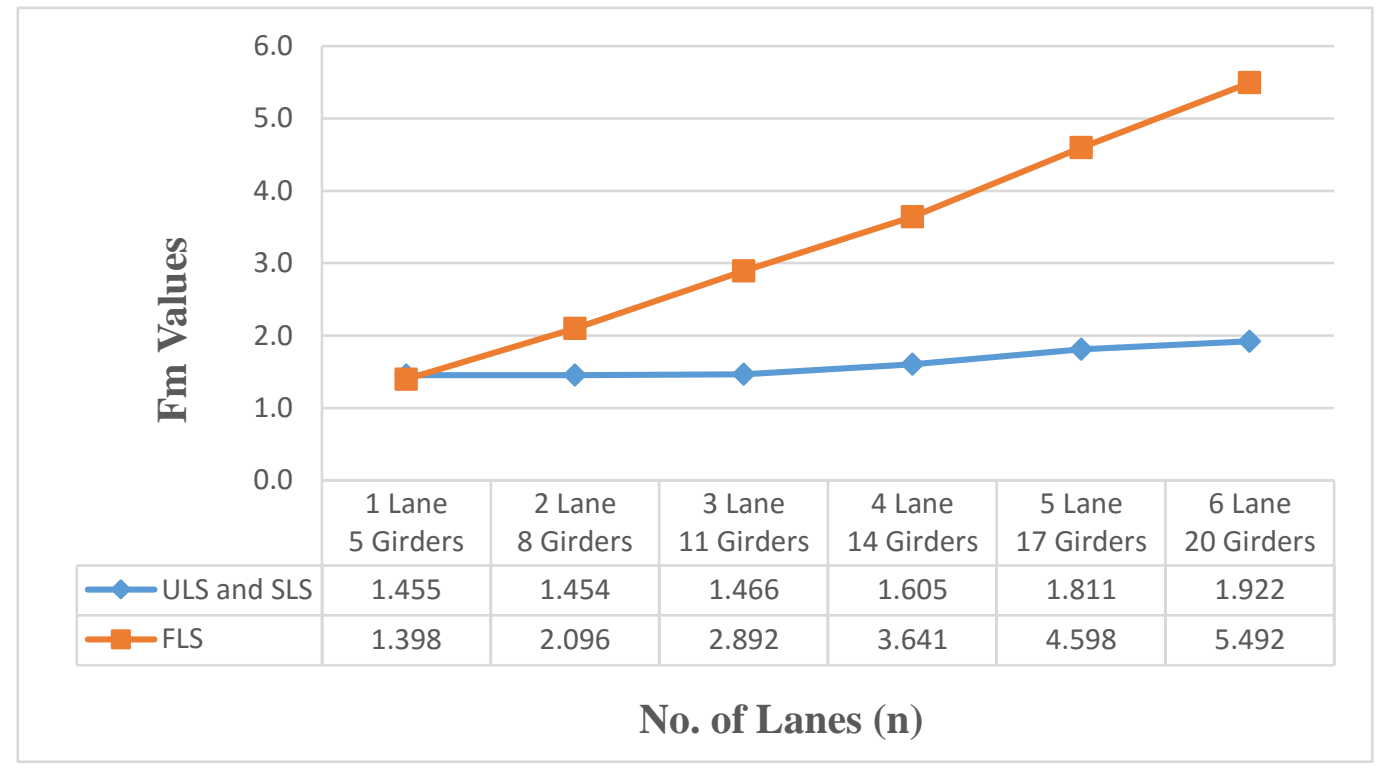

Figure A. 33: Effect of number of lanes on moment distribution factor (B700, 10m Span)

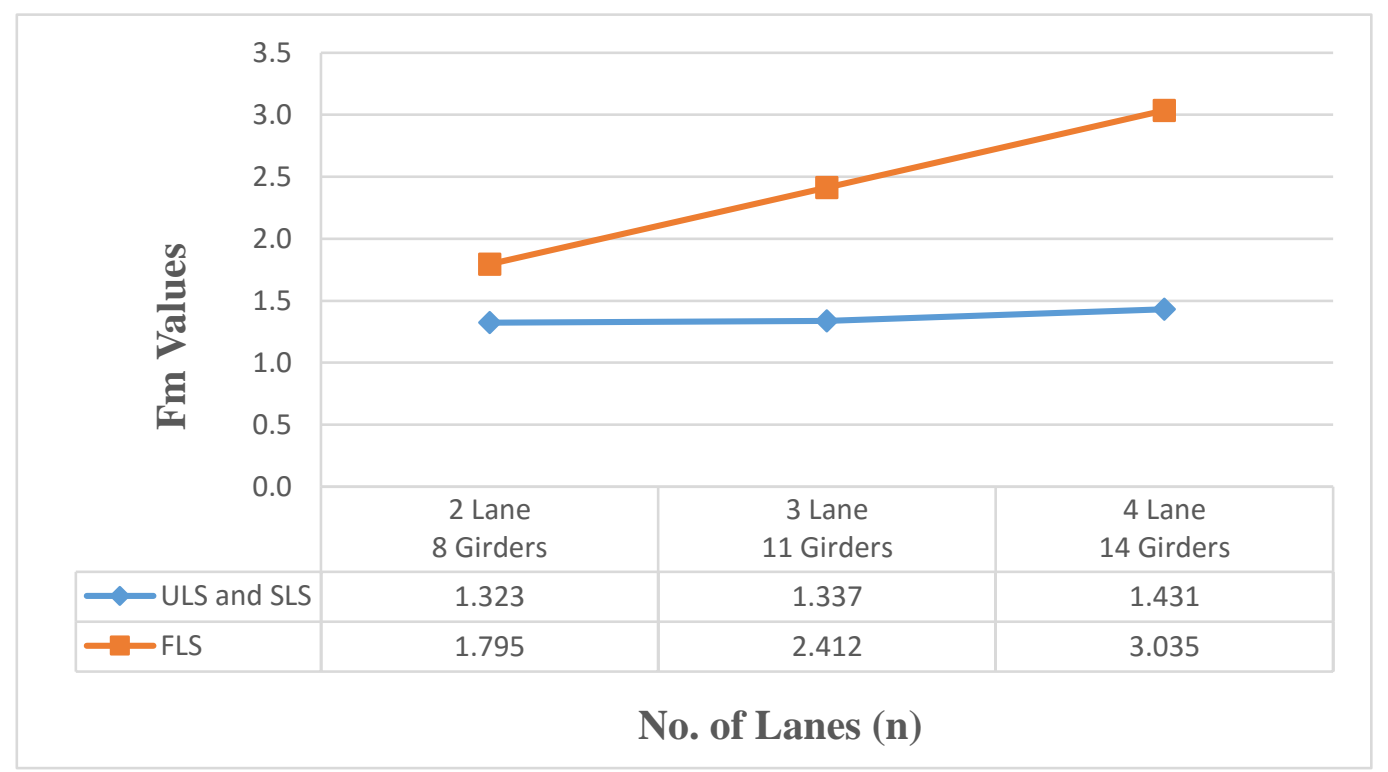

Figure A. 34: Effect of number of lanes on moment distribution factor (B700, 13m Span) 


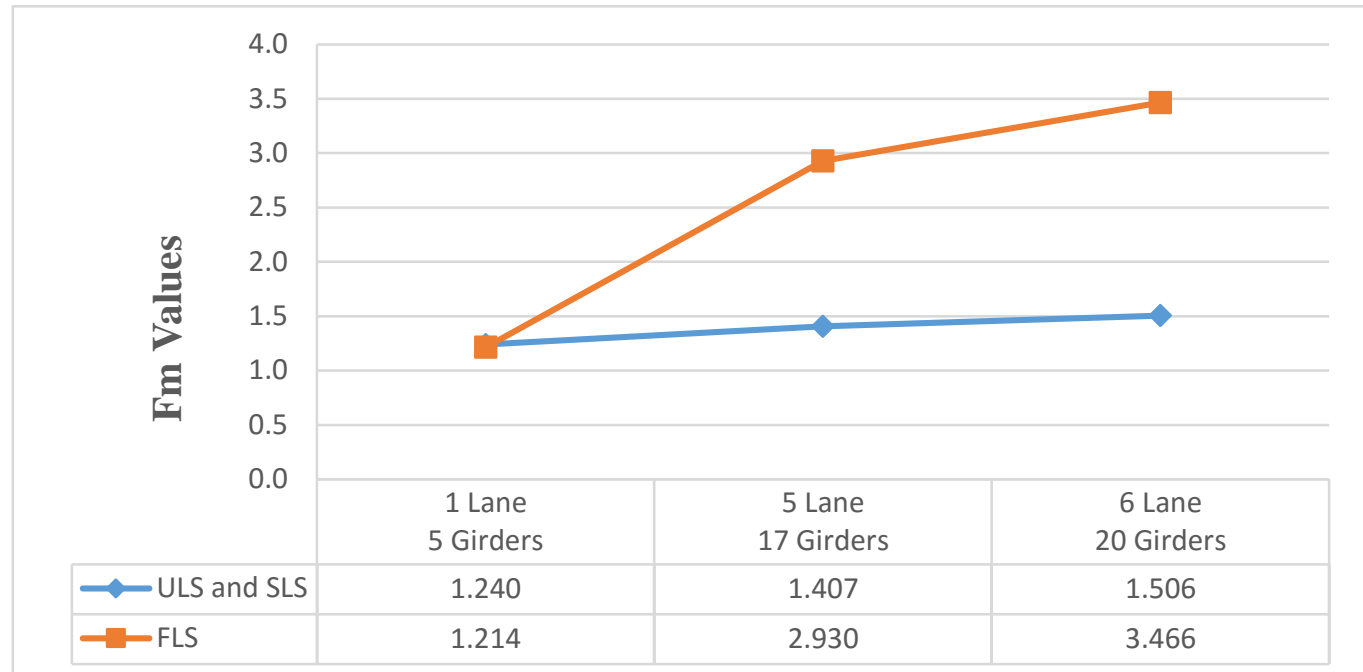

No. of Lanes (n)

Figure A. 35: Effect of number of lanes on moment distribution factor (B800, 20m Span)

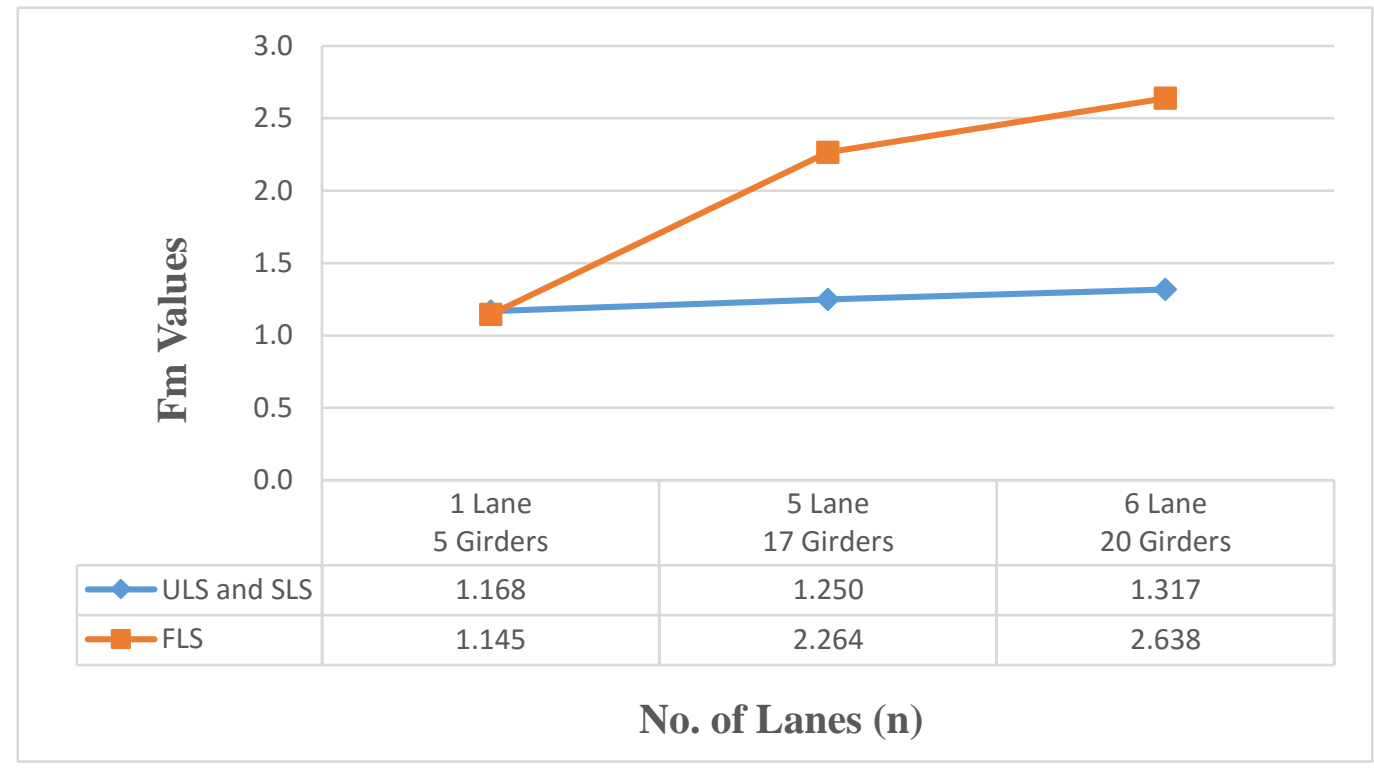

Figure A. 36: Effect of number of lanes on moment distribution factor (B1000, 32m Span) 


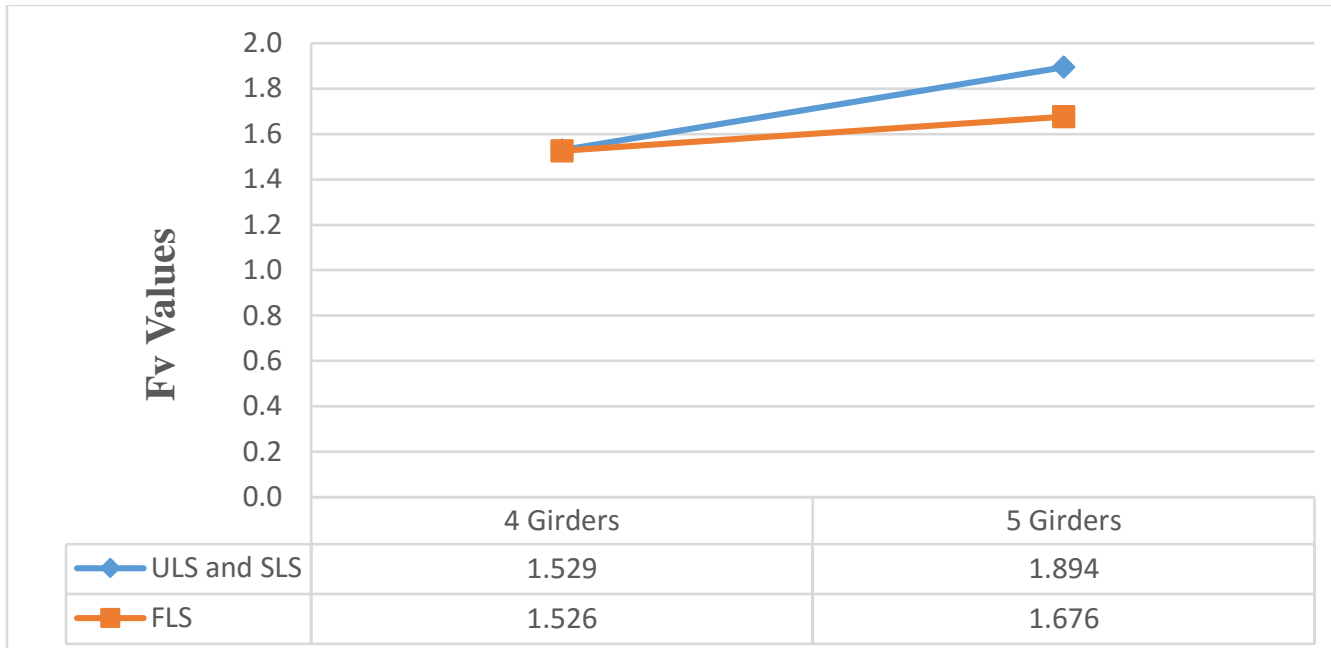

No. of Girders (N)

Figure A. 37: Effect of number of girders on shear distribution factor (B700, one-lane, 10m Span)

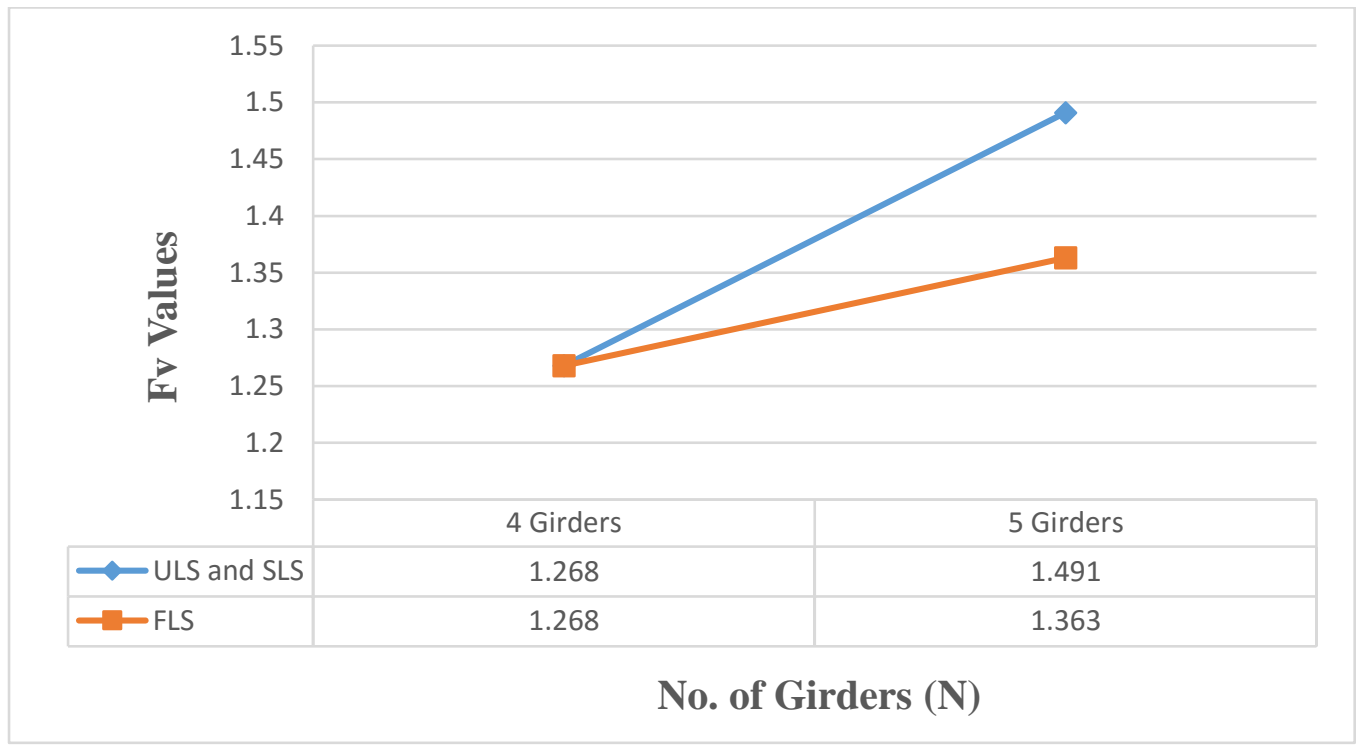

Figure A. 38: Effect of number of girders on shear distribution factor (B800, one-lane, 20m Span) 


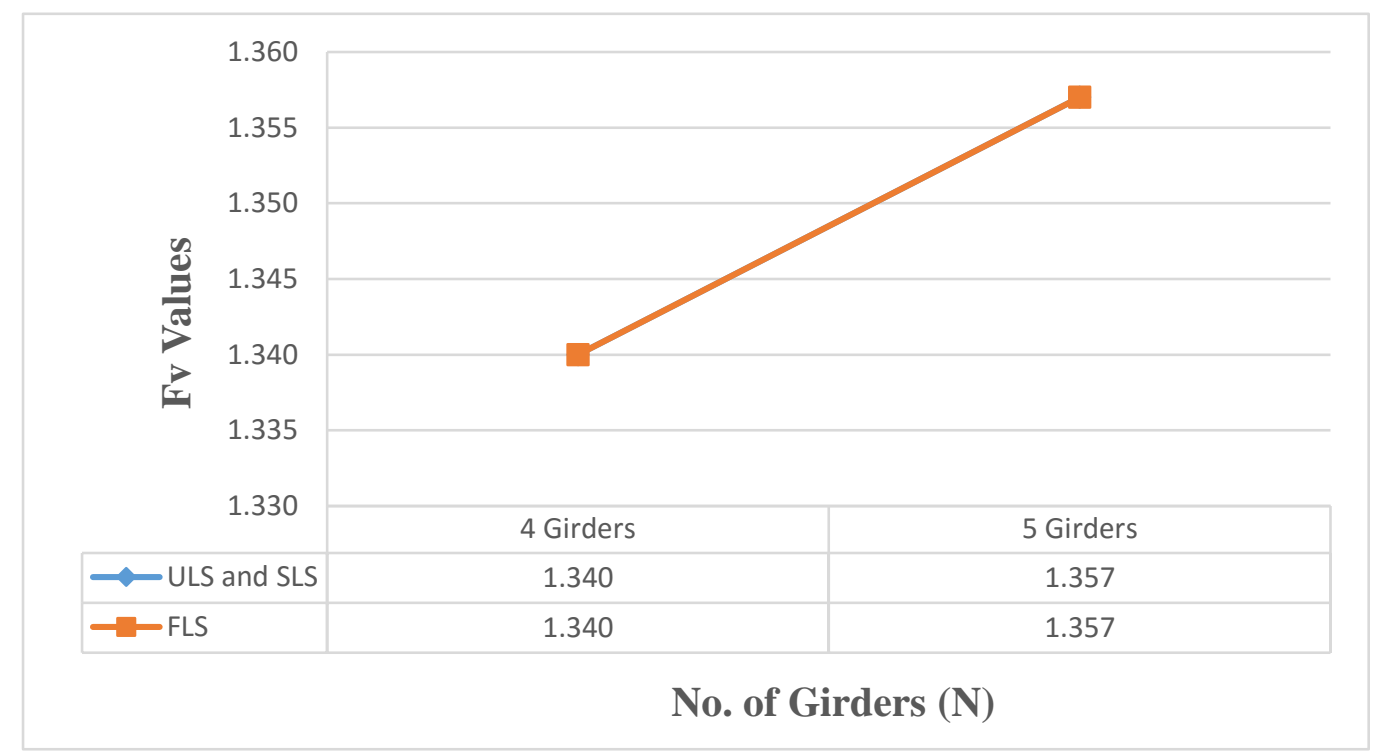

Figure A. 39: Effect of number of girders on shear distribution factor (B1000, one-lane, 32m Span)

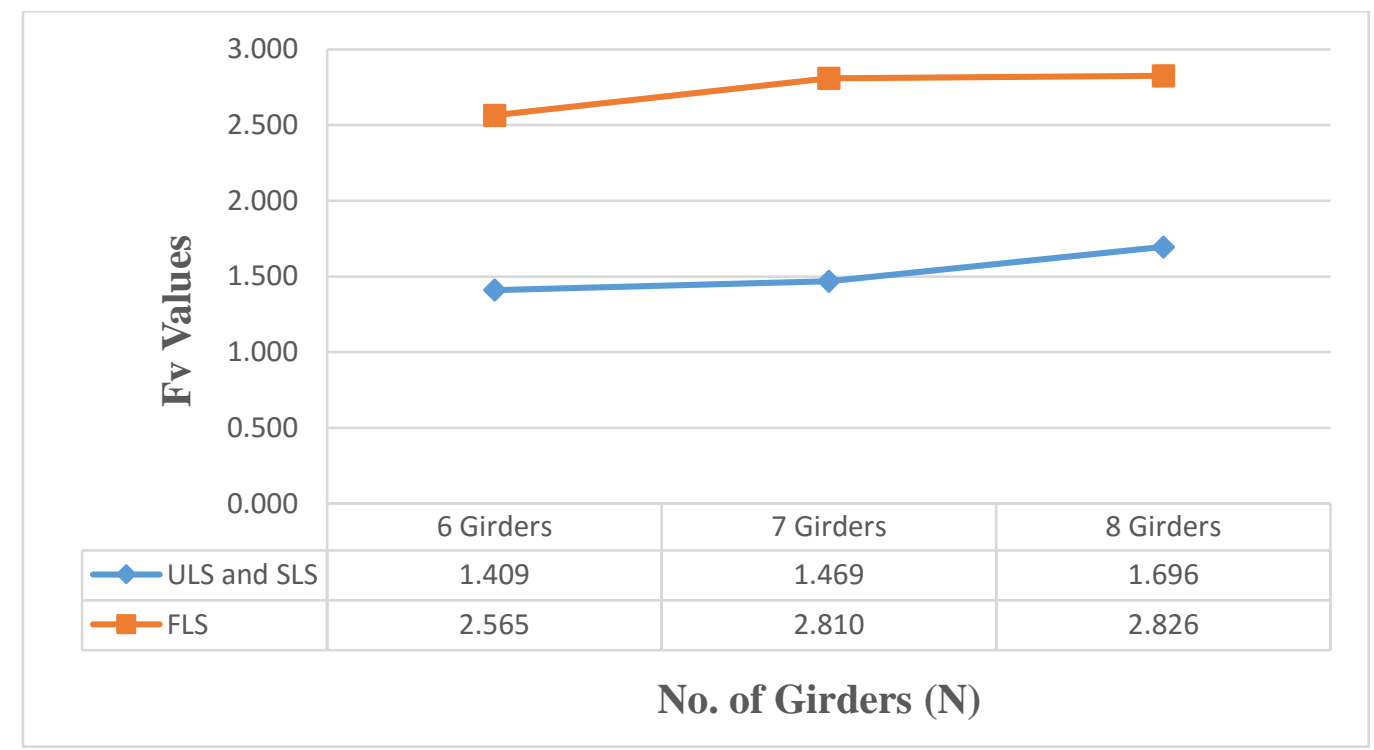

Figure A. 40: Effect of number of girders on shear distribution factor (B700, two-lane, 10m Span) 


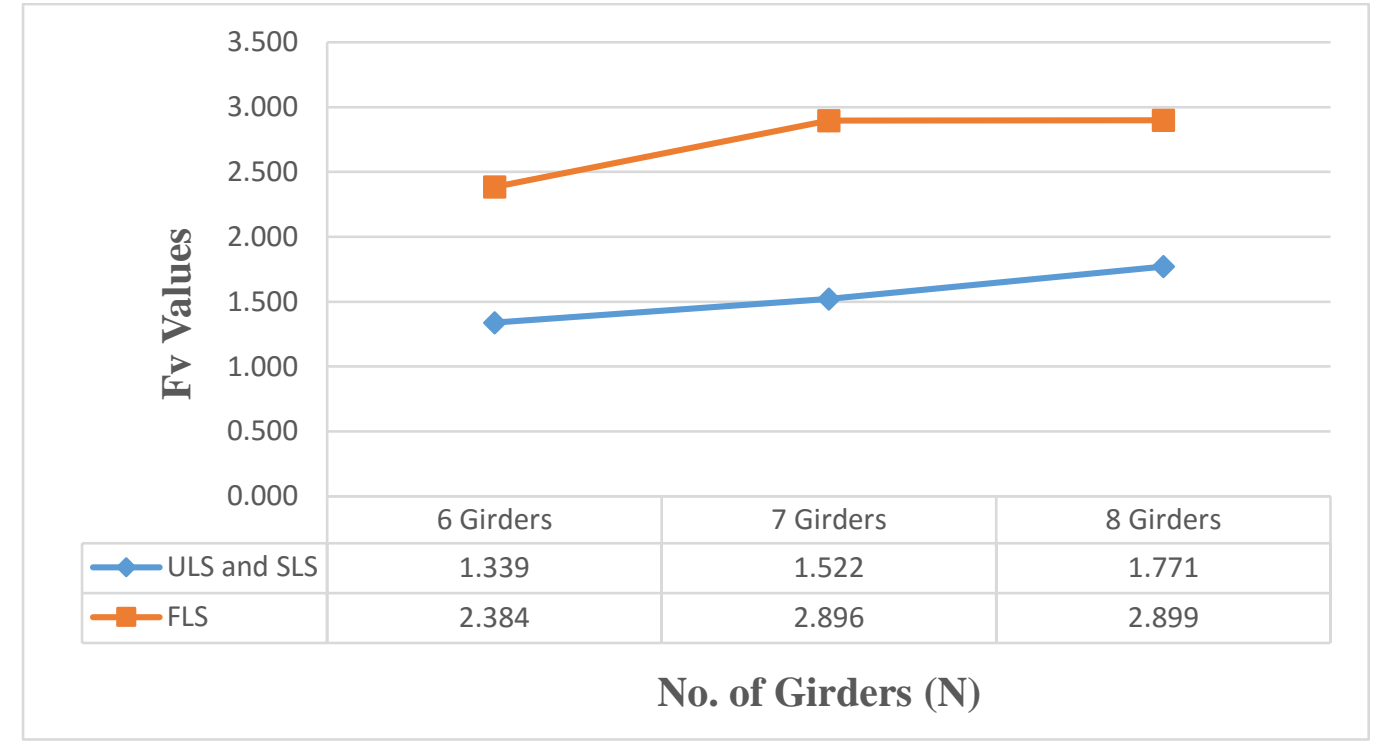

Figure A. 41: Effect of number of girders on shear distribution factor (B700, two-lane, 13m Span)

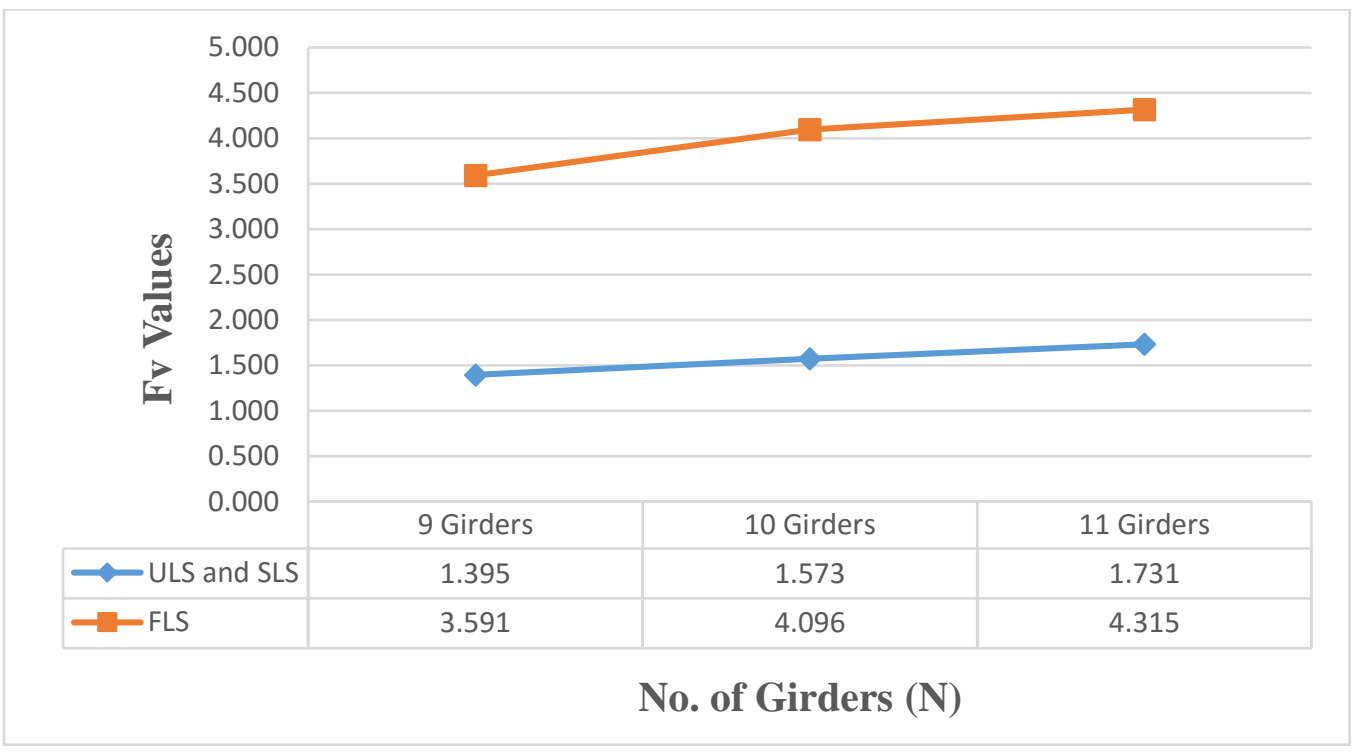

Figure A. 42: Effect of number of girders on shear distribution factor (B700, three-lane, 10m Span) 


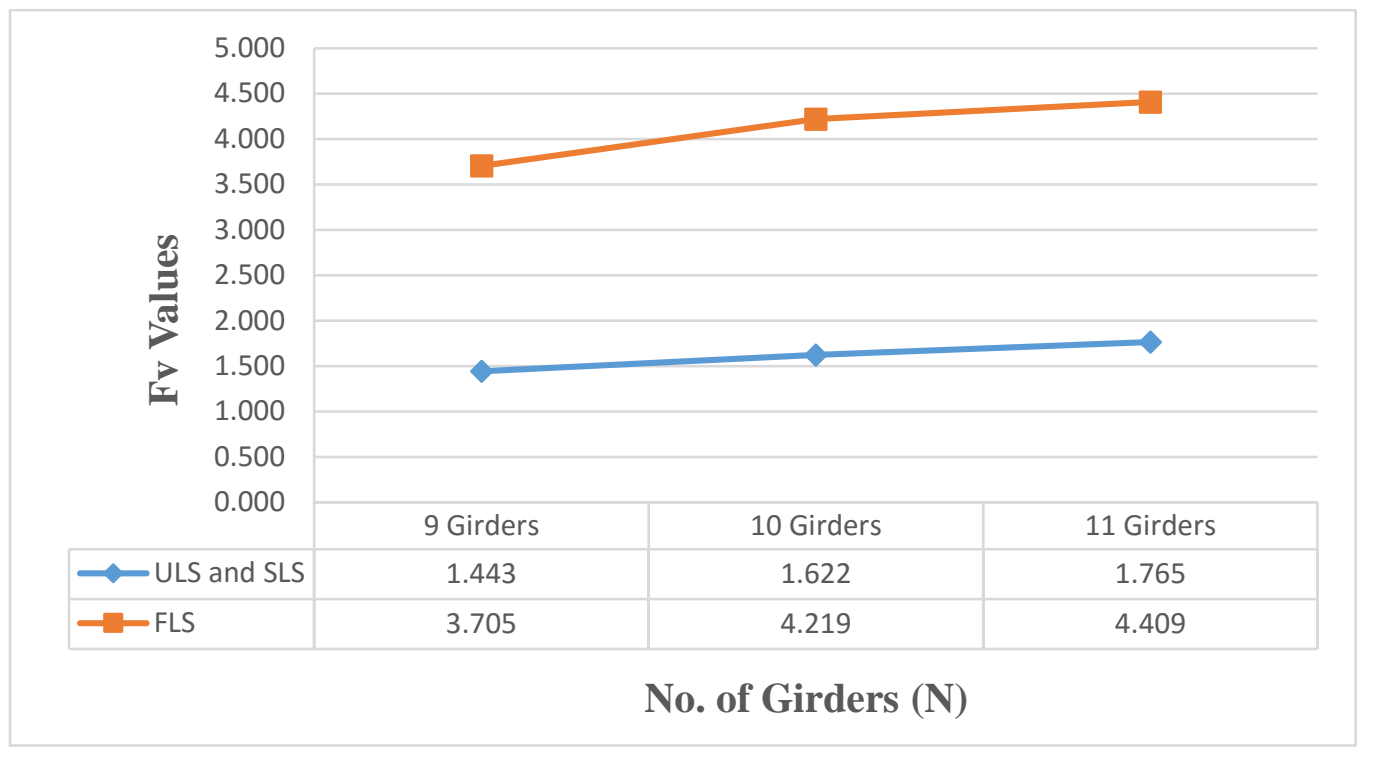

Figure A. 43: Effect of number of girders on shear distribution factor (B700, three-lane, 13m Span)

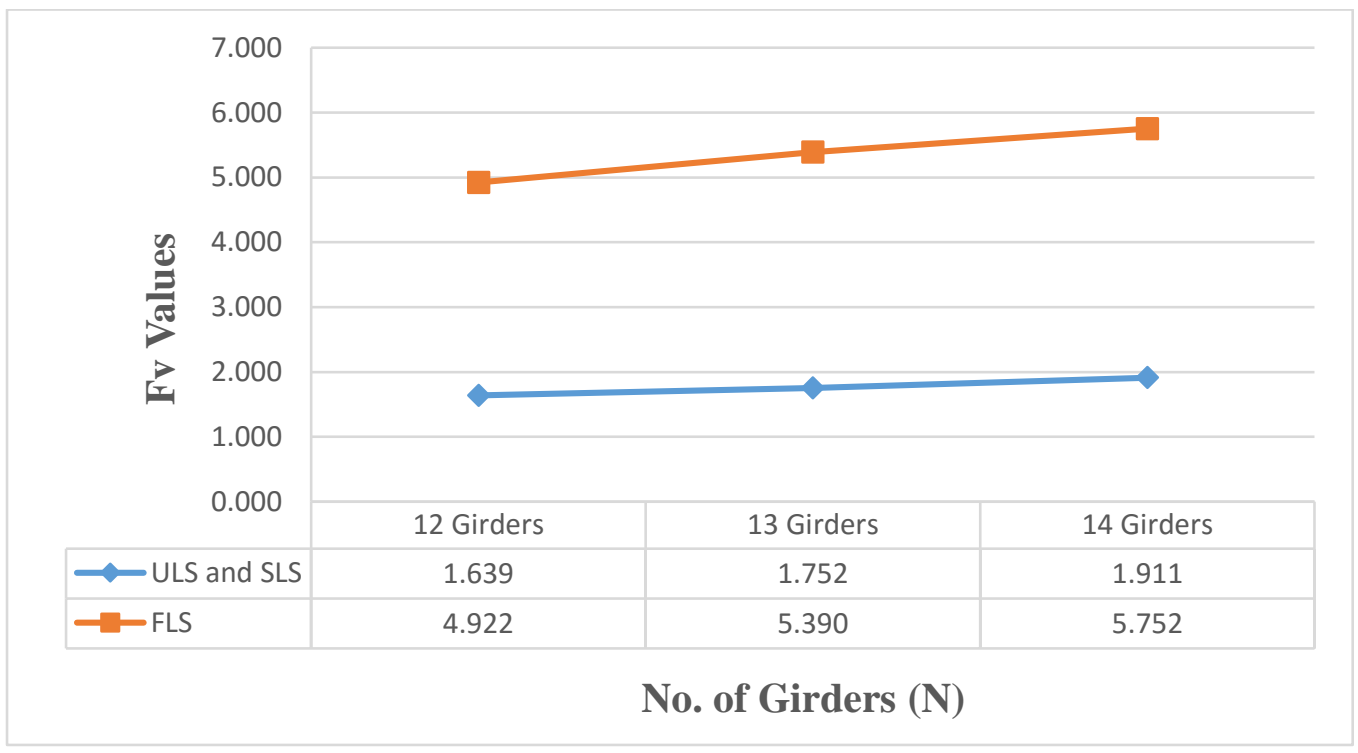

Figure A. 44: Effect of number of girders on shear distribution factor (B700, four-lane, 10m Span) 


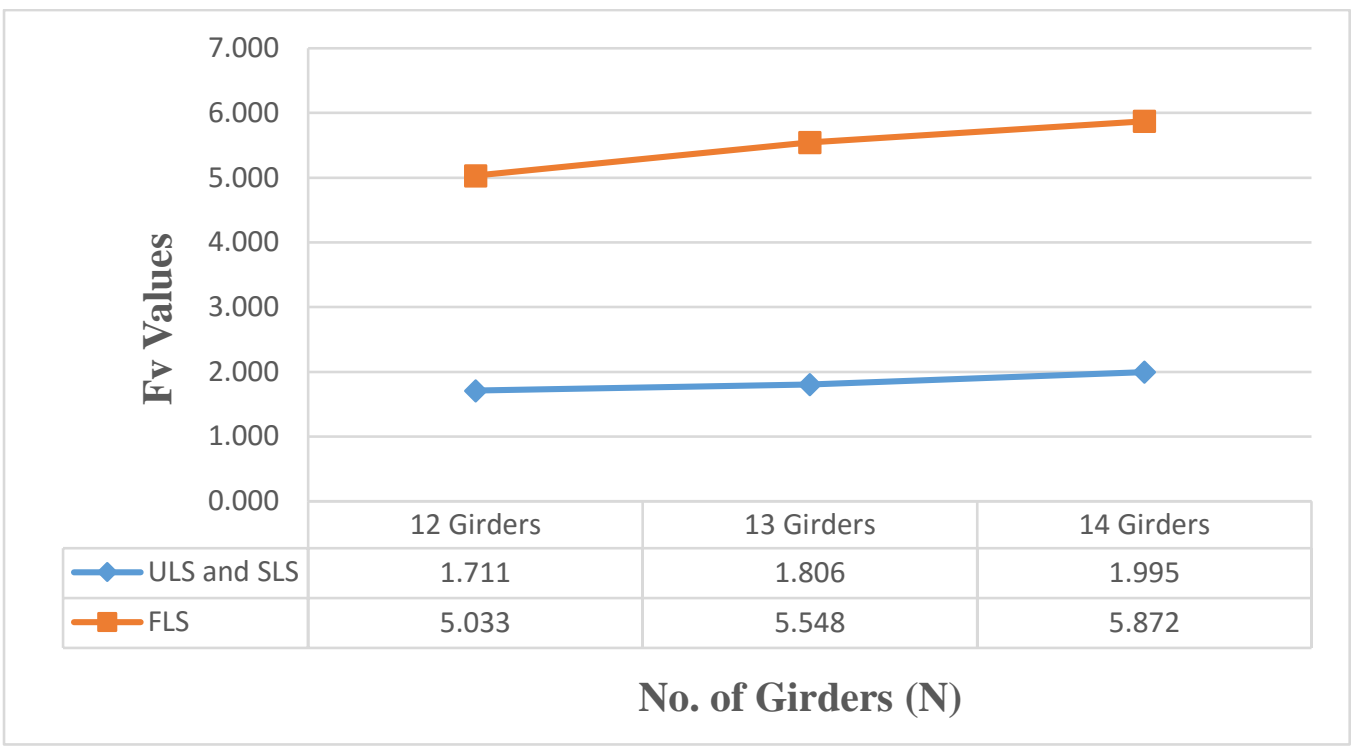

Figure A. 45: Effect of number of girders on shear distribution factor (B700, four-lane, 13m Span)

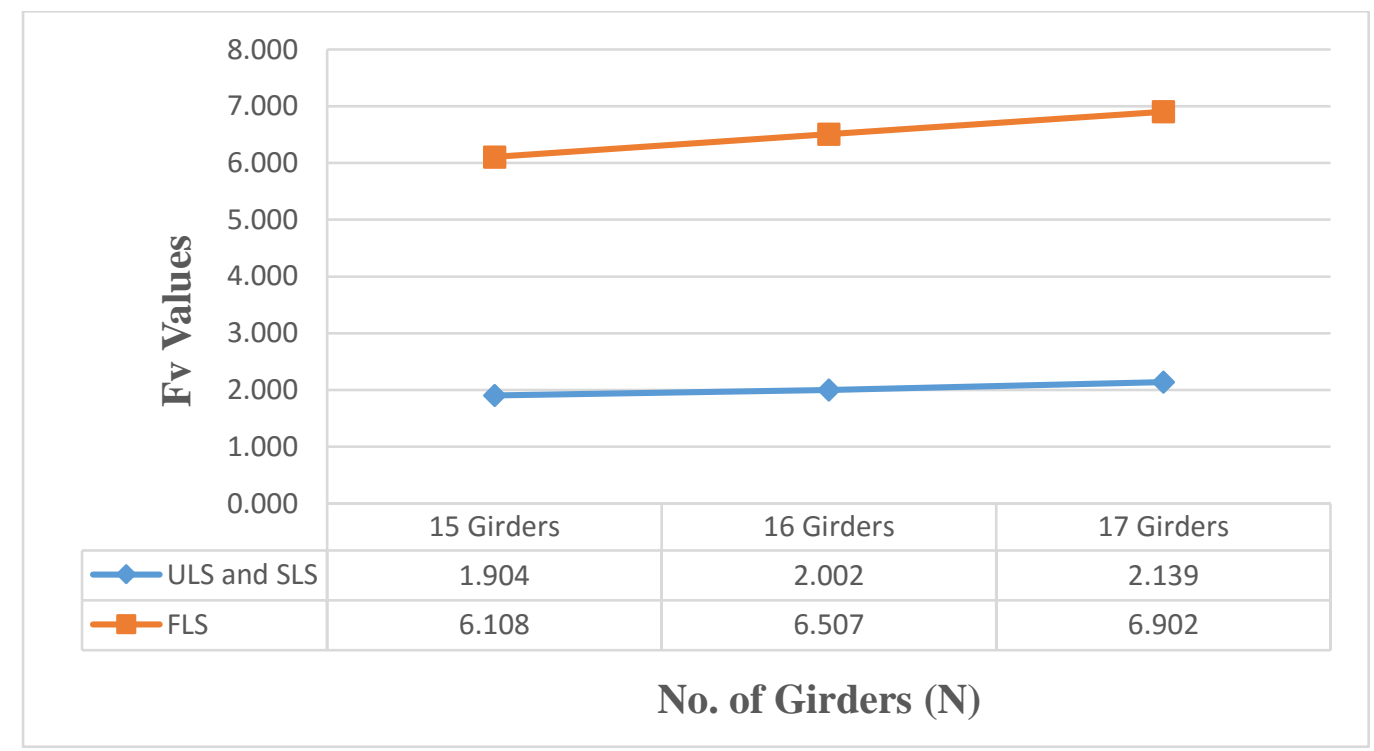

Figure A. 46: Effect of number of girders on shear distribution factor (B700, five-lane, $10 \mathrm{~m}$ Span) 


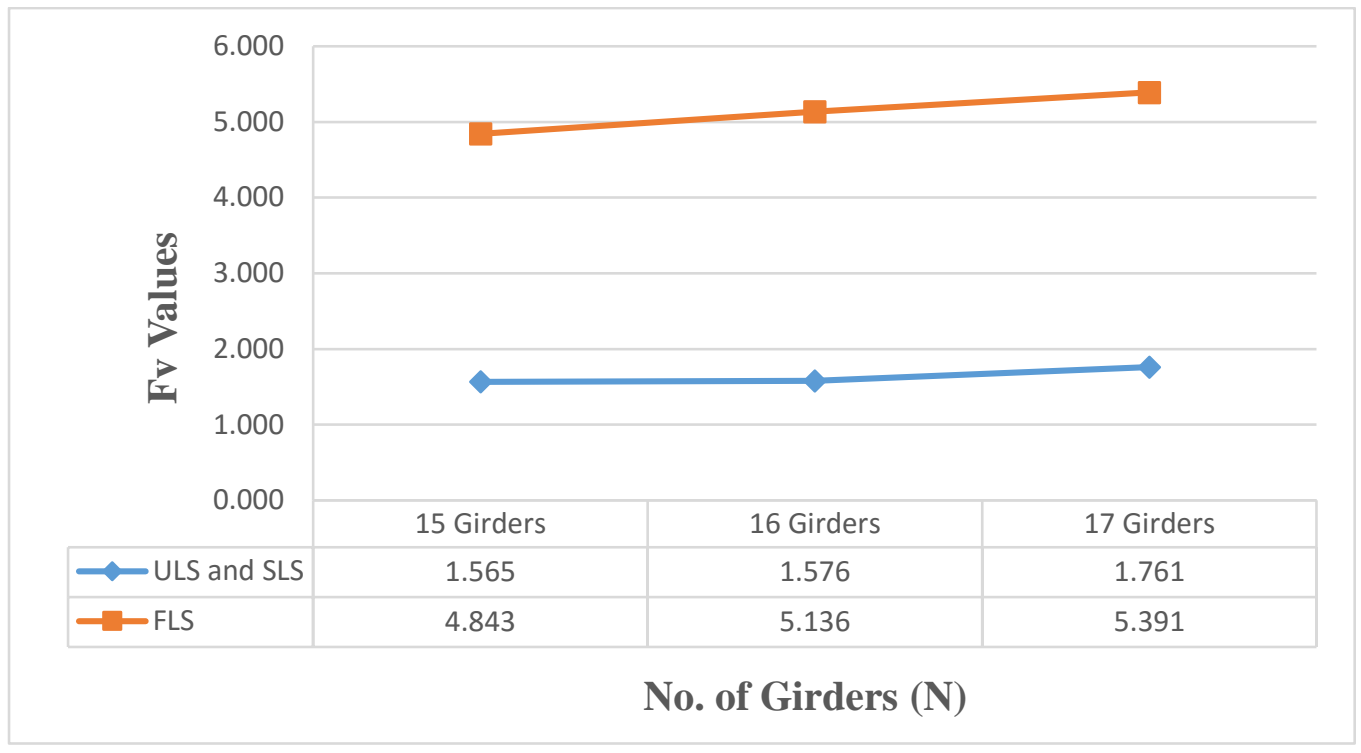

Figure A. 47: Effect of number of girders on shear distribution factor (B800, five-lane, 20m Span)

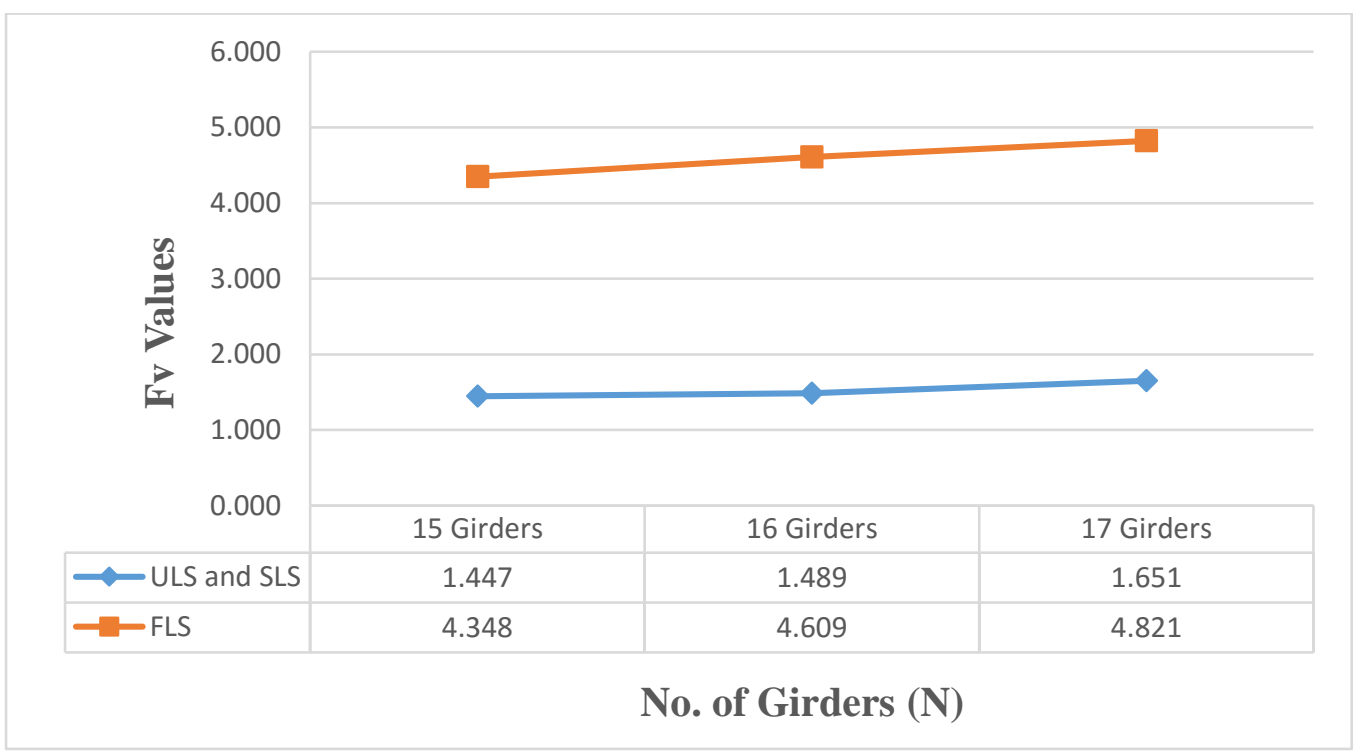

Figure A. 48: Effect of number of girders on shear distribution factor (B1000, five-lane, 32m Span) 


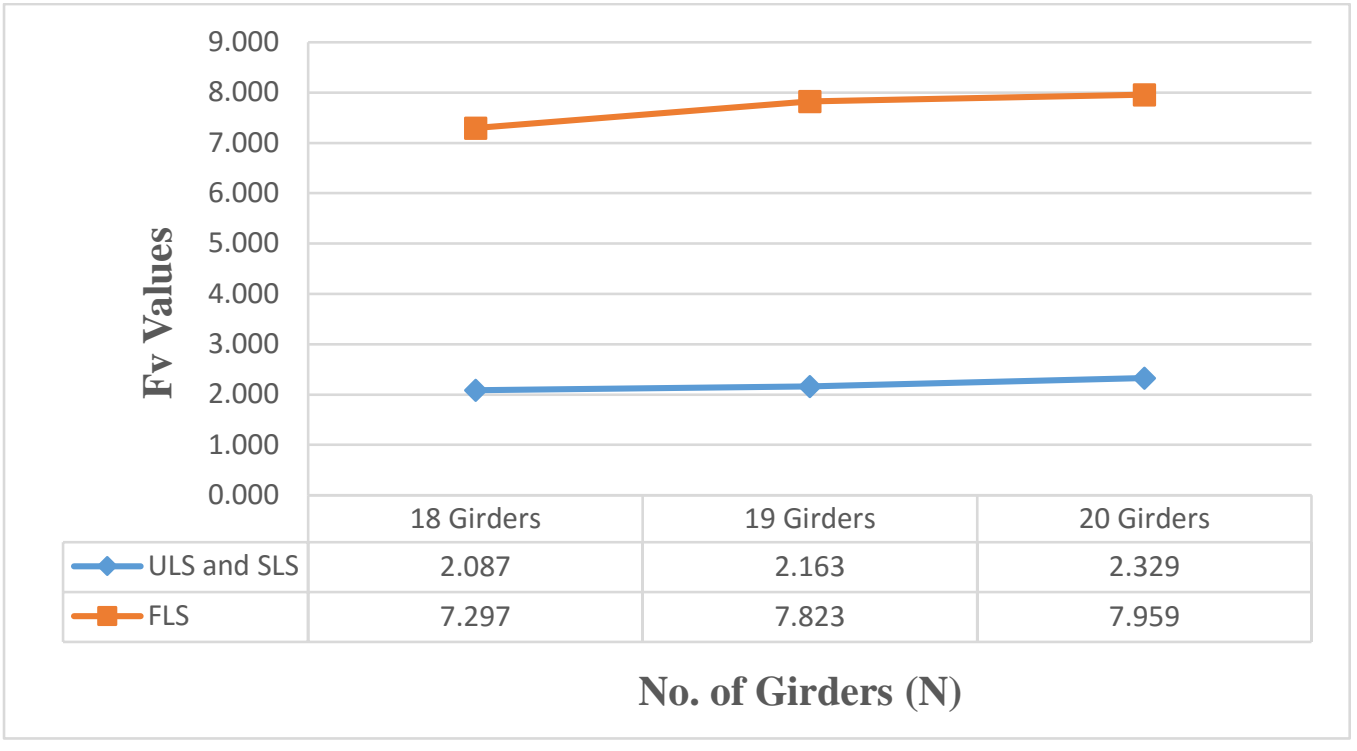

Figure A. 49: Effect of number of girders on shear distribution factor (B700, six-lane, 10m Span)

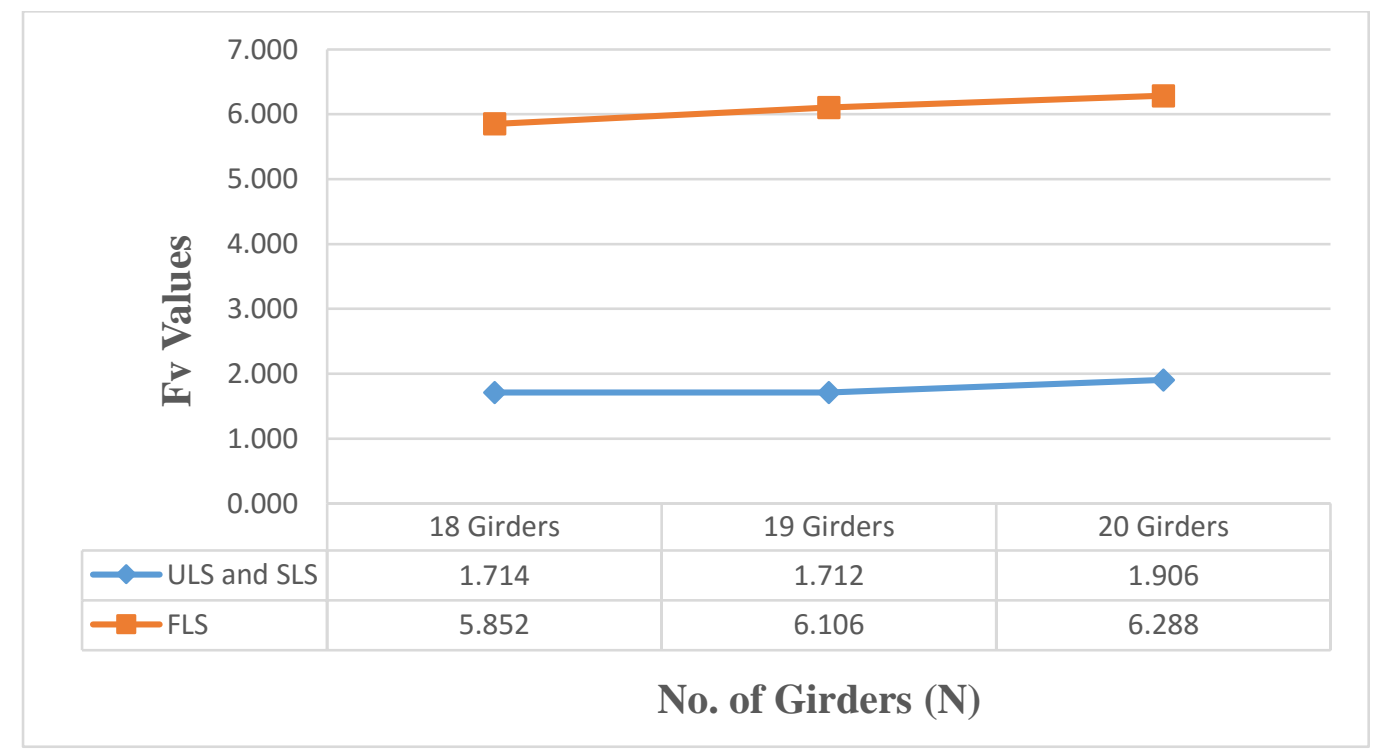

Figure A. 50: Effect of number of girders on shear distribution factor (B800, six-lane, 20m Span) 


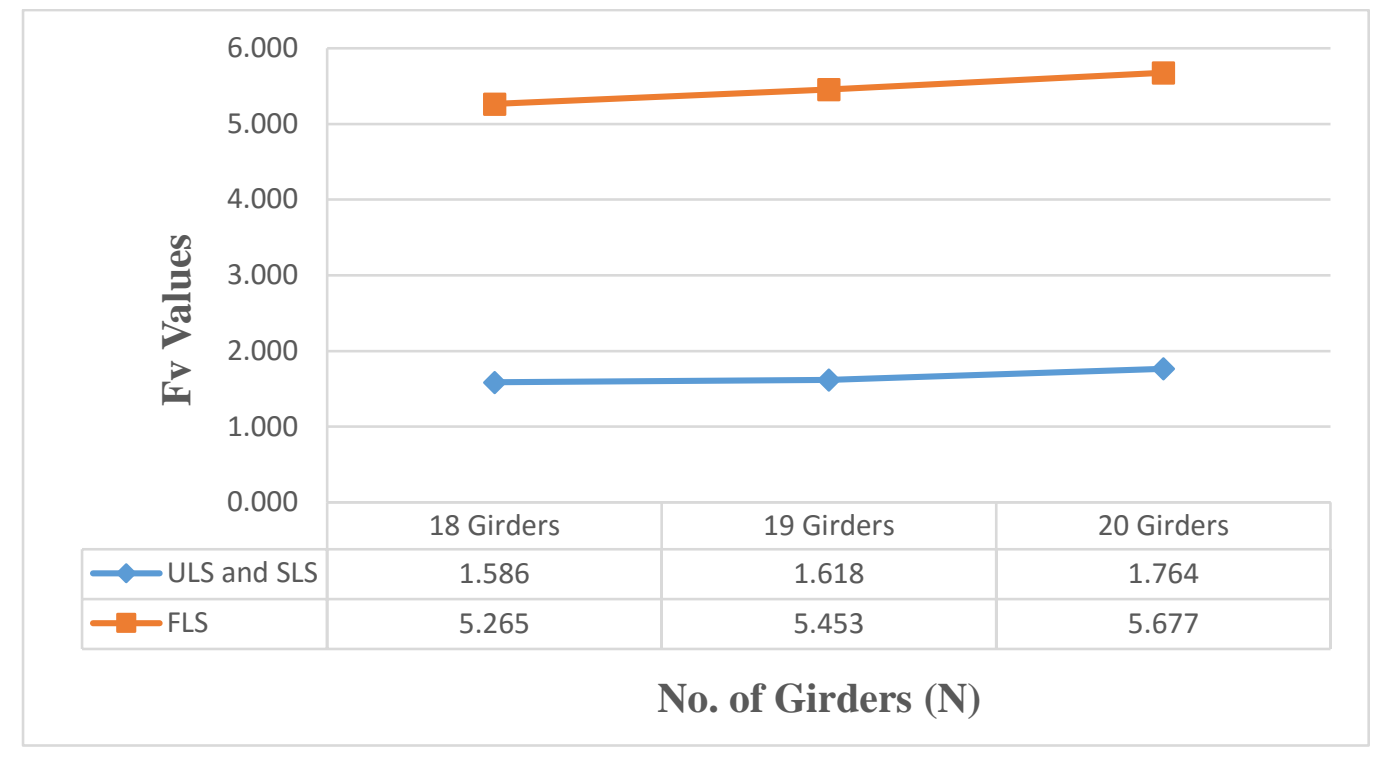

Figure A. 51: Effect of number of girders on shear distribution factor (B1000, six-lane, 32m Span)

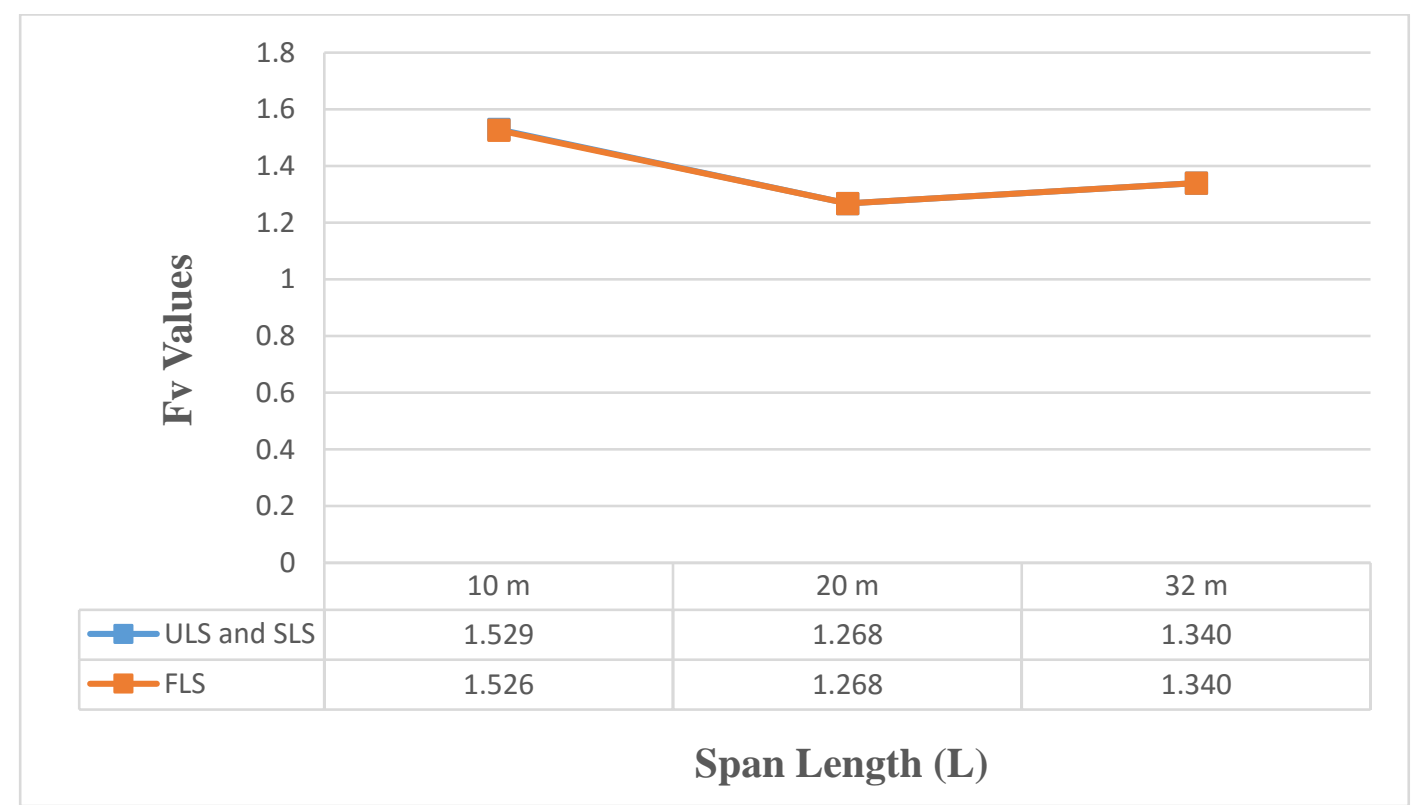

Figure A. 52: Effect of span length on shear distribution factor (one-lane, 4 girders) 


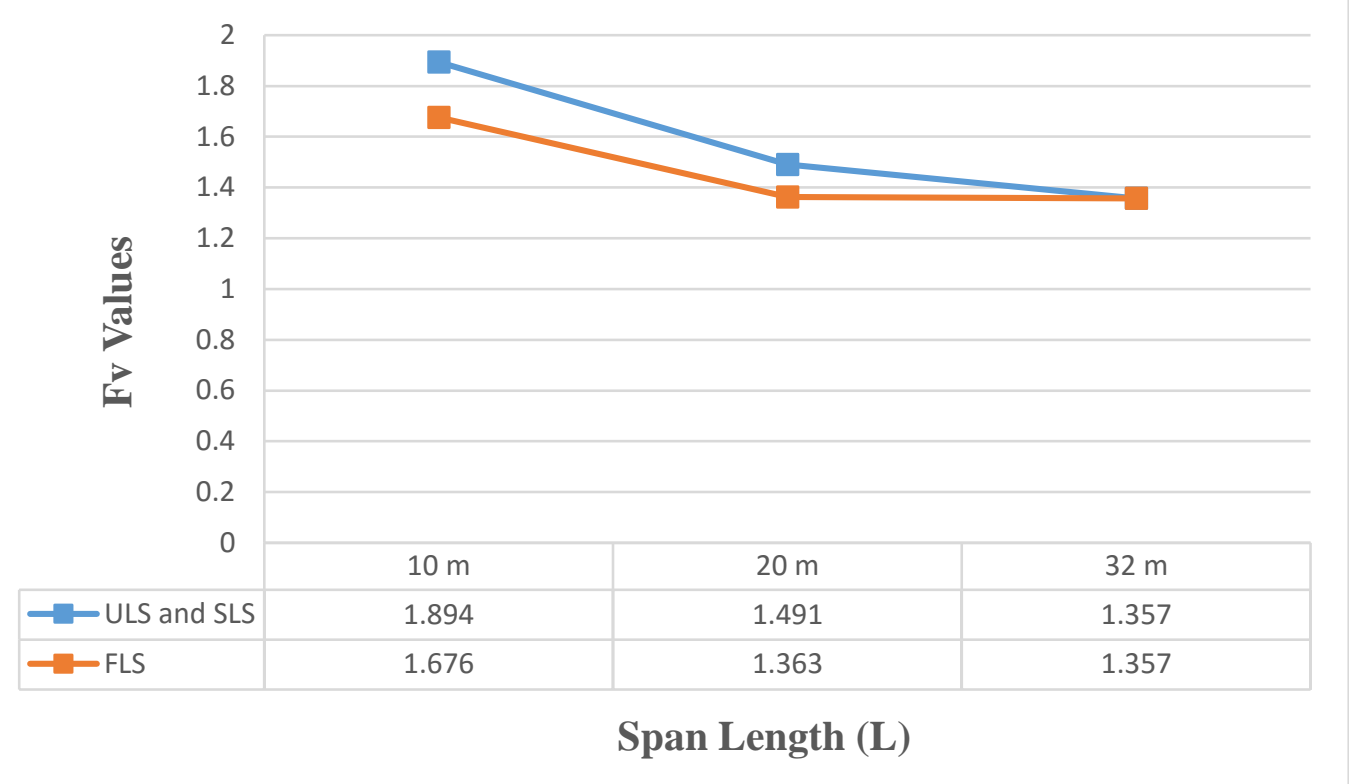

Figure A. 53: Effect of span length on shear distribution factor (one-lane, 5 girders)

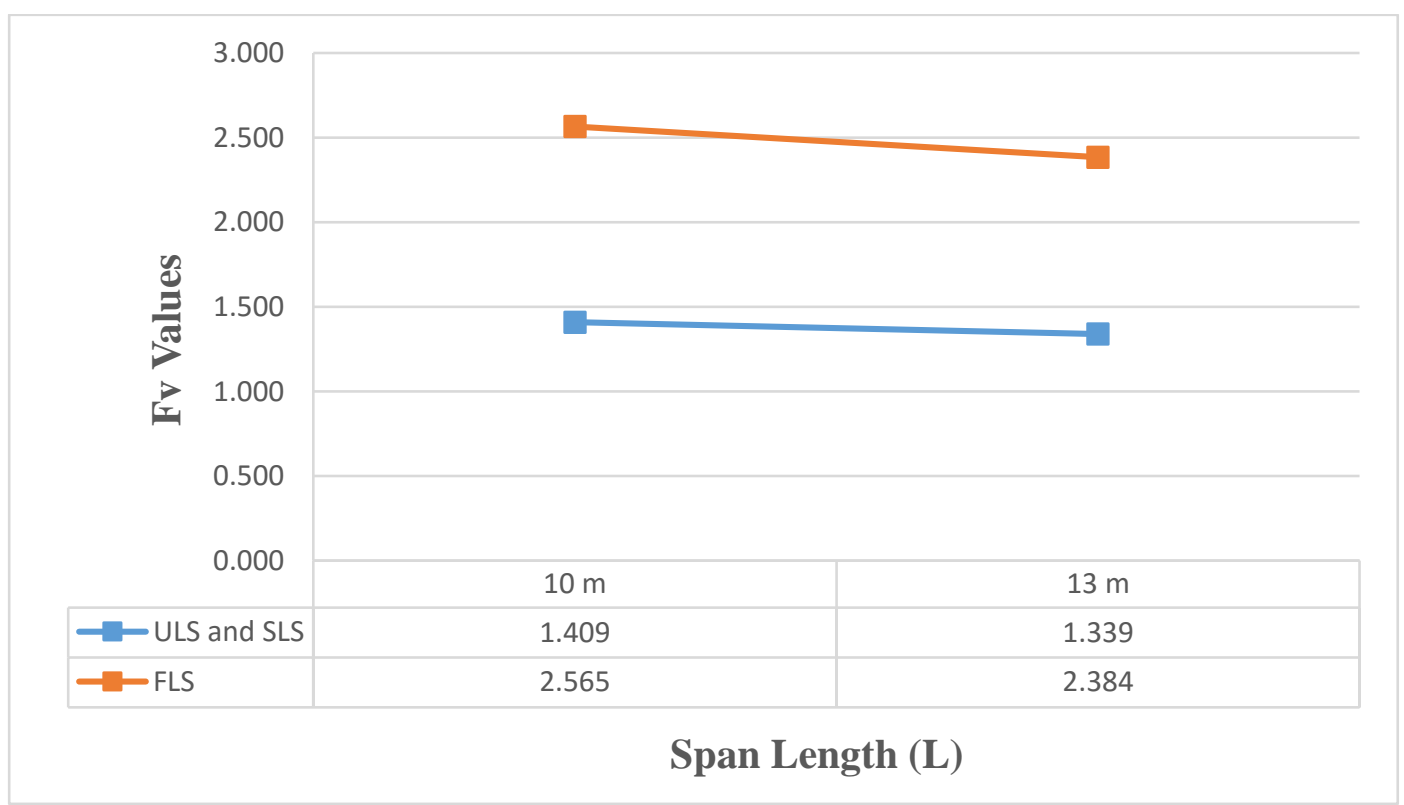

Figure A. 54: Effect of span length on shear distribution factor (two-lane, 6 girders) 


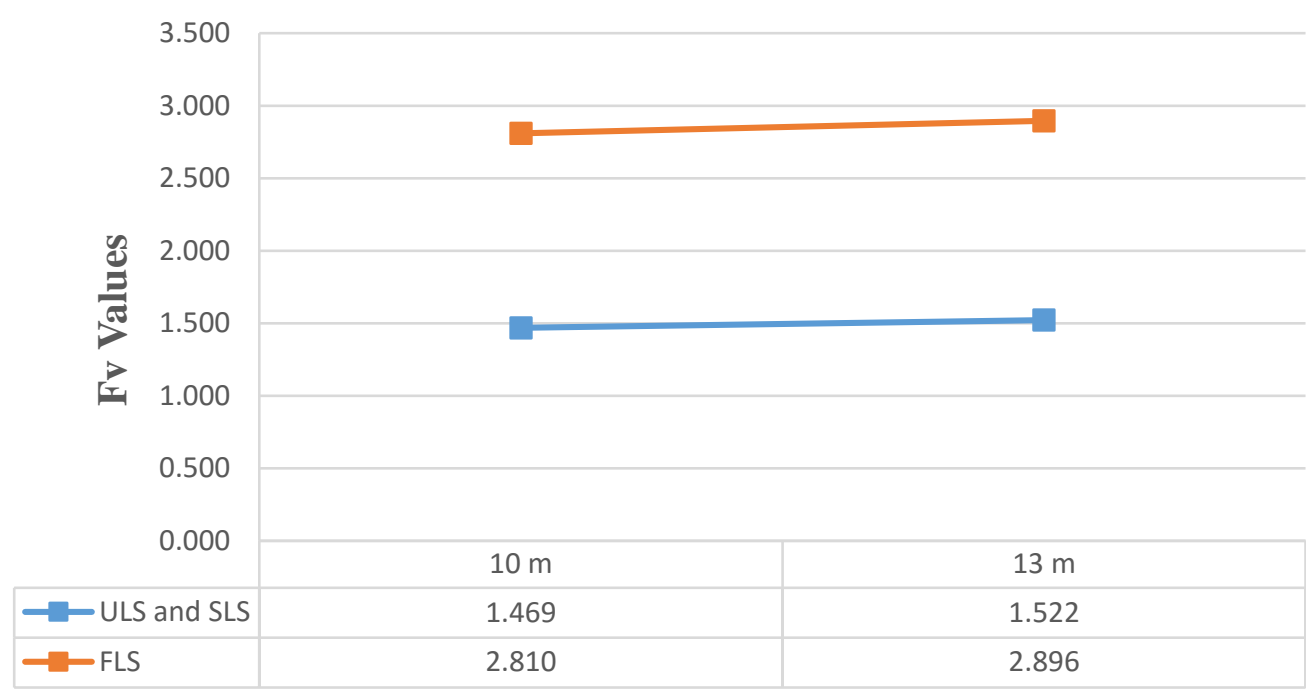

Span Length (L)

Figure A. 55: Effect of span length on shear distribution factor (two-lane, 7 girders)

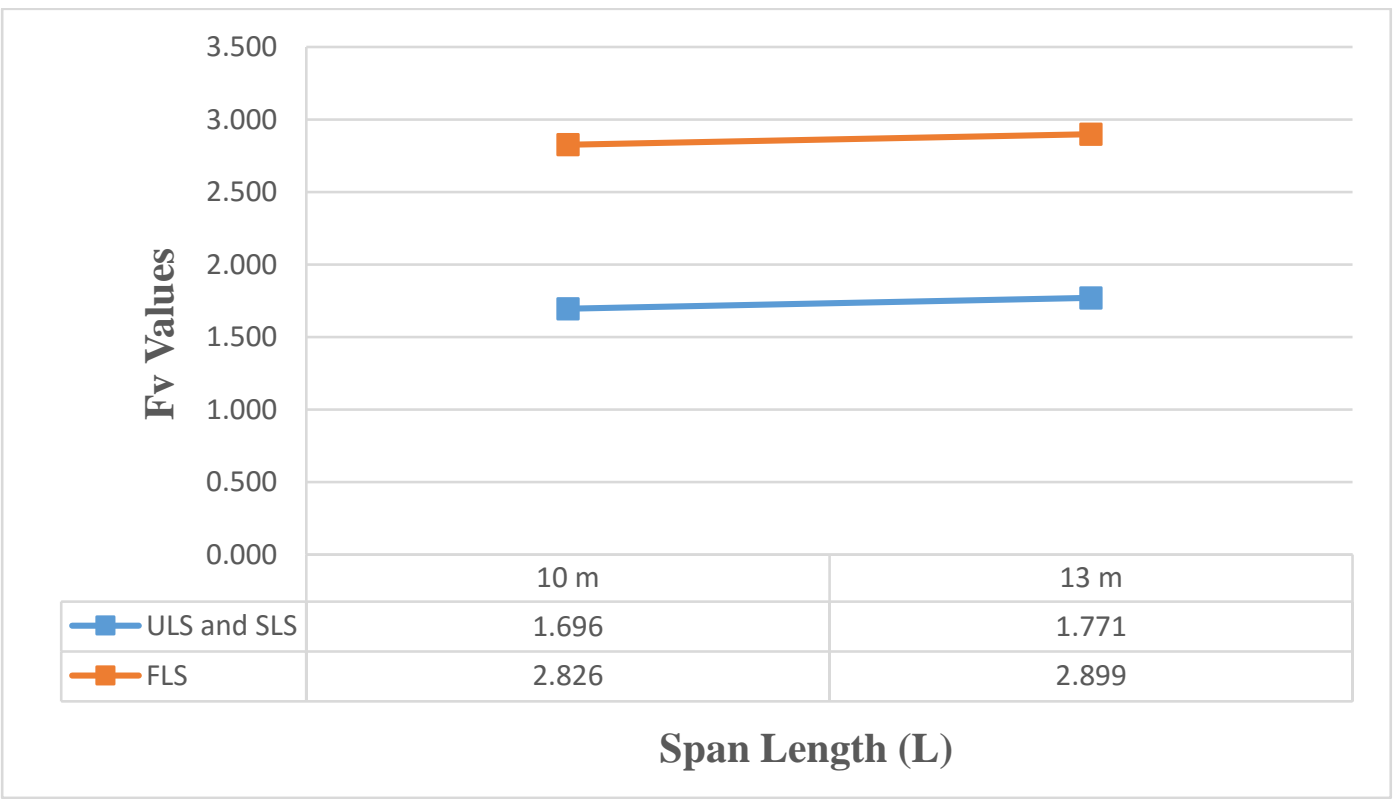

Figure A. 56: Effect of span length on shear distribution factor (two-lane, 8 girders) 


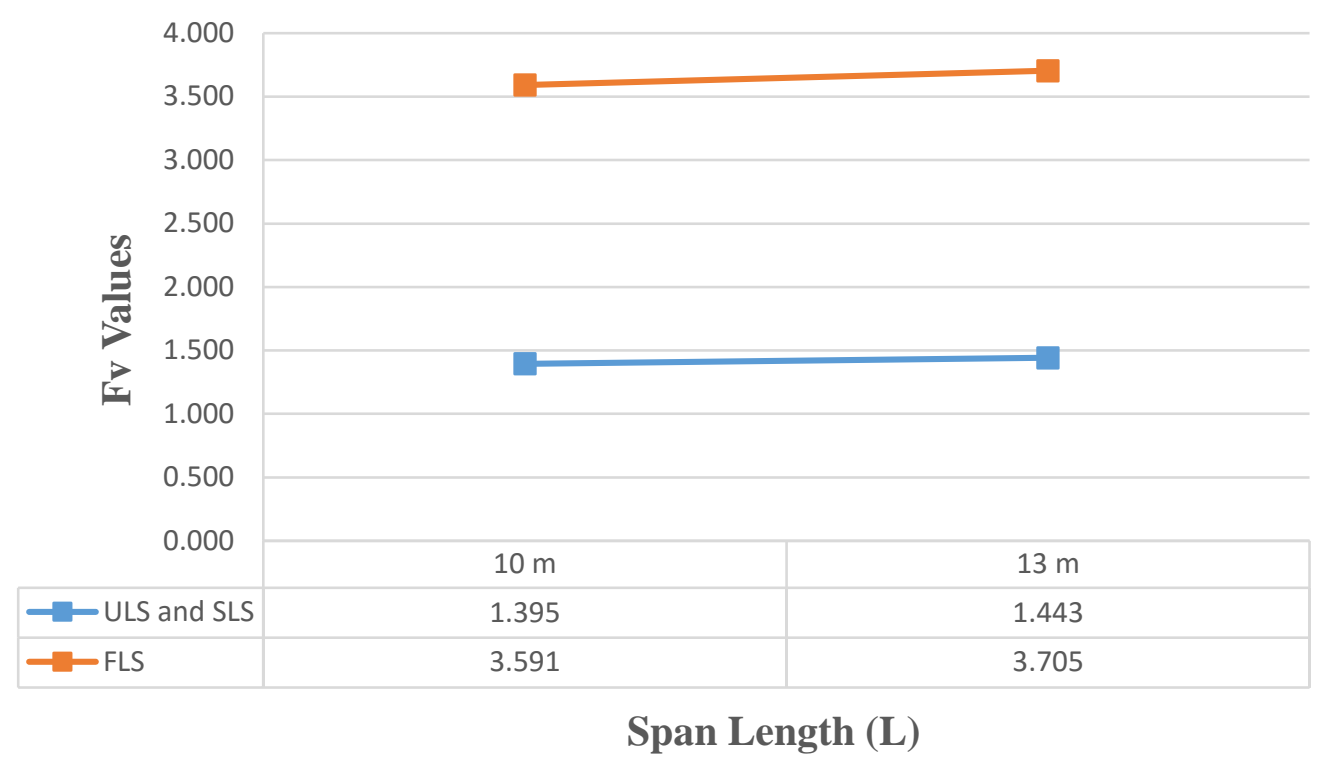

Figure A. 57: Effect of span length on shear distribution factor (three-lane, 9 girders)

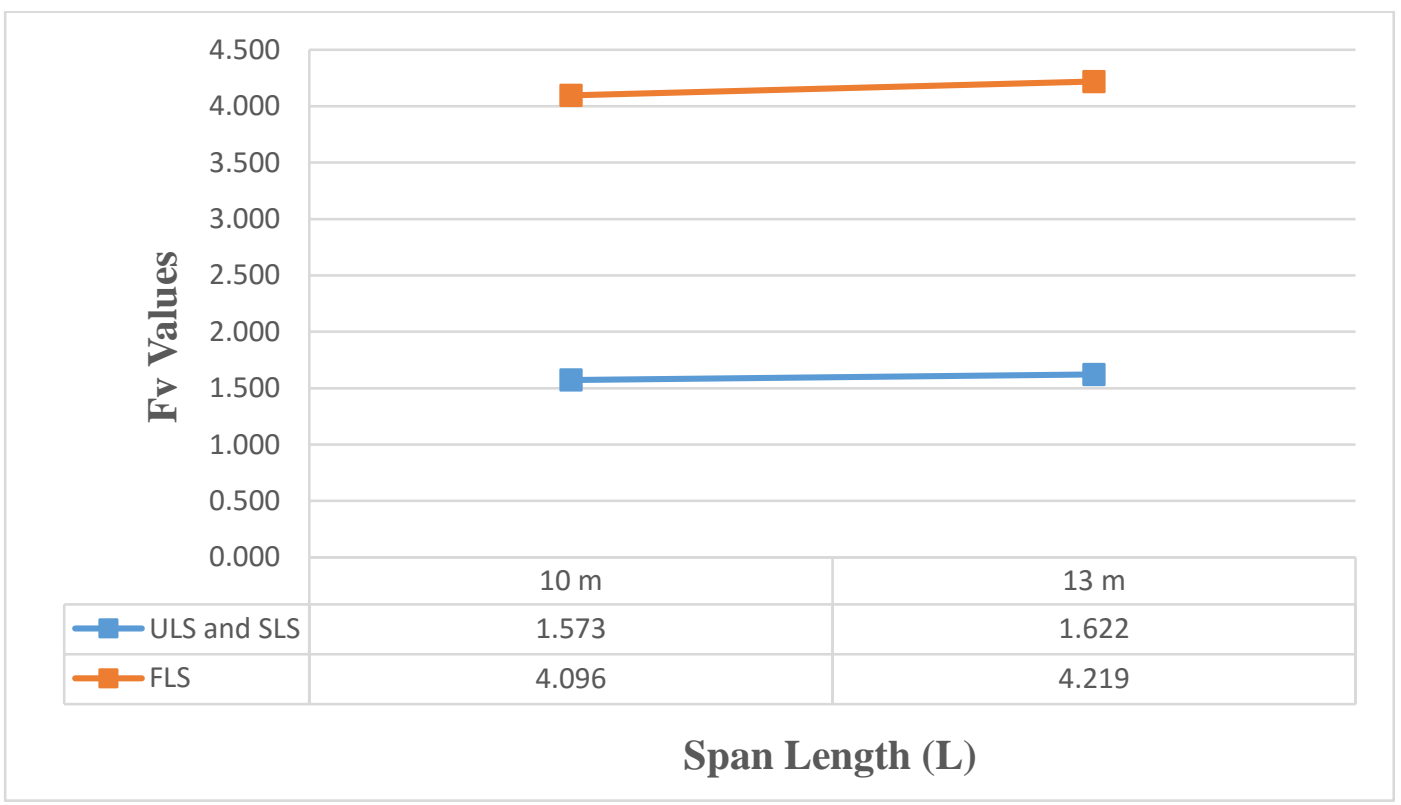

Figure A. 58: Effect of span length on shear distribution factor (three-lane, 10 girders) 


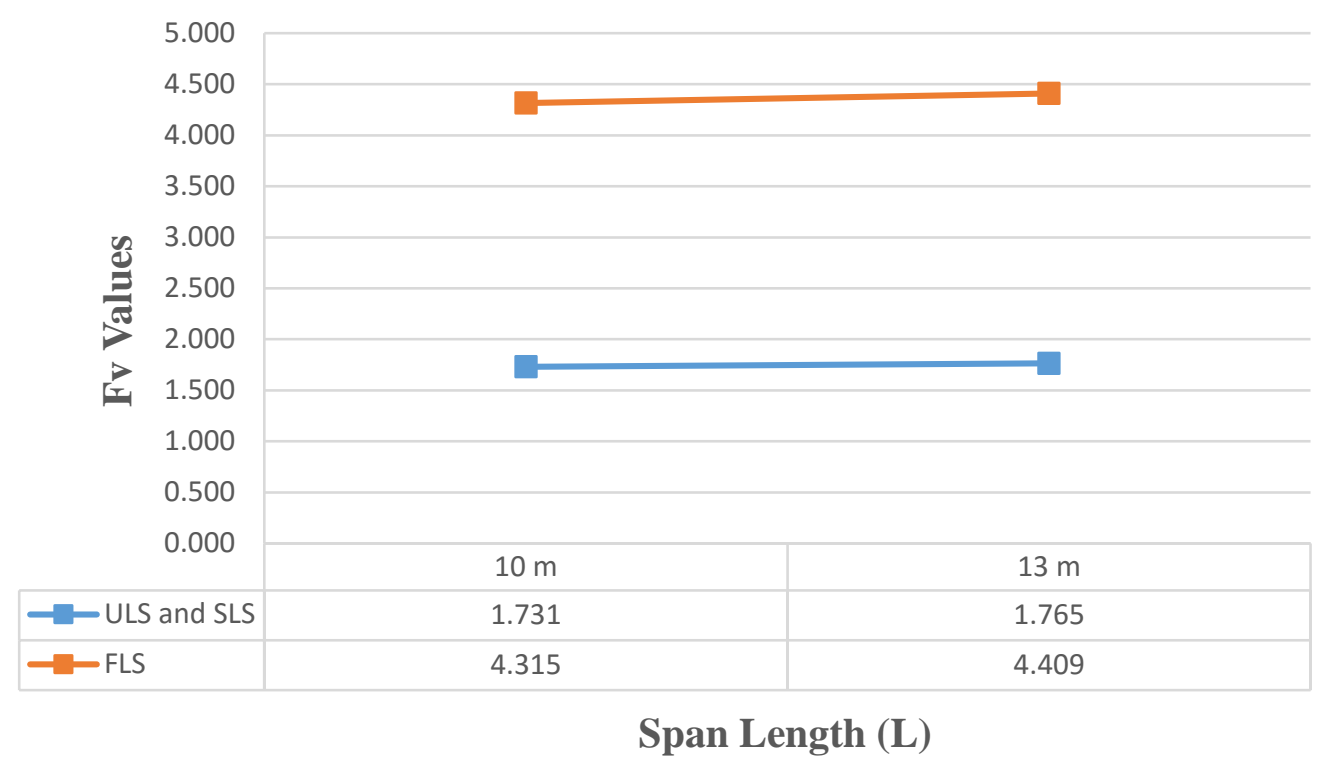

Figure A. 59: Effect of span length on shear distribution factor (three-lane, 11 girders)

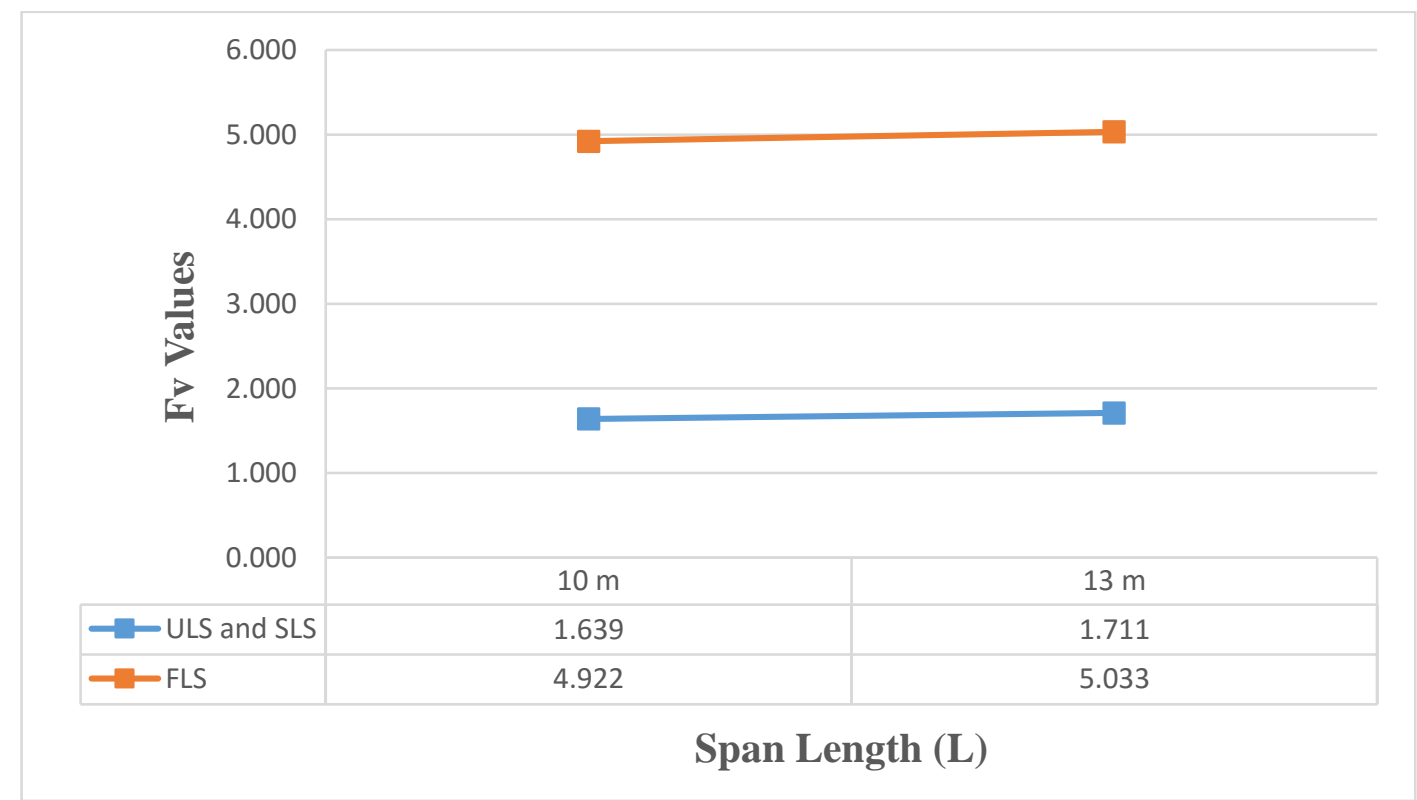

Figure A. 60: Effect of span length on shear distribution factor (four-lane, 12 girders) 


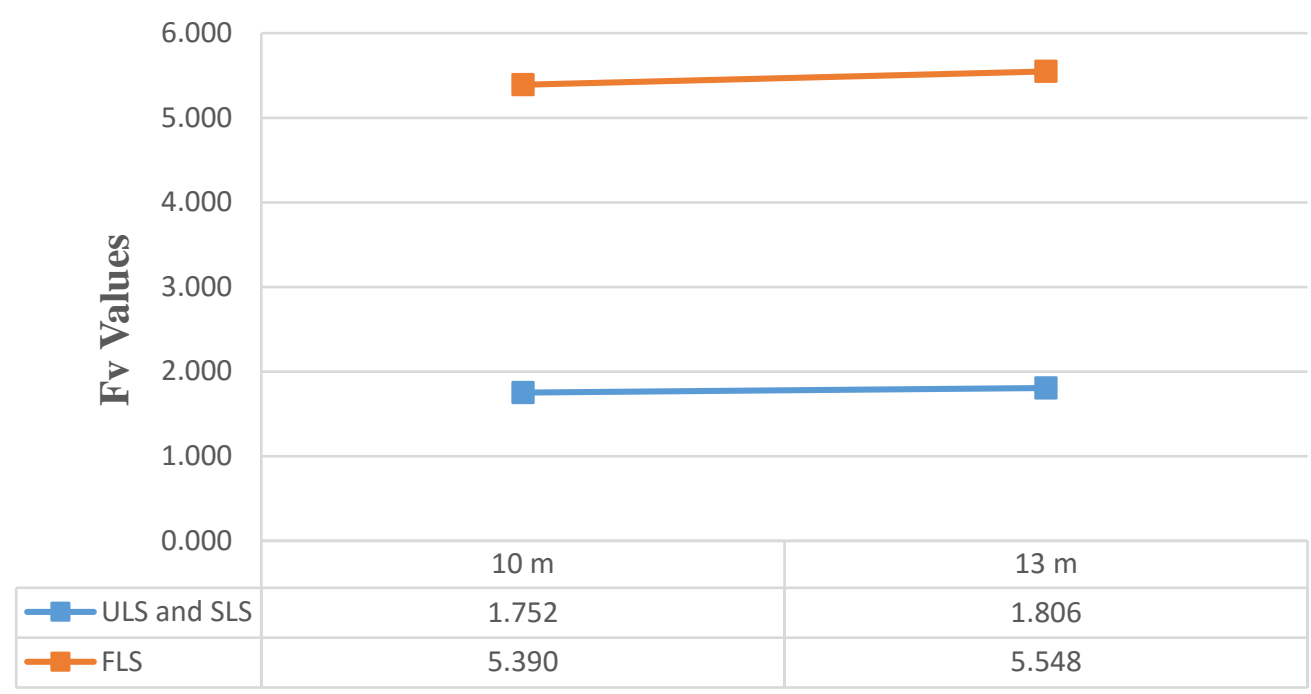

Span Length (L)

Figure A. 61: Effect of span length on shear distribution factor (four-lane, 13 girders)

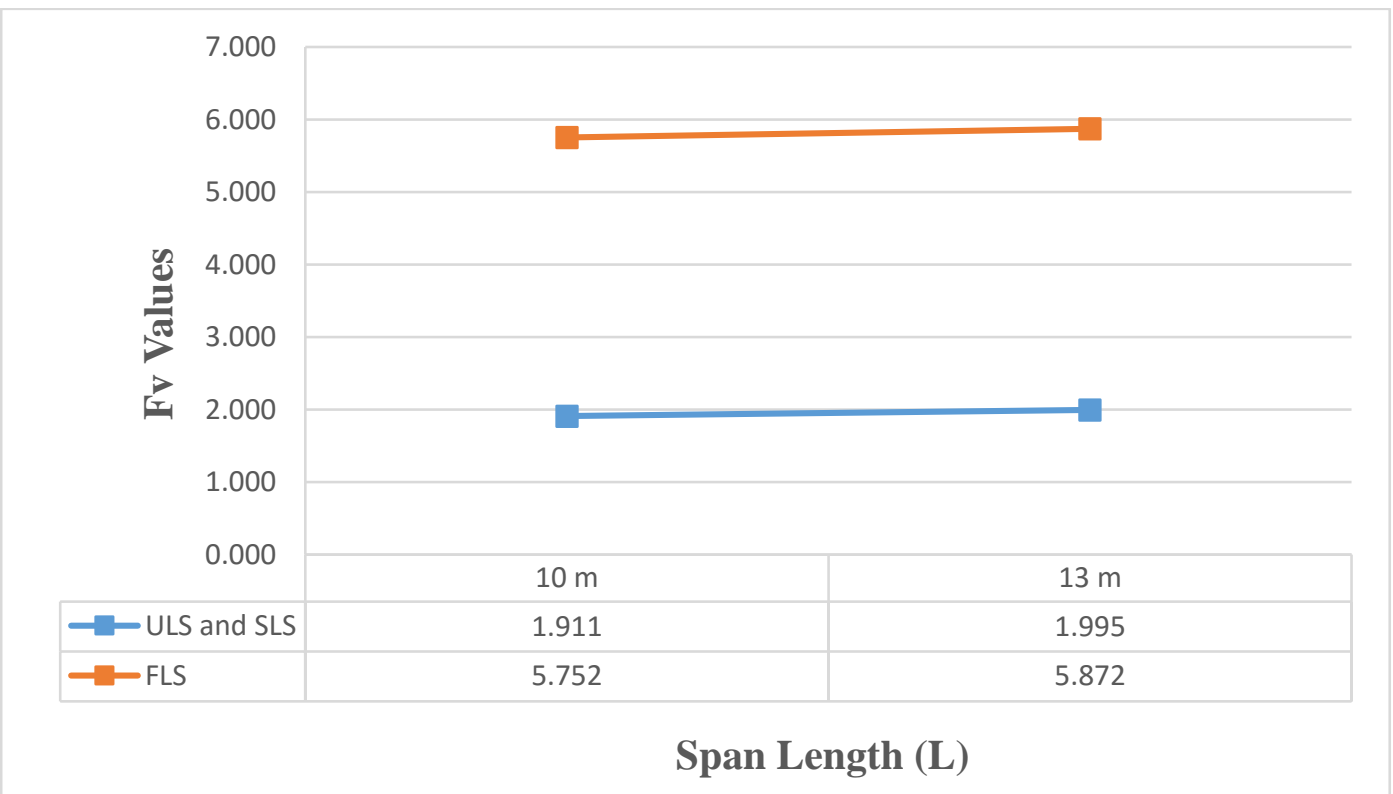

Figure A. 62: Effect of span length on shear distribution factor (four-lane, 14 girders) 


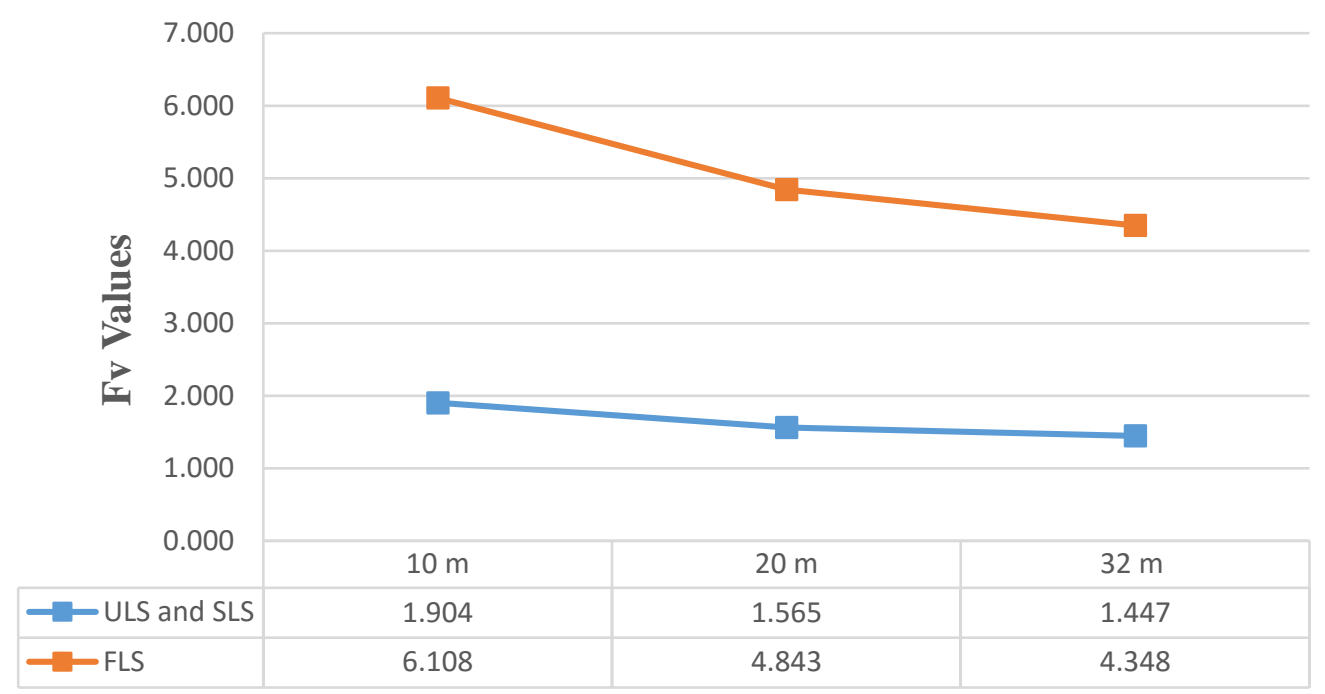

Span Length (L)

Figure A. 63: Effect of span length on shear distribution factor (five-lane, 15 girders)

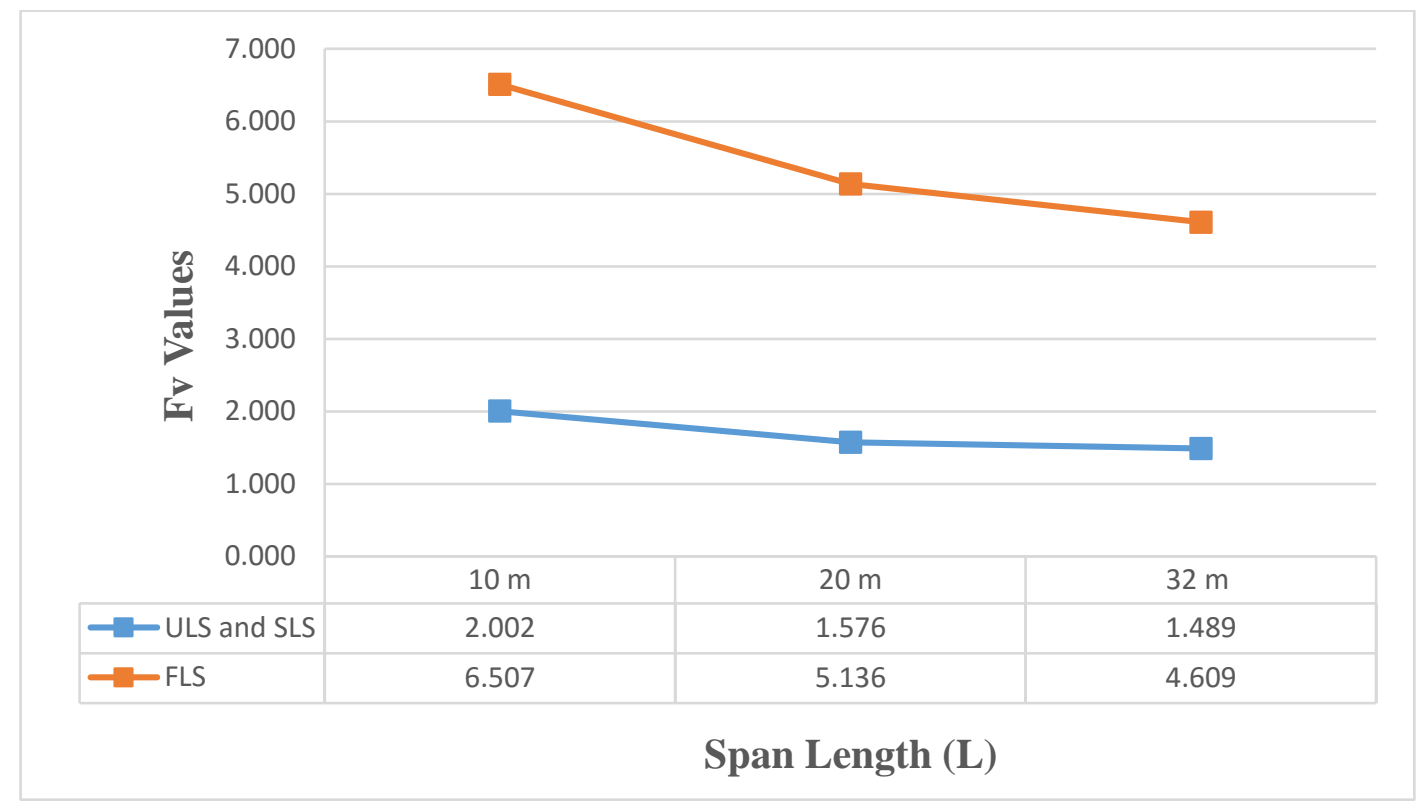

Figure A. 64: Effect of span length on shear distribution factor (five-lane, 16 girders) 


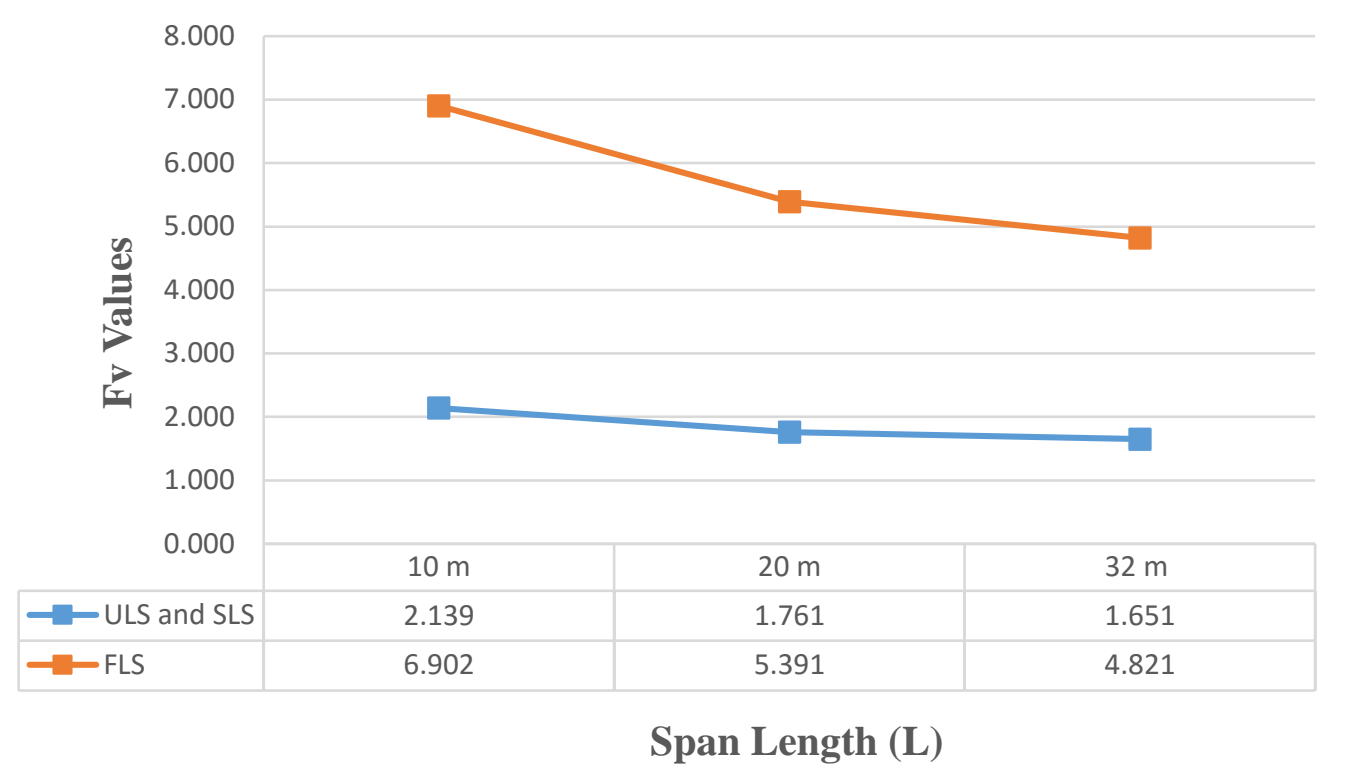

Figure A. 65: Effect of span length on shear distribution factor (five-lane, 17 girders)

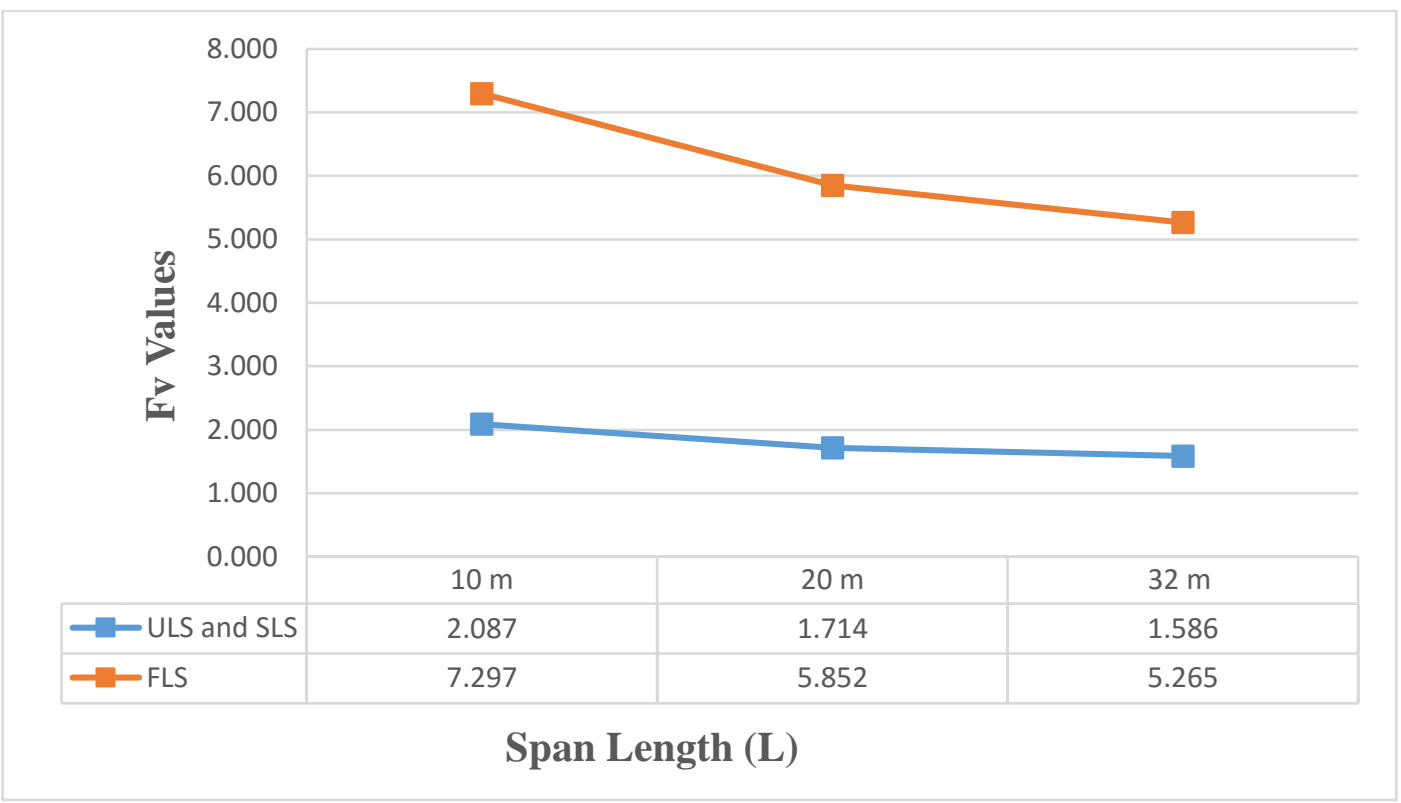

Figure A. 66: Effect of span length on shear distribution factor (six-lane, 18 girders) 


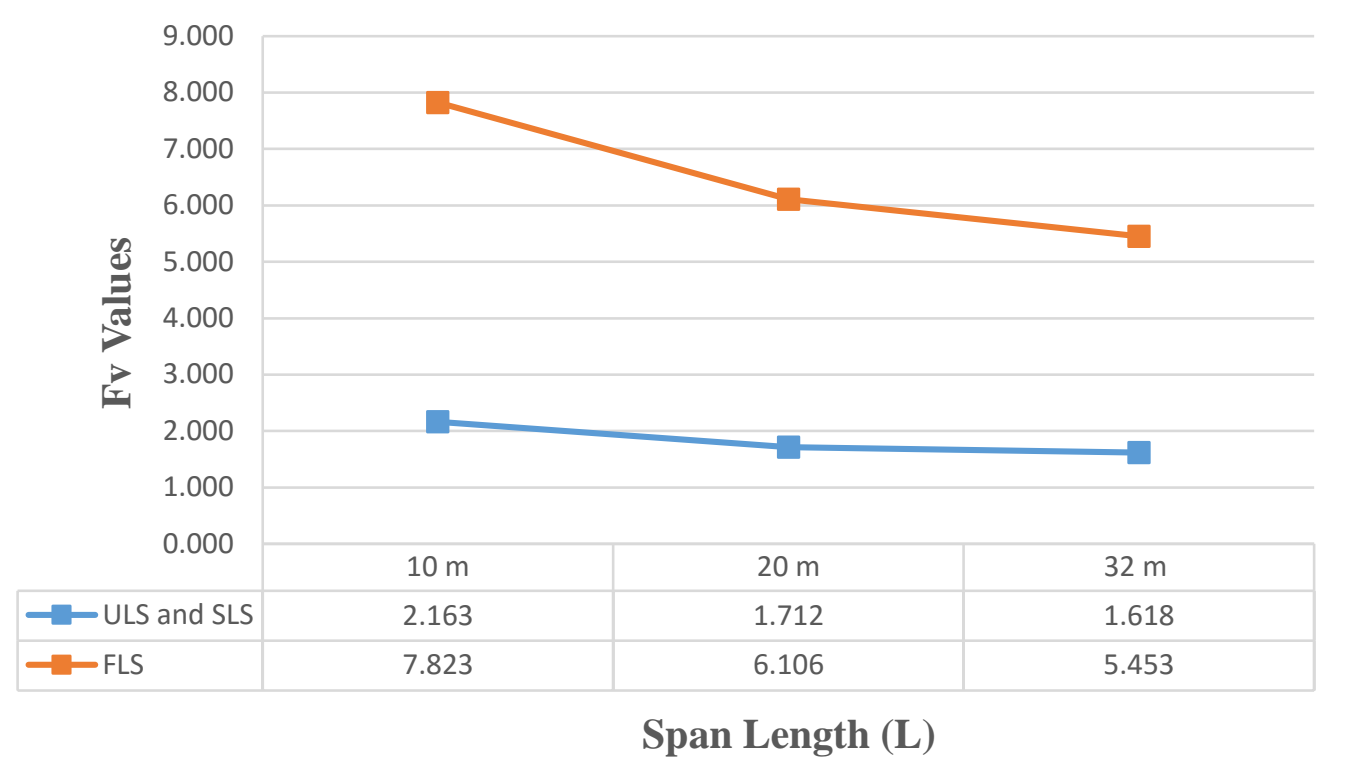

Figure A. 67: Effect of span length on shear distribution factor (six-lane, 19 girders)

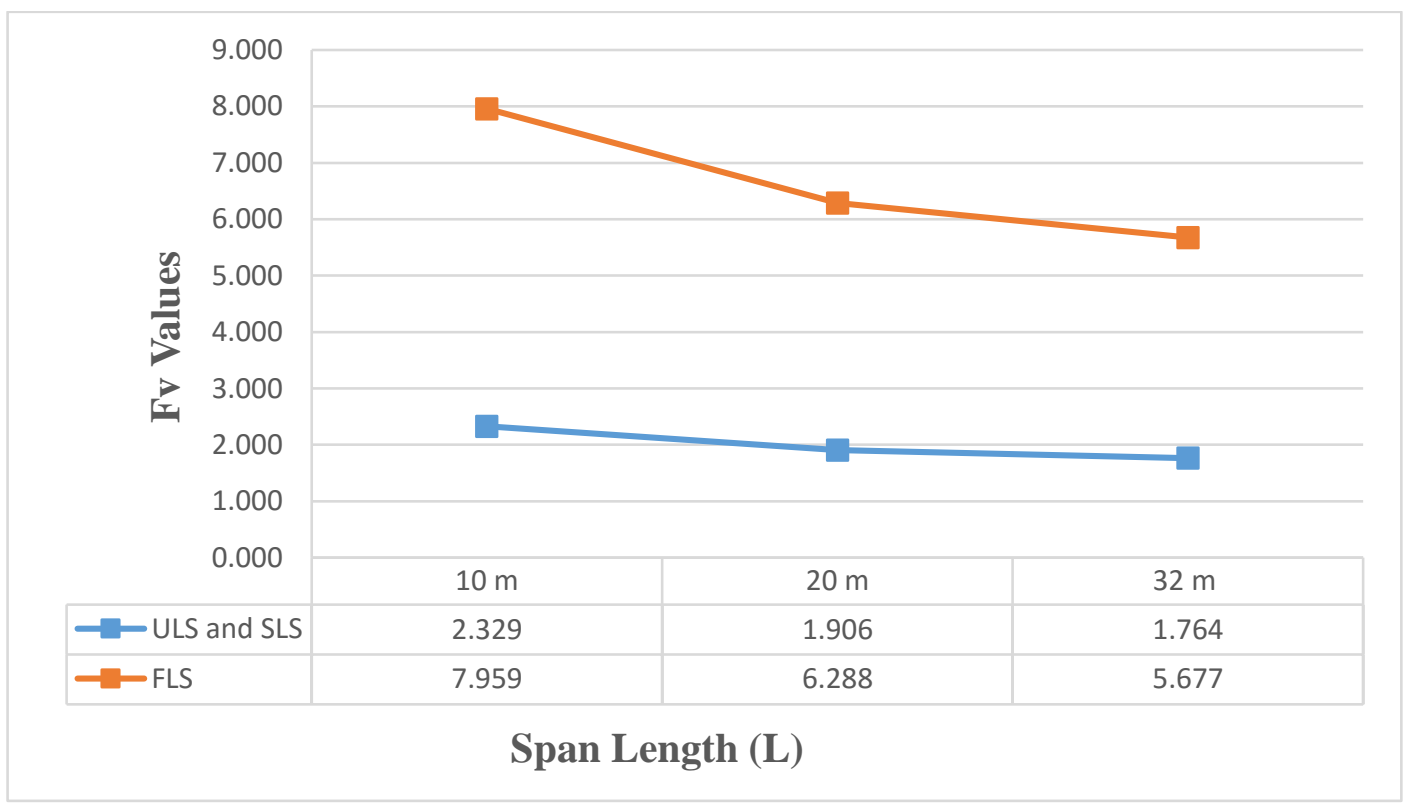

Figure A. 68: Effect of span length on shear distribution factor (six-lane, 20 girders) 


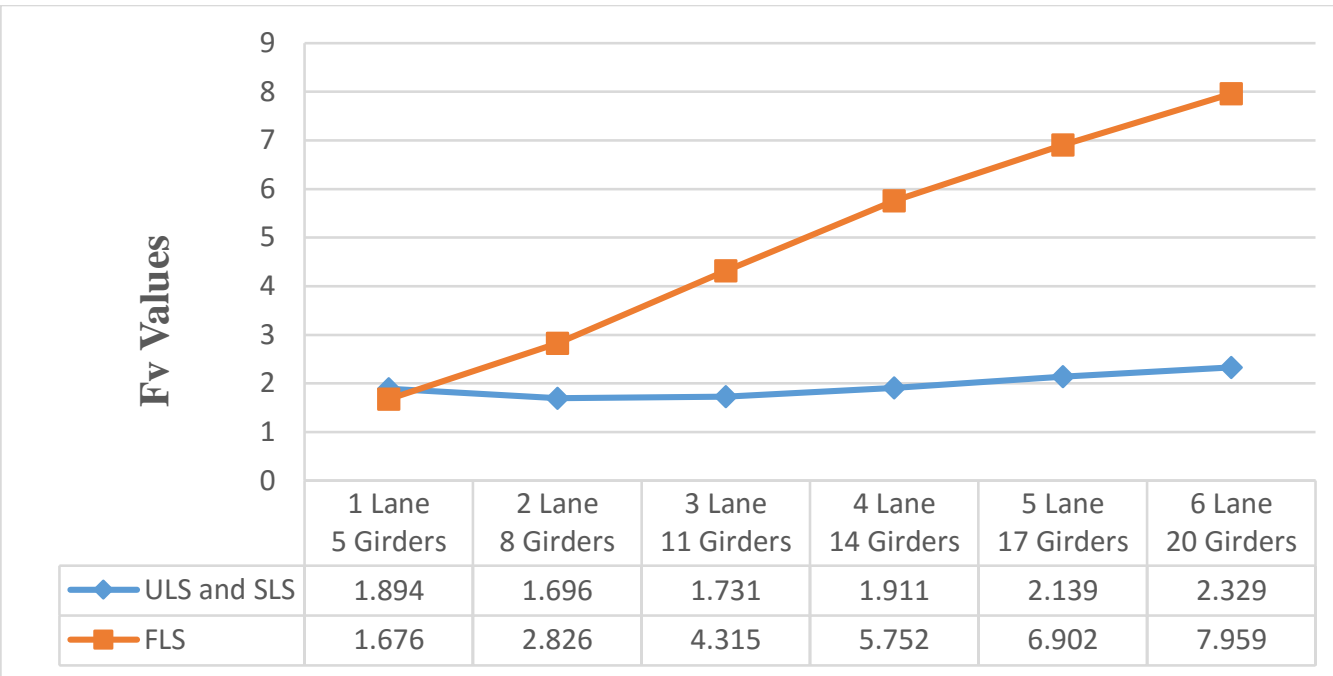

No. of Lanes (n)

Figure A. 69: Effect of number of lanes on shear distribution factor (B700, 10m span)

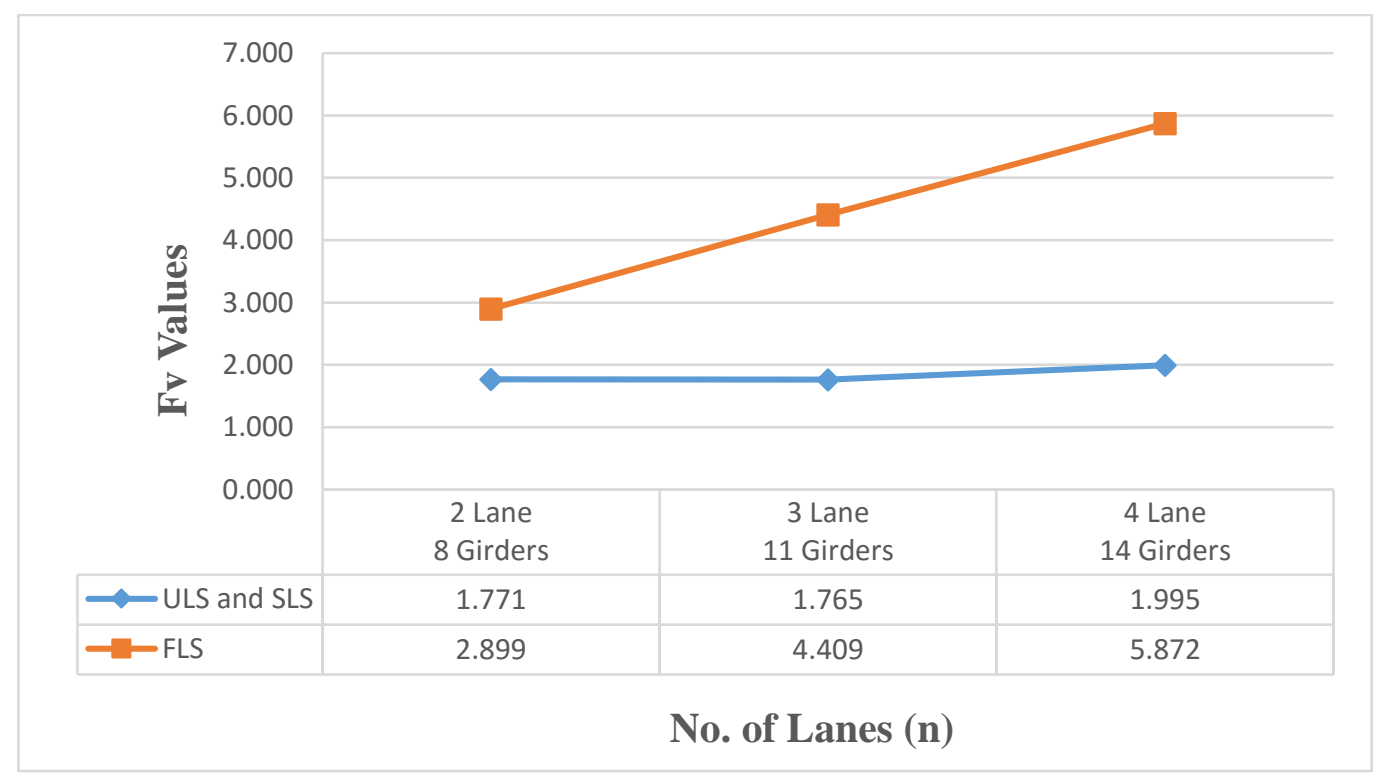

Figure A. 70: Effect of number of lanes on shear distribution factor (B700, 13m span) 


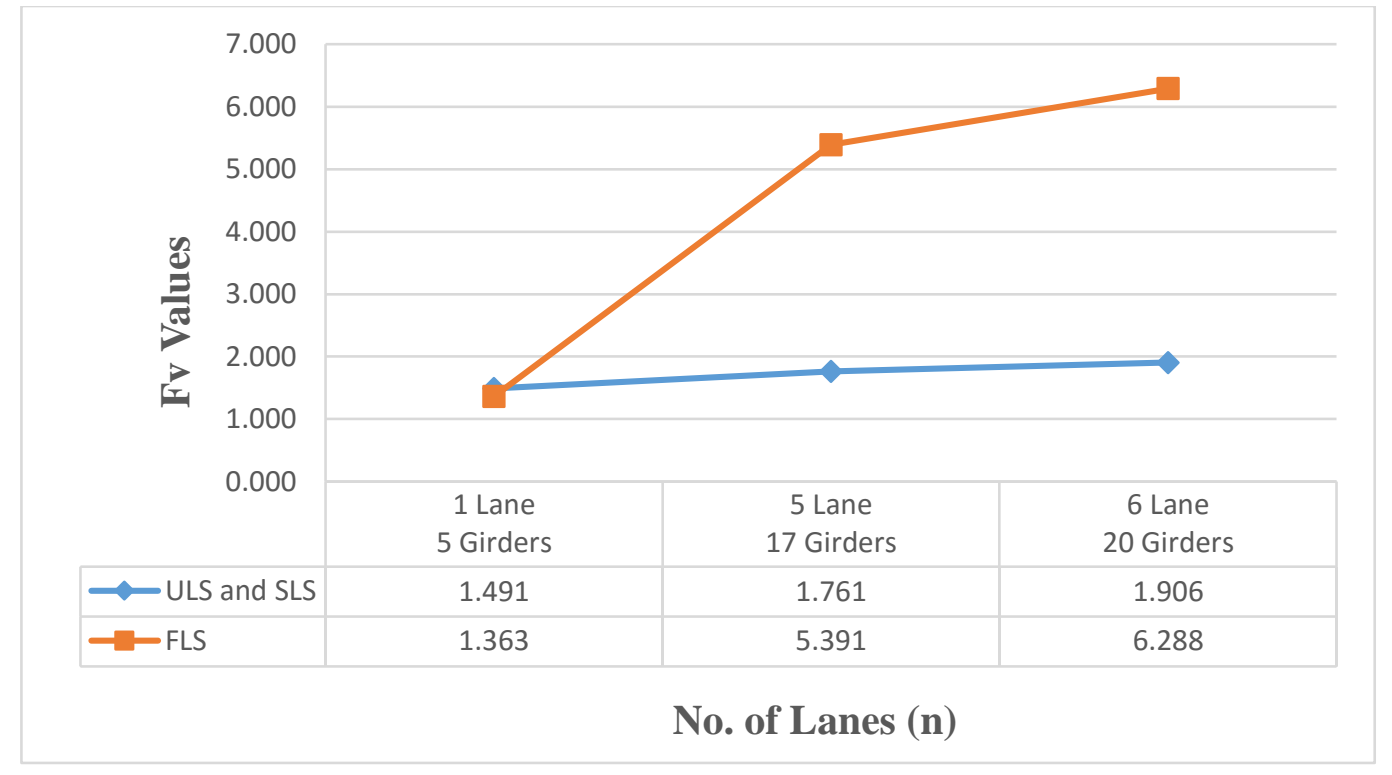

Figure A. 71: Effect of number of lanes on shear distribution factor (B800, 20m span)

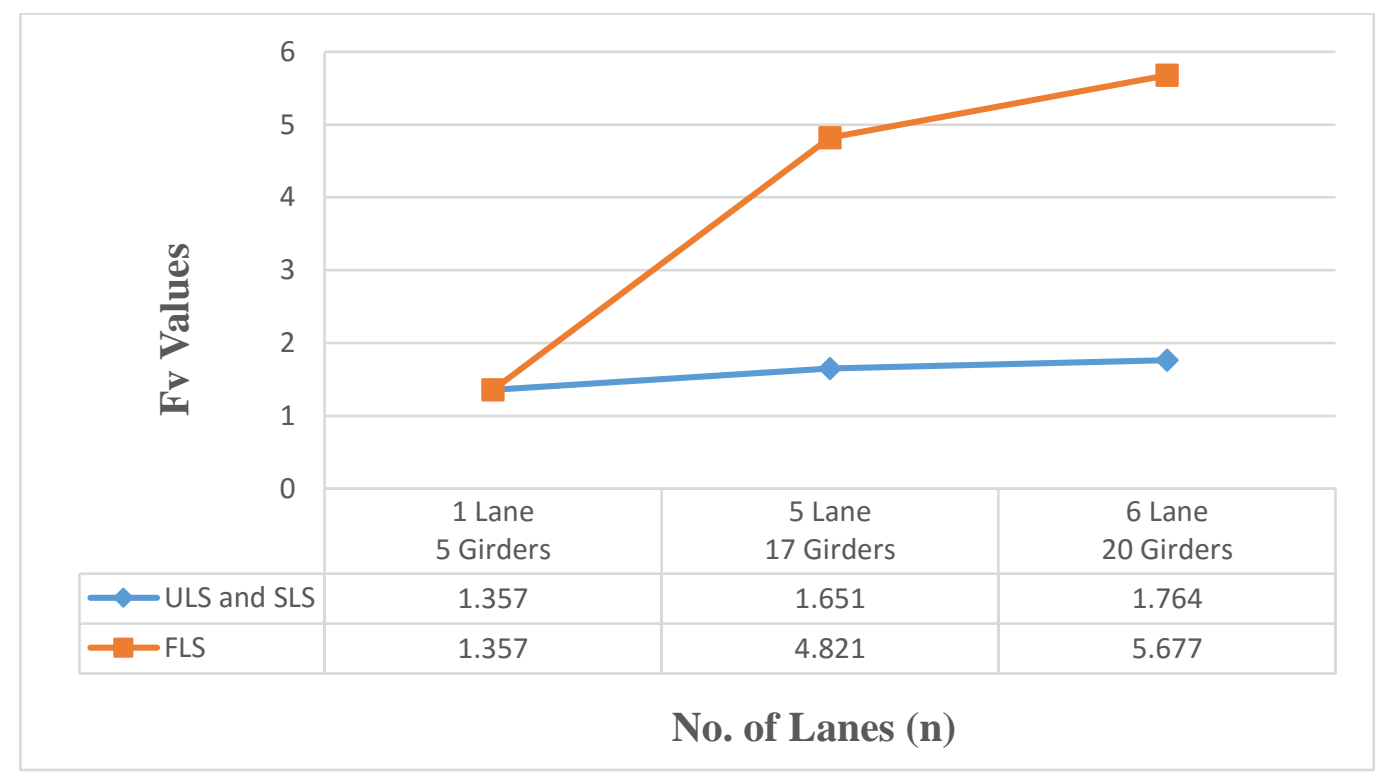

Figure A. 72: Effect of number of lanes on shear distribution factor (B1000, 32m span) 


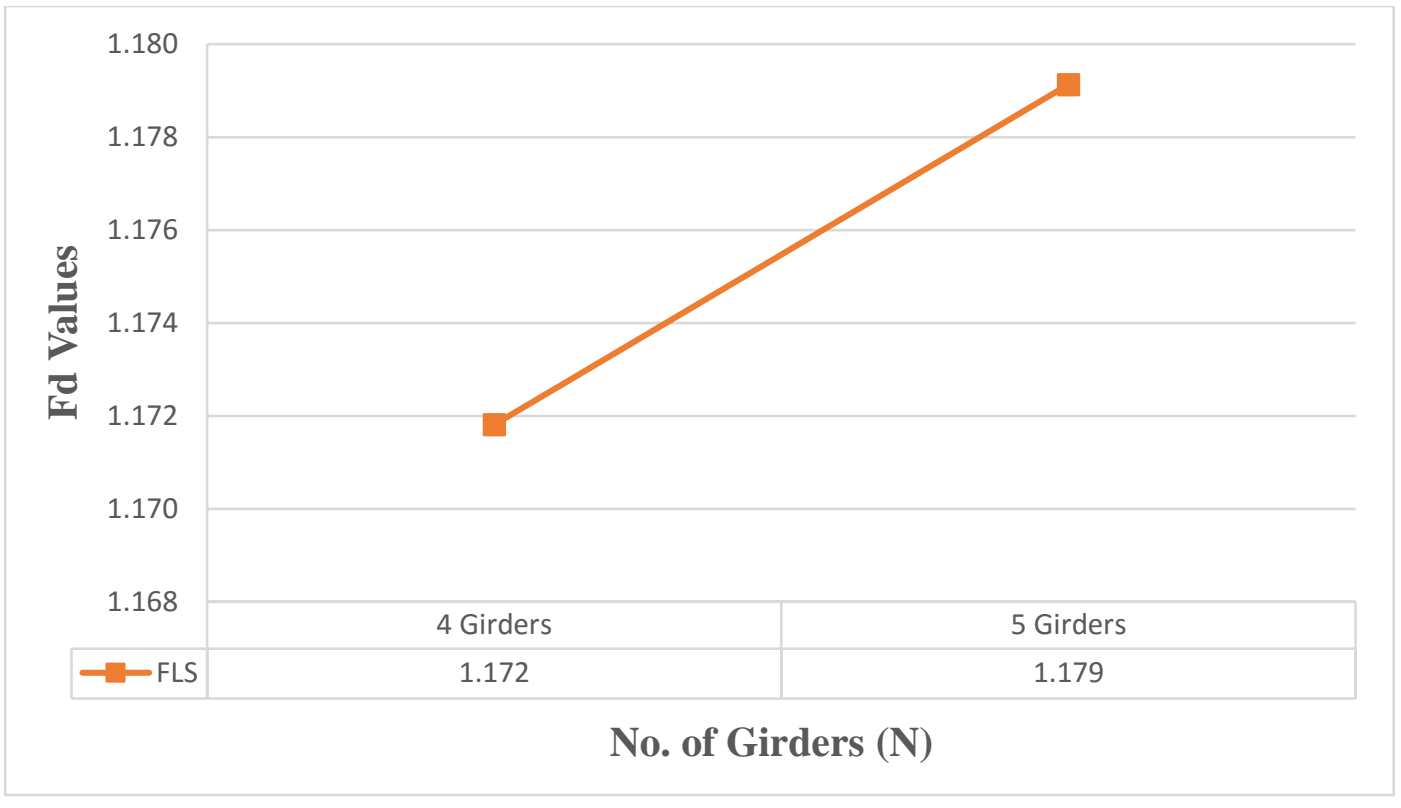

Figure A. 73: Effect of number of girders on deflection distribution factor (B700, one-lane, 10m span)

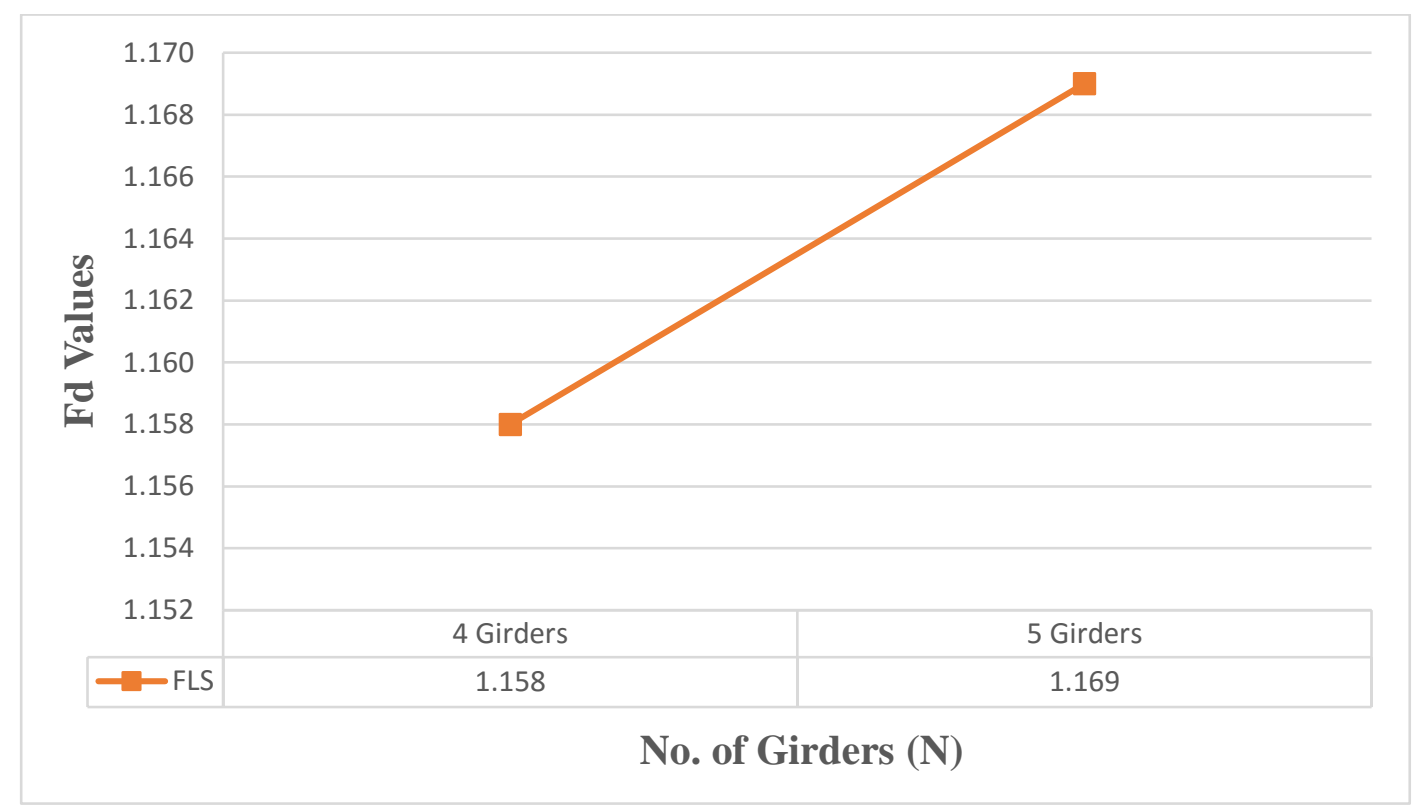

Figure A. 74: Effect of number of girders on deflection distribution factor (B800, one-lane, 20m span) 


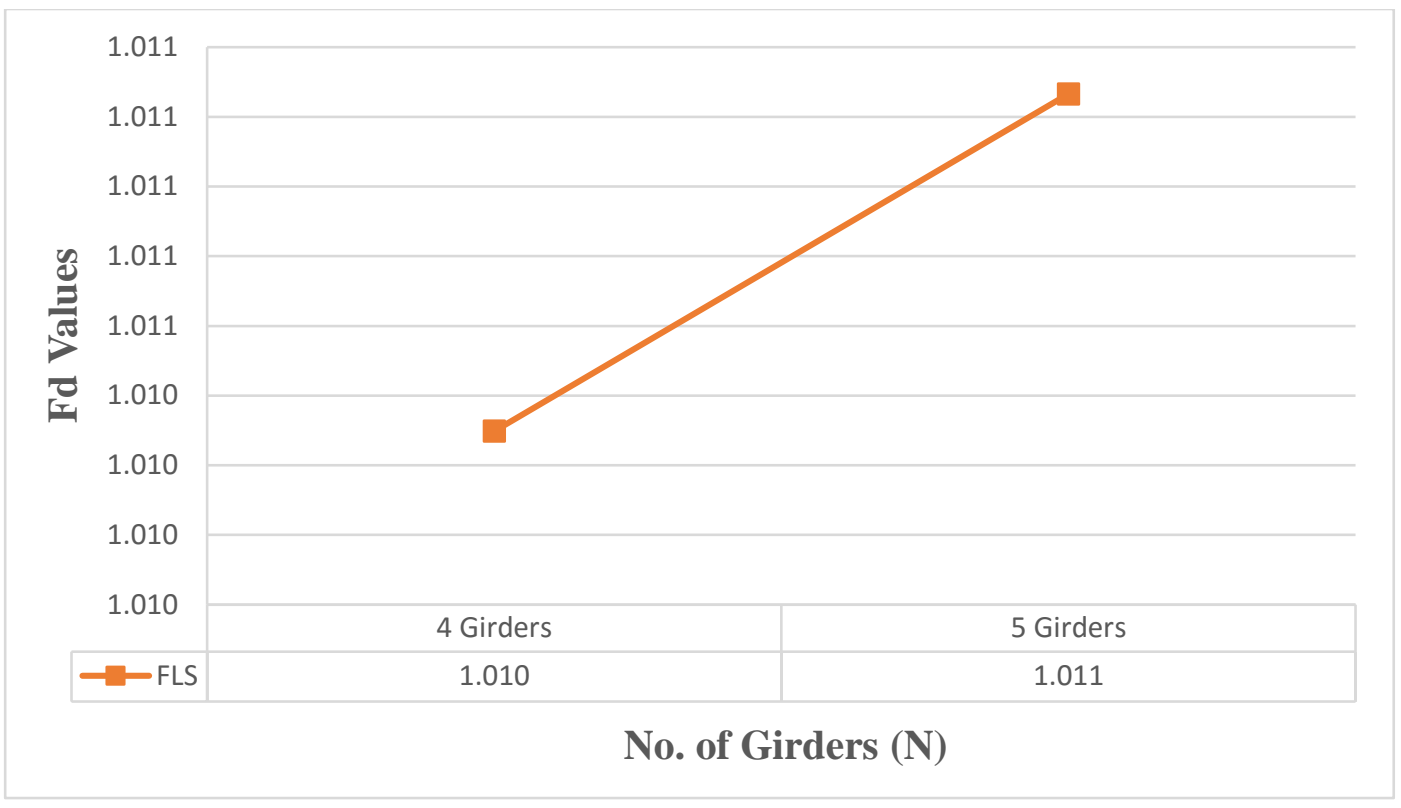

Figure A. 75: Effect of number of girders on deflection distribution factor (B1000, one-lane, 32m span)

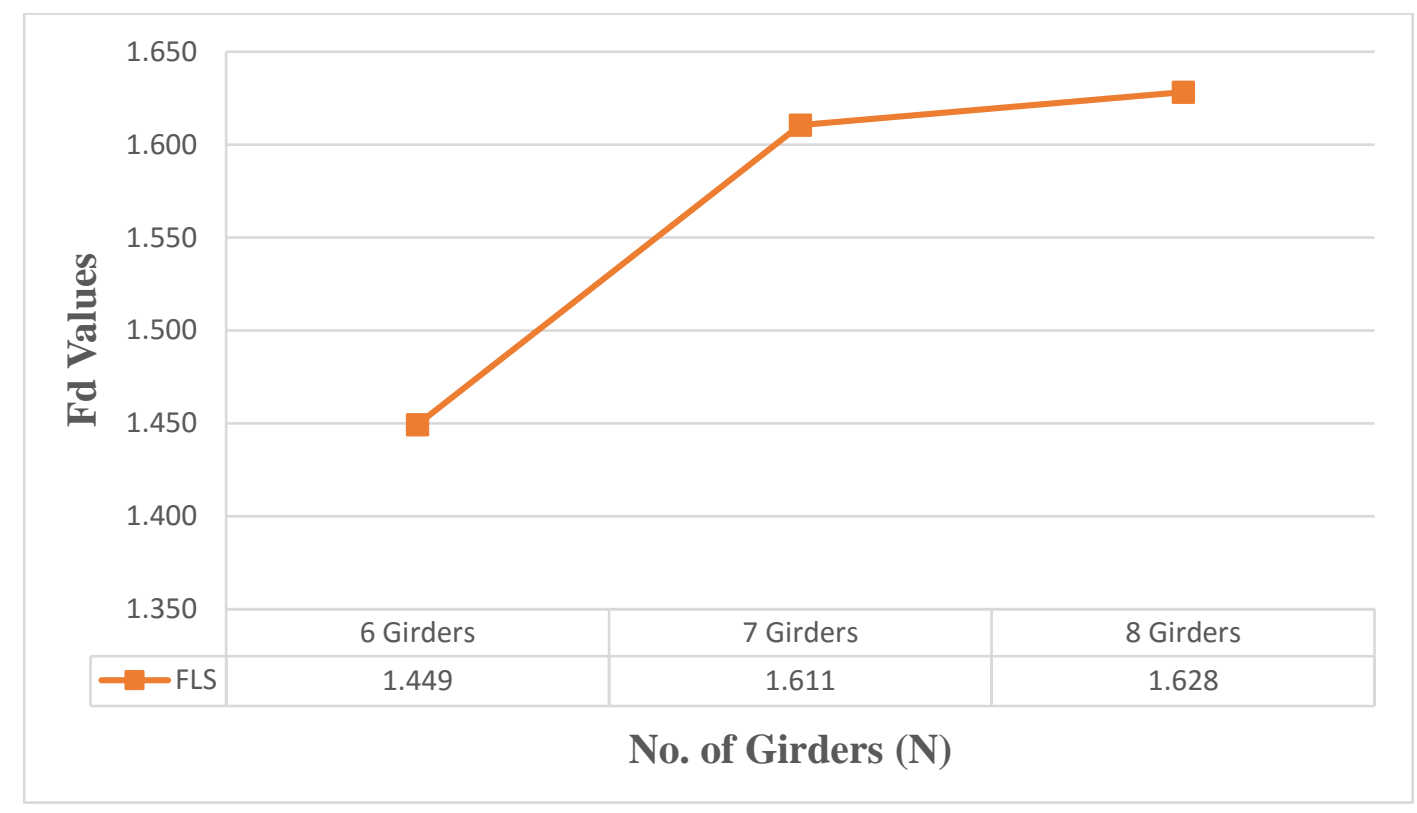

Figure A. 76: Effect of number of girders on deflection distribution factor (B700, two-lane, 10m span) 


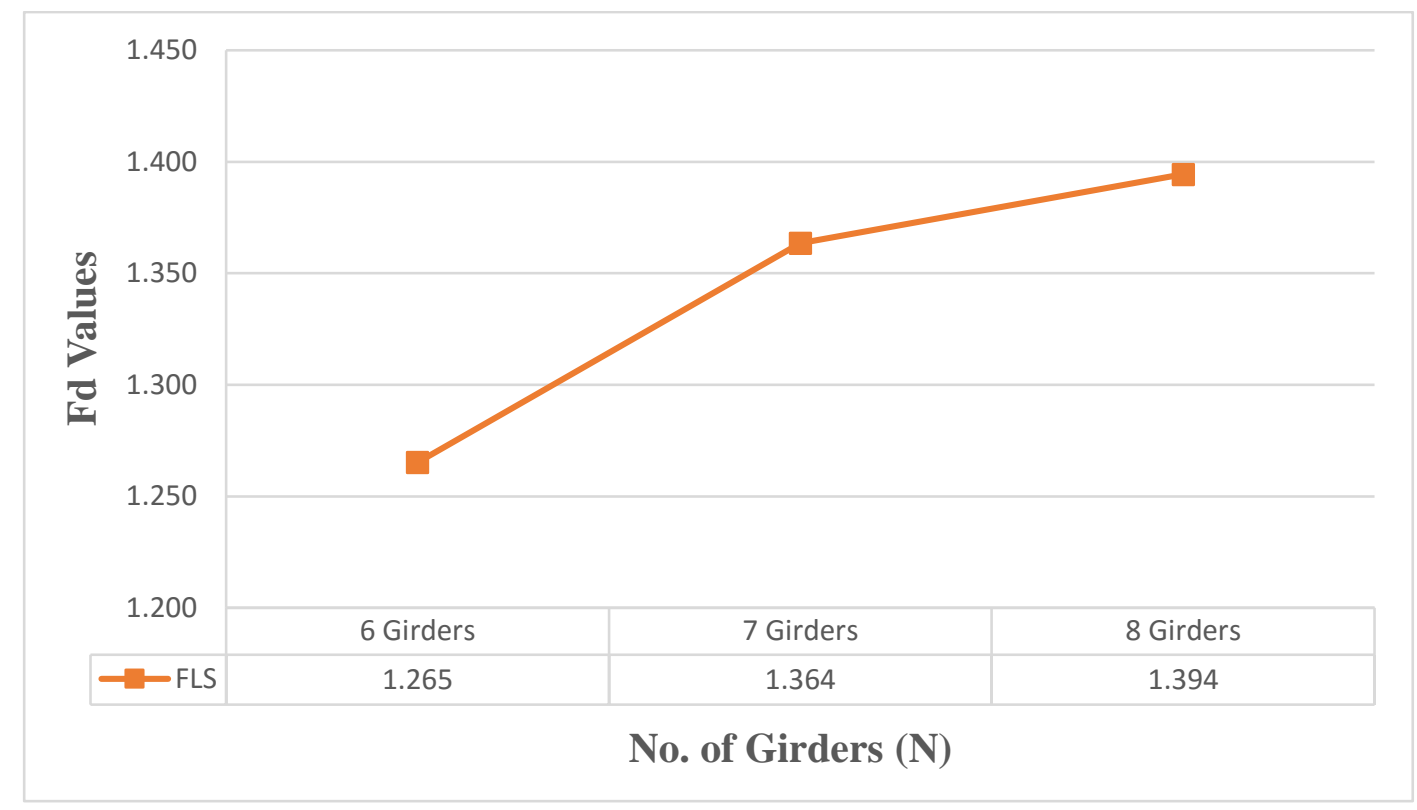

Figure A. 77: Effect of number of girders on deflection distribution factor (B700, two-lane, 13m span)

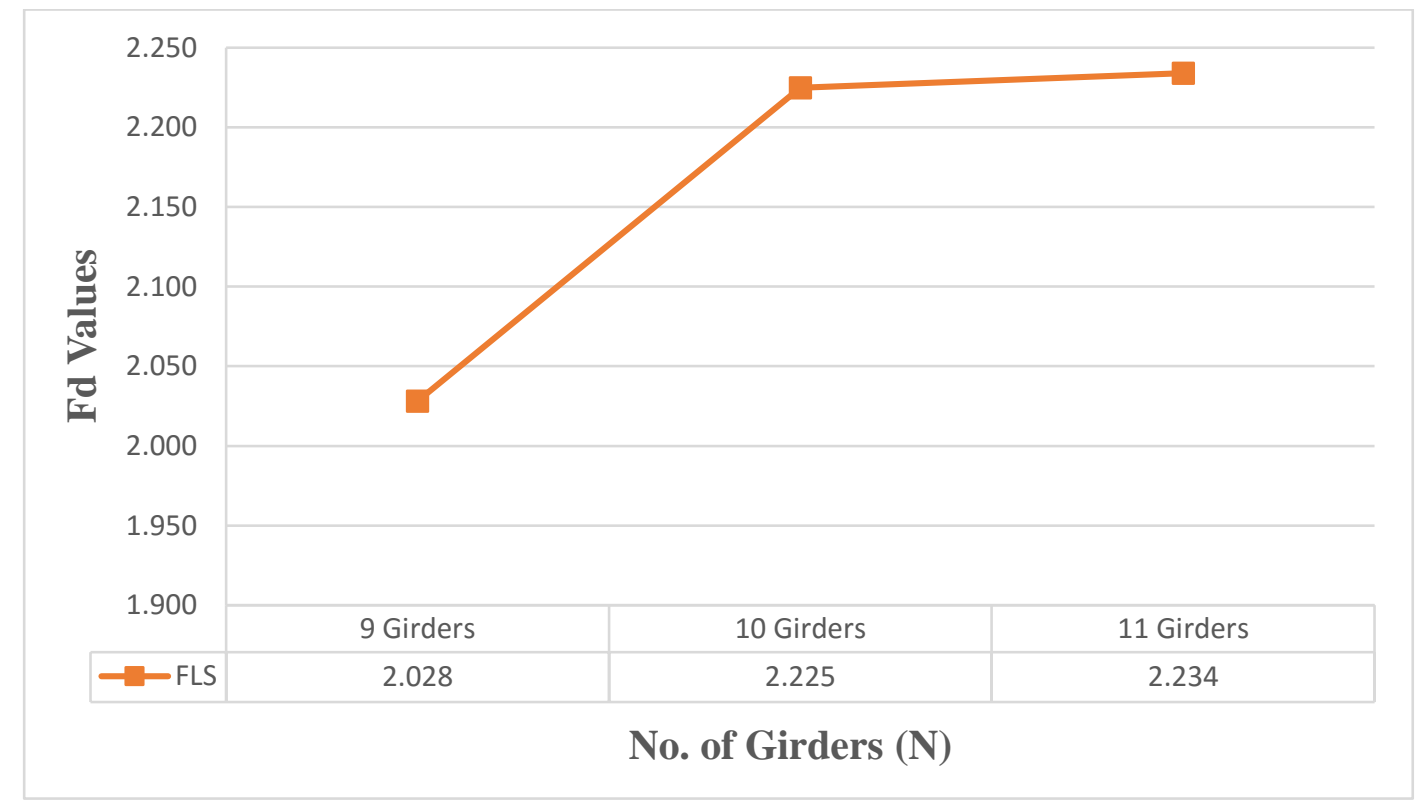

Figure A. 78: Effect of number of girders on deflection distribution factor $(B 700$, threelane, 10m span) 


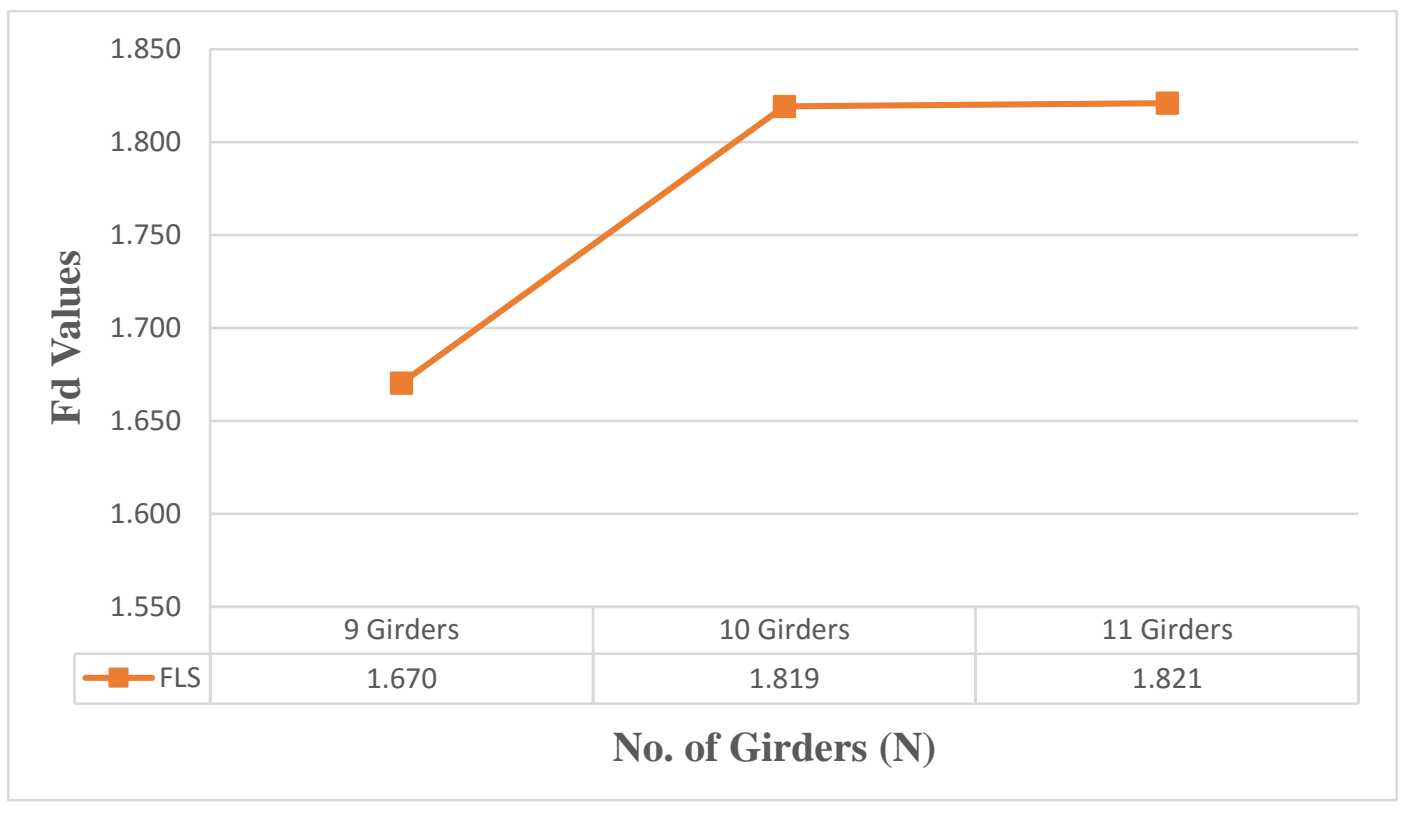

Figure A. 79: Effect of number of girders on deflection distribution factor (B700, threelane, 13m span)

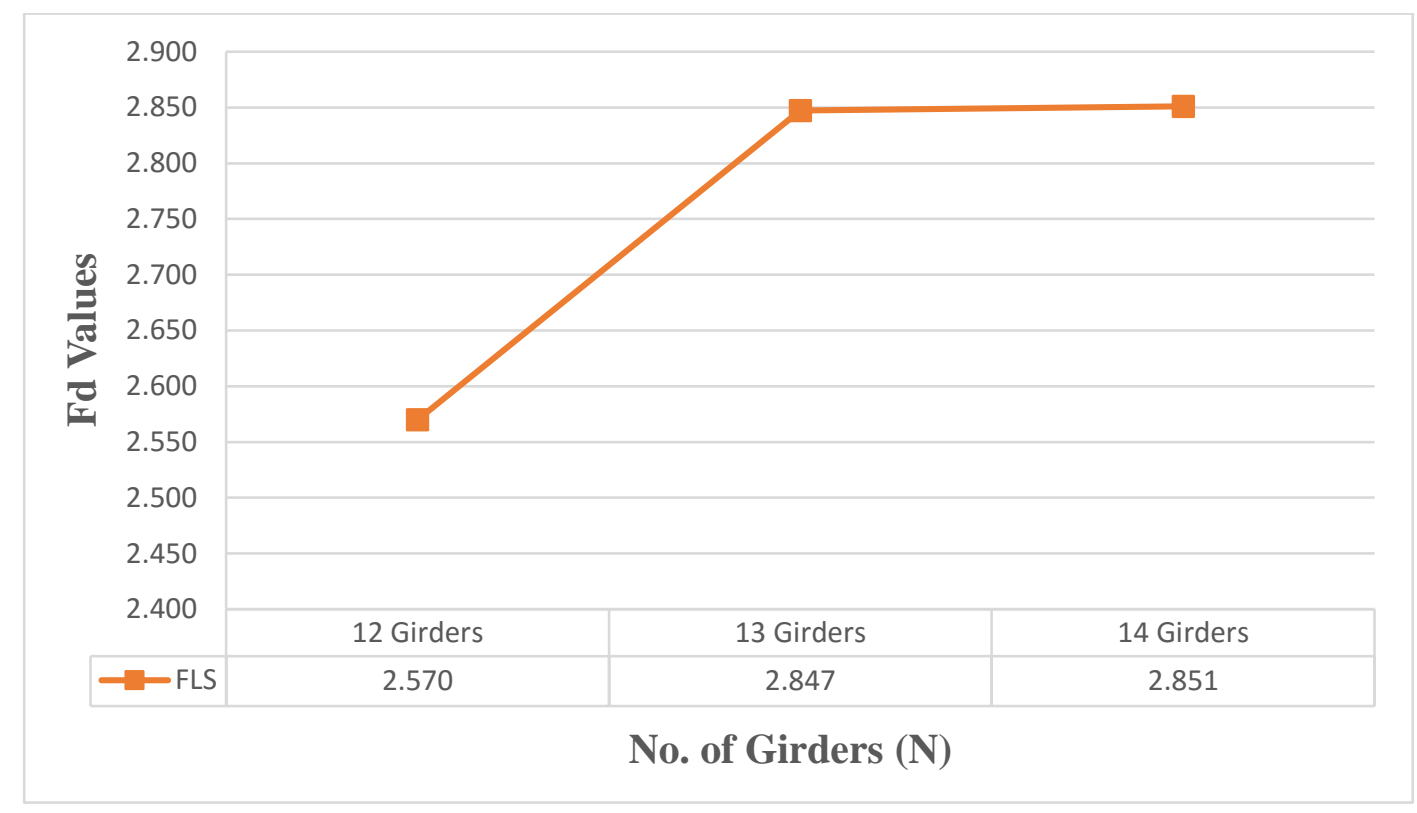

Figure A. 80: Effect of number of girders on deflection distribution factor (B700, four-lane, 10m span) 


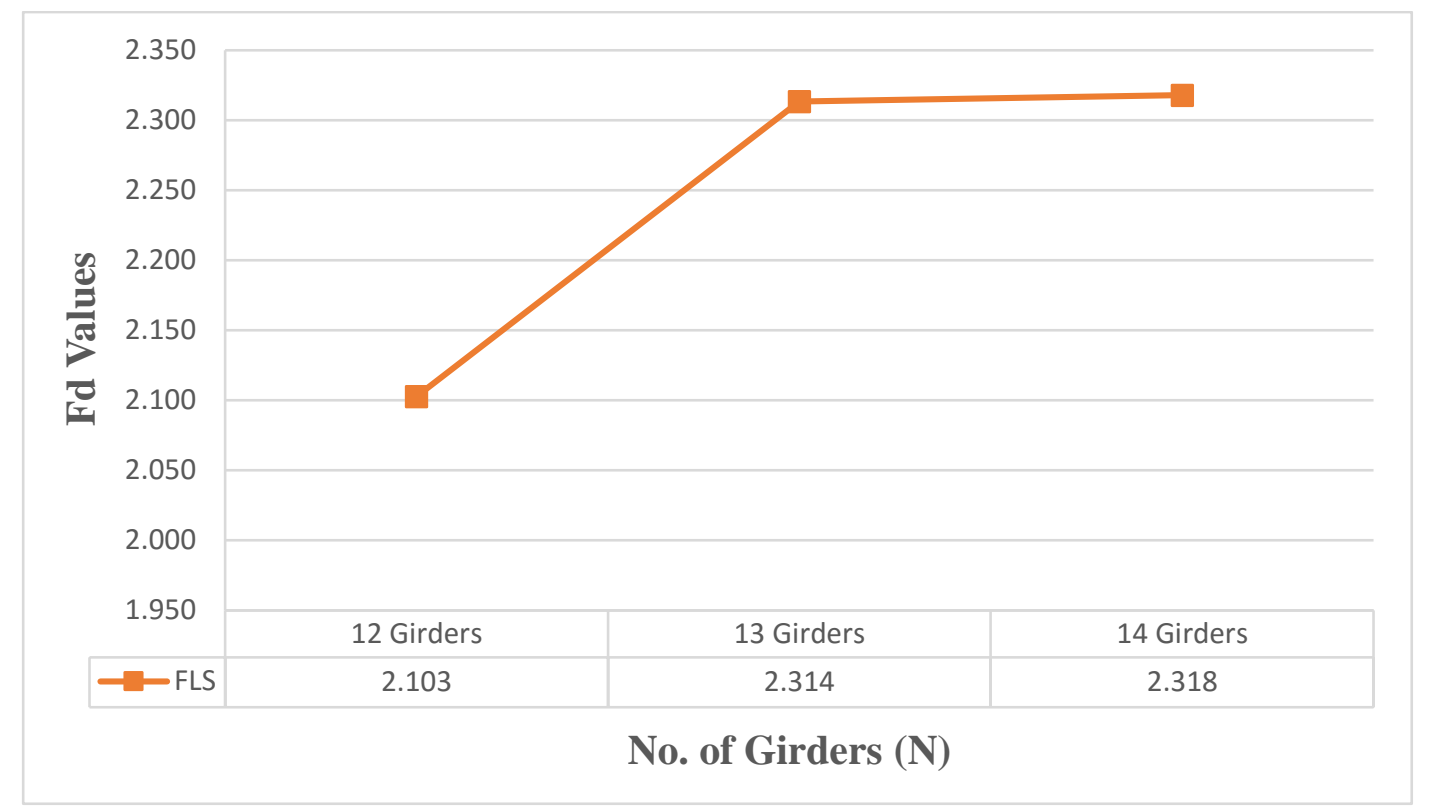

Figure A. 81: Effect of number of girders on deflection distribution factor (B700, four-lane, 13m span)

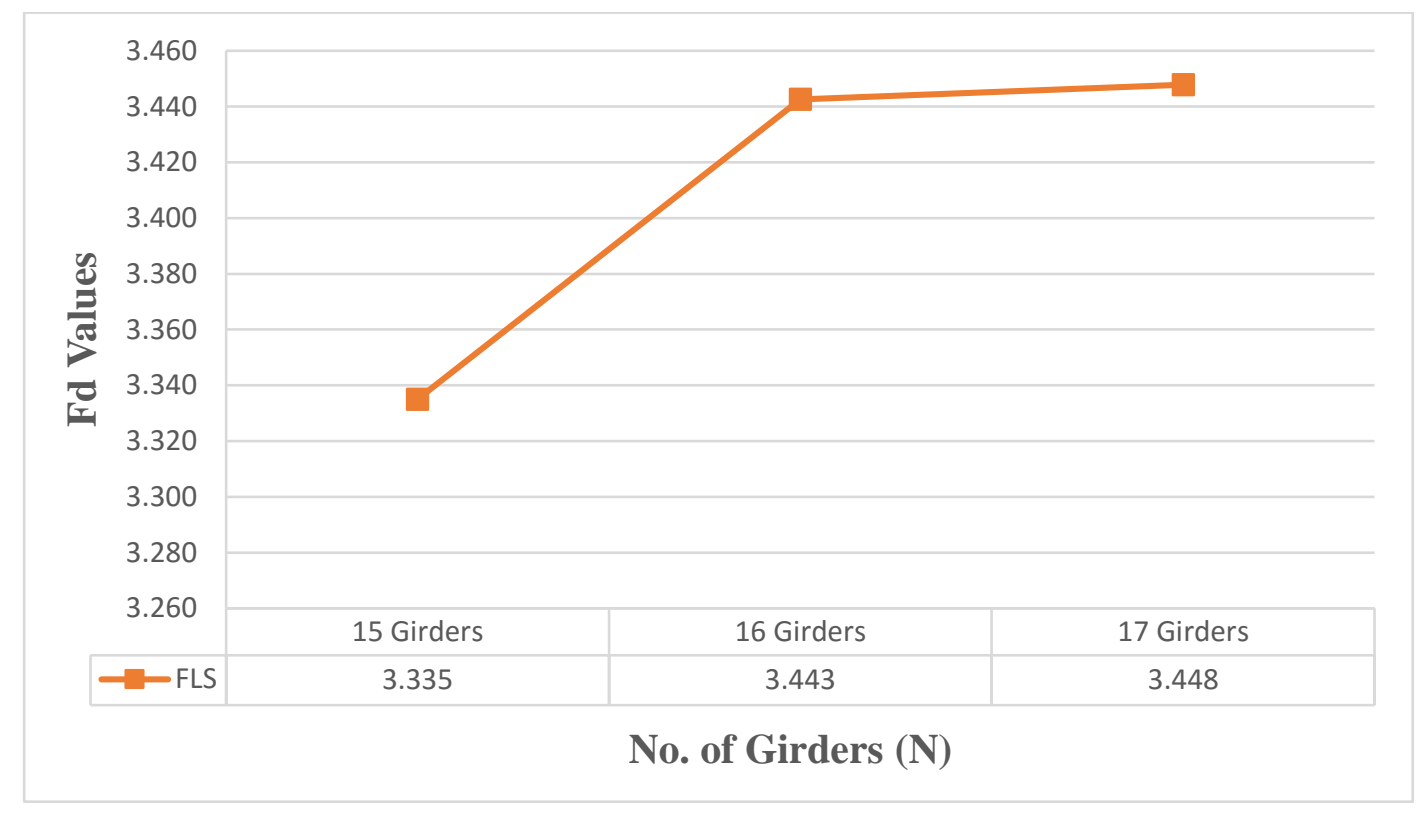

Figure A. 82: Effect of number of girders on deflection distribution factor (B700, five-lane, 10m span) 


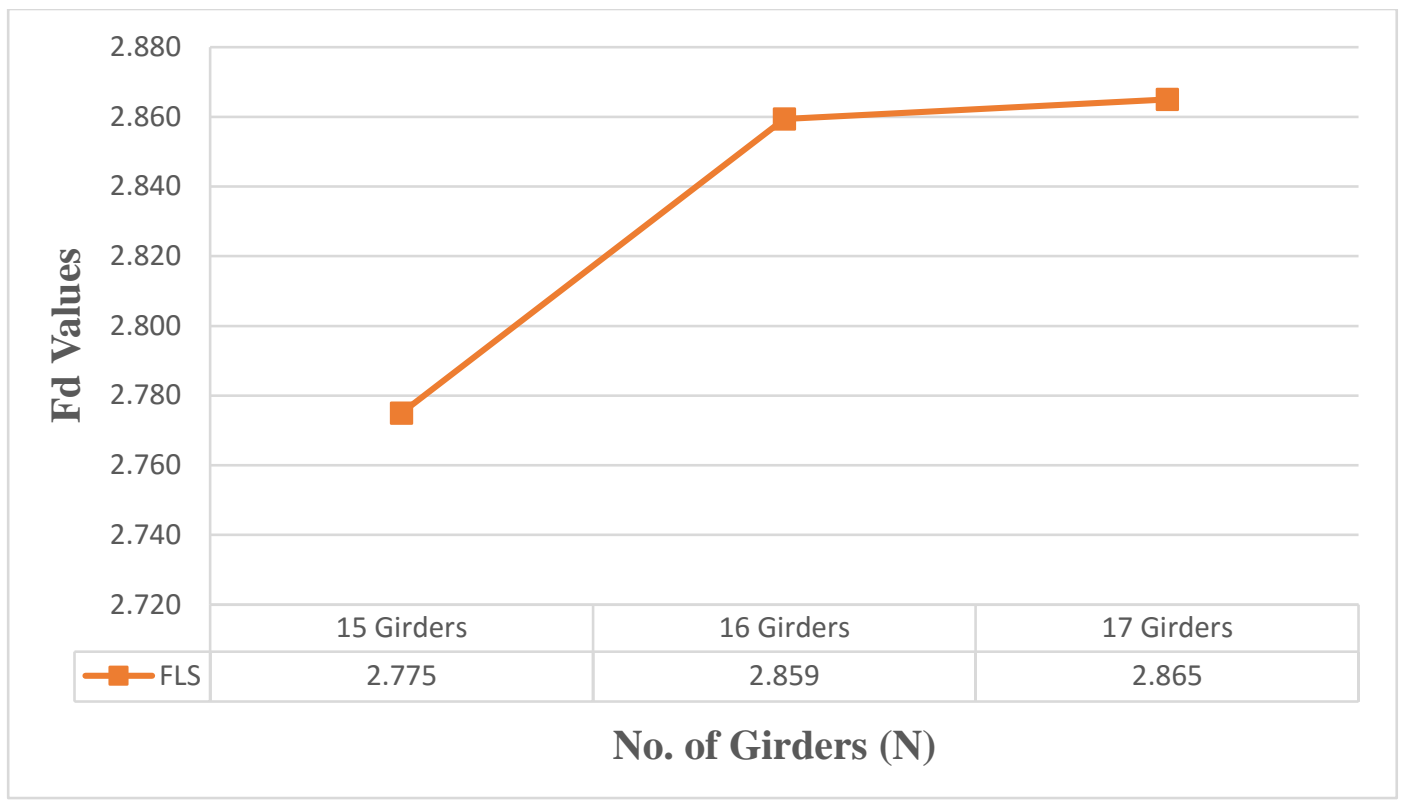

Figure A. 83: Effect of number of girders on deflection distribution factor (B800, five-lane, 20m span)

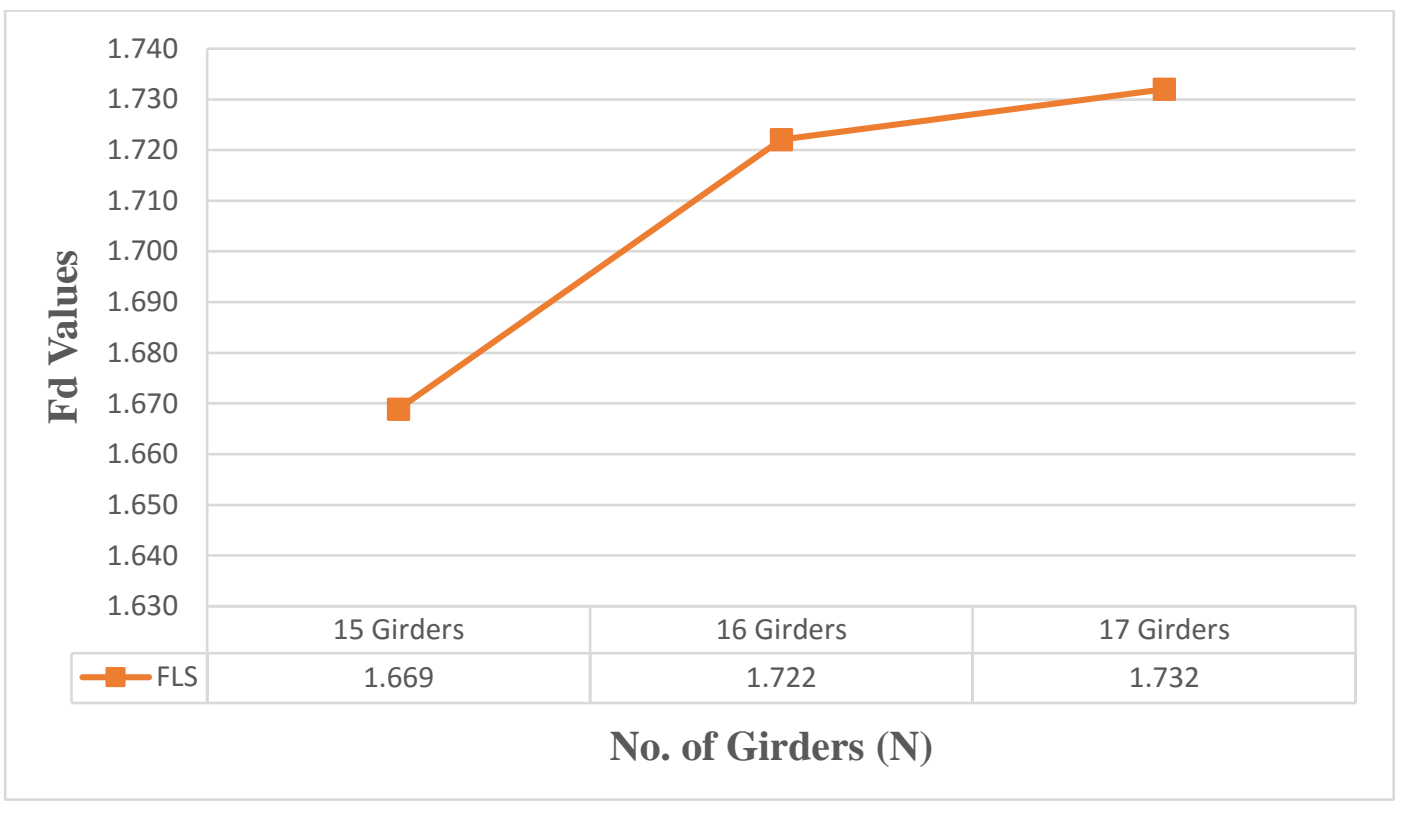

Figure A. 84: Effect of number of girders on deflection distribution factor (B1000, fivelane, 32m span) 


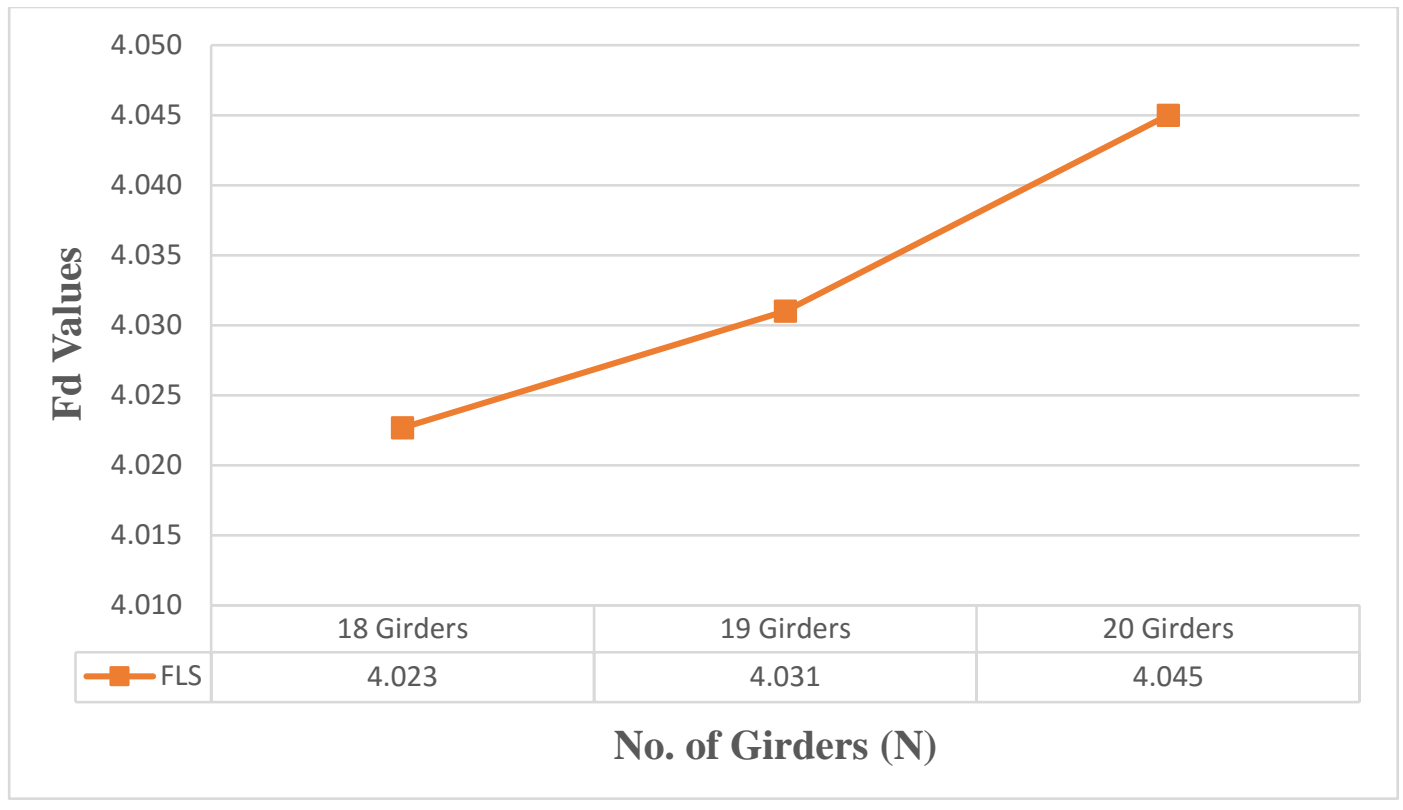

Figure A. 85: Effect of number of girders on deflection distribution factor (B700, six-lane, 10m span)

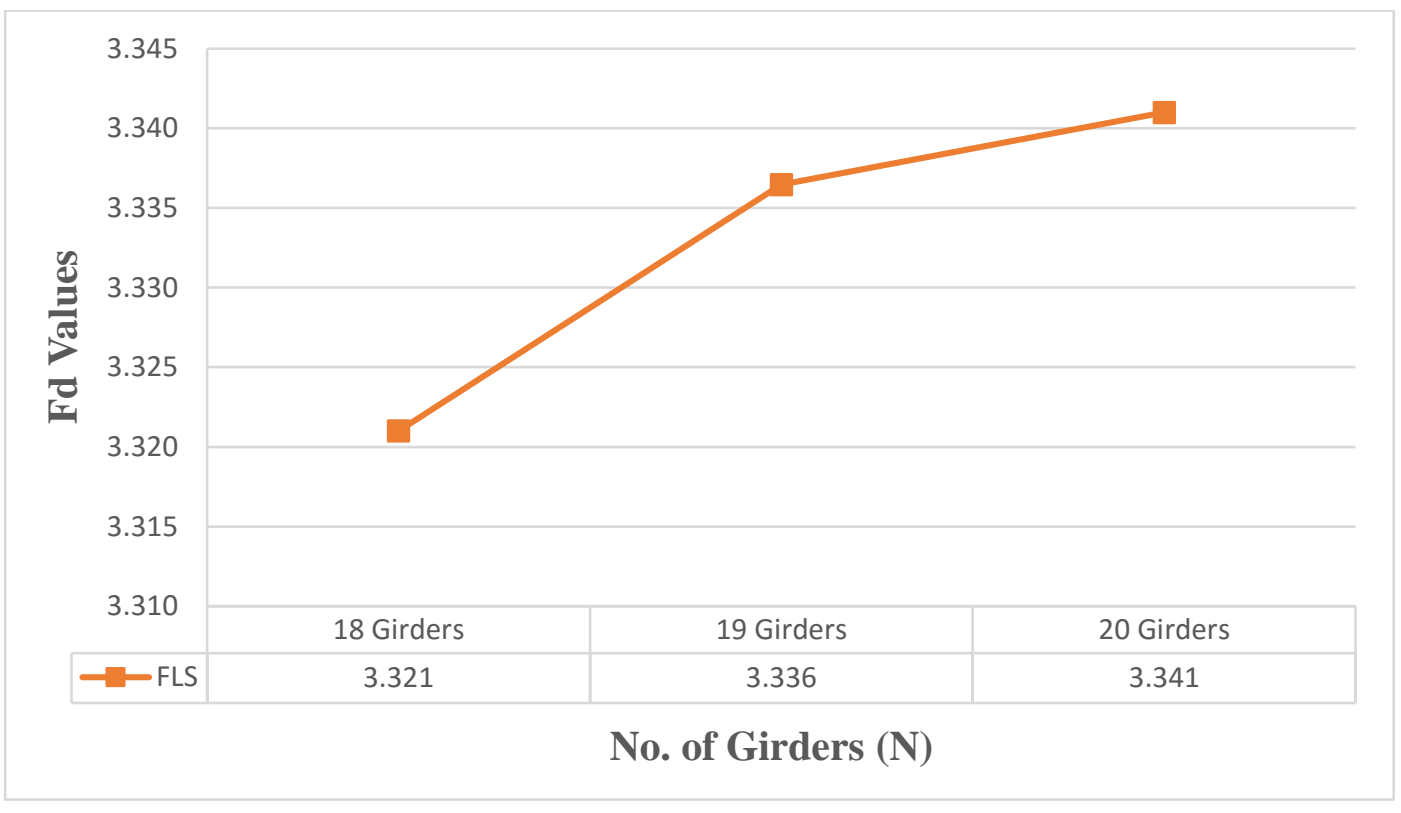

Figure A. 86: Effect of number of girders on deflection distribution factor (B800, six-lane, 20m span) 


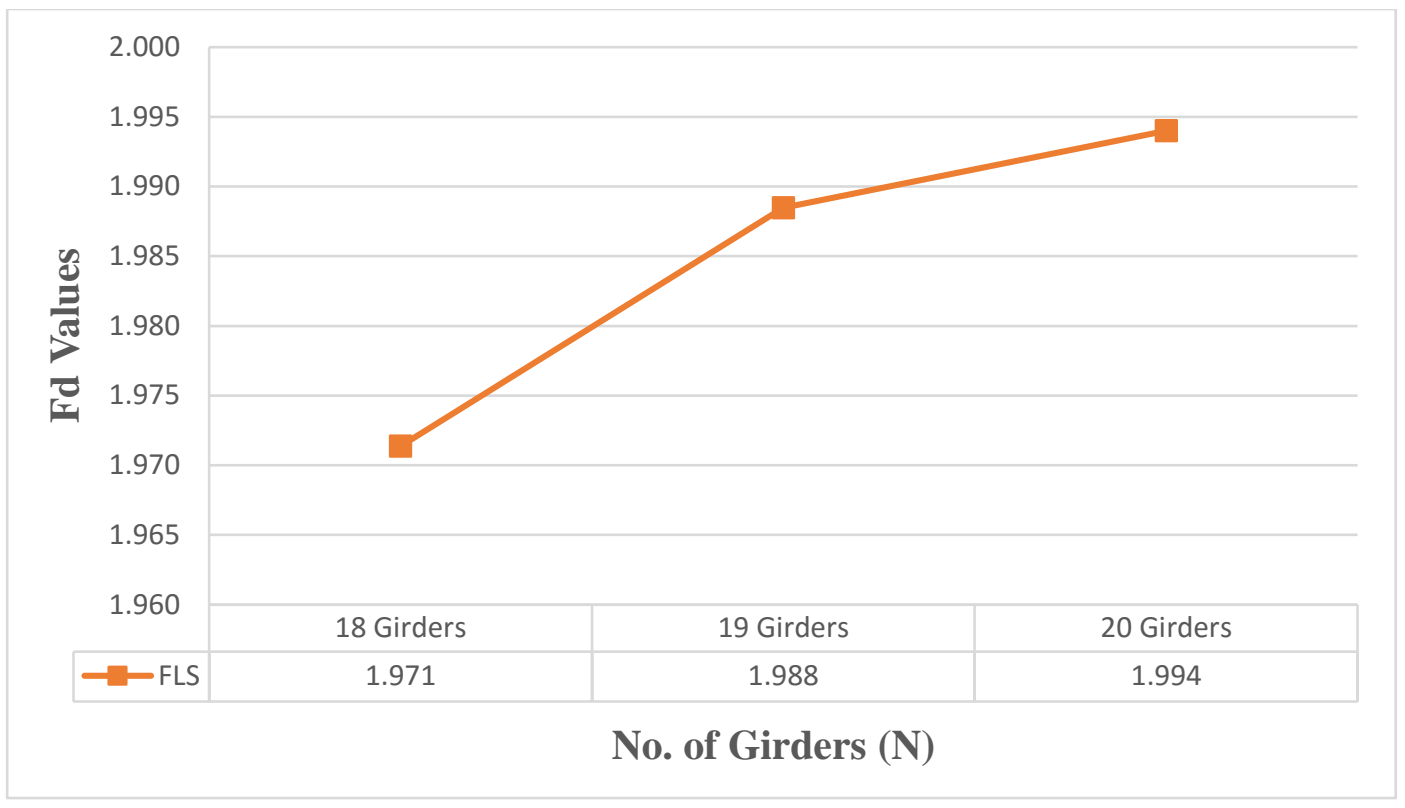

Figure A. 87: Effect of number of girders on deflection distribution factor (B1000, six-lane, 32m span)

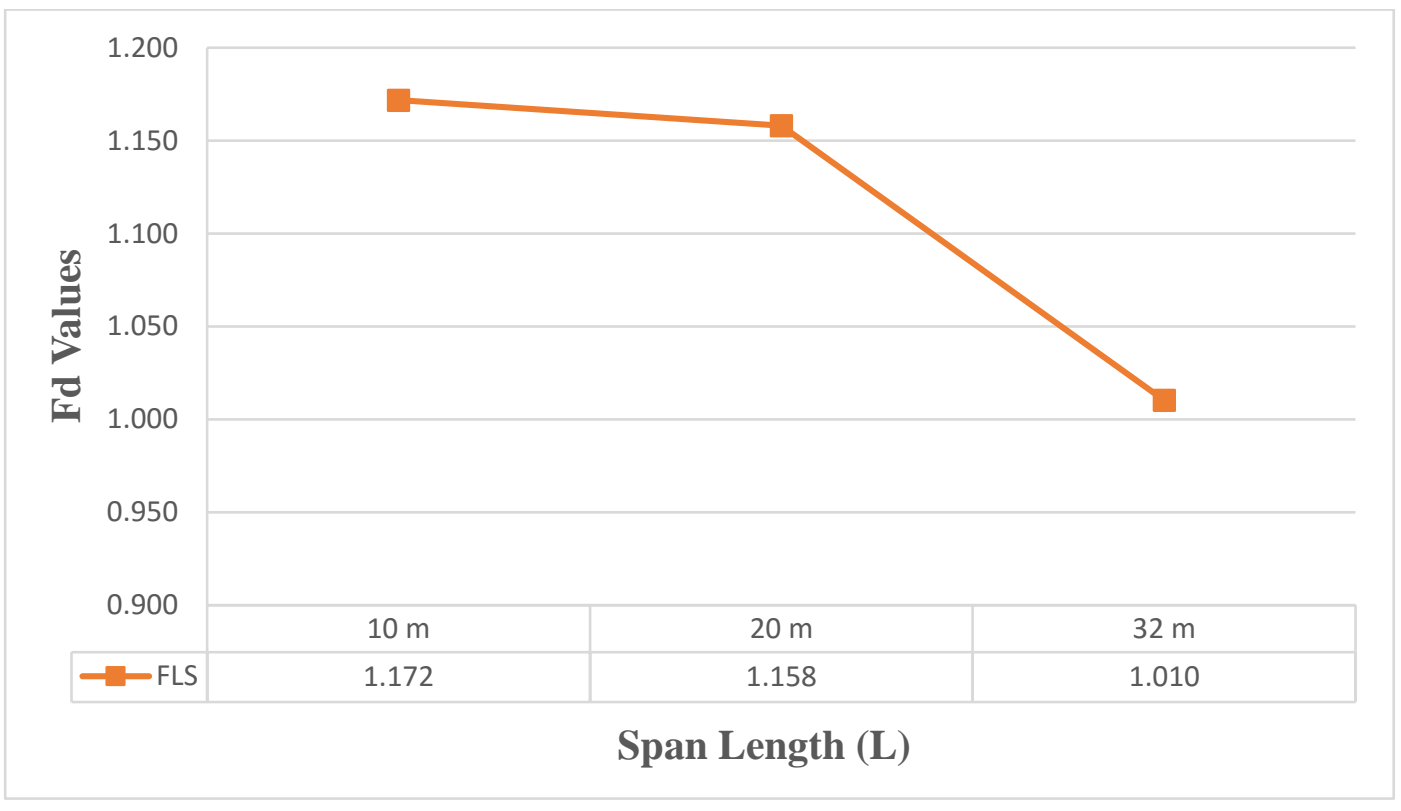

Figure A. 88: Effect of span length on deflection distribution factor (one-lane, 4 girders) 


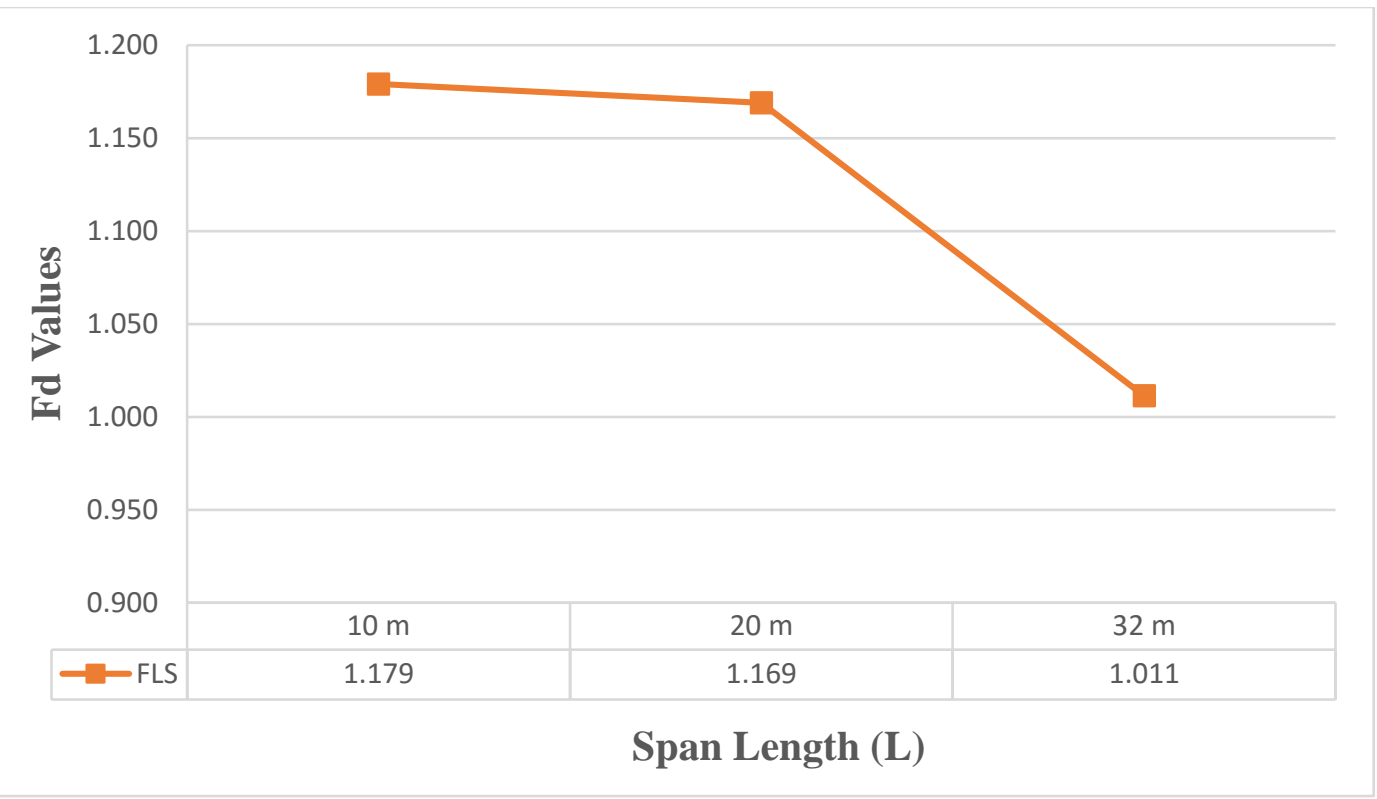

Figure A. 89: Effect of span length on deflection distribution factor (one-lane, 5 girders)

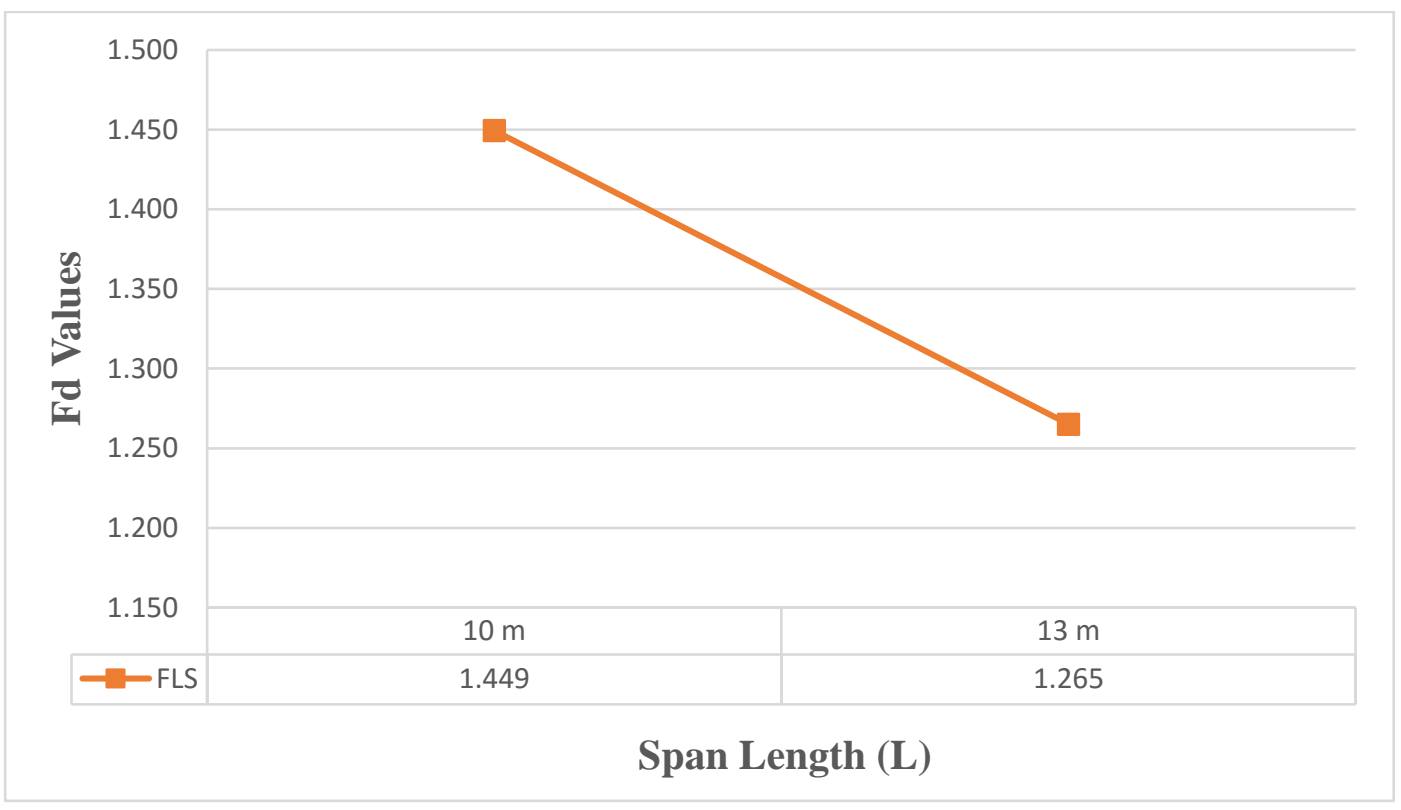

Figure A. 90: Effect of span length on deflection distribution factor (two-lane, 6 girders) 


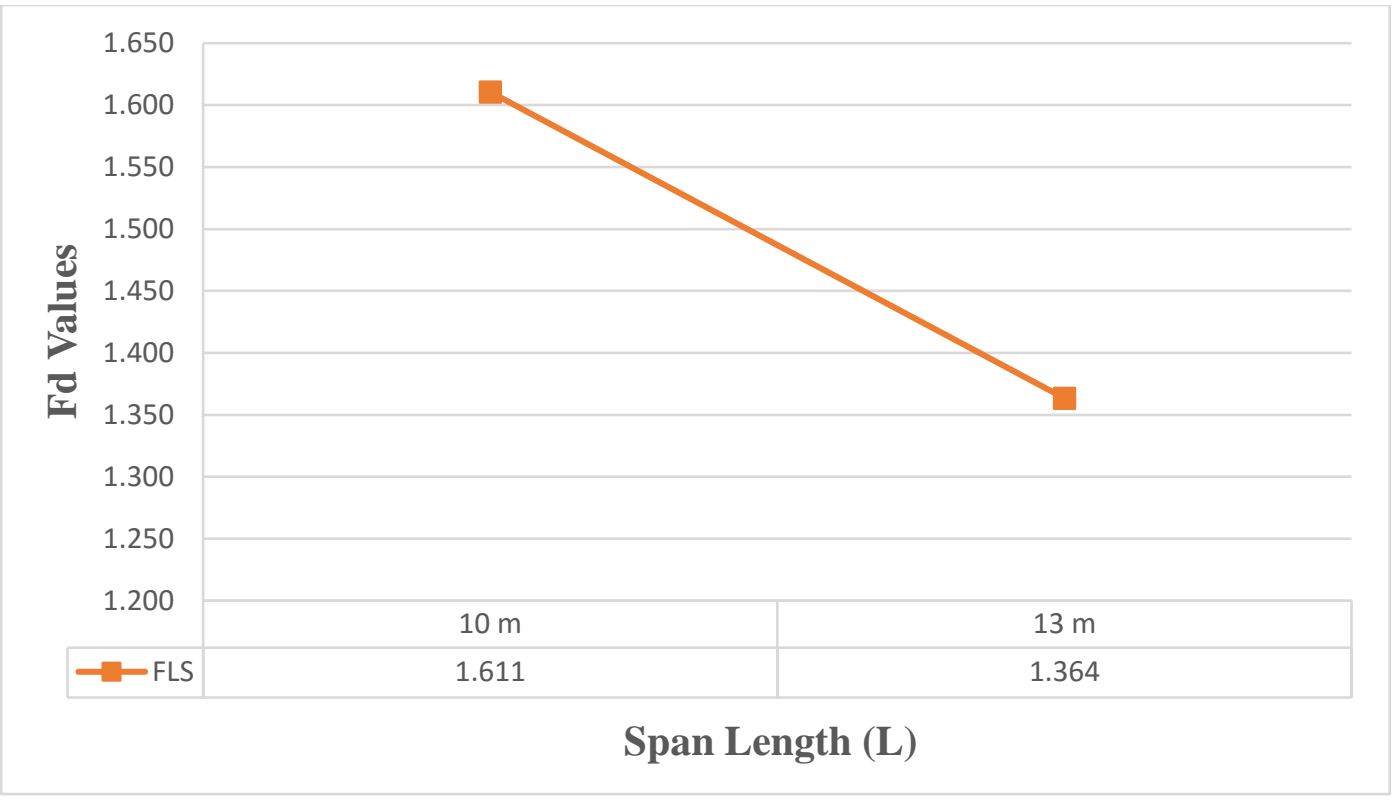

Figure A. 91: Effect of span length on deflection distribution factor (two-lane, 7 girders)

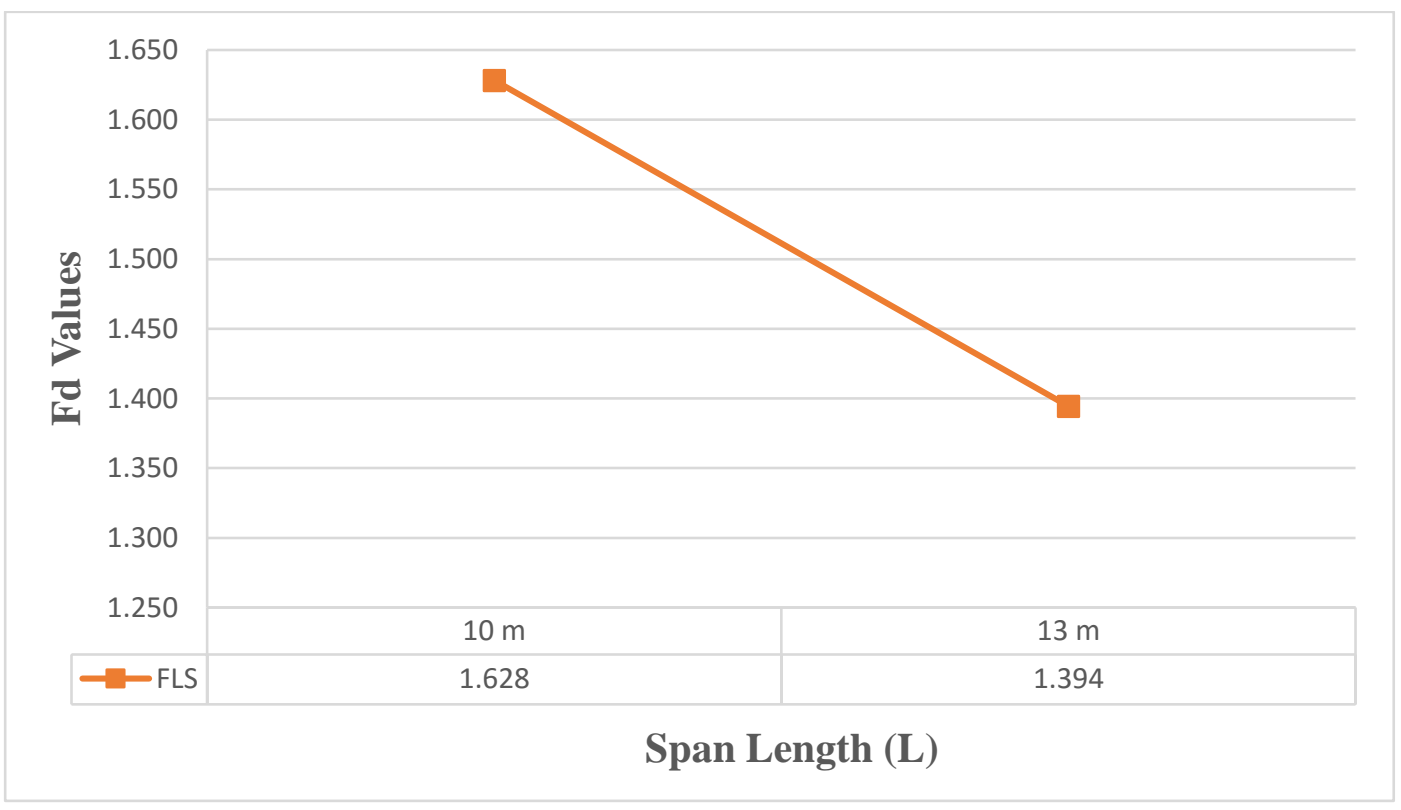

Figure A. 92: Effect of span length on deflection distribution factor (one-lane, 8 girders) 


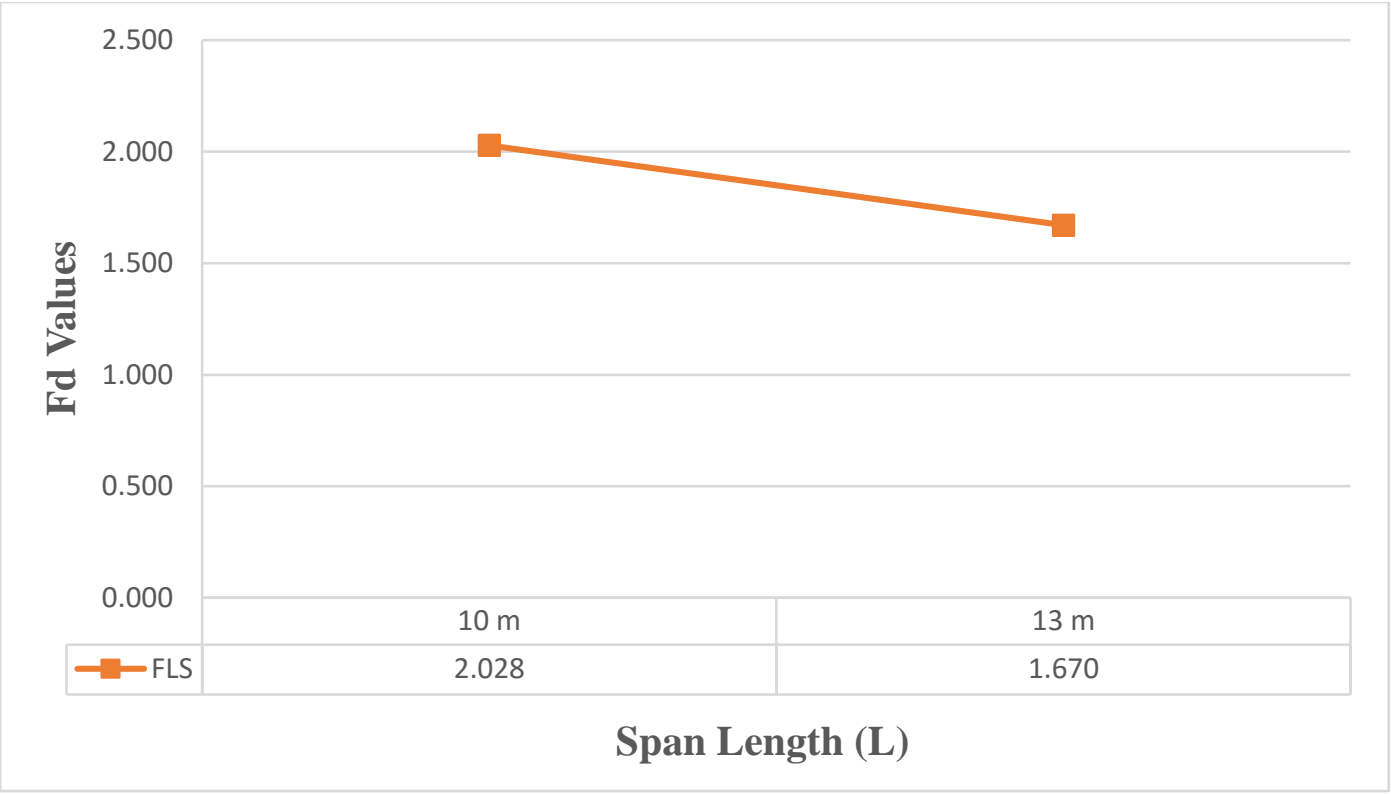

Figure A. 93: Effect of span length on deflection distribution factor (three-lane, 9 girders)

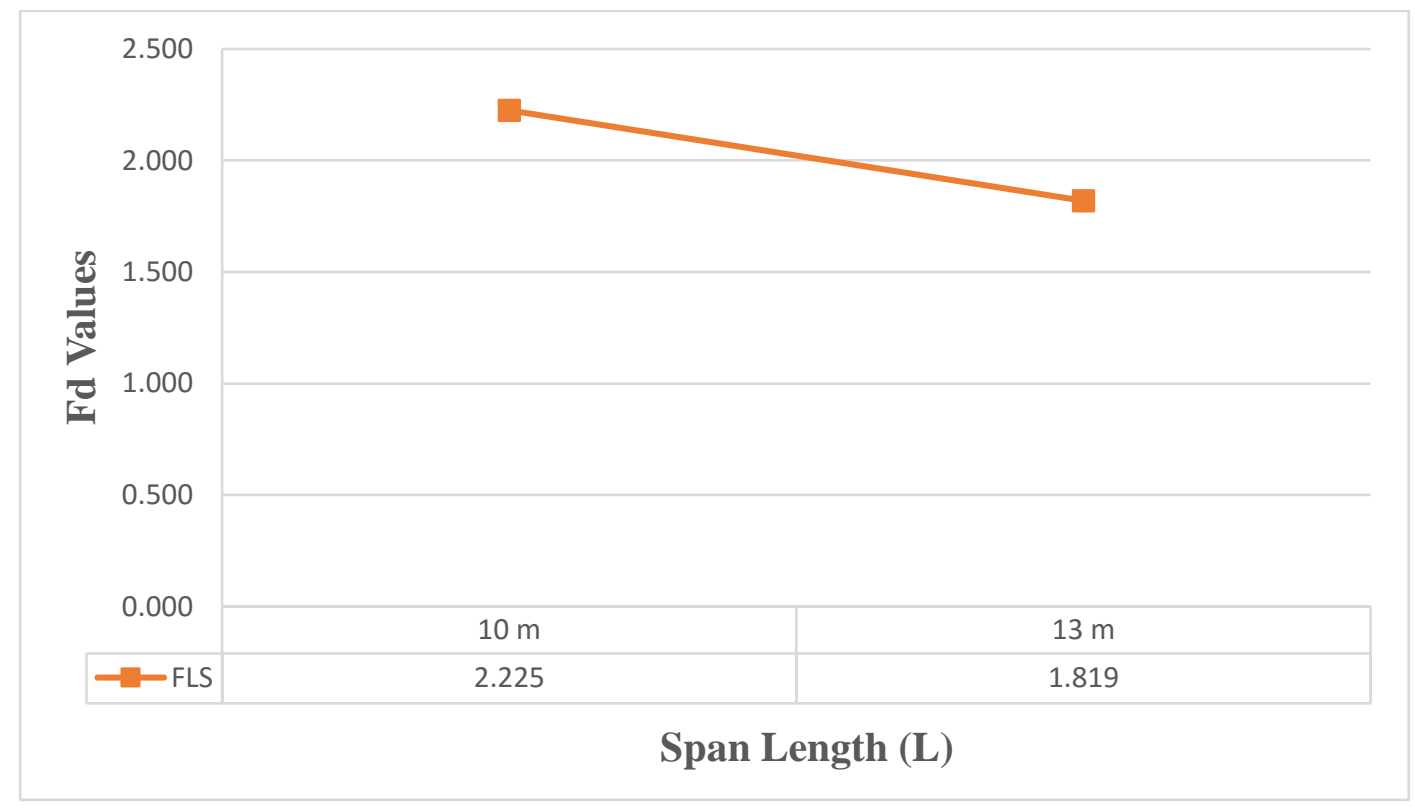

Figure A. 94: Effect of span length on deflection distribution factor (three-lane, 10 girders) 


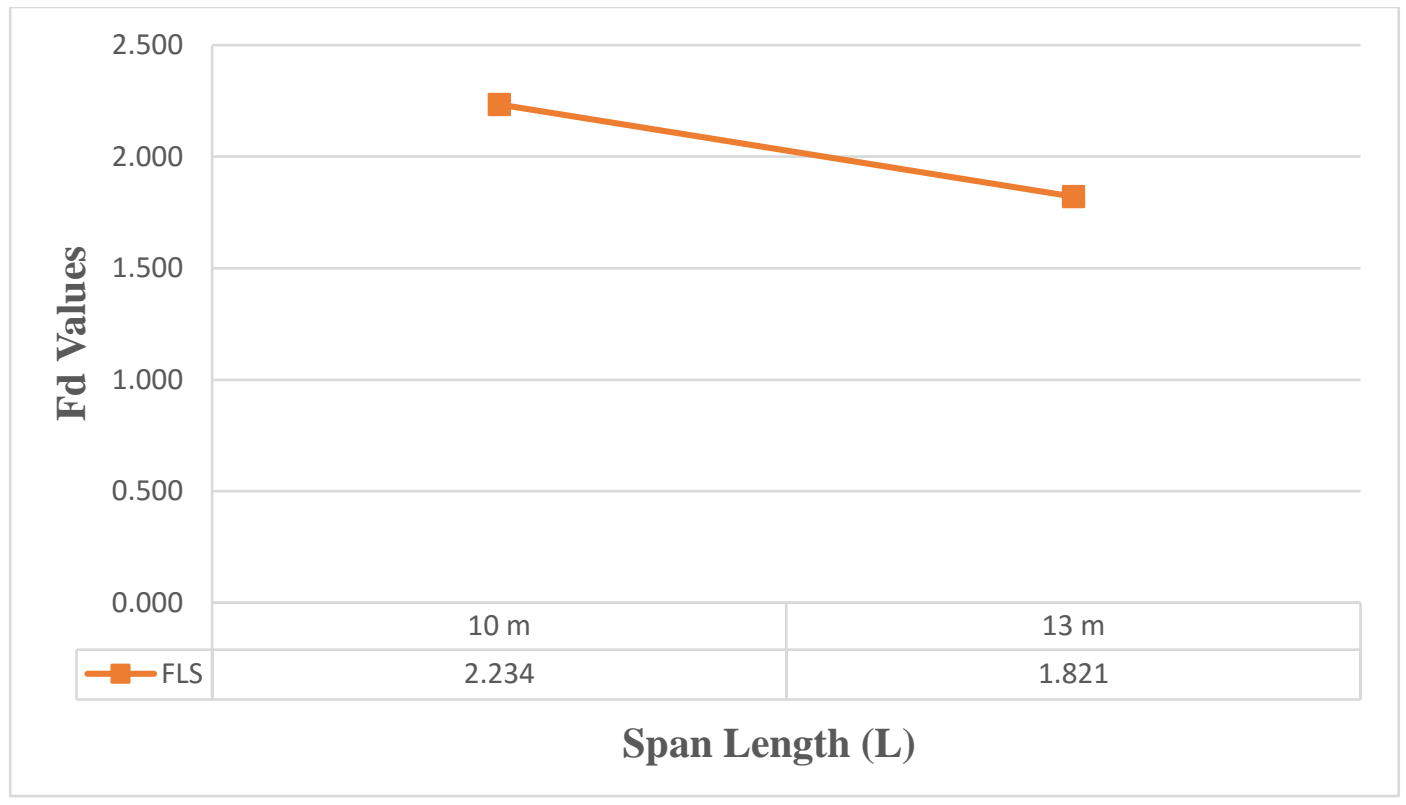

Figure A. 95: Effect of span length on deflection distribution factor (three-lane, 11 girders)

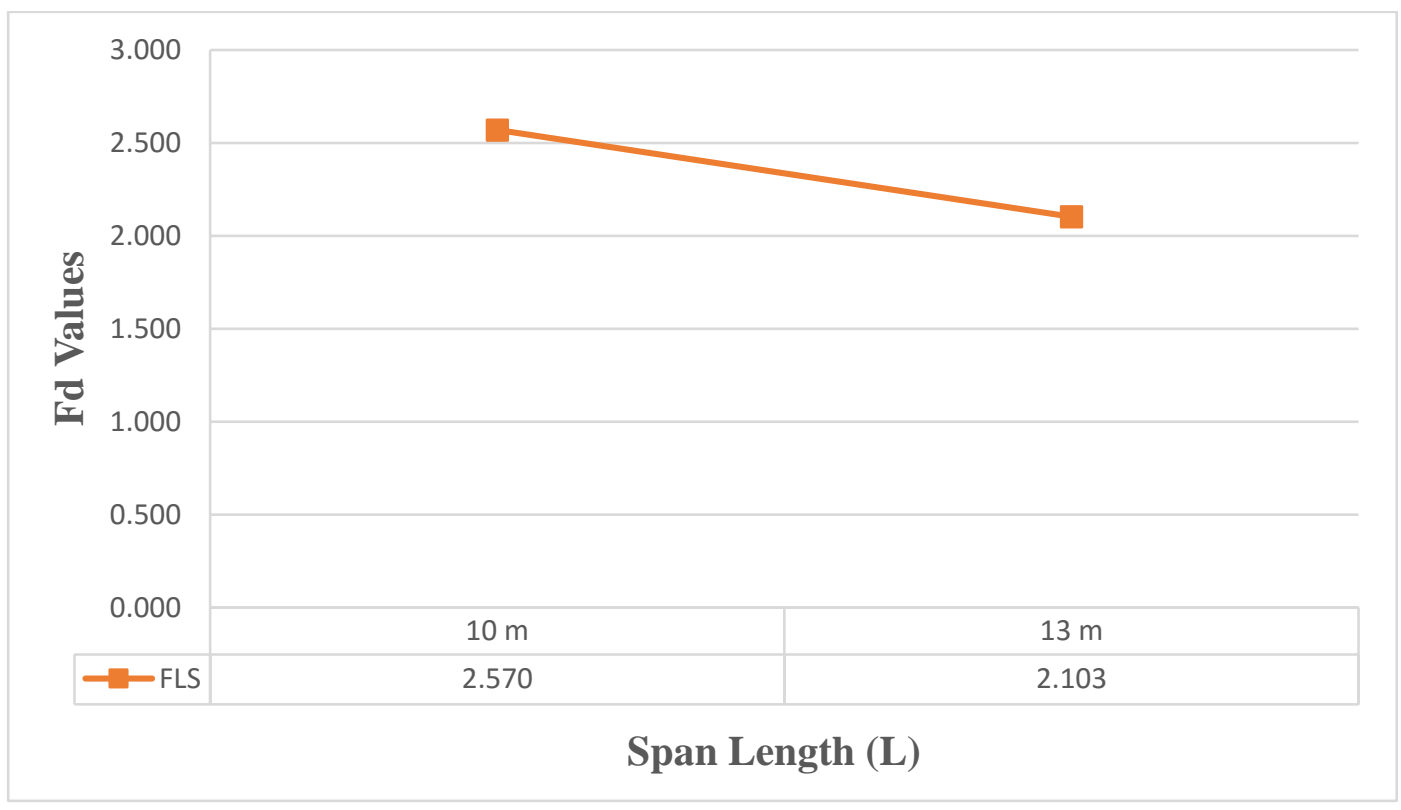

Figure A. 96: Effect of span length on deflection distribution factor (four-lane, 12 girders) 


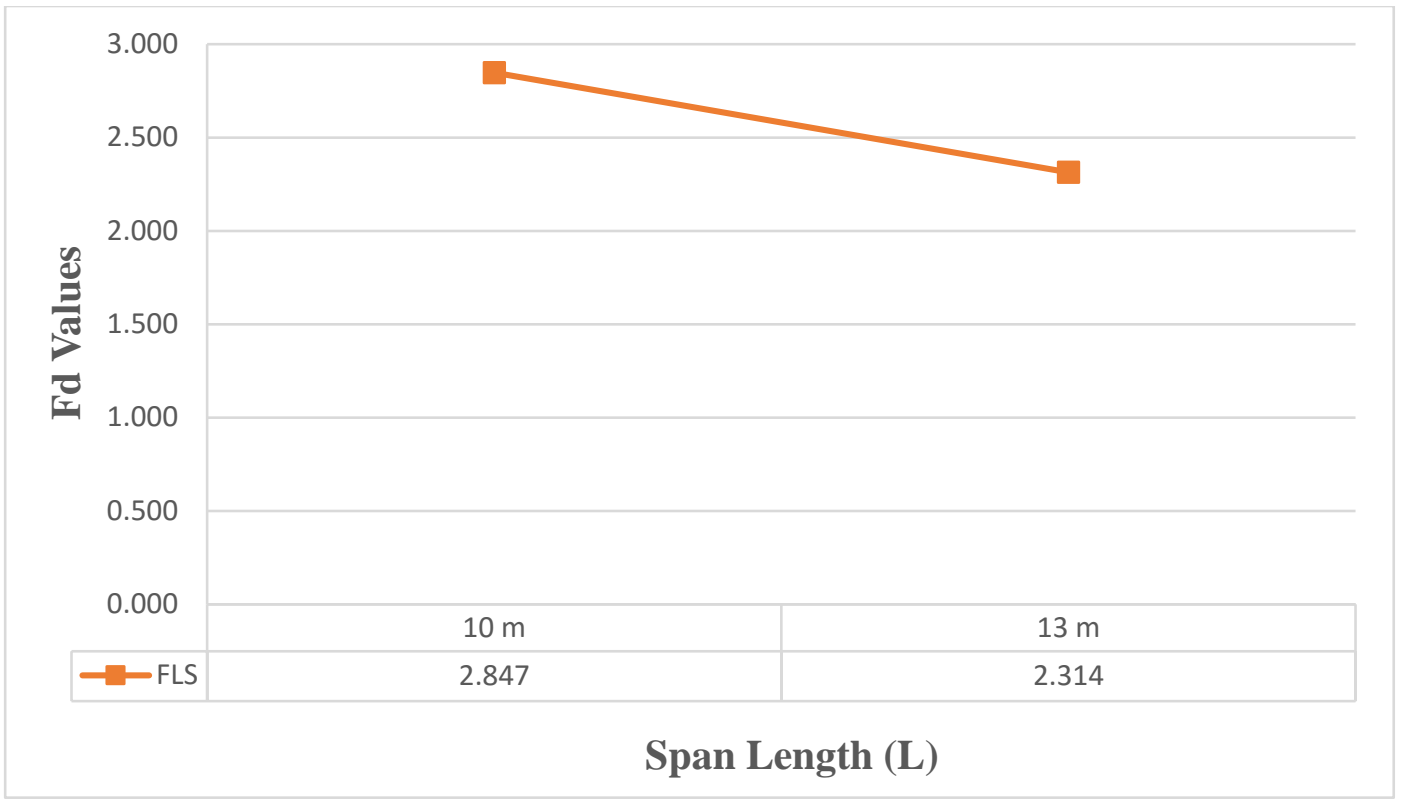

Figure A. 97: Effect of span length on deflection distribution factor (four-lane, 13 girders)

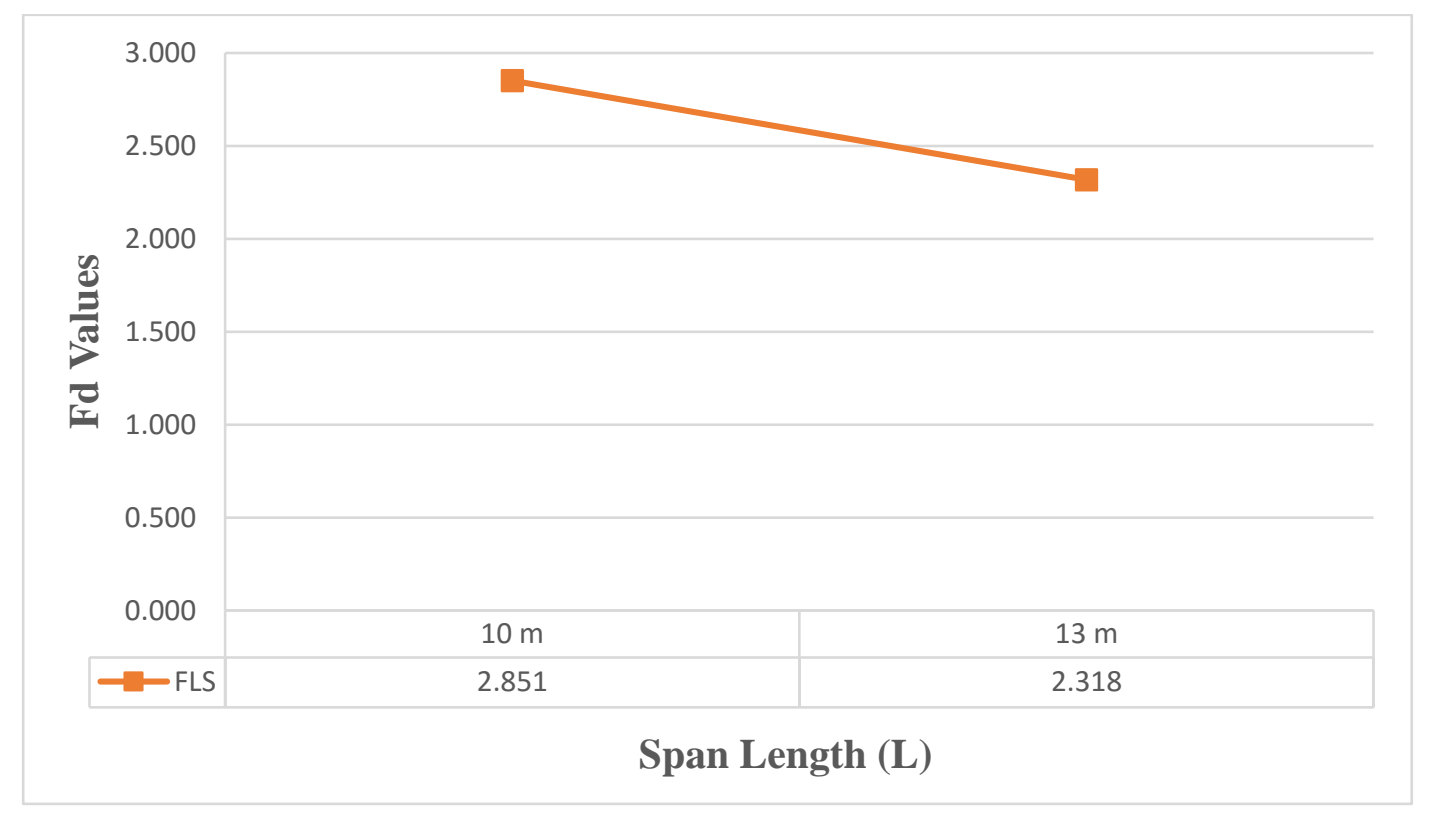

Figure A. 98: Effect of span length on deflection distribution factor (four-lane, 14 girders) 


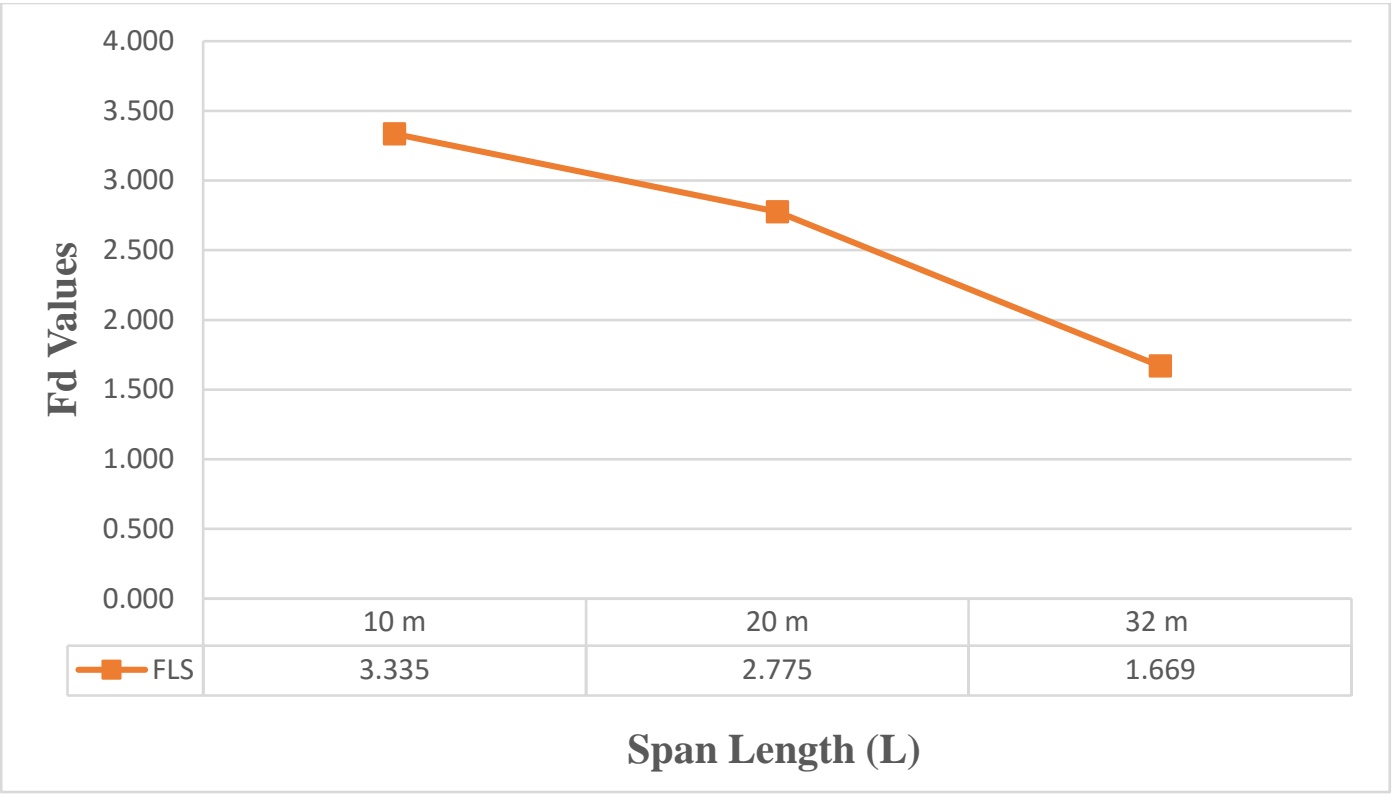

Figure A. 99: Effect of span length on deflection distribution factor (five-lane, 15 girders)

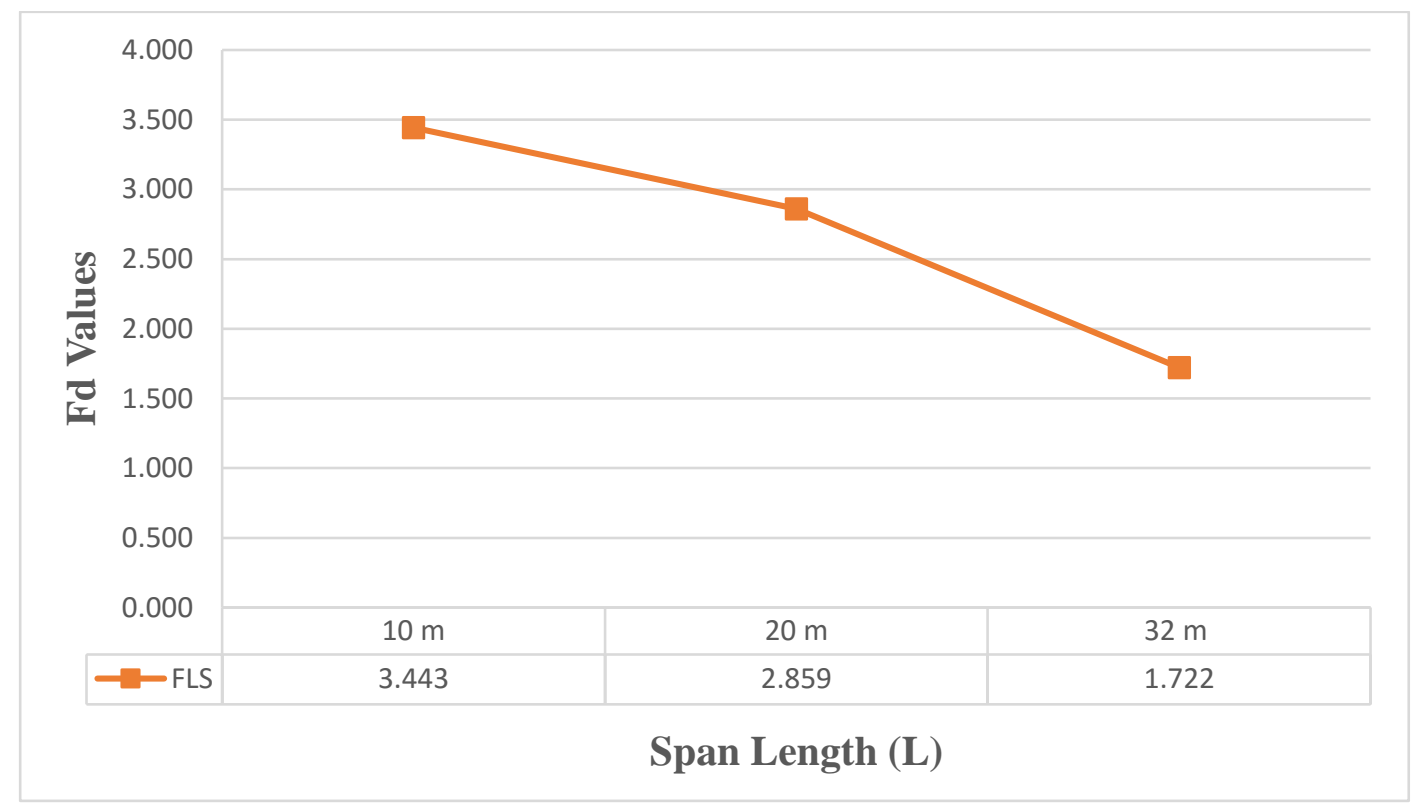

Figure A. 100: Effect of span length on deflection distribution factor (five-lane, 16 girders) 


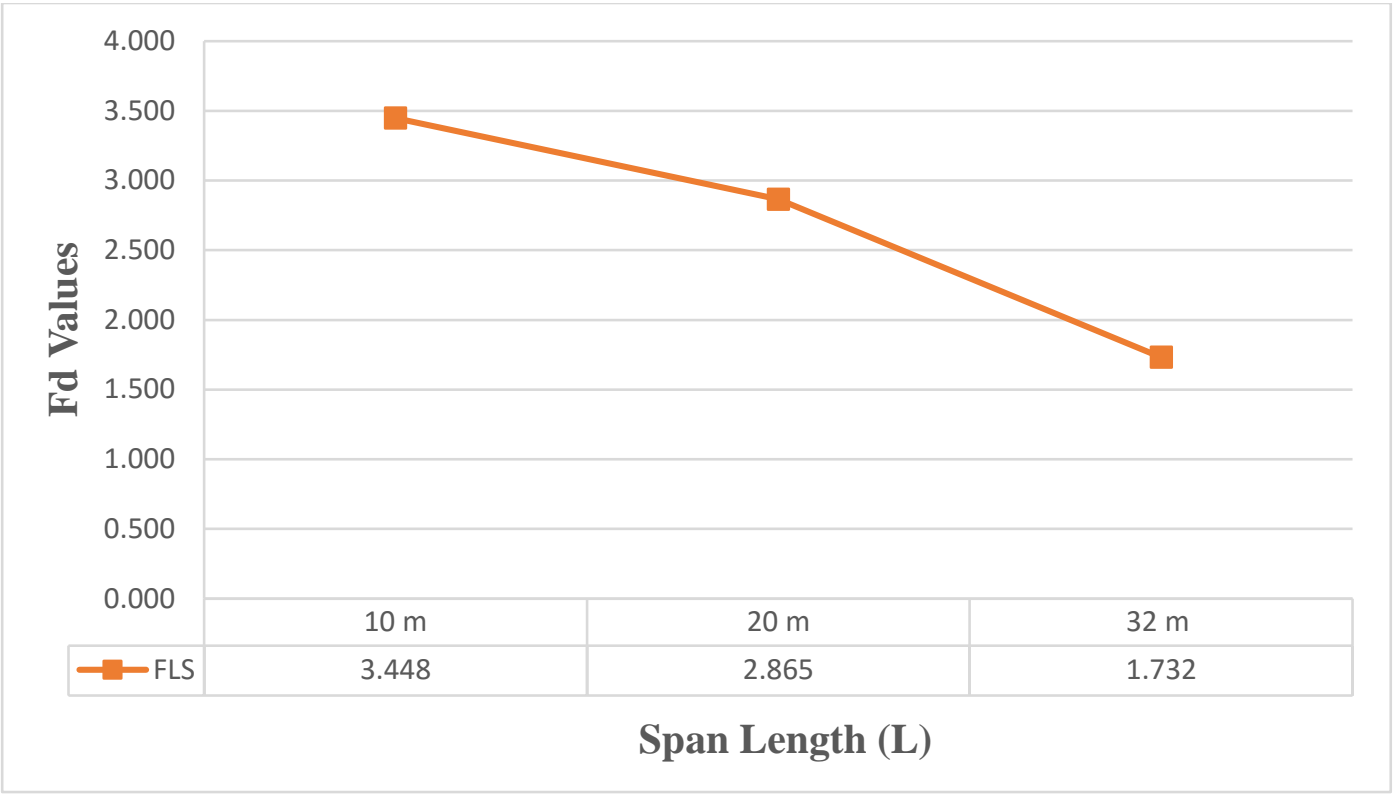

Figure A. 101: Effect of span length on deflection distribution factor (five-lane, 17 girders)

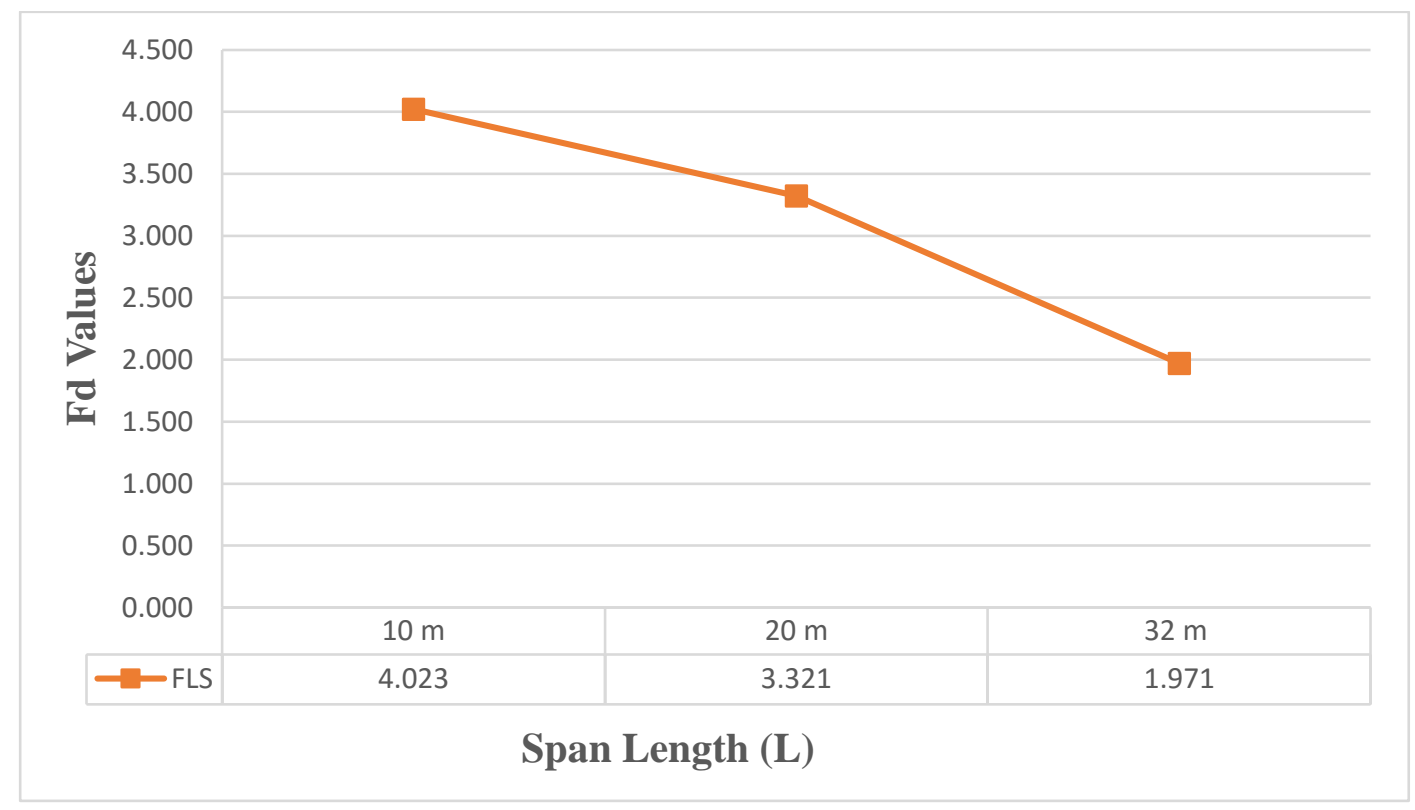

Figure A. 102: Effect of span length on deflection distribution factor (six-lane, 18 girders) 


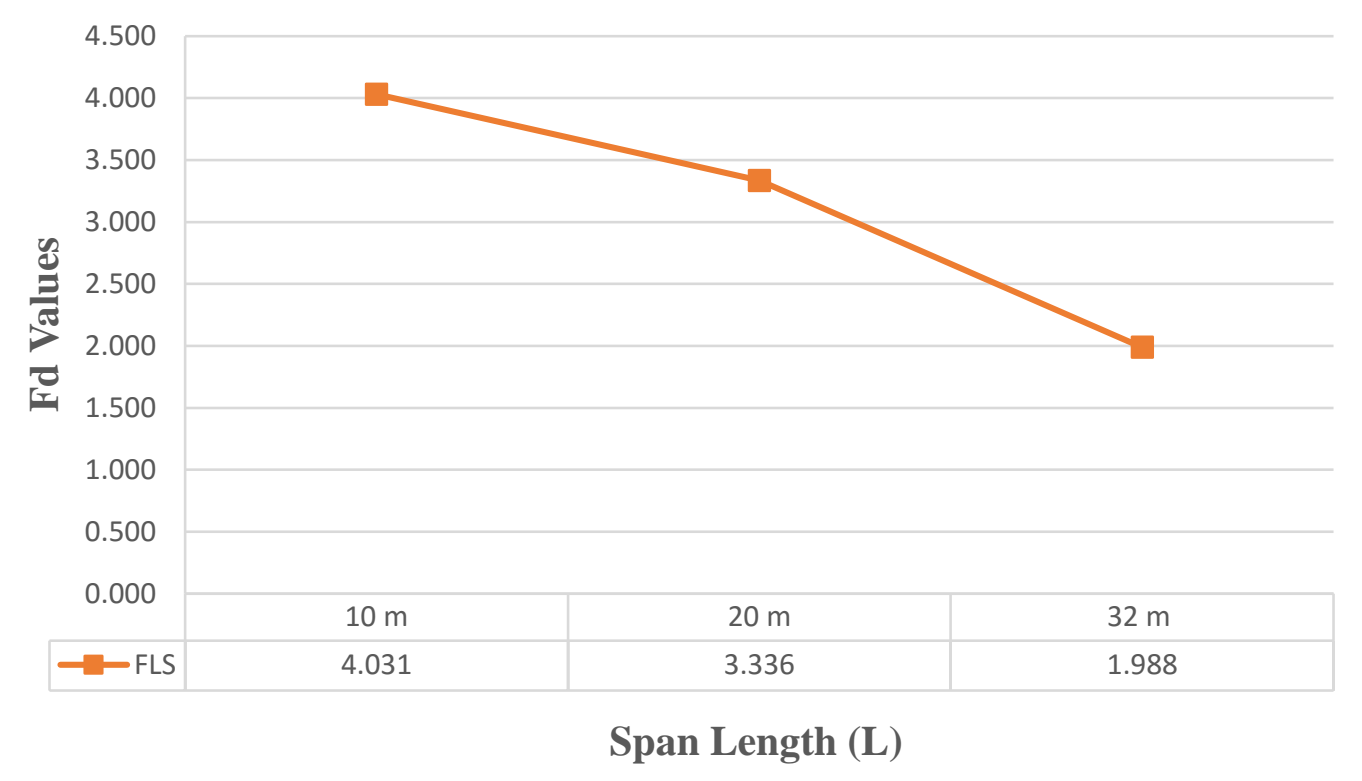

Figure A. 103: Effect of span length on deflection distribution factor (six-lane, 19 girders)

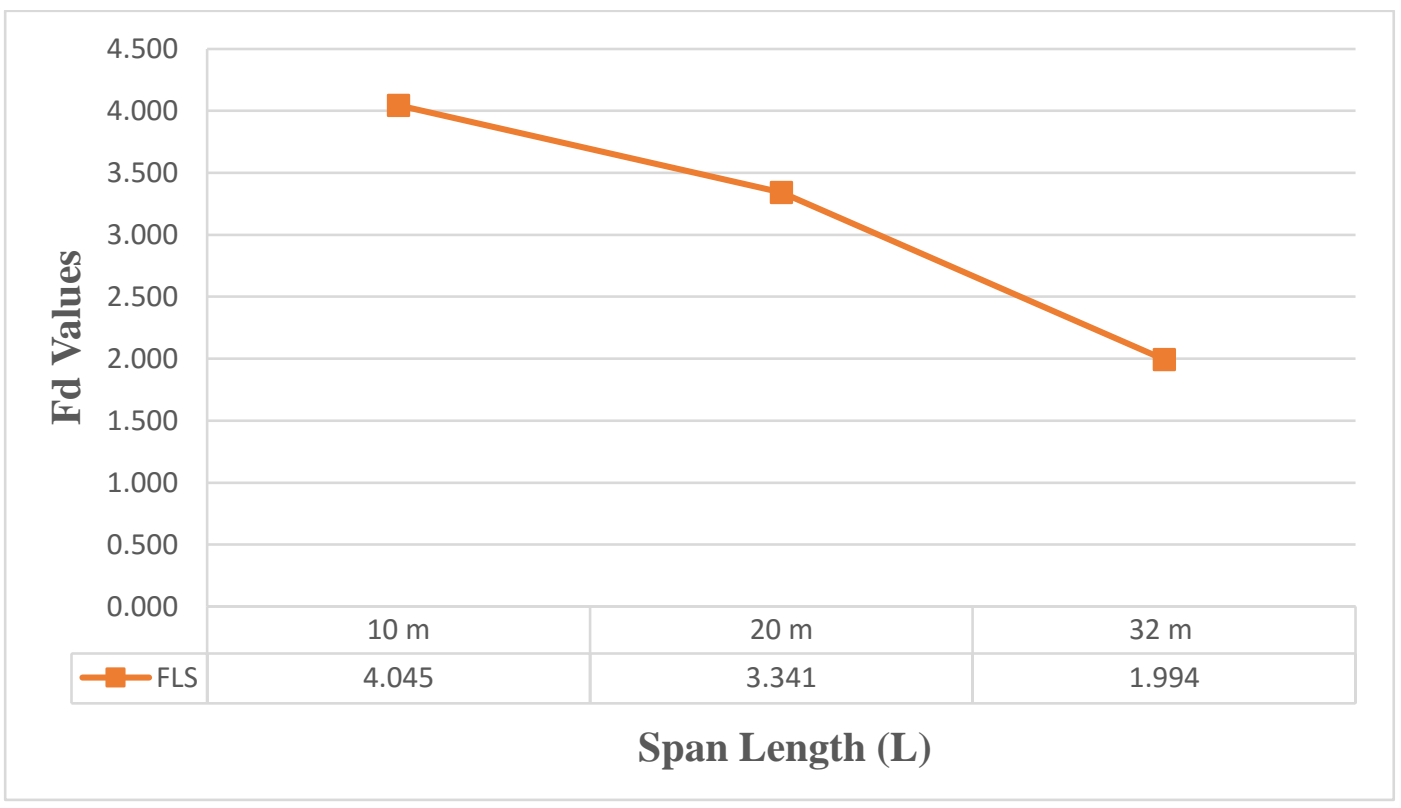

Figure A. 104: Effect of span length on deflection distribution factor (six-lane, 20 girders) 


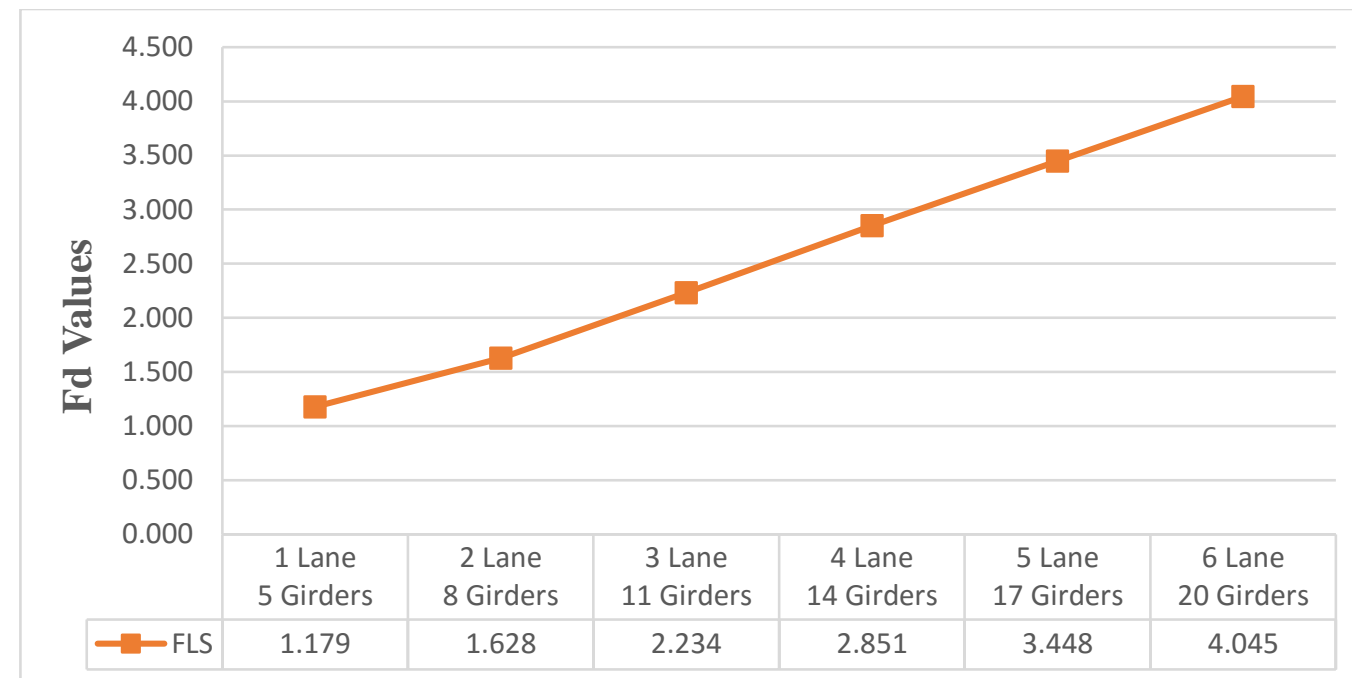

No. of Lanes (n)

Figure A. 105: Effect of number of lanes on deflection distribution factor (B700, 10 girders)

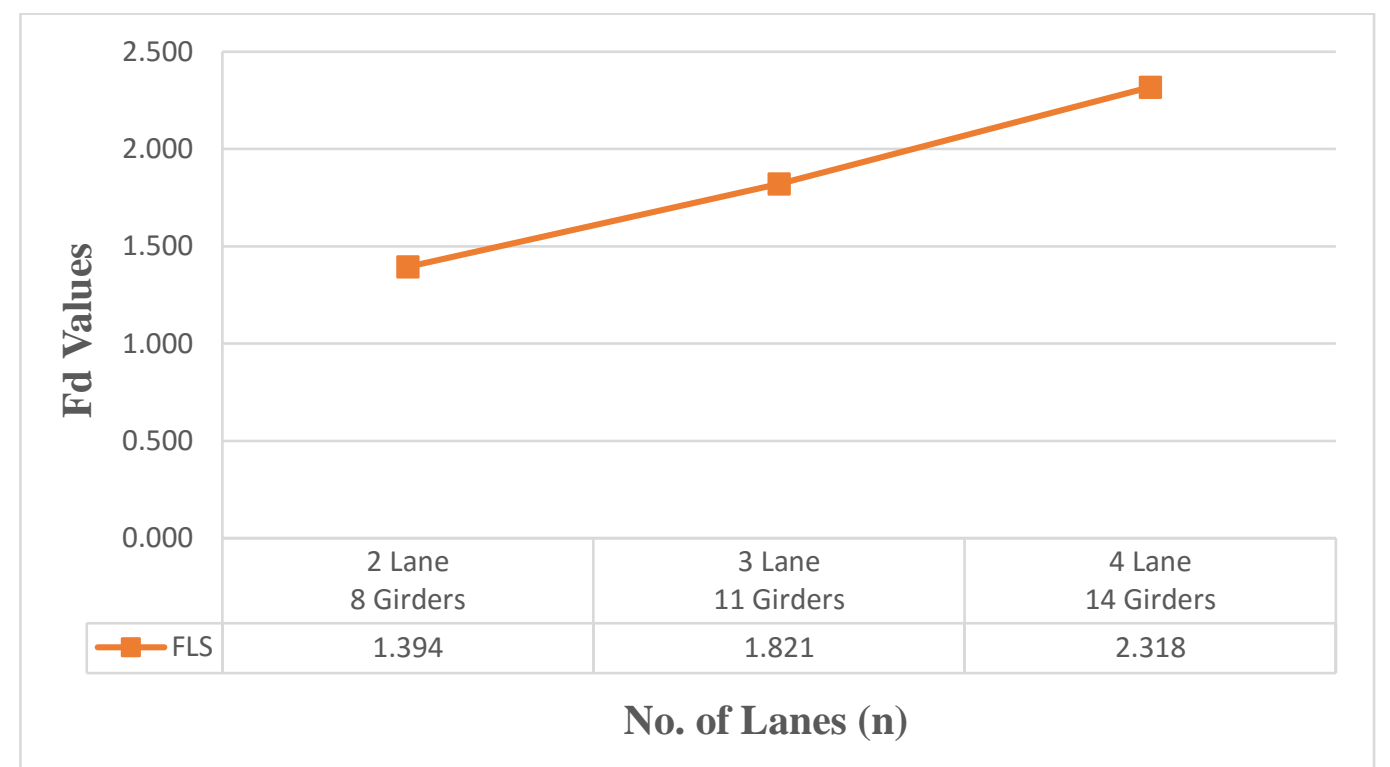

Figure A. 106: Effect of number of lanes on deflection distribution factor (B700, 13 girders) 


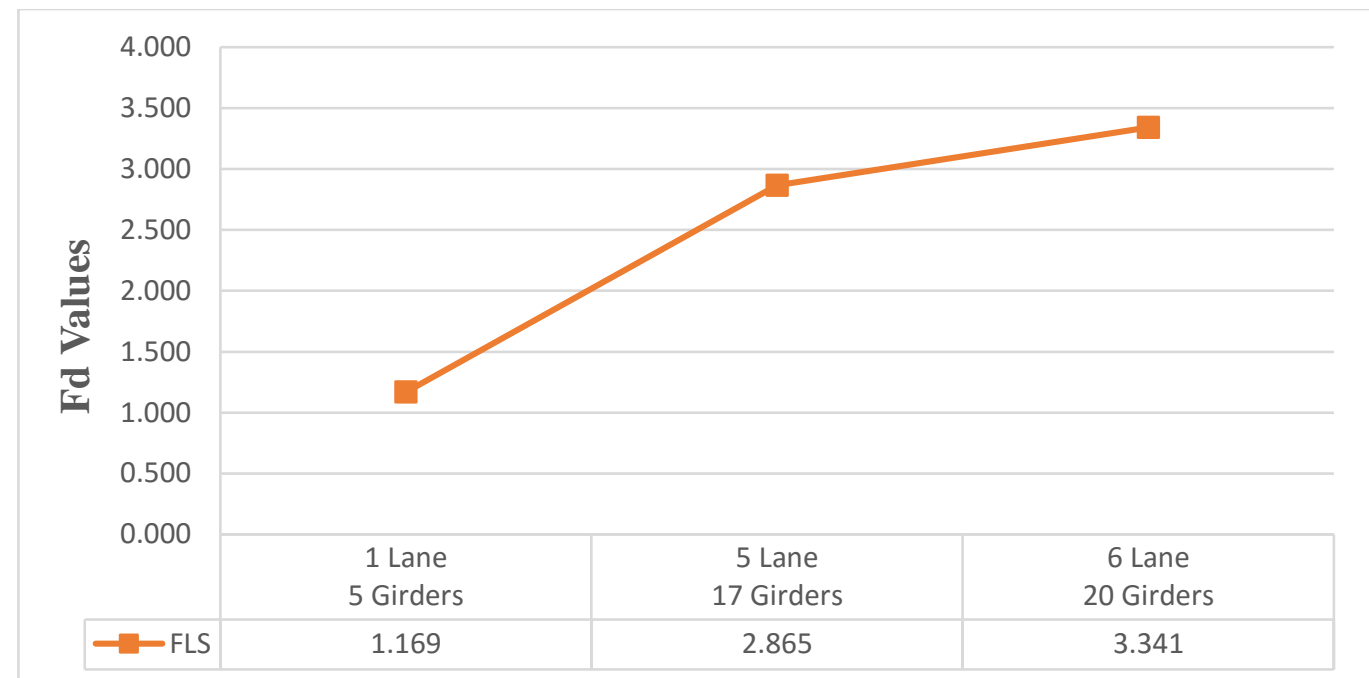

No. of Lanes (n)

Figure A. 107: Effect of number of lanes on deflection distribution factor (B800, 20 girders)

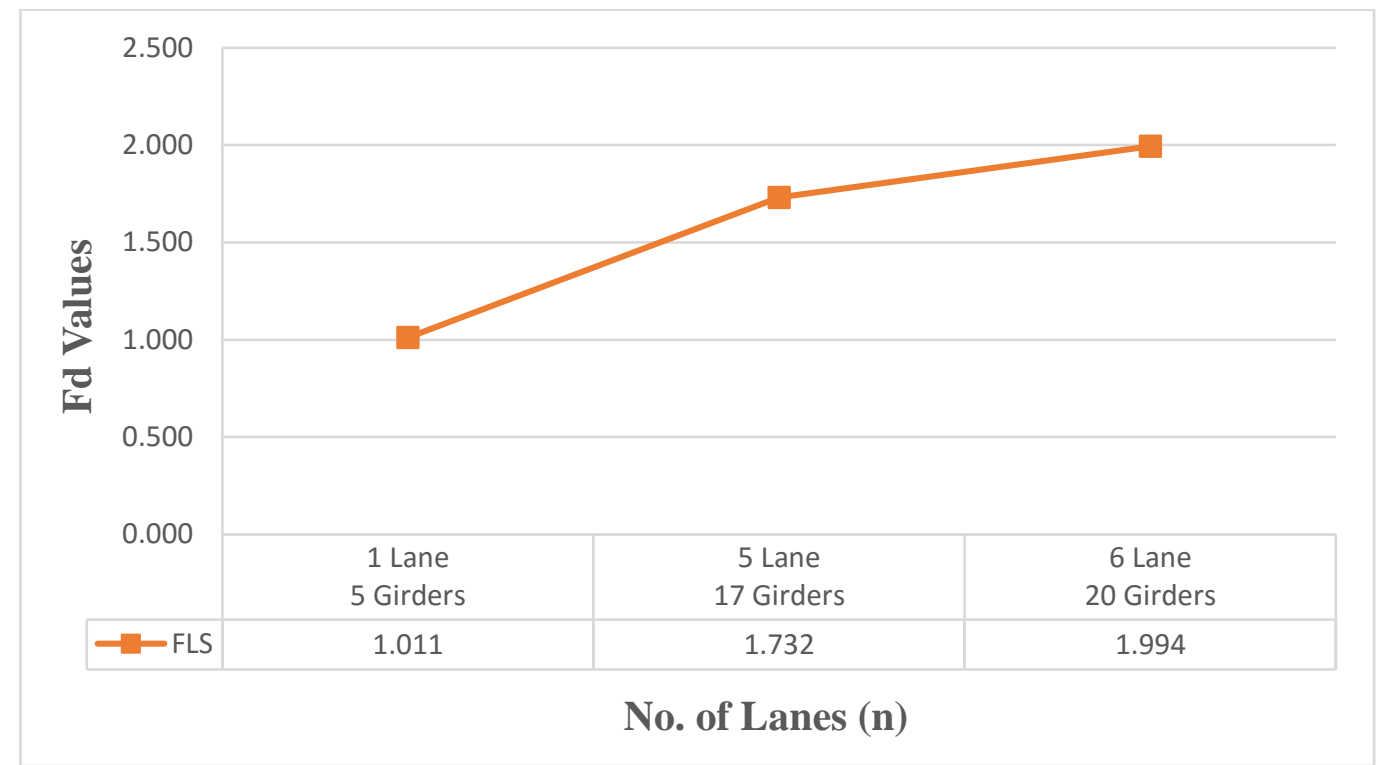

Figure A. 108: Effect of number of lanes on deflection distribution factor $(\mathrm{B} 1000,32$ girders) 


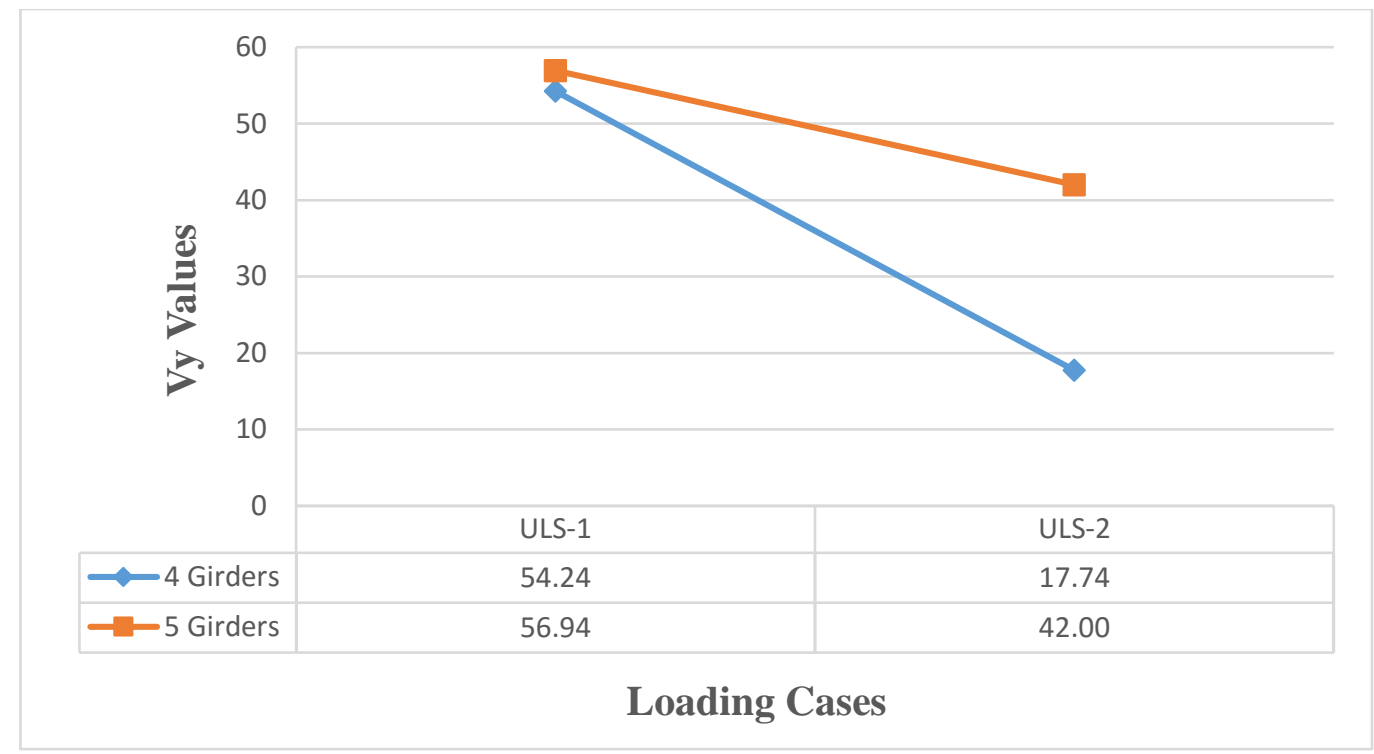

Figure A. 109: Effect of loading cases on transverse shear (one-lane, 10m span)

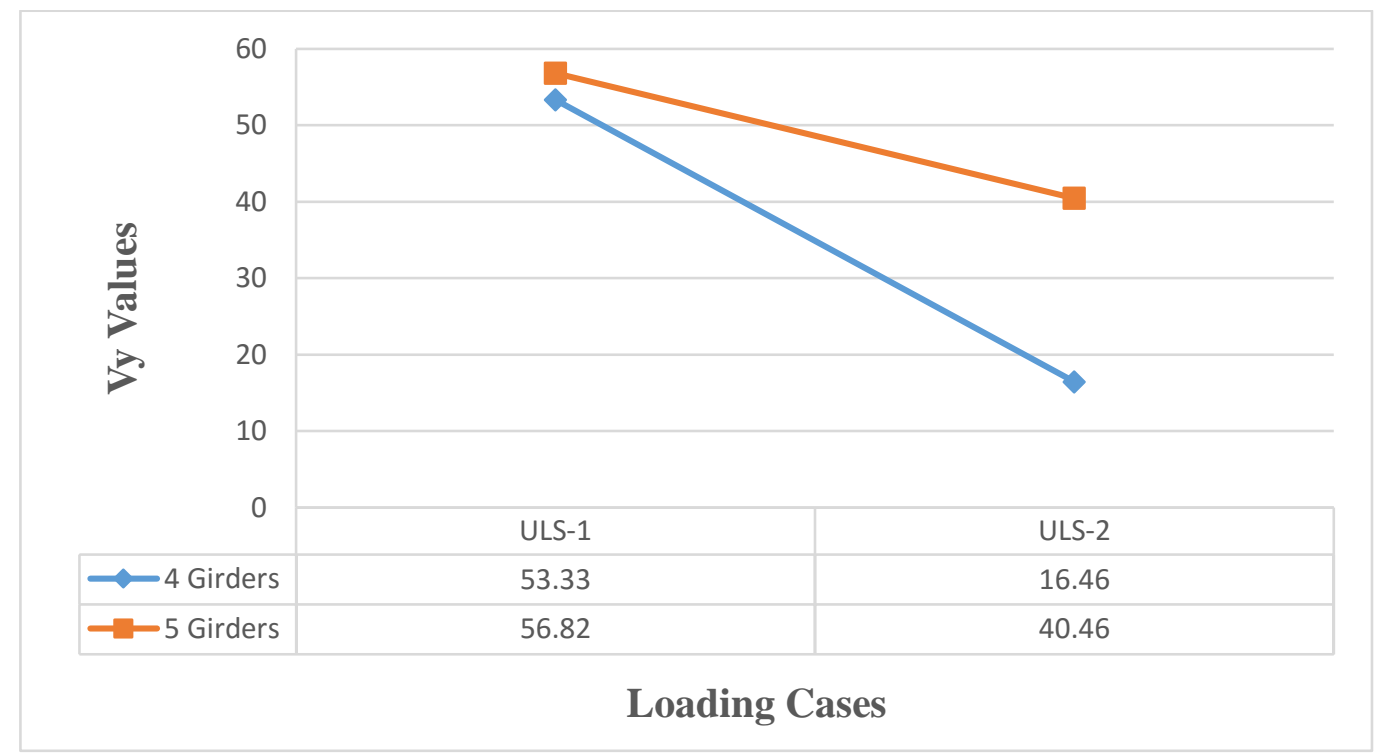

Figure A. 110: Effect of loading cases on transverse shear (one-lane, 20m span) 


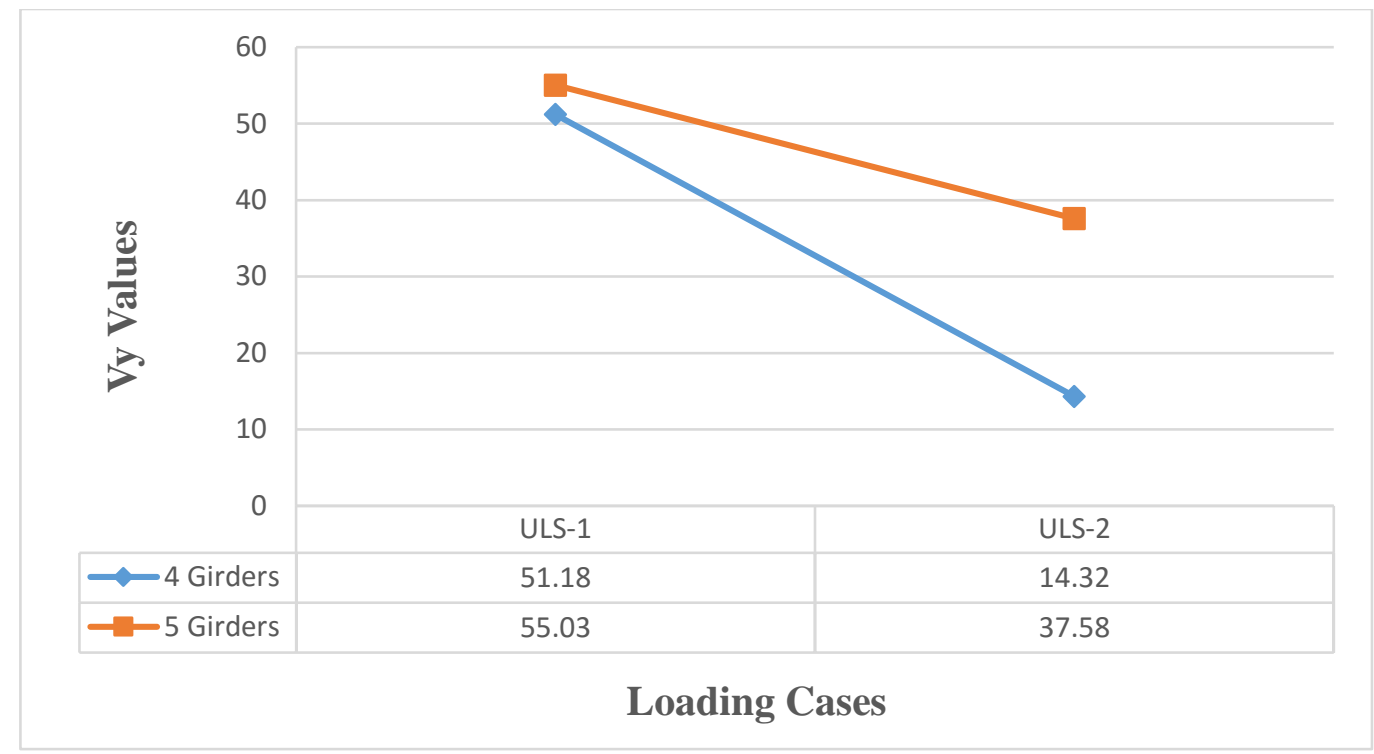

Figure A. 111: Effect of loading cases on transverse shear (one-lane, 32m span)

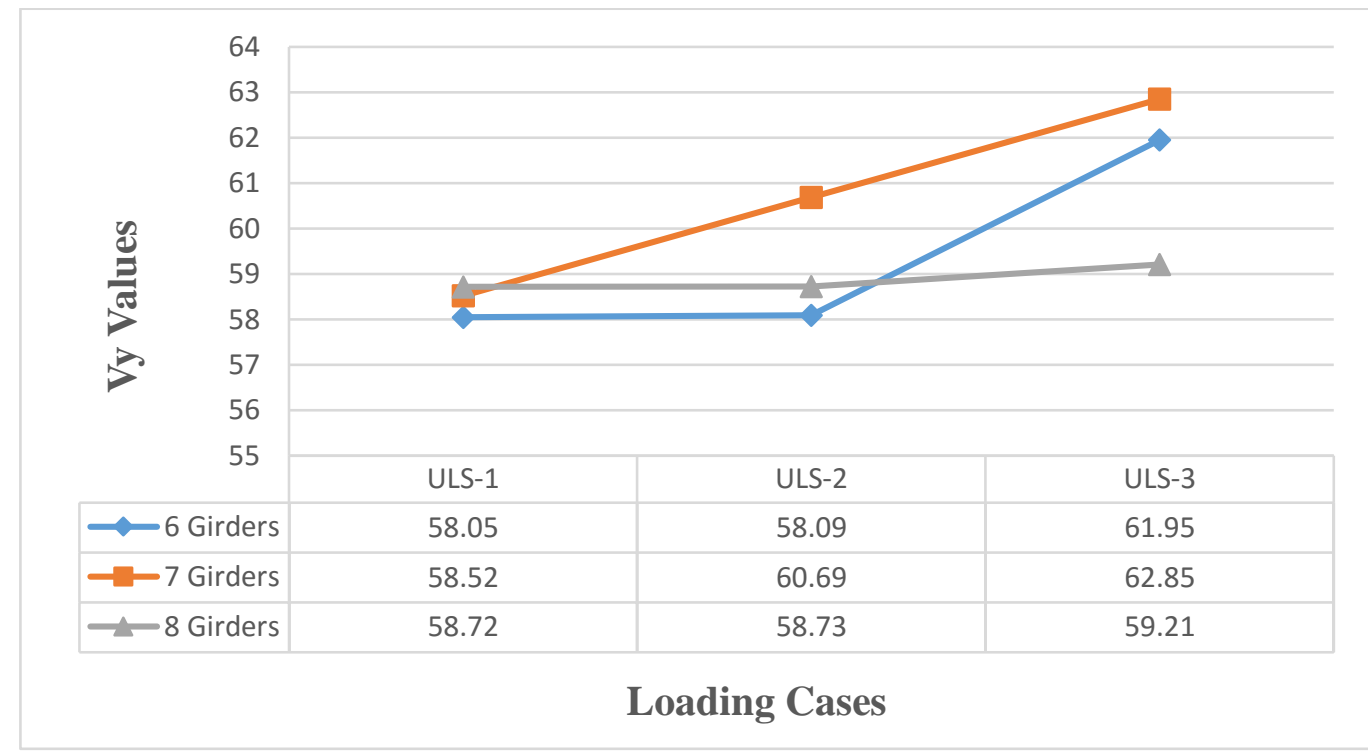

Figure A. 112: Effect of loading cases on transverse shear (two-lane, 10m span) 


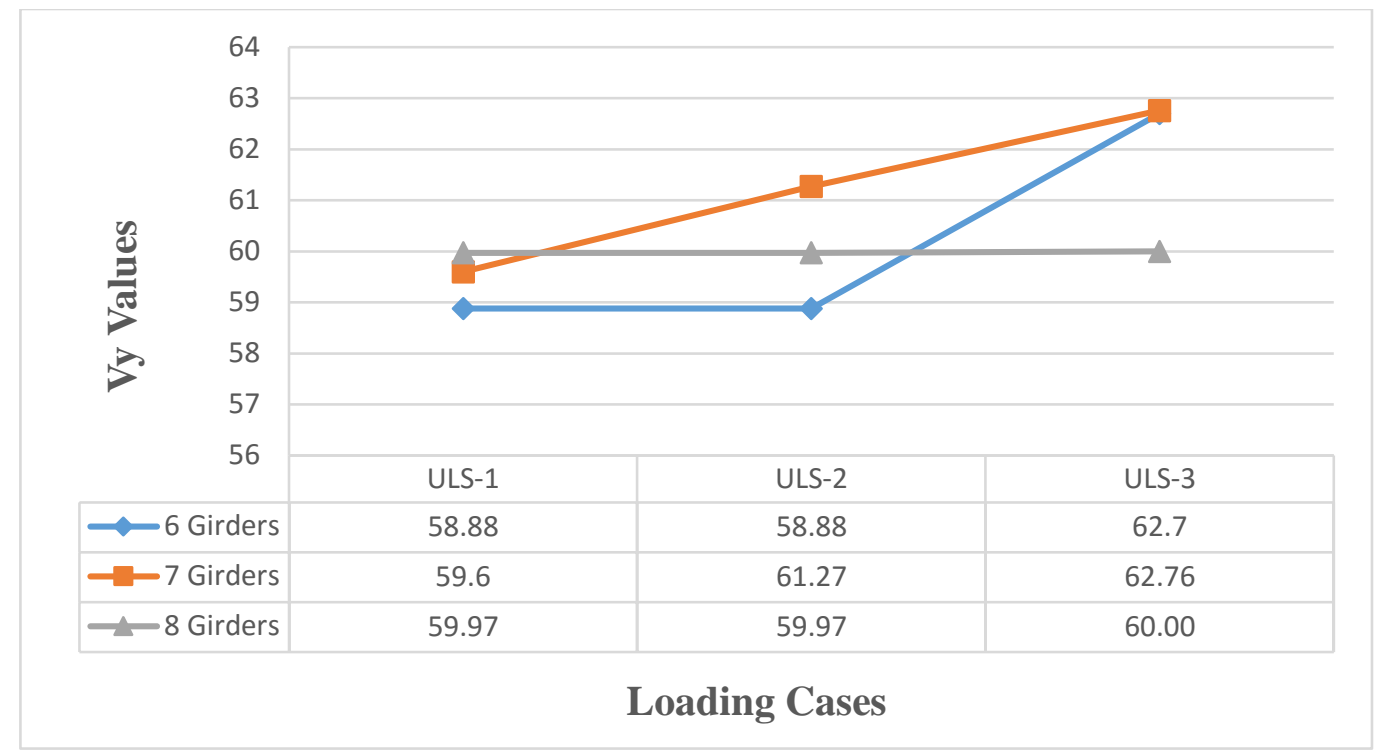

Figure A. 113: Effect of loading cases on transverse shear (two-lane, 13m span)

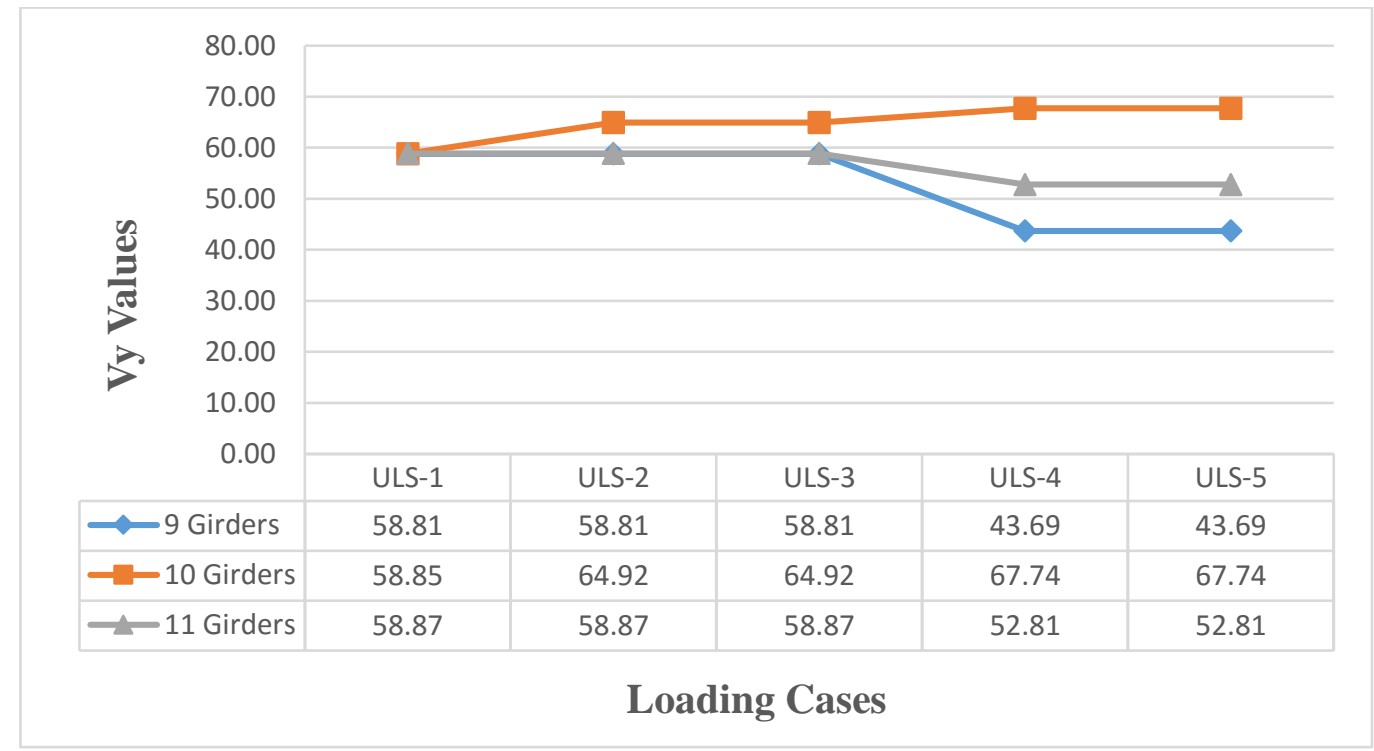

Figure A. 114: Effect of loading cases on transverse shear (three-lane, 10m span) 


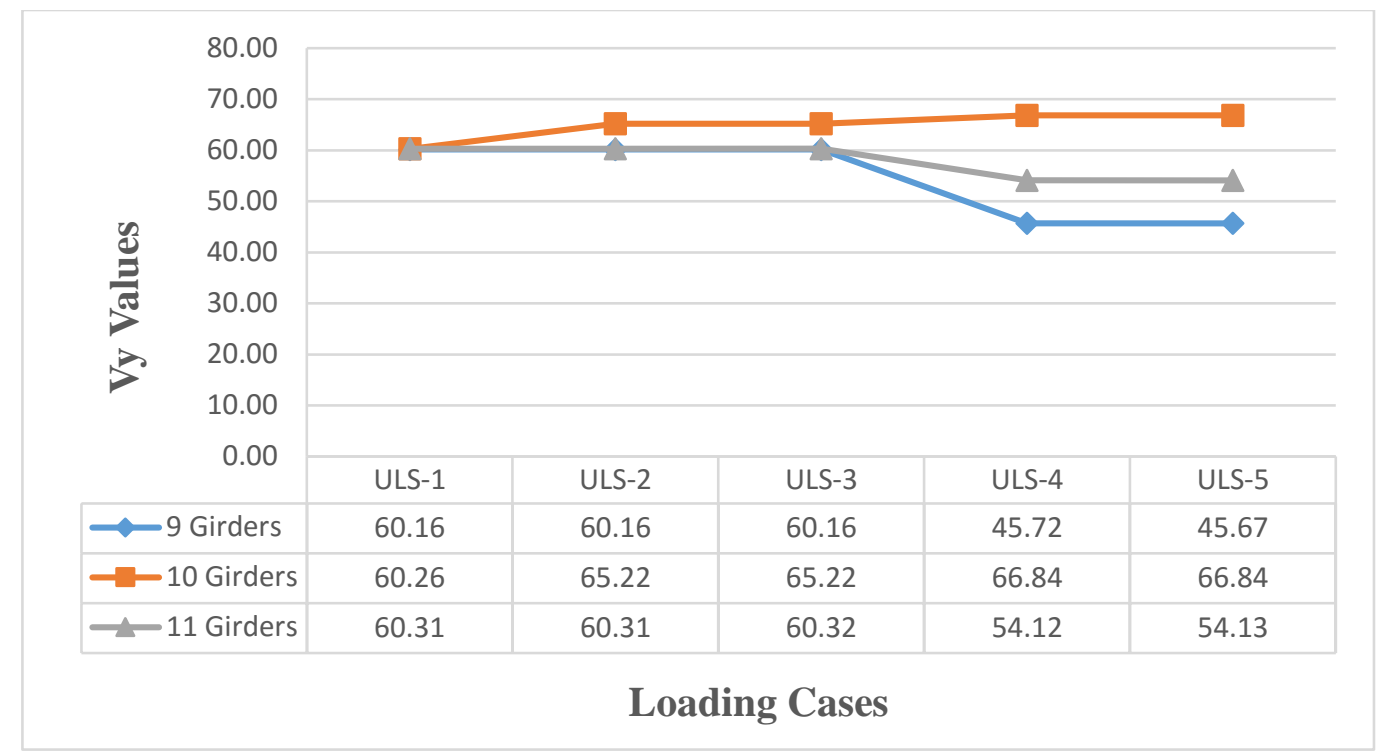

Figure A. 115: Effect of loading cases on transverse shear (three-lane, 13m span)

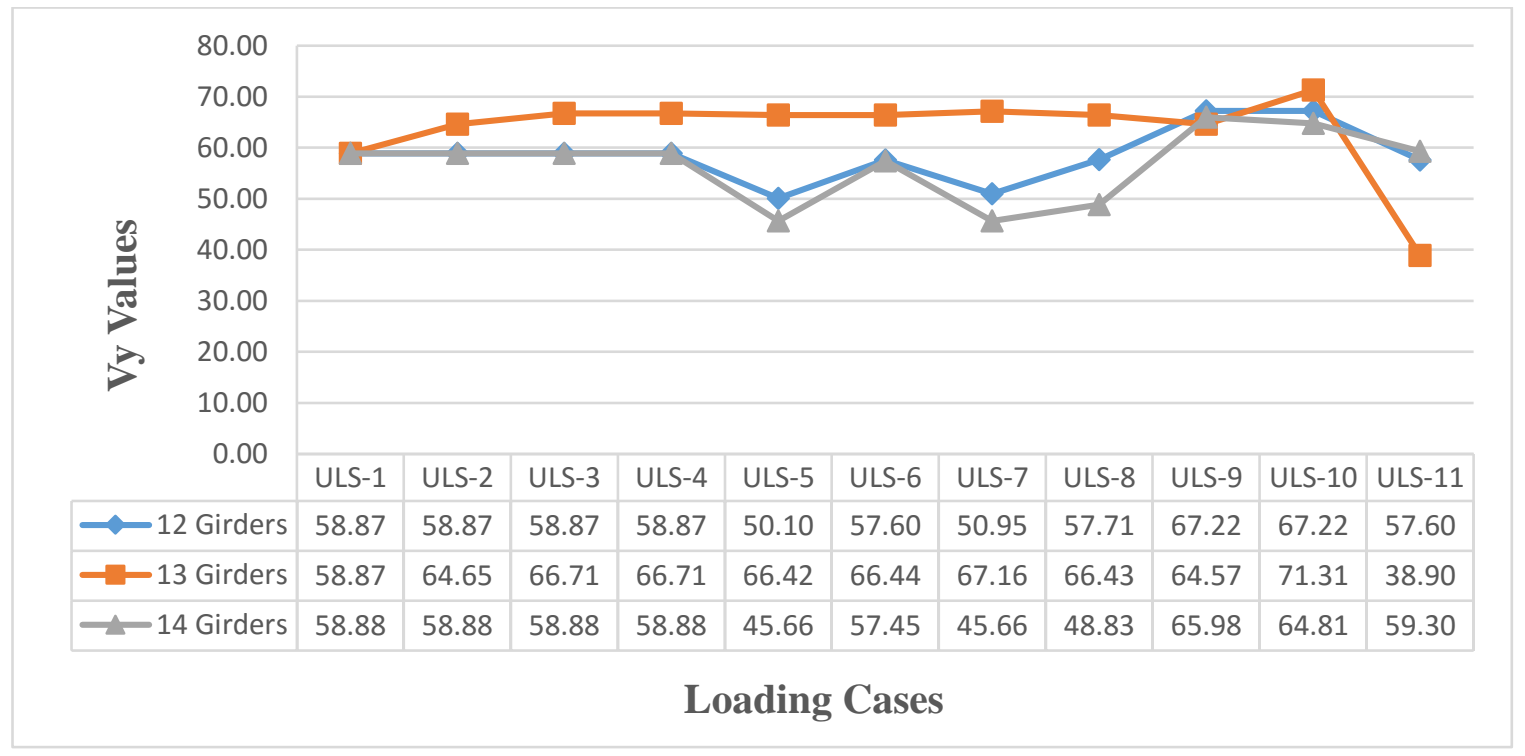

Figure A. 116: Effect of loading cases on transverse shear (four-lane, 10m span) 


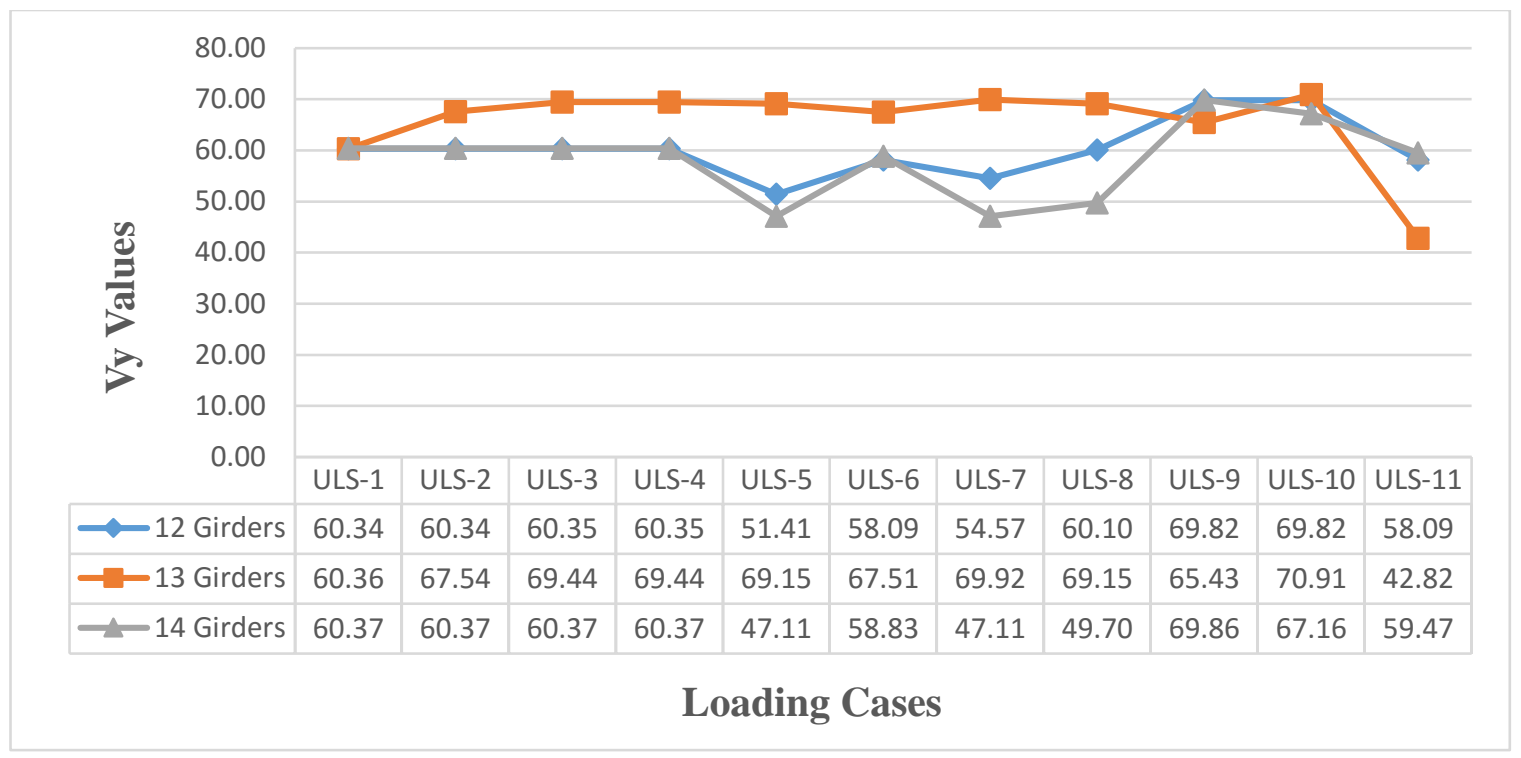

Figure A. 117: Effect of loading cases on transverse shear (four-lane, 13m span)

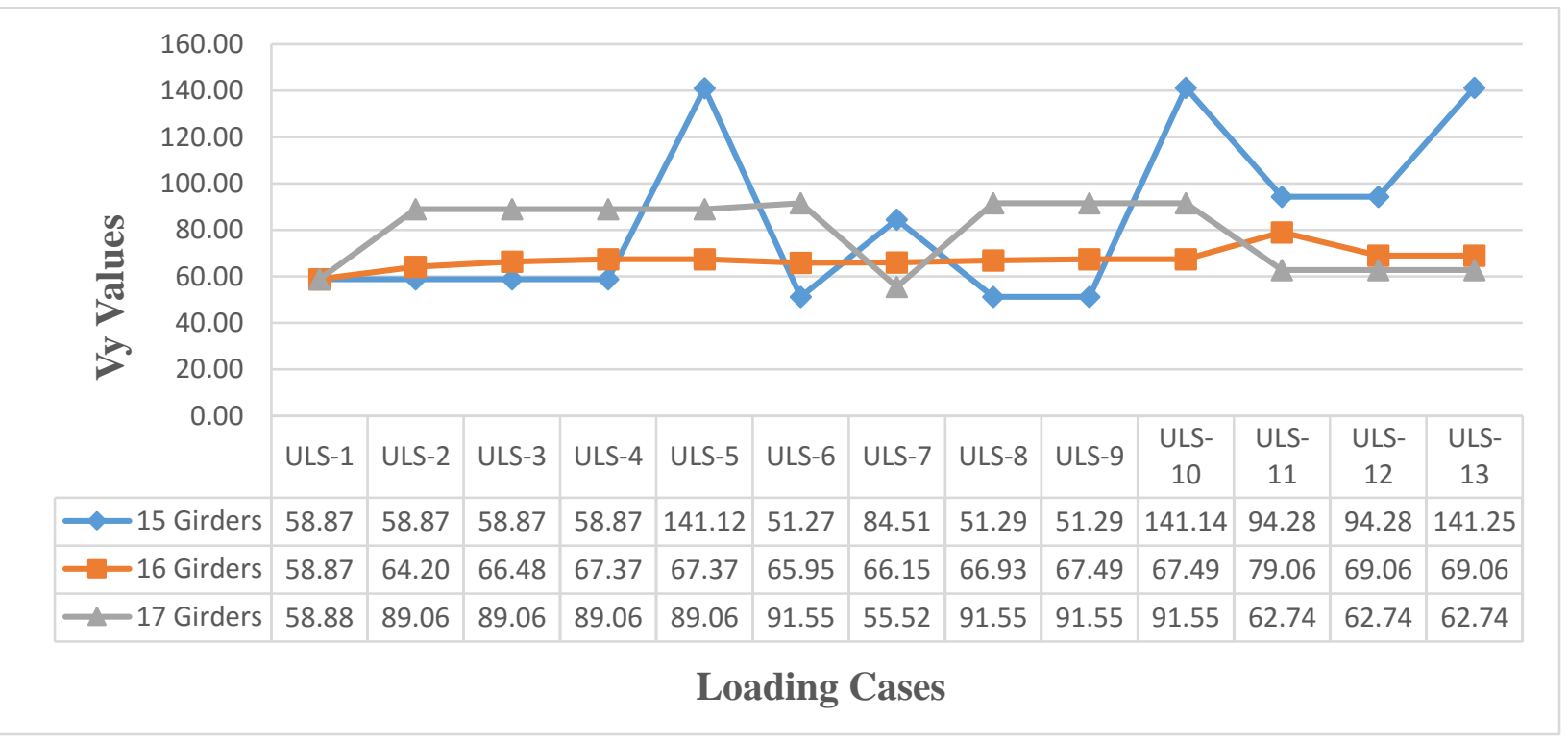

Figure A. 118: Effect of loading cases on transverse shear (five-lane, 10m span) 


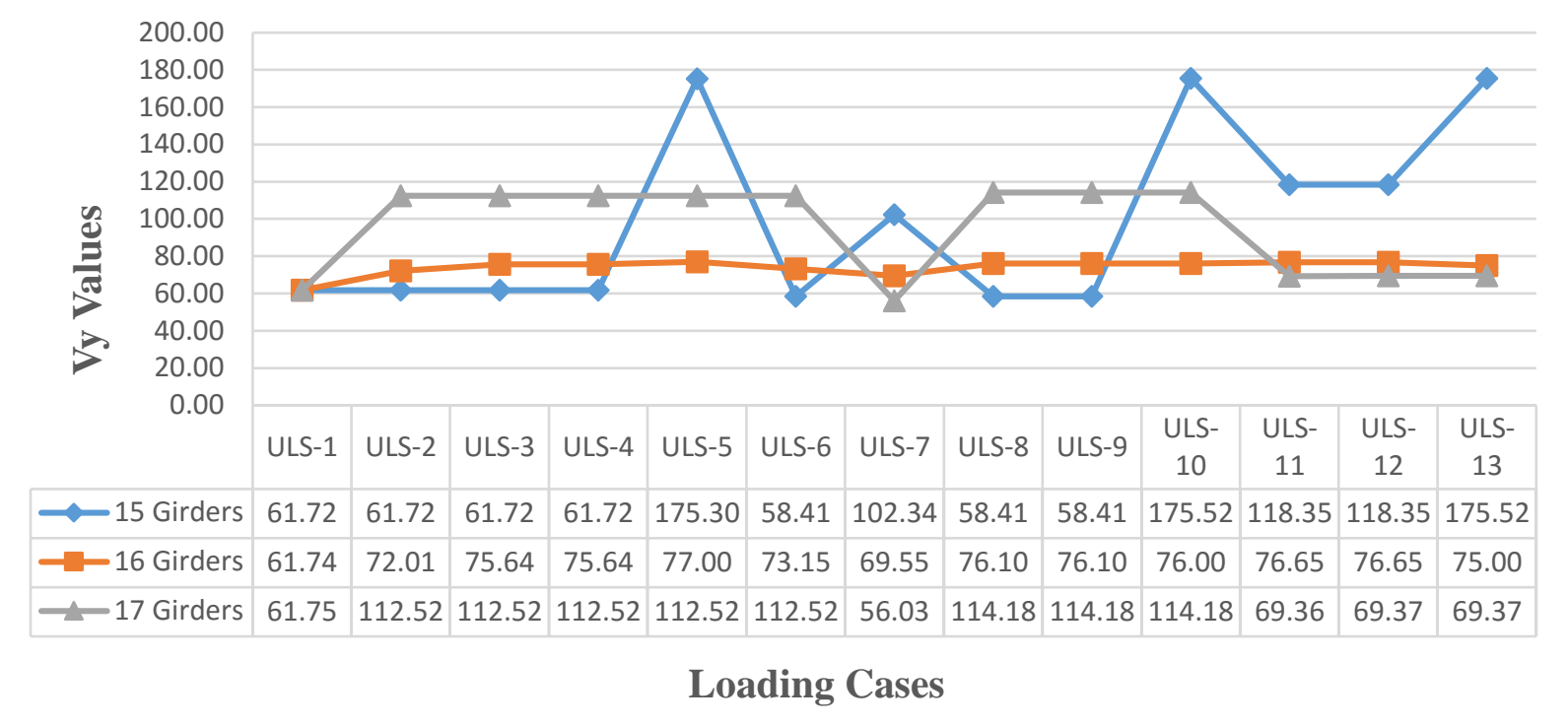

Figure A. 119: Effect of loading cases on transverse shear (five-lane, 20m span)

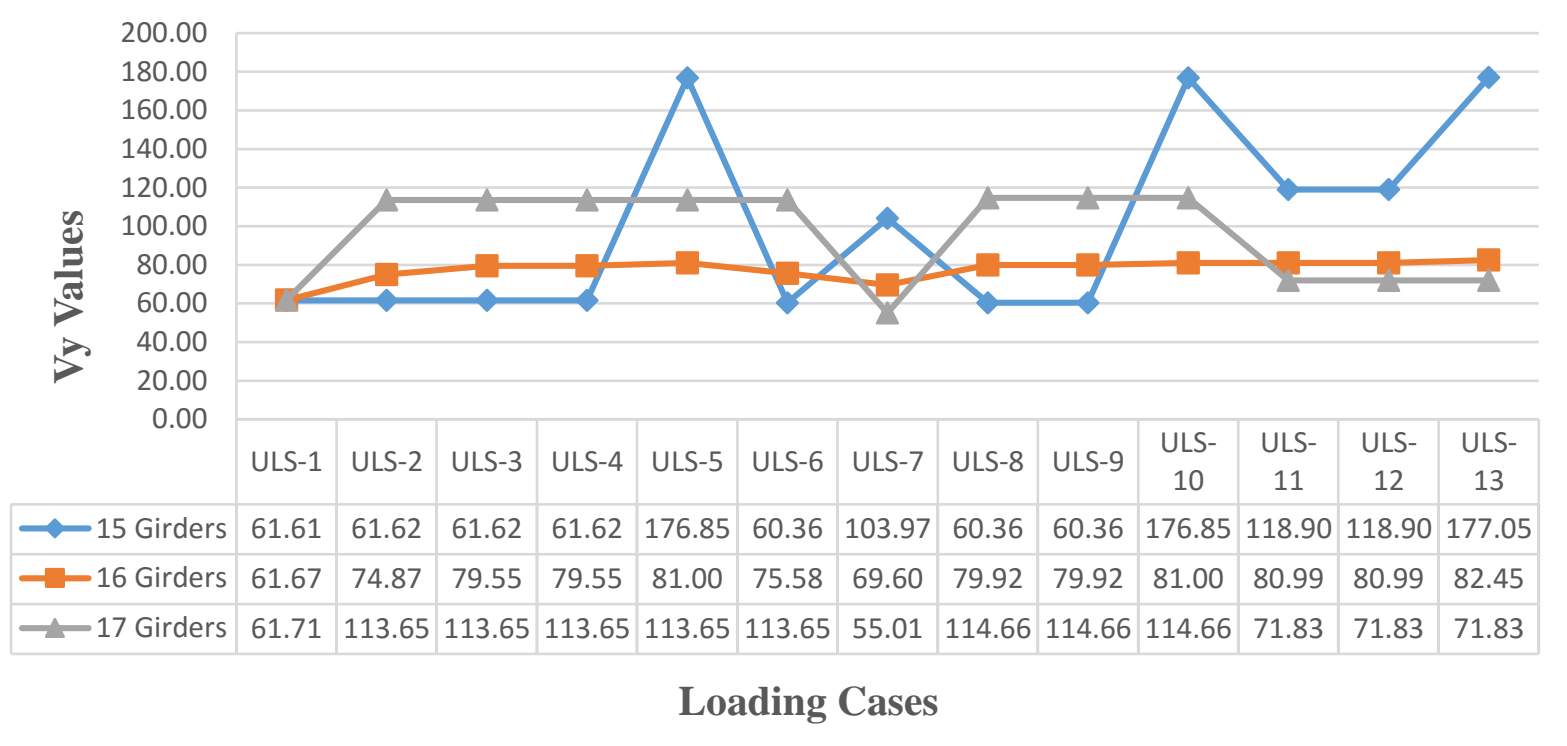

Figure A. 120: Effect of loading cases on transverse shear (five-lane, 32m span) 


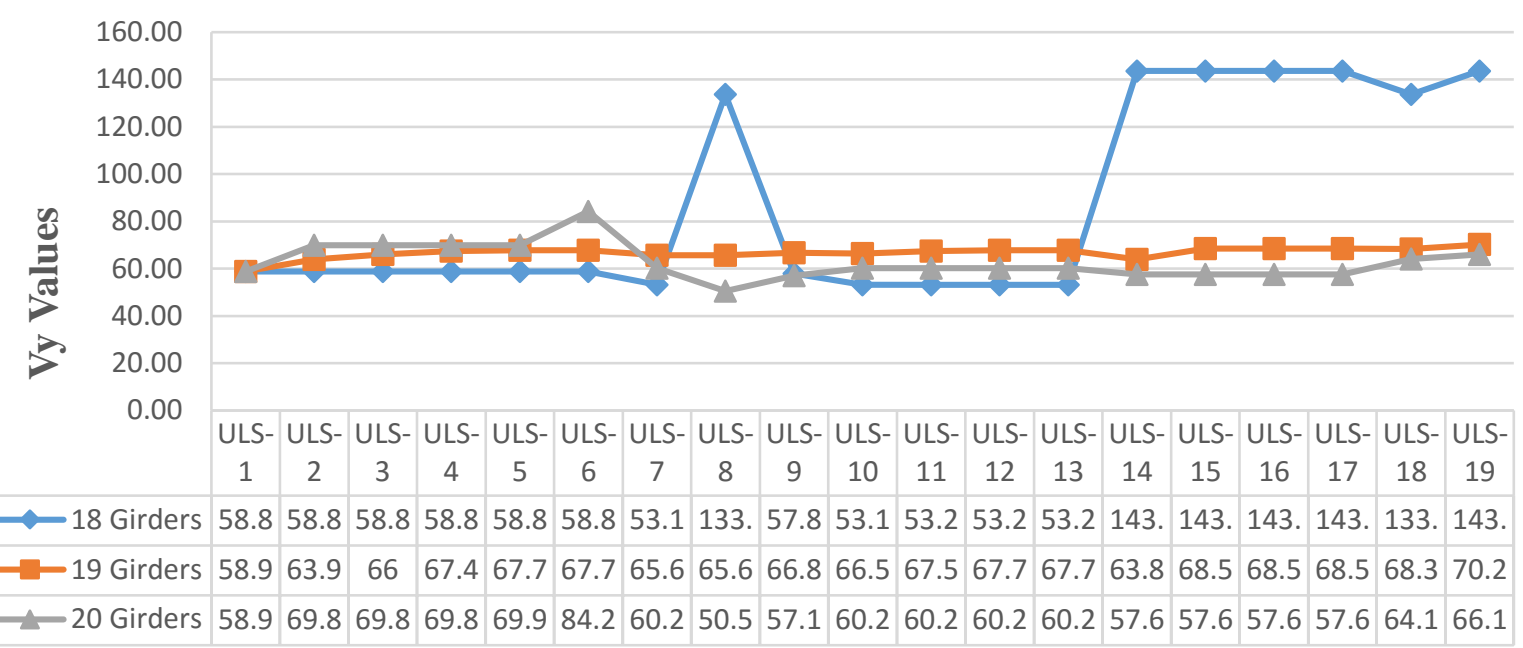

Loading Cases

Figure A. 121: Effect of loading cases on transverse shear (six-lane, 10m span)

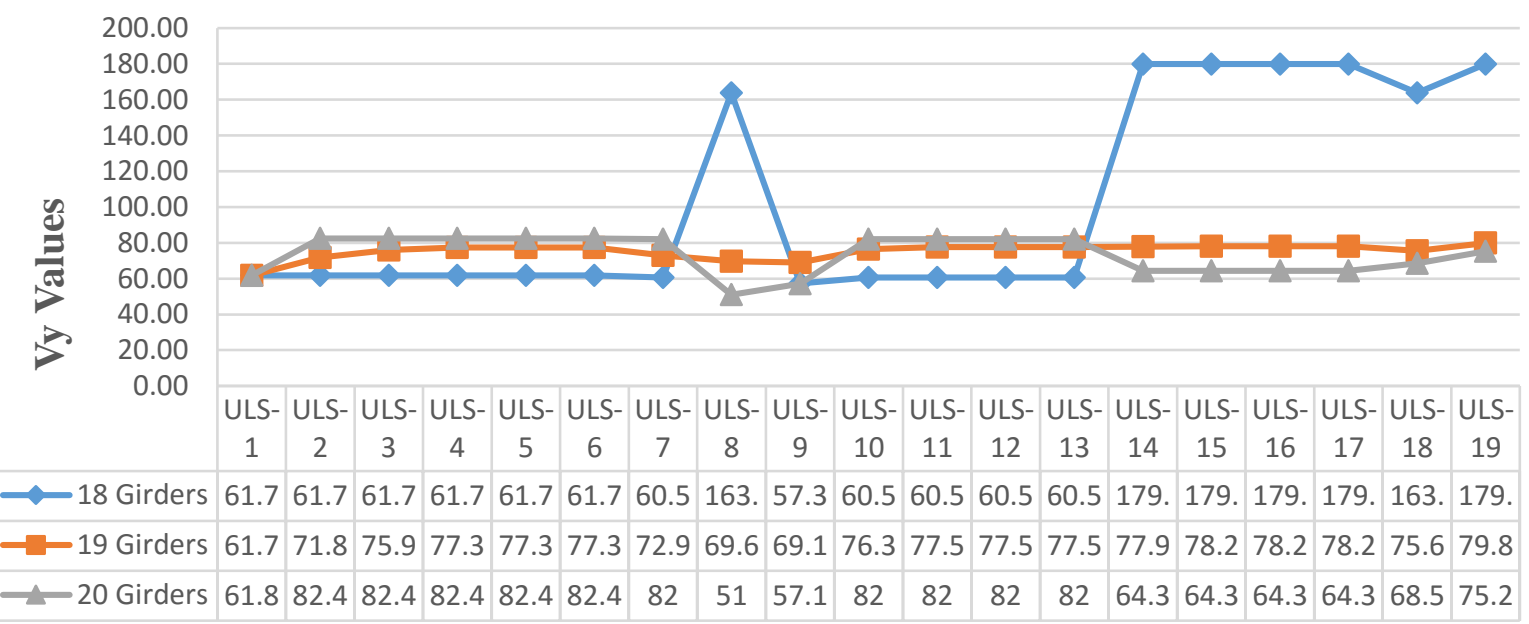

\section{Loading Cases}

Figure A. 122: Effect of loading cases on transverse shear (six-lane, 20m span) 


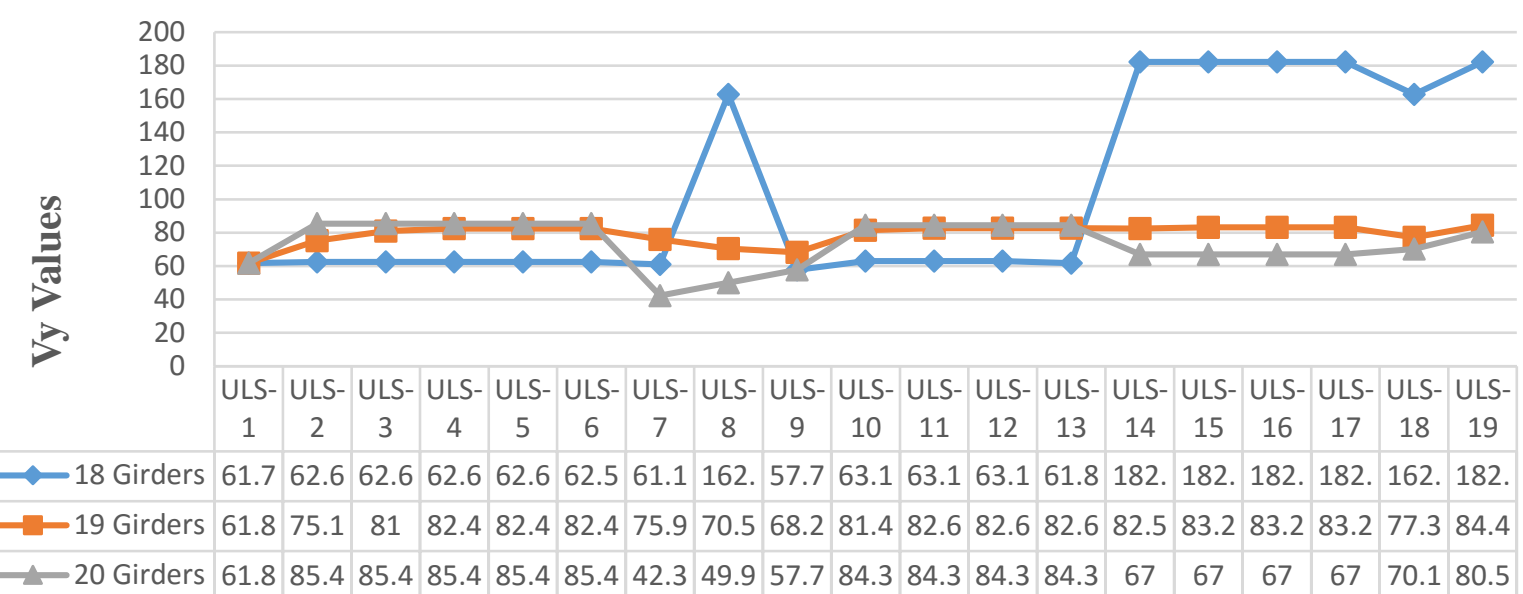

Loading Cases

Figure A. 123: Effect of loading cases on transverse shear (six-lane, 32m span)

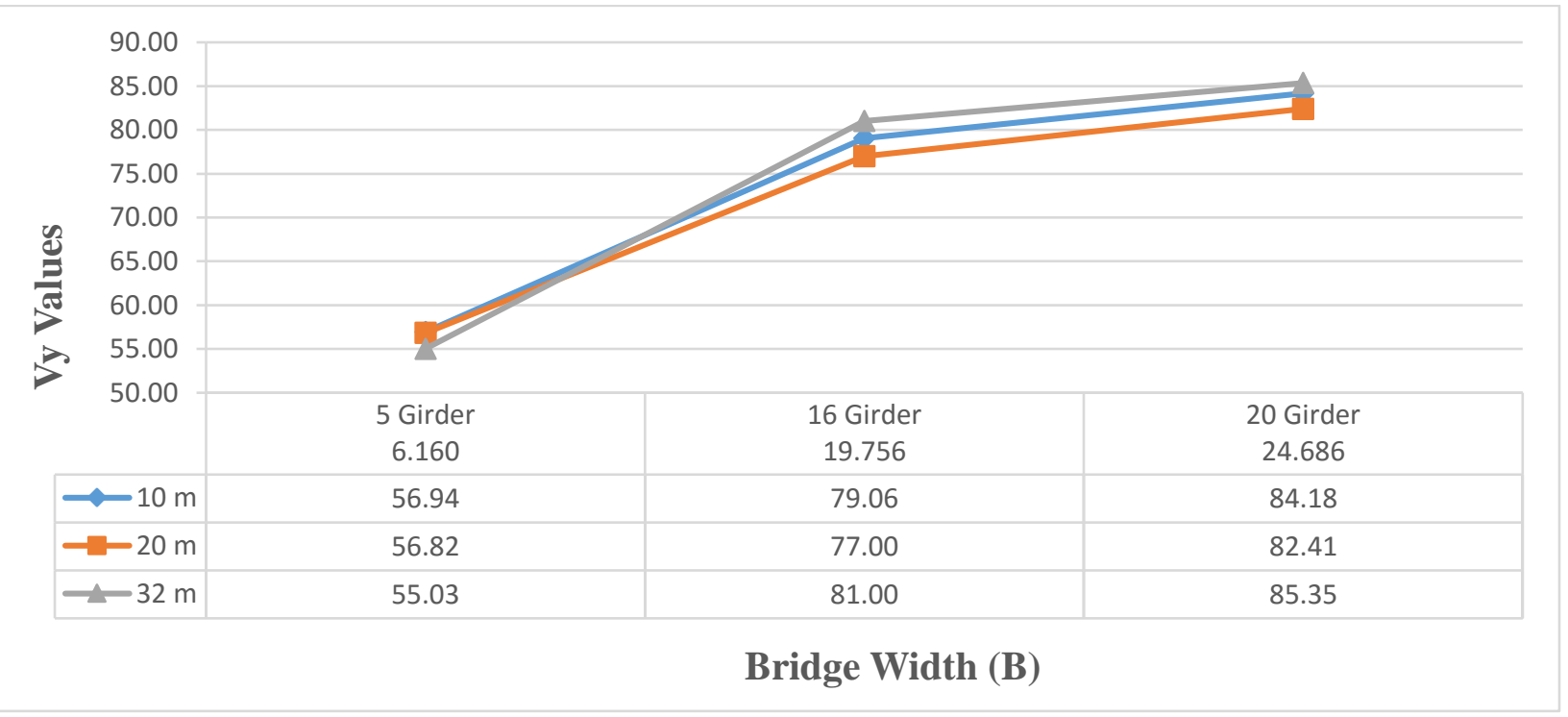

Figure A. 124: Effect of bridge width on transverse shear (5 girders, 16 girders, and 20 girders) 


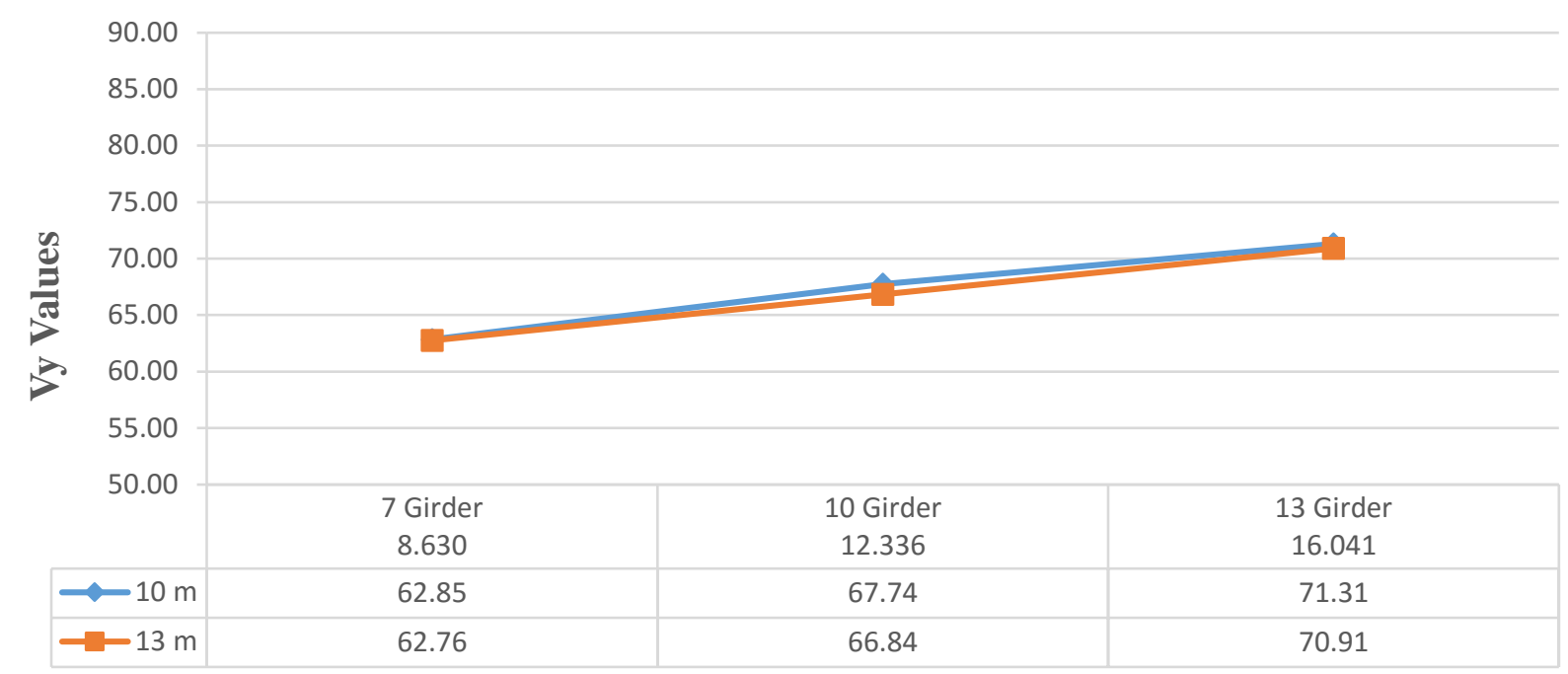

Bridge Width

Figure A. 125: Effect of bridge width on transverse shear (7 girders, 10 girders, and 13 girders)

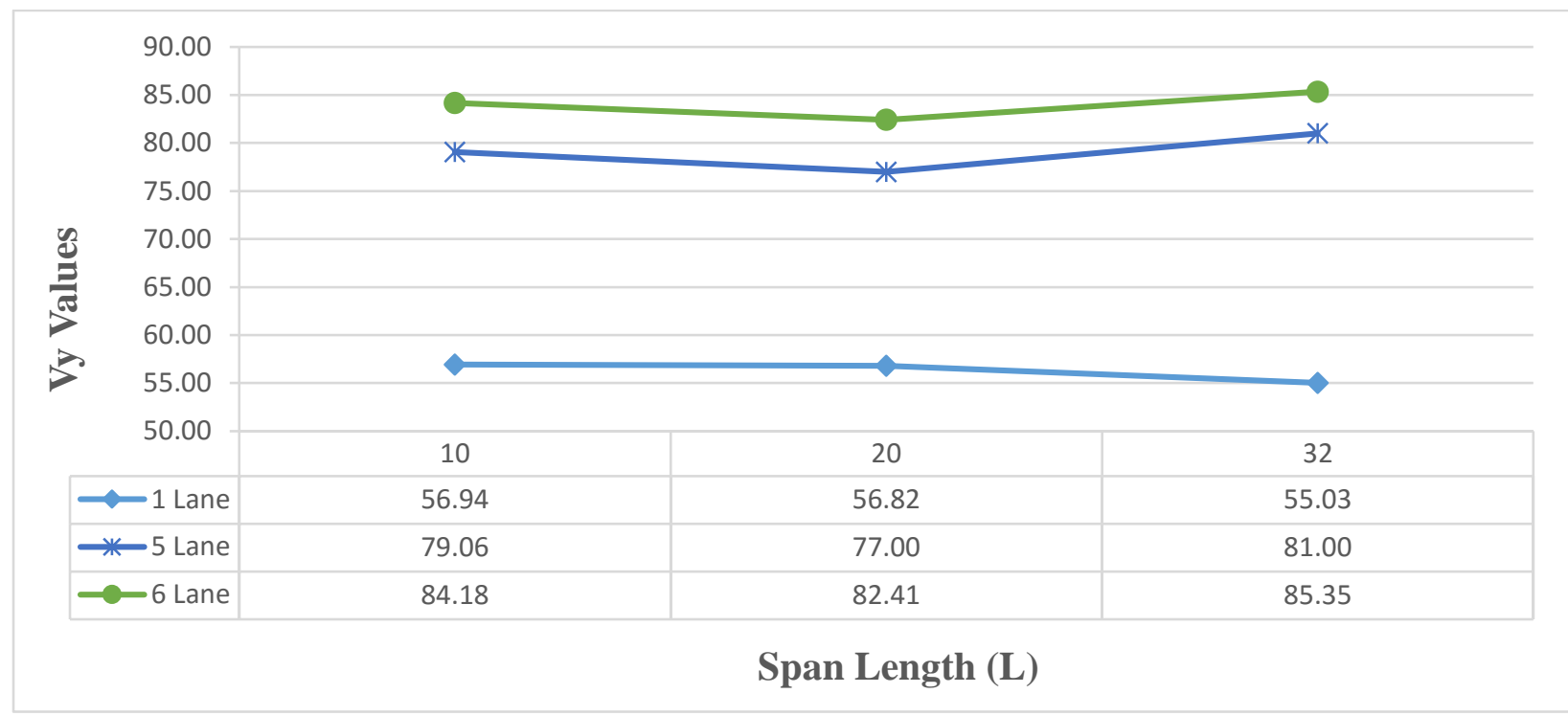

Figure A. 126: Effect of span length on transverse shear (one-lane, five-lanes, and six-lanes) 


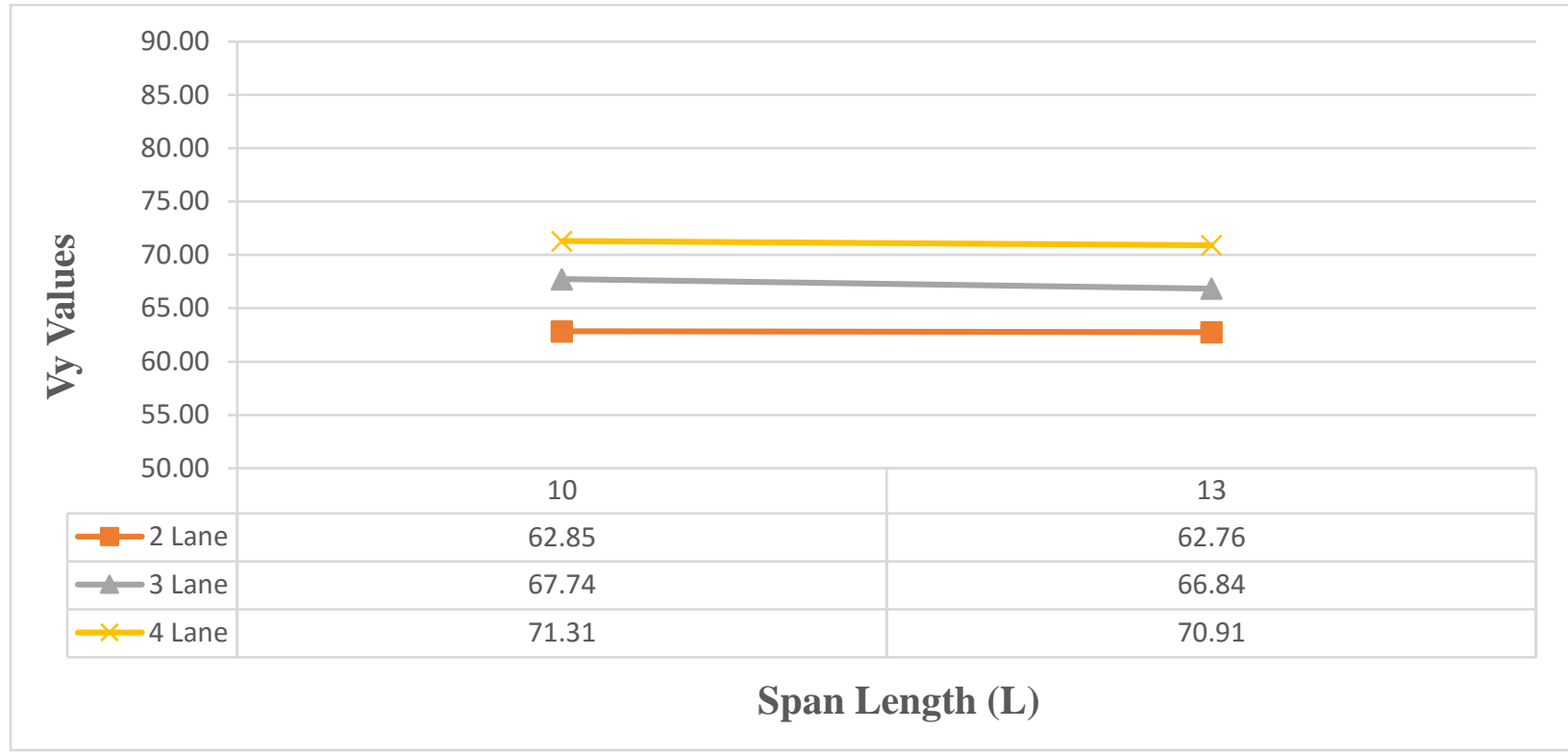

Figure A. 127: Effect of span length on transverse shear (two-lane, three-lanes, and fourlanes)

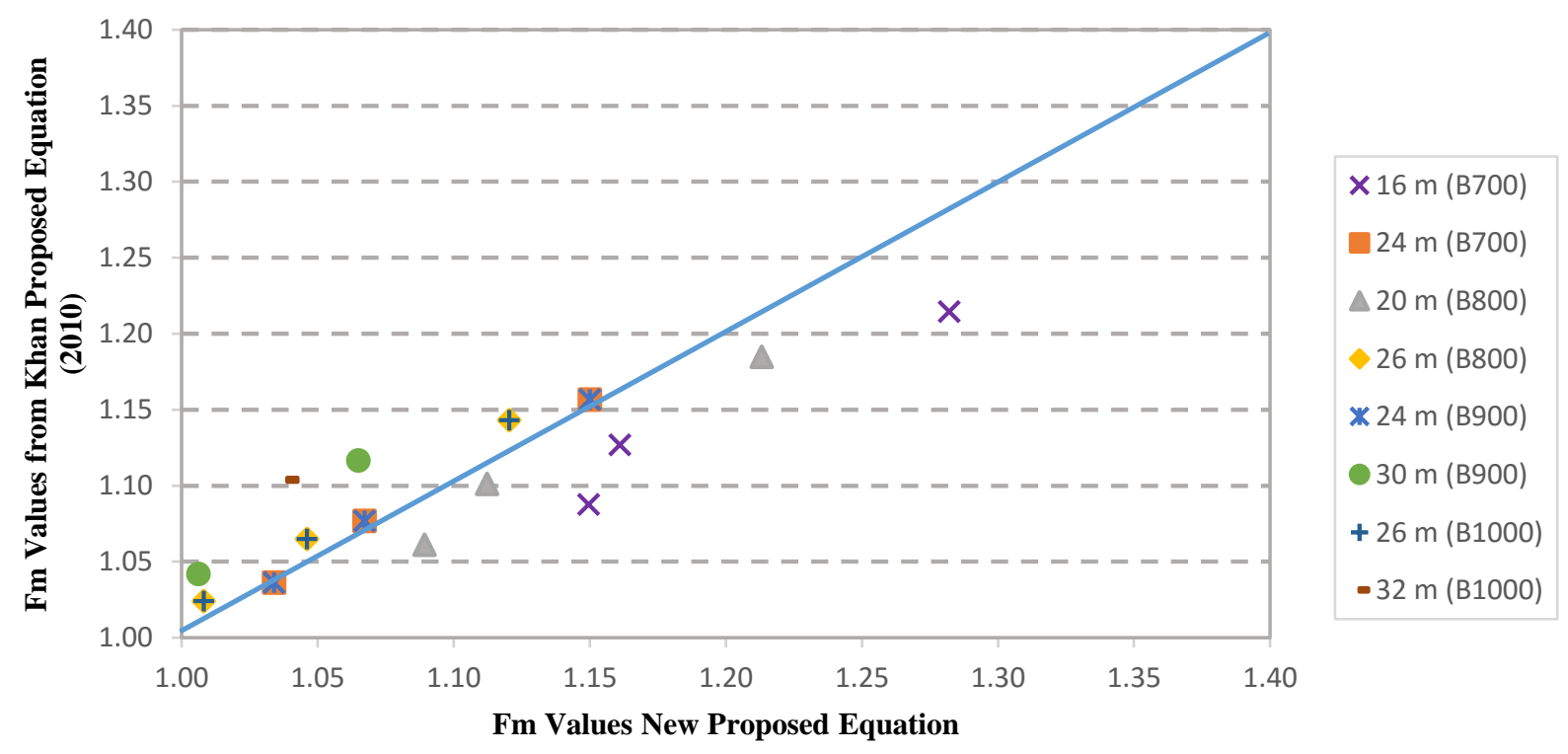

Figure A. 128: Comparison between the FEA results from the current study and those from Khan 2010 study (two-lane, Fm at ULS) 


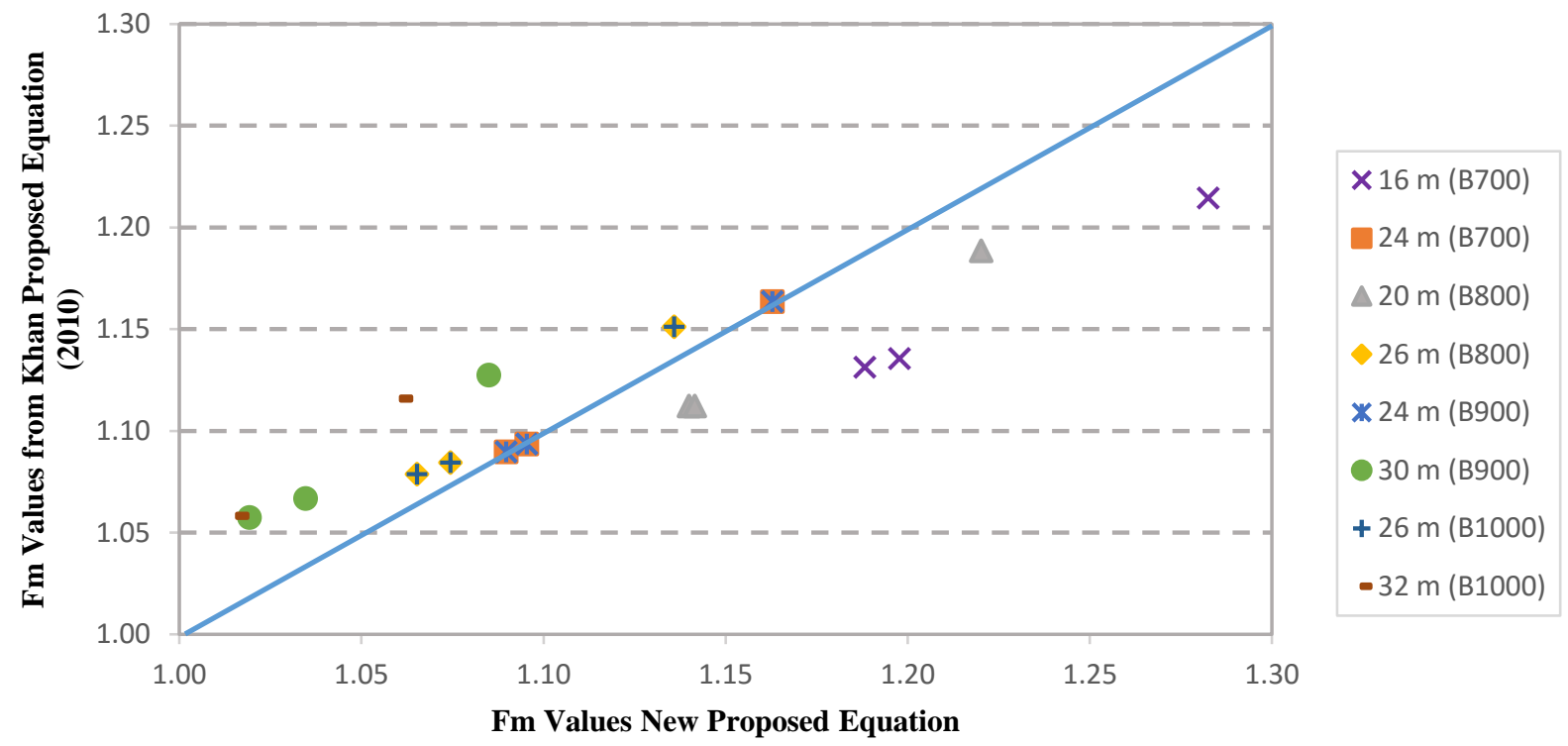

Figure A. 129: Comparison between the FEA results from the current study and those from Khan 2010 study (three-lane, Fm at ULS)

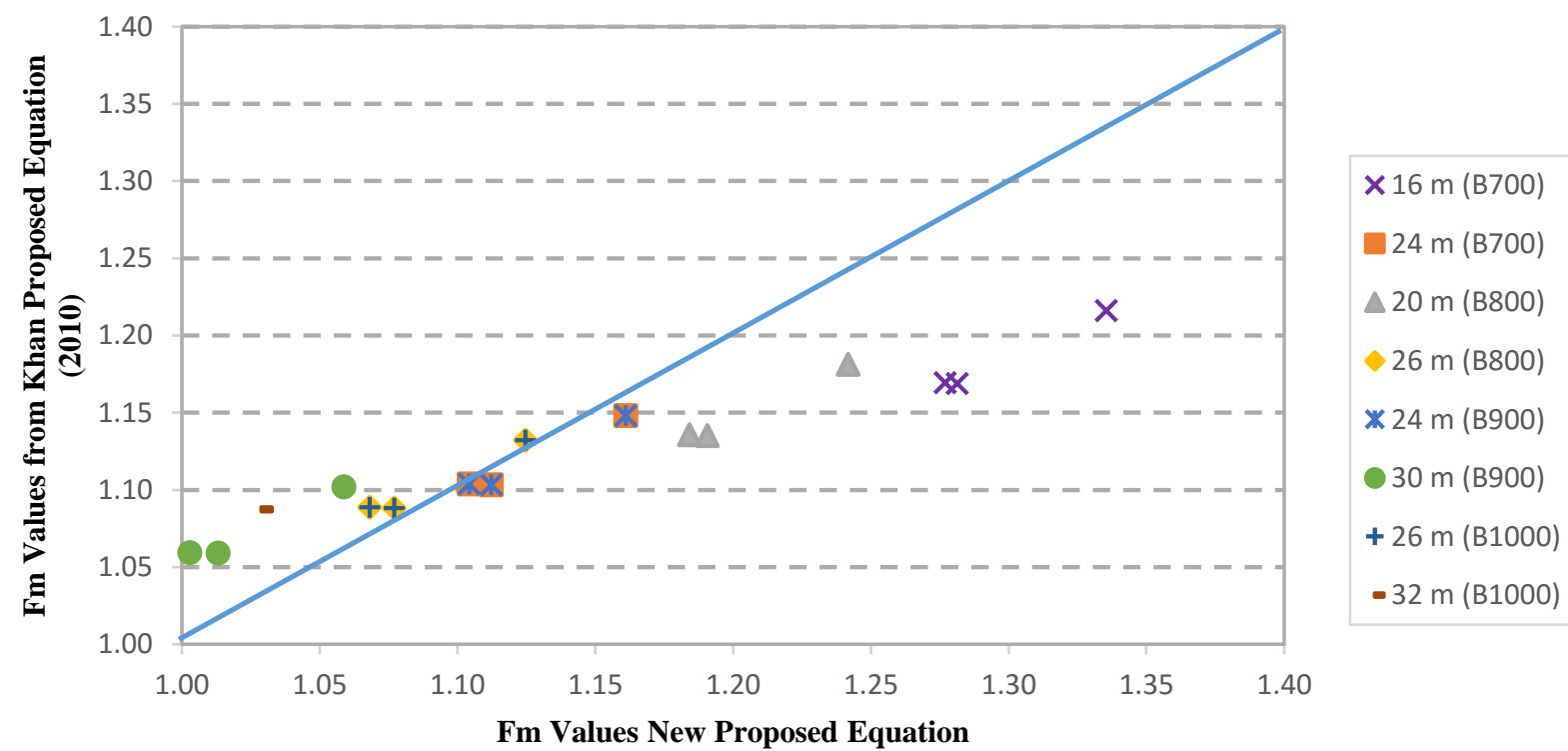

Figure A. 130: Comparison between the FEA results from the current study and those from Khan 2010 study (four-lane, Fm at ULS) 


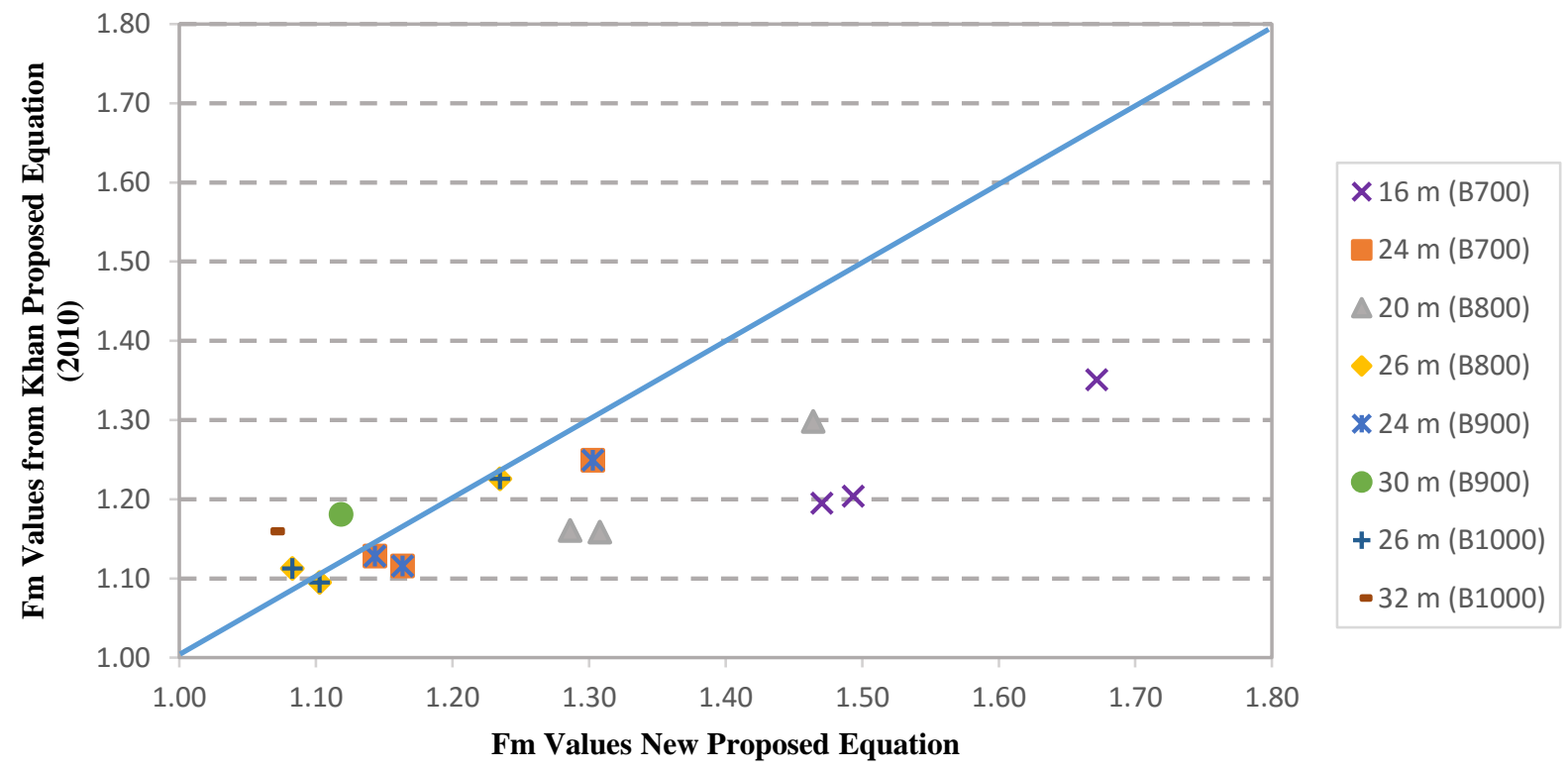

Figure A. 131: Comparison between the FEA results from the current study and those from Khan 2010 study (two-lane, Fm at FLS)

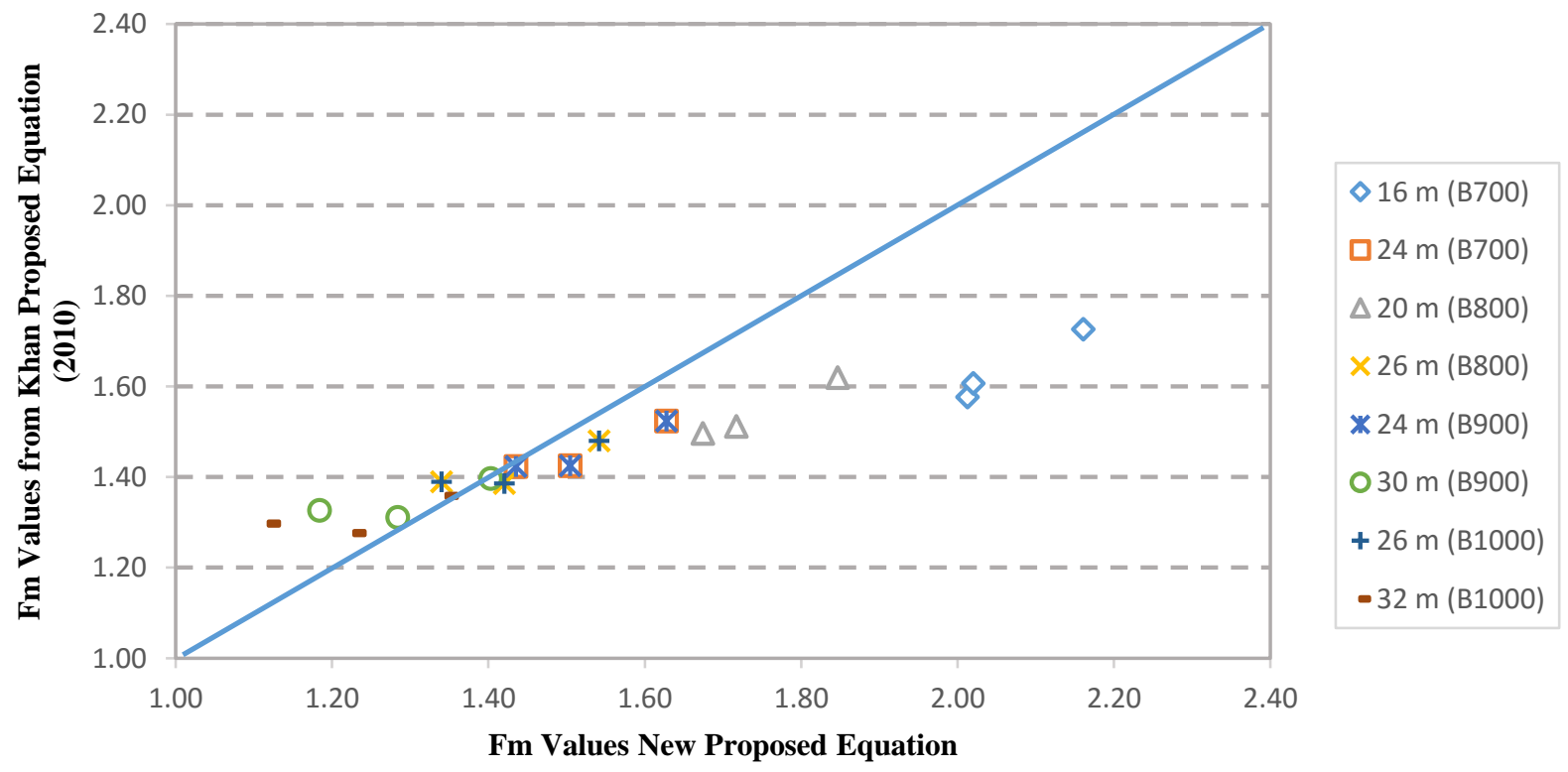

Figure A. 132: Comparison between the FEA results from the current study and those from Khan 2010 study (three-lane, Fm at FLS) 


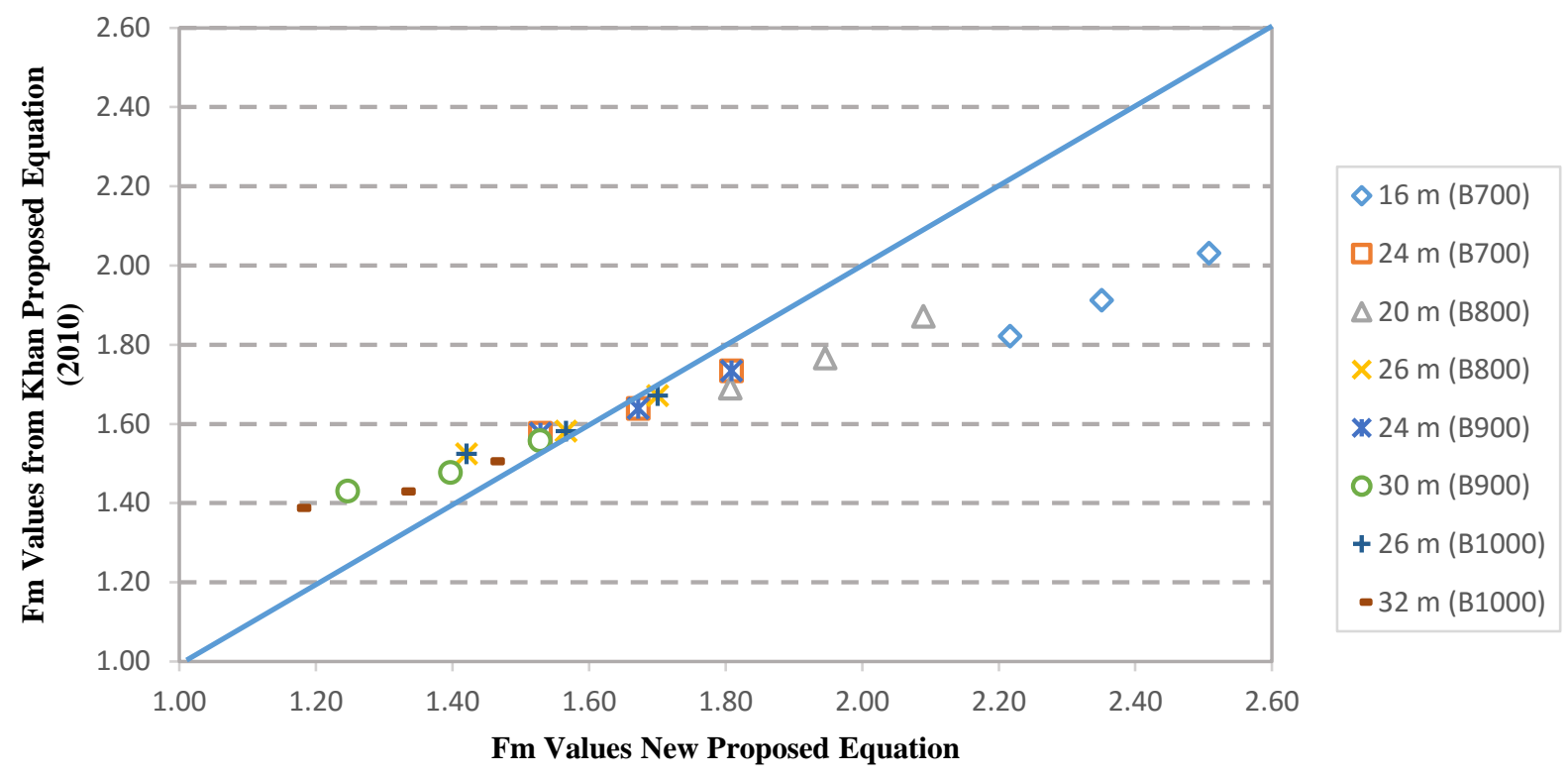

Figure A. 133: Comparison between the FEA results from the current study and those from Khan 2010 study (two-lane, Fm at FLS)

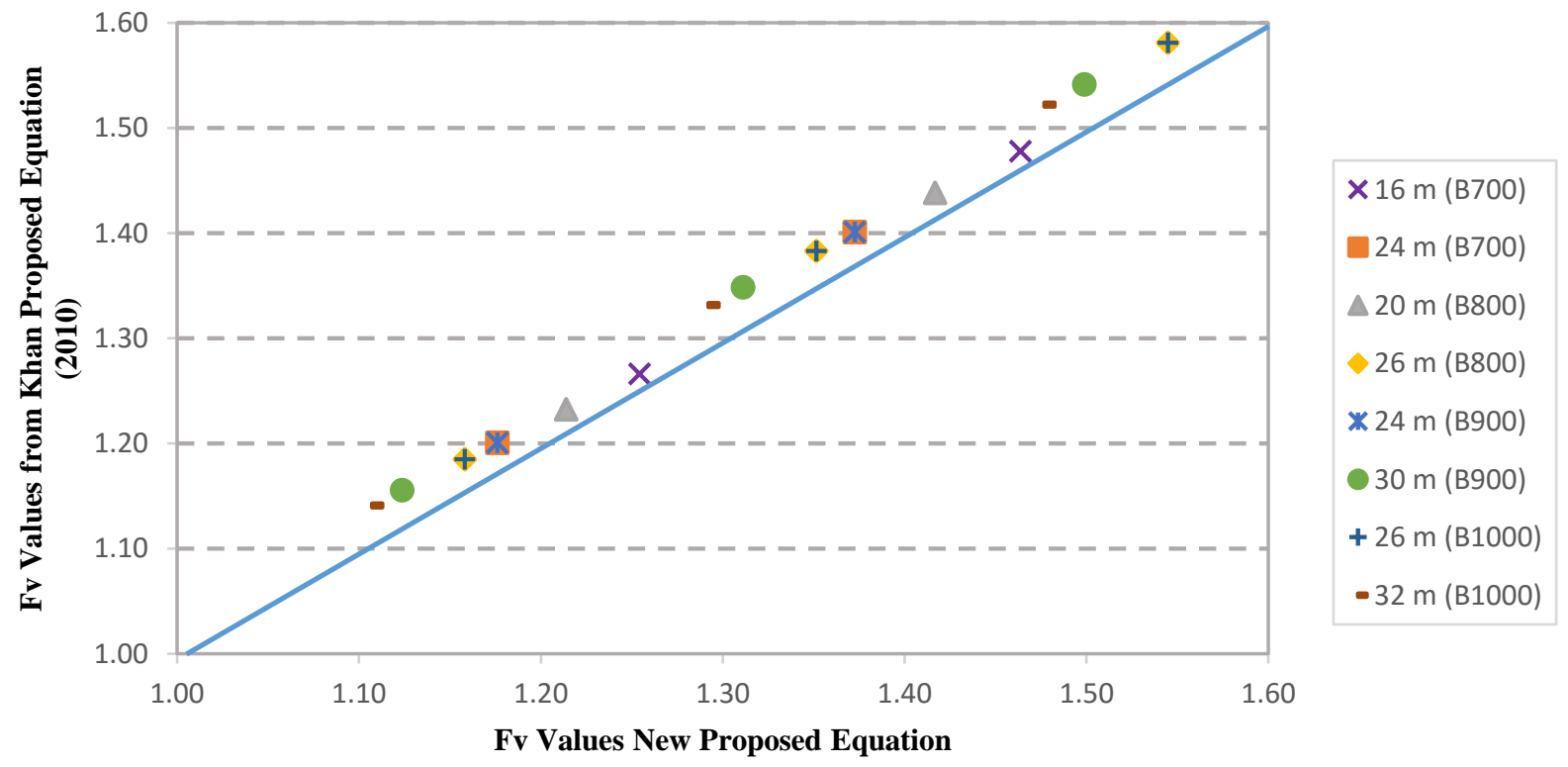

Figure A. 134: Comparison between the FEA results from the current study and those from Khan 2010 study (two-lane, Fv at ULS) 


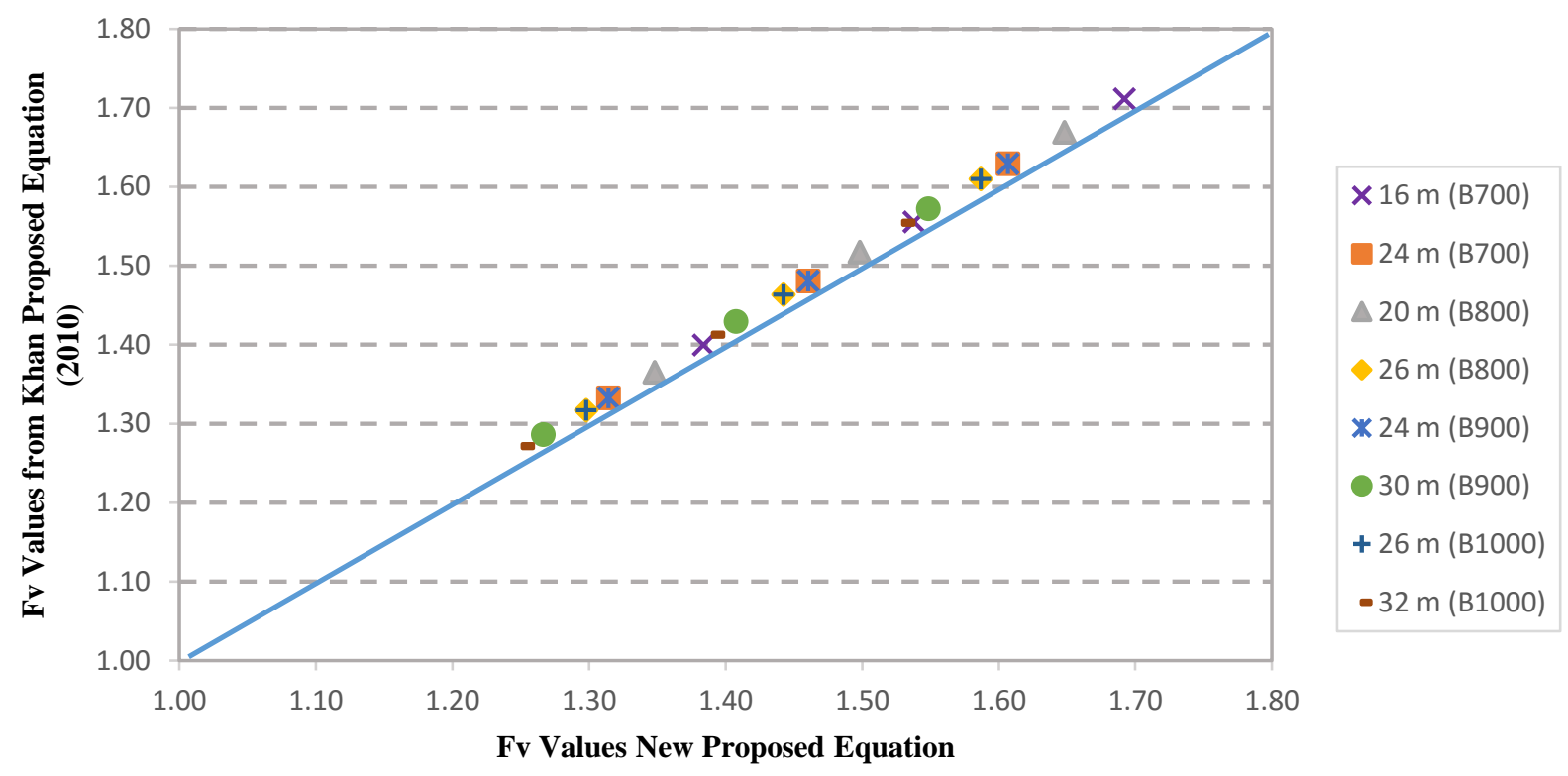

Figure A. 135: Comparison between the FEA results from the current study and those from Khan 2010 study (three-lane, Fv at ULS)

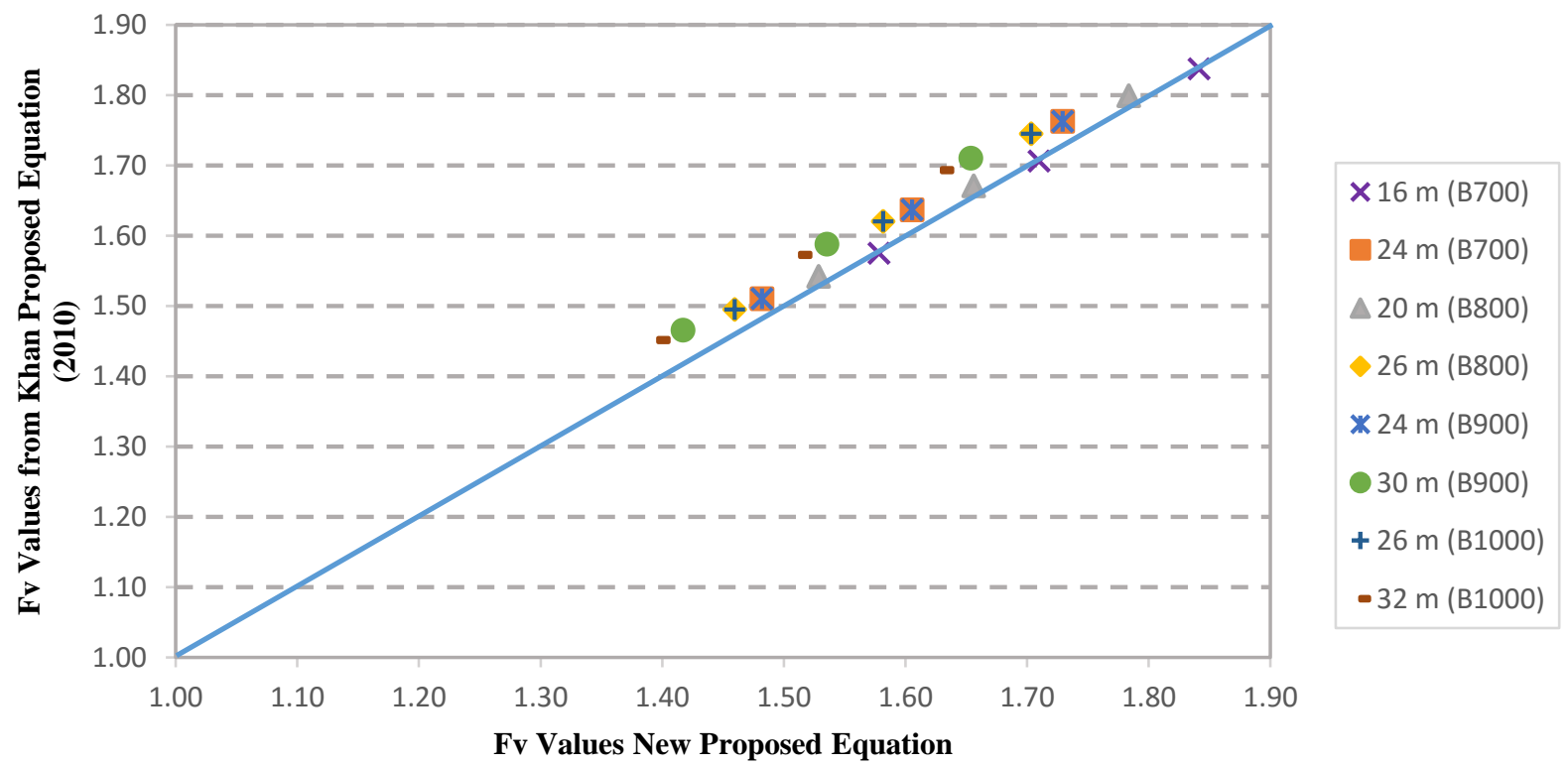

Figure A. 136: Comparison between the FEA results from the current study and those from Khan 2010 study (four-lane, Fv at ULS) 


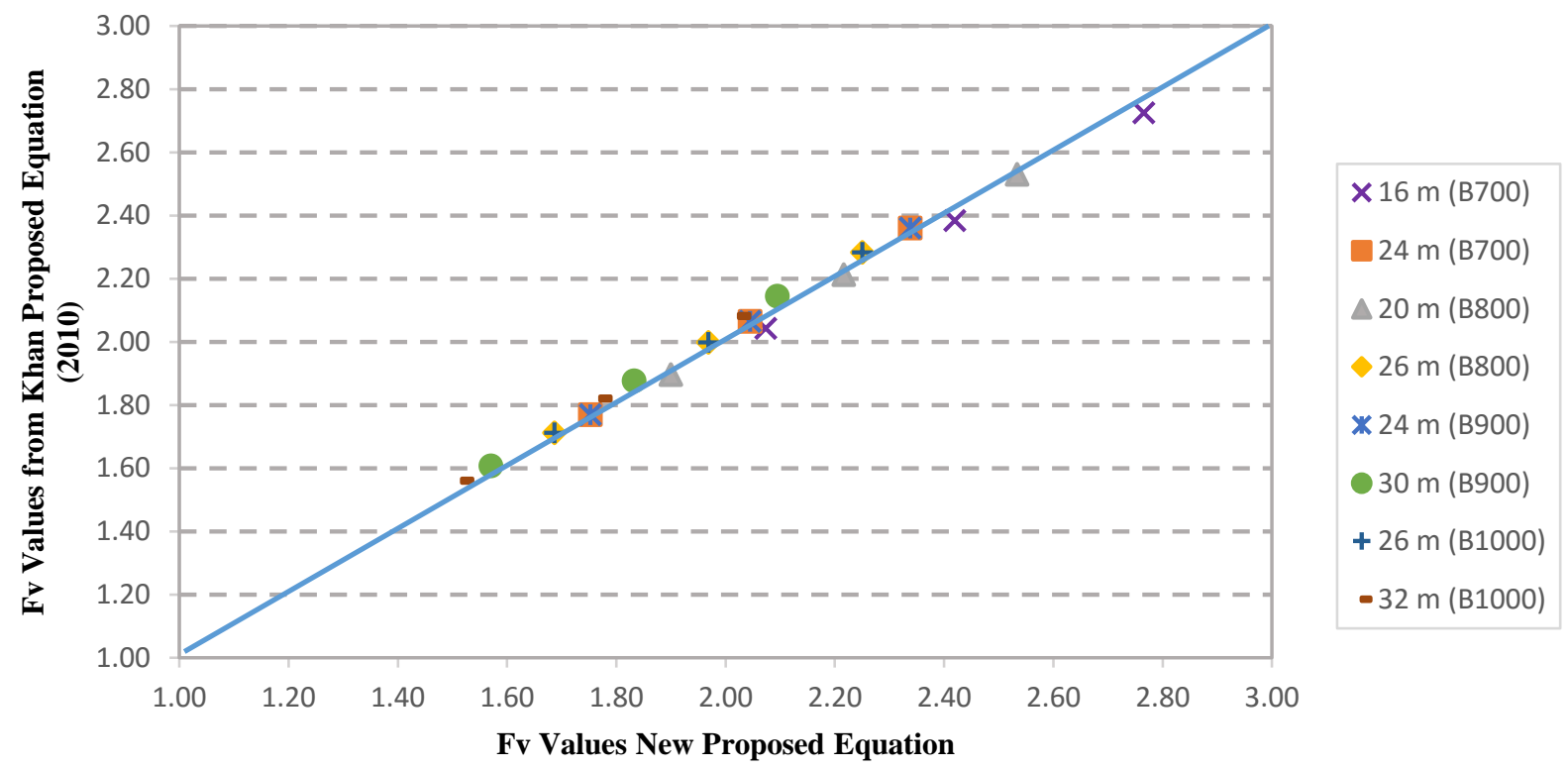

Figure A. 137: Comparison between the FEA results from the current study and those from Khan 2010 study (two-lane, Fv at FLS)

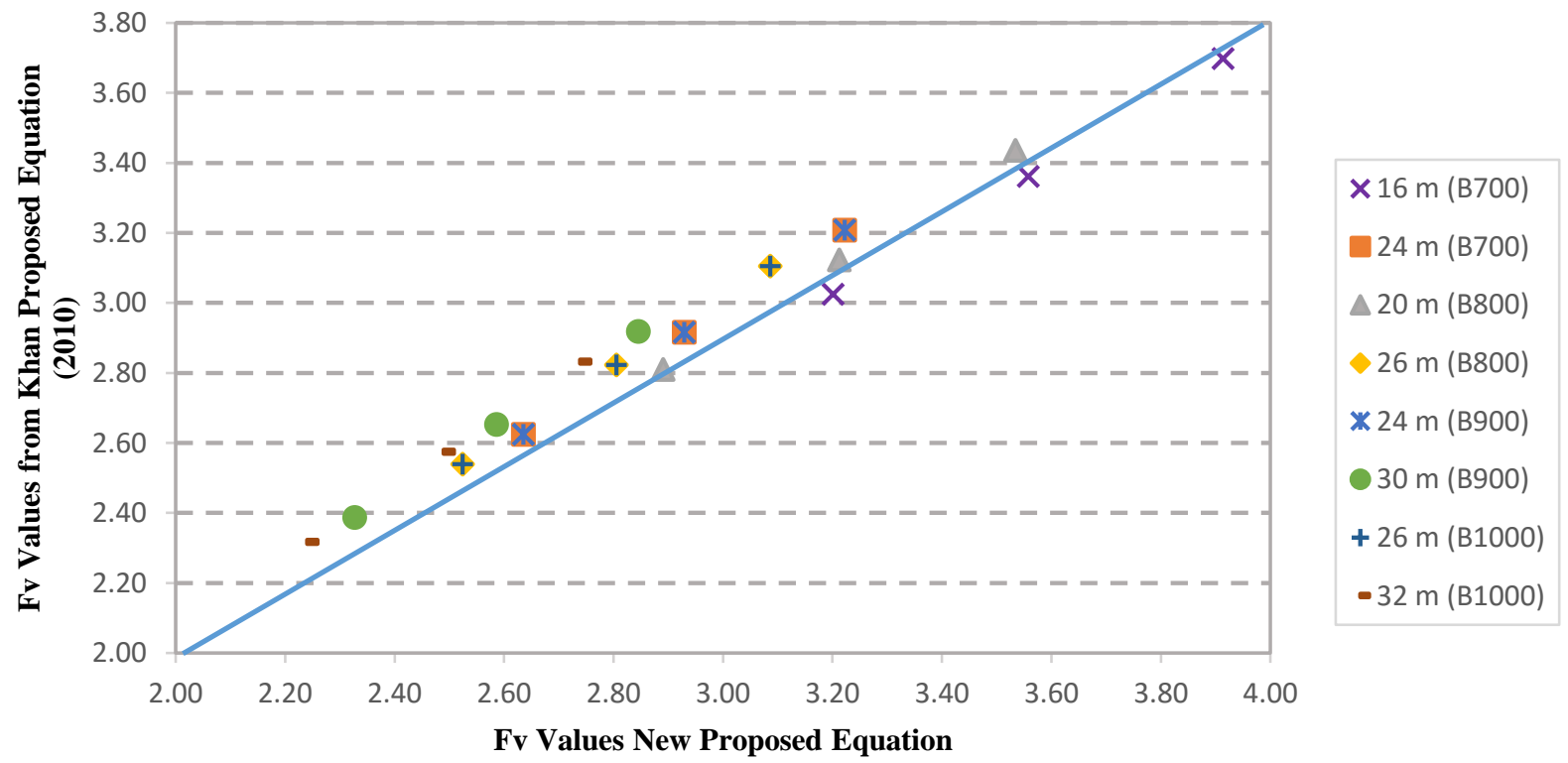

Figure A. 138: Comparison between the FEA results from the current study and those from Khan 2010 study (three-lane, Fv at FLS) 


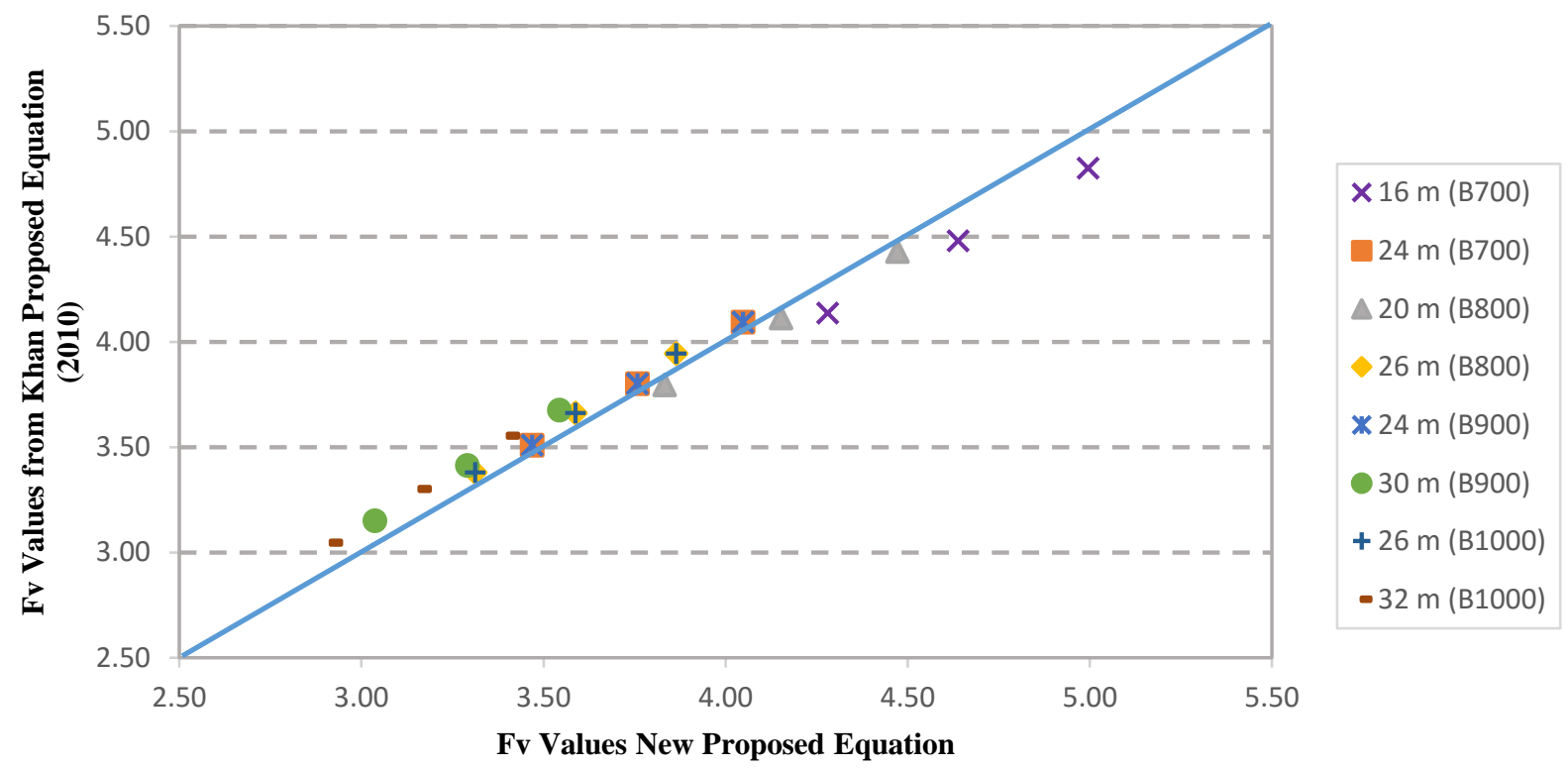

Figure A. 139: Comparison between the FEA results from the current study and those from Khan 2010 study (four-lane, Fv at FLS)

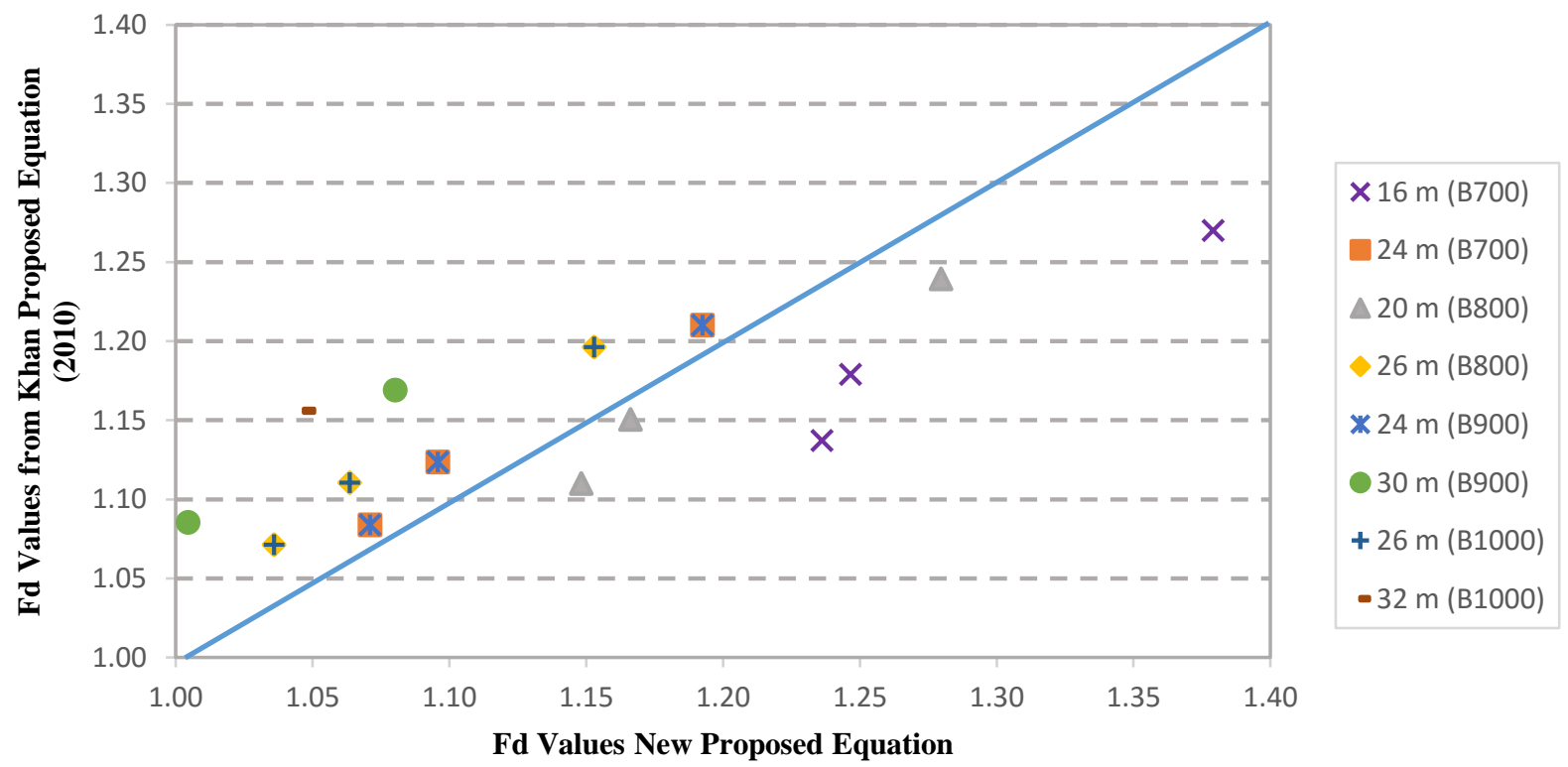

Figure A. 140: Comparison between the FEA results from the current study and those from Khan 2010 study (two-lane, Fd at FLS) 


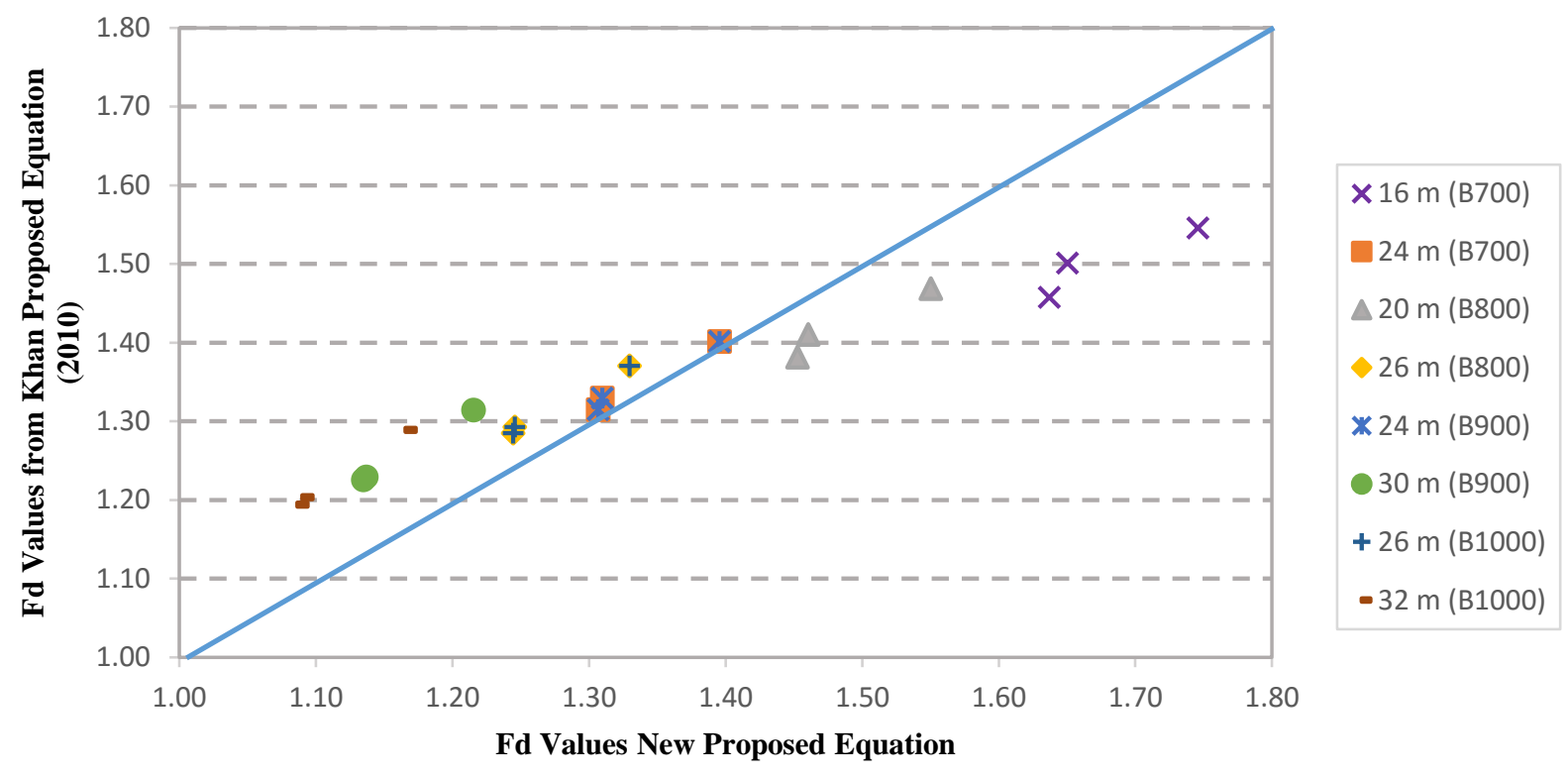

Figure A. 141: Comparison between the FEA results from the current study and those from Khan 2010 study (three-lane, Fd at FLS)

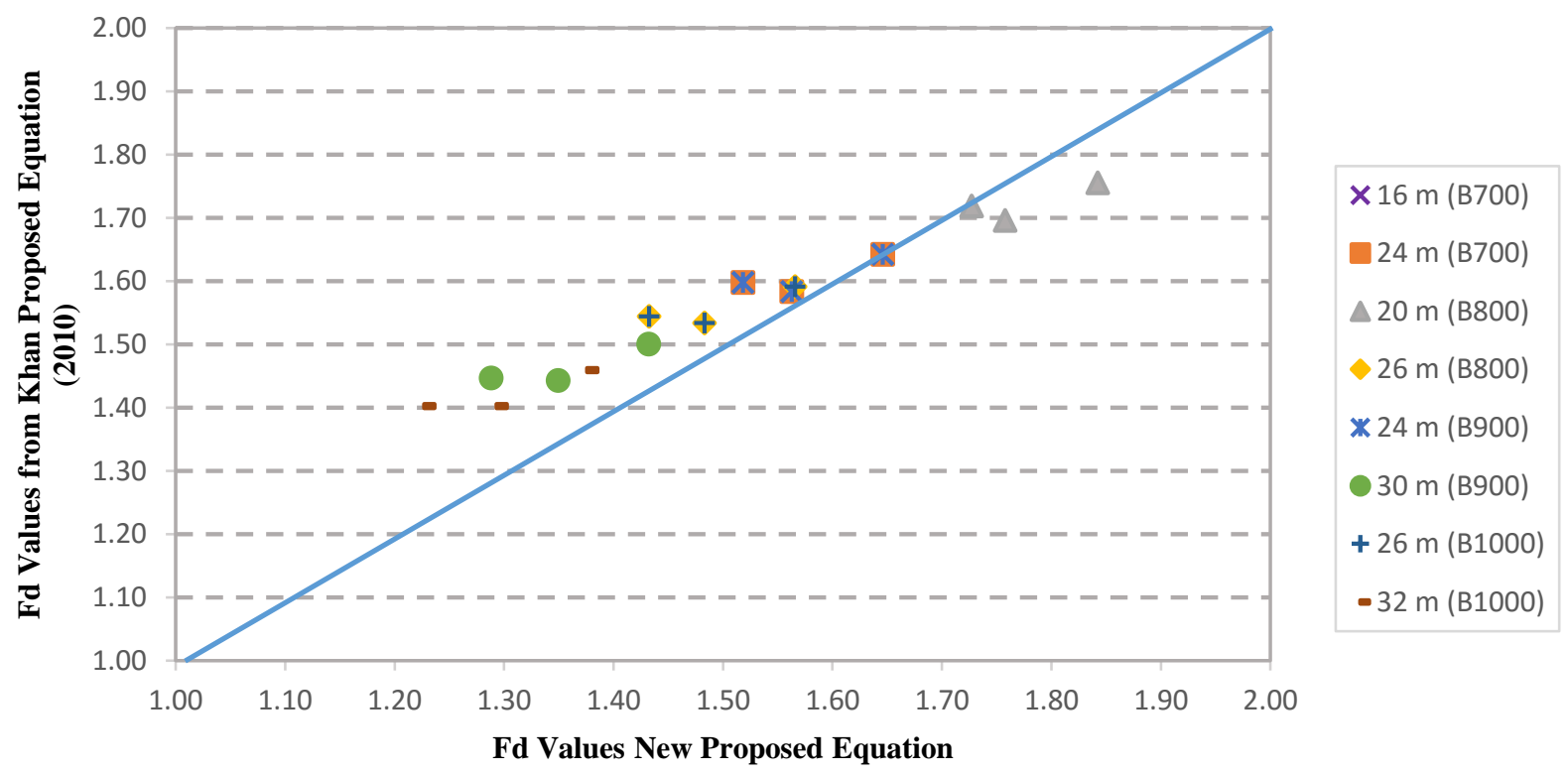

Figure A. 142: Comparison between the FEA results from the current study and those from Khan 2010 study (four-lane, Fd at FLS) 


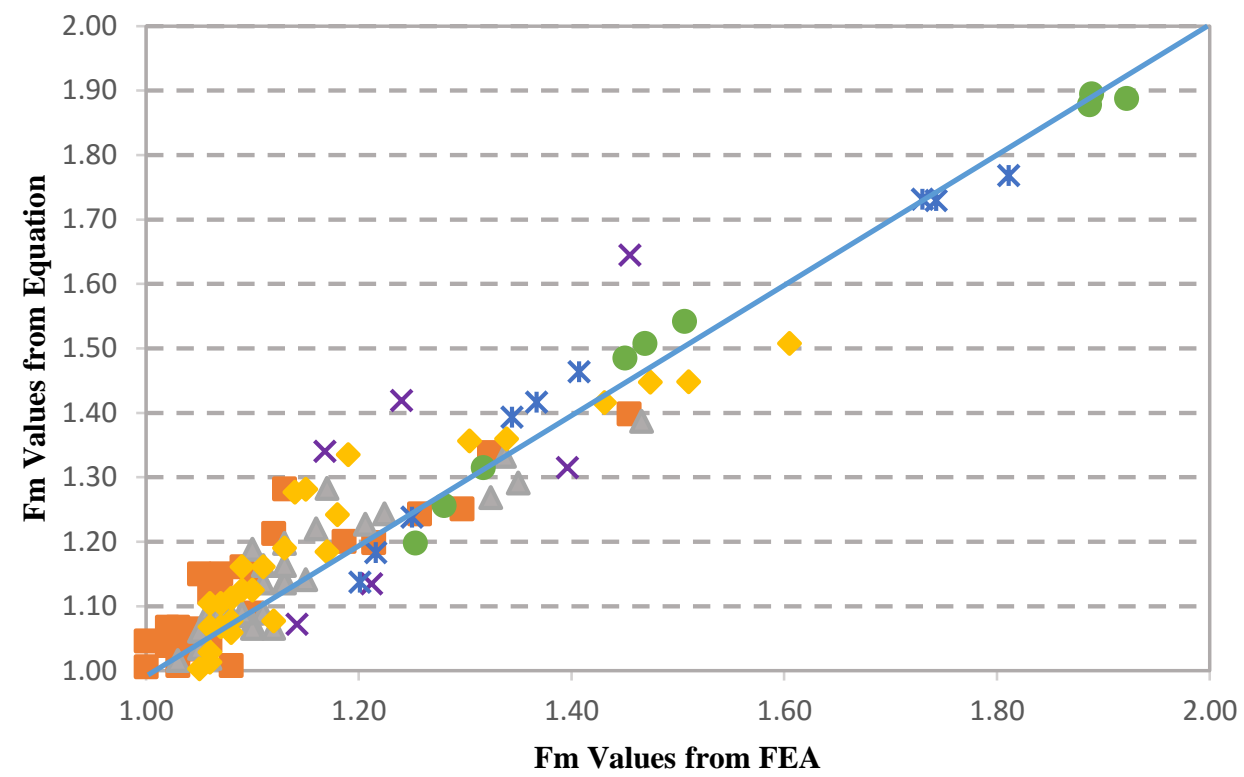

X One Design Lane Two Design Lanes

$\triangle$ Three Design Lanes Four Design Lanes * Five Design Lanes Six Design Lanes

Figure A. 143: Correlation between the FEA results and those from the proposed equations for box girder bridges at ULS design for moment (Based on CHBDC 2006)

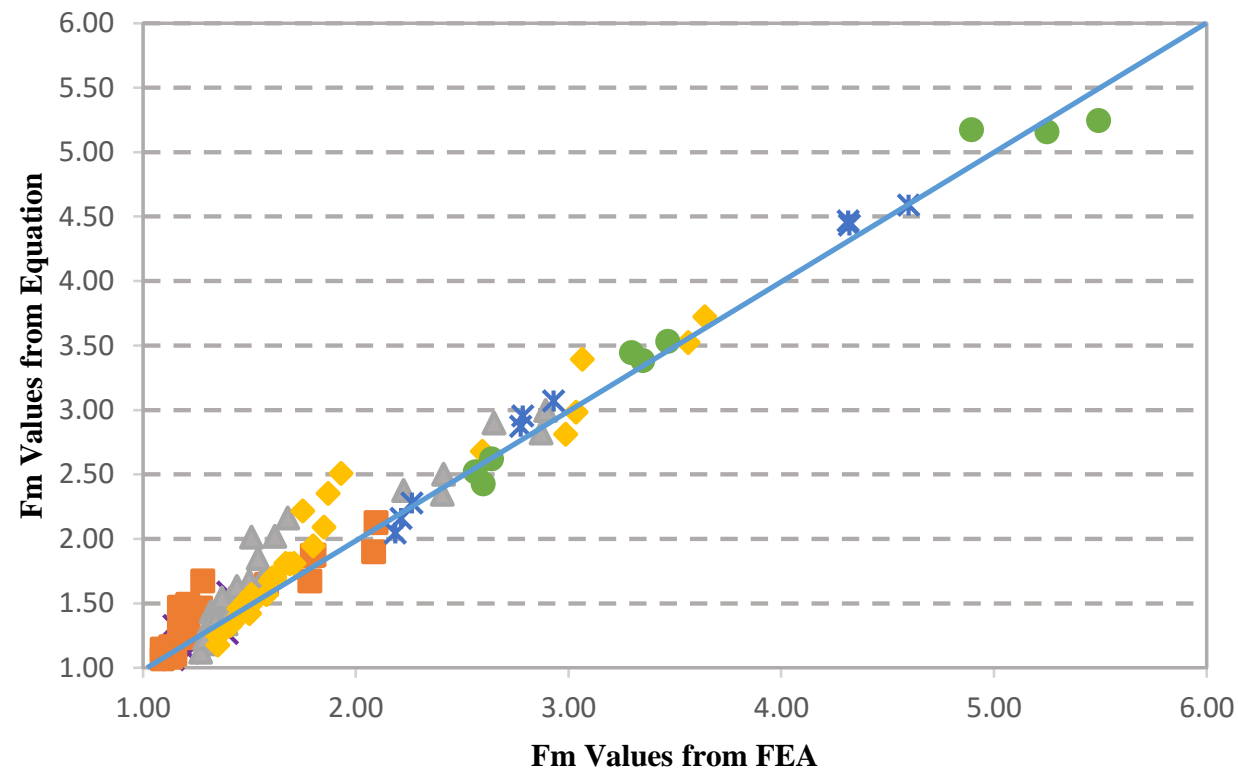

X One Design Lane Two Design Lanes

$\triangle$ Three Design Lanes Four Design Lanes ※ Five Design Lanes Six Design Lanes

Figure A. 144: Correlation between the FEA results and those from the proposed equations for box girder bridges at FLS design for moment (Based on CHBDC 2006) 


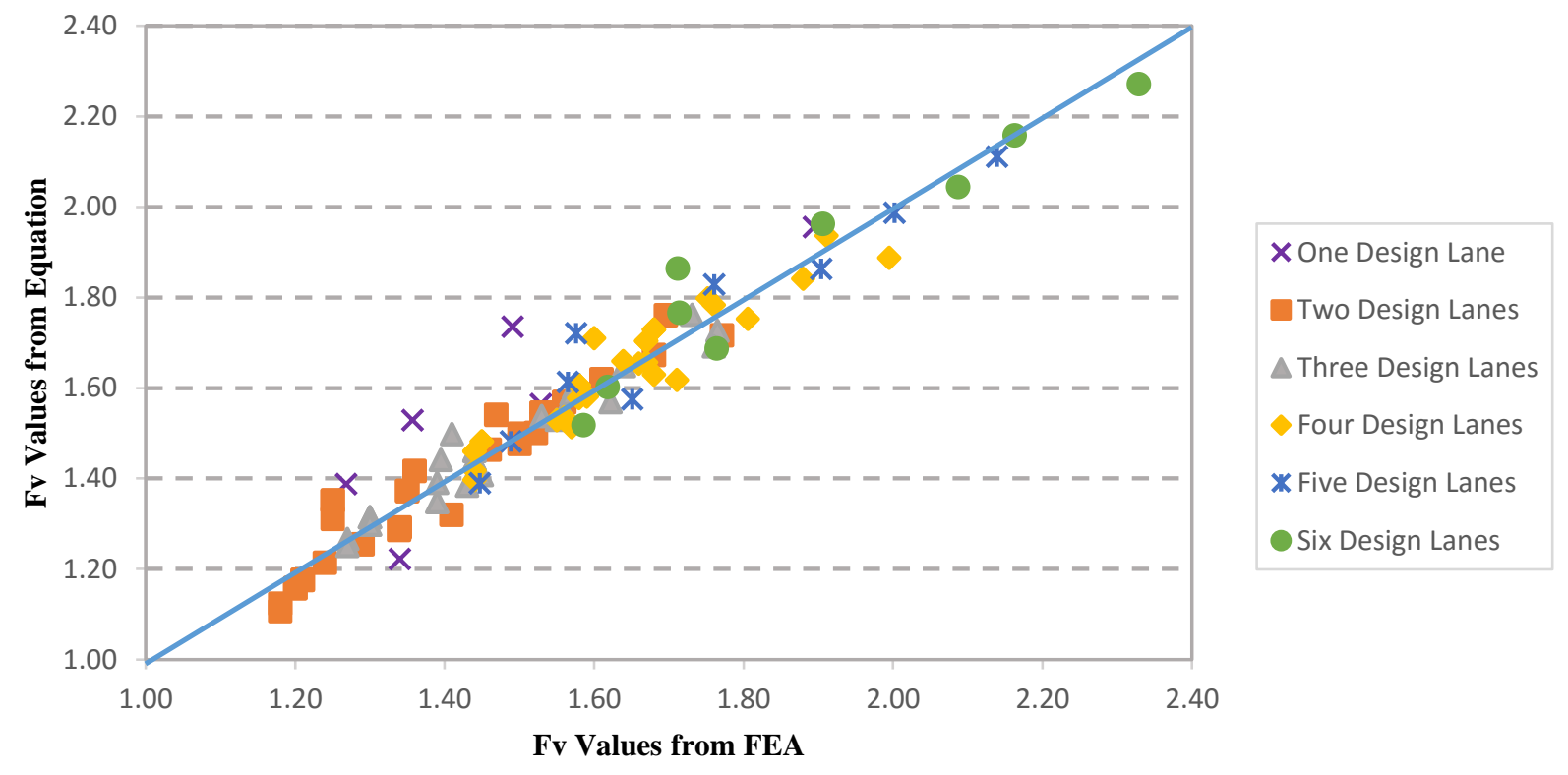

Figure A. 145: Correlation between the FEA results and those from the proposed equations for box girder bridges at ULS design for shear (Based on CHBDC 2006)

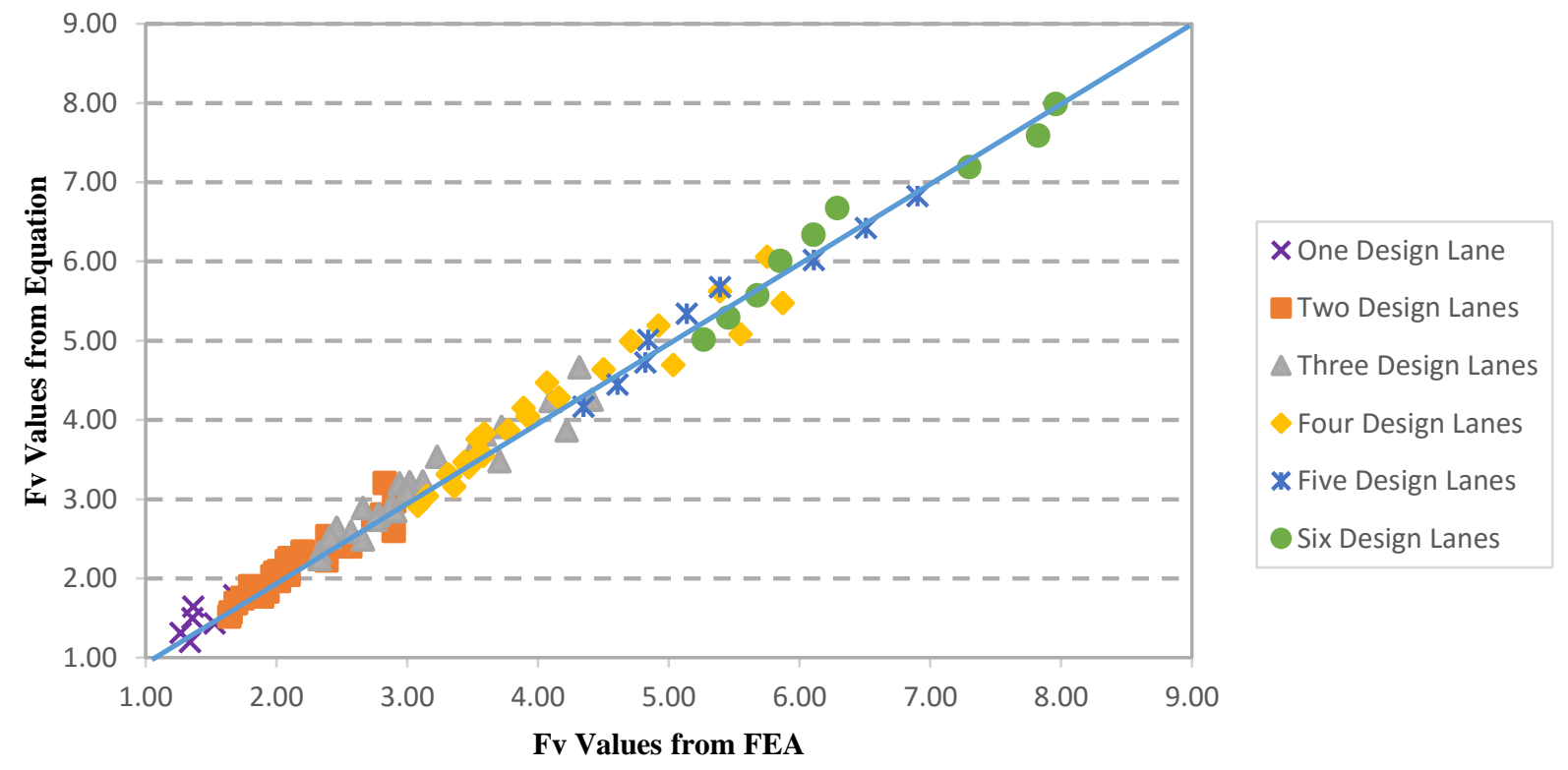

Figure A. 146: Correlation between the FEA results and those from the proposed equations for box girder bridges at FLS design for shear (Based on CHBDC 2006) 


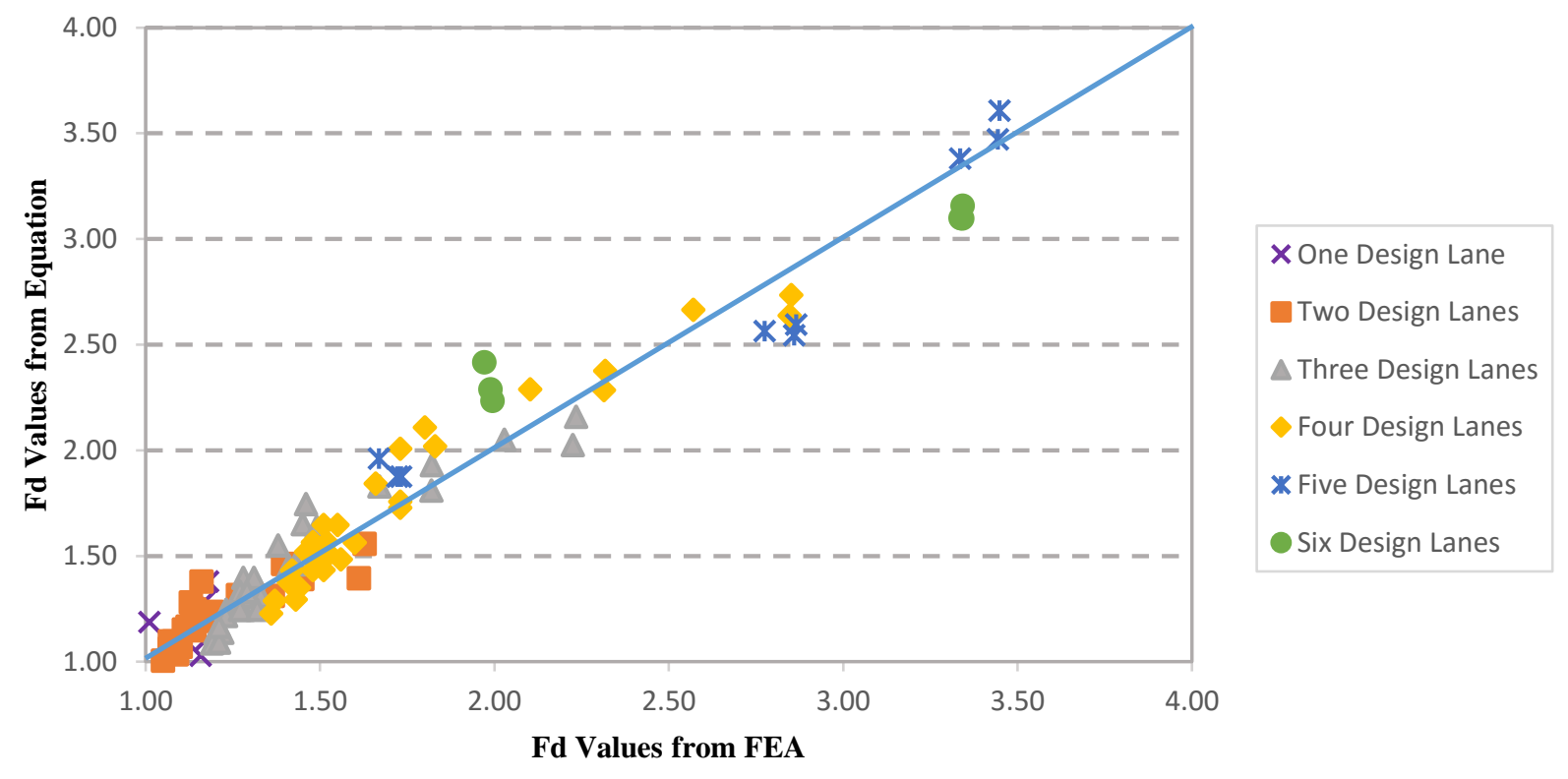

Figure A. 147: Correlation between the FEA results and those from the proposed equations for box girder bridges at FLS design for deflection (Based on CHBDC 2006)

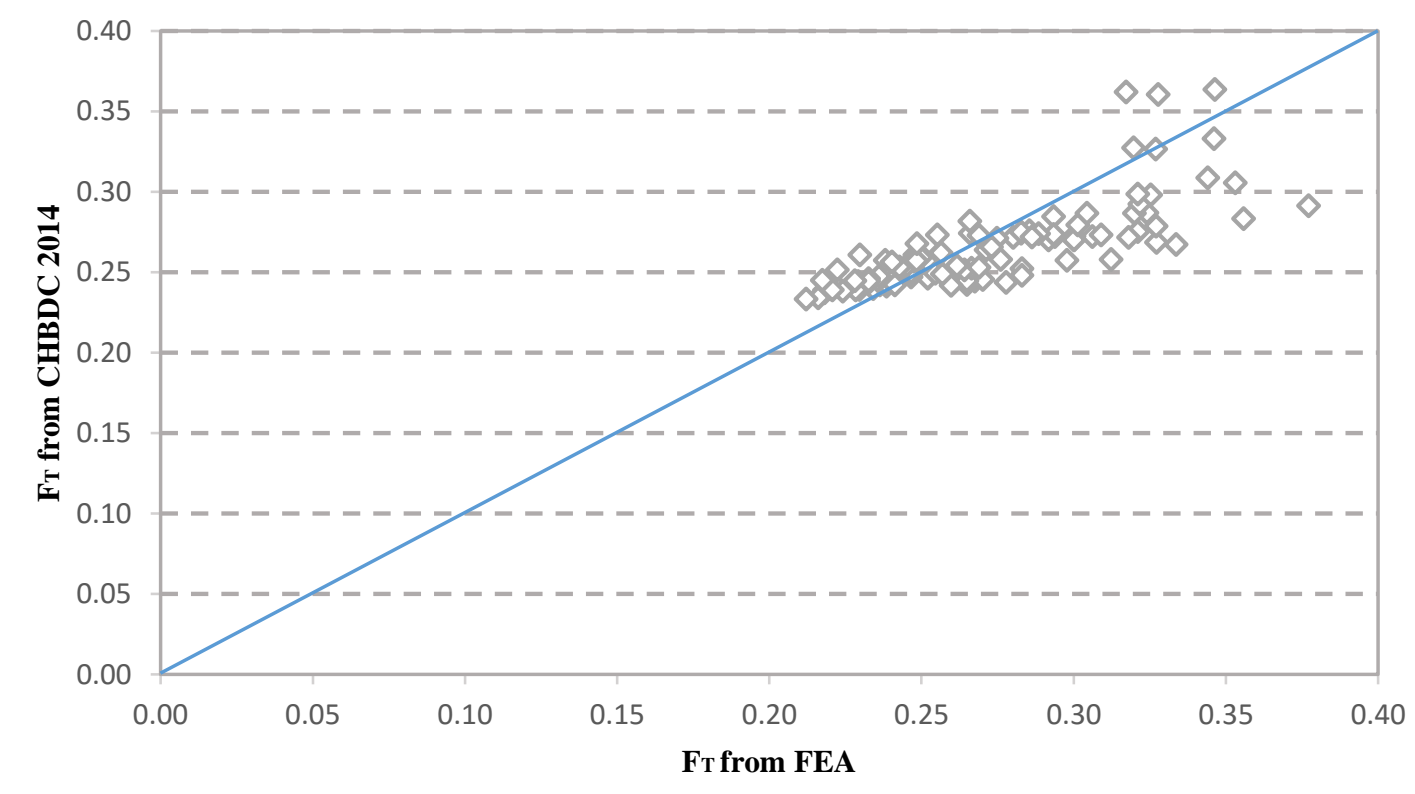

Figure A. 148: Comparison between the FEA results and those from CHBDC for box girder bridges at ULS design for moment (Based on CHBDC 2014) 


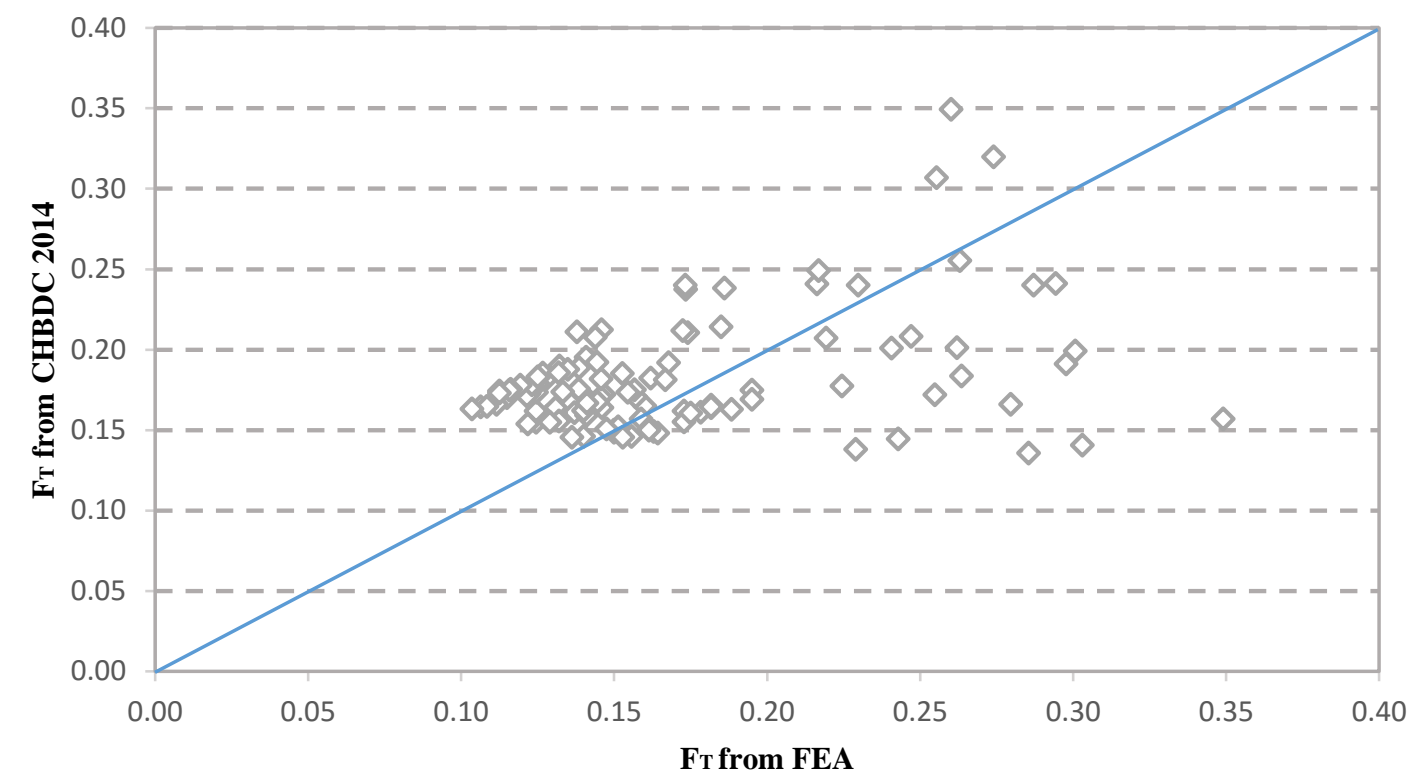

Figure A. 149: Comparison between the FEA results and those from CHBDC for box girder bridges at FLS design for moment (Based on CHBDC 2014)

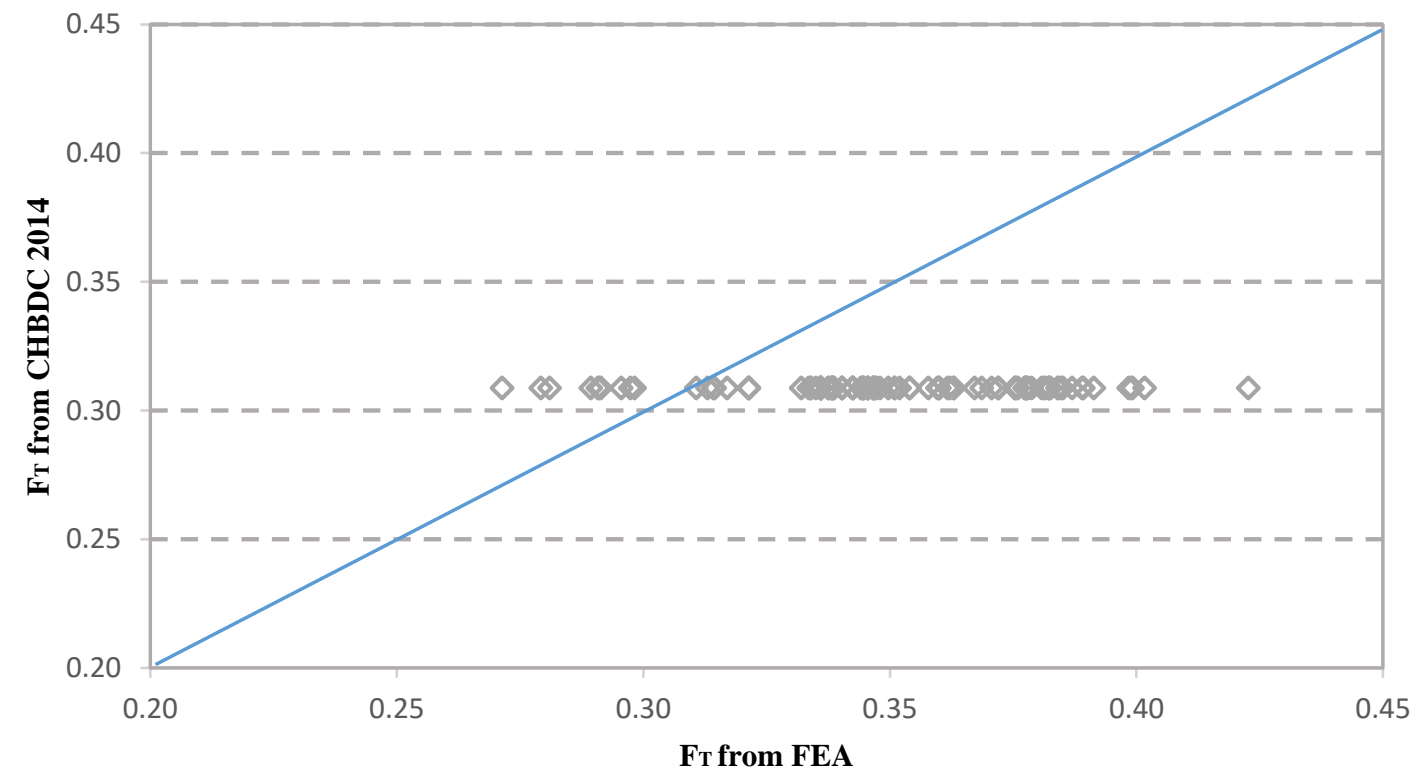

Figure A. 150: Comparison between the FEA results and those from CHBDC for box girder bridges at ULS design for shear (Based on CHBDC 2014) 


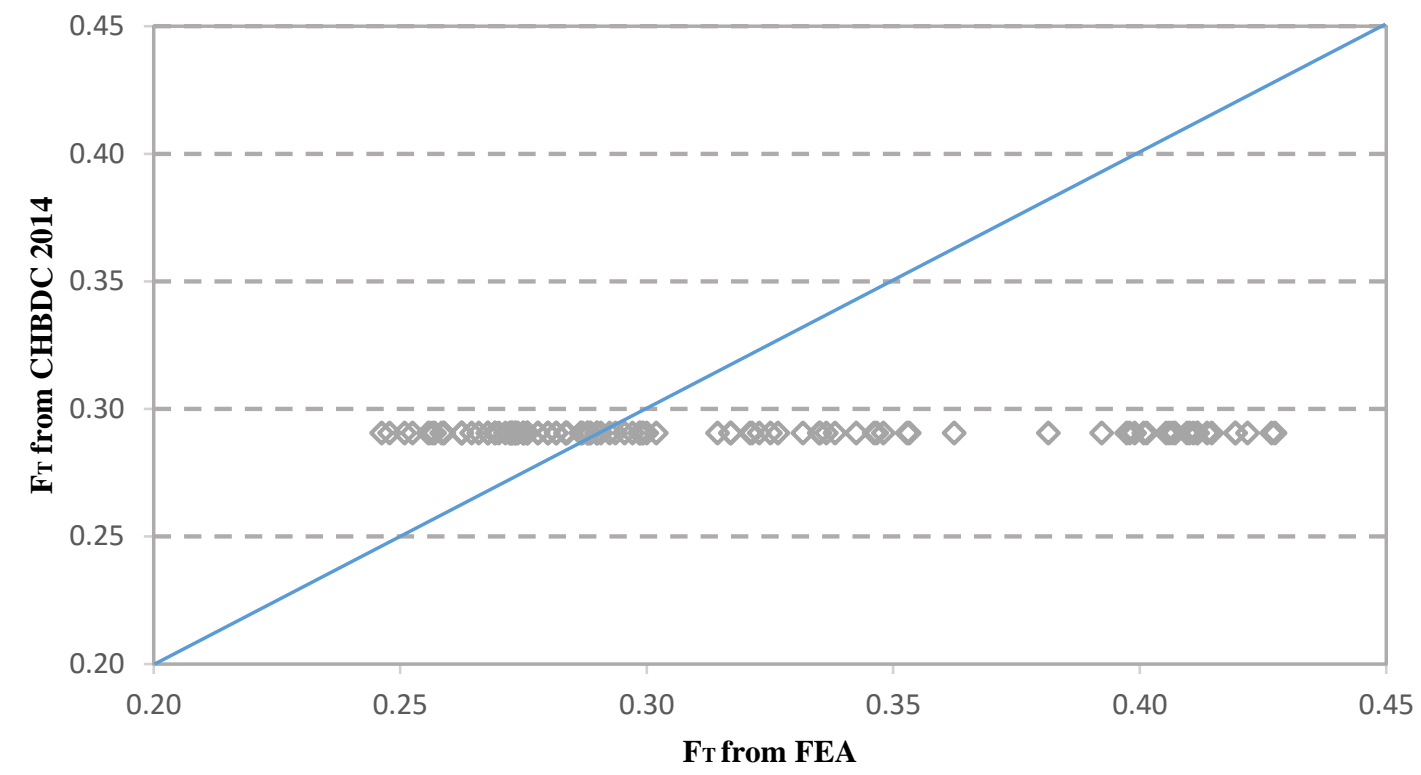

Figure A. 151: Comparison between the FEA results and those from CHBDC for box girder bridges at FLS design for shear (Based on CHBDC 2014)

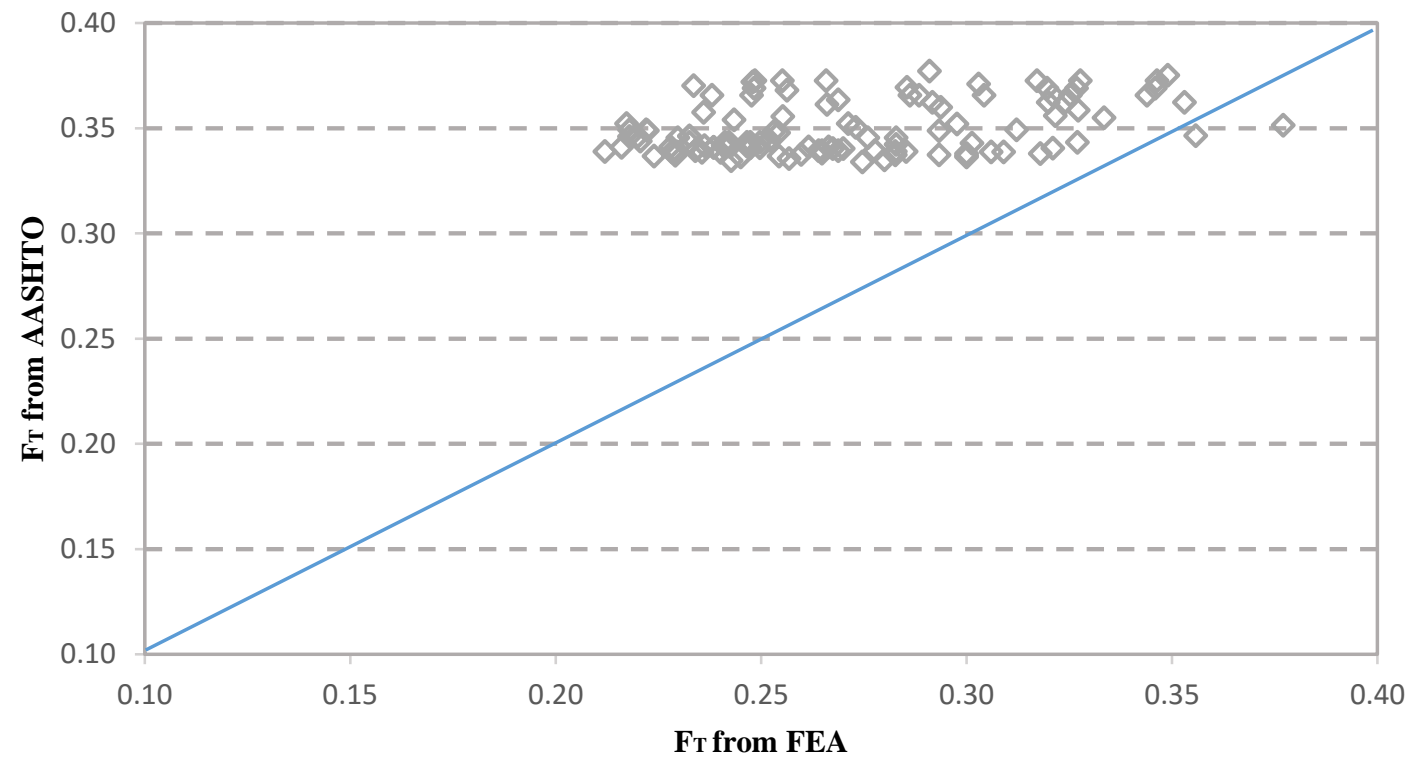

Figure A. 152: Comparison between the FEA results and those from AASHTO-LRFD 2012 for box girder bridges at ULS design for moment 


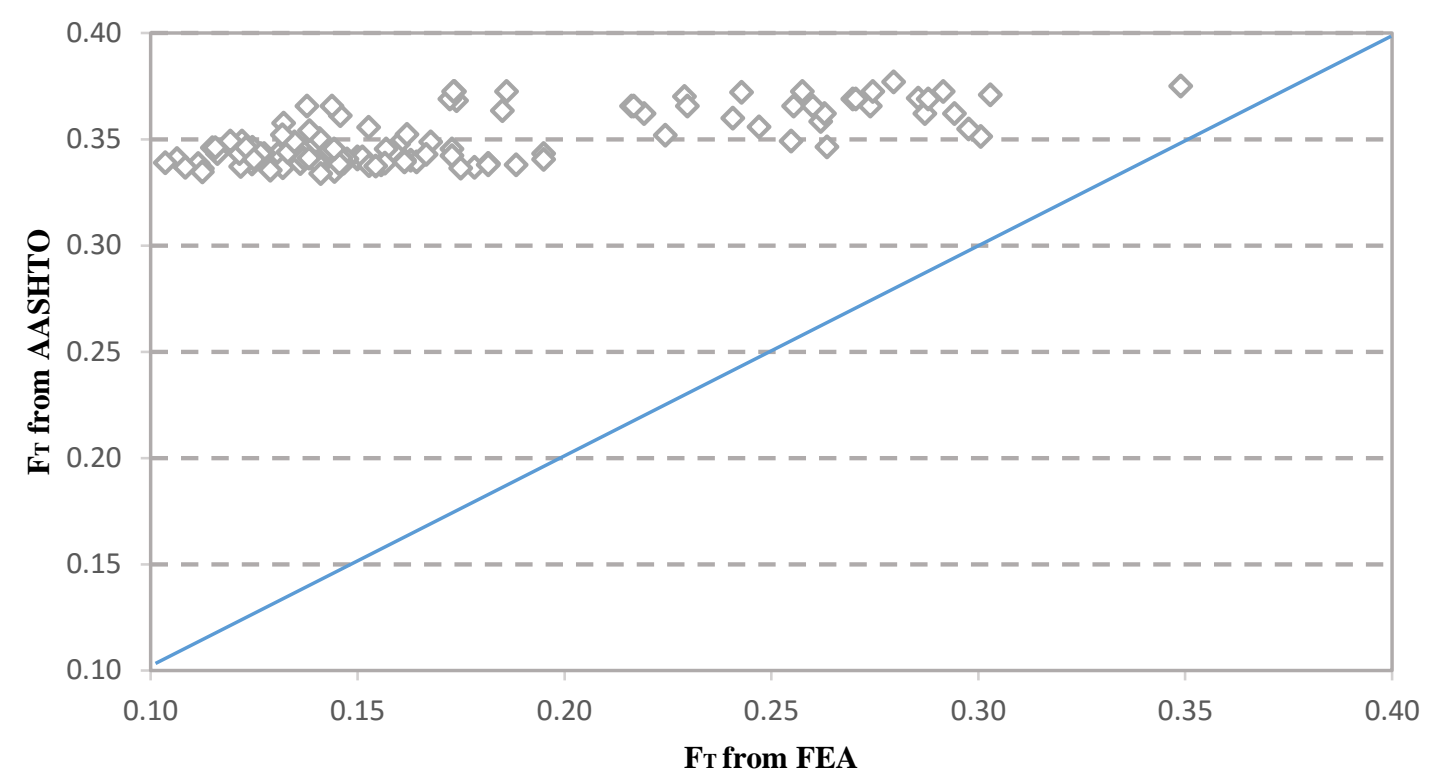

Figure A. 153: Comparison between the FEA results and those from AASHTO-LRFD 2012 for box girder bridges at FLS design for moment

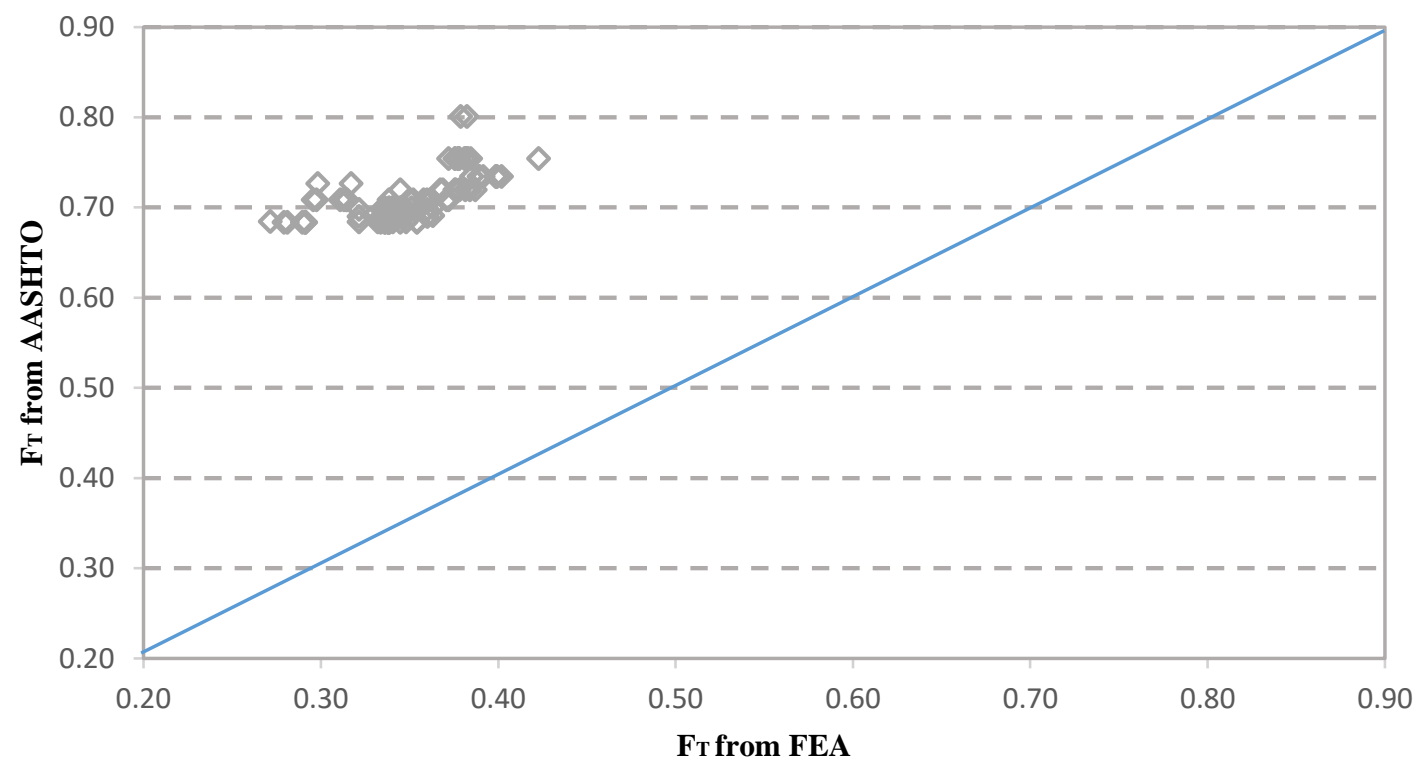

Figure A. 154: Comparison between the FEA results and those from AASHTO-LRFD 2012 for box girder bridges at ULS design for shear 


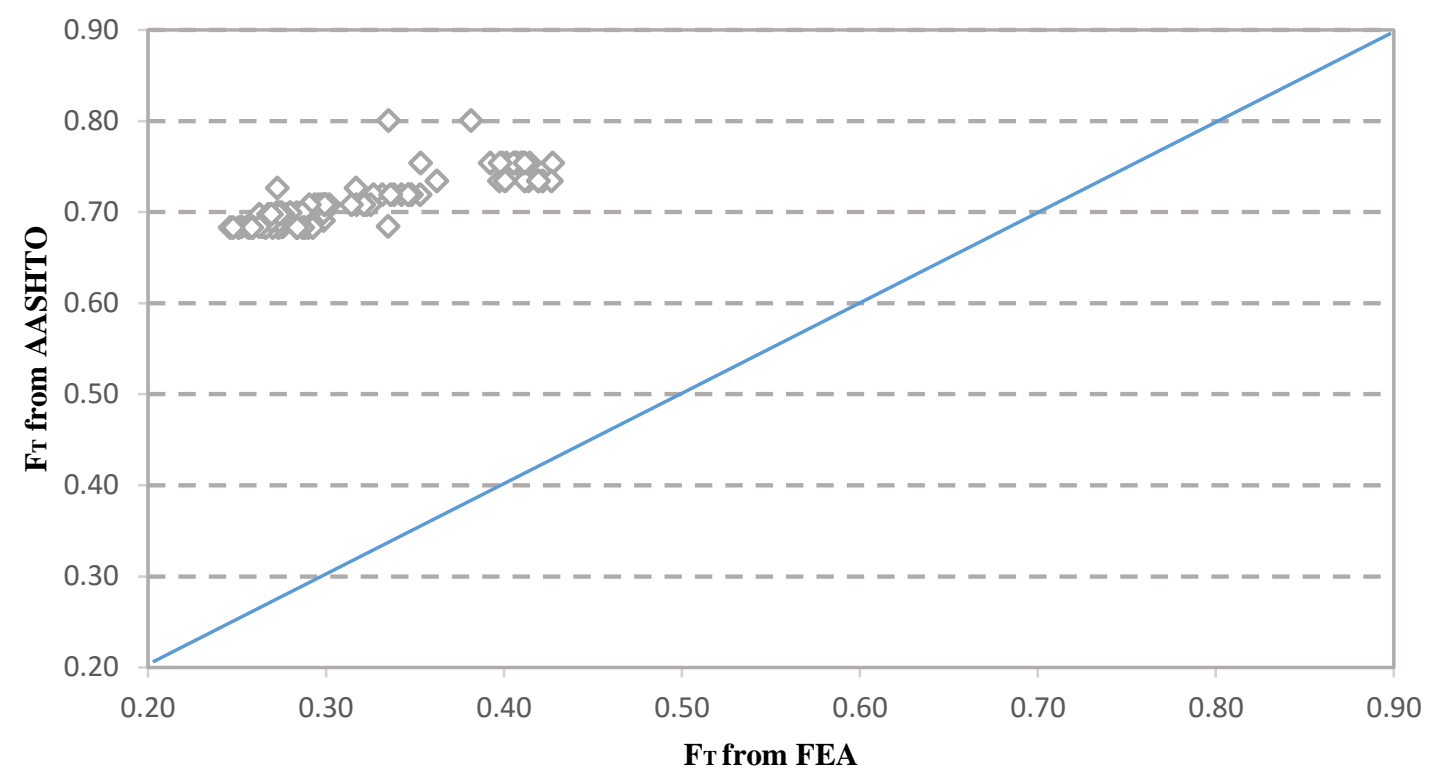

Figure A. 155: Comparison between the FEA results and those from AASHTO-LRFD 2012 for box girder bridges at FLS design for shear

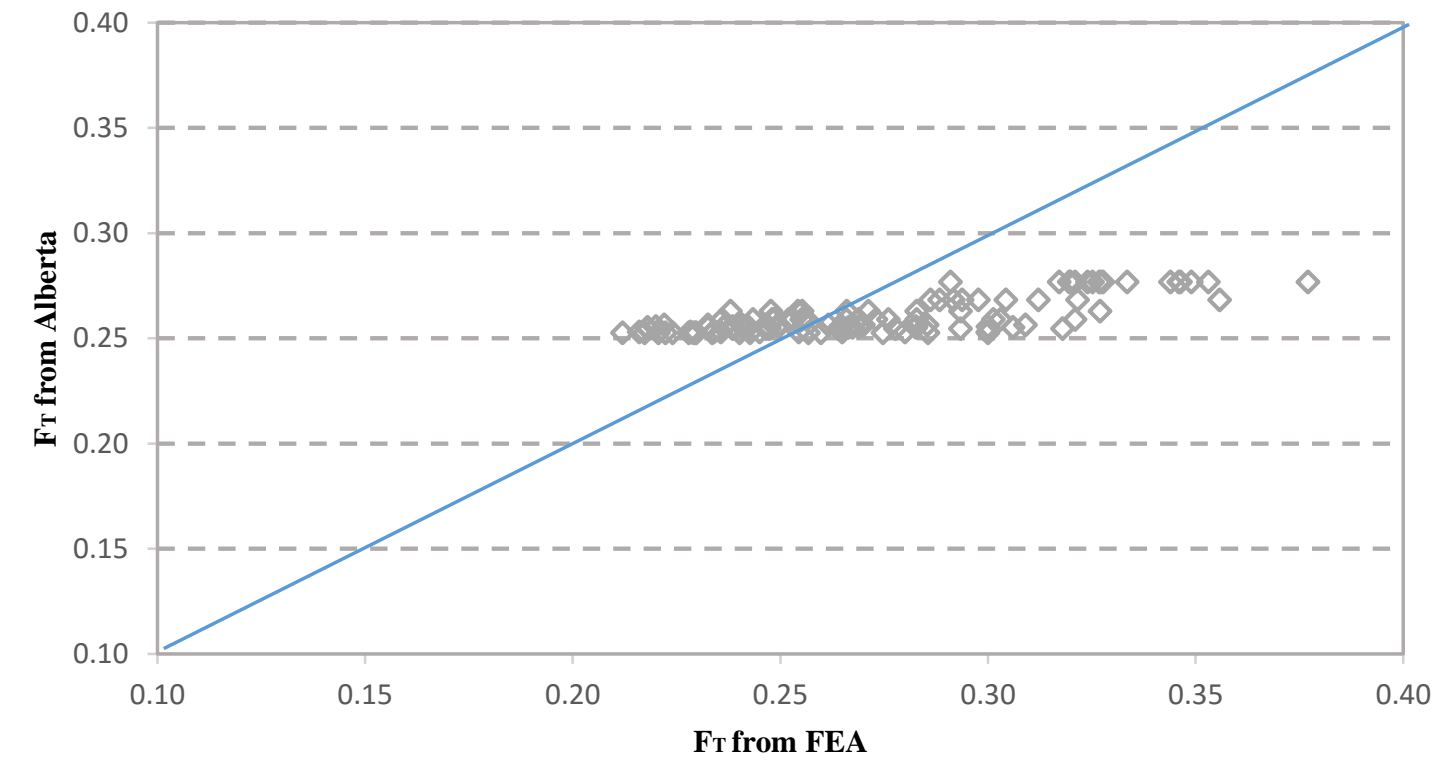

Figure A. 156: Comparison between the FEA results and those from Alberta Bridge Load Manual 2015 for box girder bridges at ULS design for moment 


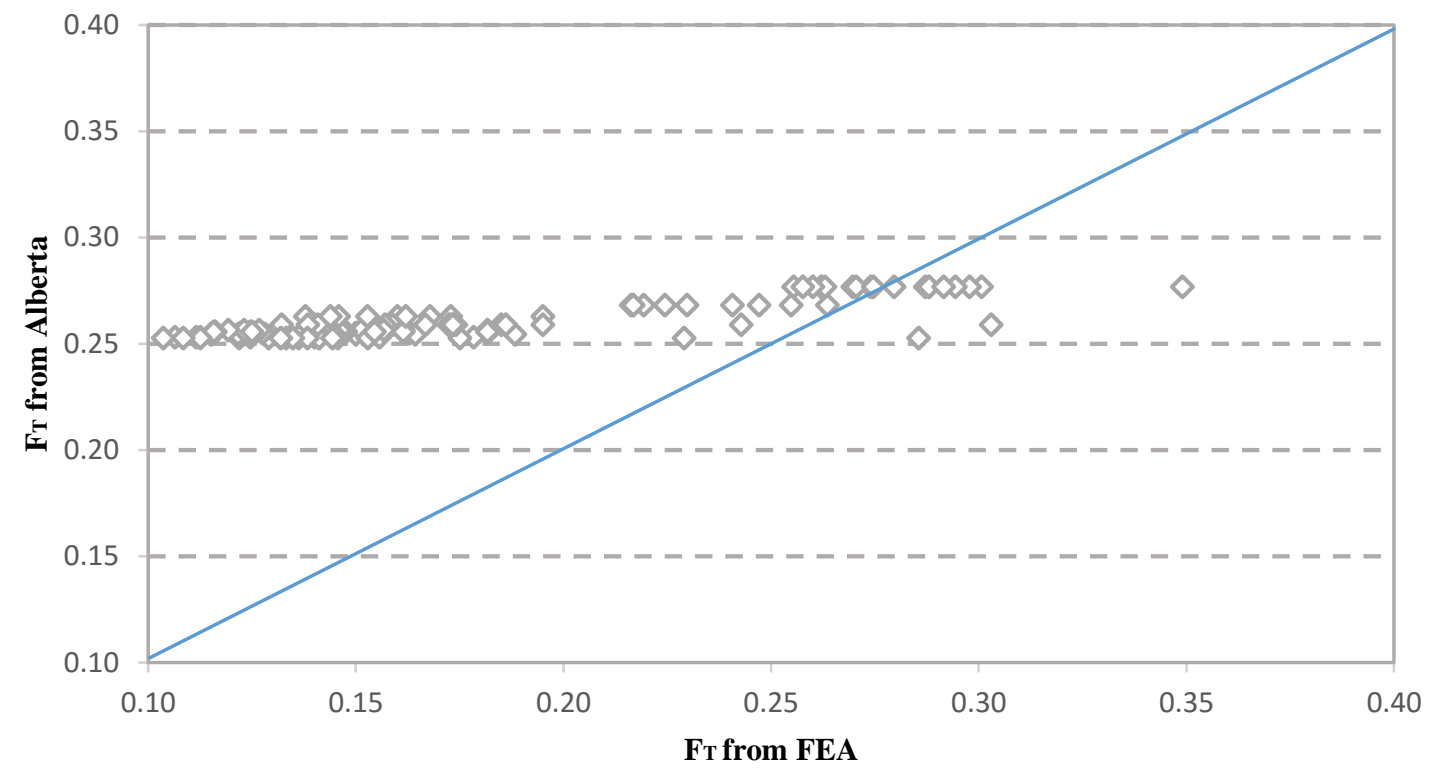

Figure A. 157: Comparison between the FEA results and those from Alberta Bridge Load Manual 2015 for box girder bridges at FLS design for moment

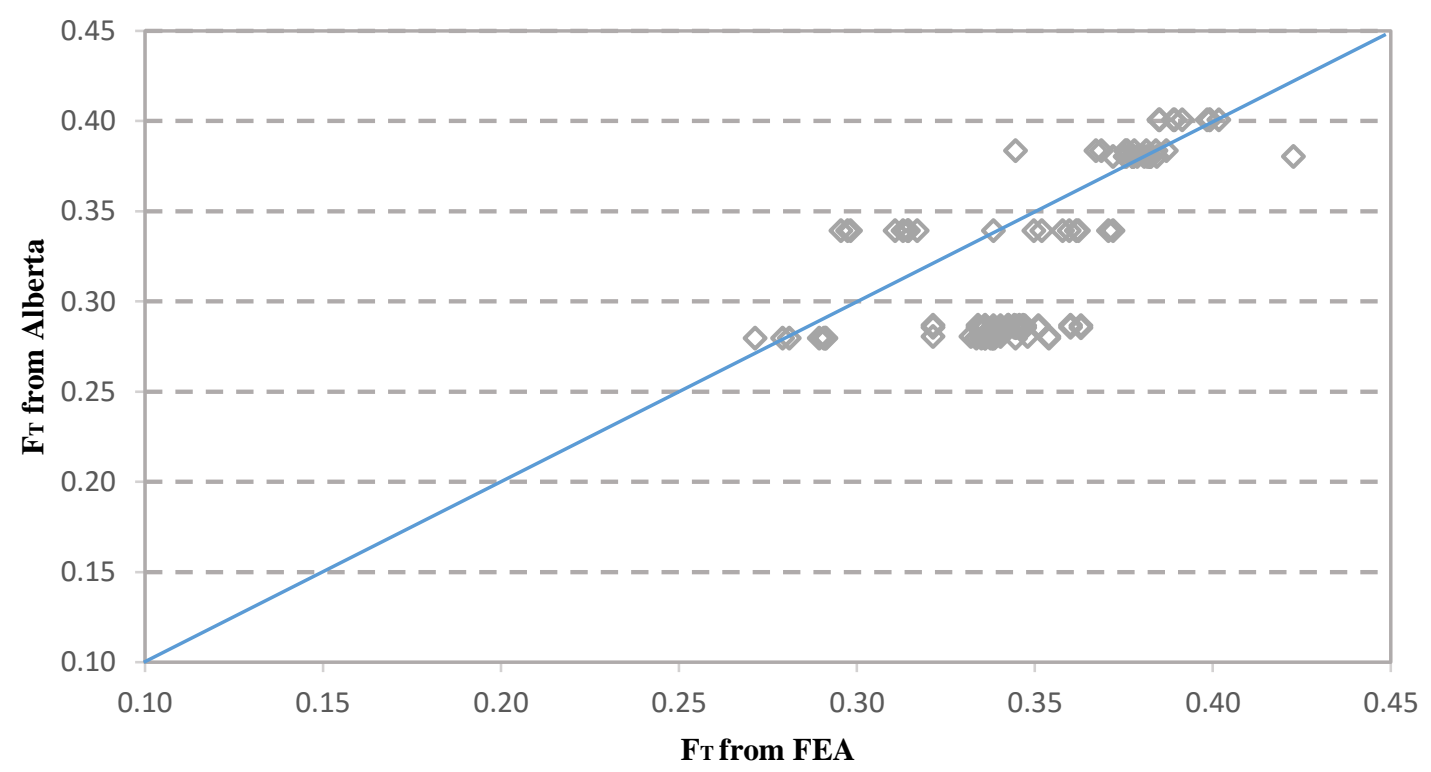

Figure A. 158: Comparison between the FEA results and those from Alberta Bridge Load Manual 2015 for box girder bridges at ULS design for shear 


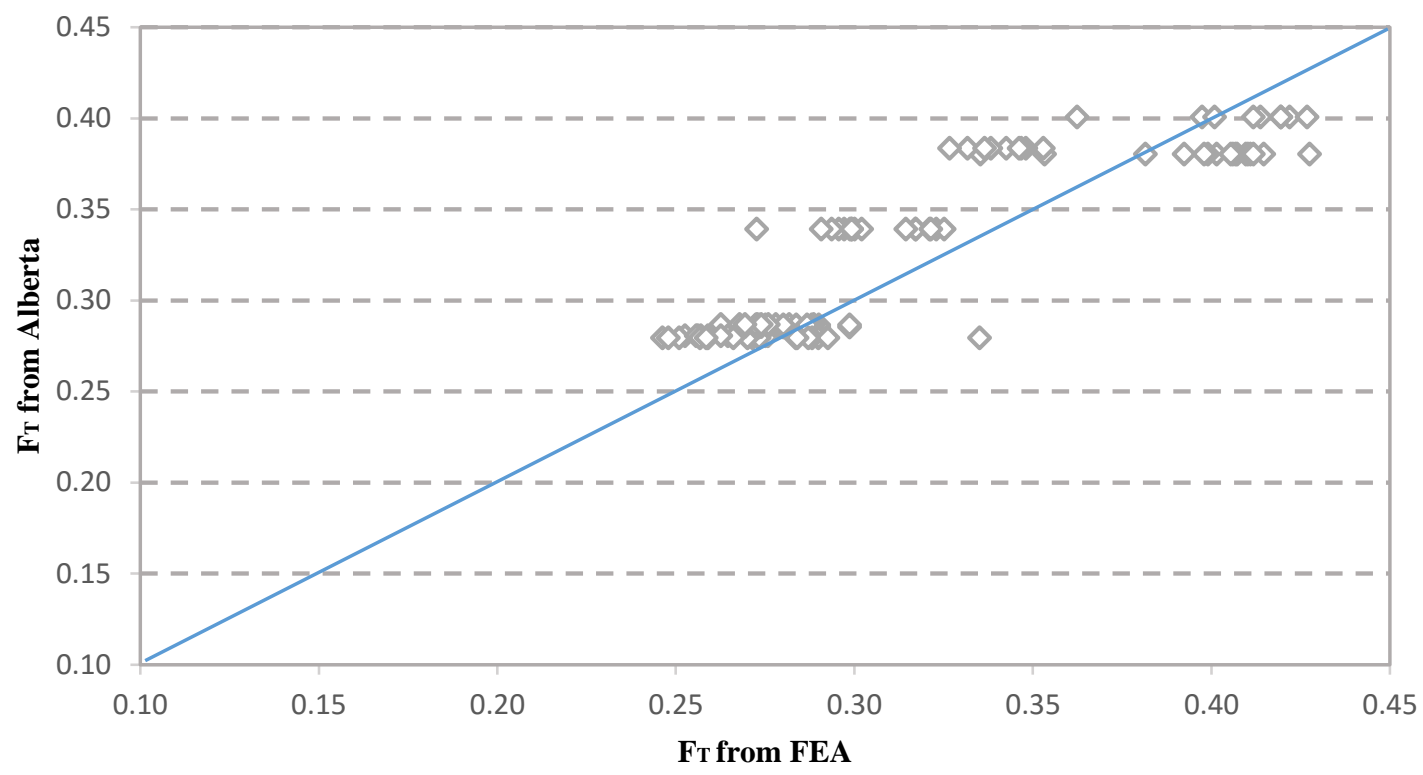

Figure A. 159: Comparison between the FEA results and those from Alberta Bridge Load Manual 2015 for box girder bridges at FLS design for shear

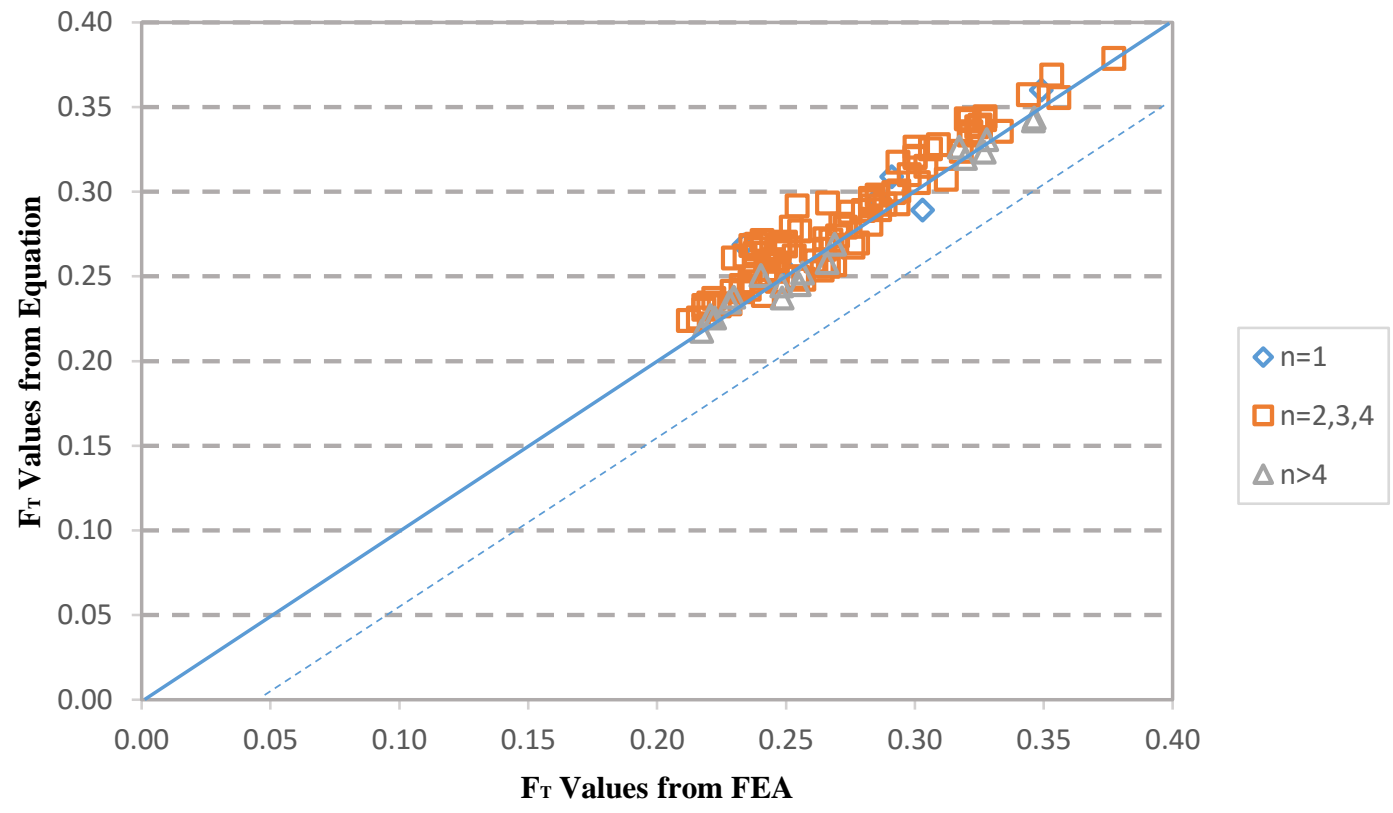

Figure A. 160: Correlation between the FEA results and those from the proposed equations for box girder bridges at ULS design for moment (Based on CHBDC 2014) 


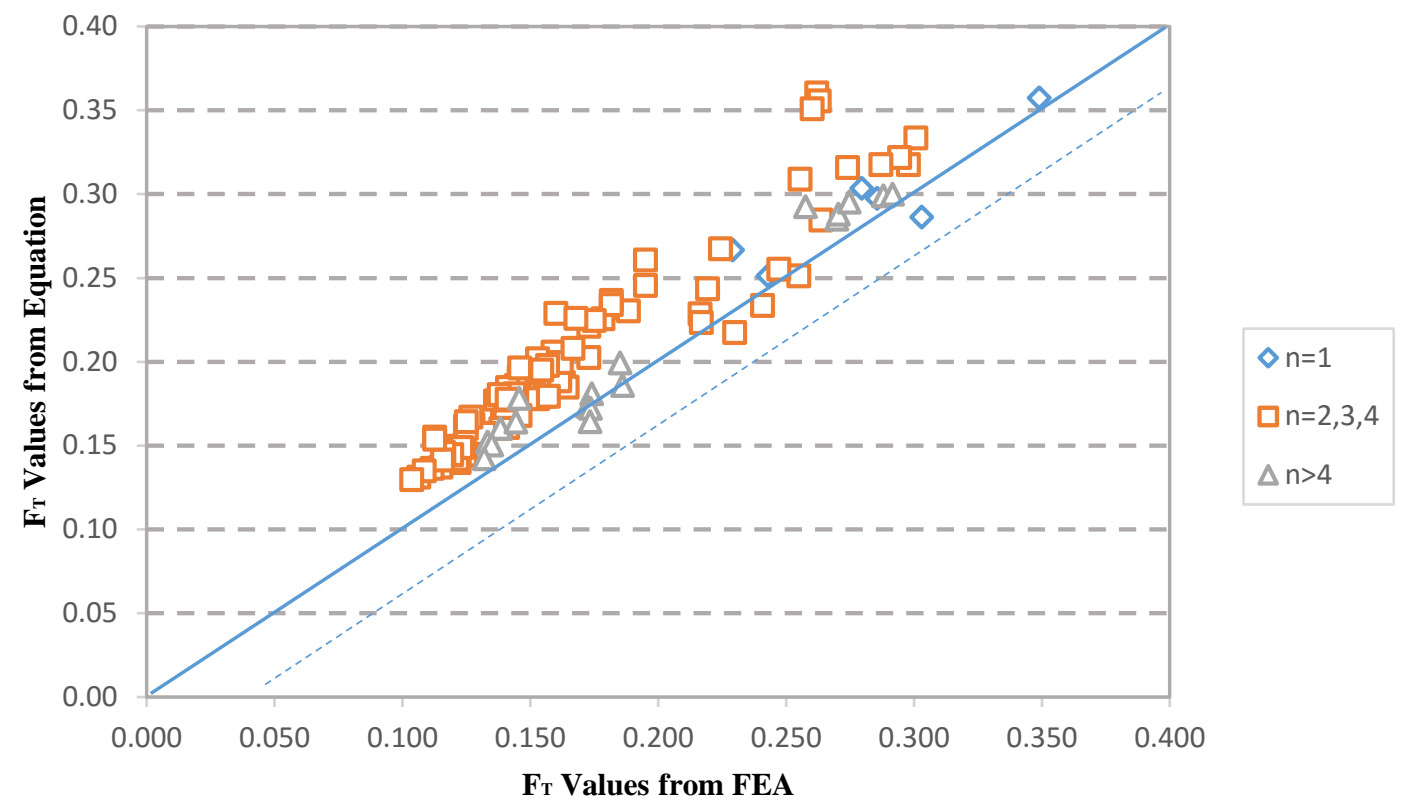

Figure A. 161: Correlation between the FEA results and those from the proposed equations for box girder bridges at FLS design for moment (Based on CHBDC 2014)

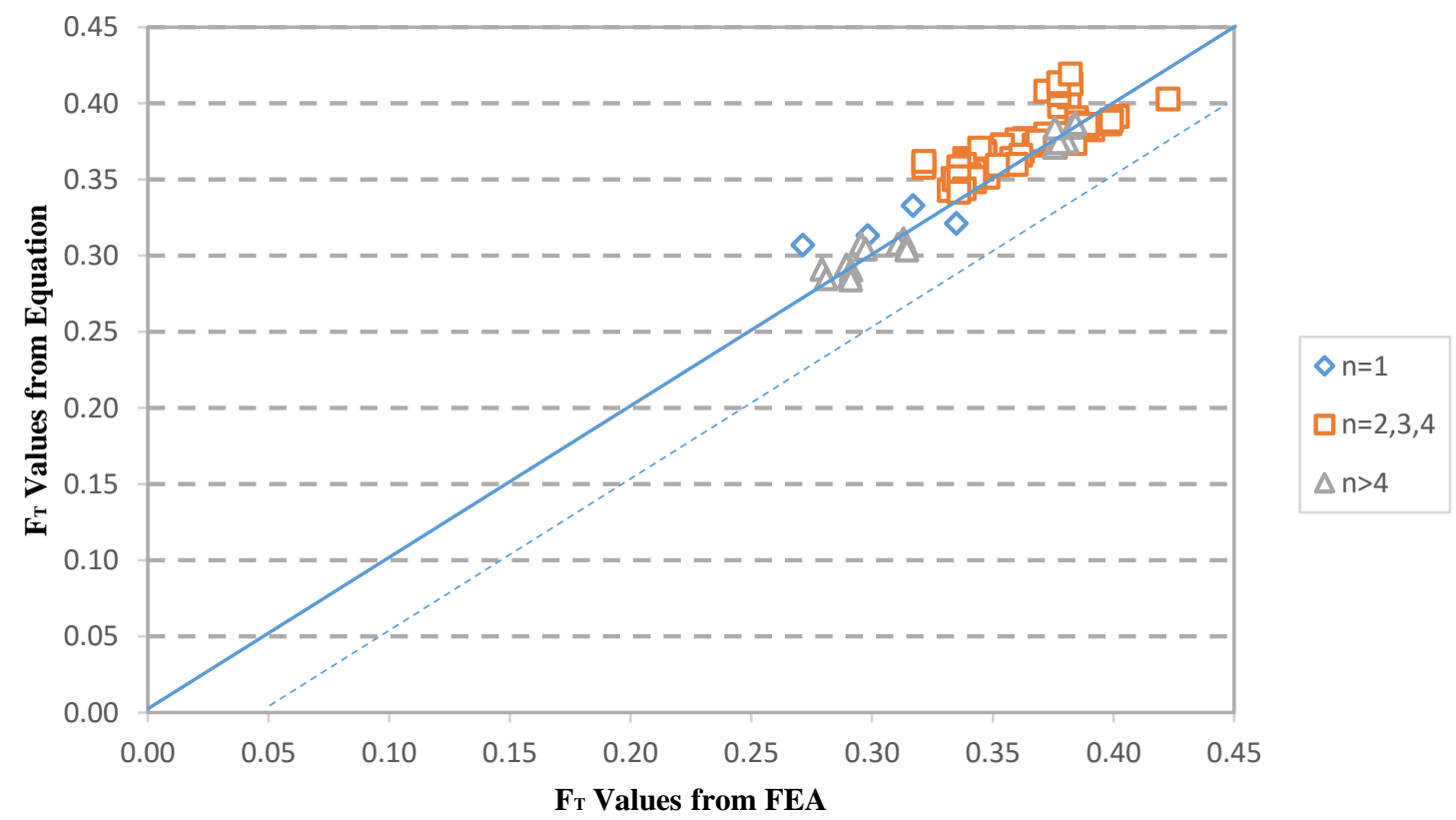

Figure A. 162: Correlation between the FEA results and those from the proposed equations for box girder bridges at ULS design for shear (Based on CHBDC 2014) 


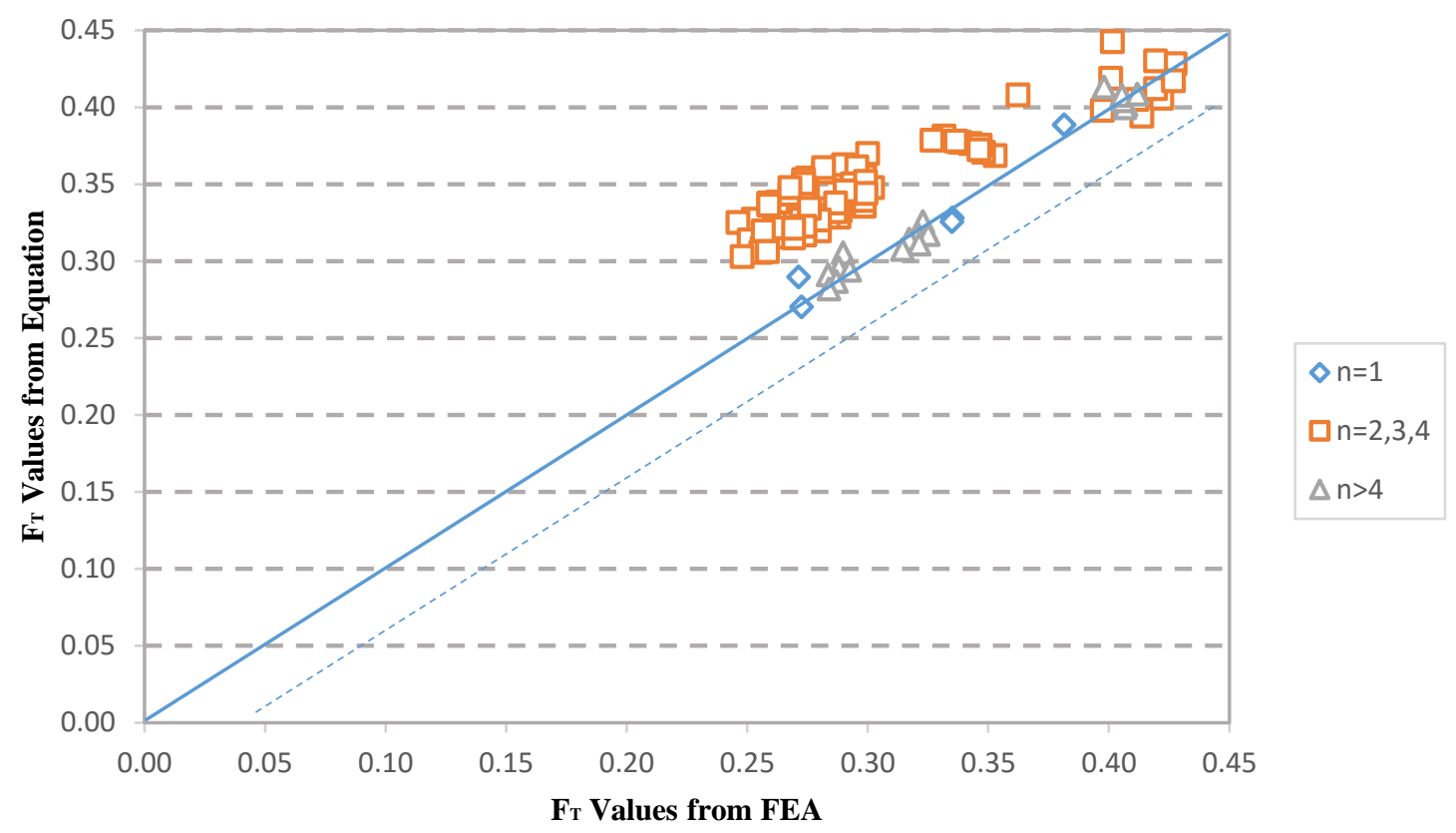

Figure A. 163: Correlation between the FEA results and those from the proposed equations for box girder bridges at FLS design for shear (Based on CHBDC 2014) 
Table A. 1: One-Lane Bridge Moment Distribution Factors $\left(F_{m}\right)$ at Serviceability, Ultimate and Fatigue Limit States

\begin{tabular}{|c|c|c|c|c|c|c|c|c|c|c|c|}
\hline \multicolumn{12}{|c|}{ One Lane Bridge: B700, $10 \mathrm{~m}$ Span Length } \\
\hline Bridge Configurations & Load cases & $\mathbf{n}$ & $\mathbf{R}_{\mathbf{L}}$ & $\mathbf{R}_{\mathbf{L}}^{\prime}$ & $\mathbf{N}$ & $\begin{array}{c}\mathbf{I} \\
\left(\mathbf{m}^{4}\right)\end{array}$ & $\begin{array}{l}\mathbf{y}_{\mathbf{b}} \\
(\mathbf{m})\end{array}$ & $\begin{array}{c}\mathbf{M}_{\mathbf{T}} \\
(\mathbf{k N} / \mathbf{m})\end{array}$ & $\begin{array}{c}\left(\sigma_{\text {straight }}\right)_{\text {truck }} \\
(\mathrm{MPa})\end{array}$ & $\begin{array}{c}\sigma_{\mathrm{FE}} \\
(\mathrm{MPa})\end{array}$ & $\left(\mathbf{F}_{\mathbf{m}}\right)_{\mathrm{FE}}$ \\
\hline \multirow{3}{*}{$\begin{array}{c}4 \text { Box Girders } \\
\text { 3.926m Bridge Width }\end{array}$} & ULS-1 & 1 & 1 & 1 & 4 & 0.0309 & 0.3761 & 651.00 & 7.924 & 2.540 & 1.282 \\
\hline & ULS-2 & 1 & 1 & 1 & 4 & 0.0309 & 0.3761 & 651.00 & 7.924 & 2.765 & 1.396 \\
\hline & FLS-3 & 1 & 1 & 1 & 4 & 0.0309 & 0.3761 & 651.00 & 7.924 & 2.765 & 1.396 \\
\hline \multirow{3}{*}{$\begin{array}{c}5 \text { Box Girders } \\
\text { 5.160m Bridge Width }\end{array}$} & ULS-1 & 1 & 1 & 1 & 5 & 0.0309 & 0.3761 & 651.00 & 7.924 & 2.306 & 1.455 \\
\hline & ULS-2 & 1 & 1 & 1 & 5 & 0.0309 & 0.3761 & 651.00 & 7.924 & 2.215 & 1.398 \\
\hline & FLS-3 & 1 & 1 & 1 & 5 & 0.0309 & 0.3761 & 651.00 & 7.924 & 2.215 & 1.398 \\
\hline
\end{tabular}

\begin{tabular}{|c|c|c|c|c|c|c|c|c|c|c|c|}
\hline \multicolumn{12}{|c|}{ One Lane Bridge: B800, 20 m Span Length } \\
\hline Bridge Configration & Load cases & $\mathbf{n}$ & $\mathbf{R}_{\mathbf{L}}$ & $\mathbf{R}_{\mathbf{L}}^{\prime}$ & $\mathbf{N}$ & $\begin{array}{c}I \\
\left(\mathbf{m}^{4}\right)\end{array}$ & $\begin{array}{l}\mathbf{y}_{\mathbf{b}} \\
(\mathbf{m})\end{array}$ & $\begin{array}{c}\mathbf{M}_{\mathrm{T}} \\
(\mathbf{k N} / \mathbf{m})\end{array}$ & $\begin{array}{c}\left(\sigma_{\text {straight }}\right)_{\text {truck }} \\
(\mathrm{MPa})\end{array}$ & $\begin{array}{c}\sigma_{\mathrm{FE}} \\
(\mathrm{MPa})\end{array}$ & $\left(\mathbf{F}_{\mathbf{m}}\right)_{\mathbf{F E}}$ \\
\hline \multirow{3}{*}{$\begin{array}{c}4 \text { Box Girders } \\
\text { 3.926m Bridge Width }\end{array}$} & ULS-1 & 1 & 1 & 1 & 4 & 0.0441 & 0.4324 & 1686.15 & 16.533 & 4.822 & 1.167 \\
\hline & ULS-2 & 1 & 1 & 1 & 4 & 0.0441 & 0.4324 & 1686.15 & 16.533 & 5.008 & 1.212 \\
\hline & FLS-3 & 1 & 1 & 1 & 4 & 0.0441 & 0.4324 & 1686.15 & 16.533 & 5.008 & 1.212 \\
\hline \multirow{3}{*}{$\begin{array}{c}5 \text { Box Girders } \\
5.160 \mathrm{~m} \text { Bridge Width }\end{array}$} & ULS-1 & 1 & 1 & 1 & 5 & 0.0441 & 0.4324 & 1686.15 & 16.533 & 4.101 & 1.240 \\
\hline & ULS-2 & 1 & 1 & 1 & 5 & 0.0441 & 0.4324 & 1686.15 & 16.533 & 4.015 & 1.214 \\
\hline & FLS-3 & 1 & 1 & 1 & 5 & 0.0441 & 0.4324 & 1686.15 & 16.533 & 4.015 & 1.214 \\
\hline
\end{tabular}

\begin{tabular}{|c|c|c|c|c|c|c|c|c|c|c|c|}
\hline \multicolumn{12}{|c|}{ One Lane Bridge: B1000, 32 m Span Length } \\
\hline Bridge Configration & Load cases & $\mathbf{n}$ & $\mathbf{R}_{\mathbf{L}}$ & $\mathbf{R}_{\mathbf{L}}^{\prime}$ & $\mathbf{N}$ & $\begin{array}{c}\mathbf{I} \\
\left(\mathbf{m}^{4}\right)\end{array}$ & $\begin{array}{l}\mathbf{y}_{\mathbf{b}} \\
(\mathbf{m})\end{array}$ & $\begin{array}{c}\mathbf{M}_{\mathrm{T}} \\
(\mathbf{k N} / \mathbf{m})\end{array}$ & $\begin{array}{c}\left(\sigma_{\text {straight }}\right)_{\text {truck }} \\
(\mathrm{MPa})\end{array}$ & $\begin{array}{c}\sigma_{\mathrm{FE}} \\
(\mathrm{MPa})\end{array}$ & $\left(\mathbf{F}_{\mathbf{m}}\right)_{\mathrm{FE}}$ \\
\hline \multirow{3}{*}{$\begin{array}{l}4 \text { Box Girders } \\
\text { 3.926m Bridge Width }\end{array}$} & ULS-1 & 1 & 1 & 1 & 4 & 0.0787 & 0.5433 & 3336.11 & 23.031 & 6.462 & 1.122 \\
\hline & ULS-2 & 1 & 1 & 1 & 4 & 0.0787 & 0.5433 & 3336.11 & 23.031 & 6.577 & 1.142 \\
\hline & FLS-3 & 1 & 1 & 1 & 4 & 0.0787 & 0.5433 & 3336.11 & 23.031 & 6.577 & 1.142 \\
\hline \multirow{3}{*}{$\begin{array}{c}5 \text { Box Girders } \\
5.160 \mathrm{~m} \text { Bridge Width }\end{array}$} & ULS-1 & 1 & 1 & 1 & 5 & 0.0787 & 0.5433 & 3336.11 & 23.031 & 5.381 & 1.168 \\
\hline & ULS-2 & 1 & 1 & 1 & 5 & 0.0787 & 0.5433 & 3336.11 & 23.031 & 5.273 & 1.145 \\
\hline & FLS-3 & 1 & 1 & 1 & 5 & 0.0787 & 0.5433 & 3336.11 & 23.031 & 5.273 & 1.145 \\
\hline
\end{tabular}


Table A. 2: One-Lane Bridge Shear Distribution Factors $\left(F_{v}\right)$ at Serviceability, Ultimate and Fatigue Limit States

\begin{tabular}{|c|c|c|c|c|c|c|c|c|}
\hline \multicolumn{9}{|c|}{ One Lane Bridge: B700, 10 m Span Length } \\
\hline Bridge Configurations & Load cases & $\mathbf{n}$ & $\mathbf{R}_{\mathbf{L}}$ & $\mathbf{R}_{\mathbf{L}}^{\prime}$ & $\mathbf{N}$ & $\begin{array}{c}\left(\mathbf{R}_{\text {straight }}\right)_{\text {truck }} \\
(\mathbf{k N})\end{array}$ & $\begin{array}{l}\mathbf{R}_{\mathrm{FE}} \\
(\mathrm{kN})\end{array}$ & $\left(F_{v}\right)_{F E}$ \\
\hline \multirow{3}{*}{$\begin{array}{c}4 \text { Box Girders } \\
\text { 3.926m Bridge Width }\end{array}$} & ULS-1 & 1 & 1 & 1 & 4 & 301.70 & 115.317 & 1.529 \\
\hline & ULS-2 & 1 & 1 & 1 & 4 & 301.70 & 115.089 & 1.526 \\
\hline & FLS-3 & 1 & 1 & 1 & 4 & 301.70 & 115.089 & 1.526 \\
\hline \multirow{3}{*}{$\begin{array}{c}5 \text { Box Girders } \\
\text { 5.160m Bridge Width }\end{array}$} & ULS-1 & 1 & 1 & 1 & 5 & 301.70 & 114.300 & 1.894 \\
\hline & ULS-2 & 1 & 1 & 1 & 5 & 301.70 & 101.148 & 1.676 \\
\hline & FLS-3 & 1 & 1 & 1 & 5 & 301.70 & 101.148 & 1.676 \\
\hline
\end{tabular}

\begin{tabular}{|c|c|c|c|c|c|c|c|c|}
\hline \multicolumn{9}{|c|}{ One Lane Bridge: B800, 20 m Span Length } \\
\hline Bridge Configurations & Load cases & $\mathbf{n}$ & $\mathbf{R}_{\mathbf{L}}$ & $\mathbf{R}_{\mathbf{L}}^{\prime}$ & $\mathbf{N}$ & $\begin{array}{c}\left(\mathbf{R}_{\text {straight }}\right)_{\text {truck }} \\
(\mathbf{k N})\end{array}$ & $\begin{array}{l}R_{\text {FE. }} \\
(k N)\end{array}$ & $\left(F_{v}\right)_{F E}$ \\
\hline \multirow{3}{*}{$\begin{array}{c}4 \text { Box Girders } \\
\text { 3.926m Bridge Width }\end{array}$} & ULS-1 & 1 & 1 & 1 & 4 & 411.95 & 126.172 & 1.225 \\
\hline & ULS-2 & 1 & 1 & 1 & 4 & 411.95 & 130.583 & 1.268 \\
\hline & FLS-3 & 1 & 1 & 1 & 4 & 411.95 & 130.583 & 1.268 \\
\hline \multirow{3}{*}{$\begin{array}{c}5 \text { Box Girders } \\
\text { 5.160m Bridge Width }\end{array}$} & ULS-1 & 1 & 1 & 1 & 5 & 411.95 & 122.879 & 1.491 \\
\hline & ULS-2 & 1 & 1 & 1 & 5 & 411.95 & 112.272 & 1.363 \\
\hline & FLS-3 & 1 & 1 & 1 & 5 & 411.95 & 112.272 & 1.363 \\
\hline
\end{tabular}

\begin{tabular}{|c|c|c|c|c|c|c|c|c|}
\hline \multicolumn{9}{|c|}{ One Lane Bridge: B1000, 32 m Span Length } \\
\hline Bridge Configurations & Load cases & $\mathbf{n}$ & $\mathbf{R}_{\mathbf{L}}$ & $\mathbf{R}_{\mathbf{L}}^{\prime}$ & $\mathbf{N}$ & $\begin{array}{c}\left(\mathbf{R}_{\text {straight }}\right)_{\text {truck }} \\
(\mathbf{k N})\end{array}$ & $\begin{array}{l}R_{\text {FE. }} \\
(k N)\end{array}$ & $\left(\mathbf{F}_{\mathbf{v}}\right)_{\mathrm{FE}}$ \\
\hline \multirow{3}{*}{$\begin{array}{c}4 \text { Box Girders } \\
\text { 3.926m Bridge Width }\end{array}$} & ULS-1 & 1 & 1 & 1 & 4 & 458.40 & 127.686 & 1.114 \\
\hline & ULS-2 & 1 & 1 & 1 & 4 & 458.40 & 153.533 & 1.340 \\
\hline & FLS-3 & 1 & 1 & 1 & 4 & 458.40 & 153.533 & 1.340 \\
\hline \multirow{3}{*}{$\begin{array}{c}5 \text { Box Girders } \\
5.160 \mathrm{~m} \text { Bridge Width }\end{array}$} & ULS-1 & 1 & 1 & 1 & 5 & 458.40 & 123.280 & 1.345 \\
\hline & ULS-2 & 1 & 1 & 1 & 5 & 458.40 & 124.410 & 1.357 \\
\hline & FLS-3 & 1 & 1 & 1 & 5 & 458.40 & 124.410 & 1.357 \\
\hline
\end{tabular}


Table A. 3: One-Lane Bridge Deflection Distribution Factors $\left(F_{d}\right)$ at Fatigue Limit States

\begin{tabular}{|c|c|c|c|c|c|c|c|c|}
\hline \multicolumn{9}{|c|}{ One Lane Bridge: B700, 10 m Span Length } \\
\hline Bridge Configurations & Load cases & $\mathbf{n}$ & $\mathbf{R}_{\mathbf{L}}$ & $\mathbf{R}_{\mathbf{L}}^{\prime}$ & $\mathbf{N}$ & $\begin{array}{c}\left(\Delta_{\text {straight }}\right)_{\text {truck }} \\
(\mathbf{m m})\end{array}$ & $\begin{array}{l}\Delta_{\mathrm{FE}} \\
(\mathbf{m m})\end{array}$ & $\left(\mathbf{F}_{\mathbf{d}}\right)_{\mathrm{FE}}$ \\
\hline $\begin{array}{c}4 \text { Box Girders } \\
\text { 3.926m Bridge Width }\end{array}$ & FLS-3 & 1 & 1 & 1 & 4 & 6.967 & 2.041 & 1.172 \\
\hline $\begin{array}{c}5 \text { Box Girders } \\
5.160 \mathrm{~m} \text { Bridge Width }\end{array}$ & FLS-3 & 1 & 1 & 1 & 5 & 6.967 & 1.643 & 1.179 \\
\hline
\end{tabular}

\begin{tabular}{|c|c|c|c|c|c|c|c|c|}
\hline \multicolumn{9}{|c|}{ One Lane Bridge: B800, 20 m Span Length } \\
\hline Bridge Configurations & Load cases & $\mathbf{n}$ & $\mathbf{R}_{\mathbf{L}}$ & $\mathbf{R}_{\mathbf{L}}^{\prime}$ & $\mathbf{N}$ & $\begin{array}{c}\left(\Delta_{\text {straight }}\right)_{\text {truck }} \\
(\mathbf{m m})\end{array}$ & $\begin{array}{c}\Delta_{\text {FE. }} \\
(\mathbf{m m})\end{array}$ & $\left(\mathbf{F}_{\mathbf{d}}\right)_{\mathrm{FE}}$ \\
\hline $\begin{array}{c}4 \text { Box Girders } \\
\text { 3.926m Bridge Width }\end{array}$ & FLS-3 & 1 & 1 & 1 & 4 & 40.859 & 11.83 & 1.158 \\
\hline $\begin{array}{c}5 \text { Box Girders } \\
5.160 \mathrm{~m} \text { Bridge Width }\end{array}$ & FLS-3 & 1 & 1 & 1 & 5 & 40.859 & 9.55 & 1.169 \\
\hline
\end{tabular}

\begin{tabular}{|c|c|c|c|c|c|c|c|c|}
\hline \multicolumn{9}{|c|}{ One Lane Bridge: B1000, $32 \mathrm{~m}$ Span Length } \\
\hline Bridge Configurations & Load cases & $\mathbf{n}$ & $\mathbf{R}_{\mathbf{L}}$ & $\mathbf{R}_{\mathbf{L}}^{\prime}$ & $\mathbf{N}$ & $\begin{array}{c}\left(\Delta_{\text {straight }}\right)_{\text {truck }} \\
(\mathrm{mm})\end{array}$ & $\begin{array}{c}\Delta_{\mathrm{FE}} \\
(\mathbf{m m})\end{array}$ & $\left(\mathbf{F}_{\mathbf{d}}\right)_{\mathbf{F E}}$ \\
\hline $\begin{array}{c}4 \text { Box Girders } \\
\text { 3.926m Bridge Width }\end{array}$ & FLS-3 & 1 & 1 & 1 & 4 & 159.157 & 40.199 & 1.010 \\
\hline $\begin{array}{c}5 \text { Box Girders } \\
5.160 \mathrm{~m} \text { Bridge Width }\end{array}$ & FLS-3 & 1 & 1 & 1 & 5 & 159.157 & 32.19 & 1.011 \\
\hline
\end{tabular}


Table A. 4: Two-Lane Bridge Moment Distribution Factors $\left(F_{m}\right)$ at Serviceability, Ultimate and Fatigue Limit States

\begin{tabular}{|c|c|c|c|c|c|c|c|c|c|c|c|}
\hline \multicolumn{12}{|c|}{ Two Lane Bridge: B700, 10 m Span Length } \\
\hline Bridge Configurations & Load cases & $\mathbf{n}$ & $\mathbf{R}_{\mathbf{L}}$ & $\mathbf{R}_{\mathbf{L}}^{\prime}$ & $\mathbf{N}$ & $\begin{array}{c}I \\
\left(\mathbf{m}^{4}\right)\end{array}$ & $\begin{array}{l}\mathbf{y}_{\mathbf{b}} \\
(\mathbf{m})\end{array}$ & $\begin{array}{c}\mathbf{M}_{\mathrm{T}} \\
(\mathbf{k N} / \mathbf{m})\end{array}$ & $\begin{array}{c}\left(\sigma_{\text {straight }}\right)_{\text {truck }} \\
(\mathrm{MPa})\end{array}$ & $\begin{array}{c}\sigma_{\mathrm{FE}} \\
(\mathrm{MPa})\end{array}$ & $\left(\mathbf{F}_{\mathrm{m}}\right)_{\mathrm{FE}}$ \\
\hline \multirow{4}{*}{$\begin{array}{c}6 \text { Box Girders } \\
6.395 \mathrm{~m} \text { Bridge Width }\end{array}$} & ULS-1 & 2 & 0.9 & 1 & 6 & 0.0309 & 0.3761 & 651.00 & 7.924 & 2.209 & 0.929 \\
\hline & ULS-2 & 2 & 0.9 & 0.9 & 6 & 0.0309 & 0.3761 & 651.00 & 7.924 & 3.281 & 1.242 \\
\hline & ULS-3 & 2 & 0.9 & 0.9 & 6 & 0.0309 & 0.3761 & 651.00 & 7.924 & 3.319 & 1.257 \\
\hline & FLS-4 & 2 & 0.9 & 1 & 6 & 0.0309 & 0.3761 & 651.00 & 7.924 & 2.383 & 1.804 \\
\hline \multirow{4}{*}{$\begin{array}{c}7 \text { Box Girders } \\
\text { 7.630m Bridge Width }\end{array}$} & ULS-1 & 2 & 0.9 & 1 & 7 & 0.0309 & 0.3761 & 651.00 & 7.924 & 2.168 & 1.064 \\
\hline & ULS-2 & 2 & 0.9 & 0.9 & 7 & 0.0309 & 0.3761 & 651.00 & 7.924 & 2.869 & 1.267 \\
\hline & ULS-3 & 2 & 0.9 & 0.9 & 7 & 0.0309 & 0.3761 & 651.00 & 7.924 & 2.937 & 1.297 \\
\hline & FLS-4 & 2 & 0.9 & 1 & 7 & 0.0309 & 0.3761 & 651.00 & 7.924 & 2.359 & 2.084 \\
\hline \multirow{4}{*}{$\begin{array}{c}\text { 8 Box Girders } \\
\text { 8.865m Bridge Width }\end{array}$} & ULS-1 & 2 & 0.9 & 1 & 8 & 0.0309 & 0.3761 & 651.00 & 7.924 & 2.151 & 1.207 \\
\hline & ULS-2 & 2 & 0.9 & 0.9 & 8 & 0.0309 & 0.3761 & 651.00 & 7.924 & 2.692 & 1.359 \\
\hline & ULS-3 & 2 & 0.9 & 0.9 & 8 & 0.0309 & 0.3761 & 651.00 & 7.924 & 2.880 & 1.454 \\
\hline & FLS-4 & 2 & 0.9 & 1 & 8 & 0.0309 & 0.3761 & 651.00 & 7.924 & 2.076 & 2.096 \\
\hline
\end{tabular}

\begin{tabular}{|c|c|c|c|c|c|c|c|c|c|c|c|}
\hline \multicolumn{12}{|c|}{ Two Lane Bridge: B700, 13 m Span Length } \\
\hline Bridge Configration & Load cases & $\mathbf{n}$ & $\mathbf{R}_{\mathbf{L}}$ & $\mathbf{R}_{\mathbf{L}}^{\prime}$ & $\mathbf{N}$ & $\begin{array}{c}\mathbf{I} \\
\left(\mathbf{m}^{4}\right)\end{array}$ & $\begin{array}{l}\mathbf{y}_{\mathbf{b}} \\
(\mathbf{m})\end{array}$ & $\begin{array}{c}\mathbf{M}_{\mathrm{T}} \\
(\mathbf{k N} / \mathbf{m})\end{array}$ & $\begin{array}{c}\left(\sigma_{\text {straight }}\right)_{\text {truck }} \\
(\mathrm{MPa})\end{array}$ & $\begin{array}{c}\sigma_{\mathrm{FE}} \\
(\mathrm{MPa})\end{array}$ & $\left(\mathbf{F}_{\mathrm{m}}\right)_{\mathrm{FE}}$ \\
\hline \multirow{4}{*}{$\begin{array}{l}6 \text { Box Girders } \\
6.395 m \text { Bridge Width }\end{array}$} & ULS-1 & 2 & 0.9 & 1 & 6 & 0.0309 & 0.3761 & 898.50 & 10.936 & 2.711 & 0.826 \\
\hline & ULS-2 & 2 & 0.9 & 0.9 & 6 & 0.0309 & 0.3761 & 898.50 & 10.936 & 4.285 & 1.175 \\
\hline & ULS-3 & 2 & 0.9 & 0.9 & 6 & 0.0309 & 0.3761 & 898.50 & 10.936 & 4.324 & 1.186 \\
\hline & FLS-4 & 2 & 0.9 & 1 & 6 & 0.0309 & 0.3761 & 898.50 & 10.936 & 2.881 & 1.581 \\
\hline \multirow{4}{*}{$\begin{array}{c}7 \text { Box Girders } \\
\text { 7.630m Bridge Width }\end{array}$} & ULS-1 & 2 & 0.9 & 1 & 7 & 0.0309 & 0.3761 & 898.50 & 10.936 & 2.612 & 0.929 \\
\hline & ULS-2 & 2 & 0.9 & 0.9 & 7 & 0.0309 & 0.3761 & 898.50 & 10.936 & 3.738 & 1.196 \\
\hline & ULS-3 & 2 & 0.9 & 0.9 & 7 & 0.0309 & 0.3761 & 898.50 & 10.936 & 3.794 & 1.214 \\
\hline & FLS-4 & 2 & 0.9 & 1 & 7 & 0.0309 & 0.3761 & 898.50 & 10.936 & 2.787 & 1.784 \\
\hline \multirow{4}{*}{$\begin{array}{c}8 \text { Box Girders } \\
\text { 8.865m Bridge Width }\end{array}$} & ULS-1 & 2 & 0.9 & 1 & 8 & 0.0309 & 0.3761 & 898.50 & 10.936 & 2.561 & 1.041 \\
\hline & ULS-2 & 2 & 0.9 & 0.9 & 8 & 0.0309 & 0.3761 & 898.50 & 10.936 & 3.464 & 1.267 \\
\hline & ULS-3 & 2 & 0.9 & 0.9 & 8 & 0.0309 & 0.3761 & 898.50 & 10.936 & 3.618 & 1.323 \\
\hline & FLS-4 & 2 & 0.9 & 1 & 8 & 0.0309 & 0.3761 & 898.50 & 10.936 & 2.454 & 1.795 \\
\hline
\end{tabular}


Table A. 5: Two-Lane Bridge Shear Distribution Factors $\left(F_{v}\right)$ at Serviceability, Ultimate and Fatigue Limit States

\begin{tabular}{|c|c|c|c|c|c|c|c|c|}
\hline \multicolumn{9}{|c|}{ Two Lane Bridge: B700, $10 \mathrm{~m}$ Span Length } \\
\hline Bridge Configurations & Load cases & $\mathbf{n}$ & $\mathbf{R}_{\mathbf{L}}$ & $\mathbf{R}_{\mathbf{L}}^{\prime}$ & $\mathbf{N}$ & $\begin{array}{c}\left(\mathbf{R}_{\text {straight }}\right)_{\text {truck }} \\
(\mathbf{k N})\end{array}$ & $\begin{array}{l}\mathbf{R}_{\mathrm{FE}} \\
(\mathrm{kN})\end{array}$ & $\left(\mathbf{F}_{\mathbf{v}}\right)_{\mathrm{FE} .}$ \\
\hline \multirow{4}{*}{$\begin{array}{c}6 \text { Box Girders } \\
\text { 6.395m Bridge Width }\end{array}$} & ULS-1 & 2 & 0.9 & 1 & 6 & 301.70 & 120.103 & 1.327 \\
\hline & ULS-2 & 2 & 0.9 & 0.9 & 6 & 301.70 & 140.893 & 1.401 \\
\hline & ULS-3 & 2 & 0.9 & 0.9 & 6 & 301.70 & 141.735 & 1.409 \\
\hline & FLS-4 & 2 & 0.9 & 1 & 6 & 301.70 & 128.998 & 2.565 \\
\hline \multirow{4}{*}{$\begin{array}{c}7 \text { Box Girders } \\
\text { 7.630m Bridge Width }\end{array}$} & ULS-1 & 2 & 0.9 & 1 & 7 & 301.70 & 113.95 & 1.469 \\
\hline & ULS-2 & 2 & 0.9 & 0.9 & 7 & 301.70 & 126.545 & 1.468 \\
\hline & ULS-3 & 2 & 0.9 & 0.9 & 7 & 301.70 & 126.585 & 1.469 \\
\hline & FLS-4 & 2 & 0.9 & 1 & 7 & 301.70 & 121.099 & 2.810 \\
\hline \multirow{4}{*}{$\begin{array}{c}8 \text { Box Girders } \\
\text { 8.865m Bridge Width }\end{array}$} & ULS-1 & 2 & 0.9 & 1 & 8 & 301.70 & 113.924 & 1.678 \\
\hline & ULS-2 & 2 & 0.9 & 0.9 & 8 & 301.70 & 125.286 & 1.661 \\
\hline & ULS-3 & 2 & 0.9 & 0.9 & 8 & 301.70 & 127.888 & 1.696 \\
\hline & FLS-4 & 2 & 0.9 & 1 & 8 & 301.70 & 106.577 & 2.826 \\
\hline
\end{tabular}

\begin{tabular}{|c|c|c|c|c|c|c|c|c|}
\hline \multicolumn{9}{|c|}{ Two Lane Bridge: B700, 13 m Span Length } \\
\hline Bridge Configurations & Load cases & $\mathbf{n}$ & $\mathbf{R}_{\mathbf{L}}$ & $\mathbf{R}_{\mathbf{L}}^{\prime}$ & $\mathbf{N}$ & $\begin{array}{c}\left(\mathbf{R}_{\text {straight }}\right)_{\text {truck }} \\
(\mathbf{k N})\end{array}$ & $\begin{array}{l}\mathbf{R}_{\mathrm{FE}} \\
(\mathrm{kN})\end{array}$ & $\left(F_{v}\right)_{F E}$ \\
\hline \multirow{4}{*}{$\begin{array}{c}6 \text { Box Girders } \\
\text { 6.395m Bridge Width }\end{array}$} & ULS-1 & 2 & 0.9 & 1 & 6 & 305.75 & 113.339 & 1.236 \\
\hline & ULS-2 & 2 & 0.9 & 0.9 & 6 & 305.75 & 135.599 & 1.330 \\
\hline & ULS-3 & 2 & 0.9 & 0.9 & 6 & 305.75 & 136.480 & 1.339 \\
\hline & FLS-4 & 2 & 0.9 & 1 & 6 & 305.75 & 121.504 & 2.384 \\
\hline \multirow{4}{*}{$\begin{array}{c}7 \text { Box Girders } \\
\text { 7.630m Bridge Width }\end{array}$} & ULS-1 & 2 & 0.9 & 1 & 7 & 305.75 & 117.915 & 1.500 \\
\hline & ULS-2 & 2 & 0.9 & 0.9 & 7 & 305.75 & 131.803 & 1.509 \\
\hline & ULS-3 & 2 & 0.9 & 0.9 & 7 & 305.75 & 132.926 & 1.522 \\
\hline & FLS-4 & 2 & 0.9 & 1 & 7 & 305.75 & 126.483 & 2.896 \\
\hline \multirow{4}{*}{$\begin{array}{c}8 \text { Box Girders } \\
\text { 8.865m Bridge Width }\end{array}$} & ULS-1 & 2 & 0.9 & 1 & 8 & 305.75 & 117.790 & 1.712 \\
\hline & ULS-2 & 2 & 0.9 & 0.9 & 8 & 305.75 & 131.479 & 1.720 \\
\hline & ULS-3 & 2 & 0.9 & 0.9 & 8 & 305.75 & 135.340 & 1.771 \\
\hline & FLS-4 & 2 & 0.9 & 1 & 8 & 305.75 & 110.785 & 2.899 \\
\hline
\end{tabular}


Table A. 6: Two-Lane Bridge Deflection Distribution Factors $\left(F_{d}\right)$ at Fatigue Limit States

\begin{tabular}{cccccccccc}
\hline \multicolumn{7}{c}{ Two Lane Bridge: B700, 10 m Span Length } & & & \\
\hline Bridge Configurations & Load cases & $\mathbf{n}$ & $\mathbf{R}_{\mathbf{L}}$ & $\mathbf{R}_{\mathbf{L}}^{\prime}$ & $\mathbf{N}$ & $\begin{array}{c}\left(\Delta_{\text {straight }}\right)_{\text {truck }} \\
(\mathbf{m m})\end{array}$ & $\begin{array}{c}\Delta_{\text {FE. }} \\
(\mathbf{m m})\end{array}$ & $\left(\mathbf{F}_{\mathbf{d}}\right)_{\mathbf{F E} .}$ \\
\hline $\begin{array}{c}\mathbf{6} \text { Box Girders } \\
\mathbf{6 . 3 9 5 m} \text { Bridge Width }\end{array}$ & FLS-4 & 2 & 0.9 & 1 & 6 & 6.967 & 1.683 & 1.449 \\
\hline $\begin{array}{c}\mathbf{7} \text { Box Girders } \\
\mathbf{7 . 6 3 0 m} \text { Bridge Width }\end{array}$ & FLS-4 & 2 & 0.9 & 1 & 7 & 6.967 & 1.603 & 1.611 \\
\hline $\begin{array}{c}\mathbf{8} \text { Box Girders } \\
\mathbf{8 . 8 6 5 m} \text { Bridge Width }\end{array}$ & FLS-4 & 2 & 0.9 & 1 & 8 & 6.967 & 1.418 & 1.628 \\
\hline
\end{tabular}

\begin{tabular}{|c|c|c|c|c|c|c|c|c|}
\hline \multicolumn{9}{|c|}{ Two Lane Bridge: B700, 13 m Span Length } \\
\hline Bridge Configurations & Load cases & $\mathbf{n}$ & $\mathbf{R}_{\mathbf{L}}$ & $\mathbf{R}_{\mathbf{L}}^{\prime}$ & $\mathbf{N}$ & $\begin{array}{c}\left(\Delta_{\text {straight }}\right)_{\text {truck }} \\
(\mathbf{m m})\end{array}$ & $\begin{array}{c}\Delta_{\text {FE. }} \\
(\mathbf{m m})\end{array}$ & $\left(\mathbf{F}_{\mathbf{d}}\right)_{\mathbf{F E}}$ \\
\hline $\begin{array}{c}6 \text { Box Girders } \\
\text { 6.395m Bridge Width }\end{array}$ & FLS-4 & 2 & 0.9 & 1 & 6 & 16.110 & 3.397 & 1.265 \\
\hline $\begin{array}{c}7 \text { Box Girders } \\
\text { 7.630m Bridge Width }\end{array}$ & FLS-4 & 2 & 0.9 & 1 & 7 & 16.110 & 3.138 & 1.364 \\
\hline $\begin{array}{c}8 \text { Box Girders } \\
\text { 8.865m Bridge Width }\end{array}$ & FLS-4 & 2 & 0.9 & 1 & 8 & 16.110 & 2.808 & 1.394 \\
\hline
\end{tabular}




\section{Table A. 7: Three-Lane Bridge Moment Distribution Factors $\left(F_{m}\right)$ at Serviceability, Ultimate and Fatigue Limit States}

\begin{tabular}{|c|c|c|c|c|c|c|c|c|c|c|c|}
\hline \multicolumn{12}{|c|}{ Three Lane Bridge: B700, 10 m Span Length } \\
\hline Bridge Configurations & Load cases & $\mathbf{n}$ & $\mathbf{R}_{\mathbf{L}}$ & $\mathbf{R}_{\mathbf{L}}^{\prime}$ & $\mathbf{N}$ & $\begin{array}{c}\mathbf{I} \\
\left(\mathbf{m}^{4}\right)\end{array}$ & $\begin{array}{l}\mathbf{y}_{\mathbf{b}} \\
(\mathbf{m}) \\
\end{array}$ & $\begin{array}{c}\mathbf{M}_{\mathrm{T}} \\
(\mathbf{k N} / \mathbf{m})\end{array}$ & $\begin{array}{c}\left(\sigma_{\text {straight }}\right)_{\text {truck }} \\
(\mathrm{MPa})\end{array}$ & $\begin{array}{c}\sigma_{\mathrm{FE}} \\
(\mathrm{MPa})\end{array}$ & $\left(\mathbf{F}_{\mathrm{m}}\right)_{\mathrm{FE}}$ \\
\hline \multirow{7}{*}{$\begin{array}{c}9 \text { Box Girders } \\
\text { 11.10m Bridge Width }\end{array}$} & ULS-1 & 3 & 0.8 & 1 & 9 & 0.0309 & 0.3761 & 651.00 & 7.924 & 2.143 & 1.014 \\
\hline & ULS-2 & 3 & 0.8 & 0.9 & 9 & 0.0309 & 0.3761 & 651.00 & 7.924 & 2.869 & 1.222 \\
\hline & ULS-3 & 3 & 0.8 & 0.8 & 9 & 0.0309 & 0.3761 & 651.00 & 7.924 & 3.277 & 1.241 \\
\hline & ULS-4 & 3 & 0.8 & 0.9 & 9 & 0.0309 & 0.3761 & 651.00 & 7.924 & 3.108 & 1.324 \\
\hline & ULS-5 & 3 & 0.8 & 0.8 & 9 & 0.0309 & 0.3761 & 651.00 & 7.924 & 3.383 & 1.281 \\
\hline & FLS-6 & 3 & 0.8 & 1 & 9 & 0.0309 & 0.3761 & 651.00 & 7.924 & 2.332 & 2.649 \\
\hline & FLS-7 & 3 & 0.8 & 1 & 9 & 0.0309 & 0.3761 & 651.00 & 7.924 & 1.685 & 1.914 \\
\hline \multirow{7}{*}{$\begin{array}{c}10 \text { Box Girders } \\
12.336 \mathrm{~m} \text { Bridge Width }\end{array}$} & ULS-1 & 3 & 0.8 & 1 & 10 & 0.0309 & 0.3761 & 651.00 & 7.924 & 2.140 & 1.125 \\
\hline & ULS-2 & 3 & 0.8 & 0.9 & 10 & 0.0309 & 0.3761 & 651.00 & 7.924 & 2.761 & 1.307 \\
\hline & ULS-3 & 3 & 0.8 & 0.8 & 10 & 0.0309 & 0.3761 & 651.00 & 7.924 & 3.013 & 1.268 \\
\hline & ULS-4 & 3 & 0.8 & 0.9 & 10 & 0.0309 & 0.3761 & 651.00 & 7.924 & 2.852 & 1.350 \\
\hline & ULS-5 & 3 & 0.8 & 0.8 & 10 & 0.0309 & 0.3761 & 651.00 & 7.924 & 3.118 & 1.312 \\
\hline & FLS-6 & 3 & 0.8 & 1 & 10 & 0.0309 & 0.3761 & 651.00 & 7.924 & 2.275 & 2.871 \\
\hline & FLS-7 & 3 & 0.8 & 1 & 10 & 0.0309 & 0.3761 & 651.00 & 7.924 & 2.0395 & 2.574 \\
\hline \multirow{7}{*}{$\begin{array}{l}11 \text { Box Girders } \\
\text { 13.571m Bridge Width }\end{array}$} & ULS-1 & 3 & 0.8 & 1 & 11 & 0.0309 & 0.3761 & 651.00 & 7.924 & 2.138 & 1.237 \\
\hline & ULS-2 & 3 & 0.8 & 0.9 & 11 & 0.0309 & 0.3761 & 651.00 & 7.924 & 2.675 & 1.393 \\
\hline & ULS-3 & 3 & 0.8 & 0.8 & 11 & 0.0309 & 0.3761 & 651.00 & 7.924 & 3.006 & 1.391 \\
\hline & ULS-4 & 3 & 0.8 & 0.9 & 11 & 0.0309 & 0.3761 & 651.00 & 7.924 & 2.732 & 1.422 \\
\hline & ULS-5 & 3 & 0.8 & 0.8 & 11 & 0.0309 & 0.3761 & 651.00 & 7.924 & 3.168 & 1.466 \\
\hline & FLS-6 & 3 & 0.8 & 1 & 11 & 0.0309 & 0.3761 & 651.00 & 7.924 & 2.083 & 2.892 \\
\hline & FLS-7 & 3 & 0.8 & 1 & 11 & 0.0309 & 0.3761 & 651.00 & 7.924 & 1.639 & 2.275 \\
\hline
\end{tabular}

\begin{tabular}{|c|c|c|c|c|c|c|c|c|c|c|c|}
\hline \multicolumn{12}{|c|}{ Three Lane Bridge: B700, 13 m Span Length } \\
\hline Bridge Configration & Load cases & $\mathbf{n}$ & $\mathbf{R}_{\mathbf{L}}$ & $\mathbf{R}_{\mathbf{L}}^{\prime}$ & $\mathbf{N}$ & $\begin{array}{c}I \\
\left(\mathbf{m}^{4}\right)\end{array}$ & $\begin{array}{l}\mathbf{y}_{\mathbf{b}} \\
(\mathbf{m})\end{array}$ & $\begin{array}{c}\mathbf{M}_{\mathrm{T}} \\
(\mathbf{k N} / \mathbf{m}) \\
\end{array}$ & $\begin{array}{c}\left(\sigma_{\text {straight }}\right)_{\text {truck }} \\
(\mathrm{MPa})\end{array}$ & $\begin{array}{c}\sigma_{\mathrm{FE}} \\
(\mathrm{MPa})\end{array}$ & $\left(\mathbf{F}_{\mathrm{m}}\right)_{\mathrm{FE}}$ \\
\hline \multirow{7}{*}{$\begin{array}{c}9 \text { Box Girders } \\
11.10 \mathrm{~m} \text { Bridge Width }\end{array}$} & ULS-1 & 3 & 0.8 & 1 & 9 & 0.0309 & 0.3761 & 898.50 & 10.936 & 2.535 & 0.869 \\
\hline & ULS-2 & 3 & 0.8 & 0.9 & 9 & 0.0309 & 0.3761 & 898.50 & 10.936 & 3.608 & 1.113 \\
\hline & ULS-3 & 3 & 0.8 & 0.8 & 9 & 0.0309 & 0.3761 & 898.50 & 10.936 & 4.276 & 1.173 \\
\hline & ULS-4 & 3 & 0.8 & 0.9 & 9 & 0.0309 & 0.3761 & 898.50 & 10.936 & 3.842 & 1.186 \\
\hline & ULS-5 & 3 & 0.8 & 0.8 & 9 & 0.0309 & 0.3761 & 898.50 & 10.936 & 4.395 & 1.206 \\
\hline & FLS-6 & 3 & 0.8 & 1 & 9 & 0.0309 & 0.3761 & 898.50 & 10.936 & 2.703 & 2.224 \\
\hline & FLS-7 & 3 & 0.8 & 1 & 9 & 0.0309 & 0.3761 & 898.50 & 10.936 & 1.993 & 1.640 \\
\hline \multirow{7}{*}{$\begin{array}{l}10 \text { Box Girders } \\
12.336 \mathrm{~m} \text { Bridge Width }\end{array}$} & ULS-1 & 3 & 0.8 & 1 & 10 & 0.0309 & 0.3761 & 898.50 & 10.936 & 2.521 & 0.961 \\
\hline & ULS-2 & 3 & 0.8 & 0.9 & 10 & 0.0309 & 0.3761 & 898.50 & 10.936 & 3.463 & 1.187 \\
\hline & ULS-3 & 3 & 0.8 & 0.8 & 10 & 0.0309 & 0.3761 & 898.50 & 10.936 & 3.915 & 1.193 \\
\hline & ULS-4 & 3 & 0.8 & 0.9 & 10 & 0.0309 & 0.3761 & 898.50 & 10.936 & 3.527 & 1.209 \\
\hline & ULS-5 & 3 & 0.8 & 0.8 & 10 & 0.0309 & 0.3761 & 898.50 & 10.936 & 4.017 & 1.224 \\
\hline & FLS-6 & 3 & 0.8 & 1 & 10 & 0.0309 & 0.3761 & 898.50 & 10.936 & 2.632 & 2.407 \\
\hline & FLS-7 & 3 & 0.8 & 1 & 10 & 0.0309 & 0.3761 & 898.50 & 10.936 & 2.313 & 2.115 \\
\hline \multirow{7}{*}{$\begin{array}{l}11 \text { Box Girders } \\
\text { 13.571m Bridge Width }\end{array}$} & ULS-1 & 3 & 0.8 & 1 & 11 & 0.0309 & 0.3761 & 898.50 & 10.936 & 2.513 & 1.053 \\
\hline & ULS-2 & 3 & 0.8 & 0.9 & 11 & 0.0309 & 0.3761 & 898.50 & 10.936 & 3.348 & 1.263 \\
\hline & ULS-3 & 3 & 0.8 & 0.8 & 11 & 0.0309 & 0.3761 & 898.50 & 10.936 & 3.827 & 1.283 \\
\hline & ULS-4 & 3 & 0.8 & 0.9 & 11 & 0.0309 & 0.3761 & 898.50 & 10.936 & 3.289 & 1.241 \\
\hline & ULS-5 & 3 & 0.8 & 0.8 & 11 & 0.0309 & 0.3761 & 898.50 & 10.936 & 3.989 & 1.337 \\
\hline & FLS-6 & 3 & 0.8 & 1 & 11 & 0.0309 & 0.3761 & 898.50 & 10.936 & 2.398 & 2.412 \\
\hline & FLS-7 & 3 & 0.8 & 1 & 11 & 0.0309 & 0.3761 & 898.50 & 10.936 & 1.890 & 1.901 \\
\hline
\end{tabular}


Table A. 8: Three-Lane Bridge Shear Distribution Factors $\left(F_{v}\right)$ at Serviceability, Ultimate and Fatigue Limit States

\begin{tabular}{|c|c|c|c|c|c|c|c|c|}
\hline \multicolumn{9}{|c|}{ Three Lane Bridge: B700, $10 \mathrm{~m}$ Span Length } \\
\hline Bridge Configurations & Load cases & $\mathbf{n}$ & $\mathbf{R}_{\mathbf{L}}$ & $\mathbf{R}_{\mathbf{L}}^{\prime}$ & $\mathbf{N}$ & $\begin{array}{c}\left(\mathbf{R}_{\text {straight }}\right)_{\text {truck }} \\
(\mathbf{k N})\end{array}$ & $\begin{array}{l}R_{\text {FE. }} \\
(\mathrm{kN})\end{array}$ & $\left(\mathbf{F}_{\mathrm{v}}\right)_{\mathrm{FE}}$ \\
\hline \multirow{7}{*}{$\begin{array}{c}9 \text { Box Girders } \\
\text { 11.10m Bridge Width }\end{array}$} & ULS-1 & 3 & 0.8 & 1 & 9 & 301.70 & 112.212 & 1.395 \\
\hline & ULS-2 & 3 & 0.8 & 0.9 & 9 & 301.70 & 121.239 & 1.356 \\
\hline & ULS-3 & 3 & 0.8 & 0.8 & 9 & 301.70 & 123.514 & 1.228 \\
\hline & ULS-4 & 3 & 0.8 & 0.9 & 9 & 301.70 & 123.516 & 1.382 \\
\hline & ULS-5 & 3 & 0.8 & 0.8 & 9 & 301.70 & 124.344 & 1.236 \\
\hline & FLS-6 & 3 & 0.8 & 1 & 9 & 301.70 & 120.394 & 3.591 \\
\hline & FLS-7 & 3 & 0.8 & 1 & 9 & 301.70 & 100.283 & 2.992 \\
\hline \multirow{7}{*}{$\begin{array}{l}10 \text { Box Girders } \\
\text { 12.336m Bridge Width }\end{array}$} & ULS-1 & 3 & 0.8 & 1 & 10 & 301.70 & 113.875 & 1.573 \\
\hline & ULS-2 & 3 & 0.8 & 0.9 & 10 & 301.70 & 120.986 & 1.504 \\
\hline & ULS-3 & 3 & 0.8 & 0.8 & 10 & 301.70 & 125.224 & 1.384 \\
\hline & ULS-4 & 3 & 0.8 & 0.9 & 10 & 301.70 & 125.479 & 1.560 \\
\hline & ULS-5 & 3 & 0.8 & 0.8 & 10 & 301.70 & 125.479 & 1.386 \\
\hline & FLS-6 & 3 & 0.8 & 1 & 10 & 301.70 & 123.569 & 4.096 \\
\hline & FLS-7 & 3 & 0.8 & 1 & 10 & 301.70 & 114.184 & 3.785 \\
\hline \multirow{7}{*}{$\begin{array}{l}11 \text { Box Girders } \\
\text { 13.571m Bridge Width }\end{array}$} & ULS-1 & 3 & 0.8 & 1 & 11 & 301.70 & 113.941 & 1.731 \\
\hline & ULS-2 & 3 & 0.8 & 0.9 & 11 & 301.70 & 118.004 & 1.613 \\
\hline & ULS-3 & 3 & 0.8 & 0.8 & 11 & 301.70 & 118.004 & 1.434 \\
\hline & ULS-4 & 3 & 0.8 & 0.9 & 11 & 301.70 & 119.870 & 1.639 \\
\hline & ULS-5 & 3 & 0.8 & 0.8 & 11 & 301.70 & 119.870 & 1.457 \\
\hline & FLS-6 & 3 & 0.8 & 1 & 11 & 301.70 & 118.361 & 4.315 \\
\hline & FLS-7 & 3 & 0.8 & 1 & 11 & 301.70 & 100.759 & 3.674 \\
\hline \multicolumn{9}{|c|}{ Three Lane Bridge: B700, 13 m Span Length } \\
\hline Bridge Configurations & Load cases & $\mathbf{n}$ & $\mathbf{R}_{\mathbf{L}}$ & $\mathbf{R}_{\mathbf{L}}^{\prime}$ & $\mathbf{N}$ & $\begin{array}{c}\left(\mathbf{R}_{\text {straight }}\right)_{\text {truck }} \\
(\mathbf{k N})\end{array}$ & $\begin{array}{l}\mathbf{R}_{\mathrm{FE}} \\
(\mathrm{kN})\end{array}$ & $\left(\mathbf{F}_{\mathrm{v}}\right)_{\mathrm{FE}}$ \\
\hline \multirow{7}{*}{$\begin{array}{c}9 \text { Box Girders } \\
\text { 11.10m Bridge Width }\end{array}$} & ULS-1 & 3 & 0.8 & 1 & 9 & 305.75 & 116.063 & 1.424 \\
\hline & ULS-2 & 3 & 0.8 & 0.9 & 9 & 305.75 & 128.909 & 1.423 \\
\hline & ULS-3 & 3 & 0.8 & 0.8 & 9 & 305.75 & 131.258 & 1.288 \\
\hline & ULS-4 & 3 & 0.8 & 0.9 & 9 & 305.75 & 130.708 & 1.443 \\
\hline & ULS-5 & 3 & 0.8 & 0.8 & 9 & 305.75 & 132.555 & 1.301 \\
\hline & FLS-6 & 3 & 0.8 & 1 & 9 & 305.75 & 125.854 & 3.705 \\
\hline & FLS-7 & 3 & 0.8 & 1 & 9 & 305.75 & 104.600 & 3.079 \\
\hline \multirow{7}{*}{$\begin{array}{l}10 \text { Box Girders } \\
\text { 12.336m Bridge Width }\end{array}$} & ULS-1 & 3 & 0.8 & 1 & 10 & 305.75 & 117.693 & 1.604 \\
\hline & ULS-2 & 3 & 0.8 & 0.9 & 10 & 305.75 & 125.441 & 1.539 \\
\hline & ULS-3 & 3 & 0.8 & 0.8 & 10 & 305.75 & 130.863 & 1.427 \\
\hline & ULS-4 & 3 & 0.8 & 0.9 & 10 & 305.75 & 132.246 & 1.622 \\
\hline & ULS-5 & 3 & 0.8 & 0.8 & 10 & 305.75 & 132.246 & 1.442 \\
\hline & FLS-6 & 3 & 0.8 & 1 & 10 & 305.75 & 128.994 & 4.219 \\
\hline & FLS-7 & 3 & 0.8 & 1 & 10 & 305.75 & 118.895 & 3.889 \\
\hline \multirow{7}{*}{$\begin{array}{l}11 \text { Box Girders } \\
\text { 13.571m Bridge Width }\end{array}$} & ULS-1 & 3 & 0.8 & 1 & 11 & 305.75 & 117.736 & 1.765 \\
\hline & ULS-2 & 3 & 0.8 & 0.9 & 11 & 305.75 & 124.683 & 1.682 \\
\hline & ULS-3 & 3 & 0.8 & 0.8 & 11 & 305.75 & 124.683 & 1.495 \\
\hline & ULS-4 & 3 & 0.8 & 0.9 & 11 & 305.75 & 127.549 & 1.721 \\
\hline & ULS-5 & 3 & 0.8 & 0.8 & 11 & 305.75 & 127.549 & 1.530 \\
\hline & FLS-6 & 3 & 0.8 & 1 & 11 & 305.75 & 122.550 & 4.409 \\
\hline & FLS-7 & 3 & 0.8 & 1 & 11 & 305.75 & 105.038 & 3.779 \\
\hline
\end{tabular}


Table A. 9: Three-Lane Bridge Deflection Distribution Factors $\left(F_{d}\right)$ at Fatigue Limit States

\begin{tabular}{|c|c|c|c|c|c|c|c|c|}
\hline \multicolumn{9}{|c|}{ Three Lane Bridge: B700, 10 m Span Length } \\
\hline Bridge Configurations & Load cases & $\mathbf{n}$ & $\mathbf{R}_{\mathbf{L}}$ & $\mathbf{R}_{\mathbf{L}}^{\prime}$ & $\mathbf{N}$ & $\begin{array}{c}\left(\Delta_{\text {straight }}\right)_{\text {truck }} \\
(\mathbf{m m})\end{array}$ & $\begin{array}{c}\Delta_{\text {FE. }} \\
(\mathbf{m m})\end{array}$ & $\left(\mathbf{F}_{\mathbf{d}}\right)_{\mathrm{FE}}$ \\
\hline 9 Box Girders & FLS-6 & 3 & 0.8 & 1 & 9 & 6.967 & 1.57 & 2.028 \\
\hline 11.10m Bridge Width & FLS-7 & 3 & 0.8 & 1 & 9 & 6.967 & 1.249 & 1.613 \\
\hline 10 Box Girders & FLS-6 & 3 & 0.8 & 1 & 10 & 6.967 & 1.55 & 2.225 \\
\hline $12.336 \mathrm{~m}$ Bridge Width & FLS-7 & 3 & 0.8 & 1 & 10 & 6.967 & 1.320 & 1.895 \\
\hline 11 Box Girders & FLS-6 & 3 & 0.8 & 1 & 11 & 6.967 & 1.415 & 2.234 \\
\hline 13.571m Bridge Width & FLS-7 & 3 & 0.8 & 1 & 11 & 6.967 & 1.221 & 1.928 \\
\hline
\end{tabular}

Three Lane Bridge: B700, 13 m Span Length

\begin{tabular}{|c|c|c|c|c|c|c|c|c|}
\hline Bridge Configurations & Load cases & $\mathbf{n}$ & $\mathbf{R}_{\mathbf{L}}$ & $\mathbf{R}_{\mathbf{L}}^{\prime}$ & $\mathbf{N}$ & $\begin{array}{c}\left(\Delta_{\text {straight }}\right)_{\text {truck }} \\
(\mathbf{m m})\end{array}$ & $\begin{array}{c}\Delta_{\text {FE. }} \\
(\mathbf{m m})\end{array}$ & $\left(\mathbf{F}_{\mathbf{d}}\right)_{\mathrm{FE}}$ \\
\hline 9 Box Girders & FLS-6 & 3 & 0.8 & 1 & 9 & 16.110 & 2.99 & 1.670 \\
\hline $11.10 \mathrm{~m}$ Bridge Width & FLS-7 & 3 & 0.8 & 1 & 9 & 16.110 & 2.429 & 1.357 \\
\hline 10 Box Girders & FLS-6 & 3 & 0.8 & 1 & 10 & 16.110 & 2.931 & 1.819 \\
\hline $12.336 \mathrm{~m}$ Bridge Width & FLS-7 & 3 & 0.8 & 1 & 10 & 16.110 & 2.418 & 1.501 \\
\hline 11 Box Girders & FLS-6 & 3 & 0.8 & 1 & 11 & 16.110 & 2.667 & 1.821 \\
\hline 13.571m Bridge Width & FLS-7 & 3 & 0.8 & 1 & 11 & 16.110 & 2.258 & 1.542 \\
\hline
\end{tabular}


Table A. 10: Four-Lane Bridge Moment Distribution Factors $\left(F_{m}\right)$ at Serviceability, Ultimate and Fatigue Limit States

\begin{tabular}{|c|c|c|c|c|c|c|c|c|c|c|c|}
\hline \multicolumn{12}{|c|}{ Four Lane Bridge: B700, 10 m Span Length } \\
\hline Bridge Configurations & Load cases & $\mathbf{n}$ & $\mathbf{R}_{\mathbf{L}}$ & $\mathbf{R}_{\mathbf{L}}^{\prime}$ & $\mathbf{N}$ & $\begin{array}{c}\mathbf{I} \\
\left(\mathbf{m}^{4}\right)\end{array}$ & $\begin{array}{l}\mathbf{y}_{\mathbf{b}} \\
(\mathbf{m})\end{array}$ & $\begin{array}{c}\mathbf{M}_{\mathrm{T}} \\
(\mathbf{k N} / \mathbf{m})\end{array}$ & $\begin{array}{c}\left(\sigma_{\text {straight }}\right)_{\text {truck }} \\
(\mathrm{MPa})\end{array}$ & $\begin{array}{c}\sigma_{\mathrm{FE}} \\
(\mathrm{MPa})\end{array}$ & $\left(F_{m}\right)_{F E}$ \\
\hline \multirow{13}{*}{$\begin{array}{c}12 \text { Box Girders } \\
\text { 14.805m Bridge Width }\end{array}$} & ULS-1 & 4 & 0.7 & 1 & 12 & 0.0309 & 0.3761 & 651.00 & 7.924 & 2.137 & 1.156 \\
\hline & ULS-2 & 4 & 0.7 & 0.9 & 12 & 0.0309 & 0.3761 & 651.00 & 7.924 & 2.828 & 1.377 \\
\hline & ULS-3 & 4 & 0.7 & 0.8 & 12 & 0.0309 & 0.3761 & 651.00 & 7.924 & 3.048 & 1.319 \\
\hline & ULS-4 & 4 & 0.7 & 0.7 & 12 & 0.0309 & 0.3761 & 651.00 & 7.924 & 3.352 & 1.269 \\
\hline & ULS-5 & 4 & 0.7 & 0.9 & 12 & 0.0309 & 0.3761 & 651.00 & 7.924 & 3.029 & 1.474 \\
\hline & ULS-6 & 4 & 0.7 & 0.9 & 12 & 0.0309 & 0.3761 & 651.00 & 7.924 & 2.634 & 1.282 \\
\hline & ULS-7 & 4 & 0.7 & 0.8 & 12 & 0.0309 & 0.3761 & 651.00 & 7.924 & 3.272 & 1.416 \\
\hline & ULS-8 & 4 & 0.7 & 0.7 & 12 & 0.0309 & 0.3761 & 651.00 & 7.924 & 3.328 & 1.260 \\
\hline & ULS-9 & 4 & 0.7 & 0.7 & 12 & 0.0309 & 0.3761 & 651.00 & 7.924 & 3.373 & 1.277 \\
\hline & ULS-10 & 4 & 0.7 & 0.7 & 12 & 0.0309 & 0.3761 & 651.00 & 7.924 & 3.464 & 1.312 \\
\hline & ULS-11 & 4 & 0.7 & 0.9 & 12 & 0.0309 & 0.3761 & 651.00 & 7.924 & 2.541 & 1.237 \\
\hline & FLS-12 & 4 & 0.7 & 1 & 12 & 0.0309 & 0.3761 & 651.00 & 7.924 & 2.024 & 3.065 \\
\hline & FLS-13 & 4 & 0.7 & 1 & 12 & 0.0309 & 0.3761 & 651.00 & 7.924 & 1.975 & 2.991 \\
\hline \multirow{13}{*}{$\begin{array}{c}13 \text { Box Girders } \\
\text { 16.041m Bridge Width }\end{array}$} & ULS-1 & 4 & 0.7 & 1 & 13 & 0.0309 & 0.3761 & 651.00 & 7.924 & 2.137 & 1.252 \\
\hline & ULS-2 & 4 & 0.7 & 0.9 & 13 & 0.0309 & 0.3761 & 651.00 & 7.924 & 2.756 & 1.453 \\
\hline & ULS-3 & 4 & 0.7 & 0.8 & 13 & 0.0309 & 0.3761 & 651.00 & 7.924 & 2.933 & 1.375 \\
\hline & ULS-4 & 4 & 0.7 & 0.7 & 13 & 0.0309 & 0.3761 & 651.00 & 7.924 & 3.075 & 1.261 \\
\hline & ULS-5 & 4 & 0.7 & 0.9 & 13 & 0.0309 & 0.3761 & 651.00 & 7.924 & 2.864 & 1.510 \\
\hline & ULS-6 & 4 & 0.7 & 0.9 & 13 & 0.0309 & 0.3761 & 651.00 & 7.924 & 2.470 & 1.303 \\
\hline & ULS-7 & 4 & 0.7 & 0.8 & 13 & 0.0309 & 0.3761 & 651.00 & 7.924 & 3.059 & 1.434 \\
\hline & ULS-8 & 4 & 0.7 & 0.7 & 13 & 0.0309 & 0.3761 & 651.00 & 7.924 & 3.081 & 1.264 \\
\hline & ULS-9 & 4 & 0.7 & 0.7 & 13 & 0.0309 & 0.3761 & 651.00 & 7.924 & 3.169 & 1.300 \\
\hline & ULS-10 & 4 & 0.7 & 0.7 & 13 & 0.0309 & 0.3761 & 651.00 & 7.924 & 3.231 & 1.325 \\
\hline & ULS-11 & 4 & 0.7 & 0.9 & 13 & 0.0309 & 0.3761 & 651.00 & 7.924 & 2.356 & 1.242 \\
\hline & FLS-12 & 4 & 0.7 & 1 & 13 & 0.0309 & 0.3761 & 651.00 & 7.924 & 2.171 & 3.562 \\
\hline & FLS-13 & 4 & 0.7 & 1 & 13 & 0.0309 & 0.3761 & 651.00 & 7.924 & 2.056 & 3.373 \\
\hline \multirow{13}{*}{$\begin{array}{c}14 \text { Box Girders } \\
\text { 17.275m Bridge Width }\end{array}$} & ULS-1 & 4 & 0.7 & 1 & 14 & 0.0309 & 0.3761 & 651.00 & 7.924 & 2.137 & 1.348 \\
\hline & ULS-2 & 4 & 0.7 & 0.9 & 14 & 0.0309 & 0.3761 & 651.00 & 7.924 & 2.693 & 1.529 \\
\hline & ULS-3 & 4 & 0.7 & 0.8 & 14 & 0.0309 & 0.3761 & 651.00 & 7.924 & 3.025 & 1.527 \\
\hline & ULS-4 & 4 & 0.7 & 0.7 & 14 & 0.0309 & 0.3761 & 651.00 & 7.924 & 3.144 & 1.389 \\
\hline & ULS-5 & 4 & 0.7 & 0.9 & 14 & 0.0309 & 0.3761 & 651.00 & 7.924 & 2.759 & 1.567 \\
\hline & ULS-6 & 4 & 0.7 & 0.9 & 14 & 0.0309 & 0.3761 & 651.00 & 7.924 & 2.606 & 1.480 \\
\hline & ULS-7 & 4 & 0.7 & 0.8 & 14 & 0.0309 & 0.3761 & 651.00 & 7.924 & 3.179 & 1.605 \\
\hline & ULS-8 & 4 & 0.7 & 0.7 & 14 & 0.0309 & 0.3761 & 651.00 & 7.924 & 3.173 & 1.402 \\
\hline & ULS-9 & 4 & 0.7 & 0.7 & 14 & 0.0309 & 0.3761 & 651.00 & 7.924 & 3.298 & 1.457 \\
\hline & ULS-10 & 4 & 0.7 & 0.7 & 14 & 0.0309 & 0.3761 & 651.00 & 7.924 & 3.237 & 1.430 \\
\hline & ULS-11 & 4 & 0.7 & 0.9 & 14 & 0.0309 & 0.3761 & 651.00 & 7.924 & 2.486 & 1.412 \\
\hline & FLS-12 & 4 & 0.7 & 1 & 14 & 0.0309 & 0.3761 & 651.00 & 7.924 & 2.061 & 3.641 \\
\hline & FLS-13 & 4 & 0.7 & 1 & 14 & 0.0309 & 0.3761 & 651.00 & 7.924 & 1.716 & 3.032 \\
\hline
\end{tabular}




\begin{tabular}{|c|c|c|c|c|c|c|c|c|c|c|c|}
\hline \multicolumn{12}{|c|}{ Four Lane Bridge: B700, 13 m Span Length } \\
\hline Bridge Configurations & Load cases & $\mathbf{n}$ & $\mathbf{R}_{\mathbf{L}}$ & $\mathbf{R}_{\mathbf{L}}^{\prime}$ & $\mathbf{N}$ & $\begin{array}{c}\mathbf{I} \\
\left(\mathbf{m}^{4}\right)\end{array}$ & $\begin{array}{l}\mathbf{y}_{\mathbf{b}} \\
(\mathbf{m})\end{array}$ & $\begin{array}{c}\mathbf{M}_{\mathrm{T}} \\
(\mathbf{k N} / \mathbf{m})\end{array}$ & $\begin{array}{c}\left(\sigma_{\text {straight }}\right)_{\text {truck }} \\
(\mathrm{MPa})\end{array}$ & $\begin{array}{c}\sigma_{\mathrm{FE}} \\
(\mathbf{M P a})\end{array}$ & $\left(\mathbf{F}_{\mathrm{m}}\right)_{\mathrm{FE}}$ \\
\hline \multirow{13}{*}{$\begin{array}{l}\text { 12 Box Girders } \\
\text { 14.805m Bridge Width }\end{array}$} & ULS-1 & 4 & 0.7 & 1 & 12 & 0.0309 & 0.3761 & 898.50 & 10.936 & 2.509 & 0.983 \\
\hline & ULS-2 & 4 & 0.7 & 0.9 & 12 & 0.0309 & 0.3761 & 898.50 & 10.936 & 3.512 & 1.239 \\
\hline & ULS-3 & 4 & 0.7 & 0.8 & 12 & 0.0309 & 0.3761 & 898.50 & 10.936 & 3.941 & 1.236 \\
\hline & ULS-4 & 4 & 0.7 & 0.7 & 12 & 0.0309 & 0.3761 & 898.50 & 10.936 & 4.349 & 1.193 \\
\hline & ULS-5 & 4 & 0.7 & 0.9 & 12 & 0.0309 & 0.3761 & 898.50 & 10.936 & 3.697 & 1.304 \\
\hline & ULS-6 & 4 & 0.7 & 0.9 & 12 & 0.0309 & 0.3761 & 898.50 & 10.936 & 3.128 & 1.103 \\
\hline & ULS-7 & 4 & 0.7 & 0.8 & 12 & 0.0309 & 0.3761 & 898.50 & 10.936 & 4.148 & 1.300 \\
\hline & ULS-8 & 4 & 0.7 & 0.7 & 12 & 0.0309 & 0.3761 & 898.50 & 10.936 & 4.334 & 1.189 \\
\hline & ULS-9 & 4 & 0.7 & 0.7 & 12 & 0.0309 & 0.3761 & 898.50 & 10.936 & 4.380 & 1.202 \\
\hline & ULS-10 & 4 & 0.7 & 0.7 & 12 & 0.0309 & 0.3761 & 898.50 & 10.936 & 4.470 & 1.226 \\
\hline & ULS-11 & 4 & 0.7 & 0.9 & 12 & 0.0309 & 0.3761 & 898.50 & 10.936 & 3.032 & 1.069 \\
\hline & FLS-12 & 4 & 0.7 & 1 & 12 & 0.0309 & 0.3761 & 898.50 & 10.936 & 2.365 & 2.595 \\
\hline & FLS-13 & 4 & 0.7 & 1 & 12 & 0.0309 & 0.3761 & 898.50 & 10.936 & 2.219 & 2.435 \\
\hline \multirow{13}{*}{$\begin{array}{c}13 \text { Box Girders } \\
\text { 16.041m Bridge Width }\end{array}$} & ULS-1 & 4 & 0.7 & 1 & 13 & 0.0309 & 0.3761 & 898.50 & 10.936 & 2.507 & 1.064 \\
\hline & ULS-2 & 4 & 0.7 & 0.9 & 13 & 0.0309 & 0.3761 & 898.50 & 10.936 & 3.426 & 1.309 \\
\hline & ULS-3 & 4 & 0.7 & 0.8 & 13 & 0.0309 & 0.3761 & 898.50 & 10.936 & 3.786 & 1.286 \\
\hline & ULS-4 & 4 & 0.7 & 0.7 & 13 & 0.0309 & 0.3761 & 898.50 & 10.936 & 4.011 & 1.192 \\
\hline & ULS-5 & 4 & 0.7 & 0.9 & 13 & 0.0309 & 0.3761 & 898.50 & 10.936 & 3.505 & 1.339 \\
\hline & ULS-6 & 4 & 0.7 & 0.9 & 13 & 0.0309 & 0.3761 & 898.50 & 10.936 & 2.937 & 1.122 \\
\hline & ULS-7 & 4 & 0.7 & 0.8 & 13 & 0.0309 & 0.3761 & 898.50 & 10.936 & 3.892 & 1.322 \\
\hline & ULS-8 & 4 & 0.7 & 0.7 & 13 & 0.0309 & 0.3761 & 898.50 & 10.936 & 4.006 & 1.191 \\
\hline & ULS-9 & 4 & 0.7 & 0.7 & 13 & 0.0309 & 0.3761 & 898.50 & 10.936 & 4.107 & 1.221 \\
\hline & ULS-10 & 4 & 0.7 & 0.7 & 13 & 0.0309 & 0.3761 & 898.50 & 10.936 & 4.165 & 1.238 \\
\hline & ULS-11 & 4 & 0.7 & 0.9 & 13 & 0.0309 & 0.3761 & 898.50 & 10.936 & 2.828 & 1.081 \\
\hline & FLS-12 & 4 & 0.7 & 1 & 13 & 0.0309 & 0.3761 & 898.50 & 10.936 & 2.513 & 2.987 \\
\hline & FLS-13 & 4 & 0.7 & 1 & 13 & 0.0309 & 0.3761 & 898.50 & 10.936 & 2.287 & 2.719 \\
\hline \multirow{13}{*}{$\begin{array}{c}14 \text { Box Girders } \\
\text { 17.275m Bridge Width }\end{array}$} & ULS-1 & 4 & 0.7 & 1 & 14 & 0.0309 & 0.3761 & 898.50 & 10.936 & 2.506 & 1.146 \\
\hline & ULS-2 & 4 & 0.7 & 0.9 & 14 & 0.0309 & 0.3761 & 898.50 & 10.936 & 3.350 & 1.378 \\
\hline & ULS-3 & 4 & 0.7 & 0.8 & 14 & 0.0309 & 0.3761 & 898.50 & 10.936 & 3.768 & 1.378 \\
\hline & ULS-4 & 4 & 0.7 & 0.7 & 14 & 0.0309 & 0.3761 & 898.50 & 10.936 & 4.028 & 1.289 \\
\hline & ULS-5 & 4 & 0.7 & 0.9 & 14 & 0.0309 & 0.3761 & 898.50 & 10.936 & 3.285 & 1.352 \\
\hline & ULS-6 & 4 & 0.7 & 0.9 & 14 & 0.0309 & 0.3761 & 898.50 & 10.936 & 3.048 & 1.254 \\
\hline & ULS-7 & 4 & 0.7 & 0.8 & 14 & 0.0309 & 0.3761 & 898.50 & 10.936 & 3.913 & 1.431 \\
\hline & ULS-8 & 4 & 0.7 & 0.7 & 14 & 0.0309 & 0.3761 & 898.50 & 10.936 & 4.027 & 1.289 \\
\hline & ULS-9 & 4 & 0.7 & 0.7 & 14 & 0.0309 & 0.3761 & 898.50 & 10.936 & 4.173 & 1.336 \\
\hline & ULS-10 & 4 & 0.7 & 0.7 & 14 & 0.0309 & 0.3761 & 898.50 & 10.936 & 4.110 & 1.315 \\
\hline & ULS-11 & 4 & 0.7 & 0.9 & 14 & 0.0309 & 0.3761 & 898.50 & 10.936 & 2.933 & 1.207 \\
\hline & FLS-12 & 4 & 0.7 & 1 & 14 & 0.0309 & 0.3761 & 898.50 & 10.936 & 2.371 & 3.035 \\
\hline & FLS-13 & 4 & 0.7 & 1 & 14 & 0.0309 & 0.3761 & 898.50 & 10.936 & 1.932 & 2.473 \\
\hline
\end{tabular}


Table A. 11: Four-Lane Bridge Shear Distribution Factors $\left(F_{v}\right)$ at Serviceability, Ultimate and Fatigue Limit States

\begin{tabular}{|c|c|c|c|c|c|c|c|c|}
\hline \multicolumn{9}{|c|}{ Four Lane Bridge: B700, $10 \mathrm{~m}$ Span Length } \\
\hline Bridge Configurations & Load cases & $\mathbf{n}$ & $\mathbf{R}_{\mathbf{L}}$ & $\mathbf{R}_{\mathbf{L}}^{\prime}$ & $\mathbf{N}$ & $\begin{array}{c}\left(\mathbf{R}_{\text {straight }}\right)_{\text {truck }} \\
(\mathbf{k N})\end{array}$ & $\begin{array}{l}\mathbf{R}_{\mathrm{FE}} \\
(\mathrm{kN})\end{array}$ & $\left(\mathbf{F}_{\mathrm{v}}\right)_{\mathrm{FE}}$ \\
\hline \multirow{13}{*}{$\begin{array}{l}12 \text { Box Girders } \\
14.805 m \text { Bridge Width }\end{array}$} & ULS-1 & 4 & 0.7 & 1 & 12 & 301.70 & 114.116 & 1.621 \\
\hline & ULS-2 & 4 & 0.7 & 0.9 & 12 & 301.70 & 117.717 & 1.505 \\
\hline & ULS-3 & 4 & 0.7 & 0.8 & 12 & 301.70 & 127.599 & 1.450 \\
\hline & ULS-4 & 4 & 0.7 & 0.7 & 12 & 301.70 & 127.599 & 1.269 \\
\hline & ULS-5 & 4 & 0.7 & 0.9 & 12 & 301.70 & 118.49 & 1.515 \\
\hline & ULS-6 & 4 & 0.7 & 0.9 & 12 & 301.70 & 128.221 & 1.639 \\
\hline & ULS-7 & 4 & 0.7 & 0.8 & 12 & 301.70 & 127.681 & 1.451 \\
\hline & ULS-8 & 4 & 0.7 & 0.7 & 12 & 301.70 & 119.332 & 1.187 \\
\hline & ULS-9 & 4 & 0.7 & 0.7 & 12 & 301.70 & 127.697 & 1.270 \\
\hline & ULS-10 & 4 & 0.7 & 0.7 & 12 & 301.70 & 129.060 & 1.283 \\
\hline & ULS-11 & 4 & 0.7 & 0.9 & 12 & 301.70 & 126.857 & 1.622 \\
\hline & FLS-12 & 4 & 0.7 & 1 & 12 & 301.70 & 117.412 & 4.670 \\
\hline & FLS-13 & 4 & 0.7 & 1 & 12 & 301.70 & 123.756 & 4.922 \\
\hline \multirow{13}{*}{$\begin{array}{c}13 \text { Box Girders } \\
\text { 16.041m Bridge Width }\end{array}$} & ULS-1 & 4 & 0.7 & 1 & 13 & 301.70 & 113.866 & 1.752 \\
\hline & ULS-2 & 4 & 0.7 & 0.9 & 13 & 301.70 & 119.069 & 1.649 \\
\hline & ULS-3 & 4 & 0.7 & 0.8 & 13 & 301.70 & 125.683 & 1.547 \\
\hline & ULS-4 & 4 & 0.7 & 0.7 & 13 & 301.70 & 128.585 & 1.385 \\
\hline & ULS-5 & 4 & 0.7 & 0.9 & 13 & 301.70 & 125.288 & 1.735 \\
\hline & ULS-6 & 4 & 0.7 & 0.9 & 13 & 301.70 & 125.683 & 1.741 \\
\hline & ULS-7 & 4 & 0.7 & 0.8 & 13 & 301.70 & 125.683 & 1.547 \\
\hline & ULS-8 & 4 & 0.7 & 0.7 & 13 & 301.70 & 125.377 & 1.351 \\
\hline & ULS-9 & 4 & 0.7 & 0.7 & 13 & 301.70 & 128.177 & 1.381 \\
\hline & ULS-10 & 4 & 0.7 & 0.7 & 13 & 301.70 & 128.585 & 1.385 \\
\hline & ULS-11 & 4 & 0.7 & 0.9 & 13 & 301.70 & 125.308 & 1.736 \\
\hline & FLS-12 & 4 & 0.7 & 1 & 13 & 301.70 & 125.101 & 5.390 \\
\hline & FLS-13 & 4 & 0.7 & 1 & 13 & 301.70 & 120.275 & 5.183 \\
\hline \multirow{13}{*}{$\begin{array}{c}14 \text { Box Girders } \\
\text { 17.275m Bridge Width }\end{array}$} & ULS-1 & 4 & 0.7 & 1 & 14 & 301.70 & 113.916 & 1.888 \\
\hline & ULS-2 & 4 & 0.7 & 0.9 & 14 & 301.70 & 120.132 & 1.792 \\
\hline & ULS-3 & 4 & 0.7 & 0.8 & 14 & 301.70 & 126.242 & 1.674 \\
\hline & ULS-4 & 4 & 0.7 & 0.7 & 14 & 301.70 & 126.242 & 1.465 \\
\hline & ULS-5 & 4 & 0.7 & 0.9 & 14 & 301.70 & 120.132 & 1.792 \\
\hline & ULS-6 & 4 & 0.7 & 0.9 & 14 & 301.70 & 128.136 & 1.911 \\
\hline & ULS-7 & 4 & 0.7 & 0.8 & 14 & 301.70 & 126.388 & 1.676 \\
\hline & ULS-8 & 4 & 0.7 & 0.7 & 14 & 301.70 & 121.688 & 1.412 \\
\hline & ULS-9 & 4 & 0.7 & 0.7 & 14 & 301.70 & 122.353 & 1.419 \\
\hline & ULS-10 & 4 & 0.7 & 0.7 & 14 & 301.70 & 128.794 & 1.494 \\
\hline & ULS-11 & 4 & 0.7 & 0.9 & 14 & 301.70 & 121.921 & 1.819 \\
\hline & FLS-12 & 4 & 0.7 & 1 & 14 & 301.70 & 123.965 & 5.752 \\
\hline & FLS-13 & 4 & 0.7 & 1 & 14 & 301.70 & 106.804 & 4.956 \\
\hline
\end{tabular}




\begin{tabular}{|c|c|c|c|c|c|c|c|c|}
\hline \multicolumn{9}{|c|}{ Four Lane Bridge: B700, 13 m Span Length } \\
\hline Bridge Configurations & Load cases & $\mathbf{n}$ & $\mathbf{R}_{\mathbf{L}}$ & $\mathbf{R}_{\mathbf{L}}^{\prime}$ & $\mathbf{N}$ & $\begin{array}{c}\left(\mathbf{R}_{\text {straight }}\right)_{\text {truck }} \\
(\mathbf{k N})\end{array}$ & $\begin{array}{l}\mathbf{R}_{\mathrm{FE}} \\
(\mathrm{kN})\end{array}$ & $\left(F_{v}\right)_{F E}$ \\
\hline \multirow{13}{*}{$\begin{array}{c}12 \text { Box Girders } \\
\text { 14.805m Bridge Width }\end{array}$} & ULS-1 & 4 & 0.7 & 1 & 12 & 305.75 & 117.912 & 1.653 \\
\hline & ULS-2 & 4 & 0.7 & 0.9 & 12 & 305.75 & 124.194 & 1.567 \\
\hline & ULS-3 & 4 & 0.7 & 0.8 & 12 & 305.75 & 135.333 & 1.518 \\
\hline & ULS-4 & 4 & 0.7 & 0.7 & 12 & 305.75 & 135.333 & 1.328 \\
\hline & ULS-5 & 4 & 0.7 & 0.9 & 12 & 305.75 & 125.506 & 1.583 \\
\hline & ULS-6 & 4 & 0.7 & 0.9 & 12 & 305.75 & 135.610 & 1.711 \\
\hline & ULS-7 & 4 & 0.7 & 0.8 & 12 & 305.75 & 135.480 & 1.519 \\
\hline & ULS-8 & 4 & 0.7 & 0.7 & 12 & 305.75 & 127.515 & 1.251 \\
\hline & ULS-9 & 4 & 0.7 & 0.7 & 12 & 305.75 & 135.496 & 1.329 \\
\hline & ULS-10 & 4 & 0.7 & 0.7 & 12 & 305.75 & 137.375 & 1.348 \\
\hline & ULS-11 & 4 & 0.7 & 0.9 & 12 & 305.75 & 133.731 & 1.687 \\
\hline & FLS-12 & 4 & 0.7 & 1 & 12 & 305.75 & 122.688 & 4.815 \\
\hline & FLS-13 & 4 & 0.7 & 1 & 12 & 305.75 & 128.229 & 5.033 \\
\hline \multirow{13}{*}{$\begin{array}{l}13 \text { Box Girders } \\
\text { 16.041m Bridge Width }\end{array}$} & ULS-1 & 4 & 0.7 & 1 & 13 & 305.75 & 117.661 & 1.787 \\
\hline & ULS-2 & 4 & 0.7 & 0.9 & 13 & 305.75 & 123.409 & 1.687 \\
\hline & ULS-3 & 4 & 0.7 & 0.8 & 13 & 305.75 & 130.313 & 1.583 \\
\hline & ULS-4 & 4 & 0.7 & 0.7 & 13 & 305.75 & 135.742 & 1.443 \\
\hline & ULS-5 & 4 & 0.7 & 0.9 & 13 & 305.75 & 132.174 & 1.806 \\
\hline & ULS-6 & 4 & 0.7 & 0.9 & 13 & 305.75 & 130.719 & 1.786 \\
\hline & ULS-7 & 4 & 0.7 & 0.8 & 13 & 305.75 & 132.174 & 1.606 \\
\hline & ULS-8 & 4 & 0.7 & 0.7 & 13 & 305.75 & 132.266 & 1.406 \\
\hline & ULS-9 & 4 & 0.7 & 0.7 & 13 & 305.75 & 135.311 & 1.438 \\
\hline & ULS-10 & 4 & 0.7 & 0.7 & 13 & 305.75 & 136.148 & 1.447 \\
\hline & ULS-11 & 4 & 0.7 & 0.9 & 13 & 305.75 & 129.936 & 1.776 \\
\hline & FLS-12 & 4 & 0.7 & 1 & 13 & 305.75 & 130.482 & 5.548 \\
\hline & FLS-13 & 4 & 0.7 & 1 & 13 & 305.75 & 125.074 & 5.318 \\
\hline \multirow{13}{*}{$\begin{array}{c}\text { 14 Box Girders } \\
\text { 17.275m Bridge Width }\end{array}$} & ULS-1 & 4 & 0.7 & 1 & 14 & 305.75 & 117.702 & 1.925 \\
\hline & ULS-2 & 4 & 0.7 & 0.9 & 14 & 305.75 & 124.680 & 1.835 \\
\hline & ULS-3 & 4 & 0.7 & 0.8 & 14 & 305.75 & 133.258 & 1.743 \\
\hline & ULS-4 & 4 & 0.7 & 0.7 & 14 & 305.75 & 133.258 & 1.525 \\
\hline & ULS-5 & 4 & 0.7 & 0.9 & 14 & 305.75 & 125.056 & 1.841 \\
\hline & ULS-6 & 4 & 0.7 & 0.9 & 14 & 305.75 & 135.581 & 1.995 \\
\hline & ULS-7 & 4 & 0.7 & 0.8 & 14 & 305.75 & 133.509 & 1.747 \\
\hline & ULS-8 & 4 & 0.7 & 0.7 & 14 & 305.75 & 128.263 & 1.468 \\
\hline & ULS-9 & 4 & 0.7 & 0.7 & 14 & 305.75 & 129.492 & 1.482 \\
\hline & ULS-10 & 4 & 0.7 & 0.7 & 14 & 305.75 & 137.009 & 1.568 \\
\hline & ULS-11 & 4 & 0.7 & 0.9 & 14 & 305.75 & 128.106 & 1.885 \\
\hline & FLS-12 & 4 & 0.7 & 1 & 14 & 305.75 & 128.236 & 5.872 \\
\hline & FLS-13 & 4 & 0.7 & 1 & 14 & 305.75 & 111.110 & 5.088 \\
\hline
\end{tabular}


Table A. 12: Four-Lane Bridge Deflection Distribution Factors $\left(F_{d}\right)$ at Fatigue Limit States

\begin{tabular}{|c|c|c|c|c|c|c|c|c|}
\hline \multicolumn{9}{|c|}{ Four Lane Bridge: B700, 10 m Span Length } \\
\hline Bridge Configurations & Load cases & $\mathbf{n}$ & $\mathbf{R}_{\mathbf{L}}$ & $\mathbf{R}_{\mathbf{L}}^{\prime}$ & $\mathbf{N}$ & $\begin{array}{c}\left(\Delta_{\text {straight }}\right)_{\text {truck }} \\
(\mathrm{mm})\end{array}$ & $\begin{array}{c}\Delta_{\mathrm{FE}} \\
(\mathbf{m m})\end{array}$ & $\left(\mathbf{F}_{\mathbf{d}}\right)_{\mathrm{FE}}$ \\
\hline 12 Box Girders & FLS-12 & 4 & 0.7 & 1 & 12 & 6.967 & 1.492 & 2.570 \\
\hline $14.805 \mathrm{~m}$ Bridge Width & FLS-13 & 4 & 0.7 & 1 & 12 & 6.967 & 1.290 & 2.222 \\
\hline 13 Box Girders & FLS-12 & 4 & 0.7 & 1 & 13 & 6.967 & 1.526 & 2.847 \\
\hline 16.041m Bridge Width & FLS-13 & 4 & 0.7 & 1 & 13 & 6.967 & 1.295 & 2.416 \\
\hline 14 Box Girders & FLS-12 & 4 & 0.7 & 1 & 14 & 6.967 & 1.419 & 2.851 \\
\hline $17.275 \mathrm{~m}$ Bridge Width & FLS-13 & 4 & 0.7 & 1 & 14 & 6.967 & 1.227 & 2.466 \\
\hline
\end{tabular}

Four Lane Bridge: B700, 13 m Span Length

\begin{tabular}{|c|c|c|c|c|c|c|c|c|}
\hline Bridge Configurations & Load cases & $\mathbf{n}$ & $\mathbf{R}_{\mathbf{L}}$ & $\mathbf{R}_{\mathbf{L}}^{\prime}$ & $\mathbf{N}$ & $\begin{array}{c}\left(\Delta_{\text {straight }}\right)_{\text {truck }} \\
(\mathbf{m m})\end{array}$ & $\begin{array}{c}\Delta_{\mathrm{FE}} \\
(\mathbf{m m})\end{array}$ & $\left(\mathbf{F}_{\mathbf{d}}\right)_{\mathrm{FE}}$ \\
\hline 12 Box Girders & FLS-12 & 4 & 0.7 & 1 & 12 & 16.110 & 2.823 & 2.103 \\
\hline $14.805 \mathrm{~m}$ Bridge Width & FLS-13 & 4 & 0.7 & 1 & 12 & 16.110 & 2.319 & 1.727 \\
\hline 13 Box Girders & FLS-12 & 4 & 0.7 & 1 & 13 & 16.110 & 2.867 & 2.314 \\
\hline $16.041 \mathrm{~m}$ Bridge Width & FLS-13 & 4 & 0.7 & 1 & 13 & 16.110 & 2.301 & 1.857 \\
\hline 14 Box Girders & FLS-12 & 4 & 0.7 & 1 & 14 & 16.110 & 2.667 & 2.318 \\
\hline $17.275 \mathrm{~m}$ Bridge Width & FLS-13 & 4 & 0.7 & 1 & 14 & 16.110 & 2.194 & 1.907 \\
\hline
\end{tabular}




\section{Table A. 13: Five-Lane Bridge Moment Distribution Factors $\left(F_{m}\right)$ at Serviceability, Ultimate and Fatigue Limit States}

\begin{tabular}{|c|c|c|c|c|c|c|c|c|c|c|c|}
\hline \multicolumn{12}{|c|}{ Five Lane Bridge: B700, 10 m Span Length } \\
\hline Bridge Configurations & Load cases & $\mathbf{n}$ & $\mathbf{R}_{\mathbf{L}}$ & $\mathbf{R}_{\mathbf{L}}^{\prime}$ & $\mathbf{N}$ & $\begin{array}{c}\text { I } \\
\left(\mathbf{m}^{\mathbf{4}}\right)\end{array}$ & $\begin{array}{l}\mathbf{y}_{\mathbf{b}} \\
(\mathbf{m})\end{array}$ & $\begin{array}{c}\mathbf{M}_{\mathbf{T}} \\
(\mathbf{k N} / \mathbf{m})\end{array}$ & $\begin{array}{c}\left(\sigma_{\text {straight }}\right)_{\text {truck }} \\
(\mathrm{MPa})\end{array}$ & $\begin{array}{c}\sigma_{\mathrm{FE}} \\
(\mathrm{MPa})\end{array}$ & $\left(\mathbf{F}_{\mathbf{m}}\right)_{\mathbf{F E}}$ \\
\hline \multirow{16}{*}{$\begin{array}{c}\text { 15 Box Girders } \\
\text { 18.510m Bridge Width }\end{array}$} & ULS-1 & 5 & 0.6 & 1 & 15 & 0.0309 & 0.3761 & 651.00 & 7.924 & 2.137 & 1.348 \\
\hline & ULS-2 & 5 & 0.6 & 0.9 & 15 & 0.0309 & 0.3761 & 651.00 & 7.924 & 2.815 & 1.599 \\
\hline & ULS-3 & 5 & 0.6 & 0.8 & 15 & 0.0309 & 0.3761 & 651.00 & 7.924 & 3.023 & 1.526 \\
\hline & ULS-4 & 5 & 0.6 & 0.7 & 15 & 0.0309 & 0.3761 & 651.00 & 7.924 & 3.110 & 1.374 \\
\hline & ULS-5 & 5 & 0.6 & 0.6 & 15 & 0.0309 & 0.3761 & 651.00 & 7.924 & 3.392 & 1.284 \\
\hline & ULS-6 & 5 & 0.6 & 0.9 & 15 & 0.0309 & 0.3761 & 651.00 & 7.924 & 3.047 & 1.730 \\
\hline & ULS-7 & 5 & 0.6 & 0.9 & 15 & 0.0309 & 0.3761 & 651.00 & 7.924 & 2.671 & 1.517 \\
\hline & ULS-8 & 5 & 0.6 & 0.8 & 15 & 0.0309 & 0.3761 & 651.00 & 7.924 & 3.277 & 1.654 \\
\hline & ULS-9 & 5 & 0.6 & 0.7 & 15 & 0.0309 & 0.3761 & 651.00 & 7.924 & 3.349 & 1.479 \\
\hline & ULS-10 & 5 & 0.6 & 0.6 & 15 & 0.0309 & 0.3761 & 651.00 & 7.924 & 3.398 & 1.287 \\
\hline & ULS-11 & 5 & 0.6 & 0.8 & 15 & 0.0309 & 0.3761 & 651.00 & 7.924 & 3.268 & 1.650 \\
\hline & ULS-12 & 5 & 0.6 & 0.7 & 15 & 0.0309 & 0.3761 & 651.00 & 7.924 & 3.458 & 1.527 \\
\hline & ULS-13 & 5 & 0.6 & 0.6 & 15 & 0.0309 & 0.3761 & 651.00 & 7.924 & 3.526 & 1.335 \\
\hline & FLS-14 & 5 & 0.6 & 1 & 15 & 0.0309 & 0.3761 & 651.00 & 7.924 & 2.282 & 4.320 \\
\hline & FLS-15 & 5 & 0.6 & 1 & 15 & 0.0309 & 0.3761 & 651.00 & 7.924 & 2.013 & 3.811 \\
\hline & FLS-16 & 5 & 0.6 & 1 & 15 & 0.0309 & 0.3761 & 651.00 & 7.924 & 1.611 & 3.050 \\
\hline \multirow{16}{*}{$\begin{array}{c}16 \text { Box Girders } \\
\text { 19.745m Bridge Width }\end{array}$} & ULS-1 & 5 & 0.6 & 1 & 16 & 0.0309 & 0.3761 & 651.00 & 7.924 & 2.137 & 1.438 \\
\hline & ULS-2 & 5 & 0.6 & 0.9 & 16 & 0.0309 & 0.3761 & 651.00 & 7.924 & 2.758 & 1.671 \\
\hline & ULS-3 & 5 & 0.6 & 0.8 & 16 & 0.0309 & 0.3761 & 651.00 & 7.924 & 2.934 & 1.580 \\
\hline & ULS-4 & 5 & 0.6 & 0.7 & 16 & 0.0309 & 0.3761 & 651.00 & 7.924 & 3.034 & 1.430 \\
\hline & ULS-5 & 5 & 0.6 & 0.6 & 16 & 0.0309 & 0.3761 & 651.00 & 7.924 & 3.122 & 1.261 \\
\hline & ULS-6 & 5 & 0.6 & 0.9 & 16 & 0.0309 & 0.3761 & 651.00 & 7.924 & 2.877 & 1.743 \\
\hline & ULS-7 & 5 & 0.6 & 0.9 & 16 & 0.0309 & 0.3761 & 651.00 & 7.924 & 2.487 & 1.507 \\
\hline & ULS-8 & 5 & 0.6 & 0.8 & 16 & 0.0309 & 0.3761 & 651.00 & 7.924 & 3.072 & 1.654 \\
\hline & ULS-9 & 5 & 0.6 & 0.7 & 16 & 0.0309 & 0.3761 & 651.00 & 7.924 & 3.133 & 1.476 \\
\hline & ULS-10 & 5 & 0.6 & 0.6 & 16 & 0.0309 & 0.3761 & 651.00 & 7.924 & 3.181 & 1.285 \\
\hline & ULS-11 & 5 & 0.6 & 0.8 & 16 & 0.0309 & 0.3761 & 651.00 & 7.924 & 3.056 & 1.646 \\
\hline & ULS-12 & 5 & 0.6 & 0.7 & 16 & 0.0309 & 0.3761 & 651.00 & 7.924 & 3.225 & 1.519 \\
\hline & ULS-13 & 5 & 0.6 & 0.6 & 16 & 0.0309 & 0.3761 & 651.00 & 7.924 & 3.279 & 1.324 \\
\hline & FLS-14 & 5 & 0.6 & 1 & 16 & 0.0309 & 0.3761 & 651.00 & 7.924 & 2.137 & 4.315 \\
\hline & FLS-15 & 5 & 0.6 & 1 & 16 & 0.0309 & 0.3761 & 651.00 & 7.924 & 2.012 & 4.063 \\
\hline & FLS-16 & 5 & 0.6 & 1 & 16 & 0.0309 & 0.3761 & 651.00 & 7.924 & 1.994 & 4.026 \\
\hline \multirow{16}{*}{$\begin{array}{c}17 \text { Box Girders } \\
\text { 20.980m Bridge Width }\end{array}$} & ULS-1 & 5 & 0.6 & 1 & 17 & 0.0309 & 0.3761 & 651.00 & 7.924 & 2.137 & 1.528 \\
\hline & ULS-2 & 5 & 0.6 & 0.9 & 17 & 0.0309 & 0.3761 & 651.00 & 7.924 & 2.706 & 1.742 \\
\hline & ULS-3 & 5 & 0.6 & 0.8 & 17 & 0.0309 & 0.3761 & 651.00 & 7.924 & 3.024 & 1.730 \\
\hline & ULS-4 & 5 & 0.6 & 0.7 & 17 & 0.0309 & 0.3761 & 651.00 & 7.924 & 3.138 & 1.571 \\
\hline & ULS-5 & 5 & 0.6 & 0.6 & 17 & 0.0309 & 0.3761 & 651.00 & 7.924 & 3.178 & 1.364 \\
\hline & ULS-6 & 5 & 0.6 & 0.9 & 17 & 0.0309 & 0.3761 & 651.00 & 7.924 & 2.728 & 1.756 \\
\hline & ULS-7 & 5 & 0.6 & 0.9 & 17 & 0.0309 & 0.3761 & 651.00 & 7.924 & 2.649 & 1.705 \\
\hline & ULS-8 & 5 & 0.6 & 0.8 & 17 & 0.0309 & 0.3761 & 651.00 & 7.924 & 3.165 & 1.811 \\
\hline & ULS-9 & 5 & 0.6 & 0.7 & 17 & 0.0309 & 0.3761 & 651.00 & 7.924 & 3.279 & 1.642 \\
\hline & ULS-10 & 5 & 0.6 & 0.6 & 17 & 0.0309 & 0.3761 & 651.00 & 7.924 & 3.313 & 1.422 \\
\hline & ULS-11 & 5 & 0.6 & 0.8 & 17 & 0.0309 & 0.3761 & 651.00 & 7.924 & 2.928 & 1.675 \\
\hline & ULS-12 & 5 & 0.6 & 0.7 & 17 & 0.0309 & 0.3761 & 651.00 & 7.924 & 3.251 & 1.627 \\
\hline & ULS-13 & 5 & 0.6 & 0.6 & 17 & 0.0309 & 0.3761 & 651.00 & 7.924 & 3.383 & 1.452 \\
\hline & FLS-14 & 5 & 0.6 & 1 & 17 & 0.0309 & 0.3761 & 651.00 & 7.924 & 2.143 & 4.598 \\
\hline & FLS-15 & 5 & 0.6 & 1 & 17 & 0.0309 & 0.3761 & 651.00 & 7.924 & 1.808 & 3.879 \\
\hline & FLS-16 & 5 & 0.6 & 1 & 17 & 0.0309 & 0.3761 & 651.00 & 7.924 & 1.607 & 3.448 \\
\hline
\end{tabular}




\begin{tabular}{|c|c|c|c|c|c|c|c|c|c|c|c|}
\hline \multicolumn{12}{|c|}{ Five Lane Bridge: B800, 20 m Span Length } \\
\hline Bridge Configurations & Load cases & $\mathbf{n}$ & $\mathbf{R}_{\mathbf{L}}$ & $\mathbf{R}_{\mathbf{L}}^{\prime}$ & $\mathbf{N}$ & $\begin{array}{c}I \\
\left(\mathbf{m}^{4}\right)\end{array}$ & $\begin{array}{l}\mathbf{y}_{\mathbf{b}} \\
(\mathbf{m})\end{array}$ & $\begin{array}{c}\mathbf{M}_{\mathrm{T}} \\
(\mathbf{k N} / \mathbf{m})\end{array}$ & $\begin{array}{c}\left(\sigma_{\text {straight }}\right)_{\text {truck }} \\
(\mathrm{MPa})\end{array}$ & $\begin{array}{c}\sigma_{\mathrm{FE}} \\
(\mathrm{MPa})\end{array}$ & $\left(\mathbf{F}_{\mathbf{m}}\right)_{\mathrm{FE}}$ \\
\hline \multirow{16}{*}{$\begin{array}{c}15 \text { Box Girders } \\
18.510 \mathrm{~m} \text { Bridge Width }\end{array}$} & ULS-1 & 5 & 0.6 & 1 & 15 & 0.0441 & 0.4324 & 1686.15 & 16.533 & 3.029 & 0.916 \\
\hline & ULS-2 & 5 & 0.6 & 0.9 & 15 & 0.0441 & 0.4324 & 1686.15 & 16.533 & 4.557 & 1.240 \\
\hline & ULS-3 & 5 & 0.6 & 0.8 & 15 & 0.0441 & 0.4324 & 1686.15 & 16.533 & 5.421 & 1.312 \\
\hline & ULS-4 & 5 & 0.6 & 0.7 & 15 & 0.0441 & 0.4324 & 1686.15 & 16.533 & 5.934 & 1.256 \\
\hline & ULS-5 & 5 & 0.6 & 0.6 & 15 & 0.0441 & 0.4324 & 1686.15 & 16.533 & 6.385 & 1.159 \\
\hline & ULS-6 & 5 & 0.6 & 0.9 & 15 & 0.0441 & 0.4324 & 1686.15 & 16.533 & 4.646 & 1.265 \\
\hline & ULS-7 & 5 & 0.6 & 0.9 & 15 & 0.0441 & 0.4324 & 1686.15 & 16.533 & 3.833 & 1.043 \\
\hline & ULS-8 & 5 & 0.6 & 0.8 & 15 & 0.0441 & 0.4324 & 1686.15 & 16.533 & 5.555 & 1.344 \\
\hline & ULS-9 & 5 & 0.6 & 0.7 & 15 & 0.0441 & 0.4324 & 1686.15 & 16.533 & 6.095 & 1.290 \\
\hline & ULS-10 & 5 & 0.6 & 0.6 & 15 & 0.0441 & 0.4324 & 1686.15 & 16.533 & 6.466 & 1.173 \\
\hline & ULS-11 & 5 & 0.6 & 0.8 & 15 & 0.0441 & 0.4324 & 1686.15 & 16.533 & 5.436 & 1.315 \\
\hline & ULS-12 & 5 & 0.6 & 0.7 & 15 & 0.0441 & 0.4324 & 1686.15 & 16.533 & 6.027 & 1.276 \\
\hline & ULS-13 & 5 & 0.6 & 0.6 & 15 & 0.0441 & 0.4324 & 1686.15 & 16.533 & 6.544 & 1.187 \\
\hline & FLS-14 & 5 & 0.6 & 1 & 15 & 0.0441 & 0.4324 & 1686.15 & 16.533 & 3.059 & 2.775 \\
\hline & FLS-15 & 5 & 0.6 & 1 & 15 & 0.0441 & 0.4324 & 1686.15 & 16.533 & 2.533 & 2.298 \\
\hline & FLS-16 & 5 & 0.6 & 1 & 15 & 0.0441 & 0.4324 & 1686.15 & 16.533 & 2.095 & 1.901 \\
\hline \multirow{16}{*}{$\begin{array}{c}16 \text { Box Girders } \\
\text { 19.745m Bridge Width }\end{array}$} & ULS-1 & 5 & 0.6 & 1 & 16 & 0.0441 & 0.4324 & 1686.15 & 16.533 & 3.025 & 0.976 \\
\hline & ULS-2 & 5 & 0.6 & 0.9 & 16 & 0.0441 & 0.4324 & 1686.15 & 16.533 & 4.483 & 1.302 \\
\hline & ULS-3 & 5 & 0.6 & 0.8 & 16 & 0.0441 & 0.4324 & 1686.15 & 16.533 & 5.269 & 1.360 \\
\hline & ULS-4 & 5 & 0.6 & 0.7 & 16 & 0.0441 & 0.4324 & 1686.15 & 16.533 & 5.713 & 1.290 \\
\hline & ULS-5 & 5 & 0.6 & 0.6 & 16 & 0.0441 & 0.4324 & 1686.15 & 16.533 & 6.010 & 1.163 \\
\hline & ULS-6 & 5 & 0.6 & 0.9 & 16 & 0.0441 & 0.4324 & 1686.15 & 16.533 & 4.466 & 1.297 \\
\hline & ULS-7 & 5 & 0.6 & 0.9 & 16 & 0.0441 & 0.4324 & 1686.15 & 16.533 & 3.624 & 1.052 \\
\hline & ULS-8 & 5 & 0.6 & 0.8 & 16 & 0.0441 & 0.4324 & 1686.15 & 16.533 & 5.297 & 1.367 \\
\hline & ULS-9 & 5 & 0.6 & 0.7 & 16 & 0.0441 & 0.4324 & 1686.15 & 16.533 & 5.765 & 1.302 \\
\hline & ULS-10 & 5 & 0.6 & 0.6 & 16 & 0.0441 & 0.4324 & 1686.15 & 16.533 & 6.075 & 1.176 \\
\hline & ULS-11 & 5 & 0.6 & 0.8 & 16 & 0.0441 & 0.4324 & 1686.15 & 16.533 & 5.132 & 1.324 \\
\hline & ULS-12 & 5 & 0.6 & 0.7 & 16 & 0.0441 & 0.4324 & 1686.15 & 16.533 & 5.683 & 1.283 \\
\hline & ULS-13 & 5 & 0.6 & 0.6 & 16 & 0.0441 & 0.4324 & 1686.15 & 16.533 & 6.145 & 1.189 \\
\hline & FLS-14 & 5 & 0.6 & 1 & 16 & 0.0441 & 0.4324 & 1686.15 & 16.533 & 2.877 & 2.784 \\
\hline & FLS-15 & 5 & 0.6 & 1 & 16 & 0.0441 & 0.4324 & 1686.15 & 16.533 & 2.495 & 2.415 \\
\hline & FLS-16 & 5 & 0.6 & 1 & 16 & 0.0441 & 0.4324 & 1686.15 & 16.533 & 2.391 & 2.314 \\
\hline \multirow{16}{*}{$\begin{array}{c}17 \text { Box Girders } \\
\text { 20.980m Bridge Width }\end{array}$} & ULS-1 & 5 & 0.6 & 1 & 17 & 0.0441 & 0.4324 & 1686.15 & 16.533 & 3.022 & 1.036 \\
\hline & ULS-2 & 5 & 0.6 & 0.9 & 17 & 0.0441 & 0.4324 & 1686.15 & 16.533 & 4.415 & 1.362 \\
\hline & ULS-3 & 5 & 0.6 & 0.8 & 17 & 0.0441 & 0.4324 & 1686.15 & 16.533 & 5.133 & 1.407 \\
\hline & ULS-4 & 5 & 0.6 & 0.7 & 17 & 0.0441 & 0.4324 & 1686.15 & 16.533 & 5.562 & 1.334 \\
\hline & ULS-5 & 5 & 0.6 & 0.6 & 17 & 0.0441 & 0.4324 & 1686.15 & 16.533 & 5.909 & 1.215 \\
\hline & ULS-6 & 5 & 0.6 & 0.9 & 17 & 0.0441 & 0.4324 & 1686.15 & 16.533 & 4.188 & 1.292 \\
\hline & ULS-7 & 5 & 0.6 & 0.9 & 17 & 0.0441 & 0.4324 & 1686.15 & 16.533 & 3.644 & 1.124 \\
\hline & ULS-8 & 5 & 0.6 & 0.8 & 17 & 0.0441 & 0.4324 & 1686.15 & 16.533 & 5.088 & 1.395 \\
\hline & ULS-9 & 5 & 0.6 & 0.7 & 17 & 0.0441 & 0.4324 & 1686.15 & 16.533 & 5.644 & 1.354 \\
\hline & ULS-10 & 5 & 0.6 & 0.6 & 17 & 0.0441 & 0.4324 & 1686.15 & 16.533 & 5.994 & 1.233 \\
\hline & ULS-11 & 5 & 0.6 & 0.8 & 17 & 0.0441 & 0.4324 & 1686.15 & 16.533 & 4.766 & 1.307 \\
\hline & ULS-12 & 5 & 0.6 & 0.7 & 17 & 0.0441 & 0.4324 & 1686.15 & 16.533 & 5.436 & 1.304 \\
\hline & ULS-13 & 5 & 0.6 & 0.6 & 17 & 0.0441 & 0.4324 & 1686.15 & 16.533 & 6.058 & 1.246 \\
\hline & FLS-14 & 5 & 0.6 & 1 & 17 & 0.0441 & 0.4324 & 1686.15 & 16.533 & 2.849 & 2.930 \\
\hline & FLS-15 & 5 & 0.6 & 1 & 17 & 0.0441 & 0.4324 & 1686.15 & 16.533 & 2.291 & 2.356 \\
\hline & FLS-16 & 5 & 0.6 & 1 & 17 & 0.0441 & 0.4324 & 1686.15 & 16.533 & 2.041 & 2.099 \\
\hline
\end{tabular}




\begin{tabular}{|c|c|c|c|c|c|c|c|c|c|c|c|}
\hline \multicolumn{12}{|c|}{ Five Lane Bridge: B1000, 32 m Span Length } \\
\hline Bridge Configurations & Load cases & $\mathbf{n}$ & $\mathbf{R}_{\mathbf{L}}$ & $\mathbf{R}_{\mathbf{L}}^{\prime}$ & $\mathbf{N}$ & $\begin{array}{c}I \\
\left(\mathbf{m}^{4}\right)\end{array}$ & $\begin{array}{l}\mathbf{y}_{\mathbf{b}} \\
(\mathbf{m})\end{array}$ & $\begin{array}{c}\mathbf{M}_{\mathrm{T}} \\
(\mathbf{k N} / \mathbf{m})\end{array}$ & $\begin{array}{c}\left(\sigma_{\text {straight }}\right)_{\text {truck }} \\
(\mathrm{MPa})\end{array}$ & $\begin{array}{c}\sigma_{\mathrm{FE}} \\
(\mathrm{MPa})\end{array}$ & $\left(\mathbf{F}_{\mathbf{m}}\right)_{\mathrm{FE}}$ \\
\hline \multirow{16}{*}{$\begin{array}{c}15 \text { Box Girders } \\
\text { 18.510m Bridge Width }\end{array}$} & ULS-1 & 5 & 0.6 & 1 & 15 & 0.0787 & 0.5433 & 3336.11 & 23.031 & 3.333 & 0.724 \\
\hline & ULS-2 & 5 & 0.6 & 0.9 & 15 & 0.0787 & 0.5433 & 3336.11 & 23.031 & 5.334 & 1.042 \\
\hline & ULS-3 & 5 & 0.6 & 0.8 & 15 & 0.0787 & 0.5433 & 3336.11 & 23.031 & 6.740 & 1.171 \\
\hline & ULS-4 & 5 & 0.6 & 0.7 & 15 & 0.0787 & 0.5433 & 3336.11 & 23.031 & 7.791 & 1.184 \\
\hline & ULS-5 & 5 & 0.6 & 0.6 & 15 & 0.0787 & 0.5433 & 3336.11 & 23.031 & 8.685 & 1.131 \\
\hline & ULS-6 & 5 & 0.6 & 0.9 & 15 & 0.0787 & 0.5433 & 3336.11 & 23.031 & 5.408 & 1.057 \\
\hline & ULS-7 & 5 & 0.6 & 0.9 & 15 & 0.0787 & 0.5433 & 3336.11 & 23.031 & 4.541 & 0.887 \\
\hline & ULS-8 & 5 & 0.6 & 0.8 & 15 & 0.0787 & 0.5433 & 3336.11 & 23.031 & 6.836 & 1.187 \\
\hline & ULS-9 & 5 & 0.6 & 0.7 & 15 & 0.0787 & 0.5433 & 3336.11 & 23.031 & 7.904 & 1.201 \\
\hline & ULS-10 & 5 & 0.6 & 0.6 & 15 & 0.0787 & 0.5433 & 3336.11 & 23.031 & 6.732 & 0.877 \\
\hline & ULS-11 & 5 & 0.6 & 0.8 & 15 & 0.0787 & 0.5433 & 3336.11 & 23.031 & 6.732 & 1.169 \\
\hline & ULS-12 & 5 & 0.6 & 0.7 & 15 & 0.0787 & 0.5433 & 3336.11 & 23.031 & 7.803 & 1.186 \\
\hline & ULS-13 & 5 & 0.6 & 0.6 & 15 & 0.0787 & 0.5433 & 3336.11 & 23.031 & 8.817 & 1.149 \\
\hline & FLS-14 & 5 & 0.6 & 1 & 15 & 0.0787 & 0.5433 & 3336.11 & 23.031 & 3.355 & 2.185 \\
\hline & FLS-15 & 5 & 0.6 & 1 & 15 & 0.0787 & 0.5433 & 3336.11 & 23.031 & 2.768 & 1.803 \\
\hline & FLS-16 & 5 & 0.6 & 1 & 15 & 0.0787 & 0.5433 & 3336.11 & 23.031 & 2.378 & 1.549 \\
\hline \multirow{16}{*}{$\begin{array}{c}16 \text { Box Girders } \\
\text { 19.745m Bridge Width }\end{array}$} & ULS-1 & 5 & 0.6 & 1 & 16 & 0.0787 & 0.5433 & 3336.11 & 23.031 & 3.312 & 0.767 \\
\hline & ULS-2 & 5 & 0.6 & 0.9 & 16 & 0.0787 & 0.5433 & 3336.11 & 23.031 & 5.230 & 1.090 \\
\hline & ULS-3 & 5 & 0.6 & 0.8 & 16 & 0.0787 & 0.5433 & 3336.11 & 23.031 & 6.531 & 1.210 \\
\hline & ULS-4 & 5 & 0.6 & 0.7 & 16 & 0.0787 & 0.5433 & 3336.11 & 23.031 & 7.471 & 1.211 \\
\hline & ULS-5 & 5 & 0.6 & 0.6 & 16 & 0.0787 & 0.5433 & 3336.11 & 23.031 & 8.229 & 1.143 \\
\hline & ULS-6 & 5 & 0.6 & 0.9 & 16 & 0.0787 & 0.5433 & 3336.11 & 23.031 & 5.222 & 1.088 \\
\hline & ULS-7 & 5 & 0.6 & 0.9 & 16 & 0.0787 & 0.5433 & 3336.11 & 23.031 & 4.287 & 0.893 \\
\hline & ULS-8 & 5 & 0.6 & 0.8 & 16 & 0.0787 & 0.5433 & 3336.11 & 23.031 & 6.545 & 1.213 \\
\hline & ULS-9 & 5 & 0.6 & 0.7 & 16 & 0.0787 & 0.5433 & 3336.11 & 23.031 & 7.502 & 1.216 \\
\hline & ULS-10 & 5 & 0.6 & 0.6 & 16 & 0.0787 & 0.5433 & 3336.11 & 23.031 & 8.274 & 1.150 \\
\hline & ULS-11 & 5 & 0.6 & 0.8 & 16 & 0.0787 & 0.5433 & 3336.11 & 23.031 & 6.395 & 1.185 \\
\hline & ULS-12 & 5 & 0.6 & 0.7 & 16 & 0.0787 & 0.5433 & 3336.11 & 23.031 & 7.359 & 1.193 \\
\hline & ULS-13 & 5 & 0.6 & 0.6 & 16 & 0.0787 & 0.5433 & 3336.11 & 23.031 & 8.288 & 1.152 \\
\hline & FLS-14 & 5 & 0.6 & 1 & 16 & 0.0787 & 0.5433 & 3336.11 & 23.031 & 3.185 & 2.213 \\
\hline & FLS-15 & 5 & 0.6 & 1 & 16 & 0.0787 & 0.5433 & 3336.11 & 23.031 & 2.750 & 1.911 \\
\hline & FLS-16 & 5 & 0.6 & 1 & 16 & 0.0787 & 0.5433 & 3336.11 & 23.031 & 2.608 & 1.812 \\
\hline \multirow{16}{*}{$\begin{array}{c}17 \text { Box Girders } \\
\text { 20.980m Bridge Width }\end{array}$} & ULS-1 & 5 & 0.6 & 1 & 17 & 0.0787 & 0.5433 & 3336.11 & 23.031 & 3.296 & 0.811 \\
\hline & ULS-2 & 5 & 0.6 & 0.9 & 17 & 0.0787 & 0.5433 & 3336.11 & 23.031 & 5.141 & 1.138 \\
\hline & ULS-3 & 5 & 0.6 & 0.8 & 17 & 0.0787 & 0.5433 & 3336.11 & 23.031 & 6.348 & 1.250 \\
\hline & ULS-4 & 5 & 0.6 & 0.7 & 17 & 0.0787 & 0.5433 & 3336.11 & 23.031 & 7.191 & 1.239 \\
\hline & ULS-5 & 5 & 0.6 & 0.6 & 17 & 0.0787 & 0.5433 & 3336.11 & 23.031 & 7.918 & 1.169 \\
\hline & ULS-6 & 5 & 0.6 & 0.9 & 17 & 0.0787 & 0.5433 & 3336.11 & 23.031 & 4.921 & 1.090 \\
\hline & ULS-7 & 5 & 0.6 & 0.9 & 17 & 0.0787 & 0.5433 & 3336.11 & 23.031 & 4.231 & 0.937 \\
\hline & ULS-8 & 5 & 0.6 & 0.8 & 17 & 0.0787 & 0.5433 & 3336.11 & 23.031 & 6.156 & 1.212 \\
\hline & ULS-9 & 5 & 0.6 & 0.7 & 17 & 0.0787 & 0.5433 & 3336.11 & 23.031 & 7.162 & 1.234 \\
\hline & ULS-10 & 5 & 0.6 & 0.6 & 17 & 0.0787 & 0.5433 & 3336.11 & 23.031 & 7.972 & 1.177 \\
\hline & ULS-11 & 5 & 0.6 & 0.8 & 17 & 0.0787 & 0.5433 & 3336.11 & 23.031 & 5.957 & 1.173 \\
\hline & ULS-12 & 5 & 0.6 & 0.7 & 17 & 0.0787 & 0.5433 & 3336.11 & 23.031 & 6.978 & 1.202 \\
\hline & ULS-13 & 5 & 0.6 & 0.6 & 17 & 0.0787 & 0.5433 & 3336.11 & 23.031 & 8.012 & 1.183 \\
\hline & FLS-14 & 5 & 0.6 & 1 & 17 & 0.0787 & 0.5433 & 3336.11 & 23.031 & 3.067 & 2.264 \\
\hline & FLS-15 & 5 & 0.6 & 1 & 17 & 0.0787 & 0.5433 & 3336.11 & 23.031 & 2.525 & 1.864 \\
\hline & FLS-16 & 5 & 0.6 & 1 & 17 & 0.0787 & 0.5433 & 3336.11 & 23.031 & 2.260 & 1.668 \\
\hline
\end{tabular}


Table A. 14: Five-Lane Bridge Shear Distribution Factors $\left(F_{v}\right)$ at Serviceability, Ultimate and Fatigue Limit States

\begin{tabular}{|c|c|c|c|c|c|c|c|c|}
\hline \multicolumn{9}{|c|}{ Five Lane Bridge: B700, 10 m Span Length } \\
\hline Bridge Configurations & Load cases & $\mathbf{n}$ & $\mathbf{R}_{\mathbf{L}}$ & $\mathbf{R}_{\mathbf{L}}^{\prime}$ & $\mathbf{N}$ & $\begin{array}{c}\left(\mathbf{R}_{\text {straight }}\right)_{\text {truck }} \\
(\mathbf{k N})\end{array}$ & $\begin{array}{l}\mathbf{R}_{\mathrm{FE}} \\
(\mathrm{kN})\end{array}$ & $\left(\mathbf{F}_{\mathrm{v}}\right)_{\mathrm{FE} .}$ \\
\hline \multirow{16}{*}{$\begin{array}{l}15 \text { Box Girders } \\
\text { 18.510m Bridge Width }\end{array}$} & ULS-1 & 5 & 0.6 & 1 & 15 & 301.70 & 114.043 & 1.890 \\
\hline & ULS-2 & 5 & 0.6 & 0.9 & 15 & 301.70 & 117.508 & 1.753 \\
\hline & ULS-3 & 5 & 0.6 & 0.8 & 15 & 301.70 & 126.803 & 1.681 \\
\hline & ULS-4 & 5 & 0.6 & 0.7 & 15 & 301.70 & 126.803 & 1.471 \\
\hline & ULS-5 & 5 & 0.6 & 0.6 & 15 & 301.70 & 126.803 & 1.261 \\
\hline & ULS-6 & 5 & 0.6 & 0.9 & 15 & 301.70 & 115.862 & 1.728 \\
\hline & ULS-7 & 5 & 0.6 & 0.9 & 15 & 301.70 & 127.685 & 1.904 \\
\hline & ULS-8 & 5 & 0.6 & 0.8 & 15 & 301.70 & 126.900 & 1.682 \\
\hline & ULS-9 & 5 & 0.6 & 0.7 & 15 & 301.70 & 126.900 & 1.472 \\
\hline & ULS-10 & 5 & 0.6 & 0.6 & 15 & 301.70 & 126.900 & 1.262 \\
\hline & ULS-11 & 5 & 0.6 & 0.8 & 15 & 301.70 & 128.576 & 1.705 \\
\hline & ULS-12 & 5 & 0.6 & 0.7 & 15 & 301.70 & 128.576 & 1.492 \\
\hline & ULS-13 & 5 & 0.6 & 0.6 & 15 & 301.70 & 128.576 & 1.279 \\
\hline & FLS-14 & 5 & 0.6 & 1 & 15 & 301.70 & 121.858 & 6.059 \\
\hline & FLS-15 & 5 & 0.6 & 1 & 15 & 301.70 & 122.847 & 6.108 \\
\hline & FLS-16 & 5 & 0.6 & 1 & 15 & 301.70 & 100.483 & 4.996 \\
\hline \multirow{16}{*}{$\begin{array}{c}\text { 16 Box Girders } \\
\text { 19.745m Bridge Width }\end{array}$} & ULS-1 & 5 & 0.6 & 1 & 16 & 301.70 & 113.240 & 2.002 \\
\hline & ULS-2 & 5 & 0.6 & 0.9 & 16 & 301.70 & 116.635 & 1.856 \\
\hline & ULS-3 & 5 & 0.6 & 0.8 & 16 & 301.70 & 122.312 & 1.730 \\
\hline & ULS-4 & 5 & 0.6 & 0.7 & 16 & 301.70 & 125.060 & 1.548 \\
\hline & ULS-5 & 5 & 0.6 & 0.6 & 16 & 301.70 & 127.306 & 1.350 \\
\hline & ULS-6 & 5 & 0.6 & 0.9 & 16 & 301.70 & 118.079 & 1.879 \\
\hline & ULS-7 & 5 & 0.6 & 0.9 & 16 & 301.70 & 124.539 & 1.981 \\
\hline & ULS-8 & 5 & 0.6 & 0.8 & 16 & 301.70 & 122.312 & 1.730 \\
\hline & ULS-9 & 5 & 0.6 & 0.7 & 16 & 301.70 & 125.06 & 1.548 \\
\hline & ULS-10 & 5 & 0.6 & 0.6 & 16 & 301.70 & 127.306 & 1.350 \\
\hline & ULS-11 & 5 & 0.6 & 0.8 & 16 & 301.70 & 127.382 & 1.801 \\
\hline & ULS-12 & 5 & 0.6 & 0.7 & 16 & 301.70 & 127.382 & 1.576 \\
\hline & ULS-13 & 5 & 0.6 & 0.6 & 16 & 301.70 & 127.382 & 1.351 \\
\hline & FLS-14 & 5 & 0.6 & 1 & 16 & 301.70 & 112.234 & 5.952 \\
\hline & FLS-15 & 5 & 0.6 & 1 & 16 & 301.70 & 122.704 & 6.507 \\
\hline & FLS-16 & 5 & 0.6 & 1 & 16 & 301.70 & 114.213 & 6.057 \\
\hline \multirow{16}{*}{$\begin{array}{c}17 \text { Box Girders } \\
\text { 20.980m Bridge Width }\end{array}$} & ULS-1 & 5 & 0.6 & 1 & 17 & 301.70 & 113.890 & 2.139 \\
\hline & ULS-2 & 5 & 0.6 & 0.9 & 17 & 301.70 & 122.001 & 2.062 \\
\hline & ULS-3 & 5 & 0.6 & 0.8 & 17 & 301.70 & 123.981 & 1.863 \\
\hline & ULS-4 & 5 & 0.6 & 0.7 & 17 & 301.70 & 124.395 & 1.636 \\
\hline & ULS-5 & 5 & 0.6 & 0.6 & 17 & 301.70 & 124.519 & 1.403 \\
\hline & ULS-6 & 5 & 0.6 & 0.9 & 17 & 301.70 & 122.001 & 2.062 \\
\hline & ULS-7 & 5 & 0.6 & 0.9 & 17 & 301.70 & 124.785 & 2.109 \\
\hline & ULS-8 & 5 & 0.6 & 0.8 & 17 & 301.70 & 123.981 & 1.863 \\
\hline & ULS-9 & 5 & 0.6 & 0.7 & 17 & 301.70 & 124.395 & 1.636 \\
\hline & ULS-10 & 5 & 0.6 & 0.6 & 17 & 301.70 & 124.519 & 1.403 \\
\hline & ULS-11 & 5 & 0.6 & 0.8 & 17 & 301.70 & 125.435 & 1.885 \\
\hline & ULS-12 & 5 & 0.6 & 0.7 & 17 & 301.70 & 125.435 & 1.649 \\
\hline & ULS-13 & 5 & 0.6 & 0.6 & 17 & 301.70 & 125.435 & 1.414 \\
\hline & FLS-14 & 5 & 0.6 & 1 & 17 & 301.70 & 122.490 & 6.902 \\
\hline & FLS-15 & 5 & 0.6 & 1 & 17 & 301.70 & 118.661 & 6.686 \\
\hline & FLS-16 & 5 & 0.6 & 1 & 17 & 301.70 & 101.608 & 5.725 \\
\hline
\end{tabular}




\begin{tabular}{|c|c|c|c|c|c|c|c|c|}
\hline \multicolumn{9}{|c|}{ Five Lane Bridge: B800, 20 m Span Length } \\
\hline Bridge Configurations & Load cases & $\mathbf{n}$ & $\mathbf{R}_{\mathbf{L}}$ & $\mathbf{R}_{\mathbf{L}}^{\prime}$ & $\mathbf{N}$ & $\begin{array}{c}\left(\mathbf{R}_{\text {straight }}\right)_{\text {truck }} \\
(\mathbf{k N})\end{array}$ & $\begin{array}{l}\mathbf{R}_{\mathrm{FE}} \\
(\mathrm{kN})\end{array}$ & $\left(F_{\mathrm{v}}\right)_{\mathrm{FE}}$ \\
\hline \multirow{16}{*}{$\begin{array}{c}15 \text { Box Girders } \\
\text { 18.510m Bridge Width }\end{array}$} & ULS-1 & 5 & 0.6 & 1 & 15 & 411.95 & 120.016 & 1.457 \\
\hline & ULS-2 & 5 & 0.6 & 0.9 & 15 & 411.95 & 130.460 & 1.425 \\
\hline & ULS-3 & 5 & 0.6 & 0.8 & 15 & 411.95 & 143.684 & 1.395 \\
\hline & ULS-4 & 5 & 0.6 & 0.7 & 15 & 411.95 & 144.262 & 1.226 \\
\hline & ULS-5 & 5 & 0.6 & 0.6 & 15 & 411.95 & 144.262 & 1.051 \\
\hline & ULS-6 & 5 & 0.6 & 0.9 & 15 & 411.95 & 135.830 & 1.484 \\
\hline & ULS-7 & 5 & 0.6 & 0.9 & 15 & 411.95 & 143.276 & 1.565 \\
\hline & ULS-8 & 5 & 0.6 & 0.8 & 15 & 411.95 & 143.982 & 1.398 \\
\hline & ULS-9 & 5 & 0.6 & 0.7 & 15 & 411.95 & 144.560 & 1.228 \\
\hline & ULS-10 & 5 & 0.6 & 0.6 & 15 & 411.95 & 144.560 & 1.053 \\
\hline & ULS-11 & 5 & 0.6 & 0.8 & 15 & 411.95 & 147.144 & 1.429 \\
\hline & ULS-12 & 5 & 0.6 & 0.7 & 15 & 411.95 & 147.722 & 1.255 \\
\hline & ULS-13 & 5 & 0.6 & 0.6 & 15 & 411.95 & 147.722 & 1.076 \\
\hline & FLS-14 & 5 & 0.6 & 1 & 15 & 411.95 & 132.994 & 4.843 \\
\hline & FLS-15 & 5 & 0.6 & 1 & 15 & 411.95 & 131.234 & 4.779 \\
\hline & FLS-16 & 5 & 0.6 & 1 & 15 & 411.95 & 109.167 & 3.975 \\
\hline \multirow{16}{*}{$\begin{array}{c}16 \text { Box Girders } \\
\text { 19.745m Bridge Width }\end{array}$} & ULS-1 & 5 & 0.6 & 1 & 16 & 411.95 & 119.493 & 1.547 \\
\hline & ULS-2 & 5 & 0.6 & 0.9 & 16 & 411.95 & 128.645 & 1.499 \\
\hline & ULS-3 & 5 & 0.6 & 0.8 & 16 & 411.95 & 133.610 & 1.384 \\
\hline & ULS-4 & 5 & 0.6 & 0.7 & 16 & 411.95 & 138.473 & 1.255 \\
\hline & ULS-5 & 5 & 0.6 & 0.6 & 16 & 411.95 & 142.615 & 1.108 \\
\hline & ULS-6 & 5 & 0.6 & 0.9 & 16 & 411.95 & 134.710 & 1.570 \\
\hline & ULS-7 & 5 & 0.6 & 0.9 & 16 & 411.95 & 135.282 & 1.576 \\
\hline & ULS-8 & 5 & 0.6 & 0.8 & 16 & 411.95 & 134.814 & 1.396 \\
\hline & ULS-9 & 5 & 0.6 & 0.7 & 16 & 411.95 & 138.473 & 1.255 \\
\hline & ULS-10 & 5 & 0.6 & 0.6 & 16 & 411.95 & 142.615 & 1.108 \\
\hline & ULS-11 & 5 & 0.6 & 0.8 & 16 & 411.95 & 144.920 & 1.501 \\
\hline & ULS-12 & 5 & 0.6 & 0.7 & 16 & 411.95 & 144.920 & 1.313 \\
\hline & ULS-13 & 5 & 0.6 & 0.6 & 16 & 411.95 & 144.920 & 1.126 \\
\hline & FLS-14 & 5 & 0.6 & 1 & 16 & 411.95 & 123.750 & 4.806 \\
\hline & FLS-15 & 5 & 0.6 & 1 & 16 & 411.95 & 132.224 & 5.136 \\
\hline & FLS-16 & 5 & 0.6 & 1 & 16 & 411.95 & 126.238 & 4.903 \\
\hline \multirow{16}{*}{$\begin{array}{l}17 \text { Box Girders } \\
\text { 20.980m Bridge Width }\end{array}$} & ULS-1 & 5 & 0.6 & 1 & 17 & 411.95 & 119.713 & 1.647 \\
\hline & ULS-2 & 5 & 0.6 & 0.9 & 17 & 411.95 & 130.855 & 1.620 \\
\hline & ULS-3 & 5 & 0.6 & 0.8 & 17 & 411.95 & 140.580 & 1.547 \\
\hline & ULS-4 & 5 & 0.6 & 0.7 & 17 & 411.95 & 140.862 & 1.356 \\
\hline & ULS-5 & 5 & 0.6 & 0.6 & 17 & 411.95 & 140.862 & 1.163 \\
\hline & ULS-6 & 5 & 0.6 & 0.9 & 17 & 411.95 & 132.705 & 1.643 \\
\hline & ULS-7 & 5 & 0.6 & 0.9 & 17 & 411.95 & 142.216 & 1.761 \\
\hline & ULS-8 & 5 & 0.6 & 0.8 & 17 & 411.95 & 140.964 & 1.551 \\
\hline & ULS-9 & 5 & 0.6 & 0.7 & 17 & 411.95 & 141.246 & 1.360 \\
\hline & ULS-10 & 5 & 0.6 & 0.6 & 17 & 411.95 & 142.066 & 1.173 \\
\hline & ULS-11 & 5 & 0.6 & 0.8 & 17 & 411.95 & 145.303 & 1.599 \\
\hline & ULS-12 & 5 & 0.6 & 0.7 & 17 & 411.95 & 145.585 & 1.402 \\
\hline & ULS-13 & 5 & 0.6 & 0.6 & 17 & 411.95 & 145.585 & 1.202 \\
\hline & FLS-14 & 5 & 0.6 & 1 & 17 & 411.95 & 130.639 & 5.391 \\
\hline & FLS-15 & 5 & 0.6 & 1 & 17 & 411.95 & 125.928 & 5.197 \\
\hline & FLS-16 & 5 & 0.6 & 1 & 17 & 411.95 & 110.024 & 4.540 \\
\hline
\end{tabular}




\begin{tabular}{|c|c|c|c|c|c|c|c|c|}
\hline \multicolumn{9}{|c|}{ Five Lane Bridge: B1000, 32 m Span Length } \\
\hline Bridge Configurations & Load cases & $\mathbf{n}$ & $\mathbf{R}_{\mathbf{L}}$ & $\mathbf{R}_{\mathbf{L}}^{\prime}$ & $\mathbf{N}$ & $\begin{array}{c}\left(\mathbf{R}_{\text {straight }}\right)_{\text {truck }} \\
(\mathbf{k N})\end{array}$ & $\begin{array}{l}\mathbf{R}_{\mathrm{FE}} \\
(\mathrm{kN})\end{array}$ & $\left(F_{\mathrm{v}}\right)_{\mathrm{FE}}$ \\
\hline \multirow{16}{*}{15 Box Girders - 18.510m Bridge Width } & ULS-1 & 5 & 0.6 & 1 & 15 & 458.40 & 118.46 & 1.292 \\
\hline & ULS-2 & 5 & 0.6 & 0.9 & 15 & 458.40 & 134.613 & 1.321 \\
\hline & ULS-3 & 5 & 0.6 & 0.8 & 15 & 458.40 & 149.199 & 1.302 \\
\hline & ULS-4 & 5 & 0.6 & 0.7 & 15 & 458.40 & 152.719 & 1.166 \\
\hline & ULS-5 & 5 & 0.6 & 0.6 & 15 & 458.40 & 153.152 & 1.002 \\
\hline & ULS-6 & 5 & 0.6 & 0.9 & 15 & 458.40 & 145.303 & 1.426 \\
\hline & ULS-7 & 5 & 0.6 & 0.9 & 15 & 458.40 & 147.355 & 1.447 \\
\hline & ULS-8 & 5 & 0.6 & 0.8 & 15 & 458.40 & 149.735 & 1.307 \\
\hline & ULS-9 & 5 & 0.6 & 0.7 & 15 & 458.40 & 153.254 & 1.170 \\
\hline & ULS-10 & 5 & 0.6 & 0.6 & 15 & 458.40 & 153.254 & 1.003 \\
\hline & ULS-11 & 5 & 0.6 & 0.8 & 15 & 458.40 & 153.629 & 1.341 \\
\hline & ULS-12 & 5 & 0.6 & 0.7 & 15 & 458.40 & 157.149 & 1.200 \\
\hline & ULS-13 & 5 & 0.6 & 0.6 & 15 & 458.40 & 157.189 & 1.029 \\
\hline & FLS-14 & 5 & 0.6 & 1 & 15 & 458.40 & 132.871 & 4.348 \\
\hline & FLS-15 & 5 & 0.6 & 1 & 15 & 458.40 & 130.626 & 4.274 \\
\hline & FLS-16 & 5 & 0.6 & 1 & 15 & 458.40 & 110.238 & 3.607 \\
\hline \multirow{16}{*}{$\begin{array}{l}\text { 16 Box Girders } \\
\text { 19.745m Bridge Width }\end{array}$} & ULS-1 & 5 & 0.6 & 1 & 16 & 458.40 & 118.192 & 1.375 \\
\hline & ULS-2 & 5 & 0.6 & 0.9 & 16 & 458.40 & 132.743 & 1.390 \\
\hline & ULS-3 & 5 & 0.6 & 0.8 & 16 & 458.40 & 138.073 & 1.285 \\
\hline & ULS-4 & 5 & 0.6 & 0.7 & 16 & 458.40 & 143.475 & 1.168 \\
\hline & ULS-5 & 5 & 0.6 & 0.6 & 16 & 458.40 & 149.351 & 1.043 \\
\hline & ULS-6 & 5 & 0.6 & 0.9 & 16 & 458.40 & 142.174 & 1.489 \\
\hline & ULS-7 & 5 & 0.6 & 0.9 & 16 & 458.40 & 138.407 & 1.449 \\
\hline & ULS-8 & 5 & 0.6 & 0.8 & 16 & 458.40 & 144.058 & 1.341 \\
\hline & ULS-9 & 5 & 0.6 & 0.7 & 16 & 458.40 & 144.588 & 1.178 \\
\hline & ULS-10 & 5 & 0.6 & 0.6 & 16 & 458.40 & 149.351 & 1.043 \\
\hline & ULS-11 & 5 & 0.6 & 0.8 & 16 & 458.40 & 153.317 & 1.427 \\
\hline & ULS-12 & 5 & 0.6 & 0.7 & 16 & 458.40 & 153.317 & 1.249 \\
\hline & ULS-13 & 5 & 0.6 & 0.6 & 16 & 458.40 & 153.317 & 1.070 \\
\hline & FLS-14 & 5 & 0.6 & 1 & 16 & 458.40 & 124.587 & 4.349 \\
\hline & FLS-15 & 5 & 0.6 & 1 & 16 & 458.40 & 132.059 & 4.609 \\
\hline & FLS-16 & 5 & 0.6 & 1 & 16 & 458.40 & 128.794 & 4.495 \\
\hline \multirow{16}{*}{$\begin{array}{l}17 \text { Box Girders } \\
\text { 20.980m Bridge Width }\end{array}$} & ULS-1 & 5 & 0.6 & 1 & 17 & 458.40 & 118.138 & 1.460 \\
\hline & ULS-2 & 5 & 0.6 & 0.9 & 17 & 458.40 & 131.33 & 1.461 \\
\hline & ULS-3 & 5 & 0.6 & 0.8 & 17 & 458.40 & 147.259 & 1.456 \\
\hline & ULS-4 & 5 & 0.6 & 0.7 & 17 & 458.40 & 149.884 & 1.297 \\
\hline & ULS-5 & 5 & 0.6 & 0.6 & 17 & 458.40 & 149.884 & 1.112 \\
\hline & ULS-6 & 5 & 0.6 & 0.9 & 17 & 458.40 & 136.453 & 1.518 \\
\hline & ULS-7 & 5 & 0.6 & 0.9 & 17 & 458.40 & 148.426 & 1.651 \\
\hline & ULS-8 & 5 & 0.6 & 0.8 & 17 & 458.40 & 147.922 & 1.463 \\
\hline & ULS-9 & 5 & 0.6 & 0.7 & 17 & 458.40 & 150.548 & 1.303 \\
\hline & ULS-10 & 5 & 0.6 & 0.6 & 17 & 458.40 & 151.819 & 1.126 \\
\hline & ULS-11 & 5 & 0.6 & 0.8 & 17 & 458.40 & 153.613 & 1.519 \\
\hline & ULS-12 & 5 & 0.6 & 0.7 & 17 & 458.40 & 156.238 & 1.352 \\
\hline & ULS-13 & 5 & 0.6 & 0.6 & 17 & 458.40 & 156.238 & 1.159 \\
\hline & FLS-14 & 5 & 0.6 & 1 & 17 & 458.40 & 130.004 & 4.821 \\
\hline & FLS-15 & 5 & 0.6 & 1 & 17 & 458.40 & 124.467 & 4.616 \\
\hline & FLS-16 & 5 & 0.6 & 1 & 17 & 458.40 & 110.744 & 4.107 \\
\hline
\end{tabular}




\section{Table A. 15: Five-Lane Bridge Deflection Distribution Factors $\left(F_{d}\right)$ at Fatigue Limit States}

\begin{tabular}{|c|c|c|c|c|c|c|c|c|}
\hline \multicolumn{9}{|c|}{ Five Lane Bridge: B700, $10 \mathrm{~m}$ Span Length } \\
\hline Bridge Configurations & Load cases & $\mathbf{n}$ & $\mathbf{R}_{\mathbf{L}}$ & $\mathbf{R}_{\mathbf{L}}^{\prime}$ & $\mathbf{N}$ & $\begin{array}{c}\left(\Delta_{\text {straight }}\right)_{\text {truck }} \\
(\mathbf{m m})\end{array}$ & $\begin{array}{l}\Delta_{\text {FE. }} \\
(\mathbf{m m})\end{array}$ & $\left(F_{d}\right)_{F E}$ \\
\hline \multirow{3}{*}{$\begin{array}{l}15 \text { Box Girders } \\
\text { 18.510m Bridge Width }\end{array}$} & FLS-14 & 5 & 0.6 & 1 & 15 & 6.967 & 1.549 & 3.335 \\
\hline & FLS-15 & 5 & 0.6 & 1 & 15 & 6.967 & 1.291 & 2.780 \\
\hline & FLS-16 & 5 & 0.6 & 1 & 15 & 6.967 & 1.193 & 2.569 \\
\hline \multirow{3}{*}{$\begin{array}{c}16 \text { Box Girders } \\
\text { 19.745m Bridge Width }\end{array}$} & FLS-14 & 5 & 0.6 & 1 & 16 & 6.967 & 1.499 & 3.443 \\
\hline & FLS-15 & 5 & 0.6 & 1 & 16 & 6.967 & 1.287 & 2.956 \\
\hline & FLS-16 & 5 & 0.6 & 1 & 16 & 6.967 & 1.271 & 2.919 \\
\hline \multirow{3}{*}{$\begin{array}{c}17 \text { Box Girders } \\
\text { 20.980m Bridge Width }\end{array}$} & FLS-14 & 5 & 0.6 & 1 & 17 & 6.967 & 1.413 & 3.448 \\
\hline & FLS-15 & 5 & 0.6 & 1 & 17 & 6.967 & 1.247 & 3.043 \\
\hline & FLS-16 & 5 & 0.6 & 1 & 17 & 6.967 & 1.190 & 2.904 \\
\hline
\end{tabular}

\begin{tabular}{|c|c|c|c|c|c|c|c|c|}
\hline \multicolumn{9}{|c|}{ Five Lane Bridge: B800, $20 \mathrm{~m}$ Span Length } \\
\hline Bridge Configurations & Load cases & $\mathbf{n}$ & $\mathbf{R}_{\mathbf{L}}$ & $\mathbf{R}_{\mathbf{L}}^{\prime}$ & $\mathbf{N}$ & $\begin{array}{c}\left(\Delta_{\text {straight }}\right)_{\text {truck }} \\
(\mathbf{m m})\end{array}$ & $\begin{array}{c}\Delta_{\mathrm{FE}} \\
(\mathbf{m m})\end{array}$ & $\left(F_{d}\right)_{F E}$ \\
\hline \multirow{3}{*}{$\begin{array}{l}\text { 15 Box Girders } \\
\text { 18.510m Bridge Width }\end{array}$} & FLS-14 & 5 & 0.6 & 1 & 15 & 40.859 & 7.559 & 2.775 \\
\hline & FLS-15 & 5 & 0.6 & 1 & 15 & 40.859 & 5.712 & 2.097 \\
\hline & FLS-16 & 5 & 0.6 & 1 & 15 & 40.859 & 5.239 & 1.923 \\
\hline \multirow{3}{*}{$\begin{array}{l}\text { 16 Box Girders } \\
\text { 19.745m Bridge Width }\end{array}$} & FLS-14 & 5 & 0.6 & 1 & 16 & 40.859 & 7.302 & 2.859 \\
\hline & FLS-15 & 5 & 0.6 & 1 & 16 & 40.859 & 5.611 & 2.197 \\
\hline & FLS-16 & 5 & 0.6 & 1 & 16 & 40.859 & 5.262 & 2.061 \\
\hline \multirow{3}{*}{$\begin{array}{l}17 \text { Box Girders } \\
\text { 20.980m Bridge Width }\end{array}$} & FLS-14 & 5 & 0.6 & 1 & 17 & 40.859 & 6.885 & 2.865 \\
\hline & FLS-15 & 5 & 0.6 & 1 & 17 & 40.859 & 5.382 & 2.239 \\
\hline & FLS-16 & 5 & 0.6 & 1 & 17 & 40.859 & 5.081 & 2.114 \\
\hline
\end{tabular}

\begin{tabular}{|c|c|c|c|c|c|c|c|c|}
\hline \multicolumn{9}{|c|}{ Five Lane Bridge: B1000, $32 \mathrm{~m}$ Span Length } \\
\hline Bridge Configurations & Load cases & $\mathbf{n}$ & $\mathbf{R}_{\mathrm{L}}$ & $\mathbf{R}_{\mathbf{L}}^{\prime}$ & $\mathbf{N}$ & $\begin{array}{c}\left(\Delta_{\text {straight }}\right)_{\text {truck }} \\
(\mathbf{m m})\end{array}$ & $\begin{array}{c}\Delta_{\mathrm{FE}} \\
(\mathbf{m m})\end{array}$ & $\left(F_{d}\right)_{F E}$ \\
\hline \multirow{3}{*}{$\begin{array}{l}\text { 15 Box Girders } \\
\text { 18.510m Bridge Width }\end{array}$} & FLS-14 & 5 & 0.6 & 1 & 15 & 159.157 & 17.708 & 1.669 \\
\hline & FLS-15 & 5 & 0.6 & 1 & 15 & 159.157 & 13.686 & 1.290 \\
\hline & FLS-16 & 5 & 0.6 & 1 & 15 & 159.157 & 12.677 & 1.195 \\
\hline \multirow{3}{*}{$\begin{array}{c}16 \text { Box Girders } \\
\text { 19.745m Bridge Width }\end{array}$} & FLS-14 & 5 & 0.6 & 1 & 16 & 159.157 & 17.130 & 1.722 \\
\hline & FLS-15 & 5 & 0.6 & 1 & 16 & 159.157 & 13.204 & 1.327 \\
\hline & FLS-16 & 5 & 0.6 & 1 & 16 & 159.157 & 12.295 & 1.236 \\
\hline \multirow{3}{*}{$\begin{array}{l}17 \text { Box Girders } \\
\text { 20.980m Bridge Width }\end{array}$} & FLS-14 & 5 & 0.6 & 1 & 17 & 159.157 & 16.211 & 1.732 \\
\hline & FLS-15 & 5 & 0.6 & 1 & 17 & 159.157 & 12.674 & 1.354 \\
\hline & FLS-16 & 5 & 0.6 & 1 & 17 & 159.157 & 11.826 & 1.263 \\
\hline
\end{tabular}


Table A. 16: Six-Lane Bridge Moment Distribution Factors $\left(F_{m}\right)$ at Serviceability, Ultimate

\begin{tabular}{|c|c|c|c|c|c|c|c|c|c|c|c|}
\hline \multirow[b]{2}{*}{ Bridge Configurations } & \multirow[b]{2}{*}{ Load cases } & \multicolumn{10}{|c|}{ Six Lane Bridge: B700, $10 \mathrm{~m}$ Span Length } \\
\hline & & $\mathbf{n}$ & $\mathbf{R}_{\mathbf{L}}$ & $\mathbf{R}_{\mathbf{L}}^{\prime}$ & $\mathbf{N}$ & $\begin{array}{c}\mathbf{I} \\
\left(\mathbf{m}^{\mathbf{4}}\right)\end{array}$ & $\begin{array}{l}\mathbf{y}_{\mathbf{b}} \\
(\mathbf{m})\end{array}$ & $\begin{array}{c}\mathbf{M}_{\mathbf{T}} \\
(\mathbf{k N} / \mathbf{m})\end{array}$ & $\begin{array}{c}\left(\sigma_{\text {straight }}\right)_{\text {truck }} \\
(\mathrm{MPa})\end{array}$ & $\begin{array}{c}\sigma_{\mathrm{FE}} \\
(\mathrm{MPa})\end{array}$ & $\left(\mathbf{F}_{\mathbf{m}}\right)_{\mathbf{F E}}$ \\
\hline \multirow{22}{*}{$\begin{array}{c}18 \text { Box Girders } \\
22.216 \mathrm{~m} \text { Bridge Width }\end{array}$} & ULS-1 & 6 & 0.55 & 1 & 18 & 0.0309 & 0.3761 & 651.00 & 7.924 & 2.137 & 1.471 \\
\hline & ULS-2 & 6 & 0.55 & 0.9 & 18 & 0.0309 & 0.3761 & 651.00 & 7.924 & 2.806 & 1.738 \\
\hline & ULS-3 & 6 & 0.55 & 0.8 & 18 & 0.0309 & 0.3761 & 651.00 & 7.924 & 3.010 & 1.658 \\
\hline & ULS-4 & 6 & 0.55 & 0.7 & 18 & 0.0309 & 0.3761 & 651.00 & 7.924 & 3.072 & 1.480 \\
\hline & ULS-5 & 6 & 0.55 & 0.6 & 18 & 0.0309 & 0.3761 & 651.00 & 7.924 & 3.188 & 1.317 \\
\hline & ULS-6 & 6 & 0.55 & 0.55 & 18 & 0.0309 & 0.3761 & 651.00 & 7.924 & 3.383 & 1.281 \\
\hline & ULS-7 & 6 & 0.55 & 0.9 & 18 & 0.0309 & 0.3761 & 651.00 & 7.924 & 3.049 & 1.889 \\
\hline & ULS-8 & 6 & 0.55 & 0.9 & 18 & 0.0309 & 0.3761 & 651.00 & 7.924 & 2.672 & 1.655 \\
\hline & ULS-9 & 6 & 0.55 & 0.9 & 18 & 0.0309 & 0.3761 & 651.00 & 7.924 & 2.587 & 1.603 \\
\hline & ULS-10 & 6 & 0.55 & 0.8 & 18 & 0.0309 & 0.3761 & 651.00 & 7.924 & 3.274 & 1.803 \\
\hline & ULS-11 & 6 & 0.55 & 0.7 & 18 & 0.0309 & 0.3761 & 651.00 & 7.924 & 3.342 & 1.610 \\
\hline & ULS-12 & 6 & 0.55 & 0.6 & 18 & 0.0309 & 0.3761 & 651.00 & 7.924 & 3.363 & 1.389 \\
\hline & ULS-13 & 6 & 0.55 & 0.55 & 18 & 0.0309 & 0.3761 & 651.00 & 7.924 & 3.385 & 1.282 \\
\hline & ULS-14 & 6 & 0.55 & 0.8 & 18 & 0.0309 & 0.3761 & 651.00 & 7.924 & 3.271 & 1.801 \\
\hline & ULS-15 & 6 & 0.55 & 0.7 & 18 & 0.0309 & 0.3761 & 651.00 & 7.924 & 3.452 & 1.663 \\
\hline & ULS-16 & 6 & 0.55 & 0.6 & 18 & 0.0309 & 0.3761 & 651.00 & 7.924 & 3.507 & 1.449 \\
\hline & ULS-17 & 6 & 0.55 & 0.55 & 18 & 0.0309 & 0.3761 & 651.00 & 7.924 & 3.527 & 1.335 \\
\hline & ULS-18 & 6 & 0.55 & 0.7 & 18 & 0.0309 & 0.3761 & 651.00 & 7.924 & 3.265 & 1.573 \\
\hline & ULS-19 & 6 & 0.55 & 0.55 & 18 & 0.0309 & 0.3761 & 651.00 & 7.924 & 3.511 & 1.329 \\
\hline & FLS-20 & 6 & 0.55 & 1 & 18 & 0.0309 & 0.3761 & 651.00 & 7.924 & 2.310 & 5.248 \\
\hline & FLS-21 & 6 & 0.55 & 1 & 18 & 0.0309 & 0.3761 & 651.00 & 7.924 & 2.042 & 4.639 \\
\hline & FLS-22 & 6 & 0.55 & 1 & 18 & 0.0309 & 0.3761 & 651.00 & 7.924 & 1.745 & 3.964 \\
\hline \multirow{22}{*}{$\begin{array}{c}\text { 19 Box Girders } \\
\text { 23.450m Bridge Width }\end{array}$} & ULS-1 & 6 & 0.55 & 1 & 19 & 0.0309 & 0.3761 & 651.00 & 7.924 & 2.137 & 1.553 \\
\hline & ULS-2 & 6 & 0.55 & 0.9 & 19 & 0.0309 & 0.3761 & 651.00 & 7.924 & 2.759 & 1.804 \\
\hline & ULS-3 & 6 & 0.55 & 0.8 & 19 & 0.0309 & 0.3761 & 651.00 & 7.924 & 2.936 & 1.707 \\
\hline & ULS-4 & 6 & 0.55 & 0.7 & 19 & 0.0309 & 0.3761 & 651.00 & 7.924 & 3.028 & 1.540 \\
\hline & ULS-5 & 6 & 0.55 & 0.6 & 19 & 0.0309 & 0.3761 & 651.00 & 7.924 & 3.083 & 1.344 \\
\hline & ULS-6 & 6 & 0.55 & 0.55 & 19 & 0.0309 & 0.3761 & 651.00 & 7.924 & 3.153 & 1.260 \\
\hline & ULS-7 & 6 & 0.55 & 0.9 & 19 & 0.0309 & 0.3761 & 651.00 & 7.924 & 2.886 & 1.887 \\
\hline & ULS-8 & 6 & 0.55 & 0.9 & 19 & 0.0309 & 0.3761 & 651.00 & 7.924 & 2.511 & 1.642 \\
\hline & ULS-9 & 6 & 0.55 & 0.9 & 19 & 0.0309 & 0.3761 & 651.00 & 7.924 & 2.435 & 1.592 \\
\hline & ULS-10 & 6 & 0.55 & 0.8 & 19 & 0.0309 & 0.3761 & 651.00 & 7.924 & 3.081 & 1.791 \\
\hline & ULS-11 & 6 & 0.55 & 0.7 & 19 & 0.0309 & 0.3761 & 651.00 & 7.924 & 3.137 & 1.596 \\
\hline & ULS-12 & 6 & 0.55 & 0.6 & 19 & 0.0309 & 0.3761 & 651.00 & 7.924 & 3.168 & 1.381 \\
\hline & ULS-13 & 6 & 0.55 & 0.55 & 19 & 0.0309 & 0.3761 & 651.00 & 7.924 & 3.182 & 1.272 \\
\hline & ULS-14 & 6 & 0.55 & 0.8 & 19 & 0.0309 & 0.3761 & 651.00 & 7.924 & 3.079 & 1.790 \\
\hline & ULS-15 & 6 & 0.55 & 0.7 & 19 & 0.0309 & 0.3761 & 651.00 & 7.924 & 3.247 & 1.652 \\
\hline & ULS-16 & 6 & 0.55 & 0.6 & 19 & 0.0309 & 0.3761 & 651.00 & 7.924 & 3.295 & 1.437 \\
\hline & ULS-17 & 6 & 0.55 & 0.55 & 19 & 0.0309 & 0.3761 & 651.00 & 7.924 & 3.311 & 1.323 \\
\hline & ULS-18 & 6 & 0.55 & 0.7 & 19 & 0.0309 & 0.3761 & 651.00 & 7.924 & 3.104 & 1.579 \\
\hline & ULS-19 & 6 & 0.55 & 0.55 & 19 & 0.0309 & 0.3761 & 651.00 & 7.924 & 3.320 & 1.327 \\
\hline & FLS-20 & 6 & 0.55 & 1 & 19 & 0.0309 & 0.3761 & 651.00 & 7.924 & 2.041 & 4.894 \\
\hline & FLS-21 & 6 & 0.55 & 1 & 19 & 0.0309 & 0.3761 & 651.00 & 7.924 & 1.923 & 4.611 \\
\hline & FLS-22 & 6 & 0.55 & 1 & 19 & 0.0309 & 0.3761 & 651.00 & 7.924 & 2.033 & 4.875 \\
\hline \multirow{22}{*}{$\begin{array}{c}20 \text { Box Girders } \\
24.686 \mathrm{~m} \text { Bridge Width }\end{array}$} & ULS-1 & 6 & 0.55 & 1 & 20 & 0.0309 & 0.3761 & 651.00 & 7.924 & 2.137 & 1.635 \\
\hline & ULS-2 & 6 & 0.55 & 0.9 & 20 & 0.0309 & 0.3761 & 651.00 & 7.924 & 2.715 & 1.869 \\
\hline & ULS-3 & 6 & 0.55 & 0.8 & 20 & 0.0309 & 0.3761 & 651.00 & 7.924 & 3.009 & 1.841 \\
\hline & ULS-4 & 6 & 0.55 & 0.7 & 20 & 0.0309 & 0.3761 & 651.00 & 7.924 & 3.128 & 1.675 \\
\hline & ULS-5 & 6 & 0.55 & 0.6 & 20 & 0.0309 & 0.3761 & 651.00 & 7.924 & 2.514 & 1.154 \\
\hline & ULS-6 & 6 & 0.55 & 0.55 & 20 & 0.0309 & 0.3761 & 651.00 & 7.924 & 3.193 & 1.343 \\
\hline & ULS-7 & 6 & 0.55 & 0.9 & 20 & 0.0309 & 0.3761 & 651.00 & 7.924 & 2.690 & 1.852 \\
\hline & ULS-8 & 6 & 0.55 & 0.9 & 20 & 0.0309 & 0.3761 & 651.00 & 7.924 & 2.623 & 1.806 \\
\hline & ULS-9 & 6 & 0.55 & 0.9 & 20 & 0.0309 & 0.3761 & 651.00 & 7.924 & 2.585 & 1.779 \\
\hline & ULS-10 & 6 & 0.55 & 0.8 & 20 & 0.0309 & 0.3761 & 651.00 & 7.924 & 3.141 & 1.922 \\
\hline & ULS-11 & 6 & 0.55 & 0.7 & 20 & 0.0309 & 0.3761 & 651.00 & 7.924 & 3.260 & 1.745 \\
\hline & ULS-12 & 6 & 0.55 & 0.6 & 20 & 0.0309 & 0.3761 & 651.00 & 7.924 & 3.292 & 1.511 \\
\hline & ULS-13 & 6 & 0.55 & 0.55 & 20 & 0.0309 & 0.3761 & 651.00 & 7.924 & 3.292 & 1.385 \\
\hline & ULS-14 & 6 & 0.55 & 0.8 & 20 & 0.0309 & 0.3761 & 651.00 & 7.924 & 2.853 & 1.746 \\
\hline & ULS-15 & 6 & 0.55 & 0.7 & 20 & 0.0309 & 0.3761 & 651.00 & 7.924 & 3.228 & 1.728 \\
\hline & ULS-16 & 6 & 0.55 & 0.6 & 20 & 0.0309 & 0.3761 & 651.00 & 7.924 & 3.347 & 1.536 \\
\hline & ULS-17 & 6 & 0.55 & 0.55 & 20 & 0.0309 & 0.3761 & 651.00 & 7.924 & 3.384 & 1.424 \\
\hline & ULS-18 & 6 & 0.55 & 0.7 & 20 & 0.0309 & 0.3761 & 651.00 & 7.924 & 3.170 & 1.697 \\
\hline & ULS-19 & 6 & 0.55 & 0.55 & 20 & 0.0309 & 0.3761 & 651.00 & 7.924 & 3.350 & 1.409 \\
\hline & FLS-20 & 6 & 0.55 & 1 & 20 & 0.0309 & 0.3761 & 651.00 & 7.924 & 2.176 & 5.492 \\
\hline & FLS-21 & 6 & 0.55 & 1 & 20 & 0.0309 & 0.3761 & 651.00 & 7.924 & 1.912 & 4.826 \\
\hline & FLS-22 & 6 & 0.55 & 1 & 20 & 0.0309 & 0.3761 & 651.00 & 7.924 & 1.702 & 4.296 \\
\hline
\end{tabular}




\begin{tabular}{|c|c|c|c|c|c|c|c|c|c|c|c|}
\hline \multicolumn{12}{|c|}{ Six Lane Bridge: B800, 20 m Span Length } \\
\hline Bridge Configurations & Load cases & $\mathbf{n}$ & $\mathbf{R}_{\mathbf{L}}$ & $\mathbf{R}_{\mathbf{L}}^{\prime}$ & $\mathbf{N}$ & $\begin{array}{c}\mathbf{I} \\
\left(\mathbf{m}^{4}\right)\end{array}$ & $\begin{array}{l}\mathbf{y}_{\mathbf{b}} \\
(\mathbf{m})\end{array}$ & $\begin{array}{c}\mathbf{M}_{\mathrm{T}} \\
(\mathbf{k N} / \mathbf{m})\end{array}$ & $\begin{array}{c}\left(\sigma_{\text {straight }}\right)_{\text {truck }} \\
(\mathrm{MPa})\end{array}$ & $\begin{array}{c}\sigma_{\mathrm{FE}} \\
(\mathrm{MPa})\end{array}$ & $\left(\mathbf{F}_{\mathbf{m}}\right)_{\mathrm{FE}}$ \\
\hline \multirow{22}{*}{$\begin{array}{c}18 \text { Box Girders } \\
22.216 \mathrm{~m} \text { Bridge Width }\end{array}$} & ULS-1 & 6 & 0.55 & 1 & 18 & 0.0441 & 0.4324 & 1686.15 & 16.533 & 3.020 & 0.996 \\
\hline & ULS-2 & 6 & 0.55 & 0.9 & 18 & 0.0441 & 0.4324 & 1686.15 & 16.533 & 4.526 & 1.344 \\
\hline & ULS-3 & 6 & 0.55 & 0.8 & 18 & 0.0441 & 0.4324 & 1686.15 & 16.533 & 5.358 & 1.414 \\
\hline & ULS-4 & 6 & 0.55 & 0.7 & 18 & 0.0441 & 0.4324 & 1686.15 & 16.533 & 5.822 & 1.345 \\
\hline & ULS-5 & 6 & 0.55 & 0.6 & 18 & 0.0441 & 0.4324 & 1686.15 & 16.533 & 6.094 & 1.206 \\
\hline & ULS-6 & 6 & 0.55 & 0.55 & 18 & 0.0441 & 0.4324 & 1686.15 & 16.533 & 6.417 & 1.164 \\
\hline & ULS-7 & 6 & 0.55 & 0.9 & 18 & 0.0441 & 0.4324 & 1686.15 & 16.533 & 4.618 & 1.371 \\
\hline & ULS-8 & 6 & 0.55 & 0.9 & 18 & 0.0441 & 0.4324 & 1686.15 & 16.533 & 3.775 & 1.121 \\
\hline & ULS-9 & 6 & 0.55 & 0.9 & 18 & 0.0441 & 0.4324 & 1686.15 & 16.533 & 3.538 & 1.051 \\
\hline & ULS-10 & 6 & 0.55 & 0.8 & 18 & 0.0441 & 0.4324 & 1686.15 & 16.533 & 5.494 & 1.450 \\
\hline & ULS-11 & 6 & 0.55 & 0.7 & 18 & 0.0441 & 0.4324 & 1686.15 & 16.533 & 5.983 & 1.382 \\
\hline & ULS-12 & 6 & 0.55 & 0.6 & 18 & 0.0441 & 0.4324 & 1686.15 & 16.533 & 6.270 & 1.241 \\
\hline & ULS-13 & 6 & 0.55 & 0.55 & 18 & 0.0441 & 0.4324 & 1686.15 & 16.533 & 6.467 & 1.173 \\
\hline & ULS-14 & 6 & 0.55 & 0.8 & 18 & 0.0441 & 0.4324 & 1686.15 & 16.533 & 5.367 & 1.417 \\
\hline & ULS-15 & 6 & 0.55 & 0.7 & 18 & 0.0441 & 0.4324 & 1686.15 & 16.533 & 5.887 & 1.360 \\
\hline & ULS-16 & 6 & 0.55 & 0.6 & 18 & 0.0441 & 0.4324 & 1686.15 & 16.533 & 6.287 & 1.245 \\
\hline & ULS-17 & 6 & 0.55 & 0.55 & 18 & 0.0441 & 0.4324 & 1686.15 & 16.533 & 6.559 & 1.190 \\
\hline & ULS-18 & 6 & 0.55 & 0.7 & 18 & 0.0441 & 0.4324 & 1686.15 & 16.533 & 5.328 & 1.230 \\
\hline & ULS-19 & 6 & 0.55 & 0.55 & 18 & 0.0441 & 0.4324 & 1686.15 & 16.533 & 6.575 & 1.193 \\
\hline & FLS-20 & 6 & 0.55 & 1 & 18 & 0.0441 & 0.4324 & 1686.15 & 16.533 & 3.076 & 3.349 \\
\hline & FLS-21 & 6 & 0.55 & 1 & 18 & 0.0441 & 0.4324 & 1686.15 & 16.533 & 2.534 & 2.759 \\
\hline & FLS-22 & 6 & 0.55 & 1 & 18 & 0.0441 & 0.4324 & 1686.15 & 16.533 & 2.168 & 2.360 \\
\hline \multirow{22}{*}{$\begin{array}{l}19 \text { Box Girders } \\
\text { 23.450m Bridge Width }\end{array}$} & ULS-1 & 6 & 0.55 & 1 & 19 & 0.0441 & 0.4324 & 1686.15 & 16.533 & 3.019 & 1.051 \\
\hline & ULS-2 & 6 & 0.55 & 0.9 & 19 & 0.0441 & 0.4324 & 1686.15 & 16.533 & 4.469 & 1.401 \\
\hline & ULS-3 & 6 & 0.55 & 0.8 & 19 & 0.0441 & 0.4324 & 1686.15 & 16.533 & 5.242 & 1.460 \\
\hline & ULS-4 & 6 & 0.55 & 0.7 & 19 & 0.0441 & 0.4324 & 1686.15 & 16.533 & 5.656 & 1.379 \\
\hline & ULS-5 & 6 & 0.55 & 0.6 & 19 & 0.0441 & 0.4324 & 1686.15 & 16.533 & 5.889 & 1.231 \\
\hline & ULS-6 & 6 & 0.55 & 0.55 & 19 & 0.0441 & 0.4324 & 1686.15 & 16.533 & 6.077 & 1.164 \\
\hline & ULS-7 & 6 & 0.55 & 0.9 & 19 & 0.0441 & 0.4324 & 1686.15 & 16.533 & 4.458 & 1.397 \\
\hline & ULS-8 & 6 & 0.55 & 0.9 & 19 & 0.0441 & 0.4324 & 1686.15 & 16.533 & 3.603 & 1.129 \\
\hline & ULS-9 & 6 & 0.55 & 0.9 & 19 & 0.0441 & 0.4324 & 1686.15 & 16.533 & 3.378 & 1.059 \\
\hline & ULS-10 & 6 & 0.55 & 0.8 & 19 & 0.0441 & 0.4324 & 1686.15 & 16.533 & 5.274 & 1.469 \\
\hline & ULS-11 & 6 & 0.55 & 0.7 & 19 & 0.0441 & 0.4324 & 1686.15 & 16.533 & 5.711 & 1.392 \\
\hline & ULS-12 & 6 & 0.55 & 0.6 & 19 & 0.0441 & 0.4324 & 1686.15 & 16.533 & 5.958 & 1.245 \\
\hline & ULS-13 & 6 & 0.55 & 0.55 & 19 & 0.0441 & 0.4324 & 1686.15 & 16.533 & 6.126 & 1.173 \\
\hline & ULS-14 & 6 & 0.55 & 0.8 & 19 & 0.0441 & 0.4324 & 1686.15 & 16.533 & 5.110 & 1.424 \\
\hline & ULS-15 & 6 & 0.55 & 0.7 & 19 & 0.0441 & 0.4324 & 1686.15 & 16.533 & 5.608 & 1.367 \\
\hline & ULS-16 & 6 & 0.55 & 0.6 & 19 & 0.0441 & 0.4324 & 1686.15 & 16.533 & 5.975 & 1.248 \\
\hline & ULS-17 & 6 & 0.55 & 0.55 & 19 & 0.0441 & 0.4324 & 1686.15 & 16.533 & 6.217 & 1.191 \\
\hline & ULS-18 & 6 & 0.55 & 0.7 & 19 & 0.0441 & 0.4324 & 1686.15 & 16.533 & 5.108 & 1.245 \\
\hline & ULS-19 & 6 & 0.55 & 0.55 & 19 & 0.0441 & 0.4324 & 1686.15 & 16.533 & 6.252 & 1.198 \\
\hline & FLS-20 & 6 & 0.55 & 1 & 19 & 0.0441 & 0.4324 & 1686.15 & 16.533 & 2.867 & 3.295 \\
\hline & FLS-21 & 6 & 0.55 & 1 & 19 & 0.0441 & 0.4324 & 1686.15 & 16.533 & 2.403 & 2.762 \\
\hline & FLS-22 & 6 & 0.55 & 1 & 19 & 0.0441 & 0.4324 & 1686.15 & 16.533 & 2.376 & 2.731 \\
\hline \multirow{22}{*}{$\begin{array}{c}20 \text { Box Girders } \\
24.686 \mathrm{~m} \text { Bridge Width }\end{array}$} & ULS-1 & 6 & 0.55 & 1 & 20 & 0.0441 & 0.4324 & 1686.15 & 16.533 & 3.018 & 1.106 \\
\hline & ULS-2 & 6 & 0.55 & 0.9 & 20 & 0.0441 & 0.4324 & 1686.15 & 16.533 & 4.416 & 1.457 \\
\hline & ULS-3 & 6 & 0.55 & 0.8 & 20 & 0.0441 & 0.4324 & 1686.15 & 16.533 & 5.134 & 1.506 \\
\hline & ULS-4 & 6 & 0.55 & 0.7 & 20 & 0.0441 & 0.4324 & 1686.15 & 16.533 & 5.506 & 1.413 \\
\hline & ULS-5 & 6 & 0.55 & 0.6 & 20 & 0.0441 & 0.4324 & 1686.15 & 16.533 & 5.795 & 1.275 \\
\hline & ULS-6 & 6 & 0.55 & 0.55 & 20 & 0.0441 & 0.4324 & 1686.15 & 16.533 & 5.978 & 1.205 \\
\hline & ULS-7 & 6 & 0.55 & 0.9 & 20 & 0.0441 & 0.4324 & 1686.15 & 16.533 & 4.237 & 1.398 \\
\hline & ULS-8 & 6 & 0.55 & 0.9 & 20 & 0.0441 & 0.4324 & 1686.15 & 16.533 & 3.581 & 1.181 \\
\hline & ULS-9 & 6 & 0.55 & 0.9 & 20 & 0.0441 & 0.4324 & 1686.15 & 16.533 & 3.483 & 1.149 \\
\hline & ULS-10 & 6 & 0.55 & 0.8 & 20 & 0.0441 & 0.4324 & 1686.15 & 16.533 & 5.049 & 1.481 \\
\hline & ULS-11 & 6 & 0.55 & 0.7 & 20 & 0.0441 & 0.4324 & 1686.15 & 16.533 & 5.582 & 1.432 \\
\hline & ULS-12 & 6 & 0.55 & 0.6 & 20 & 0.0441 & 0.4324 & 1686.15 & 16.533 & 5.875 & 1.292 \\
\hline & ULS-13 & 6 & 0.55 & 0.55 & 20 & 0.0441 & 0.4324 & 1686.15 & 16.533 & 6.058 & 1.221 \\
\hline & ULS-14 & 6 & 0.55 & 0.8 & 20 & 0.0441 & 0.4324 & 1686.15 & 16.533 & 4.769 & 1.399 \\
\hline & ULS-15 & 6 & 0.55 & 0.7 & 20 & 0.0441 & 0.4324 & 1686.15 & 16.533 & 5.137 & 1.318 \\
\hline & ULS-16 & 6 & 0.55 & 0.6 & 20 & 0.0441 & 0.4324 & 1686.15 & 16.533 & 5.818 & 1.280 \\
\hline & ULS-17 & 6 & 0.55 & 0.55 & 20 & 0.0441 & 0.4324 & 1686.15 & 16.533 & 6.160 & 1.242 \\
\hline & ULS-18 & 6 & 0.55 & 0.7 & 20 & 0.0441 & 0.4324 & 1686.15 & 16.533 & 5.094 & 1.307 \\
\hline & ULS-19 & 6 & 0.55 & 0.55 & 20 & 0.0441 & 0.4324 & 1686.15 & 16.533 & 6.125 & 1.235 \\
\hline & FLS-20 & 6 & 0.55 & 1 & 20 & 0.0441 & 0.4324 & 1686.15 & 16.533 & 2.865 & 3.466 \\
\hline & FLS-21 & 6 & 0.55 & 1 & 20 & 0.0441 & 0.4324 & 1686.15 & 16.533 & 2.360 & 2.855 \\
\hline & FLS-22 & 6 & 0.55 & 1 & 20 & 0.0441 & 0.4324 & 1686.15 & 16.533 & 2.069 & 2.503 \\
\hline
\end{tabular}




\begin{tabular}{|c|c|c|c|c|c|c|c|c|c|c|c|}
\hline \multicolumn{12}{|c|}{ Six Lane Bridge: B1000, 32 m Span Length } \\
\hline Bridge Configurations & Load cases & $\mathbf{n}$ & $\mathbf{R}_{\mathbf{L}}$ & $\mathbf{R}_{\mathbf{L}}^{\prime}$ & $\mathbf{N}$ & $\begin{array}{c}\mathbf{I} \\
\left(\mathbf{m}^{4}\right)\end{array}$ & $\begin{array}{l}\mathbf{y}_{\mathbf{b}} \\
(\mathbf{m}) \\
\end{array}$ & $\begin{array}{c}\mathbf{M}_{\mathrm{T}} \\
(\mathbf{k N} / \mathbf{m})\end{array}$ & $\begin{array}{c}\left(\sigma_{\text {straight }}\right)_{\text {truck }} \\
(\mathrm{MPa})\end{array}$ & $\begin{array}{c}\sigma_{\mathrm{FE}} \\
(\mathrm{MPa})\end{array}$ & $\left(\mathbf{F}_{\mathbf{m}}\right)_{\mathrm{FE}}$ \\
\hline \multirow{22}{*}{$\begin{array}{c}18 \text { Box Girders } \\
22.216 \mathrm{~m} \text { Bridge Width }\end{array}$} & ULS-1 & 6 & 0.55 & 1 & 18 & 0.0787 & 0.5433 & 3336.11 & 23.031 & 3.285 & 0.778 \\
\hline & ULS-2 & 6 & 0.55 & 0.9 & 18 & 0.0787 & 0.5433 & 3336.11 & 23.031 & 5.215 & 1.112 \\
\hline & ULS-3 & 6 & 0.55 & 0.8 & 18 & 0.0787 & 0.5433 & 3336.11 & 23.031 & 6.523 & 1.236 \\
\hline & ULS-4 & 6 & 0.55 & 0.7 & 18 & 0.0787 & 0.5433 & 3336.11 & 23.031 & 7.438 & 1.233 \\
\hline & ULS-5 & 6 & 0.55 & 0.6 & 18 & 0.0787 & 0.5433 & 3336.11 & 23.031 & 8.118 & 1.154 \\
\hline & ULS-6 & 6 & 0.55 & 0.55 & 18 & 0.0787 & 0.5433 & 3336.11 & 23.031 & 8.721 & 1.136 \\
\hline & ULS-7 & 6 & 0.55 & 0.9 & 18 & 0.0787 & 0.5433 & 3336.11 & 23.031 & 5.285 & 1.127 \\
\hline & ULS-8 & 6 & 0.55 & 0.9 & 18 & 0.0787 & 0.5433 & 3336.11 & 23.031 & 4.343 & 0.926 \\
\hline & ULS-9 & 6 & 0.55 & 0.9 & 18 & 0.0787 & 0.5433 & 3336.11 & 23.031 & 4.076 & 0.869 \\
\hline & ULS-10 & 6 & 0.55 & 0.8 & 18 & 0.0787 & 0.5433 & 3336.11 & 23.031 & 6.614 & 1.253 \\
\hline & ULS-11 & 6 & 0.55 & 0.7 & 18 & 0.0787 & 0.5433 & 3336.11 & 23.031 & 7.543 & 1.251 \\
\hline & ULS-12 & 6 & 0.55 & 0.6 & 18 & 0.0787 & 0.5433 & 3336.11 & 23.031 & 8.237 & 1.171 \\
\hline & ULS-13 & 6 & 0.55 & 0.55 & 18 & 0.0787 & 0.5433 & 3336.11 & 23.031 & 8.722 & 1.136 \\
\hline & ULS-14 & 6 & 0.55 & 0.8 & 18 & 0.0787 & 0.5433 & 3336.11 & 23.031 & 6.501 & 1.232 \\
\hline & ULS-15 & 6 & 0.55 & 0.7 & 18 & 0.0787 & 0.5433 & 3336.11 & 23.031 & 7.432 & 1.232 \\
\hline & ULS-16 & 6 & 0.55 & 0.6 & 18 & 0.0787 & 0.5433 & 3336.11 & 23.031 & 8.156 & 1.159 \\
\hline & ULS-17 & 6 & 0.55 & 0.55 & 18 & 0.0787 & 0.5433 & 3336.11 & 23.031 & 8.841 & 1.152 \\
\hline & ULS-18 & 6 & 0.55 & 0.7 & 18 & 0.0787 & 0.5433 & 3336.11 & 23.031 & 6.701 & 1.111 \\
\hline & ULS-19 & 6 & 0.55 & 0.55 & 18 & 0.0787 & 0.5433 & 3336.11 & 23.031 & 8.858 & 1.154 \\
\hline & FLS-20 & 6 & 0.55 & 1 & 18 & 0.0787 & 0.5433 & 3336.11 & 23.031 & 3.324 & 2.598 \\
\hline & FLS-21 & 6 & 0.55 & 1 & 18 & 0.0787 & 0.5433 & 3336.11 & 23.031 & 2.699 & 2.109 \\
\hline & FLS-22 & 6 & 0.55 & 1 & 18 & 0.0787 & 0.5433 & 3336.11 & 23.031 & 2.354 & 1.840 \\
\hline \multirow{22}{*}{$\begin{array}{l}19 \text { Box Girders } \\
\text { 23.450m Bridge Width }\end{array}$} & ULS-1 & 6 & 0.55 & 1 & 19 & 0.0787 & 0.5433 & 3336.11 & 23.031 & 3.276 & 0.819 \\
\hline & ULS-2 & 6 & 0.55 & 0.9 & 19 & 0.0787 & 0.5433 & 3336.11 & 23.031 & 5.149 & 1.159 \\
\hline & ULS-3 & 6 & 0.55 & 0.8 & 19 & 0.0787 & 0.5433 & 3336.11 & 23.031 & 6.383 & 1.277 \\
\hline & ULS-4 & 6 & 0.55 & 0.7 & 19 & 0.0787 & 0.5433 & 3336.11 & 23.031 & 7.222 & 1.264 \\
\hline & ULS-5 & 6 & 0.55 & 0.6 & 19 & 0.0787 & 0.5433 & 3336.11 & 23.031 & 7.827 & 1.174 \\
\hline & ULS-6 & 6 & 0.55 & 0.55 & 19 & 0.0787 & 0.5433 & 3336.11 & 23.031 & 8.322 & 1.144 \\
\hline & ULS-7 & 6 & 0.55 & 0.9 & 19 & 0.0787 & 0.5433 & 3336.11 & 23.031 & 5.143 & 1.157 \\
\hline & ULS-8 & 6 & 0.55 & 0.9 & 19 & 0.0787 & 0.5433 & 3336.11 & 23.031 & 4.159 & 0.936 \\
\hline & ULS-9 & 6 & 0.55 & 0.9 & 19 & 0.0787 & 0.5433 & 3336.11 & 23.031 & 3.862 & 0.869 \\
\hline & ULS-10 & 6 & 0.55 & 0.8 & 19 & 0.0787 & 0.5433 & 3336.11 & 23.031 & 6.398 & 1.280 \\
\hline & ULS-11 & 6 & 0.55 & 0.7 & 19 & 0.0787 & 0.5433 & 3336.11 & 23.031 & 7.251 & 1.269 \\
\hline & ULS-12 & 6 & 0.55 & 0.6 & 19 & 0.0787 & 0.5433 & 3336.11 & 23.031 & 7.869 & 1.180 \\
\hline & ULS-13 & 6 & 0.55 & 0.55 & 19 & 0.0787 & 0.5433 & 3336.11 & 23.031 & 8.370 & 1.151 \\
\hline & ULS-14 & 6 & 0.55 & 0.8 & 19 & 0.0787 & 0.5433 & 3336.11 & 23.031 & 6.248 & 1.250 \\
\hline & ULS-15 & 6 & 0.55 & 0.7 & 19 & 0.0787 & 0.5433 & 3336.11 & 23.031 & 7.103 & 1.243 \\
\hline & ULS-16 & 6 & 0.55 & 0.6 & 19 & 0.0787 & 0.5433 & 3336.11 & 23.031 & 7.796 & 1.169 \\
\hline & ULS-17 & 6 & 0.55 & 0.55 & 19 & 0.0787 & 0.5433 & 3336.11 & 23.031 & 8.394 & 1.154 \\
\hline & ULS-18 & 6 & 0.55 & 0.7 & 19 & 0.0787 & 0.5433 & 3336.11 & 23.031 & 6.379 & 1.116 \\
\hline & ULS-19 & 6 & 0.55 & 0.55 & 19 & 0.0787 & 0.5433 & 3336.11 & 23.031 & 8.411 & 1.156 \\
\hline & FLS-20 & 6 & 0.55 & 1 & 19 & 0.0787 & 0.5433 & 3336.11 & 23.031 & 3.104 & 2.561 \\
\hline & FLS-21 & 6 & 0.55 & 1 & 19 & 0.0787 & 0.5433 & 3336.11 & 23.031 & 2.640 & 2.178 \\
\hline & FLS-22 & 6 & 0.55 & 1 & 19 & 0.0787 & 0.5433 & 3336.11 & 23.031 & 2.506 & 2.067 \\
\hline \multirow{22}{*}{$\begin{array}{c}20 \text { Box Girders } \\
\text { 24.686m Bridge Width }\end{array}$} & ULS-1 & 6 & 0.55 & 1 & 20 & 0.0787 & 0.5433 & 3336.11 & 23.031 & 3.271 & 0.861 \\
\hline & ULS-2 & 6 & 0.55 & 0.9 & 20 & 0.0787 & 0.5433 & 3336.11 & 23.031 & 5.089 & 1.205 \\
\hline & ULS-3 & 6 & 0.55 & 0.8 & 20 & 0.0787 & 0.5433 & 3336.11 & 23.031 & 6.256 & 1.317 \\
\hline & ULS-4 & 6 & 0.55 & 0.7 & 20 & 0.0787 & 0.5433 & 3336.11 & 23.031 & 7.027 & 1.294 \\
\hline & ULS-5 & 6 & 0.55 & 0.6 & 20 & 0.0787 & 0.5433 & 3336.11 & 23.031 & 7.567 & 1.195 \\
\hline & ULS-6 & 6 & 0.55 & 0.55 & 20 & 0.0787 & 0.5433 & 3336.11 & 23.031 & 8.062 & 1.167 \\
\hline & ULS-7 & 6 & 0.55 & 0.9 & 20 & 0.0787 & 0.5433 & 3336.11 & 23.031 & 4.915 & 1.164 \\
\hline & ULS-8 & 6 & 0.55 & 0.9 & 20 & 0.0787 & 0.5433 & 3336.11 & 23.031 & 4.072 & 0.964 \\
\hline & ULS-9 & 6 & 0.55 & 0.9 & 20 & 0.0787 & 0.5433 & 3336.11 & 23.031 & 3.932 & 0.931 \\
\hline & ULS-10 & 6 & 0.55 & 0.8 & 20 & 0.0787 & 0.5433 & 3336.11 & 23.031 & 6.103 & 1.285 \\
\hline & ULS-11 & 6 & 0.55 & 0.7 & 20 & 0.0787 & 0.5433 & 3336.11 & 23.031 & 6.935 & 1.277 \\
\hline & ULS-12 & 6 & 0.55 & 0.6 & 20 & 0.0787 & 0.5433 & 3336.11 & 23.031 & 7.592 & 1.199 \\
\hline & ULS-13 & 6 & 0.55 & 0.55 & 20 & 0.0787 & 0.5433 & 3336.11 & 23.031 & 8.111 & 1.174 \\
\hline & ULS-14 & 6 & 0.55 & 0.8 & 20 & 0.0787 & 0.5433 & 3336.11 & 23.031 & 5.913 & 1.245 \\
\hline & ULS-15 & 6 & 0.55 & 0.7 & 20 & 0.0787 & 0.5433 & 3336.11 & 23.031 & 6.700 & 1.234 \\
\hline & ULS-16 & 6 & 0.55 & 0.6 & 20 & 0.0787 & 0.5433 & 3336.11 & 23.031 & 7.469 & 1.179 \\
\hline & ULS-17 & 6 & 0.55 & 0.55 & 20 & 0.0787 & 0.5433 & 3336.11 & 23.031 & 8.174 & 1.183 \\
\hline & ULS-18 & 6 & 0.55 & 0.7 & 20 & 0.0787 & 0.5433 & 3336.11 & 23.031 & 6.299 & 1.160 \\
\hline & ULS-19 & 6 & 0.55 & 0.55 & 20 & 0.0787 & 0.5433 & 3336.11 & 23.031 & 8.153 & 1.180 \\
\hline & FLS-20 & 6 & 0.55 & 1 & 20 & 0.0787 & 0.5433 & 3336.11 & 23.031 & 3.038 & 2.638 \\
\hline & FLS-21 & 6 & 0.55 & 1 & 20 & 0.0787 & 0.5433 & 3336.11 & 23.031 & 2.529 & 2.196 \\
\hline & FLS-22 & 6 & 0.55 & 1 & 20 & 0.0787 & 0.5433 & 3336.11 & 23.031 & 2.238 & 1.943 \\
\hline
\end{tabular}


Table A. 17: Five-Lane Bridge Shear Distribution Factors $\left(F_{v}\right)$ at Serviceability, Ultimate and Fatigue Limit States

\begin{tabular}{|c|c|c|c|c|c|c|c|c|}
\hline \multicolumn{9}{|c|}{ Six Lane Bridge: B700, $10 \mathrm{~m}$ Span Length } \\
\hline Bridge Configurations & Load cases & $\mathbf{n}$ & $\mathbf{R}_{\mathbf{L}}$ & $\mathbf{R}_{\mathbf{L}}^{\prime}$ & $\mathbf{N}$ & $\left(\mathbf{R}_{\text {straight }}\right)_{\text {truck }}$ & $\begin{array}{l}R_{\text {FE. }} \\
(\mathbf{k N})\end{array}$ & $\left(\mathbf{F}_{\mathbf{v}}\right)_{\mathbf{F E}}$ \\
\hline \multirow{22}{*}{$\begin{array}{c}18 \text { Box Girders } \\
22.216 \mathrm{~m} \text { Bridge Width }\end{array}$} & ULS-1 & 6 & 0.55 & 1 & 18 & 301.70 & 113.883 & 2.059 \\
\hline & ULS-2 & 6 & 0.55 & 0.9 & 18 & 301.70 & 117.267 & 1.908 \\
\hline & ULS-3 & 6 & 0.55 & 0.8 & 18 & 301.70 & 119.986 & 1.735 \\
\hline & ULS-4 & 6 & 0.55 & 0.7 & 18 & 301.70 & 127.533 & 1.614 \\
\hline & ULS-5 & 6 & 0.55 & 0.6 & 18 & 301.70 & 127.533 & 1.383 \\
\hline & ULS-6 & 6 & 0.55 & 0.55 & 18 & 301.70 & 127.533 & 1.268 \\
\hline & ULS-7 & 6 & 0.55 & 0.9 & 18 & 301.70 & 120.981 & 1.969 \\
\hline & ULS-8 & 6 & 0.55 & 0.9 & 18 & 301.70 & 123.883 & 2.016 \\
\hline & ULS-9 & 6 & 0.55 & 0.9 & 18 & 301.70 & 128.260 & 2.087 \\
\hline & ULS-10 & 6 & 0.55 & 0.8 & 18 & 301.70 & 120.981 & 1.750 \\
\hline & ULS-11 & 6 & 0.55 & 0.7 & 18 & 301.70 & 127.561 & 1.614 \\
\hline & ULS-12 & 6 & 0.55 & 0.6 & 18 & 301.70 & 127.561 & 1.384 \\
\hline & ULS-13 & 6 & 0.55 & 0.55 & 18 & 301.70 & 127.561 & 1.268 \\
\hline & ULS-14 & 6 & 0.55 & 0.8 & 18 & 301.70 & 123.883 & 1.792 \\
\hline & ULS-15 & 6 & 0.55 & 0.7 & 18 & 301.70 & 127.267 & 1.611 \\
\hline & ULS-16 & 6 & 0.55 & 0.6 & 18 & 301.70 & 127.678 & 1.385 \\
\hline & ULS-17 & 6 & 0.55 & 0.55 & 18 & 301.70 & 127.678 & 1.270 \\
\hline & ULS-18 & 6 & 0.55 & 0.7 & 18 & 301.70 & 128.984 & 1.632 \\
\hline & ULS-19 & 6 & 0.55 & 0.55 & 18 & 301.70 & 129.241 & 1.285 \\
\hline & FLS-20 & 6 & 0.55 & 1 & 18 & 301.70 & 122.305 & 7.297 \\
\hline & FLS-21 & 6 & 0.55 & 1 & 18 & 301.70 & 121.760 & 7.264 \\
\hline & FLS-22 & 6 & 0.55 & 1 & 18 & 301.70 & 104.170 & 6.215 \\
\hline \multirow{22}{*}{$\begin{array}{c}19 \text { Box Girders } \\
\text { 23.450m Bridge Width }\end{array}$} & ULS-1 & 6 & 0.55 & 1 & 19 & 301.70 & 113.345 & 2.163 \\
\hline & ULS-2 & 6 & 0.55 & 0.9 & 19 & 301.70 & 117.458 & 2.017 \\
\hline & ULS-3 & 6 & 0.55 & 0.8 & 19 & 301.70 & 120.776 & 1.844 \\
\hline & ULS-4 & 6 & 0.55 & 0.7 & 19 & 301.70 & 125.774 & 1.680 \\
\hline & ULS-5 & 6 & 0.55 & 0.6 & 19 & 301.70 & 128.500 & 1.471 \\
\hline & ULS-6 & 6 & 0.55 & 0.55 & 19 & 301.70 & 129.121 & 1.355 \\
\hline & ULS-7 & 6 & 0.55 & 0.9 & 19 & 301.70 & 118.931 & 2.043 \\
\hline & ULS-8 & 6 & 0.55 & 0.9 & 19 & 301.70 & 124.227 & 2.134 \\
\hline & ULS-9 & 6 & 0.55 & 0.9 & 19 & 301.70 & 125.774 & 2.160 \\
\hline & ULS-10 & 6 & 0.55 & 0.8 & 19 & 301.70 & 120.776 & 1.844 \\
\hline & ULS-11 & 6 & 0.55 & 0.7 & 19 & 301.70 & 125.774 & 1.680 \\
\hline & ULS-12 & 6 & 0.55 & 0.6 & 19 & 301.70 & 128.500 & 1.471 \\
\hline & ULS-13 & 6 & 0.55 & 0.55 & 19 & 301.70 & 129.121 & 1.355 \\
\hline & ULS-14 & 6 & 0.55 & 0.8 & 19 & 301.70 & 127.061 & 1.940 \\
\hline & ULS-15 & 6 & 0.55 & 0.7 & 19 & 301.70 & 127.061 & 1.697 \\
\hline & ULS-16 & 6 & 0.55 & 0.6 & 19 & 301.70 & 128.500 & 1.471 \\
\hline & ULS-17 & 6 & 0.55 & 0.55 & 19 & 301.70 & 129.121 & 1.355 \\
\hline & ULS-18 & 6 & 0.55 & 0.7 & 19 & 301.70 & 128.500 & 1.717 \\
\hline & ULS-19 & 6 & 0.55 & 0.55 & 19 & 301.70 & 129.121 & 1.355 \\
\hline & FLS-20 & 6 & 0.55 & 1 & 19 & 301.70 & 107.766 & 6.787 \\
\hline & FLS-21 & 6 & 0.55 & 1 & 19 & 301.70 & 124.227 & 7.823 \\
\hline & FLS-22 & 6 & 0.55 & 1 & 19 & 301.70 & 120.239 & 7.572 \\
\hline \multirow{22}{*}{$\begin{array}{c}\text { 20 Box Girders } \\
\text { 24.686m Bridge Width }\end{array}$} & ULS-1 & 6 & 0.55 & 1 & 20 & 301.70 & 113.886 & 2.288 \\
\hline & ULS-2 & 6 & 0.55 & 0.9 & 20 & 301.70 & 122.925 & 2.222 \\
\hline & ULS-3 & 6 & 0.55 & 0.8 & 20 & 301.70 & 125.029 & 2.009 \\
\hline & ULS-4 & 6 & 0.55 & 0.7 & 20 & 301.70 & 126.622 & 1.781 \\
\hline & ULS-5 & 6 & 0.55 & 0.6 & 20 & 301.70 & 126.622 & 1.526 \\
\hline & ULS-6 & 6 & 0.55 & 0.55 & 20 & 301.70 & 126.622 & 1.399 \\
\hline & ULS-7 & 6 & 0.55 & 0.9 & 20 & 301.70 & 122.925 & 2.222 \\
\hline & ULS-8 & 6 & 0.55 & 0.9 & 20 & 301.70 & 119.732 & 2.165 \\
\hline & ULS-9 & 6 & 0.55 & 0.9 & 20 & 301.70 & 128.824 & 2.329 \\
\hline & ULS-10 & 6 & 0.55 & 0.8 & 20 & 301.70 & 125.029 & 2.009 \\
\hline & ULS-11 & 6 & 0.55 & 0.7 & 20 & 301.70 & 126.658 & 1.781 \\
\hline & ULS-12 & 6 & 0.55 & 0.6 & 20 & 301.70 & 126.658 & 1.527 \\
\hline & ULS-13 & 6 & 0.55 & 0.55 & 20 & 301.70 & 126.658 & 1.399 \\
\hline & ULS-14 & 6 & 0.55 & 0.8 & 20 & 301.70 & 120.381 & 1.935 \\
\hline & ULS-15 & 6 & 0.55 & 0.7 & 20 & 301.70 & 126.824 & 1.783 \\
\hline & ULS-16 & 6 & 0.55 & 0.6 & 20 & 301.70 & 126.824 & 1.529 \\
\hline & ULS-17 & 6 & 0.55 & 0.55 & 20 & 301.70 & 126.824 & 1.401 \\
\hline & ULS-18 & 6 & 0.55 & 0.7 & 20 & 301.70 & 128.908 & 1.813 \\
\hline & ULS-19 & 6 & 0.55 & 0.55 & 20 & 301.70 & 129.097 & 1.426 \\
\hline & FLS-20 & 6 & 0.55 & 1 & 20 & 301.70 & 120.062 & 7.959 \\
\hline & FLS-21 & 6 & 0.55 & 1 & 20 & 301.70 & 116.786 & 7.742 \\
\hline & FLS-22 & 6 & 0.55 & 1 & 20 & 301.70 & 106.885 & 7.086 \\
\hline
\end{tabular}




\begin{tabular}{|c|c|c|c|c|c|c|c|c|}
\hline \multicolumn{9}{|c|}{ Six Lane Bridge: B800, 20 m Span Length } \\
\hline Bridge Configurations & Load cases & $\mathbf{n}$ & $\mathbf{R}_{\mathbf{L}}$ & $\mathbf{R}_{\mathbf{L}}^{\prime}$ & $\mathbf{N}$ & $\begin{array}{c}\left(\mathbf{R}_{\text {straight }}\right)_{\text {truck }} \\
(\mathbf{k N})\end{array}$ & $\begin{array}{l}\mathbf{R}_{\mathbf{F E}} \\
(\mathbf{k N})\end{array}$ & $\left(\mathbf{F}_{\mathbf{V}}\right)_{\mathbf{F E}}$ \\
\hline \multirow{22}{*}{$\begin{array}{c}18 \text { Box Girders } \\
\text { 22.216m Bridge Width }\end{array}$} & ULS-1 & 6 & 0.55 & 1 & 18 & 411.95 & 119.766 & 1.586 \\
\hline & ULS-2 & 6 & 0.55 & 0.9 & 18 & 411.95 & 130.003 & 1.549 \\
\hline & ULS-3 & 6 & 0.55 & 0.8 & 18 & 411.95 & 138.172 & 1.464 \\
\hline & ULS-4 & 6 & 0.55 & 0.7 & 18 & 411.95 & 145.114 & 1.345 \\
\hline & ULS-5 & 6 & 0.55 & 0.6 & 18 & 411.95 & 145.773 & 1.158 \\
\hline & ULS-6 & 6 & 0.55 & 0.55 & 18 & 411.95 & 145.773 & 1.062 \\
\hline & ULS-7 & 6 & 0.55 & 0.9 & 18 & 411.95 & 139.829 & 1.666 \\
\hline & ULS-8 & 6 & 0.55 & 0.9 & 18 & 411.95 & 140.346 & 1.672 \\
\hline & ULS-9 & 6 & 0.55 & 0.9 & 18 & 411.95 & 143.863 & 1.714 \\
\hline & ULS-10 & 6 & 0.55 & 0.8 & 18 & 411.95 & 139.978 & 1.483 \\
\hline & ULS-11 & 6 & 0.55 & 0.7 & 18 & 411.95 & 145.193 & 1.346 \\
\hline & ULS-12 & 6 & 0.55 & 0.6 & 18 & 411.95 & 145.851 & 1.159 \\
\hline & ULS-13 & 6 & 0.55 & 0.55 & 18 & 411.95 & 145.851 & 1.062 \\
\hline & ULS-14 & 6 & 0.55 & 0.8 & 18 & 411.95 & 142.037 & 1.505 \\
\hline & ULS-15 & 6 & 0.55 & 0.7 & 18 & 411.95 & 145.536 & 1.349 \\
\hline & ULS-16 & 6 & 0.55 & 0.6 & 18 & 411.95 & 146.195 & 1.161 \\
\hline & ULS-17 & 6 & 0.55 & 0.55 & 18 & 411.95 & 146.195 & 1.065 \\
\hline & ULS-18 & 6 & 0.55 & 0.7 & 18 & 411.95 & 147.565 & 1.368 \\
\hline & ULS-19 & 6 & 0.55 & 0.55 & 18 & 411.95 & 149.300 & 1.087 \\
\hline & FLS-20 & 6 & 0.55 & 1 & 18 & 411.95 & 133.933 & 5.852 \\
\hline & FLS-21 & 6 & 0.55 & 1 & 18 & 411.95 & 130.783 & 5.715 \\
\hline & FLS-22 & 6 & 0.55 & 1 & 18 & 411.95 & 114.642 & 5.009 \\
\hline \multirow{22}{*}{$\begin{array}{c}19 \text { Box Girders } \\
\text { 23.450m Bridge Width }\end{array}$} & ULS-1 & 6 & 0.55 & 1 & 19 & 411.95 & 119.526 & 1.671 \\
\hline & ULS-2 & 6 & 0.55 & 0.9 & 19 & 411.95 & 128.689 & 1.619 \\
\hline & ULS-3 & 6 & 0.55 & 0.8 & 19 & 411.95 & 132.999 & 1.487 \\
\hline & ULS-4 & 6 & 0.55 & 0.7 & 19 & 411.95 & 136.878 & 1.339 \\
\hline & ULS-5 & 6 & 0.55 & 0.6 & 19 & 411.95 & 141.803 & 1.189 \\
\hline & ULS-6 & 6 & 0.55 & 0.55 & 19 & 411.95 & 144.849 & 1.113 \\
\hline & ULS-7 & 6 & 0.55 & 0.9 & 19 & 411.95 & 136.098 & 1.712 \\
\hline & ULS-8 & 6 & 0.55 & 0.9 & 19 & 411.95 & 135.527 & 1.705 \\
\hline & ULS-9 & 6 & 0.55 & 0.9 & 19 & 411.95 & 135.092 & 1.699 \\
\hline & ULS-10 & 6 & 0.55 & 0.8 & 19 & 411.95 & 136.207 & 1.523 \\
\hline & ULS-11 & 6 & 0.55 & 0.7 & 19 & 411.95 & 136.878 & 1.339 \\
\hline & ULS-12 & 6 & 0.55 & 0.6 & 19 & 411.95 & 141.803 & 1.189 \\
\hline & ULS-13 & 6 & 0.55 & 0.55 & 19 & 411.95 & 144.849 & 1.113 \\
\hline & ULS-14 & 6 & 0.55 & 0.8 & 19 & 411.95 & 145.177 & 1.623 \\
\hline & ULS-15 & 6 & 0.55 & 0.7 & 19 & 411.95 & 145.177 & 1.420 \\
\hline & ULS-16 & 6 & 0.55 & 0.6 & 19 & 411.95 & 145.177 & 1.217 \\
\hline & ULS-17 & 6 & 0.55 & 0.55 & 19 & 411.95 & 145.177 & 1.116 \\
\hline & ULS-18 & 6 & 0.55 & 0.7 & 19 & 411.95 & 143.888 & 1.408 \\
\hline & ULS-19 & 6 & 0.55 & 0.55 & 19 & 411.95 & 146.935 & 1.129 \\
\hline & FLS-20 & 6 & 0.55 & 1 & 19 & 411.95 & 118.858 & 5.482 \\
\hline & FLS-21 & 6 & 0.55 & 1 & 19 & 411.95 & 132.392 & 6.106 \\
\hline & FLS-22 & 6 & 0.55 & 1 & 19 & 411.95 & 130.647 & 6.026 \\
\hline \multirow{22}{*}{$\begin{array}{c}\text { 20 Box Girders } \\
\text { 24.686m Bridge Width }\end{array}$} & ULS-1 & 6 & 0.55 & 1 & 20 & 411.95 & 119.705 & 1.761 \\
\hline & ULS-2 & 6 & 0.55 & 0.9 & 20 & 411.95 & 131.111 & 1.736 \\
\hline & ULS-3 & 6 & 0.55 & 0.8 & 20 & 411.95 & 137.811 & 1.622 \\
\hline & ULS-4 & 6 & 0.55 & 0.7 & 20 & 411.95 & 142.727 & 1.470 \\
\hline & ULS-5 & 6 & 0.55 & 0.6 & 20 & 411.95 & 142.878 & 1.261 \\
\hline & ULS-6 & 6 & 0.55 & 0.55 & 20 & 411.95 & 142.878 & 1.156 \\
\hline & ULS-7 & 6 & 0.55 & 0.9 & 20 & 411.95 & 132.683 & 1.757 \\
\hline & ULS-8 & 6 & 0.55 & 0.9 & 20 & 411.95 & 138.590 & 1.835 \\
\hline & ULS-9 & 6 & 0.55 & 0.9 & 20 & 411.95 & 143.936 & 1.906 \\
\hline & ULS-10 & 6 & 0.55 & 0.8 & 20 & 411.95 & 139.383 & 1.640 \\
\hline & ULS-11 & 6 & 0.55 & 0.7 & 20 & 411.95 & 142.839 & 1.471 \\
\hline & ULS-12 & 6 & 0.55 & 0.6 & 20 & 411.95 & 142.990 & 1.262 \\
\hline & ULS-13 & 6 & 0.55 & 0.55 & 20 & 411.95 & 142.990 & 1.157 \\
\hline & ULS-14 & 6 & 0.55 & 0.8 & 20 & 411.95 & 141.736 & 1.668 \\
\hline & ULS-15 & 6 & 0.55 & 0.7 & 20 & 411.95 & 143.325 & 1.476 \\
\hline & ULS-16 & 6 & 0.55 & 0.6 & 20 & 411.95 & 143.477 & 1.266 \\
\hline & ULS-17 & 6 & 0.55 & 0.55 & 20 & 411.95 & 143.477 & 1.161 \\
\hline & ULS-18 & 6 & 0.55 & 0.7 & 20 & 411.95 & 146.794 & 1.512 \\
\hline & ULS-19 & 6 & 0.55 & 0.55 & 20 & 411.95 & 148.251 & 1.200 \\
\hline & FLS-20 & 6 & 0.55 & 1 & 20 & 411.95 & 129.510 & 6.288 \\
\hline & FLS-21 & 6 & 0.55 & 1 & 20 & 411.95 & 125.923 & 6.114 \\
\hline & FLS-22 & 6 & 0.55 & 1 & 20 & 411.95 & 115.889 & 5.626 \\
\hline
\end{tabular}




\begin{tabular}{|c|c|c|c|c|c|c|c|c|}
\hline \multicolumn{9}{|c|}{ Six Lane Bridge: B1000, 32 m Span Length } \\
\hline Bridge Configurations & Load cases & $\mathbf{n}$ & $\mathbf{R}_{\mathbf{L}}$ & $\mathbf{R}_{\mathbf{L}}^{\prime}$ & $\mathbf{N}$ & $\begin{array}{c}\left(\mathbf{R}_{\text {straight }}\right)_{\text {truck }} \\
(\mathbf{k N})\end{array}$ & $\begin{array}{l}\mathbf{R}_{\mathbf{F E}} \\
(\mathbf{k N})\end{array}$ & $\left(\mathbf{F}_{\mathbf{v}}\right)_{\mathrm{FE}}$ \\
\hline \multirow{22}{*}{$\begin{array}{c}18 \text { Box Girders } \\
22.216 \mathrm{~m} \text { Bridge Width }\end{array}$} & ULS-1 & 6 & 0.55 & 1 & 18 & 458.40 & 118.184 & 1.406 \\
\hline & ULS-2 & 6 & 0.55 & 0.9 & 18 & 458.40 & 133.932 & 1.434 \\
\hline & ULS-3 & 6 & 0.55 & 0.8 & 18 & 458.40 & 145.584 & 1.386 \\
\hline & ULS-4 & 6 & 0.55 & 0.7 & 18 & 458.40 & 151.791 & 1.264 \\
\hline & ULS-5 & 6 & 0.55 & 0.6 & 18 & 458.40 & 155.272 & 1.109 \\
\hline & ULS-6 & 6 & 0.55 & 0.55 & 18 & 458.40 & 155.272 & 1.016 \\
\hline & ULS-7 & 6 & 0.55 & 0.9 & 18 & 458.40 & 147.948 & 1.584 \\
\hline & ULS-8 & 6 & 0.55 & 0.9 & 18 & 458.40 & 146.056 & 1.564 \\
\hline & ULS-9 & 6 & 0.55 & 0.9 & 18 & 458.40 & 148.138 & 1.586 \\
\hline & ULS-10 & 6 & 0.55 & 0.8 & 18 & 458.40 & 150.147 & 1.429 \\
\hline & ULS-11 & 6 & 0.55 & 0.7 & 18 & 458.40 & 151.904 & 1.265 \\
\hline & ULS-12 & 6 & 0.55 & 0.6 & 18 & 458.40 & 155.384 & 1.109 \\
\hline & ULS-13 & 6 & 0.55 & 0.55 & 18 & 458.40 & 155.272 & 1.016 \\
\hline & ULS-14 & 6 & 0.55 & 0.8 & 18 & 458.40 & 150.498 & 1.433 \\
\hline & ULS-15 & 6 & 0.55 & 0.7 & 18 & 458.40 & 154.195 & 1.284 \\
\hline & ULS-16 & 6 & 0.55 & 0.6 & 18 & 458.40 & 155.930 & 1.113 \\
\hline & ULS-17 & 6 & 0.55 & 0.55 & 18 & 458.40 & 156.900 & 1.027 \\
\hline & ULS-18 & 6 & 0.55 & 0.7 & 18 & 458.40 & 156.720 & 1.305 \\
\hline & ULS-19 & 6 & 0.55 & 0.55 & 18 & 458.40 & 159.819 & 1.046 \\
\hline & FLS-20 & 6 & 0.55 & 1 & 18 & 458.40 & 134.075 & 5.265 \\
\hline & FLS-21 & 6 & 0.55 & 1 & 18 & 458.40 & 130.767 & 5.135 \\
\hline & FLS-22 & 6 & 0.55 & 1 & 18 & 458.40 & 116.902 & 4.590 \\
\hline \multirow{22}{*}{$\begin{array}{c}19 \text { Box Girders } \\
\text { 23.450m Bridge Width }\end{array}$} & ULS-1 & 6 & 0.55 & 1 & 19 & 458.40 & 118.138 & 1.484 \\
\hline & ULS-2 & 6 & 0.55 & 0.9 & 19 & 458.40 & 132.58 & 1.499 \\
\hline & ULS-3 & 6 & 0.55 & 0.8 & 19 & 458.40 & 137.694 & 1.384 \\
\hline & ULS-4 & 6 & 0.55 & 0.7 & 19 & 458.40 & 141.584 & 1.245 \\
\hline & ULS-5 & 6 & 0.55 & 0.6 & 19 & 458.40 & 146.877 & 1.107 \\
\hline & ULS-6 & 6 & 0.55 & 0.55 & 19 & 458.40 & 152.041 & 1.050 \\
\hline & ULS-7 & 6 & 0.55 & 0.9 & 19 & 458.40 & 143.139 & 1.618 \\
\hline & ULS-8 & 6 & 0.55 & 0.9 & 19 & 458.40 & 139.213 & 1.574 \\
\hline & ULS-9 & 6 & 0.55 & 0.9 & 19 & 458.40 & 136.896 & 1.547 \\
\hline & ULS-10 & 6 & 0.55 & 0.8 & 19 & 458.40 & 145.011 & 1.457 \\
\hline & ULS-11 & 6 & 0.55 & 0.7 & 19 & 458.40 & 145.502 & 1.279 \\
\hline & ULS-12 & 6 & 0.55 & 0.6 & 19 & 458.40 & 146.877 & 1.107 \\
\hline & ULS-13 & 6 & 0.55 & 0.55 & 19 & 458.40 & 152.041 & 1.050 \\
\hline & ULS-14 & 6 & 0.55 & 0.8 & 19 & 458.40 & 154.230 & 1.550 \\
\hline & ULS-15 & 6 & 0.55 & 0.7 & 19 & 458.40 & 154.230 & 1.356 \\
\hline & ULS-16 & 6 & 0.55 & 0.6 & 19 & 458.40 & 154.230 & 1.162 \\
\hline & ULS-17 & 6 & 0.55 & 0.55 & 19 & 458.40 & 154.230 & 1.065 \\
\hline & ULS-18 & 6 & 0.55 & 0.7 & 19 & 458.40 & 150.672 & 1.325 \\
\hline & ULS-19 & 6 & 0.55 & 0.55 & 19 & 458.40 & 155.837 & 1.077 \\
\hline & FLS-20 & 6 & 0.55 & 1 & 19 & 458.40 & 119.645 & 4.959 \\
\hline & FLS-21 & 6 & 0.55 & 1 & 19 & 458.40 & 130.970 & 5.429 \\
\hline & FLS-22 & 6 & 0.55 & 1 & 19 & 458.40 & 131.569 & 5.453 \\
\hline \multirow{22}{*}{$\begin{array}{c}\text { 20 Box Girders } \\
\text { 24.686m Bridge Width }\end{array}$} & ULS-1 & 6 & 0.55 & 1 & 20 & 458.40 & 118.105 & 1.561 \\
\hline & ULS-2 & 6 & 0.55 & 0.9 & 20 & 458.40 & 131.425 & 1.564 \\
\hline & ULS-3 & 6 & 0.55 & 0.8 & 20 & 458.40 & 146.017 & 1.544 \\
\hline & ULS-4 & 6 & 0.55 & 0.7 & 20 & 458.40 & 149.671 & 1.385 \\
\hline & ULS-5 & 6 & 0.55 & 0.6 & 20 & 458.40 & 150.532 & 1.194 \\
\hline & ULS-6 & 6 & 0.55 & 0.55 & 20 & 458.40 & 150.532 & 1.095 \\
\hline & ULS-7 & 6 & 0.55 & 0.9 & 20 & 458.40 & 135.551 & 1.613 \\
\hline & ULS-8 & 6 & 0.55 & 0.9 & 20 & 458.40 & 146.440 & 1.743 \\
\hline & ULS-9 & 6 & 0.55 & 0.9 & 20 & 458.40 & 148.211 & 1.764 \\
\hline & ULS-10 & 6 & 0.55 & 0.8 & 20 & 458.40 & 146.650 & 1.551 \\
\hline & ULS-11 & 6 & 0.55 & 0.7 & 20 & 458.40 & 150.304 & 1.391 \\
\hline & ULS-12 & 6 & 0.55 & 0.6 & 20 & 458.40 & 150.750 & 1.196 \\
\hline & ULS-13 & 6 & 0.55 & 0.55 & 20 & 458.40 & 152.085 & 1.106 \\
\hline & ULS-14 & 6 & 0.55 & 0.8 & 20 & 458.40 & 151.842 & 1.606 \\
\hline & ULS-15 & 6 & 0.55 & 0.7 & 20 & 458.40 & 155.496 & 1.439 \\
\hline & ULS-16 & 6 & 0.55 & 0.6 & 20 & 458.40 & 155.496 & 1.234 \\
\hline & ULS-17 & 6 & 0.55 & 0.55 & 20 & 458.40 & 155.496 & 1.131 \\
\hline & ULS-18 & 6 & 0.55 & 0.7 & 20 & 458.40 & 154.819 & 1.433 \\
\hline & ULS-19 & 6 & 0.55 & 0.55 & 20 & 458.40 & 157.560 & 1.146 \\
\hline & FLS-20 & 6 & 0.55 & 1 & 20 & 458.40 & 130.107 & 5.677 \\
\hline & FLS-21 & 6 & 0.55 & 1 & 20 & 458.40 & 126.188 & 5.506 \\
\hline & FLS-22 & 6 & 0.55 & 1 & 20 & 458.40 & 116.590 & 5.087 \\
\hline
\end{tabular}


Table A. 18: Six-Lane Bridge Deflection Distribution Factors $\left(F_{d}\right)$ at Fatigue Limit States

\begin{tabular}{|c|c|c|c|c|c|c|c|c|}
\hline \multicolumn{9}{|c|}{ Six Lane Bridge: B700, $10 \mathrm{~m}$ Span Length } \\
\hline Bridge Configurations & Load cases & n & $\mathbf{R}_{\mathbf{L}}$ & $\mathbf{R}_{\mathbf{L}}^{\prime}$ & $\mathbf{N}$ & $\begin{array}{c}\left(\Delta_{\text {straight }}\right)_{\text {truck }} \\
(\mathbf{m m})\end{array}$ & $\begin{array}{c}\Delta_{\text {FE. }} \\
(\mathbf{m m})\end{array}$ & $\left(\mathbf{F}_{\mathbf{d}}\right)_{\mathrm{FE}}$ \\
\hline \multirow{3}{*}{$\begin{array}{c}18 \text { Box Girders } \\
\text { 22.216m Bridge Width }\end{array}$} & FLS-20 & 6 & 0.55 & 1 & 18 & 6.967 & 1.557 & 4.023 \\
\hline & FLS-21 & 6 & 0.55 & 1 & 18 & 6.967 & 1.294 & 3.343 \\
\hline & FLS-22 & 6 & 0.55 & 1 & 18 & 6.967 & 1.226 & 3.168 \\
\hline \multirow{3}{*}{$\begin{array}{l}19 \text { Box Girders } \\
\text { 23.450m Bridge Width }\end{array}$} & FLS-20 & 6 & 0.55 & 1 & 19 & 6.967 & 1.478 & 4.031 \\
\hline & FLS-21 & 6 & 0.55 & 1 & 19 & 6.967 & 1.274 & 3.474 \\
\hline & FLS-22 & 6 & 0.55 & 1 & 19 & 6.967 & 1.271 & 3.466 \\
\hline \multirow{3}{*}{$\begin{array}{c}20 \text { Box Girders } \\
\text { 24.686m Bridge Width }\end{array}$} & FLS-20 & 6 & 0.55 & 1 & 20 & 6.967 & 1.409 & 4.045 \\
\hline & FLS-21 & 6 & 0.55 & 1 & 20 & 6.967 & 1.264 & 3.629 \\
\hline & FLS-22 & 6 & 0.55 & 1 & 20 & 6.967 & 1.213 & 3.482 \\
\hline
\end{tabular}

\begin{tabular}{|c|c|c|c|c|c|c|c|c|}
\hline \multicolumn{9}{|c|}{ Six Lane Bridge: B800, 20 m Span Length } \\
\hline Bridge Configurations & Load cases & $\mathbf{n}$ & $\mathbf{R}_{\mathbf{L}}$ & $\mathbf{R}_{\mathbf{L}}^{\prime}$ & $\mathbf{N}$ & $\begin{array}{c}\left(\Delta_{\text {straight }}\right)_{\text {truck }} \\
(\mathbf{m m})\end{array}$ & $\begin{array}{c}\Delta_{\mathrm{FE}} \\
(\mathbf{m m})\end{array}$ & $\left(\mathbf{F}_{\mathbf{d}}\right)_{\mathrm{FE}}$ \\
\hline \multirow{3}{*}{$\begin{array}{c}18 \text { Box Girders } \\
\text { 22.216m Bridge Width }\end{array}$} & FLS-20 & 6 & 0.55 & 1 & 18 & 40.859 & 7.588 & 3.343 \\
\hline & FLS-21 & 6 & 0.55 & 1 & 18 & 40.859 & 5.635 & 2.482 \\
\hline & FLS-22 & 6 & 0.55 & 1 & 18 & 40.859 & 5.094 & 2.244 \\
\hline \multirow{3}{*}{$\begin{array}{c}19 \text { Box Girders } \\
\text { 23.450m Bridge Width }\end{array}$} & FLS-20 & 6 & 0.55 & 1 & 19 & 40.859 & 7.175 & 3.336 \\
\hline & FLS-21 & 6 & 0.55 & 1 & 19 & 40.859 & 5.531 & 2.572 \\
\hline & FLS-22 & 6 & 0.55 & 1 & 19 & 40.859 & 5.102 & 2.373 \\
\hline \multirow{3}{*}{$\begin{array}{c}20 \text { Box Girders } \\
\text { 24.686m Bridge Width }\end{array}$} & FLS-20 & 6 & 0.55 & 1 & 20 & 40.859 & 6.825 & 3.341 \\
\hline & FLS-21 & 6 & 0.55 & 1 & 20 & 40.859 & 5.035 & 2.465 \\
\hline & FLS-22 & 6 & 0.55 & 1 & 20 & 40.859 & 4.973 & 2.434 \\
\hline
\end{tabular}

\begin{tabular}{|c|c|c|c|c|c|c|c|c|}
\hline \multicolumn{9}{|c|}{ Six Lane Bridge: B1000, 32 m Span Length } \\
\hline Bridge Configurations & Load cases & $\mathbf{n}$ & $\mathbf{R}_{\mathrm{L}}$ & $\mathbf{R}_{\mathbf{L}}^{\prime}$ & $\mathbf{N}$ & $\begin{array}{c}\left(\Delta_{\text {straight }}\right)_{\text {truck }} \\
(\mathbf{m m})\end{array}$ & $\begin{array}{l}\Delta_{\mathrm{FE}} \\
(\mathbf{m m})\end{array}$ & $\left(\mathbf{F}_{\mathbf{d}}\right)_{\mathrm{FE}}$ \\
\hline \multirow{3}{*}{$\begin{array}{c}18 \text { Box Girders } \\
\text { 22.216m Bridge Width }\end{array}$} & FLS-20 & 6 & 0.55 & 1 & 18 & 159.157 & 17.431 & 1.971 \\
\hline & FLS-21 & 6 & 0.55 & 1 & 18 & 159.157 & 13.105 & 1.482 \\
\hline & FLS-22 & 6 & 0.55 & 1 & 18 & 159.157 & 11.659 & 1.319 \\
\hline \multirow{3}{*}{$\begin{array}{l}19 \text { Box Girders } \\
\text { 23.450m Bridge Width }\end{array}$} & FLS-20 & 6 & 0.55 & 1 & 19 & 159.157 & 16.657 & 1.988 \\
\hline & FLS-21 & 6 & 0.55 & 1 & 19 & 159.157 & 12.709 & 1.517 \\
\hline & FLS-22 & 6 & 0.55 & 1 & 19 & 159.157 & 11.447 & 1.367 \\
\hline \multirow{3}{*}{$\begin{array}{c}\text { 20 Box Girders } \\
\text { 24.686m Bridge Width }\end{array}$} & FLS-20 & 6 & 0.55 & 1 & 20 & 159.157 & 15.866 & 1.994 \\
\hline & FLS-21 & 6 & 0.55 & 1 & 20 & 159.157 & 12.255 & 1.540 \\
\hline & FLS-22 & 6 & 0.55 & 1 & 20 & 159.157 & 11.119 & 1.397 \\
\hline
\end{tabular}


Table A. 19: One-Lane Bridge Transverse Shear $\left(V_{y}\right)$ at Serviceability, Ultimate and Fatigue Limit States

\begin{tabular}{|c|c|c|c|c|c|c|c|c|}
\hline \multicolumn{9}{|c|}{ One Lane Bridge: B700, $10 \mathrm{~m}$ Span Length } \\
\hline Bridge Configurations & Load cases & $\mathbf{n}$ & $\mathbf{R}_{\mathbf{L}}$ & $\mathbf{R}_{\mathbf{L}}^{\prime}$ & $\mathbf{N}$ & $\begin{array}{c}\mathbf{D}_{\mathbf{x}} \\
(\mathbf{k N} / \mathbf{m})\end{array}$ & $\begin{array}{c}D_{x y} \\
(k N / m)\end{array}$ & $\begin{array}{l}\left(\mathrm{V}_{\mathbf{y}}\right)_{\mathrm{FE}} \\
(\mathrm{kN} / \mathbf{m})\end{array}$ \\
\hline \multirow{3}{*}{$\begin{array}{c}4 \text { Box Girders } \\
\text { 3.926m Deck Width }\end{array}$} & ULS-1 & 1 & 1 & 1 & 4 & 700232.60 & 578668.43 & 54.24 \\
\hline & ULS-2 & 1 & 1 & 1 & 4 & 700232.60 & 578668.43 & 17.74 \\
\hline & FLS-3 & 1 & 1 & 1 & 4 & 700232.60 & 578668.43 & 17.74 \\
\hline \multirow{3}{*}{$\begin{array}{c}5 \text { Box Girders } \\
\text { 5.160m Deck Width }\end{array}$} & ULS-1 & 1 & 1 & 1 & 5 & 700232.60 & 578668.43 & 56.94 \\
\hline & ULS-2 & 1 & 1 & 1 & 5 & 700232.60 & 578668.43 & 42.00 \\
\hline & FLS-3 & 1 & 1 & 1 & 5 & 700232.60 & 578668.43 & 42.00 \\
\hline
\end{tabular}

\begin{tabular}{ccccccccccc}
\hline \multicolumn{1}{c}{ One Lane Bridge: B800, 20 m Span Length } \\
\hline Bridge Configurations & Load cases & $\mathbf{n}$ & $\mathbf{R}_{\mathbf{L}}$ & $\mathbf{R}_{\mathbf{L}}^{\prime}$ & $\mathbf{N}$ & $\begin{array}{c}\mathbf{D}_{\mathbf{x}} \\
(\mathbf{k N} / \mathbf{m})\end{array}$ & $\begin{array}{c}\mathbf{D}_{\mathbf{x y}} \\
(\mathbf{k N} / \mathbf{m})\end{array}$ & $\begin{array}{c}\left(\mathbf{V}_{\mathbf{y}}\right)_{\mathbf{F E}} \\
(\mathbf{k N} / \mathbf{m})\end{array}$ \\
\hline \multirow{2}{*}{ 4 Box Girders } & ULS-1 & 1 & 1 & 1 & 4 & 999838.10 & 765503.32 & 53.33 \\
3.926m Deck Width & ULS-2 & 1 & 1 & 1 & 4 & 999838.10 & 765503.32 & 16.46 \\
\hline \multirow{2}{*}{ 5 Box Girders } & FLS-3 & 1 & 1 & 1 & 4 & 999838.10 & 765503.32 & 16.46 \\
\hline 5.160m Deck Width & ULS-1 & 1 & 1 & 1 & 5 & 999838.10 & 765503.32 & 56.82 \\
& ULS-2 & 1 & 1 & 1 & 5 & 999838.10 & 765503.32 & 40.46 \\
\hline & FLS-3 & 1 & 1 & 1 & 5 & 999838.10 & 765503.32 & 40.46 \\
\hline
\end{tabular}

\begin{tabular}{ccccccccccc}
\hline & \multicolumn{7}{c}{ One Lane Bridge: B1000, 32 m Span Length } & & \\
\hline Bridge Configurations & Load cases & $\mathbf{n}$ & $\mathbf{R}_{\mathbf{L}}$ & $\mathbf{R}_{\mathbf{L}}^{\prime}$ & $\mathbf{N}$ & $\begin{array}{c}\mathbf{D}_{\mathbf{x}} \\
(\mathbf{k N} / \mathbf{m})\end{array}$ & $\begin{array}{c}\mathbf{D}_{\mathbf{x y}} \\
(\mathbf{k N} / \mathbf{m})\end{array}$ & $\begin{array}{c}\left(\mathbf{V}_{\mathbf{y}}\right)_{\mathbf{F E}} \\
(\mathbf{k N} / \mathbf{m})\end{array}$ \\
\hline $\begin{array}{c}\text { 4 Box Girders } \\
\text { 3.926m Deck Width }\end{array}$ & ULS-1 & 1 & 1 & 1 & 4 & 1784291.00 & 1175063.31 & 51.18 \\
& ULS-2 & 1 & 1 & 1 & 4 & 1784291.00 & 1175063.31 & 14.32 \\
\cline { 2 - 9 } 5 Box Girders & FLS-3 & 1 & 1 & 1 & 4 & 1784291.00 & 1175063.31 & 14.32 \\
\hline 5.160m Deck Width & ULS-1 & 1 & 1 & 1 & 5 & 1784291.00 & 1175063.31 & 55.03 \\
& ULS-2 & 1 & 1 & 1 & 5 & 1784291.00 & 1175063.31 & 37.58 \\
\hline & FLS-3 & 1 & 1 & 1 & 5 & 1784291.00 & 1175063.31 & 37.58 \\
\hline
\end{tabular}


Table A. 20: Two-Lane Bridge Transverse Shear $\left(V_{y}\right)$ at Serviceability, Ultimate and Fatigue Limit States

\begin{tabular}{|c|c|c|c|c|c|c|c|c|}
\hline \multicolumn{9}{|c|}{ Two Lane Bridge: B700, 10 m Span Length } \\
\hline Bridge Configurations & Load cases & $\mathbf{n}$ & $\mathbf{R}_{\mathbf{L}}$ & $\mathbf{R}_{\mathbf{L}}^{\prime}$ & $\mathbf{N}$ & $\underset{(\mathbf{k N} / \mathbf{m})}{\mathbf{D}_{\mathbf{x}}}$ & $\begin{array}{c}\mathbf{D}_{\mathbf{x y}} \\
(\mathbf{k N} / \mathbf{m})\end{array}$ & $\begin{array}{l}\left(\mathrm{V}_{\mathbf{y}}\right)_{\mathrm{FE}} \\
(\mathrm{kN} / \mathbf{m})\end{array}$ \\
\hline \multirow{4}{*}{$\begin{array}{l}6 \text { Box Girders } \\
6.395 \mathrm{~m} \text { Bridge Width }\end{array}$} & ULS-1 & 2 & 0.9 & 1 & 6 & 700232.60 & 578668.43 & 58.05 \\
\hline & ULS-2 & 2 & 0.9 & 0.9 & 6 & 700232.60 & 578668.43 & 58.09 \\
\hline & ULS-3 & 2 & 0.9 & 0.9 & 6 & 700232.60 & 578668.43 & 61.95 \\
\hline & FLS-4 & 2 & 0.9 & 1 & 6 & 700232.60 & 578668.43 & 61.96 \\
\hline \multirow{4}{*}{$\begin{array}{c}7 \text { Box Girders } \\
\text { 7.630m Bridge Width }\end{array}$} & ULS-1 & 2 & 0.9 & 1 & 7 & 700232.60 & 578668.43 & 58.52 \\
\hline & ULS-2 & 2 & 0.9 & 0.9 & 7 & 700232.60 & 578668.43 & 60.69 \\
\hline & ULS-3 & 2 & 0.9 & 0.9 & 7 & 700232.60 & 578668.43 & 62.34 \\
\hline & FLS-4 & 2 & 0.9 & 1 & 7 & 700232.60 & 578668.43 & 27.66 \\
\hline \multirow{4}{*}{$\begin{array}{c}\text { 8 Box Girders } \\
\text { 8.865m Bridge Width }\end{array}$} & ULS-1 & 2 & 0.9 & 1 & 8 & 700232.60 & 578668.43 & 58.72 \\
\hline & ULS-2 & 2 & 0.9 & 0.9 & 8 & 700232.60 & 578668.43 & 58.73 \\
\hline & ULS-3 & 2 & 0.9 & 0.9 & 8 & 700232.60 & 578668.43 & 59.21 \\
\hline & FLS-4 & 2 & 0.9 & 1 & 8 & 700232.60 & 578668.43 & 52.04 \\
\hline
\end{tabular}

\begin{tabular}{|c|c|c|c|c|c|c|c|c|}
\hline \multicolumn{9}{|c|}{ Two Lane Bridge: B700, 13 m Span Length } \\
\hline Bridge Configurations & Load cases & $\mathbf{n}$ & $\mathbf{R}_{\mathbf{L}}$ & $\mathbf{R}_{\mathbf{L}}^{\prime}$ & $\mathbf{N}$ & $\begin{array}{c}\mathbf{D}_{\mathbf{x}} \\
(\mathbf{k N} / \mathbf{m})\end{array}$ & $\begin{array}{c}\mathbf{D}_{\mathbf{x y}} \\
(\mathbf{k N} / \mathbf{m})\end{array}$ & $\begin{array}{l}\left(\mathbf{V}_{\mathbf{y}}\right)_{\mathrm{FE}} \\
(\mathbf{k N} / \mathbf{m})\end{array}$ \\
\hline \multirow{4}{*}{$\begin{array}{c}6 \text { Box Girders } \\
\text { 6.395m Bridge Width }\end{array}$} & ULS-1 & 2 & 0.9 & 1 & 6 & 700232.60 & 578668.43 & 58.88 \\
\hline & ULS-2 & 2 & 0.9 & 0.9 & 6 & 700232.60 & 578668.43 & 58.88 \\
\hline & ULS-3 & 2 & 0.9 & 0.9 & 6 & 700232.60 & 578668.43 & 62.70 \\
\hline & FLS-4 & 2 & 0.9 & 1 & 6 & 700232.60 & 578668.43 & 62.70 \\
\hline \multirow{4}{*}{$\begin{array}{c}7 \text { Box Girders } \\
\text { 7.630m Bridge Width }\end{array}$} & ULS-1 & 2 & 0.9 & 1 & 7 & 700232.60 & 578668.43 & 59.60 \\
\hline & ULS-2 & 2 & 0.9 & 0.9 & 7 & 700232.60 & 578668.43 & 61.27 \\
\hline & ULS-3 & 2 & 0.9 & 0.9 & 7 & 700232.60 & 578668.43 & 62.76 \\
\hline & FLS-4 & 2 & 0.9 & 1 & 7 & 700232.60 & 578668.43 & 28.72 \\
\hline \multirow{4}{*}{$\begin{array}{c}\text { 8 Box Girders } \\
\text { 8.865m Bridge Width }\end{array}$} & ULS-1 & 2 & 0.9 & 1 & 8 & 700232.60 & 578668.43 & 59.97 \\
\hline & ULS-2 & 2 & 0.9 & 0.9 & 8 & 700232.60 & 578668.43 & 59.97 \\
\hline & ULS-3 & 2 & 0.9 & 0.9 & 8 & 700232.60 & 578668.43 & 60.00 \\
\hline & FLS-4 & 2 & 0.9 & 1 & 8 & 700232.60 & 578668.43 & 52.99 \\
\hline
\end{tabular}


Table A. 21: Three-Lane Bridge Transverse Shear $\left(V_{y}\right)$ at Serviceability, Ultimate and Fatigue Limit States

\begin{tabular}{|c|c|c|c|c|c|c|c|c|}
\hline \multicolumn{9}{|c|}{ Three Lane Bridge: B700, 10 m Span Length } \\
\hline Bridge Configurations & Load cases & $\mathbf{n}$ & $\mathbf{R}_{\mathbf{L}}$ & $\mathbf{R}_{\mathbf{L}}^{\prime}$ & $\mathbf{N}$ & $\begin{array}{c}\mathbf{D}_{\mathbf{x}} \\
(\mathbf{k N} / \mathbf{m})\end{array}$ & $\begin{array}{c}\mathbf{D}_{\mathrm{xy}} \\
(\mathbf{k N} / \mathbf{m})\end{array}$ & $\begin{array}{l}\left(\mathrm{V}_{\mathrm{y}}\right)_{\mathrm{FE}} \\
(\mathrm{kN} / \mathbf{m})\end{array}$ \\
\hline \multirow{7}{*}{$\begin{array}{c}9 \text { Box Girders } \\
\text { 11.10m Bridge Width }\end{array}$} & ULS-1 & 3 & 0.8 & 1 & 9 & 700232.59 & 578668.4 & 58.81 \\
\hline & ULS-2 & 3 & 0.8 & 0.9 & 9 & 700232.59 & 578668.4 & 58.81 \\
\hline & ULS-3 & 3 & 0.8 & 0.8 & 9 & 700232.59 & 578668.4 & 58.81 \\
\hline & ULS-4 & 3 & 0.8 & 0.9 & 9 & 700232.59 & 578668.4 & 43.69 \\
\hline & ULS-5 & 3 & 0.8 & 0.8 & 9 & 700232.59 & 578668.4 & 43.69 \\
\hline & FLS-6 & 3 & 0.8 & 1 & 9 & 700232.59 & 578668.4 & 27.96 \\
\hline & FLS-7 & 3 & 0.8 & 1 & 9 & 700232.59 & 578668.4 & 43.37 \\
\hline \multirow{7}{*}{$\begin{array}{c}10 \text { Box Girders } \\
\text { 12.336m Bridge Width }\end{array}$} & ULS-1 & 3 & 0.8 & 1 & 10 & 700232.59 & 578668.4 & 58.85 \\
\hline & ULS-2 & 3 & 0.8 & 0.9 & 10 & 700232.59 & 578668.4 & 64.92 \\
\hline & ULS-3 & 3 & 0.8 & 0.8 & 10 & 700232.59 & 578668.4 & 64.92 \\
\hline & ULS-4 & 3 & 0.8 & 0.9 & 10 & 700232.59 & 578668.4 & 66.74 \\
\hline & ULS-5 & 3 & 0.8 & 0.8 & 10 & 700232.59 & 578668.4 & 66.74 \\
\hline & FLS-6 & 3 & 0.8 & 1 & 10 & 700232.59 & 578668.4 & 30.42 \\
\hline & FLS-7 & 3 & 0.8 & 1 & 10 & 700232.59 & 578668.4 & 23.08 \\
\hline \multirow{7}{*}{$\begin{array}{l}\text { 11 Box Girders } \\
\text { 13.571m Bridge Width }\end{array}$} & ULS-1 & 3 & 0.8 & 1 & 11 & 700232.59 & 578668.4 & 58.87 \\
\hline & ULS-2 & 3 & 0.8 & 0.9 & 11 & 700232.59 & 578668.4 & 58.87 \\
\hline & ULS-3 & 3 & 0.8 & 0.8 & 11 & 700232.59 & 578668.4 & 58.87 \\
\hline & ULS-4 & 3 & 0.8 & 0.9 & 11 & 700232.59 & 578668.4 & 52.81 \\
\hline & ULS-5 & 3 & 0.8 & 0.8 & 11 & 700232.59 & 578668.4 & 52.81 \\
\hline & FLS-6 & 3 & 0.8 & 1 & 11 & 700232.59 & 578668.4 & 57.81 \\
\hline & FLS-7 & 3 & 0.8 & 1 & 11 & 700232.59 & 578668.4 & 43.52 \\
\hline \multicolumn{9}{|c|}{ Three Lane Bridge: B700, 13 m Span Length } \\
\hline Bridge Configurations & Load cases & $\mathbf{n}$ & $\mathbf{R}_{\mathbf{L}}$ & $\mathbf{R}_{\mathbf{L}}^{\prime}$ & $\mathbf{N}$ & $\begin{array}{c}\mathbf{D}_{\mathbf{x}} \\
(\mathbf{k N} / \mathbf{m})\end{array}$ & $\begin{array}{c}D_{x y} \\
(k N / m)\end{array}$ & $\begin{array}{l}\left(\mathbf{V}_{\mathbf{y}}\right)_{\mathrm{FE}} \\
(\mathbf{k N} / \mathbf{m})\end{array}$ \\
\hline \multirow{7}{*}{$\begin{array}{l}9 \text { Box Girders } \\
\text { 11.10m Bridge Width }\end{array}$} & ULS-1 & 3 & 0.8 & 1 & 9 & 700232.59 & 578668.43 & 60.16 \\
\hline & ULS-2 & 3 & 0.8 & 0.9 & 9 & 700232.59 & 578668.43 & 60.16 \\
\hline & ULS-3 & 3 & 0.8 & 0.8 & 9 & 700232.59 & 578668.43 & 60.16 \\
\hline & ULS-4 & 3 & 0.8 & 0.9 & 9 & 700232.59 & 578668.43 & 45.72 \\
\hline & ULS-5 & 3 & 0.8 & 0.8 & 9 & 700232.59 & 578668.43 & 45.67 \\
\hline & FLS-6 & 3 & 0.8 & 1 & 9 & 700232.59 & 578668.43 & 29.46 \\
\hline & FLS-7 & 3 & 0.8 & 1 & 9 & 700232.59 & 578668.43 & 43.55 \\
\hline \multirow{7}{*}{$\begin{array}{c}10 \text { Box Girders } \\
\text { 12.336m Bridge Width }\end{array}$} & ULS-1 & 3 & 0.8 & 1 & 10 & 700232.59 & 578668.43 & 60.26 \\
\hline & ULS-2 & 3 & 0.8 & 0.9 & 10 & 700232.59 & 578668.43 & 67.22 \\
\hline & ULS-3 & 3 & 0.8 & 0.8 & 10 & 700232.59 & 578668.43 & 67.22 \\
\hline & ULS-4 & 3 & 0.8 & 0.9 & 10 & 700232.59 & 578668.43 & 68.84 \\
\hline & ULS-5 & 3 & 0.8 & 0.8 & 10 & 700232.59 & 578668.43 & 68.84 \\
\hline & FLS-6 & 3 & 0.8 & 1 & 10 & 700232.59 & 578668.43 & 31.95 \\
\hline & FLS-7 & 3 & 0.8 & 1 & 10 & 700232.59 & 578668.43 & 23.47 \\
\hline \multirow{7}{*}{$\begin{array}{l}11 \text { Box Girders } \\
\text { 13.571m Bridge Width }\end{array}$} & ULS-1 & 3 & 0.8 & 1 & 11 & 700232.59 & 578668.43 & 60.31 \\
\hline & ULS-2 & 3 & 0.8 & 0.9 & 11 & 700232.59 & 578668.43 & 60.31 \\
\hline & ULS-3 & 3 & 0.8 & 0.8 & 11 & 700232.59 & 578668.43 & 60.32 \\
\hline & ULS-4 & 3 & 0.8 & 0.9 & 11 & 700232.59 & 578668.43 & 54.12 \\
\hline & ULS-5 & 3 & 0.8 & 0.8 & 11 & 700232.59 & 578668.43 & 54.13 \\
\hline & FLS-6 & 3 & 0.8 & 1 & 11 & 700232.59 & 578668.43 & 59.06 \\
\hline & FLS-7 & 3 & 0.8 & 1 & 11 & 700232.59 & 578668.43 & 43.75 \\
\hline
\end{tabular}


Table A. 22: Four-Lane Bridge Transverse Shear $\left(V_{y}\right)$ at Serviceability, Ultimate and Fatigue Limit States

\begin{tabular}{|c|c|c|c|c|c|c|c|c|}
\hline \multicolumn{9}{|c|}{ Four Lane Bridge: B700, 10 m Span Length } \\
\hline Bridge Configurations & Load cases & $\mathbf{n}$ & $\mathbf{R}_{\mathbf{L}}$ & $\mathbf{R}_{\mathbf{L}}^{\prime}$ & $\mathbf{N}$ & $\begin{array}{c}\mathbf{D}_{\mathbf{x}} \\
(\mathbf{k N} / \mathbf{m})\end{array}$ & $\begin{array}{c}D_{x y} \\
(k N / m)\end{array}$ & $\begin{array}{l}\left(\mathbf{V}_{\mathbf{y}}\right)_{\mathrm{FE}} \\
(\mathbf{k N} / \mathbf{m})\end{array}$ \\
\hline \multirow{13}{*}{$\begin{array}{c}12 \text { Box Girders } \\
\text { 14.805m Bridge Width }\end{array}$} & ULS-1 & 4 & 0.7 & 1 & 12 & 700232.60 & 578668.43 & 58.87 \\
\hline & ULS-2 & 4 & 0.7 & 0.9 & 12 & 700232.60 & 578668.43 & 58.87 \\
\hline & ULS-3 & 4 & 0.7 & 0.8 & 12 & 700232.60 & 578668.43 & 58.87 \\
\hline & ULS-4 & 4 & 0.7 & 0.7 & 12 & 700232.60 & 578668.43 & 58.87 \\
\hline & ULS-5 & 4 & 0.7 & 0.9 & 12 & 700232.60 & 578668.43 & 50.10 \\
\hline & ULS-6 & 4 & 0.7 & 0.9 & 12 & 700232.60 & 578668.43 & 57.60 \\
\hline & ULS-7 & 4 & 0.7 & 0.8 & 12 & 700232.60 & 578668.43 & 50.95 \\
\hline & ULS-8 & 4 & 0.7 & 0.7 & 12 & 700232.60 & 578668.43 & 57.71 \\
\hline & ULS-9 & 4 & 0.7 & 0.7 & 12 & 700232.60 & 578668.43 & 67.22 \\
\hline & ULS-10 & 4 & 0.7 & 0.7 & 12 & 700232.60 & 578668.43 & 67.22 \\
\hline & ULS-11 & 4 & 0.7 & 0.9 & 12 & 700232.60 & 578668.43 & 57.60 \\
\hline & FLS-12 & 4 & 0.7 & 1 & 12 & 700232.60 & 578668.43 & 37.86 \\
\hline & FLS-13 & 4 & 0.7 & 1 & 12 & 700232.60 & 578668.43 & 57.60 \\
\hline \multirow{13}{*}{$\begin{array}{c}13 \text { Box Girders } \\
\text { 16.041m Bridge Width }\end{array}$} & ULS-1 & 4 & 0.7 & 1 & 13 & 700232.60 & 578668.43 & 58.87 \\
\hline & ULS-2 & 4 & 0.7 & 0.9 & 13 & 700232.60 & 578668.43 & 64.65 \\
\hline & ULS-3 & 4 & 0.7 & 0.8 & 13 & 700232.60 & 578668.43 & 66.71 \\
\hline & ULS-4 & 4 & 0.7 & 0.7 & 13 & 700232.60 & 578668.43 & 66.71 \\
\hline & ULS-5 & 4 & 0.7 & 0.9 & 13 & 700232.60 & 578668.43 & 66.42 \\
\hline & ULS-6 & 4 & 0.7 & 0.9 & 13 & 700232.60 & 578668.43 & 66.44 \\
\hline & ULS-7 & 4 & 0.7 & 0.8 & 13 & 700232.60 & 578668.43 & 67.16 \\
\hline & ULS-8 & 4 & 0.7 & 0.7 & 13 & 700232.60 & 578668.43 & 66.43 \\
\hline & ULS-9 & 4 & 0.7 & 0.7 & 13 & 700232.60 & 578668.43 & 64.57 \\
\hline & ULS-10 & 4 & 0.7 & 0.7 & 13 & 700232.60 & 578668.43 & 69.31 \\
\hline & ULS-11 & 4 & 0.7 & 0.9 & 13 & 700232.60 & 578668.43 & 38.90 \\
\hline & FLS-12 & 4 & 0.7 & 1 & 13 & 700232.60 & 578668.43 & 33.25 \\
\hline & FLS-13 & 4 & 0.7 & 1 & 13 & 700232.60 & 578668.43 & 25.34 \\
\hline \multirow{13}{*}{$\begin{array}{c}\text { 14 Box Girders } \\
\text { 17.275m Bridge Width }\end{array}$} & ULS-1 & 4 & 0.7 & 1 & 14 & 700232.60 & 578668.43 & 58.88 \\
\hline & ULS-2 & 4 & 0.7 & 0.9 & 14 & 700232.60 & 578668.43 & 58.88 \\
\hline & ULS-3 & 4 & 0.7 & 0.8 & 14 & 700232.60 & 578668.43 & 58.88 \\
\hline & ULS-4 & 4 & 0.7 & 0.7 & 14 & 700232.60 & 578668.43 & 58.88 \\
\hline & ULS-5 & 4 & 0.7 & 0.9 & 14 & 700232.60 & 578668.43 & 45.66 \\
\hline & ULS-6 & 4 & 0.7 & 0.9 & 14 & 700232.60 & 578668.43 & 57.45 \\
\hline & ULS-7 & 4 & 0.7 & 0.8 & 14 & 700232.60 & 578668.43 & 45.66 \\
\hline & ULS-8 & 4 & 0.7 & 0.7 & 14 & 700232.60 & 578668.43 & 48.83 \\
\hline & ULS-9 & 4 & 0.7 & 0.7 & 14 & 700232.60 & 578668.43 & 65.98 \\
\hline & ULS-10 & 4 & 0.7 & 0.7 & 14 & 700232.60 & 578668.43 & 64.81 \\
\hline & ULS-11 & 4 & 0.7 & 0.9 & 14 & 700232.60 & 578668.43 & 59.30 \\
\hline & FLS-12 & 4 & 0.7 & 1 & 14 & 700232.60 & 578668.43 & 60.62 \\
\hline & FLS-13 & 4 & 0.7 & 1 & 14 & 700232.60 & 578668.43 & 49.98 \\
\hline
\end{tabular}




\begin{tabular}{|c|c|c|c|c|c|c|c|c|}
\hline \multicolumn{9}{|c|}{ Four Lane Bridge: B700, 13 m Span Length } \\
\hline Bridge Configurations & Load cases & $\mathbf{n}$ & $\mathbf{R}_{\mathbf{L}}$ & $\mathbf{R}_{\mathbf{L}}^{\prime}$ & $\mathbf{N}$ & $\begin{array}{c}\mathbf{D}_{\mathbf{x}} \\
(\mathbf{k N} / \mathbf{m})\end{array}$ & $\begin{array}{c}\mathbf{D}_{\mathbf{x y}} \\
(\mathbf{k N} / \mathbf{m})\end{array}$ & $\begin{array}{l}\left(\mathbf{V}_{\mathbf{y}}\right)_{\mathrm{FE}} \\
(\mathbf{k N} / \mathbf{m})\end{array}$ \\
\hline \multirow{13}{*}{$\begin{array}{c}12 \text { Box Girders } \\
14.805 \mathrm{~m} \text { Bridge Width }\end{array}$} & ULS-1 & 4 & 0.7 & 1 & 12 & 700232.59 & 578668.43 & 60.34 \\
\hline & ULS-2 & 4 & 0.7 & 0.9 & 12 & 700232.59 & 578668.43 & 60.34 \\
\hline & ULS-3 & 4 & 0.7 & 0.8 & 12 & 700232.59 & 578668.43 & 60.35 \\
\hline & ULS-4 & 4 & 0.7 & 0.7 & 12 & 700232.59 & 578668.43 & 60.35 \\
\hline & ULS-5 & 4 & 0.7 & 0.9 & 12 & 700232.59 & 578668.43 & 51.41 \\
\hline & ULS-6 & 4 & 0.7 & 0.9 & 12 & 700232.59 & 578668.43 & 58.09 \\
\hline & ULS-7 & 4 & 0.7 & 0.8 & 12 & 700232.59 & 578668.43 & 54.57 \\
\hline & ULS-8 & 4 & 0.7 & 0.7 & 12 & 700232.59 & 578668.43 & 60.10 \\
\hline & ULS-9 & 4 & 0.7 & 0.7 & 12 & 700232.59 & 578668.43 & 69.82 \\
\hline & ULS-10 & 4 & 0.7 & 0.7 & 12 & 700232.59 & 578668.43 & 69.82 \\
\hline & ULS-11 & 4 & 0.7 & 0.9 & 12 & 700232.59 & 578668.43 & 58.09 \\
\hline & FLS-12 & 4 & 0.7 & 1 & 12 & 700232.59 & 578668.43 & 39.37 \\
\hline & FLS-13 & 4 & 0.7 & 1 & 12 & 700232.59 & 578668.43 & 58.09 \\
\hline \multirow{13}{*}{$\begin{array}{c}13 \text { Box Girders } \\
\text { 16.041m Bridge Width }\end{array}$} & ULS-1 & 4 & 0.7 & 1 & 13 & 700232.59 & 578668.43 & 60.36 \\
\hline & ULS-2 & 4 & 0.7 & 0.9 & 13 & 700232.59 & 578668.43 & 67.54 \\
\hline & ULS-3 & 4 & 0.7 & 0.8 & 13 & 700232.59 & 578668.43 & 69.44 \\
\hline & ULS-4 & 4 & 0.7 & 0.7 & 13 & 700232.59 & 578668.43 & 69.44 \\
\hline & ULS-5 & 4 & 0.7 & 0.9 & 13 & 700232.59 & 578668.43 & 69.15 \\
\hline & ULS-6 & 4 & 0.7 & 0.9 & 13 & 700232.59 & 578668.43 & 67.51 \\
\hline & ULS-7 & 4 & 0.7 & 0.8 & 13 & 700232.59 & 578668.43 & 69.92 \\
\hline & ULS-8 & 4 & 0.7 & 0.7 & 13 & 700232.59 & 578668.43 & 69.15 \\
\hline & ULS-9 & 4 & 0.7 & 0.7 & 13 & 700232.59 & 578668.43 & 65.43 \\
\hline & ULS-10 & 4 & 0.7 & 0.7 & 13 & 700232.59 & 578668.43 & 71.91 \\
\hline & ULS-11 & 4 & 0.7 & 0.9 & 13 & 700232.59 & 578668.43 & 42.82 \\
\hline & FLS-12 & 4 & 0.7 & 1 & 13 & 700232.59 & 578668.43 & 34.84 \\
\hline & FLS-13 & 4 & 0.7 & 1 & 13 & 700232.59 & 578668.43 & 26.12 \\
\hline \multirow{13}{*}{$\begin{array}{c}\text { 14 Box Girders } \\
\text { 17.275m Bridge Width }\end{array}$} & ULS-1 & 4 & 0.7 & 1 & 14 & 700232.59 & 578668.43 & 60.37 \\
\hline & ULS-2 & 4 & 0.7 & 0.9 & 14 & 700232.59 & 578668.43 & 60.37 \\
\hline & ULS-3 & 4 & 0.7 & 0.8 & 14 & 700232.59 & 578668.43 & 60.37 \\
\hline & ULS-4 & 4 & 0.7 & 0.7 & 14 & 700232.59 & 578668.43 & 60.37 \\
\hline & ULS-5 & 4 & 0.7 & 0.9 & 14 & 700232.59 & 578668.43 & 47.11 \\
\hline & ULS-6 & 4 & 0.7 & 0.9 & 14 & 700232.59 & 578668.43 & 58.83 \\
\hline & ULS-7 & 4 & 0.7 & 0.8 & 14 & 700232.59 & 578668.43 & 47.11 \\
\hline & ULS-8 & 4 & 0.7 & 0.7 & 14 & 700232.59 & 578668.43 & 49.70 \\
\hline & ULS-9 & 4 & 0.7 & 0.7 & 14 & 700232.59 & 578668.43 & 69.86 \\
\hline & ULS-10 & 4 & 0.7 & 0.7 & 14 & 700232.59 & 578668.43 & 67.16 \\
\hline & ULS-11 & 4 & 0.7 & 0.9 & 14 & 700232.59 & 578668.43 & 59.47 \\
\hline & FLS-12 & 4 & 0.7 & 1 & 14 & 700232.59 & 578668.43 & 61.88 \\
\hline & FLS-13 & 4 & 0.7 & 1 & 14 & 700232.59 & 578668.43 & 50.48 \\
\hline
\end{tabular}


Table A. 23: Five-Lane Bridge Transverse Shear $\left(V_{y}\right)$ at Serviceability, Ultimate and Fatigue Limit States

\begin{tabular}{|c|c|c|c|c|c|c|c|c|}
\hline \multicolumn{9}{|c|}{ Five Lane Bridge: B700, $10 \mathrm{~m}$ Span Length } \\
\hline Bridge Configurations & Load cases & $\mathbf{n}$ & $\mathbf{R}_{\mathbf{L}}$ & $\mathbf{R}_{\mathbf{L}}^{\prime}$ & $\mathbf{N}$ & $\begin{array}{c}\mathbf{D}_{\mathbf{x}} \\
(\mathbf{k N} / \mathbf{m})\end{array}$ & $\begin{array}{c}\mathbf{D}_{\mathrm{xy}} \\
(\mathbf{k N} / \mathbf{m})\end{array}$ & $\begin{array}{l}\left(\mathbf{V}_{\mathbf{y}}\right)_{\mathrm{FE}} \\
(\mathbf{k N} / \mathbf{m})\end{array}$ \\
\hline \multirow{16}{*}{$\begin{array}{l}15 \text { Box Girders } \\
\text { 18.510m Bridge Width }\end{array}$} & ULS-1 & 5 & 0.6 & 1 & 15 & 700232.60 & 578668.43 & 58.87 \\
\hline & ULS-2 & 5 & 0.6 & 0.9 & 15 & 700232.60 & 578668.43 & 58.87 \\
\hline & ULS-3 & 5 & 0.6 & 0.8 & 15 & 700232.60 & 578668.43 & 58.87 \\
\hline & ULS-4 & 5 & 0.6 & 0.7 & 15 & 700232.60 & 578668.43 & 58.87 \\
\hline & ULS-5 & 5 & 0.6 & 0.6 & 15 & 700232.60 & 578668.43 & 141.12 \\
\hline & ULS-6 & 5 & 0.6 & 0.9 & 15 & 700232.60 & 578668.43 & 51.27 \\
\hline & ULS-7 & 5 & 0.6 & 0.9 & 15 & 700232.60 & 578668.43 & 84.51 \\
\hline & ULS-8 & 5 & 0.6 & 0.8 & 15 & 700232.60 & 578668.43 & 51.29 \\
\hline & ULS-9 & 5 & 0.6 & 0.7 & 15 & 700232.60 & 578668.43 & 51.29 \\
\hline & ULS-10 & 5 & 0.6 & 0.6 & 15 & 700232.60 & 578668.43 & 141.14 \\
\hline & ULS-11 & 5 & 0.6 & 0.8 & 15 & 700232.60 & 578668.43 & 94.28 \\
\hline & ULS-12 & 5 & 0.6 & 0.7 & 15 & 700232.60 & 578668.43 & 94.28 \\
\hline & ULS-13 & 5 & 0.6 & 0.6 & 15 & 700232.60 & 578668.43 & 141.25 \\
\hline & FLS-14 & 5 & 0.6 & 1 & 15 & 700232.60 & 578668.43 & 30.18 \\
\hline & FLS-15 & 5 & 0.6 & 1 & 15 & 700232.60 & 578668.43 & 21.02 \\
\hline & FLS-16 & 5 & 0.6 & 1 & 15 & 700232.60 & 578668.43 & 43.61 \\
\hline \multirow{16}{*}{$\begin{array}{l}\text { 16 Box Girders } \\
\text { 19.745m Bridge Width }\end{array}$} & ULS-1 & 5 & 0.6 & 1 & 16 & 700232.60 & 578668.43 & 58.87 \\
\hline & ULS-2 & 5 & 0.6 & 0.9 & 16 & 700232.60 & 578668.43 & 64.20 \\
\hline & ULS-3 & 5 & 0.6 & 0.8 & 16 & 700232.60 & 578668.43 & 66.48 \\
\hline & ULS-4 & 5 & 0.6 & 0.7 & 16 & 700232.60 & 578668.43 & 67.37 \\
\hline & ULS-5 & 5 & 0.6 & 0.6 & 16 & 700232.60 & 578668.43 & 67.37 \\
\hline & ULS-6 & 5 & 0.6 & 0.9 & 16 & 700232.60 & 578668.43 & 65.95 \\
\hline & ULS-7 & 5 & 0.6 & 0.9 & 16 & 700232.60 & 578668.43 & 66.15 \\
\hline & ULS-8 & 5 & 0.6 & 0.8 & 16 & 700232.60 & 578668.43 & 66.93 \\
\hline & ULS-9 & 5 & 0.6 & 0.7 & 16 & 700232.60 & 578668.43 & 67.49 \\
\hline & ULS-10 & 5 & 0.6 & 0.6 & 16 & 700232.60 & 578668.43 & 67.49 \\
\hline & ULS-11 & 5 & 0.6 & 0.8 & 16 & 700232.60 & 578668.43 & 69.06 \\
\hline & ULS-12 & 5 & 0.6 & 0.7 & 16 & 700232.60 & 578668.43 & 69.06 \\
\hline & ULS-13 & 5 & 0.6 & 0.6 & 16 & 700232.60 & 578668.43 & 69.06 \\
\hline & FLS-14 & 5 & 0.6 & 1 & 16 & 700232.60 & 578668.43 & 36.72 \\
\hline & FLS-15 & 5 & 0.6 & 1 & 16 & 700232.60 & 578668.43 & 27.61 \\
\hline & FLS-16 & 5 & 0.6 & 1 & 16 & 700232.60 & 578668.43 & 23.40 \\
\hline \multirow{16}{*}{$\begin{array}{c}17 \text { Box Girders } \\
\text { 20.980m Bridge Width }\end{array}$} & ULS-1 & 5 & 0.6 & 1 & 17 & 700232.60 & 578668.43 & 58.88 \\
\hline & ULS-2 & 5 & 0.6 & 0.9 & 17 & 700232.60 & 578668.43 & 89.06 \\
\hline & ULS-3 & 5 & 0.6 & 0.8 & 17 & 700232.60 & 578668.43 & 89.06 \\
\hline & ULS-4 & 5 & 0.6 & 0.7 & 17 & 700232.60 & 578668.43 & 89.06 \\
\hline & ULS-5 & 5 & 0.6 & 0.6 & 17 & 700232.60 & 578668.43 & 89.06 \\
\hline & ULS-6 & 5 & 0.6 & 0.9 & 17 & 700232.60 & 578668.43 & 91.55 \\
\hline & ULS-7 & 5 & 0.6 & 0.9 & 17 & 700232.60 & 578668.43 & 55.52 \\
\hline & ULS-8 & 5 & 0.6 & 0.8 & 17 & 700232.60 & 578668.43 & 91.55 \\
\hline & ULS-9 & 5 & 0.6 & 0.7 & 17 & 700232.60 & 578668.43 & 91.55 \\
\hline & ULS-10 & 5 & 0.6 & 0.6 & 17 & 700232.60 & 578668.43 & 91.55 \\
\hline & ULS-11 & 5 & 0.6 & 0.8 & 17 & 700232.60 & 578668.43 & 62.74 \\
\hline & ULS-12 & 5 & 0.6 & 0.7 & 17 & 700232.60 & 578668.43 & 62.74 \\
\hline & ULS-13 & 5 & 0.6 & 0.6 & 17 & 700232.60 & 578668.43 & 62.74 \\
\hline & FLS-14 & 5 & 0.6 & 1 & 17 & 700232.60 & 578668.43 & 60.97 \\
\hline & FLS-15 & 5 & 0.6 & 1 & 17 & 700232.60 & 578668.43 & 55.52 \\
\hline & FLS-16 & 5 & 0.6 & 1 & 17 & 700232.60 & 578668.43 & 43.62 \\
\hline
\end{tabular}




\begin{tabular}{|c|c|c|c|c|c|c|c|c|}
\hline \multicolumn{9}{|c|}{ Five Lane Bridge: B800, 20 m Span Length } \\
\hline Bridge Configurations & Load cases & $\mathbf{n}$ & $\mathbf{R}_{\mathbf{L}}$ & $\mathbf{R}_{\mathbf{L}}^{\prime}$ & $\mathbf{N}$ & $\begin{array}{c}\mathbf{D}_{\mathbf{x}} \\
(\mathbf{k N} / \mathbf{m})\end{array}$ & $\begin{array}{c}\mathbf{D}_{\mathrm{xy}} \\
(\mathrm{kN} / \mathbf{m})\end{array}$ & $\begin{array}{l}\left(\mathbf{V}_{\mathbf{y}}\right)_{\mathrm{FE}} \\
(\mathbf{k N} / \mathbf{m})\end{array}$ \\
\hline \multirow{16}{*}{$\begin{array}{c}\text { 15 Box Girders } \\
\text { 18.510m Bridge Width }\end{array}$} & ULS-1 & 5 & 0.6 & 1 & 15 & 999838.10 & 765503.32 & 61.72 \\
\hline & ULS-2 & 5 & 0.6 & 0.9 & 15 & 999838.10 & 765503.32 & 61.72 \\
\hline & ULS-3 & 5 & 0.6 & 0.8 & 15 & 999838.10 & 765503.32 & 61.72 \\
\hline & ULS-4 & 5 & 0.6 & 0.7 & 15 & 999838.10 & 765503.32 & 61.72 \\
\hline & ULS-5 & 5 & 0.6 & 0.6 & 15 & 999838.10 & 765503.32 & 175.3 \\
\hline & ULS-6 & 5 & 0.6 & 0.9 & 15 & 999838.10 & 765503.32 & 58.41 \\
\hline & ULS-7 & 5 & 0.6 & 0.9 & 15 & 999838.10 & 765503.32 & 102.34 \\
\hline & ULS-8 & 5 & 0.6 & 0.8 & 15 & 999838.10 & 765503.32 & 58.41 \\
\hline & ULS-9 & 5 & 0.6 & 0.7 & 15 & 999838.10 & 765503.32 & 58.41 \\
\hline & ULS-10 & 5 & 0.6 & 0.6 & 15 & 999838.10 & 765503.32 & 175.52 \\
\hline & ULS-11 & 5 & 0.6 & 0.8 & 15 & 999838.10 & 765503.32 & 118.35 \\
\hline & ULS-12 & 5 & 0.6 & 0.7 & 15 & 999838.10 & 765503.32 & 118.35 \\
\hline & ULS-13 & 5 & 0.6 & 0.6 & 15 & 999838.10 & 765503.32 & 175.52 \\
\hline & FLS-14 & 5 & 0.6 & 1 & 15 & 999838.10 & 765503.32 & 33.16 \\
\hline & FLS-15 & 5 & 0.6 & 1 & 15 & 999838.10 & 765503.32 & 22.69 \\
\hline & FLS-16 & 5 & 0.6 & 1 & 15 & 999838.10 & 765503.32 & 42.53 \\
\hline \multirow{16}{*}{$\begin{array}{c}16 \text { Box Girders } \\
\text { 19.745m Bridge Width }\end{array}$} & ULS-1 & 5 & 0.6 & 1 & 16 & 999838.10 & 765503.32 & 61.74 \\
\hline & ULS-2 & 5 & 0.6 & 0.9 & 16 & 999838.10 & 765503.32 & 72.01 \\
\hline & ULS-3 & 5 & 0.6 & 0.8 & 16 & 999838.10 & 765503.32 & 75.64 \\
\hline & ULS-4 & 5 & 0.6 & 0.7 & 16 & 999838.10 & 765503.32 & 75.64 \\
\hline & ULS-5 & 5 & 0.6 & 0.6 & 16 & 999838.10 & 765503.32 & 79.00 \\
\hline & ULS-6 & 5 & 0.6 & 0.9 & 16 & 999838.10 & 765503.32 & 73.15 \\
\hline & ULS-7 & 5 & 0.6 & 0.9 & 16 & 999838.10 & 765503.32 & 69.55 \\
\hline & ULS-8 & 5 & 0.6 & 0.8 & 16 & 999838.10 & 765503.32 & 76.10 \\
\hline & ULS-9 & 5 & 0.6 & 0.7 & 16 & 999838.10 & 765503.32 & 76.10 \\
\hline & ULS-10 & 5 & 0.6 & 0.6 & 16 & 999838.10 & 765503.32 & 79.00 \\
\hline & ULS-11 & 5 & 0.6 & 0.8 & 16 & 999838.10 & 765503.32 & 77.65 \\
\hline & ULS-12 & 5 & 0.6 & 0.7 & 16 & 999838.10 & 765503.32 & 77.65 \\
\hline & ULS-13 & 5 & 0.6 & 0.6 & 16 & 999838.10 & 765503.32 & 79.00 \\
\hline & FLS-14 & 5 & 0.6 & 1 & 16 & 999838.10 & 765503.32 & 39.37 \\
\hline & FLS-15 & 5 & 0.6 & 1 & 16 & 999838.10 & 765503.32 & 32.06 \\
\hline & FLS-16 & 5 & 0.6 & 1 & 16 & 999838.10 & 765503.32 & 61.75 \\
\hline \multirow{16}{*}{$\begin{array}{c}17 \text { Box Girders } \\
\text { 20.980m Bridge Width }\end{array}$} & ULS-1 & 5 & 0.6 & 1 & 17 & 999838.10 & 765503.32 & 61.75 \\
\hline & ULS-2 & 5 & 0.6 & 0.9 & 17 & 999838.10 & 765503.32 & 112.52 \\
\hline & ULS-3 & 5 & 0.6 & 0.8 & 17 & 999838.10 & 765503.32 & 112.52 \\
\hline & ULS-4 & 5 & 0.6 & 0.7 & 17 & 999838.10 & 765503.32 & 112.52 \\
\hline & ULS-5 & 5 & 0.6 & 0.6 & 17 & 999838.10 & 765503.32 & 112.53 \\
\hline & ULS-6 & 5 & 0.6 & 0.9 & 17 & 999838.10 & 765503.32 & 114.18 \\
\hline & ULS-7 & 5 & 0.6 & 0.9 & 17 & 999838.10 & 765503.32 & 56.03 \\
\hline & ULS-8 & 5 & 0.6 & 0.8 & 17 & 999838.10 & 765503.32 & 114.18 \\
\hline & ULS-9 & 5 & 0.6 & 0.7 & 17 & 999838.10 & 765503.32 & 114.19 \\
\hline & ULS-10 & 5 & 0.6 & 0.6 & 17 & 999838.10 & 765503.32 & 114.19 \\
\hline & ULS-11 & 5 & 0.6 & 0.8 & 17 & 999838.10 & 765503.32 & 69.36 \\
\hline & ULS-12 & 5 & 0.6 & 0.7 & 17 & 999838.10 & 765503.32 & 69.37 \\
\hline & ULS-13 & 5 & 0.6 & 0.6 & 17 & 999838.10 & 765503.32 & 69.37 \\
\hline & FLS-14 & 5 & 0.6 & 1 & 17 & 999838.10 & 765503.32 & 80.23 \\
\hline & FLS-15 & 5 & 0.6 & 1 & 17 & 999838.10 & 765503.32 & 56.03 \\
\hline & FLS-16 & 5 & 0.6 & 1 & 17 & 999838.10 & 765503.32 & 72.01 \\
\hline
\end{tabular}




\begin{tabular}{|c|c|c|c|c|c|c|c|c|}
\hline \multicolumn{9}{|c|}{ Five Lane Bridge: B1000, 32 m Span Length } \\
\hline Bridge Configurations & Load cases & $\mathbf{n}$ & $\mathbf{R}_{\mathbf{L}}$ & $\mathbf{R}_{\mathbf{L}}^{\prime}$ & $\mathbf{N}$ & $\begin{array}{c}\mathbf{D}_{\mathbf{x}} \\
(\mathbf{k N} / \mathbf{m})\end{array}$ & $\begin{array}{c}\mathbf{D}_{\mathbf{x y}} \\
(\mathbf{k N} / \mathbf{m})\end{array}$ & $\begin{array}{l}\left(\mathrm{V}_{\mathbf{y}}\right)_{\mathrm{FE}} \\
(\mathrm{kN} / \mathbf{m})\end{array}$ \\
\hline \multirow{16}{*}{$\begin{array}{c}15 \text { Box Girders } \\
\text { 18.510m Bridge Width }\end{array}$} & ULS-1 & 5 & 0.6 & 1 & 15 & 1784291.00 & 1175063.31 & 61.61 \\
\hline & ULS-2 & 5 & 0.6 & 0.9 & 15 & 1784291.00 & 1175063.31 & 61.62 \\
\hline & ULS-3 & 5 & 0.6 & 0.8 & 15 & 1784291.00 & 1175063.31 & 61.62 \\
\hline & ULS-4 & 5 & 0.6 & 0.7 & 15 & 1784291.00 & 1175063.31 & 61.62 \\
\hline & ULS-5 & 5 & 0.6 & 0.6 & 15 & 1784291.00 & 1175063.31 & 176.85 \\
\hline & ULS-6 & 5 & 0.6 & 0.9 & 15 & 1784291.00 & 1175063.31 & 60.36 \\
\hline & ULS-7 & 5 & 0.6 & 0.9 & 15 & 1784291.00 & 1175063.31 & 103.97 \\
\hline & ULS-8 & 5 & 0.6 & 0.8 & 15 & 1784291.00 & 1175063.31 & 60.36 \\
\hline & ULS-9 & 5 & 0.6 & 0.7 & 15 & 1784291.00 & 1175063.31 & 60.36 \\
\hline & ULS-10 & 5 & 0.6 & 0.6 & 15 & 1784291.00 & 1175063.31 & 176.85 \\
\hline & ULS-11 & 5 & 0.6 & 0.8 & 15 & 1784291.00 & 1175063.31 & 118.9 \\
\hline & ULS-12 & 5 & 0.6 & 0.7 & 15 & 1784291.00 & 1175063.31 & 118.9 \\
\hline & ULS-13 & 5 & 0.6 & 0.6 & 15 & 1784291.00 & 1175063.31 & 177.05 \\
\hline & FLS-14 & 5 & 0.6 & 1 & 15 & 1784291.00 & 1175063.31 & 33.11 \\
\hline & FLS-15 & 5 & 0.6 & 1 & 15 & 1784291.00 & 1175063.31 & 22.44 \\
\hline & FLS-16 & 5 & 0.6 & 1 & 15 & 1784291.00 & 1175063.31 & 25.75 \\
\hline \multirow{16}{*}{$\begin{array}{c}16 \text { Box Girders } \\
\text { 19.745m Bridge Width }\end{array}$} & ULS-1 & 5 & 0.6 & 1 & 16 & 1784291.00 & 1175063.31 & 61.67 \\
\hline & ULS-2 & 5 & 0.6 & 0.9 & 16 & 1784291.00 & 1175063.31 & 74.87 \\
\hline & ULS-3 & 5 & 0.6 & 0.8 & 16 & 1784291.00 & 1175063.31 & 79.55 \\
\hline & ULS-4 & 5 & 0.6 & 0.7 & 16 & 1784291.00 & 1175063.31 & 79.55 \\
\hline & ULS-5 & 5 & 0.6 & 0.6 & 16 & 1784291.00 & 1175063.31 & 82.45 \\
\hline & ULS-6 & 5 & 0.6 & 0.9 & 16 & 1784291.00 & 1175063.31 & 75.58 \\
\hline & ULS-7 & 5 & 0.6 & 0.9 & 16 & 1784291.00 & 1175063.31 & 69.60 \\
\hline & ULS-8 & 5 & 0.6 & 0.8 & 16 & 1784291.00 & 1175063.31 & 79.92 \\
\hline & ULS-9 & 5 & 0.6 & 0.7 & 16 & 1784291.00 & 1175063.31 & 79.92 \\
\hline & ULS-10 & 5 & 0.6 & 0.6 & 16 & 1784291.00 & 1175063.31 & 82.45 \\
\hline & ULS-11 & 5 & 0.6 & 0.8 & 16 & 1784291.00 & 1175063.31 & 80.99 \\
\hline & ULS-12 & 5 & 0.6 & 0.7 & 16 & 1784291.00 & 1175063.31 & 80.99 \\
\hline & ULS-13 & 5 & 0.6 & 0.6 & 16 & 1784291.00 & 1175063.31 & 82.45 \\
\hline & FLS-14 & 5 & 0.6 & 1 & 16 & 1784291.00 & 1175063.31 & 38.69 \\
\hline & FLS-15 & 5 & 0.6 & 1 & 16 & 1784291.00 & 1175063.31 & 33.83 \\
\hline & FLS-16 & 5 & 0.6 & 1 & 16 & 1784291.00 & 1175063.31 & 24.21 \\
\hline \multirow{16}{*}{$\begin{array}{c}17 \text { Box Girders } \\
\text { 20.980m Bridge Width }\end{array}$} & ULS-1 & 5 & 0.6 & 1 & 17 & 1784291.00 & 1175063.31 & 61.71 \\
\hline & ULS-2 & 5 & 0.6 & 0.9 & 17 & 1784291.00 & 1175063.31 & 113.65 \\
\hline & ULS-3 & 5 & 0.6 & 0.8 & 17 & 1784291.00 & 1175063.31 & 113.65 \\
\hline & ULS-4 & 5 & 0.6 & 0.7 & 17 & 1784291.00 & 1175063.31 & 113.65 \\
\hline & ULS-5 & 5 & 0.6 & 0.6 & 17 & 1784291.00 & 1175063.31 & 113.65 \\
\hline & ULS-6 & 5 & 0.6 & 0.9 & 17 & 1784291.00 & 1175063.31 & 114.66 \\
\hline & ULS-7 & 5 & 0.6 & 0.9 & 17 & 1784291.00 & 1175063.31 & 55.01 \\
\hline & ULS-8 & 5 & 0.6 & 0.8 & 17 & 1784291.00 & 1175063.31 & 114.66 \\
\hline & ULS-9 & 5 & 0.6 & 0.7 & 17 & 1784291.00 & 1175063.31 & 114.67 \\
\hline & ULS-10 & 5 & 0.6 & 0.6 & 17 & 1784291.00 & 1175063.31 & 114.67 \\
\hline & ULS-11 & 5 & 0.6 & 0.8 & 17 & 1784291.00 & 1175063.31 & 71.83 \\
\hline & ULS-12 & 5 & 0.6 & 0.7 & 17 & 1784291.00 & 1175063.31 & 71.83 \\
\hline & ULS-13 & 5 & 0.6 & 0.6 & 17 & 1784291.00 & 1175063.31 & 71.83 \\
\hline & FLS-14 & 5 & 0.6 & 1 & 17 & 1784291.00 & 1175063.31 & 26.420 \\
\hline & FLS-15 & 5 & 0.6 & 1 & 17 & 1784291.00 & 1175063.31 & 20.720 \\
\hline & FLS-16 & 5 & 0.6 & 1 & 17 & 1784291.00 & 1175063.31 & 39.940 \\
\hline
\end{tabular}


Table A. 24: Six-Lane Bridge Transverse Shear $\left(V_{y}\right)$ at Serviceability, Ultimate and Fatigue Limit States

\begin{tabular}{|c|c|c|c|c|c|c|c|c|}
\hline \multicolumn{9}{|c|}{ Six Lane Bridge: B700, 10 m Span Length } \\
\hline Bridge Configurations & Load cases & $\mathbf{n}$ & $\mathbf{R}_{\mathbf{L}}$ & $\mathbf{R}_{\mathbf{L}}^{\prime}$ & $\mathbf{N}$ & $\begin{array}{c}\mathbf{D}_{\mathbf{x}} \\
(\mathbf{k N} / \mathbf{m})\end{array}$ & $\begin{array}{c}\mathbf{D}_{\mathbf{x y}} \\
(\mathbf{k N} / \mathbf{m})\end{array}$ & $\begin{array}{l}\left(\mathbf{V}_{\mathbf{y}}\right)_{\mathbf{F E}} \\
(\mathbf{k N} / \mathbf{m})\end{array}$ \\
\hline \multirow{22}{*}{$\begin{array}{c}18 \text { Box Girders } \\
22.216 \mathrm{~m} \text { Bridge Width }\end{array}$} & ULS-1 & 6 & 0.55 & 1 & 18 & 700232.60 & 578668.43 & 58.88 \\
\hline & ULS-2 & 6 & 0.55 & 0.9 & 18 & 700232.60 & 578668.43 & 58.88 \\
\hline & ULS-3 & 6 & 0.55 & 0.8 & 18 & 700232.60 & 578668.43 & 58.88 \\
\hline & ULS-4 & 6 & 0.55 & 0.7 & 18 & 700232.60 & 578668.43 & 58.88 \\
\hline & ULS-5 & 6 & 0.55 & 0.6 & 18 & 700232.60 & 578668.43 & 58.88 \\
\hline & ULS-6 & 6 & 0.55 & 0.55 & 18 & 700232.60 & 578668.43 & 58.88 \\
\hline & ULS-7 & 6 & 0.55 & 0.9 & 18 & 700232.60 & 578668.43 & 53.19 \\
\hline & ULS-8 & 6 & 0.55 & 0.9 & 18 & 700232.60 & 578668.43 & 133.76 \\
\hline & ULS-9 & 6 & 0.55 & 0.9 & 18 & 700232.60 & 578668.43 & 57.86 \\
\hline & ULS-10 & 6 & 0.55 & 0.8 & 18 & 700232.60 & 578668.43 & 53.19 \\
\hline & ULS-11 & 6 & 0.55 & 0.7 & 18 & 700232.60 & 578668.43 & 53.20 \\
\hline & ULS-12 & 6 & 0.55 & 0.6 & 18 & 700232.60 & 578668.43 & 53.20 \\
\hline & ULS-13 & 6 & 0.55 & 0.55 & 18 & 700232.60 & 578668.43 & 53.20 \\
\hline & ULS-14 & 6 & 0.55 & 0.8 & 18 & 700232.60 & 578668.43 & 143.62 \\
\hline & ULS-15 & 6 & 0.55 & 0.7 & 18 & 700232.60 & 578668.43 & 143.62 \\
\hline & ULS-16 & 6 & 0.55 & 0.6 & 18 & 700232.60 & 578668.43 & 143.62 \\
\hline & ULS-17 & 6 & 0.55 & 0.55 & 18 & 700232.60 & 578668.43 & 143.62 \\
\hline & ULS-18 & 6 & 0.55 & 0.7 & 18 & 700232.60 & 578668.43 & 133.67 \\
\hline & ULS-19 & 6 & 0.55 & 0.55 & 18 & 700232.60 & 578668.43 & 143.62 \\
\hline & FLS-20 & 6 & 0.55 & 1 & 18 & 700232.60 & 578668.43 & 29.16 \\
\hline & FLS-21 & 6 & 0.55 & 1 & 18 & 700232.60 & 578668.43 & 21.61 \\
\hline & FLS-22 & 6 & 0.55 & 1 & 18 & 700232.60 & 578668.43 & 52.73 \\
\hline \multirow{22}{*}{$\begin{array}{c}19 \text { Box Girders } \\
\text { 23.450m Bridge Width }\end{array}$} & ULS-1 & 6 & 0.55 & 1 & 19 & 700232.60 & 578668.43 & 58.87 \\
\hline & ULS-2 & 6 & 0.55 & 0.9 & 19 & 700232.60 & 578668.43 & 63.88 \\
\hline & ULS-3 & 6 & 0.55 & 0.8 & 19 & 700232.60 & 578668.43 & 66.01 \\
\hline & ULS-4 & 6 & 0.55 & 0.7 & 19 & 700232.60 & 578668.43 & 67.35 \\
\hline & ULS-5 & 6 & 0.55 & 0.6 & 19 & 700232.60 & 578668.43 & 67.70 \\
\hline & ULS-6 & 6 & 0.55 & 0.55 & 19 & 700232.60 & 578668.43 & 67.70 \\
\hline & ULS-7 & 6 & 0.55 & 0.9 & 19 & 700232.60 & 578668.43 & 65.61 \\
\hline & ULS-8 & 6 & 0.55 & 0.9 & 19 & 700232.60 & 578668.43 & 65.62 \\
\hline & ULS-9 & 6 & 0.55 & 0.9 & 19 & 700232.60 & 578668.43 & 66.78 \\
\hline & ULS-10 & 6 & 0.55 & 0.8 & 19 & 700232.60 & 578668.43 & 66.46 \\
\hline & ULS-11 & 6 & 0.55 & 0.7 & 19 & 700232.60 & 578668.43 & 67.48 \\
\hline & ULS-12 & 6 & 0.55 & 0.6 & 19 & 700232.60 & 578668.43 & 67.73 \\
\hline & ULS-13 & 6 & 0.55 & 0.55 & 19 & 700232.60 & 578668.43 & 67.73 \\
\hline & ULS-14 & 6 & 0.55 & 0.8 & 19 & 700232.60 & 578668.43 & 63.84 \\
\hline & ULS-15 & 6 & 0.55 & 0.7 & 19 & 700232.60 & 578668.43 & 68.53 \\
\hline & ULS-16 & 6 & 0.55 & 0.6 & 19 & 700232.60 & 578668.43 & 68.53 \\
\hline & ULS-17 & 6 & 0.55 & 0.55 & 19 & 700232.60 & 578668.43 & 68.53 \\
\hline & ULS-18 & 6 & 0.55 & 0.7 & 19 & 700232.60 & 578668.43 & 68.34 \\
\hline & ULS-19 & 6 & 0.55 & 0.55 & 19 & 700232.60 & 578668.43 & 70.18 \\
\hline & FLS-20 & 6 & 0.55 & 1 & 19 & 700232.60 & 578668.43 & 40.97 \\
\hline & FLS-21 & 6 & 0.55 & 1 & 19 & 700232.60 & 578668.43 & 30.5 \\
\hline & FLS-22 & 6 & 0.55 & 1 & 19 & 700232.60 & 578668.43 & 25.14 \\
\hline \multirow{22}{*}{$\begin{array}{c}\text { 20 Box Girders } \\
\text { 24.686m Bridge Width }\end{array}$} & ULS-1 & 6 & 0.55 & 1 & 20 & 700232.60 & 578668.43 & 58.88 \\
\hline & ULS-2 & 6 & 0.55 & 0.9 & 20 & 700232.60 & 578668.43 & 69.84 \\
\hline & ULS-3 & 6 & 0.55 & 0.8 & 20 & 700232.60 & 578668.43 & 69.84 \\
\hline & ULS-4 & 6 & 0.55 & 0.7 & 20 & 700232.60 & 578668.43 & 69.84 \\
\hline & ULS-5 & 6 & 0.55 & 0.6 & 20 & 700232.60 & 578668.43 & 69.86 \\
\hline & ULS-6 & 6 & 0.55 & 0.55 & 20 & 700232.60 & 578668.43 & 69.87 \\
\hline & ULS-7 & 6 & 0.55 & 0.9 & 20 & 700232.60 & 578668.43 & 60.18 \\
\hline & ULS-8 & 6 & 0.55 & 0.9 & 20 & 700232.60 & 578668.43 & 50.52 \\
\hline & ULS-9 & 6 & 0.55 & 0.9 & 20 & 700232.60 & 578668.43 & 57.12 \\
\hline & ULS-10 & 6 & 0.55 & 0.8 & 20 & 700232.60 & 578668.43 & 60.18 \\
\hline & ULS-11 & 6 & 0.55 & 0.7 & 20 & 700232.60 & 578668.43 & 60.18 \\
\hline & ULS-12 & 6 & 0.55 & 0.6 & 20 & 700232.60 & 578668.43 & 60.18 \\
\hline & ULS-13 & 6 & 0.55 & 0.55 & 20 & 700232.60 & 578668.43 & 60.18 \\
\hline & ULS-14 & 6 & 0.55 & 0.8 & 20 & 700232.60 & 578668.43 & 57.63 \\
\hline & ULS-15 & 6 & 0.55 & 0.7 & 20 & 700232.60 & 578668.43 & 57.64 \\
\hline & ULS-16 & 6 & 0.55 & 0.6 & 20 & 700232.60 & 578668.43 & 57.64 \\
\hline & ULS-17 & 6 & 0.55 & 0.55 & 20 & 700232.60 & 578668.43 & 57.64 \\
\hline & ULS-18 & 6 & 0.55 & 0.7 & 20 & 700232.60 & 578668.43 & 64.05 \\
\hline & ULS-19 & 6 & 0.55 & 0.55 & 20 & 700232.60 & 578668.43 & 66.08 \\
\hline & FLS-20 & 6 & 0.55 & 1 & 20 & 700232.60 & 578668.43 & 23.48 \\
\hline & FLS-21 & 6 & 0.55 & 1 & 20 & 700232.60 & 578668.43 & 58.39 \\
\hline & FLS-22 & 6 & 0.55 & 1 & 20 & 700232.60 & 578668.43 & 49.81 \\
\hline
\end{tabular}


Six Lane Bridge: B800, 20 m Span Length

\begin{tabular}{|c|c|c|c|c|c|c|c|c|}
\hline \multicolumn{9}{|c|}{ Six Lane Bridge: B800, 20 m Span Length } \\
\hline Bridge Configurations & Load cases & $\mathbf{n}$ & $\mathbf{R}_{\mathbf{L}}$ & $\mathbf{R}_{\mathbf{L}}^{\prime}$ & $\mathbf{N}$ & $\begin{array}{c}\mathbf{D}_{\mathbf{x}} \\
(\mathbf{k} \mathbf{N} / \mathbf{m})\end{array}$ & $\begin{array}{c}\mathbf{D}_{\mathbf{x y}} \\
(\mathbf{k} \mathbf{N} / \mathbf{m})\end{array}$ & $\begin{array}{l}\left(\mathbf{V}_{\mathbf{y}}\right)_{\mathbf{F E}} \\
(\mathbf{k N} / \mathbf{m})\end{array}$ \\
\hline \multirow{22}{*}{$\begin{array}{c}18 \text { Box Girders } \\
\text { 22.216m Bridge Width }\end{array}$} & ULS-1 & 6 & 0.55 & 1 & 18 & 999838.10 & 765503.32 & 61.76 \\
\hline & ULS-2 & 6 & 0.55 & 0.9 & 18 & 999838.10 & 765503.32 & 61.76 \\
\hline & ULS-3 & 6 & 0.55 & 0.8 & 18 & 999838.10 & 765503.32 & 61.76 \\
\hline & ULS-4 & 6 & 0.55 & 0.7 & 18 & 999838.10 & 765503.32 & 61.76 \\
\hline & ULS-5 & 6 & 0.55 & 0.6 & 18 & 999838.10 & 765503.32 & 61.76 \\
\hline & ULS-6 & 6 & 0.55 & 0.55 & 18 & 999838.10 & 765503.32 & 61.76 \\
\hline & ULS-7 & 6 & 0.55 & 0.9 & 18 & 999838.10 & 765503.32 & 60.58 \\
\hline & ULS-8 & 6 & 0.55 & 0.9 & 18 & 999838.10 & 765503.32 & 163.73 \\
\hline & ULS-9 & 6 & 0.55 & 0.9 & 18 & 999838.10 & 765503.32 & 57.31 \\
\hline & ULS-10 & 6 & 0.55 & 0.8 & 18 & 999838.10 & 765503.32 & 60.58 \\
\hline & ULS-11 & 6 & 0.55 & 0.7 & 18 & 999838.10 & 765503.32 & 60.58 \\
\hline & ULS-12 & 6 & 0.55 & 0.6 & 18 & 999838.10 & 765503.32 & 60.58 \\
\hline & ULS-13 & 6 & 0.55 & 0.55 & 18 & 999838.10 & 765503.32 & 60.58 \\
\hline & ULS-14 & 6 & 0.55 & 0.8 & 18 & 999838.10 & 765503.32 & 179.92 \\
\hline & ULS-15 & 6 & 0.55 & 0.7 & 18 & 999838.10 & 765503.32 & 179.92 \\
\hline & ULS-16 & 6 & 0.55 & 0.6 & 18 & 999838.10 & 765503.32 & 179.92 \\
\hline & ULS-17 & 6 & 0.55 & 0.55 & 18 & 999838.10 & 765503.32 & 179.92 \\
\hline & ULS-18 & 6 & 0.55 & 0.7 & 18 & 999838.10 & 765503.32 & 163.74 \\
\hline & ULS-19 & 6 & 0.55 & 0.55 & 18 & 999838.10 & 765503.32 & 179.92 \\
\hline & FLS-20 & 6 & 0.55 & 1 & 18 & 999838.10 & 765503.32 & 32.30 \\
\hline & FLS-21 & 6 & 0.55 & 1 & 18 & 999838.10 & 765503.32 & 23.38 \\
\hline & FLS-22 & 6 & 0.55 & 1 & 18 & 999838.10 & 765503.32 & 19.40 \\
\hline \multirow{22}{*}{$\begin{array}{c}19 \text { Box Girders } \\
\text { 23.450m Bridge Width }\end{array}$} & ULS-1 & 6 & 0.55 & 1 & 19 & 999838.10 & 765503.32 & 61.76 \\
\hline & ULS-2 & 6 & 0.55 & 0.9 & 19 & 999838.10 & 765503.32 & 71.86 \\
\hline & ULS-3 & 6 & 0.55 & 0.8 & 19 & 999838.10 & 765503.32 & 75.90 \\
\hline & ULS-4 & 6 & 0.55 & 0.7 & 19 & 999838.10 & 765503.32 & 77.32 \\
\hline & ULS-5 & 6 & 0.55 & 0.6 & 19 & 999838.10 & 765503.32 & 77.32 \\
\hline & ULS-6 & 6 & 0.55 & 0.55 & 19 & 999838.10 & 765503.32 & 77.32 \\
\hline & ULS-7 & 6 & 0.55 & 0.9 & 19 & 999838.10 & 765503.32 & 72.99 \\
\hline & ULS-8 & 6 & 0.55 & 0.9 & 19 & 999838.10 & 765503.32 & 69.63 \\
\hline & ULS-9 & 6 & 0.55 & 0.9 & 19 & 999838.10 & 765503.32 & 69.10 \\
\hline & ULS-10 & 6 & 0.55 & 0.8 & 19 & 999838.10 & 765503.32 & 76.37 \\
\hline & ULS-11 & 6 & 0.55 & 0.7 & 19 & 999838.10 & 765503.32 & 77.55 \\
\hline & ULS-12 & 6 & 0.55 & 0.6 & 19 & 999838.10 & 765503.32 & 77.55 \\
\hline & ULS-13 & 6 & 0.55 & 0.55 & 19 & 999838.10 & 765503.32 & 77.55 \\
\hline & ULS-14 & 6 & 0.55 & 0.8 & 19 & 999838.10 & 765503.32 & 77.90 \\
\hline & ULS-15 & 6 & 0.55 & 0.7 & 19 & 999838.10 & 765503.32 & 78.20 \\
\hline & ULS-16 & 6 & 0.55 & 0.6 & 19 & 999838.10 & 765503.32 & 78.20 \\
\hline & ULS-17 & 6 & 0.55 & 0.55 & 19 & 999838.10 & 765503.32 & 78.20 \\
\hline & ULS-18 & 6 & 0.55 & 0.7 & 19 & 999838.10 & 765503.32 & 75.64 \\
\hline & ULS-19 & 6 & 0.55 & 0.55 & 19 & 999838.10 & 765503.32 & 79.86 \\
\hline & FLS-20 & 6 & 0.55 & 1 & 19 & 999838.10 & 765503.32 & 43.58 \\
\hline & FLS-21 & 6 & 0.55 & 1 & 19 & 999838.10 & 765503.32 & 31.18 \\
\hline & FLS-22 & 6 & 0.55 & 1 & 19 & 999838.10 & 765503.32 & 25.04 \\
\hline \multirow{22}{*}{$\begin{array}{c}\text { 20 Box Girders } \\
\text { 24.686m Bridge Width }\end{array}$} & ULS-1 & 6 & 0.55 & 1 & 20 & 999838.10 & 765503.32 & 61.76 \\
\hline & ULS-2 & 6 & 0.55 & 0.9 & 20 & 999838.10 & 765503.32 & 87.39 \\
\hline & ULS-3 & 6 & 0.55 & 0.8 & 20 & 999838.10 & 765503.32 & 87.39 \\
\hline & ULS-4 & 6 & 0.55 & 0.7 & 20 & 999838.10 & 765503.32 & 87.39 \\
\hline & ULS-5 & 6 & 0.55 & 0.6 & 20 & 999838.10 & 765503.32 & 87.39 \\
\hline & ULS-6 & 6 & 0.55 & 0.55 & 20 & 999838.10 & 765503.32 & 87.41 \\
\hline & ULS-7 & 6 & 0.55 & 0.9 & 20 & 999838.10 & 765503.32 & 81.95 \\
\hline & ULS-8 & 6 & 0.55 & 0.9 & 20 & 999838.10 & 765503.32 & 50.98 \\
\hline & ULS-9 & 6 & 0.55 & 0.9 & 20 & 999838.10 & 765503.32 & 57.11 \\
\hline & ULS-10 & 6 & 0.55 & 0.8 & 20 & 999838.10 & 765503.32 & 86.95 \\
\hline & ULS-11 & 6 & 0.55 & 0.7 & 20 & 999838.10 & 765503.32 & 86.95 \\
\hline & ULS-12 & 6 & 0.55 & 0.6 & 20 & 999838.10 & 765503.32 & 86.95 \\
\hline & ULS-13 & 6 & 0.55 & 0.55 & 20 & 999838.10 & 765503.32 & 86.95 \\
\hline & ULS-14 & 6 & 0.55 & 0.8 & 20 & 999838.10 & 765503.32 & 64.32 \\
\hline & ULS-15 & 6 & 0.55 & 0.7 & 20 & 999838.10 & 765503.32 & 64.32 \\
\hline & ULS-16 & 6 & 0.55 & 0.6 & 20 & 999838.10 & 765503.32 & 64.33 \\
\hline & ULS-17 & 6 & 0.55 & 0.55 & 20 & 999838.10 & 765503.32 & 64.33 \\
\hline & ULS-18 & 6 & 0.55 & 0.7 & 20 & 999838.10 & 765503.32 & 68.45 \\
\hline & ULS-19 & 6 & 0.55 & 0.55 & 20 & 999838.10 & 765503.32 & 75.23 \\
\hline & FLS-20 & 6 & 0.55 & 1 & 20 & 999838.10 & 765503.32 & 26.64 \\
\hline & FLS-21 & 6 & 0.55 & 1 & 20 & 999838.10 & 765503.32 & 59.27 \\
\hline & FLS-22 & 6 & 0.55 & 1 & 20 & 999838.10 & 765503.32 & 49.19 \\
\hline
\end{tabular}




\begin{tabular}{|c|c|c|c|c|c|c|c|c|}
\hline \multicolumn{9}{|c|}{ Six Lane Bridge: B1000, 32 m Span Length } \\
\hline Bridge Configurations & Load cases & $\mathbf{n}$ & $\mathbf{R}_{\mathbf{L}}$ & $\mathbf{R}_{\mathbf{L}}^{\prime}$ & $\mathbf{N}$ & $\begin{array}{c}\mathbf{D}_{\mathbf{x}} \\
(\mathbf{k N} / \mathbf{m})\end{array}$ & $\begin{array}{c}\mathbf{D}_{\mathbf{x y}} \\
(\mathbf{k N} / \mathbf{m})\end{array}$ & $\begin{array}{l}\left(\mathbf{V}_{\mathbf{y}}\right)_{\mathbf{F E}} \\
(\mathbf{k N} / \mathbf{m})\end{array}$ \\
\hline \multirow{22}{*}{$\begin{array}{c}18 \text { Box Girders } \\
\text { 22.216m Bridge Width }\end{array}$} & ULS-1 & 6 & 0.55 & 1 & 18 & 1784291.00 & 1175063.31 & 61.74 \\
\hline & ULS-2 & 6 & 0.55 & 0.9 & 18 & 1784291.00 & 1175063.31 & 62.58 \\
\hline & ULS-3 & 6 & 0.55 & 0.8 & 18 & 1784291.00 & 1175063.31 & 62.58 \\
\hline & ULS-4 & 6 & 0.55 & 0.7 & 18 & 1784291.00 & 1175063.31 & 62.58 \\
\hline & ULS-5 & 6 & 0.55 & 0.6 & 18 & 1784291.00 & 1175063.31 & 62.58 \\
\hline & ULS-6 & 6 & 0.55 & 0.55 & 18 & 1784291.00 & 1175063.31 & 62.58 \\
\hline & ULS-7 & 6 & 0.55 & 0.9 & 18 & 1784291.00 & 1175063.31 & 61.06 \\
\hline & ULS-8 & 6 & 0.55 & 0.9 & 18 & 1784291.00 & 1175063.31 & 162.69 \\
\hline & ULS-9 & 6 & 0.55 & 0.9 & 18 & 1784291.00 & 1175063.31 & 57.72 \\
\hline & ULS-10 & 6 & 0.55 & 0.8 & 18 & 1784291.00 & 1175063.31 & 63.06 \\
\hline & ULS-11 & 6 & 0.55 & 0.7 & 18 & 1784291.00 & 1175063.31 & 63.07 \\
\hline & ULS-12 & 6 & 0.55 & 0.6 & 18 & 1784291.00 & 1175063.31 & 63.07 \\
\hline & ULS-13 & 6 & 0.55 & 0.55 & 18 & 1784291.00 & 1175063.31 & 61.83 \\
\hline & ULS-14 & 6 & 0.55 & 0.8 & 18 & 1784291.00 & 1175063.31 & 182.20 \\
\hline & ULS-15 & 6 & 0.55 & 0.7 & 18 & 1784291.00 & 1175063.31 & 182.20 \\
\hline & ULS-16 & 6 & 0.55 & 0.6 & 18 & 1784291.00 & 1175063.31 & 182.20 \\
\hline & ULS-17 & 6 & 0.55 & 0.55 & 18 & 1784291.00 & 1175063.31 & 182.20 \\
\hline & ULS-18 & 6 & 0.55 & 0.7 & 18 & 1784291.00 & 1175063.31 & 162.69 \\
\hline & ULS-19 & 6 & 0.55 & 0.55 & 18 & 1784291.00 & 1175063.31 & 182.20 \\
\hline & FLS-20 & 6 & 0.55 & 1 & 18 & 1784291.00 & 1175063.31 & 32.49 \\
\hline & FLS-21 & 6 & 0.55 & 1 & 18 & 1784291.00 & 1175063.31 & 23.36 \\
\hline & FLS-22 & 6 & 0.55 & 1 & 18 & 1784291.00 & 1175063.31 & 19.06 \\
\hline \multirow{22}{*}{$\begin{array}{c}19 \text { Box Girders } \\
\text { 23.450m Bridge Width }\end{array}$} & ULS-1 & 6 & 0.55 & 1 & 19 & 1784291.00 & 1175063.31 & 61.77 \\
\hline & ULS-2 & 6 & 0.55 & 0.9 & 19 & 1784291.00 & 1175063.31 & 75.13 \\
\hline & ULS-3 & 6 & 0.55 & 0.8 & 19 & 1784291.00 & 1175063.31 & 81.04 \\
\hline & ULS-4 & 6 & 0.55 & 0.7 & 19 & 1784291.00 & 1175063.31 & 82.4 \\
\hline & ULS-5 & 6 & 0.55 & 0.6 & 19 & 1784291.00 & 1175063.31 & 82.4 \\
\hline & ULS-6 & 6 & 0.55 & 0.55 & 19 & 1784291.00 & 1175063.31 & 82.4 \\
\hline & ULS-7 & 6 & 0.55 & 0.9 & 19 & 1784291.00 & 1175063.31 & 75.85 \\
\hline & ULS-8 & 6 & 0.55 & 0.9 & 19 & 1784291.00 & 1175063.31 & 70.53 \\
\hline & ULS-9 & 6 & 0.55 & 0.9 & 19 & 1784291.00 & 1175063.31 & 68.19 \\
\hline & ULS-10 & 6 & 0.55 & 0.8 & 19 & 1784291.00 & 1175063.31 & 81.41 \\
\hline & ULS-11 & 6 & 0.55 & 0.7 & 19 & 1784291.00 & 1175063.31 & 82.6 \\
\hline & ULS-12 & 6 & 0.55 & 0.6 & 19 & 1784291.00 & 1175063.31 & 82.6 \\
\hline & ULS-13 & 6 & 0.55 & 0.55 & 19 & 1784291.00 & 1175063.31 & 82.6 \\
\hline & ULS-14 & 6 & 0.55 & 0.8 & 19 & 1784291.00 & 1175063.31 & 82.5 \\
\hline & ULS-15 & 6 & 0.55 & 0.7 & 19 & 1784291.00 & 1175063.31 & 83.16 \\
\hline & ULS-16 & 6 & 0.55 & 0.6 & 19 & 1784291.00 & 1175063.31 & 83.16 \\
\hline & ULS-17 & 6 & 0.55 & 0.55 & 19 & 1784291.00 & 1175063.31 & 83.16 \\
\hline & ULS-18 & 6 & 0.55 & 0.7 & 19 & 1784291.00 & 1175063.31 & 77.27 \\
\hline & ULS-19 & 6 & 0.55 & 0.55 & 19 & 1784291.00 & 1175063.31 & 84.38 \\
\hline & FLS-20 & 6 & 0.55 & 1 & 19 & 1784291.00 & 1175063.31 & 43.16 \\
\hline & FLS-21 & 6 & 0.55 & 1 & 19 & 1784291.00 & 1175063.31 & 30.18 \\
\hline & FLS-22 & 6 & 0.55 & 1 & 19 & 1784291.00 & 1175063.31 & 23.47 \\
\hline \multirow{22}{*}{$\begin{array}{c}20 \text { Box Girders } \\
\text { 24.686m Bridge Width }\end{array}$} & ULS-1 & 6 & 0.55 & 1 & 20 & 1784291.00 & 1175063.31 & 61.79 \\
\hline & ULS-2 & 6 & 0.55 & 0.9 & 20 & 1784291.00 & 1175063.31 & 88.35 \\
\hline & ULS-3 & 6 & 0.55 & 0.8 & 20 & 1784291.00 & 1175063.31 & 88.35 \\
\hline & ULS-4 & 6 & 0.55 & 0.7 & 20 & 1784291.00 & 1175063.31 & 88.35 \\
\hline & ULS-5 & 6 & 0.55 & 0.6 & 20 & 1784291.00 & 1175063.31 & 88.35 \\
\hline & ULS-6 & 6 & 0.55 & 0.55 & 20 & 1784291.00 & 1175063.31 & 88.37 \\
\hline & ULS-7 & 6 & 0.55 & 0.9 & 20 & 1784291.00 & 1175063.31 & 42.30 \\
\hline & ULS-8 & 6 & 0.55 & 0.9 & 20 & 1784291.00 & 1175063.31 & 49.93 \\
\hline & ULS-9 & 6 & 0.55 & 0.9 & 20 & 1784291.00 & 1175063.31 & 57.68 \\
\hline & ULS-10 & 6 & 0.55 & 0.8 & 20 & 1784291.00 & 1175063.31 & 87.31 \\
\hline & ULS-11 & 6 & 0.55 & 0.7 & 20 & 1784291.00 & 1175063.31 & 87.31 \\
\hline & ULS-12 & 6 & 0.55 & 0.6 & 20 & 1784291.00 & 1175063.31 & 87.31 \\
\hline & ULS-13 & 6 & 0.55 & 0.55 & 20 & 1784291.00 & 1175063.31 & 87.31 \\
\hline & ULS-14 & 6 & 0.55 & 0.8 & 20 & 1784291.00 & 1175063.31 & 66.96 \\
\hline & ULS-15 & 6 & 0.55 & 0.7 & 20 & 1784291.00 & 1175063.31 & 66.96 \\
\hline & ULS-16 & 6 & 0.55 & 0.6 & 20 & 1784291.00 & 1175063.31 & 66.97 \\
\hline & ULS-17 & 6 & 0.55 & 0.55 & 20 & 1784291.00 & 1175063.31 & 66.97 \\
\hline & ULS-18 & 6 & 0.55 & 0.7 & 20 & 1784291.00 & 1175063.31 & 70.14 \\
\hline & ULS-19 & 6 & 0.55 & 0.55 & 20 & 1784291.00 & 1175063.31 & 80.47 \\
\hline & FLS-20 & 6 & 0.55 & 1 & 20 & 1784291.00 & 1175063.31 & 27.21 \\
\hline & FLS-21 & 6 & 0.55 & 1 & 20 & 1784291.00 & 1175063.31 & 59.09 \\
\hline & FLS-22 & 6 & 0.55 & 1 & 20 & 1784291.00 & 1175063.31 & 47.01 \\
\hline
\end{tabular}


Table A. 25: One-Lane Bridge Moment Distribution Factors Comparison at ULS for CHBDC 2014, Alberta 2015, and AASHTO 2012

\begin{tabular}{|c|c|c|c|c|c|c|c|c|c|c|c|c|c|c|c|c|}
\hline \multicolumn{17}{|c|}{ One Lane Bridge Moment Distribution Factors at Ultimate Limit States } \\
\hline \multicolumn{9}{|c|}{ Bridge Configuration } & \multicolumn{2}{|c|}{ CHBDC 2006} & \multicolumn{3}{|c|}{ CHBDC 2014} & \multirow{2}{*}{$\begin{array}{l}\text { Alberta } 2015 \\
\left(\mathrm{~F}_{\mathrm{T}}\right)_{\text {Alberta }}\end{array}$} & \multicolumn{2}{|c|}{ AASHTO 2012} \\
\hline Girder Size & $\mathbf{n}$ & $\mathbf{R}_{\mathbf{L}}$ & $\mathbf{N}$ & $\mathbf{L}(\mathbf{m})$ & B (m) & $\mu$ & $\mathbf{I}\left(\mathbf{m}^{\mathbf{4}}\right)$ & $\mathbf{J}\left(\mathbf{m}^{\mathbf{4}}\right)$ & $\left(\mathbf{F}_{\mathrm{v}}\right)_{\mathrm{FE} .}$ & $\left(\mathbf{F}_{\mathbf{v}}\right)_{\mathrm{EQ}}$. & $\left(F_{T}\right)_{\text {FE. }}$ & $\boldsymbol{\beta}$ & $\left(\mathbf{F}_{\mathrm{T}}\right)_{\mathrm{EQ}}$. & & $\left(\mathbf{F}_{\mathrm{T}}\right)_{\text {AASHTO E }}$ & AASH TO Int. \\
\hline \multirow[t]{2}{*}{ B700 } & 1 & 1 & 4 & 10 & 4.926 & 1.000 & 0.0309 & 0.0613 & 1.396 & 1.315 & 0.349 & 1.702 & - & 0.277 & 0.375 & 0.348 \\
\hline & 1 & 1 & 5 & 10 & 6.160 & 1.000 & 0.0309 & 0.0613 & 1.455 & 1.645 & 0.291 & 2.128 & - & 0.277 & 0.377 & 0.350 \\
\hline \multirow[t]{2}{*}{ B800 } & 1 & 1 & 4 & 20 & 4.926 & 1.000 & 0.0441 & 0.0810 & 1.212 & 1.135 & 0.303 & 0.884 & - & 0.259 & 0.371 & 0.344 \\
\hline & 1 & 1 & 5 & 20 & 6.160 & 1.000 & 0.0441 & 0.0810 & 1.240 & 1.419 & 0.248 & 1.105 & - & 0.259 & 0.372 & 0.345 \\
\hline \multirow[t]{2}{*}{ B1000 } & 1 & 1 & 4 & 32 & 4.926 & 1.000 & 0.0787 & 0.1244 & 1.142 & 1.072 & 0.286 & 0.596 & - & 0.253 & 0.369 & 0.343 \\
\hline & 1 & 1 & 5 & 32 & 6.16 & 1.000 & 0.0787 & 0.1244 & 1.168 & 1.341 & 0.234 & 0.745 & - & 0.253 & 0.370 & 0.344 \\
\hline
\end{tabular}

Table A. 26: One-Lane Bridge Moment Distribution Factors Comparison at FLS for CHBDC 2014, Alberta 2015, and AASHTO 2012

\begin{tabular}{|c|c|c|c|c|c|c|c|c|c|c|c|c|c|c|c|c|}
\hline \multicolumn{17}{|c|}{ One Lane Bridge Momeent Distribution Factors at Fatigue Limit States } \\
\hline \multicolumn{9}{|c|}{ Bridge Configuration } & \multicolumn{2}{|c|}{ CHBDC 2006} & \multicolumn{3}{|c|}{ CHBDC 2014} & \multirow{2}{*}{$\begin{array}{l}\text { Alberta } 2015 \\
\left(F_{T}\right)_{\text {Alberta }}\end{array}$} & \multicolumn{2}{|c|}{ AASHTO 2012} \\
\hline Girder Size & $\mathbf{n}$ & $\mathbf{R}_{\mathbf{L}}$ & $\mathbf{N}$ & $\mathbf{L}(\mathbf{m})$ & B (m) & $\boldsymbol{\mu}$ & $I\left(\mathbf{m}^{4}\right)$ & $\mathbf{J}\left(\mathbf{m}^{\mathbf{4}}\right)$ & $\left(\mathbf{F}_{\mathrm{v}}\right)_{\mathrm{FE} .}$ & $\left(\mathbf{F}_{\mathbf{v}}\right)_{\mathbf{E Q}}$. & $\left(\mathbf{F}_{\mathrm{T}}\right)_{\mathrm{FE}}$. & $\boldsymbol{\beta}$ & $\left(\mathbf{F}_{\mathrm{T}}\right)_{\mathrm{EQ}}$. & & $\left(\mathbf{F}_{\mathrm{T}}\right)_{\text {AASHTO Ext. }}$ & $\left(\mathbf{F}_{\mathrm{T}}\right)_{\text {AASHTO Int. }}$ \\
\hline \multirow[t]{2}{*}{$\mathrm{B} 700$} & 1 & 1 & 4 & 10 & 4.926 & 1.000 & 0.0309 & 0.0613 & 1.396 & 1.267 & 0.349 & 1.702 & 0.157 & 0.277 & 0.375 & 0.348 \\
\hline & 1 & 1 & 5 & 10 & 6.160 & 1.000 & 0.0309 & 0.0613 & 1.398 & 1.585 & 0.280 & 2.128 & 0.166 & 0.277 & 0.377 & 0.350 \\
\hline \multirow[t]{2}{*}{ B800 } & 1 & 1 & 4 & 20 & 4.926 & 1.000 & 0.0441 & 0.0810 & 1.212 & 1.115 & 0.303 & 0.884 & 0.141 & 0.259 & 0.371 & 0.344 \\
\hline & 1 & 1 & 5 & 20 & 6.160 & 1.000 & 0.0441 & 0.0810 & 1.214 & 1.394 & 0.243 & 1.105 & 0.144 & 0.259 & 0.372 & 0.345 \\
\hline \multirow[t]{2}{*}{ B1000 } & 1 & 1 & 4 & 32 & 4.926 & 1.000 & 0.0787 & 0.1244 & 1.142 & 1.061 & 0.286 & 0.596 & 0.136 & 0.253 & 0.369 & 0.343 \\
\hline & 1 & 1 & 5 & 32 & 6.16 & 1.000 & 0.0787 & 0.1244 & 1.145 & 1.326 & 0.229 & 0.745 & 0.138 & 0.253 & 0.370 & 0.344 \\
\hline
\end{tabular}

Table A. 27: One-Lane Bridge Shear Distribution Factors Comparison at ULS for CHBDC 2014, Alberta 2015, and AASHTO 2012

\begin{tabular}{|c|c|c|c|c|c|c|c|c|c|c|c|c|c|c|c|c|}
\hline \multicolumn{17}{|c|}{ One Lane Bridge Shear Distribution Factors at Ultimate Limit States } \\
\hline \multicolumn{9}{|c|}{ Bridge Configuration } & \multicolumn{2}{|c|}{ CHBDC 2006} & \multicolumn{3}{|c|}{ CHBDC 2014} & \multirow{2}{*}{\begin{tabular}{|l|} 
Alberta 2015 \\
$\left(F_{T}\right)_{\text {Alberta }}$ \\
\end{tabular}} & \multicolumn{2}{|c|}{ AASHTO 2012} \\
\hline Girder Size & $\mathbf{n}$ & $\mathbf{R}_{\mathbf{L}}$ & $\mathbf{N}$ & $\mathbf{L}(\mathbf{m})$ & B (m) & $\mu$ & $\mathrm{I}\left(\mathbf{m}^{4}\right)$ & $\mathbf{J}\left(\mathbf{m}^{4}\right)$ & $\left(\mathbf{F}_{\mathrm{v}}\right)_{\mathrm{FE}}$ & $\left(\mathbf{F}_{\mathrm{v}}\right)_{\mathrm{EQ}}$ & $\left(\mathrm{F}_{\mathrm{T}}\right)_{\mathrm{FE}}$ & $\boldsymbol{\beta}$ & $\left(F_{T}\right)_{E Q}$. & & $\left(\mathbf{F}_{\mathrm{T}}\right)_{\text {AASHTO }}$ & Ext. $\left(F_{T}\right)_{\text {AASHTO Int. }}$ \\
\hline \multirow[t]{2}{*}{ B700 } & 1 & 1 & 4 & 10 & 4.926 & 1.000 & 0.0309 & 0.0613 & 1.529 & 1.564 & 0.382 & 1.702 & 0.309 & 0.380 & 0.801 & 0.680 \\
\hline & 1 & 1 & 5 & 10 & 6.160 & 1.000 & 0.0309 & 0.0613 & 1.894 & 1.956 & 0.379 & 2.128 & 0.309 & 0.380 & 0.801 & 0.680 \\
\hline \multirow[t]{2}{*}{ B800 } & 1 & 1 & 4 & 20 & 4.926 & 1.000 & 0.0441 & 0.0810 & 1.268 & 1.388 & 0.317 & 0.884 & 0.309 & 0.339 & 0.727 & 0.617 \\
\hline & 1 & 1 & 5 & 20 & 6.160 & 1.000 & 0.0441 & 0.0810 & 1.491 & 1.735 & 0.298 & 1.105 & 0.309 & 0.339 & 0.727 & 0.617 \\
\hline \multirow[t]{2}{*}{ B1000 } & 1 & 1 & 4 & 32 & 4.926 & 1.000 & 0.0787 & 0.1244 & 1.340 & 1.222 & 0.335 & 0.596 & 0.309 & 0.280 & 0.685 & 0.581 \\
\hline & 1 & 1 & 5 & 32 & 6.16 & 1.000 & 0.0787 & 0.1244 & 1.357 & 1.529 & 0.271 & 0.745 & 0.309 & 0.280 & 0.685 & 0.581 \\
\hline
\end{tabular}

Table A. 28: One-Lane Bridge Shear Distribution Factors Comparison at FLS for CHBDC 2014, Alberta 2015, and AASHTO 2012

\begin{tabular}{|c|c|c|c|c|c|c|c|c|c|c|c|c|c|c|c|c|}
\hline \multicolumn{17}{|c|}{ One Lane Bridge Shear Distribution Factors at Fatigue Limit States } \\
\hline \multicolumn{9}{|c|}{ Bridge Configuration } & \multicolumn{2}{|c|}{ CHBDC 2006} & \multicolumn{3}{|c|}{ CHBDC 2014} & \multirow{2}{*}{\begin{tabular}{|l|} 
Alberta 2015 \\
$\left(\mathrm{~F}_{\mathrm{T}}\right)_{\text {Alberta }}$ \\
\end{tabular}} & \multicolumn{2}{|c|}{ AASHTO 2012 } \\
\hline Girder Size & $\mathbf{n}$ & $\mathbf{R}_{\mathbf{L}}$ & $\mathbf{N}$ & $\mathbf{L}(\mathbf{m})$ & $\mathbf{B}(\mathbf{m})$ & $\mu$ & $I\left(\mathbf{m}^{4}\right)$ & $\mathbf{J}\left(\mathbf{m}^{\mathbf{4}}\right)$ & $\left(\mathbf{F}_{\mathbf{V}}\right)_{\mathbf{F E}}$ & $\left(\mathbf{F}_{\mathbf{v}}\right)_{\mathrm{EQ}}$. & $\left(\mathbf{F}_{\mathrm{T}}\right)_{\mathrm{FE} .}$ & $\boldsymbol{\beta}$ & $\left(\mathbf{F}_{\mathrm{T}}\right)_{\mathrm{EQ}}$. & & $\left(\mathbf{F}_{\mathrm{T}}\right)_{\text {AASHTO Ext. }}$ & $\left(\mathbf{F}_{\mathrm{T}}\right)_{\text {AASHTO Int. }}$ \\
\hline \multirow[t]{2}{*}{ B700 } & 1 & 1 & 4 & 10 & 4.926 & 1.000 & 0.0309 & 0.0613 & 1.526 & 1.428 & 0.382 & 1.702 & 0.291 & 0.380 & 0.801 & 0.680 \\
\hline & 1 & 1 & 5 & 10 & 6.160 & 1.000 & 0.0309 & 0.0613 & 1.676 & 1.786 & 0.335 & 2.128 & 0.291 & 0.380 & 0.801 & 0.680 \\
\hline \multirow[t]{2}{*}{ B800 } & 1 & 1 & 4 & 20 & 4.926 & 1.000 & 0.0441 & 0.0810 & 1.268 & 1.314 & 0.317 & 0.884 & 0.291 & 0.339 & 0.727 & 0.617 \\
\hline & 1 & 1 & 5 & 20 & 6.160 & 1.000 & 0.0441 & 0.0810 & 1.363 & 1.643 & 0.273 & 1.105 & 0.291 & 0.339 & 0.727 & 0.617 \\
\hline \multirow[t]{2}{*}{ B1000 } & 1 & 1 & 4 & 32 & 4.926 & 1.000 & 0.0787 & 0.1244 & 1.340 & 1.199 & 0.335 & 0.596 & 0.291 & 0.280 & 0.685 & 0.581 \\
\hline & 1 & 1 & 5 & 32 & 6.16 & 1.000 & 0.0787 & 0.1244 & 1.357 & 1.499 & 0.271 & 0.745 & 0.291 & 0.280 & 0.685 & 0.581 \\
\hline
\end{tabular}


Table A. 29: Two-Lane Bridge Moment Distribution Factors Comparison at ULS for CHBDC 2014, Alberta 2015, and AASHTO 2012

\begin{tabular}{|c|c|c|c|c|c|c|c|c|c|c|c|c|c|c|c|c|}
\hline \multicolumn{17}{|c|}{ Two Lane Bridge Moement Distribution Factors at Ultimate Limit States } \\
\hline \multicolumn{9}{|c|}{ Bridge Configuration } & \multicolumn{2}{|c|}{ CHBDC 2006} & \multicolumn{3}{|c|}{ CHBDC 2014} & \multirow{2}{*}{\begin{tabular}{|l|} 
Alberta 2015 \\
$\left(F_{T}\right)_{\text {Alberta }}$ \\
\end{tabular}} & \multicolumn{2}{|c|}{ AASHTO 2012 } \\
\hline Girder Size & $\mathbf{n}$ & $\mathbf{R}_{\mathbf{L}}$ & $\mathbf{N}$ & $\mathbf{L}(\mathbf{m})$ & B (m) & $\mu$ & $\mathbf{I}\left(\mathbf{m}^{4}\right)$ & $\mathbf{J}\left(\mathbf{m}^{4}\right)$ & $\left(\mathbf{F}_{\mathrm{V}}\right)_{\mathrm{FE} .}$ & $\left(\mathbf{F}_{\mathbf{v}}\right)_{\mathrm{EQ}}$. & $\left(\mathbf{F}_{\mathrm{T}}\right)_{\mathrm{FE} .}$ & $\boldsymbol{\beta}$ & $\left(\mathbf{F}_{\mathrm{T}}\right)_{\mathrm{EQ}}$ & & $\left(\mathbf{F}_{\mathrm{T}}\right)_{\text {AASHTO }}$ & Ext. $\left(\mathbf{F}_{\mathrm{T}}\right)_{\text {AASHTO Int }}$ \\
\hline \multirow[t]{3}{*}{ B700 } & 2 & 0.9 & 6 & 10 & 7.396 & 0 & 0.0309 & 0.0613 & 1.257 & 1.243 & 0.377 & 2.555 & 0.291 & 0.277 & 0.351 & 0.351 \\
\hline & 2 & 0.9 & 7 & 10 & 8.631 & 0.859 & 0.0309 & 0.0613 & 1.297 & 1.251 & 0.334 & 2.982 & 0.267 & 0.277 & 0.355 & 0.355 \\
\hline & 2 & 0.9 & 8 & 10 & 9.866 & 1.000 & 0.0309 & 0.0613 & 1.454 & 1.399 & 0.327 & 3.409 & 0.269 & 0.277 & 0.358 & 0.358 \\
\hline \multirow[t]{3}{*}{ B700 } & 2 & 0.9 & 6 & 13 & 7.396 & 0 & 0.0309 & 0.0613 & 1.186 & 1.201 & 0.356 & 1.966 & 0.283 & 0.268 & 0.346 & 0.346 \\
\hline & 2 & 0.9 & 7 & 13 & 8.631 & 0.859 & 0.0309 & 0.0613 & 1.214 & 1.199 & 0.312 & 2.294 & 0.258 & 0.268 & 0.349 & 0.349 \\
\hline & 2 & 0.9 & 8 & 13 & 9.866 & 1.000 & 0.0309 & 0.0613 & 1.323 & 1.338 & 0.298 & 2.622 & 0.258 & 0.268 & 0.352 & 0.352 \\
\hline \multirow[t]{3}{*}{ B700 } & 2 & 0.9 & 6 & 16 & 7.396 & 0 & 0.0309 & 0.0613 & 1.090 & 1.161 & 0.327 & 1.597 & 0.279 & 0.263 & 0.343 & 0.343 \\
\hline & 2 & 0.9 & 7 & 16 & 8.631 & 0.859 & 0.0309 & 0.0613 & 1.100 & 1.150 & 0.283 & 1.864 & 0.252 & 0.263 & 0.345 & 0.345 \\
\hline & 2 & 0.9 & 8 & 16 & 9.866 & 1.000 & 0.0309 & 0.0613 & 1.130 & 1.282 & 0.254 & 2.130 & 0.251 & 0.263 & 0.348 & 0.348 \\
\hline \multirow[t]{3}{*}{ B700 } & 2 & 0.9 & 6 & 24 & 7.396 & 0 & 0.0309 & 0.0613 & 1.020 & 1.067 & 0.306 & 1.065 & 0.272 & 0.255 & 0.339 & 0.339 \\
\hline & 2 & 0.9 & 7 & 24 & 8.631 & 0.859 & 0.0309 & 0.0613 & 1.040 & 1.034 & 0.267 & 1.242 & 0.245 & 0.255 & 0.340 & 0.340 \\
\hline & 2 & 0.9 & 8 & 24 & 9.866 & 1.000 & 0.0309 & 0.0613 & 1.050 & 1.150 & 0.236 & 1.420 & 0.242 & 0.255 & 0.342 & 0.342 \\
\hline \multirow[t]{3}{*}{ B800 } & 2 & 0.9 & 6 & 20 & 7.396 & 0 & 0.0441 & 0.0810 & 1.070 & 1.112 & 0.321 & 1.327 & 0.275 & 0.259 & 0.340 & 0.340 \\
\hline & 2 & 0.9 & 7 & 20 & 8.631 & 0.859 & 0.0441 & 0.0810 & 1.100 & 1.089 & 0.283 & 1.549 & 0.248 & 0.259 & 0.342 & 0.342 \\
\hline & 2 & 0.9 & 8 & 20 & 9.866 & 1.000 & 0.0441 & 0.0810 & 1.120 & 1.213 & 0.252 & 1.770 & 0.246 & 0.259 & 0.344 & 0.344 \\
\hline \multirow[t]{3}{*}{ B800 } & 2 & 0.9 & 6 & 26 & 7.396 & 0 & 0.0441 & 0.0810 & 1.060 & 1.046 & 0.318 & 1.021 & 0.272 & 0.255 & 0.338 & 0.338 \\
\hline & 2 & 0.9 & 7 & 26 & 8.631 & 0.859 & 0.0441 & 0.0810 & 1.080 & 1.008 & 0.278 & 1.191 & 0.244 & 0.255 & 0.339 & 0.339 \\
\hline & 2 & 0.9 & 8 & 26 & 9.866 & 1.000 & 0.0441 & 0.0810 & 1.060 & 1.120 & 0.239 & 1.362 & 0.241 & 0.255 & 0.341 & 0.341 \\
\hline \multirow[t]{3}{*}{ B900 } & 2 & 0.9 & 6 & 24 & 7.396 & 0 & 0.0600 & 0.1022 & 1.030 & 1.067 & 0.309 & 1.149 & 0.273 & 0.256 & 0.339 & 0.339 \\
\hline & 2 & 0.9 & 7 & 24 & 8.631 & 0.859 & 0.0600 & 0.1022 & 1.050 & 1.034 & 0.270 & 1.341 & 0.246 & 0.256 & 0.340 & 0.340 \\
\hline & 2 & 0.9 & 8 & 24 & 9.866 & 1.000 & 0.0600 & 0.1022 & 1.070 & 1.150 & 0.241 & 1.532 & 0.243 & 0.256 & 0.342 & 0.342 \\
\hline \multirow[t]{3}{*}{ B900 } & 2 & 0.9 & 6 & 30 & 7.396 & 0 & 0.0600 & 0.1022 & 1.000 & 1.006 & 0.300 & 0.919 & 0.270 & 0.253 & 0.337 & 0.337 \\
\hline & 2 & 0.9 & 7 & 30 & 8.631 & 0.859 & 0.0600 & 0.1022 & 1.030 & 0.960 & 0.265 & 1.073 & 0.242 & 0.253 & 0.338 & 0.338 \\
\hline & 2 & 0.9 & 8 & 30 & 9.866 & 1.000 & 0.0600 & 0.1022 & 1.040 & 1.065 & 0.234 & 1.226 & 0.240 & 0.253 & 0.339 & 0.339 \\
\hline \multirow[t]{3}{*}{ B1000 } & 2 & 0.9 & 6 & 26 & 7.396 & 0 & 0.0787 & 0.1244 & 1.000 & 1.046 & 0.300 & 1.101 & 0.273 & 0.256 & 0.338 & 0.338 \\
\hline & 2 & 0.9 & 7 & 26 & 8.631 & 0.859 & 0.0787 & 0.1244 & 1.030 & 1.008 & 0.265 & 1.284 & 0.245 & 0.256 & 0.339 & 0.339 \\
\hline & 2 & 0.9 & 8 & 26 & 9.866 & 1.000 & 0.0787 & 0.1244 & 1.060 & 1.120 & 0.239 & 1.468 & 0.243 & 0.256 & 0.341 & 0.341 \\
\hline \multirow[t]{3}{*}{ B1000 } & 2 & 0.9 & 6 & 32 & 7.396 & 0 & 0.0787 & 0.1244 & 1.000 & 0.987 & 0.300 & 0.894 & 0.270 & 0.253 & 0.336 & 0.336 \\
\hline & 2 & 0.9 & 7 & 32 & 8.631 & 0.859 & 0.0787 & 0.1244 & 1.010 & 0.937 & 0.260 & 1.044 & 0.242 & 0.253 & 0.337 & 0.337 \\
\hline & 2 & 0.9 & 8 & 32 & 9.866 & 1.000 & 0.0787 & 0.1244 & 1.020 & 1.039 & 0.230 & 1.193 & 0.239 & 0.253 & 0.339 & 0.339 \\
\hline
\end{tabular}


Table A. 30: Two-Lane Bridge Moment Distribution Factors Comparison at FLS for CHBDC 2014, Alberta 2015, and AASHTO 2012

\begin{tabular}{|c|c|c|c|c|c|c|c|c|c|c|c|c|c|c|c|c|}
\hline \multicolumn{17}{|c|}{ Two Lane Bridge Moment Distribution Factors at Fatigue Limit States } \\
\hline \multicolumn{9}{|c|}{ Bridge Configuration } & \multicolumn{2}{|c|}{ CHBDC 2006} & \multicolumn{3}{|c|}{ CHBDC 2014} & \multirow{2}{*}{\begin{tabular}{|l|} 
Alberta 2015 \\
$\left(\mathbf{F}_{\mathrm{T}}\right)_{\text {Alberta }}$ \\
\end{tabular}} & \multicolumn{2}{|c|}{ AASHTO 2012} \\
\hline Girder Size & $\mathbf{n}$ & $\mathbf{R}_{\mathbf{L}}$ & $\mathbf{N}$ & $\mathbf{L}(\mathbf{m})$ & B (m) & $\mu$ & $I\left(\mathbf{m}^{4}\right)$ & $\mathbf{J}\left(\mathbf{m}^{4}\right)$ & $\left(\mathbf{F}_{\mathrm{v}}\right)_{\mathrm{FE}}$ & $\left(\mathbf{F}_{\mathrm{v}}\right)_{\mathrm{EQ}}$. & $\left(\mathbf{F}_{\mathrm{T}}\right)_{\mathrm{FE} .}$ & $\beta$ & $\left(\mathbf{F}_{\mathrm{T}}\right)_{\mathrm{EQ}}$ & & $\left(\mathbf{F}_{\mathrm{T}}\right)_{\text {AASHTO Ext. }}$ & $\left(\mathbf{F}_{\mathrm{T}}\right)_{\text {AASHTO Int. }}$ \\
\hline \multirow[t]{3}{*}{ B700 } & 2 & 0.9 & 6 & 10 & 7.396 & 0 & 0.0309 & 0.0613 & 1.804 & 1.872 & 0.301 & 2.555 & 0.199 & 0.277 & 0.351 & 0.351 \\
\hline & 2 & 0.9 & 7 & 10 & 8.631 & 0.859 & 0.0309 & 0.0613 & 2.084 & 1.899 & 0.298 & 2.982 & 0.191 & 0.277 & 0.355 & 0.355 \\
\hline & 2 & 0.9 & 8 & 10 & 9.866 & 1.000 & 0.0309 & 0.0613 & 2.096 & 2.125 & 0.262 & 3.409 & 0.201 & 0.277 & 0.358 & 0.358 \\
\hline \multirow[t]{3}{*}{ B700 } & 2 & 0.9 & 6 & 13 & 7.396 & 0 & 0.0309 & 0.0613 & 1.581 & 1.647 & 0.264 & 1.966 & 0.183 & 0.268 & 0.346 & 0.346 \\
\hline & 2 & 0.9 & 7 & 13 & 8.631 & 0.859 & 0.0309 & 0.0613 & 1.784 & 1.672 & 0.255 & 2.294 & 0.172 & 0.268 & 0.349 & 0.349 \\
\hline & 2 & 0.9 & 8 & 13 & 9.866 & 1.000 & 0.0309 & 0.0613 & 1.795 & 1.871 & 0.224 & 2.622 & 0.177 & 0.268 & 0.352 & 0.352 \\
\hline \multirow[t]{3}{*}{ B700 } & 2 & 0.9 & 6 & 16 & 7.396 & 0 & 0.0309 & 0.0613 & 1.170 & 1.470 & 0.195 & 1.597 & 0.175 & 0.263 & 0.343 & 0.343 \\
\hline & 2 & 0.9 & 7 & 16 & 8.631 & 0.859 & 0.0309 & 0.0613 & 1.210 & 1.493 & 0.173 & 1.864 & 0.162 & 0.263 & 0.345 & 0.345 \\
\hline & 2 & 0.9 & 8 & 16 & 9.866 & 1.000 & 0.0309 & 0.0613 & 1.280 & 1.672 & 0.160 & 2.130 & 0.165 & 0.263 & 0.348 & 0.348 \\
\hline \multirow[t]{3}{*}{ B700 } & 2 & 0.9 & 6 & 24 & 7.396 & 0 & 0.0309 & 0.0613 & 1.090 & 1.143 & 0.182 & 1.065 & 0.164 & 0.255 & 0.339 & 0.339 \\
\hline & 2 & 0.9 & 7 & 24 & 8.631 & 0.859 & 0.0309 & 0.0613 & 1.140 & 1.164 & 0.163 & 1.242 & 0.149 & 0.255 & 0.340 & 0.340 \\
\hline & 2 & 0.9 & 8 & 24 & 9.866 & 1.000 & 0.0309 & 0.0613 & 1.200 & 1.303 & 0.150 & 1.420 & 0.150 & 0.255 & 0.342 & 0.342 \\
\hline \multirow[t]{3}{*}{ B800 } & 2 & 0.9 & 6 & 20 & 7.396 & 0 & 0.0441 & 0.0810 & 1.170 & 1.286 & 0.195 & 1.327 & 0.169 & 0.259 & 0.340 & 0.340 \\
\hline & 2 & 0.9 & 7 & 20 & 8.631 & 0.859 & 0.0441 & 0.0810 & 1.210 & 1.308 & 0.173 & 1.549 & 0.155 & 0.259 & 0.342 & 0.342 \\
\hline & 2 & 0.9 & 8 & 20 & 9.866 & 1.000 & 0.0441 & 0.0810 & 1.270 & 1.464 & 0.159 & 1.770 & 0.157 & 0.259 & 0.344 & 0.344 \\
\hline \multirow[t]{3}{*}{ B800 } & 2 & 0.9 & 6 & 26 & 7.396 & 0 & 0.0441 & 0.0810 & 1.130 & 1.083 & 0.188 & 1.021 & 0.163 & 0.255 & 0.338 & 0.338 \\
\hline & 2 & 0.9 & 7 & 26 & 8.631 & 0.859 & 0.0441 & 0.0810 & 1.150 & 1.103 & 0.164 & 1.191 & 0.148 & 0.255 & 0.339 & 0.339 \\
\hline & 2 & 0.9 & 8 & 26 & 9.866 & 1.000 & 0.0441 & 0.0810 & 1.200 & 1.235 & 0.150 & 1.362 & 0.149 & 0.255 & 0.341 & 0.341 \\
\hline \multirow[t]{3}{*}{ B900 } & 2 & 0.9 & 6 & 24 & 7.396 & 0 & 0.0600 & 0.1022 & 1.090 & 1.143 & 0.182 & 1.149 & 0.165 & 0.256 & 0.339 & 0.339 \\
\hline & 2 & 0.9 & 7 & 24 & 8.631 & 0.859 & 0.0600 & 0.1022 & 1.130 & 1.164 & 0.161 & 1.341 & 0.151 & 0.256 & 0.340 & 0.340 \\
\hline & 2 & 0.9 & 8 & 24 & 9.866 & 1.000 & 0.0600 & 0.1022 & 1.210 & 1.303 & 0.151 & 1.532 & 0.152 & 0.256 & 0.342 & 0.342 \\
\hline \multirow[t]{3}{*}{ B900 } & 2 & 0.9 & 6 & 30 & 7.396 & 0 & 0.0600 & 0.1022 & 1.070 & 0.980 & 0.178 & 0.919 & 0.161 & 0.253 & 0.337 & 0.337 \\
\hline & 2 & 0.9 & 7 & 30 & 8.631 & 0.859 & 0.0600 & 0.1022 & 1.090 & 0.999 & 0.156 & 1.073 & 0.146 & 0.253 & 0.338 & 0.338 \\
\hline & 2 & 0.9 & 8 & 30 & 9.866 & 1.000 & 0.0600 & 0.1022 & 1.120 & 1.119 & 0.140 & 1.226 & 0.146 & 0.253 & 0.339 & 0.339 \\
\hline \multirow[t]{3}{*}{ B1000 } & 2 & 0.9 & 6 & 26 & 7.396 & 0 & 0.0787 & 0.1244 & 1.090 & 1.083 & 0.182 & 1.101 & 0.164 & 0.256 & 0.338 & 0.338 \\
\hline & 2 & 0.9 & 7 & 26 & 8.631 & 0.859 & 0.0787 & 0.1244 & 1.130 & 1.103 & 0.161 & 1.284 & 0.150 & 0.256 & 0.339 & 0.339 \\
\hline & 2 & 0.9 & 8 & 26 & 9.866 & 1.000 & 0.0787 & 0.1244 & 1.180 & 1.235 & 0.148 & 1.468 & 0.151 & 0.256 & 0.341 & 0.341 \\
\hline \multirow[t]{3}{*}{ B1000 } & 2 & 0.9 & 6 & 32 & 7.396 & 0 & 0.0787 & 0.1244 & 1.050 & 0.935 & 0.175 & 0.894 & 0.160 & 0.253 & 0.336 & 0.336 \\
\hline & 2 & 0.9 & 7 & 32 & 8.631 & 0.859 & 0.0787 & 0.1244 & 1.070 & 0.954 & 0.153 & 1.044 & 0.145 & 0.253 & 0.337 & 0.337 \\
\hline & 2 & 0.9 & 8 & 32 & 9.866 & 1.000 & 0.0787 & 0.1244 & 1.090 & 1.068 & 0.136 & 1.193 & 0.145 & 0.253 & 0.339 & 0.339 \\
\hline
\end{tabular}


Table A. 31: Two-Lane Bridge Shear Distribution Factors Comparison at ULS for CHBDC 2014, Alberta 2015, and AASHTO 2012

\begin{tabular}{|c|c|c|c|c|c|c|c|c|c|c|c|c|c|c|c|c|}
\hline \multicolumn{17}{|c|}{ Two Lane Bridge Shear Distribution Factors at Ultimate Limit States } \\
\hline \multicolumn{9}{|c|}{ Bridge Configuration } & \multicolumn{2}{|c|}{ CHBDC 2006} & \multicolumn{3}{|c|}{ CHBDC 2014} & \multirow{2}{*}{\begin{tabular}{|l|} 
Alberta 2015 \\
$\left(F_{T}\right)_{\text {Alberta }}$ \\
\end{tabular}} & \multicolumn{2}{|c|}{ AASHTO 2012} \\
\hline Girder Size & $\mathbf{n}$ & $\mathbf{R}_{\mathbf{L}}$ & $\mathbf{N}$ & $\mathbf{L}(\mathbf{m})$ & B (m) & $\boldsymbol{\mu}$ & $\mathbf{I}\left(\mathbf{m}^{4}\right)$ & $\mathbf{J}\left(\mathbf{m}^{\mathbf{4}}\right)$ & $\left(F_{\mathbf{v}}\right)_{\text {FE. }}$ & $\left(\mathbf{F}_{\mathrm{v}}\right)_{\mathrm{EQ}}$ & $\left(\mathbf{F}_{\mathrm{T}}\right)_{\mathrm{FE}}$. & $\boldsymbol{\beta}$ & $\left(F_{T}\right)_{E Q}$. & & $\left(\mathbf{F}_{\mathrm{T}}\right)_{\text {AASHTO }}$ & Ext. $\left(F_{T}\right)_{\text {AASH TO Int. }}$ \\
\hline \multirow[t]{3}{*}{ B700 } & 2 & 0.9 & 6 & 10 & 7.396 & 0 & 0.0309 & 0.0613 & 1.409 & 1.320 & 0.423 & 2.555 & 0.309 & 0.380 & 0.754 & 0.674 \\
\hline & 2 & 0.9 & 7 & 10 & 8.631 & 0.859 & 0.0309 & 0.0613 & 1.469 & 1.541 & 0.378 & 2.982 & 0.309 & 0.380 & 0.754 & 0.674 \\
\hline & 2 & 0.9 & 8 & 10 & 9.866 & 1.000 & 0.0309 & 0.0613 & 1.696 & 1.761 & 0.382 & 3.409 & 0.309 & 0.380 & 0.754 & 0.674 \\
\hline \multirow[t]{3}{*}{ B700 } & 2 & 0.9 & 6 & 13 & 7.396 & 0 & 0.0309 & 0.0613 & 1.339 & 1.286 & 0.402 & 1.966 & 0.309 & 0.401 & 0.735 & 0.657 \\
\hline & 2 & 0.9 & 7 & 13 & 8.631 & 0.859 & 0.0309 & 0.0613 & 1.522 & 1.501 & 0.391 & 2.294 & 0.309 & 0.401 & 0.735 & 0.657 \\
\hline & 2 & 0.9 & 8 & 13 & 9.866 & 1.000 & 0.0309 & 0.0613 & 1.771 & 1.716 & 0.398 & 2.622 & 0.309 & 0.401 & 0.735 & 0.657 \\
\hline \multirow[t]{3}{*}{ B700 } & 2 & 0.9 & 6 & 16 & 7.396 & 0 & 0.0309 & 0.0613 & 1.290 & 1.254 & 0.387 & 1.597 & 0.309 & 0.384 & 0.719 & 0.643 \\
\hline & 2 & 0.9 & 7 & 16 & 8.631 & 0.859 & 0.0309 & 0.0613 & 1.460 & 1.464 & 0.375 & 1.864 & 0.309 & 0.384 & 0.719 & 0.643 \\
\hline & 2 & 0.9 & 8 & 16 & 9.866 & 1.000 & 0.0309 & 0.0613 & 1.680 & 1.673 & 0.378 & 2.130 & 0.309 & 0.384 & 0.719 & 0.643 \\
\hline \multirow[t]{3}{*}{ B700 } & 2 & 0.9 & 6 & 24 & 7.396 & 0 & 0.0309 & 0.0613 & 1.210 & 1.176 & 0.363 & 1.065 & 0.309 & 0.286 & 0.691 & 0.618 \\
\hline & 2 & 0.9 & 7 & 24 & 8.631 & 0.859 & 0.0309 & 0.0613 & 1.350 & 1.373 & 0.347 & 1.242 & 0.309 & 0.286 & 0.691 & 0.618 \\
\hline & 2 & 0.9 & 8 & 24 & 9.866 & 1.000 & 0.0309 & 0.0613 & 1.560 & 1.569 & 0.351 & 1.420 & 0.309 & 0.286 & 0.691 & 0.618 \\
\hline \multirow[t]{3}{*}{ B800 } & 2 & 0.9 & 6 & 20 & 7.396 & 0 & 0.0441 & 0.0810 & 1.240 & 1.214 & 0.372 & 1.327 & 0.309 & 0.339 & 0.708 & 0.633 \\
\hline & 2 & 0.9 & 7 & 20 & 8.631 & 0.859 & 0.0441 & 0.0810 & 1.360 & 1.417 & 0.350 & 1.549 & 0.309 & 0.339 & 0.708 & 0.633 \\
\hline & 2 & 0.9 & 8 & 20 & 9.866 & 1.000 & 0.0441 & 0.0810 & 1.610 & 1.619 & 0.362 & 1.770 & 0.309 & 0.339 & 0.708 & 0.633 \\
\hline \multirow[t]{3}{*}{ B800 } & 2 & 0.9 & 6 & 26 & 7.396 & 0 & 0.0441 & 0.0810 & 1.200 & 1.158 & 0.360 & 1.021 & 0.309 & 0.286 & 0.690 & 0.617 \\
\hline & 2 & 0.9 & 7 & 26 & 8.631 & 0.859 & 0.0441 & 0.0810 & 1.250 & 1.351 & 0.321 & 1.191 & 0.309 & 0.286 & 0.690 & 0.617 \\
\hline & 2 & 0.9 & 8 & 26 & 9.866 & 1.000 & 0.0441 & 0.0810 & 1.530 & 1.545 & 0.344 & 1.362 & 0.309 & 0.286 & 0.690 & 0.617 \\
\hline \multirow[t]{3}{*}{ B900 } & 2 & 0.9 & 6 & 24 & 7.396 & 0 & 0.0600 & 0.1022 & 1.210 & 1.176 & 0.363 & 1.149 & 0.309 & 0.287 & 0.700 & 0.626 \\
\hline & 2 & 0.9 & 7 & 24 & 8.631 & 0.859 & 0.0600 & 0.1022 & 1.350 & 1.373 & 0.347 & 1.341 & 0.309 & 0.287 & 0.700 & 0.626 \\
\hline & 2 & 0.9 & 8 & 24 & 9.866 & 1.000 & 0.0600 & 0.1022 & 1.560 & 1.569 & 0.351 & 1.532 & 0.309 & 0.287 & 0.700 & 0.626 \\
\hline \multirow[t]{3}{*}{ B900 } & 2 & 0.9 & 6 & 30 & 7.396 & 0 & 0.0600 & 0.1022 & 1.180 & 1.124 & 0.354 & 0.919 & 0.309 & 0.281 & 0.684 & 0.612 \\
\hline & 2 & 0.9 & 7 & 30 & 8.631 & 0.859 & 0.0600 & 0.1022 & 1.250 & 1.311 & 0.321 & 1.073 & 0.309 & 0.281 & 0.684 & 0.612 \\
\hline & 2 & 0.9 & 8 & 30 & 9.866 & 1.000 & 0.0600 & 0.1022 & 1.500 & 1.499 & 0.338 & 1.226 & 0.309 & 0.281 & 0.684 & 0.612 \\
\hline \multirow[t]{3}{*}{ B1000 } & 2 & 0.9 & 6 & 26 & 7.396 & 0 & 0.0787 & 0.1244 & 1.200 & 1.158 & 0.360 & 1.101 & 0.309 & 0.287 & 0.698 & 0.624 \\
\hline & 2 & 0.9 & 7 & 26 & 8.631 & 0.859 & 0.0787 & 0.1244 & 1.250 & 1.351 & 0.321 & 1.284 & 0.309 & 0.287 & 0.698 & 0.624 \\
\hline & 2 & 0.9 & 8 & 26 & 9.866 & 1.000 & 0.0787 & 0.1244 & 1.530 & 1.545 & 0.344 & 1.468 & 0.309 & 0.287 & 0.698 & 0.624 \\
\hline \multirow[t]{3}{*}{ B1000 } & 2 & 0.9 & 6 & 32 & 7.396 & 0 & 0.0787 & 0.1244 & 1.180 & 1.107 & 0.354 & 0.894 & 0.309 & 0.280 & 0.683 & 0.611 \\
\hline & 2 & 0.9 & 7 & 32 & 8.631 & 0.859 & 0.0787 & 0.1244 & 1.340 & 1.292 & 0.345 & 1.044 & 0.309 & 0.280 & 0.683 & 0.611 \\
\hline & 2 & 0.9 & 8 & 32 & 9.866 & 1.000 & 0.0787 & 0.1244 & 1.500 & 1.477 & 0.338 & 1.193 & 0.309 & 0.280 & 0.683 & 0.611 \\
\hline
\end{tabular}


Table A. 32: Two-Lane Bridge Shear Distribution Factors Comparison at FLS for CHBDC 2014, Alberta 2015, and AASHTO 2012

\begin{tabular}{|c|c|c|c|c|c|c|c|c|c|c|c|c|c|c|c|c|}
\hline \multicolumn{17}{|c|}{ Two Lane Bridge Shear Distribution Factors at Fatigue Limit States } \\
\hline \multicolumn{9}{|c|}{ Bridge Configuration } & \multicolumn{2}{|c|}{ CHBDC 2006 } & \multicolumn{3}{|c|}{ CHBDC 2014} & \multirow{2}{*}{\begin{tabular}{|l|} 
Alberta 2015 \\
$\left(F_{T}\right)_{\text {Alberta }}$ \\
\end{tabular}} & \multicolumn{2}{|c|}{ AASHTO 2012} \\
\hline Girder Size & $\mathbf{n}$ & $\mathbf{R}_{\mathbf{L}}$ & $\mathbf{N}$ & $\mathbf{L}(\mathbf{m})$ & $\mathbf{B}(\mathbf{m})$ & $\mu$ & $I\left(\mathbf{m}^{4}\right)$ & $\mathbf{J}\left(\mathbf{m}^{4}\right)$ & $\left(\mathbf{F}_{\mathrm{v}}\right)_{\mathrm{FE}}$ & $\left(\mathbf{F}_{\mathrm{v}}\right)_{\mathrm{EQ}}$ & $\left(\mathbf{F}_{\mathrm{T}}\right)_{\mathrm{FE} .}$ & $\beta$ & $\left(\mathbf{F}_{\mathrm{T}}\right)_{\mathbf{E Q}}$. & & $\left(\mathbf{F}_{\mathrm{T}}\right)_{\text {AASHTO Ext. }}$ & $\left(\mathbf{F}_{\mathrm{T}}\right)_{\text {AASHTO Int }}$ \\
\hline \multirow[t]{3}{*}{ B700 } & 2 & 0.9 & 6 & 10 & 7.396 & 0 & 0.0309 & 0.0613 & 2.565 & 2.404 & 0.428 & 2.555 & 0.291 & 0.380 & 0.754 & 0.674 \\
\hline & 2 & 0.9 & 7 & 10 & 8.631 & 0.859 & 0.0309 & 0.0613 & 2.810 & 2.805 & 0.401 & 2.982 & 0.291 & 0.380 & 0.754 & 0.674 \\
\hline & 2 & 0.9 & 8 & 10 & 9.866 & 1.000 & 0.0309 & 0.0613 & 2.826 & 3.206 & 0.353 & 3.409 & 0.291 & 0.380 & 0.754 & 0.674 \\
\hline \multirow[t]{3}{*}{ B700 } & 2 & 0.9 & 6 & 13 & 7.396 & 0 & 0.0309 & 0.0613 & 2.384 & 2.226 & 0.397 & 1.966 & 0.291 & 0.401 & 0.735 & 0.657 \\
\hline & 2 & 0.9 & 7 & 13 & 8.631 & 0.859 & 0.0309 & 0.0613 & 2.896 & 2.598 & 0.414 & 2.294 & 0.291 & 0.401 & 0.735 & 0.657 \\
\hline & 2 & 0.9 & 8 & 13 & 9.866 & 1.000 & 0.0309 & 0.0613 & 2.899 & 2.970 & 0.362 & 2.622 & 0.291 & 0.401 & 0.735 & 0.657 \\
\hline \multirow[t]{3}{*}{ B700 } & 2 & 0.9 & 6 & 16 & 7.396 & 0 & 0.0309 & 0.0613 & 1.990 & 2.073 & 0.332 & 1.597 & 0.291 & 0.384 & 0.719 & 0.643 \\
\hline & 2 & 0.9 & 7 & 16 & 8.631 & 0.859 & 0.0309 & 0.0613 & 2.470 & 2.420 & 0.353 & 1.864 & 0.291 & 0.384 & 0.719 & 0.643 \\
\hline & 2 & 0.9 & 8 & 16 & 9.866 & 1.000 & 0.0309 & 0.0613 & 2.740 & 2.766 & 0.343 & 2.130 & 0.291 & 0.384 & 0.719 & 0.643 \\
\hline \multirow[t]{3}{*}{ B700 } & 2 & 0.9 & 6 & 24 & 7.396 & 0 & 0.0309 & 0.0613 & 1.740 & 1.752 & 0.290 & 1.065 & 0.291 & 0.286 & 0.691 & 0.618 \\
\hline & 2 & 0.9 & 7 & 24 & 8.631 & 0.859 & 0.0309 & 0.0613 & 2.090 & 2.045 & 0.299 & 1.242 & 0.291 & 0.286 & 0.691 & 0.618 \\
\hline & 2 & 0.9 & 8 & 24 & 9.866 & 1.000 & 0.0309 & 0.0613 & 2.200 & 2.338 & 0.275 & 1.420 & 0.291 & 0.286 & 0.691 & 0.618 \\
\hline \multirow[t]{3}{*}{ B800 } & 2 & 0.9 & 6 & 20 & 7.396 & 0 & 0.0441 & 0.0810 & 1.800 & 1.899 & 0.300 & 1.327 & 0.291 & 0.339 & 0.708 & 0.633 \\
\hline & 2 & 0.9 & 7 & 20 & 8.631 & 0.859 & 0.0441 & 0.0810 & 2.080 & 2.217 & 0.297 & 1.549 & 0.291 & 0.339 & 0.708 & 0.633 \\
\hline & 2 & 0.9 & 8 & 20 & 9.866 & 1.000 & 0.0441 & 0.0810 & 2.390 & 2.534 & 0.299 & 1.770 & 0.291 & 0.339 & 0.708 & 0.633 \\
\hline \multirow[t]{3}{*}{ B800 } & 2 & 0.9 & 6 & 26 & 7.396 & 0 & 0.0441 & 0.0810 & 1.690 & 1.687 & 0.282 & 1.021 & 0.291 & 0.286 & 0.690 & 0.617 \\
\hline & 2 & 0.9 & 7 & 26 & 8.631 & 0.859 & 0.0441 & 0.0810 & 2.020 & 1.969 & 0.289 & 1.191 & 0.291 & 0.286 & 0.690 & 0.617 \\
\hline & 2 & 0.9 & 8 & 26 & 9.866 & 1.000 & 0.0441 & 0.0810 & 2.100 & 2.250 & 0.263 & 1.362 & 0.291 & 0.286 & 0.690 & 0.617 \\
\hline \multirow[t]{3}{*}{ B900 } & 2 & 0.9 & 6 & 24 & 7.396 & 0 & 0.0600 & 0.1022 & 1.740 & 1.752 & 0.290 & 1.149 & 0.291 & 0.287 & 0.700 & 0.626 \\
\hline & 2 & 0.9 & 7 & 24 & 8.631 & 0.859 & 0.0600 & 0.1022 & 2.090 & 2.045 & 0.299 & 1.341 & 0.291 & 0.287 & 0.700 & 0.626 \\
\hline & 2 & 0.9 & 8 & 24 & 9.866 & 1.000 & 0.0600 & 0.1022 & 2.200 & 2.338 & 0.275 & 1.532 & 0.291 & 0.287 & 0.700 & 0.626 \\
\hline \multirow[t]{3}{*}{ B900 } & 2 & 0.9 & 6 & 30 & 7.396 & 0 & 0.0600 & 0.1022 & 1.650 & 1.570 & 0.275 & 0.919 & 0.291 & 0.281 & 0.684 & 0.612 \\
\hline & 2 & 0.9 & 7 & 30 & 8.631 & 0.859 & 0.0600 & 0.1022 & 1.930 & 1.832 & 0.276 & 1.073 & 0.291 & 0.281 & 0.684 & 0.612 \\
\hline & 2 & 0.9 & 8 & 30 & 9.866 & 1.000 & 0.0600 & 0.1022 & 2.020 & 2.094 & 0.253 & 1.226 & 0.291 & 0.281 & 0.684 & 0.612 \\
\hline \multirow[t]{3}{*}{ B1000 } & 2 & 0.9 & 6 & 26 & 7.396 & 0 & 0.0787 & 0.1244 & 1.690 & 1.687 & 0.282 & 1.101 & 0.291 & 0.287 & 0.698 & 0.624 \\
\hline & 2 & 0.9 & 7 & 26 & 8.631 & 0.859 & 0.0787 & 0.1244 & 2.020 & 1.969 & 0.289 & 1.284 & 0.291 & 0.287 & 0.698 & 0.624 \\
\hline & 2 & 0.9 & 8 & 26 & 9.866 & 1.000 & 0.0787 & 0.1244 & 2.100 & 2.250 & 0.263 & 1.468 & 0.291 & 0.287 & 0.698 & 0.624 \\
\hline \multirow[t]{3}{*}{ B1000 } & 2 & 0.9 & 6 & 32 & 7.396 & 0 & 0.0787 & 0.1244 & 1.640 & 1.517 & 0.273 & 0.894 & 0.291 & 0.280 & 0.683 & 0.611 \\
\hline & 2 & 0.9 & 7 & 32 & 8.631 & 0.859 & 0.0787 & 0.1244 & 1.890 & 1.771 & 0.270 & 1.044 & 0.291 & 0.280 & 0.683 & 0.611 \\
\hline & 2 & 0.9 & 8 & 32 & 9.866 & 1.000 & 0.0787 & 0.1244 & 1.970 & 2.024 & 0.246 & 1.193 & 0.291 & 0.280 & 0.683 & 0.611 \\
\hline
\end{tabular}


Table A. 33: Three-Lane Bridge Moment Distribution Factors Comparison at ULS for CHBDC 2014, Alberta 2015, and AASHTO 2012

\begin{tabular}{|c|c|c|c|c|c|c|c|c|c|c|c|c|c|c|c|c|}
\hline \multicolumn{17}{|c|}{ Three Lane Bridge Moement Distribution Factors at Ultimate Limit States } \\
\hline \multicolumn{9}{|c|}{ Bridge Configuration } & \multicolumn{2}{|c|}{ CHBDC 2006} & \multicolumn{3}{|c|}{ CHBDC 2014} & \multirow{2}{*}{\begin{tabular}{|l|} 
Alberta 2015 \\
$\left(F_{T}\right)_{\text {Alberta }}$ \\
\end{tabular}} & \multicolumn{2}{|c|}{ AASHTO 2012} \\
\hline Girder Size & $\mathbf{n}$ & $\mathbf{R}_{\mathbf{L}}$ & $\mathbf{N}$ & $\mathbf{L}(\mathbf{m})$ & B (m) & $\mu$ & $I\left(\mathbf{m}^{\mathbf{4}}\right)$ & $\mathbf{J}\left(\mathbf{m}^{4}\right)$ & $\left(\mathbf{F}_{\mathbf{v}}\right)_{\mathbf{F E}}$ & $\left(\mathbf{F}_{\mathbf{v}}\right)_{\mathrm{EQ}}$. & $\left(F_{T}\right)_{F E}$. & $\boldsymbol{\beta}$ & $\left(\mathbf{F}_{\mathbf{T}}\right)_{\mathbf{E Q}}$. & & $\left(\mathbf{F}_{\mathrm{T}}\right)_{\text {AASHTO }}$ & Ext. $\left(\mathbf{F}_{\mathrm{T}}\right)_{\text {AASHTO Int. }}$ \\
\hline \multirow[t]{3}{*}{ B700 } & 3 & 0.8 & 9 & 10 & 11.100 & 0 & 0.0309 & 0.0613 & 1.324 & 1.268 & 0.353 & 3.835 & 0.306 & 0.277 & 0.362 & 0.362 \\
\hline & 3 & 0.8 & 10 & 10 & 12.336 & 0.798 & 0.0309 & 0.0613 & 1.350 & 1.291 & 0.324 & 4.262 & 0.287 & 0.277 & 0.362 & 0.362 \\
\hline & 3 & 0.8 & 11 & 10 & 13.571 & 1.000 & 0.0309 & 0.0613 & 1.466 & 1.387 & 0.320 & 4.689 & 0.287 & 0.277 & 0.362 & 0.362 \\
\hline \multirow[t]{3}{*}{ B700 } & 3 & 0.8 & 9 & 13 & 11.100 & 0 & 0.0309 & 0.0613 & 1.206 & 1.227 & 0.322 & 2.950 & 0.292 & 0.268 & 0.356 & 0.356 \\
\hline & 3 & 0.8 & 10 & 13 & 12.336 & 0.798 & 0.0309 & 0.0613 & 1.224 & 1.243 & 0.294 & 3.278 & 0.272 & 0.268 & 0.360 & 0.360 \\
\hline & 3 & 0.8 & 11 & 13 & 13.571 & 1.000 & 0.0309 & 0.0613 & 1.337 & 1.333 & 0.292 & 3.607 & 0.270 & 0.268 & 0.362 & 0.362 \\
\hline \multirow[t]{3}{*}{ B700 } & 3 & 0.8 & 9 & 16 & 11.1 & 0 & 0.0309 & 0.0613 & 1.100 & 1.188 & 0.293 & 2.397 & 0.285 & 0.263 & 0.349 & 0.349 \\
\hline & 3 & 0.8 & 10 & 16 & 12.336 & 0.798 & 0.0309 & 0.0613 & 1.130 & 1.198 & 0.271 & 2.664 & 0.264 & 0.263 & 0.352 & 0.352 \\
\hline & 3 & 0.8 & 11 & 16 & 13.571 & 1.000 & 0.0309 & 0.0613 & 1.170 & 1.282 & 0.255 & 2.930 & 0.261 & 0.263 & 0.356 & 0.356 \\
\hline \multirow[t]{3}{*}{ B700 } & 3 & 0.8 & 9 & 24 & 11.1 & 0 & 0.0309 & 0.0613 & 1.060 & 1.095 & 0.283 & 1.598 & 0.274 & 0.255 & 0.339 & 0.339 \\
\hline & 3 & 0.8 & 10 & 24 & 12.336 & 0.798 & 0.0309 & 0.0613 & 1.110 & 1.090 & 0.266 & 1.776 & 0.252 & 0.255 & 0.341 & 0.341 \\
\hline & 3 & 0.8 & 11 & 24 & 13.571 & 1.000 & 0.0309 & 0.0613 & 1.110 & 1.163 & 0.242 & 1.954 & 0.248 & 0.255 & 0.343 & 0.343 \\
\hline \multirow[t]{3}{*}{ B800 } & 3 & 0.8 & 9 & 20 & 11.1 & 0 & 0.0441 & 0.0810 & 1.130 & 1.140 & 0.301 & 1.992 & 0.279 & 0.259 & 0.343 & 0.343 \\
\hline & 3 & 0.8 & 10 & 20 & 12.336 & 0.798 & 0.0441 & 0.0810 & 1.150 & 1.141 & 0.276 & 2.213 & 0.258 & 0.259 & 0.345 & 0.345 \\
\hline & 3 & 0.8 & 11 & 20 & 13.571 & 1.000 & 0.0441 & 0.0810 & 1.160 & 1.220 & 0.253 & 2.435 & 0.254 & 0.259 & 0.348 & 0.348 \\
\hline \multirow[t]{3}{*}{ B800 } & 3 & 0.8 & 9 & 26 & 11.1 & 0 & 0.0441 & 0.0810 & 1.100 & 1.074 & 0.293 & 1.532 & 0.274 & 0.255 & 0.337 & 0.337 \\
\hline & 3 & 0.8 & 10 & 26 & 12.336 & 0.798 & 0.0441 & 0.0810 & 1.100 & 1.065 & 0.264 & 1.703 & 0.252 & 0.255 & 0.339 & 0.339 \\
\hline & 3 & 0.8 & 11 & 26 & 13.571 & 1.000 & 0.0441 & 0.0810 & 1.130 & 1.136 & 0.247 & 1.873 & 0.247 & 0.255 & 0.341 & 0.341 \\
\hline \multirow[t]{3}{*}{ B900 } & 3 & 0.8 & 9 & 24 & 11.1 & 0 & 0.0600 & 0.1022 & 1.070 & 1.095 & 0.285 & 1.724 & 0.276 & 0.256 & 0.339 & 0.339 \\
\hline & 3 & 0.8 & 10 & 24 & 12.336 & 0.798 & 0.0600 & 0.1022 & 1.090 & 1.090 & 0.262 & 1.916 & 0.254 & 0.256 & 0.341 & 0.341 \\
\hline & 3 & 0.8 & 11 & 24 & 13.571 & 1.000 & 0.0600 & 0.1022 & 1.130 & 1.163 & 0.247 & 2.108 & 0.250 & 0.256 & 0.343 & 0.343 \\
\hline \multirow[t]{3}{*}{ B900 } & 3 & 0.8 & 9 & 30 & 11.1 & 0 & 0.0600 & 0.1022 & 1.050 & 1.035 & 0.280 & 1.379 & 0.272 & 0.253 & 0.335 & 0.335 \\
\hline & 3 & 0.8 & 10 & 30 & 12.336 & 0.798 & 0.0600 & 0.1022 & 1.060 & 1.019 & 0.254 & 1.533 & 0.249 & 0.253 & 0.337 & 0.337 \\
\hline & 3 & 0.8 & 11 & 30 & 13.571 & 1.000 & 0.0600 & 0.1022 & 1.080 & 1.085 & 0.236 & 1.686 & 0.245 & 0.253 & 0.338 & 0.338 \\
\hline \multirow[t]{3}{*}{ B1000 } & 3 & 0.8 & 9 & 26 & 11.1 & 0 & 0.0787 & 0.1244 & 1.060 & 1.074 & 0.283 & 1.652 & 0.275 & 0.256 & 0.337 & 0.337 \\
\hline & 3 & 0.8 & 10 & 26 & 12.336 & 0.798 & 0.0787 & 0.1244 & 1.120 & 1.065 & 0.269 & 1.836 & 0.253 & 0.256 & 0.339 & 0.339 \\
\hline & 3 & 0.8 & 11 & 26 & 13.571 & 1.000 & 0.0787 & 0.1244 & 1.110 & 1.136 & 0.242 & 2.020 & 0.249 & 0.256 & 0.341 & 0.341 \\
\hline \multirow[t]{3}{*}{ B1000 } & 3 & 0.8 & 9 & 32 & 11.1 & 0 & 0.0787 & 0.1244 & 1.030 & 1.016 & 0.275 & 1.342 & 0.271 & 0.253 & 0.334 & 0.334 \\
\hline & 3 & 0.8 & 10 & 32 & 12.336 & 0.798 & 0.0787 & 0.1244 & 1.070 & 0.997 & 0.257 & 1.492 & 0.249 & 0.253 & 0.335 & 0.335 \\
\hline & 3 & 0.8 & 11 & 32 & 13.571 & 1.000 & 0.0787 & 0.1244 & 1.050 & 1.061 & 0.229 & 1.641 & 0.244 & 0.253 & 0.337 & 0.337 \\
\hline
\end{tabular}


Table A. 34: Three-Lane Bridge Moment Distribution Factors Comparison at FLS for CHBDC 2014, Alberta 2015, and AASHTO 2012

\begin{tabular}{|c|c|c|c|c|c|c|c|c|c|c|c|c|c|c|c|c|}
\hline \multicolumn{17}{|c|}{ Three Lane Bridge Moment Distribution Factors at Fatigue Limit States } \\
\hline \multicolumn{9}{|c|}{ Bridge Configuration } & \multicolumn{2}{|c|}{ CHBDC 2006} & \multicolumn{3}{|c|}{ CHBDC 2014} & \multirow{2}{*}{\begin{tabular}{|l|} 
Alberta 2015 \\
$\left(\mathbf{F}_{\mathrm{T}}\right)_{\text {Alberta }}$ \\
\end{tabular}} & \multicolumn{2}{|c|}{ AASHTO 2012} \\
\hline Girder Size & n & $\mathbf{R}_{\mathbf{L}}$ & $\mathbf{N}$ & $\mathbf{L}(\mathbf{m})$ & B (m) & $\mu$ & $\mathbf{I}\left(\mathbf{m}^{4}\right)$ & $\mathbf{J}\left(\mathbf{m}^{4}\right)$ & $\left(\mathbf{F}_{\mathrm{V}}\right)_{\mathrm{FE}}$. & $\left(\mathbf{F}_{\mathrm{V}}\right)_{\mathbf{E Q}}$. & $\left(\mathbf{F}_{\mathrm{T}}\right)_{\mathrm{FE} .}$ & $\boldsymbol{\beta}$ & $\left(\mathbf{F}_{\mathbf{T}}\right)_{\mathbf{E Q}}$ & & $\left(\mathbf{F}_{\mathrm{T}}\right)_{\text {AASHTO Ext. }}$ & $\left(\mathrm{F}_{\mathrm{T}}\right)_{\text {AASHTO Int. }}$ \\
\hline \multirow[t]{3}{*}{ B700 } & 3 & 0.8 & 9 & 10 & 11.100 & 0 & 0.0309 & 0.0613 & 2.649 & 2.900 & 0.294 & 3.835 & 0.241 & 0.277 & 0.362 & 0.362 \\
\hline & 3 & 0.8 & 10 & 10 & 12.336 & 0.798 & 0.0309 & 0.0613 & 2.871 & 2.822 & 0.287 & 4.262 & 0.240 & 0.277 & 0.362 & 0.362 \\
\hline & 3 & 0.8 & 11 & 10 & 13.571 & 1.000 & 0.0309 & 0.0613 & 2.892 & 2.995 & 0.263 & 4.689 & 0.255 & 0.277 & 0.362 & 0.362 \\
\hline \multirow[t]{3}{*}{ B700 } & 3 & 0.8 & 9 & 13 & 11.100 & 0 & 0.0309 & 0.0613 & 2.224 & 2.375 & 0.247 & 2.950 & 0.208 & 0.268 & 0.356 & 0.356 \\
\hline & 3 & 0.8 & 10 & 13 & 12.336 & 0.798 & 0.0309 & 0.0613 & 2.407 & 2.347 & 0.241 & 3.278 & 0.201 & 0.268 & 0.360 & 0.360 \\
\hline & 3 & 0.8 & 11 & 13 & 13.571 & 1.000 & 0.0309 & 0.0613 & 2.412 & 2.500 & 0.219 & 3.607 & 0.207 & 0.268 & 0.362 & 0.362 \\
\hline \multirow[t]{3}{*}{ B700 } & 3 & 0.8 & 9 & 16 & 11.1 & 0 & 0.0309 & 0.0613 & 1.510 & 2.012 & 0.168 & 2.397 & 0.192 & 0.263 & 0.349 & 0.349 \\
\hline & 3 & 0.8 & 10 & 16 & 12.336 & 0.798 & 0.0309 & 0.0613 & 1.620 & 2.020 & 0.162 & 2.664 & 0.182 & 0.263 & 0.352 & 0.352 \\
\hline & 3 & 0.8 & 11 & 16 & 13.571 & 1.000 & 0.0309 & 0.0613 & 1.680 & 2.161 & 0.153 & 2.930 & 0.185 & 0.263 & 0.356 & 0.356 \\
\hline \multirow[t]{3}{*}{ B700 } & 3 & 0.8 & 9 & 24 & 11.1 & 0 & 0.0309 & 0.0613 & 1.320 & 1.435 & 0.147 & 1.598 & 0.172 & 0.255 & 0.339 & 0.339 \\
\hline & 3 & 0.8 & 10 & 24 & 12.336 & 0.798 & 0.0309 & 0.0613 & 1.370 & 1.504 & 0.137 & 1.776 & 0.161 & 0.255 & 0.341 & 0.341 \\
\hline & 3 & 0.8 & 11 & 24 & 13.571 & 1.000 & 0.0309 & 0.0613 & 1.440 & 1.628 & 0.131 & 1.954 & 0.160 & 0.255 & 0.343 & 0.343 \\
\hline \multirow[t]{3}{*}{ B800 } & 3 & 0.8 & 9 & 20 & 11.1 & 0 & 0.0441 & 0.0810 & 1.500 & 1.674 & 0.167 & 1.992 & 0.181 & 0.259 & 0.343 & 0.343 \\
\hline & 3 & 0.8 & 10 & 20 & 12.336 & 0.798 & 0.0441 & 0.0810 & 1.570 & 1.717 & 0.157 & 2.213 & 0.171 & 0.259 & 0.345 & 0.345 \\
\hline & 3 & 0.8 & 11 & 20 & 13.571 & 1.000 & 0.0441 & 0.0810 & 1.540 & 1.847 & 0.140 & 2.435 & 0.172 & 0.259 & 0.348 & 0.348 \\
\hline \multirow[t]{3}{*}{ B800 } & 3 & 0.8 & 9 & 26 & 11.1 & 0 & 0.0441 & 0.0810 & 1.310 & 1.340 & 0.146 & 1.532 & 0.171 & 0.255 & 0.337 & 0.337 \\
\hline & 3 & 0.8 & 10 & 26 & 12.336 & 0.798 & 0.0441 & 0.0810 & 1.410 & 1.420 & 0.141 & 1.703 & 0.159 & 0.255 & 0.339 & 0.339 \\
\hline & 3 & 0.8 & 11 & 26 & 13.571 & 1.000 & 0.0441 & 0.0810 & 1.410 & 1.542 & 0.128 & 1.873 & 0.159 & 0.255 & 0.341 & 0.341 \\
\hline \multirow[t]{3}{*}{ B900 } & 3 & 0.8 & 9 & 24 & 11.1 & 0 & 0.0600 & 0.1022 & 1.410 & 1.435 & 0.157 & 1.724 & 0.175 & 0.256 & 0.339 & 0.339 \\
\hline & 3 & 0.8 & 10 & 24 & 12.336 & 0.798 & 0.0600 & 0.1022 & 1.460 & 1.504 & 0.146 & 1.916 & 0.164 & 0.256 & 0.341 & 0.341 \\
\hline & 3 & 0.8 & 11 & 24 & 13.571 & 1.000 & 0.0600 & 0.1022 & 1.440 & 1.628 & 0.131 & 2.108 & 0.164 & 0.256 & 0.343 & 0.343 \\
\hline \multirow[t]{3}{*}{ B900 } & 3 & 0.8 & 9 & 30 & 11.1 & 0 & 0.0600 & 0.1022 & 1.300 & 1.184 & 0.144 & 1.379 & 0.167 & 0.253 & 0.335 & 0.335 \\
\hline & 3 & 0.8 & 10 & 30 & 12.336 & 0.798 & 0.0600 & 0.1022 & 1.320 & 1.284 & 0.132 & 1.533 & 0.156 & 0.253 & 0.337 & 0.337 \\
\hline & 3 & 0.8 & 11 & 30 & 13.571 & 1.000 & 0.0600 & 0.1022 & 1.370 & 1.403 & 0.125 & 1.686 & 0.155 & 0.253 & 0.338 & 0.338 \\
\hline \multirow[t]{3}{*}{ B1000 } & 3 & 0.8 & 9 & 26 & 11.1 & 0 & 0.0787 & 0.1244 & 1.390 & 1.340 & 0.154 & 1.652 & 0.173 & 0.256 & 0.337 & 0.337 \\
\hline & 3 & 0.8 & 10 & 26 & 12.336 & 0.798 & 0.0787 & 0.1244 & 1.400 & 1.420 & 0.140 & 1.836 & 0.162 & 0.256 & 0.339 & 0.339 \\
\hline & 3 & 0.8 & 11 & 26 & 13.571 & 1.000 & 0.0787 & 0.1244 & 1.370 & 1.542 & 0.125 & 2.020 & 0.162 & 0.256 & 0.341 & 0.341 \\
\hline \multirow[t]{3}{*}{ B1000 } & 3 & 0.8 & 9 & 32 & 11.1 & 0 & 0.0787 & 0.1244 & 1.270 & 1.119 & 0.141 & 1.342 & 0.167 & 0.253 & 0.334 & 0.334 \\
\hline & 3 & 0.8 & 10 & 32 & 12.336 & 0.798 & 0.0787 & 0.1244 & 1.290 & 1.228 & 0.129 & 1.492 & 0.155 & 0.253 & 0.335 & 0.335 \\
\hline & 3 & 0.8 & 11 & 32 & 13.571 & 1.000 & 0.0787 & 0.1244 & 1.340 & 1.346 & 0.122 & 1.641 & 0.154 & 0.253 & 0.337 & 0.337 \\
\hline
\end{tabular}


Table A. 35: Three-Lane Bridge Shear Distribution Factors Comparison at ULS for CHBDC 2014, Alberta 2015, and AASHTO 2012

\begin{tabular}{|c|c|c|c|c|c|c|c|c|c|c|c|c|c|c|c|c|}
\hline \multicolumn{17}{|c|}{ Three Lane Bridge Shear Distribution Factors at Ultimate Limit States } \\
\hline \multicolumn{9}{|c|}{ Bridge Configuration } & \multicolumn{2}{|c|}{ CHBDC 2006} & \multicolumn{3}{|c|}{ CHBDC 2014} & \multirow{2}{*}{\begin{tabular}{|l|} 
Alberta 2015 \\
$\left(\mathbf{F}_{\mathrm{T}}\right)_{\text {Alberta }}$ \\
\end{tabular}} & \multicolumn{2}{|c|}{ AASHTO 2012} \\
\hline Girder Size & $\mathbf{n}$ & $\mathbf{R}_{\mathbf{L}}$ & $\mathbf{N}$ & $\mathbf{L}(\mathbf{m})$ & $\mathbf{B}(\mathbf{m})$ & $\mu$ & $\mathrm{I}\left(\mathbf{m}^{4}\right)$ & $\mathbf{J}\left(\mathbf{m}^{4}\right)$ & $\left(\mathbf{F}_{\mathbf{v}}\right)_{\mathrm{FE}}$. & $\left(\mathbf{F}_{\mathbf{v}}\right)_{\mathbf{E Q}}$ & $\left(\mathbf{F}_{\mathrm{T}}\right)_{\mathrm{FE} .}$ & $\boldsymbol{\beta}$ & $\left(\mathbf{F}_{\mathrm{T}}\right)_{\mathrm{EQ}}$. & & $\left(\mathbf{F}_{\mathrm{T}}\right)_{\text {AASHTO Ext. }}\left(\mathbf{F}_{\mathrm{T}}\right.$ & T) AASHTO Int \\
\hline \multirow[t]{3}{*}{ B700 } & 3 & 0.8 & 9 & 10 & 11.100 & 0 & 0.0309 & 0.0613 & 1.395 & 1.441 & 0.372 & 3.835 & 0.309 & 0.380 & 0.754 & 0.674 \\
\hline & 3 & 0.8 & 10 & 10 & 12.336 & 0.798 & 0.0309 & 0.0613 & 1.573 & 1.602 & 0.378 & 4.262 & 0.309 & 0.380 & 0.754 & 0.674 \\
\hline & 3 & 0.8 & 11 & 10 & 13.571 & 1.000 & 0.0309 & 0.0613 & 1.731 & 1.762 & 0.378 & 4.689 & 0.309 & 0.380 & 0.754 & 0.674 \\
\hline \multirow[t]{3}{*}{ B700 } & 3 & 0.8 & 9 & 13 & 11.100 & 0 & 0.0309 & 0.0613 & 1.443 & 1.412 & 0.385 & 2.950 & 0.309 & 0.401 & 0.735 & 0.657 \\
\hline & 3 & 0.8 & 10 & 13 & 12.336 & 0.798 & 0.0309 & 0.0613 & 1.622 & 1.569 & 0.389 & 3.278 & 0.309 & 0.401 & 0.735 & 0.657 \\
\hline & 3 & 0.8 & 11 & 13 & 13.571 & 1.000 & 0.0309 & 0.0613 & 1.765 & 1.726 & 0.385 & 3.607 & 0.309 & 0.401 & 0.735 & 0.657 \\
\hline \multirow[t]{3}{*}{ B700 } & 3 & 0.8 & 9 & 16 & 11.1 & 0 & 0.0309 & 0.0613 & 1.430 & 1.384 & 0.381 & 2.397 & 0.309 & 0.384 & 0.719 & 0.643 \\
\hline & 3 & 0.8 & 10 & 16 & 12.336 & 0.798 & 0.0309 & 0.0613 & 1.530 & 1.538 & 0.367 & 2.664 & 0.309 & 0.384 & 0.719 & 0.643 \\
\hline & 3 & 0.8 & 11 & 16 & 13.571 & 1.000 & 0.0309 & 0.0613 & 1.760 & 1.692 & 0.384 & 2.930 & 0.309 & 0.384 & 0.719 & 0.643 \\
\hline \multirow[t]{3}{*}{ B700 } & 3 & 0.8 & 9 & 24 & 11.1 & 0 & 0.0309 & 0.0613 & 1.300 & 1.314 & 0.347 & 1.598 & 0.309 & 0.286 & 0.691 & 0.618 \\
\hline & 3 & 0.8 & 10 & 24 & 12.336 & 0.798 & 0.0309 & 0.0613 & 1.440 & 1.461 & 0.346 & 1.776 & 0.309 & 0.286 & 0.691 & 0.618 \\
\hline & 3 & 0.8 & 11 & 24 & 13.571 & 1.000 & 0.0309 & 0.0613 & 1.580 & 1.607 & 0.345 & 1.954 & 0.309 & 0.286 & 0.691 & 0.618 \\
\hline \multirow[t]{3}{*}{ B800 } & 3 & 0.8 & 9 & 20 & 11.1 & 0 & 0.0441 & 0.0810 & 1.390 & 1.348 & 0.371 & 1.992 & 0.309 & 0.339 & 0.708 & 0.633 \\
\hline & 3 & 0.8 & 10 & 20 & 12.336 & 0.798 & 0.0441 & 0.0810 & 1.410 & 1.498 & 0.338 & 2.213 & 0.309 & 0.339 & 0.708 & 0.633 \\
\hline & 3 & 0.8 & 11 & 20 & 13.571 & 1.000 & 0.0441 & 0.0810 & 1.640 & 1.648 & 0.358 & 2.435 & 0.309 & 0.339 & 0.708 & 0.633 \\
\hline \multirow[t]{3}{*}{ B800 } & 3 & 0.8 & 9 & 26 & 11.1 & 0 & 0.0441 & 0.0810 & 1.300 & 1.298 & 0.347 & 1.532 & 0.309 & 0.286 & 0.690 & 0.617 \\
\hline & 3 & 0.8 & 10 & 26 & 12.336 & 0.798 & 0.0441 & 0.0810 & 1.440 & 1.442 & 0.346 & 1.703 & 0.309 & 0.286 & 0.690 & 0.617 \\
\hline & 3 & 0.8 & 11 & 26 & 13.571 & 1.000 & 0.0441 & 0.0810 & 1.570 & 1.587 & 0.343 & 1.873 & 0.309 & 0.286 & 0.690 & 0.617 \\
\hline \multirow[t]{3}{*}{ B900 } & 3 & 0.8 & 9 & 24 & 11.1 & 0 & 0.0600 & 0.1022 & 1.300 & 1.314 & 0.347 & 1.724 & 0.309 & 0.287 & 0.700 & 0.626 \\
\hline & 3 & 0.8 & 10 & 24 & 12.336 & 0.798 & 0.0600 & 0.1022 & 1.440 & 1.461 & 0.346 & 1.916 & 0.309 & 0.287 & 0.700 & 0.626 \\
\hline & 3 & 0.8 & 11 & 24 & 13.571 & 1.000 & 0.0600 & 0.1022 & 1.580 & 1.607 & 0.345 & 2.108 & 0.309 & 0.287 & 0.700 & 0.626 \\
\hline \multirow[t]{3}{*}{ B900 } & 3 & 0.8 & 9 & 30 & 11.1 & 0 & 0.0600 & 0.1022 & 1.270 & 1.267 & 0.339 & 1.379 & 0.309 & 0.281 & 0.684 & 0.612 \\
\hline & 3 & 0.8 & 10 & 30 & 12.336 & 0.798 & 0.0600 & 0.1022 & 1.450 & 1.408 & 0.348 & 1.533 & 0.309 & 0.281 & 0.684 & 0.612 \\
\hline & 3 & 0.8 & 11 & 30 & 13.571 & 1.000 & 0.0600 & 0.1022 & 1.560 & 1.548 & 0.340 & 1.686 & 0.309 & 0.281 & 0.684 & 0.612 \\
\hline \multirow[t]{3}{*}{ B1000 } & 3 & 0.8 & 9 & 26 & 11.1 & 0 & 0.0787 & 0.1244 & 1.300 & 1.298 & 0.347 & 1.652 & 0.309 & 0.287 & 0.698 & 0.624 \\
\hline & 3 & 0.8 & 10 & 26 & 12.336 & 0.798 & 0.0787 & 0.1244 & 1.440 & 1.442 & 0.346 & 1.836 & 0.309 & 0.287 & 0.698 & 0.624 \\
\hline & 3 & 0.8 & 11 & 26 & 13.571 & 1.000 & 0.0787 & 0.1244 & 1.570 & 1.587 & 0.343 & 2.020 & 0.309 & 0.287 & 0.698 & 0.624 \\
\hline \multirow[t]{3}{*}{ B1000 } & 3 & 0.8 & 9 & 32 & 11.1 & 0 & 0.0787 & 0.1244 & 1.270 & 1.251 & 0.339 & 1.342 & 0.309 & 0.280 & 0.683 & 0.611 \\
\hline & 3 & 0.8 & 10 & 32 & 12.336 & 0.798 & 0.0787 & 0.1244 & 1.390 & 1.391 & 0.334 & 1.492 & 0.309 & 0.280 & 0.683 & 0.611 \\
\hline & 3 & 0.8 & 11 & 32 & 13.571 & 1.000 & 0.0787 & 0.1244 & 1.550 & 1.530 & 0.338 & 1.641 & 0.309 & 0.280 & 0.683 & 0.611 \\
\hline
\end{tabular}


Table A. 36: Three-Lane Bridge Shear Distribution Factors Comparison at FLS for CHBDC 2014, Alberta 2015, and AASHTO 2012

\begin{tabular}{|c|c|c|c|c|c|c|c|c|c|c|c|c|c|c|c|c|}
\hline \multicolumn{17}{|c|}{ Three Lane Bridge Shear Distribution Factors at Fatigue Limit States } \\
\hline \multicolumn{9}{|c|}{ Bridge Configuration } & \multicolumn{2}{|c|}{ CHBDC 2006} & \multicolumn{3}{|c|}{ CHBDC 2014} & \multirow{2}{*}{\begin{tabular}{|l|} 
Alberta 2015 \\
$\left(F_{T}\right)_{\text {Alberta }}$ \\
\end{tabular}} & \multicolumn{2}{|c|}{ AASHTO 2012} \\
\hline Girder Size & $\mathbf{n}$ & $\mathbf{R}_{\mathbf{L}}$ & $\mathbf{N}$ & $\mathbf{L}(\mathbf{m})$ & $\mathbf{B}(\mathbf{m})$ & $\mu$ & $\mathrm{I}\left(\mathbf{m}^{4}\right)$ & $\mathbf{J}\left(\mathbf{m}^{4}\right)$ & $\left(\mathbf{F}_{\mathrm{V}}\right)_{\mathrm{FE} .}$ & $\left(\mathbf{F}_{\mathrm{v}}\right)_{\mathrm{EQ}}$ & $\left(\mathbf{F}_{\mathrm{T}}\right)_{\mathrm{FE} .}$ & $\boldsymbol{\beta}$ & $\left(\mathbf{F}_{\mathrm{T}}\right)_{\mathrm{EQ}}$. & & $\left(F_{T}\right)_{\text {AASHTO Ext. }}$ & $\left(\mathbf{F}_{\mathrm{T}}\right)_{\text {AASHTO Int }}$ \\
\hline \multirow[t]{3}{*}{ B700 } & 3 & 0.8 & 9 & 10 & 11.100 & 0 & 0.0309 & 0.0613 & 3.591 & 3.815 & 0.399 & 3.835 & 0.291 & 0.380 & 0.754 & 0.674 \\
\hline & 3 & 0.8 & 10 & 10 & 12.336 & 0.798 & 0.0309 & 0.0613 & 4.096 & 4.240 & 0.410 & 4.262 & 0.291 & 0.380 & 0.754 & 0.674 \\
\hline & 3 & 0.8 & 11 & 10 & 13.571 & 1.000 & 0.0309 & 0.0613 & 4.315 & 4.664 & 0.392 & 4.689 & 0.291 & 0.380 & 0.754 & 0.674 \\
\hline \multirow[t]{3}{*}{ B700 } & 3 & 0.8 & 9 & 13 & 11.100 & 0 & 0.0309 & 0.0613 & 3.705 & 3.481 & 0.412 & 2.950 & 0.291 & 0.401 & 0.735 & 0.657 \\
\hline & 3 & 0.8 & 10 & 13 & 12.336 & 0.798 & 0.0309 & 0.0613 & 4.219 & 3.869 & 0.422 & 3.278 & 0.291 & 0.401 & 0.735 & 0.657 \\
\hline & 3 & 0.8 & 11 & 13 & 13.571 & 1.000 & 0.0309 & 0.0613 & 4.409 & 4.256 & 0.401 & 3.607 & 0.291 & 0.401 & 0.735 & 0.657 \\
\hline \multirow[t]{3}{*}{ B700 } & 3 & 0.8 & 9 & 16 & 11.1 & 0 & 0.0309 & 0.0613 & 2.940 & 3.201 & 0.327 & 2.397 & 0.291 & 0.384 & 0.719 & 0.643 \\
\hline & 3 & 0.8 & 10 & 16 & 12.336 & 0.798 & 0.0309 & 0.0613 & 3.480 & 3.557 & 0.348 & 2.664 & 0.291 & 0.384 & 0.719 & 0.643 \\
\hline & 3 & 0.8 & 11 & 16 & 13.571 & 1.000 & 0.0309 & 0.0613 & 3.720 & 3.914 & 0.338 & 2.930 & 0.291 & 0.384 & 0.719 & 0.643 \\
\hline \multirow[t]{3}{*}{ B700 } & 3 & 0.8 & 9 & 24 & 11.1 & 0 & 0.0309 & 0.0613 & 2.460 & 2.636 & 0.273 & 1.598 & 0.291 & 0.286 & 0.691 & 0.618 \\
\hline & 3 & 0.8 & 10 & 24 & 12.336 & 0.798 & 0.0309 & 0.0613 & 2.880 & 2.929 & 0.288 & 1.776 & 0.291 & 0.286 & 0.691 & 0.618 \\
\hline & 3 & 0.8 & 11 & 24 & 13.571 & 1.000 & 0.0309 & 0.0613 & 3.120 & 3.222 & 0.284 & 1.954 & 0.291 & 0.286 & 0.691 & 0.618 \\
\hline \multirow[t]{3}{*}{ B800 } & 3 & 0.8 & 9 & 20 & 11.1 & 0 & 0.0441 & 0.0810 & 2.660 & 2.891 & 0.296 & 1.992 & 0.291 & 0.339 & 0.708 & 0.633 \\
\hline & 3 & 0.8 & 10 & 20 & 12.336 & 0.798 & 0.0441 & 0.0810 & 3.020 & 3.213 & 0.302 & 2.213 & 0.291 & 0.339 & 0.708 & 0.633 \\
\hline & 3 & 0.8 & 11 & 20 & 13.571 & 1.000 & 0.0441 & 0.0810 & 3.230 & 3.535 & 0.294 & 2.435 & 0.291 & 0.339 & 0.708 & 0.633 \\
\hline \multirow[t]{3}{*}{ B800 } & 3 & 0.8 & 9 & 26 & 11.1 & 0 & 0.0441 & 0.0810 & 2.410 & 2.524 & 0.268 & 1.532 & 0.291 & 0.286 & 0.690 & 0.617 \\
\hline & 3 & 0.8 & 10 & 26 & 12.336 & 0.798 & 0.0441 & 0.0810 & 2.780 & 2.805 & 0.278 & 1.703 & 0.291 & 0.286 & 0.690 & 0.617 \\
\hline & 3 & 0.8 & 11 & 26 & 13.571 & 1.000 & 0.0441 & 0.0810 & 3.000 & 3.086 & 0.273 & 1.873 & 0.291 & 0.286 & 0.690 & 0.617 \\
\hline \multirow[t]{3}{*}{ B900 } & 3 & 0.8 & 9 & 24 & 11.1 & 0 & 0.0600 & 0.1022 & 2.460 & 2.636 & 0.273 & 1.724 & 0.291 & 0.287 & 0.700 & 0.626 \\
\hline & 3 & 0.8 & 10 & 24 & 12.336 & 0.798 & 0.0600 & 0.1022 & 2.880 & 2.929 & 0.288 & 1.916 & 0.291 & 0.287 & 0.700 & 0.626 \\
\hline & 3 & 0.8 & 11 & 24 & 13.571 & 1.000 & 0.0600 & 0.1022 & 3.120 & 3.222 & 0.284 & 2.108 & 0.291 & 0.287 & 0.700 & 0.626 \\
\hline \multirow[t]{3}{*}{ B900 } & 3 & 0.8 & 9 & 30 & 11.1 & 0 & 0.0600 & 0.1022 & 2.330 & 2.327 & 0.259 & 1.379 & 0.291 & 0.281 & 0.684 & 0.612 \\
\hline & 3 & 0.8 & 10 & 30 & 12.336 & 0.798 & 0.0600 & 0.1022 & 2.570 & 2.587 & 0.257 & 1.533 & 0.291 & 0.281 & 0.684 & 0.612 \\
\hline & 3 & 0.8 & 11 & 30 & 13.571 & 1.000 & 0.0600 & 0.1022 & 2.910 & 2.845 & 0.265 & 1.686 & 0.291 & 0.281 & 0.684 & 0.612 \\
\hline \multirow[t]{3}{*}{ B1000 } & 3 & 0.8 & 9 & 26 & 11.1 & 0 & 0.0787 & 0.1244 & 2.410 & 2.524 & 0.268 & 1.652 & 0.291 & 0.287 & 0.698 & 0.624 \\
\hline & 3 & 0.8 & 10 & 26 & 12.336 & 0.798 & 0.0787 & 0.1244 & 2.780 & 2.805 & 0.278 & 1.836 & 0.291 & 0.287 & 0.698 & 0.624 \\
\hline & 3 & 0.8 & 11 & 26 & 13.571 & 1.000 & 0.0787 & 0.1244 & 3.000 & 3.086 & 0.273 & 2.020 & 0.291 & 0.287 & 0.698 & 0.624 \\
\hline \multirow[t]{3}{*}{ B1000 } & 3 & 0.8 & 9 & 32 & 11.1 & 0 & 0.0787 & 0.1244 & 2.330 & 2.240 & 0.259 & 1.342 & 0.291 & 0.280 & 0.683 & 0.611 \\
\hline & 3 & 0.8 & 10 & 32 & 12.336 & 0.798 & 0.0787 & 0.1244 & 2.660 & 2.489 & 0.266 & 1.492 & 0.291 & 0.280 & 0.683 & 0.611 \\
\hline & 3 & 0.8 & 11 & 32 & 13.571 & 1.000 & 0.0787 & 0.1244 & 2.760 & 2.739 & 0.251 & 1.641 & 0.291 & 0.280 & 0.683 & 0.611 \\
\hline
\end{tabular}




\section{Table A. 37: Four-Lane Bridge Moment Distribution Factors Comparison at ULS for CHBDC 2014, Alberta 2015, and AASHTO 2012}

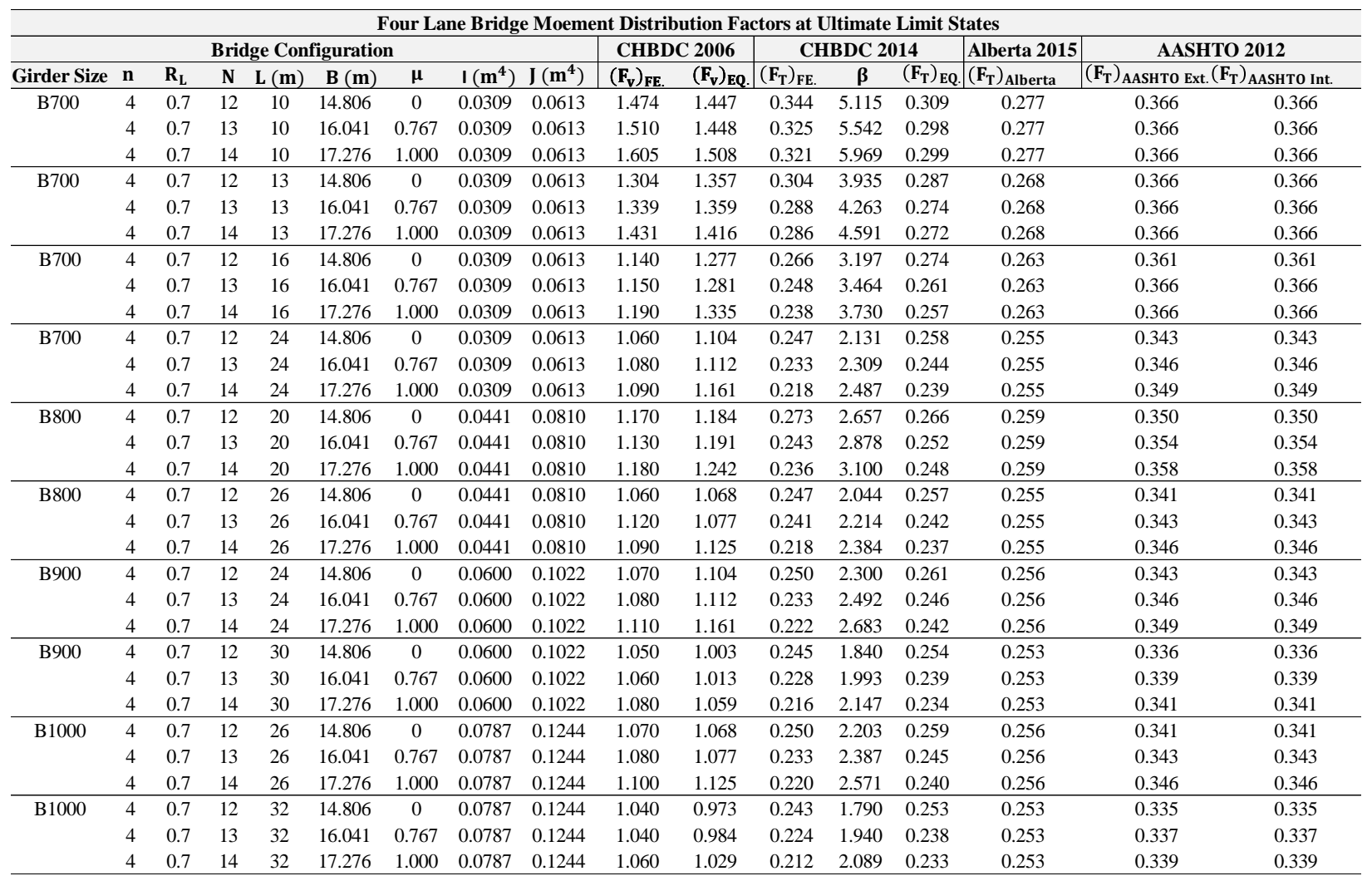


Table A. 38: Four-Lane Bridge Moment Distribution Factors Comparison at FLS for CHBDC 2014, Alberta 2015, and AASHTO 2012

\begin{tabular}{|c|c|c|c|c|c|c|c|c|c|c|c|c|c|c|c|c|}
\hline \multicolumn{17}{|c|}{ Four Lane Bridge Moment Distribution Factors at Fatigue Limit States } \\
\hline \multicolumn{9}{|c|}{ Bridge Configuration } & \multicolumn{2}{|c|}{ CHBDC 2006} & \multicolumn{3}{|c|}{ CHBDC 2014} & \multirow{2}{*}{\begin{tabular}{|l|} 
Alberta 2015 \\
$\left(F_{T}\right)_{\text {Alberta }}$ \\
\end{tabular}} & \multicolumn{2}{|c|}{ AASHTO 2012} \\
\hline Girder Size & $\mathbf{n}$ & $\mathbf{R}_{\mathbf{L}}$ & $\mathbf{N}$ & $\mathbf{L}(\mathbf{m})$ & B (m) & $\mu$ & $\mathrm{I}\left(\mathbf{m}^{4}\right)$ & $\mathbf{J}\left(\mathbf{m}^{\mathbf{4}}\right)$ & $\left(\mathbf{F}_{\mathrm{v}}\right)_{\mathrm{FE}}$ & $\left(\mathbf{F}_{\mathrm{v}}\right)_{\mathrm{EQ}}$. & $\left(\mathbf{F}_{\mathrm{T}}\right)_{\mathrm{FE} .}$ & $\boldsymbol{\beta}$ & $\left(\mathbf{F}_{\mathbf{T}}\right)_{\mathbf{E Q}}$ & & $\left(\mathbf{F}_{\mathrm{T}}\right)_{\text {AASHTO Ext. }}$ & $\left(\mathrm{F}_{\mathrm{T}}\right)_{\text {AASHTO Int. }}$ \\
\hline \multirow[t]{3}{*}{ B700 } & 4 & 0.7 & 12 & 10 & 14.806 & 0 & 0.0309 & 0.0613 & 3.065 & 3.393 & 0.255 & 5.115 & 0.307 & 0.277 & 0.366 & 0.366 \\
\hline & 4 & 0.7 & 13 & 10 & 16.041 & 0.767 & 0.0309 & 0.0613 & 3.562 & 3.521 & 0.274 & 5.542 & 0.320 & 0.277 & 0.366 & 0.366 \\
\hline & 4 & 0.7 & 14 & 10 & 17.276 & 1.000 & 0.0309 & 0.0613 & 3.641 & 3.721 & 0.260 & 5.969 & 0.349 & 0.277 & 0.366 & 0.366 \\
\hline \multirow[t]{3}{*}{ B700 } & 4 & 0.7 & 12 & 13 & 14.806 & 0 & 0.0309 & 0.0613 & 2.595 & 2.678 & 0.216 & 3.935 & 0.241 & 0.268 & 0.366 & 0.366 \\
\hline & 4 & 0.7 & 13 & 13 & 16.041 & 0.767 & 0.0309 & 0.0613 & 2.987 & 2.809 & 0.230 & 4.263 & 0.240 & 0.268 & 0.366 & 0.366 \\
\hline & 4 & 0.7 & 14 & 13 & 17.276 & 1.000 & 0.0309 & 0.0613 & 3.035 & 2.983 & 0.217 & 4.591 & 0.249 & 0.268 & 0.366 & 0.366 \\
\hline \multirow[t]{3}{*}{ B700 } & 4 & 0.7 & 12 & 16 & 14.806 & 0 & 0.0309 & 0.0613 & 1.750 & 2.216 & 0.146 & 3.197 & 0.212 & 0.263 & 0.361 & 0.361 \\
\hline & 4 & 0.7 & 13 & 16 & 16.041 & 0.767 & 0.0309 & 0.0613 & 1.870 & 2.351 & 0.144 & 3.464 & 0.208 & 0.263 & 0.366 & 0.366 \\
\hline & 4 & 0.7 & 14 & 16 & 17.276 & 1.000 & 0.0309 & 0.0613 & 1.930 & 2.508 & 0.138 & 3.730 & 0.211 & 0.263 & 0.366 & 0.366 \\
\hline \multirow[t]{3}{*}{ B700 } & 4 & 0.7 & 12 & 24 & 14.806 & 0 & 0.0309 & 0.0613 & 1.530 & 1.529 & 0.128 & 2.131 & 0.181 & 0.255 & 0.343 & 0.343 \\
\hline & 4 & 0.7 & 13 & 24 & 16.041 & 0.767 & 0.0309 & 0.0613 & 1.620 & 1.672 & 0.125 & 2.309 & 0.173 & 0.255 & 0.346 & 0.346 \\
\hline & 4 & 0.7 & 14 & 24 & 17.276 & 1.000 & 0.0309 & 0.0613 & 1.710 & 1.808 & 0.122 & 2.487 & 0.173 & 0.255 & 0.349 & 0.349 \\
\hline \multirow[t]{3}{*}{ B800 } & 4 & 0.7 & 12 & 20 & 14.806 & 0 & 0.0441 & 0.0810 & 1.690 & 1.807 & 0.141 & 2.657 & 0.195 & 0.259 & 0.350 & 0.350 \\
\hline & 4 & 0.7 & 13 & 20 & 16.041 & 0.767 & 0.0441 & 0.0810 & 1.800 & 1.946 & 0.138 & 2.878 & 0.189 & 0.259 & 0.354 & 0.354 \\
\hline & 4 & 0.7 & 14 & 20 & 17.276 & 1.000 & 0.0441 & 0.0810 & 1.850 & 2.090 & 0.132 & 3.100 & 0.190 & 0.259 & 0.358 & 0.358 \\
\hline \multirow[t]{3}{*}{ B800 } & 4 & 0.7 & 12 & 26 & 14.806 & 0 & 0.0441 & 0.0810 & 1.500 & 1.421 & 0.125 & 2.044 & 0.179 & 0.255 & 0.341 & 0.341 \\
\hline & 4 & 0.7 & 13 & 26 & 16.041 & 0.767 & 0.0441 & 0.0810 & 1.580 & 1.566 & 0.122 & 2.214 & 0.171 & 0.255 & 0.343 & 0.343 \\
\hline & 4 & 0.7 & 14 & 26 & 17.276 & 1.000 & 0.0441 & 0.0810 & 1.610 & 1.700 & 0.115 & 2.384 & 0.170 & 0.255 & 0.346 & 0.346 \\
\hline \multirow[t]{3}{*}{ B900 } & 4 & 0.7 & 12 & 24 & 14.806 & 0 & 0.0600 & 0.1022 & 1.520 & 1.529 & 0.127 & 2.300 & 0.185 & 0.256 & 0.343 & 0.343 \\
\hline & 4 & 0.7 & 13 & 24 & 16.041 & 0.767 & 0.0600 & 0.1022 & 1.600 & 1.672 & 0.123 & 2.492 & 0.178 & 0.256 & 0.346 & 0.346 \\
\hline & 4 & 0.7 & 14 & 24 & 17.276 & 1.000 & 0.0600 & 0.1022 & 1.670 & 1.808 & 0.119 & 2.683 & 0.178 & 0.256 & 0.349 & 0.349 \\
\hline \multirow[t]{3}{*}{ B900 } & 4 & 0.7 & 12 & 30 & 14.806 & 0 & 0.0600 & 0.1022 & 1.350 & 1.247 & 0.113 & 1.840 & 0.174 & 0.253 & 0.336 & 0.336 \\
\hline & 4 & 0.7 & 13 & 30 & 16.041 & 0.767 & 0.0600 & 0.1022 & 1.450 & 1.397 & 0.112 & 1.993 & 0.166 & 0.253 & 0.339 & 0.339 \\
\hline & 4 & 0.7 & 14 & 30 & 17.276 & 1.000 & 0.0600 & 0.1022 & 1.490 & 1.528 & 0.106 & 2.147 & 0.164 & 0.253 & 0.341 & 0.341 \\
\hline \multirow[t]{3}{*}{ B1000 } & 4 & 0.7 & 12 & 26 & 14.806 & 0 & 0.0787 & 0.1244 & 1.500 & 1.421 & 0.125 & 2.203 & 0.183 & 0.256 & 0.341 & 0.341 \\
\hline & 4 & 0.7 & 13 & 26 & 16.041 & 0.767 & 0.0787 & 0.1244 & 1.510 & 1.566 & 0.116 & 2.387 & 0.175 & 0.256 & 0.343 & 0.343 \\
\hline & 4 & 0.7 & 14 & 26 & 17.276 & 1.000 & 0.0787 & 0.1244 & 1.620 & 1.700 & 0.116 & 2.571 & 0.175 & 0.256 & 0.346 & 0.346 \\
\hline \multirow[t]{3}{*}{ B1000 } & 4 & 0.7 & 12 & 32 & 14.806 & 0 & 0.0787 & 0.1244 & 1.350 & 1.176 & 0.113 & 1.790 & 0.173 & 0.253 & 0.335 & 0.335 \\
\hline & 4 & 0.7 & 13 & 32 & 16.041 & 0.767 & 0.0787 & 0.1244 & 1.410 & 1.328 & 0.108 & 1.940 & 0.165 & 0.253 & 0.337 & 0.337 \\
\hline & 4 & 0.7 & 14 & 32 & 17.276 & 1.000 & 0.0787 & 0.1244 & 1.450 & 1.459 & 0.104 & 2.089 & 0.163 & 0.253 & 0.339 & 0.339 \\
\hline
\end{tabular}


Table A. 39: Four-Lane Bridge Shear Distribution Factors Comparison at ULS for CHBDC 2014, Alberta 2015, and AASHTO 2012

\begin{tabular}{|c|c|c|c|c|c|c|c|c|c|c|c|c|c|c|c|c|}
\hline \multicolumn{17}{|c|}{ Four Lane Bridge Shear Distribution Factors at Ultimate Limit States } \\
\hline \multicolumn{9}{|c|}{ Bridge Configuration } & \multicolumn{2}{|c|}{ CHBDC 2006} & \multicolumn{3}{|c|}{ CHBDC 2014} & \multirow{2}{*}{\begin{tabular}{|l|} 
Alberta 2015 \\
$\left(\mathbf{F}_{\mathrm{T}}\right)_{\text {Alberta }}$ \\
\end{tabular}} & \multicolumn{2}{|c|}{ AASHTO 2012} \\
\hline Girder Size & $\mathbf{n}$ & $\mathbf{R}_{\mathbf{L}}$ & $\mathbf{N}$ & $\mathbf{L}(\mathbf{m})$ & $\mathbf{B}(\mathbf{m})$ & $\mu$ & $I\left(\mathbf{m}^{4}\right)$ & $\mathbf{J}\left(\mathbf{m}^{4}\right)$ & $\left(\mathbf{F}_{\mathrm{v}}\right)_{\mathrm{FE}}$. & $\left(\mathbf{F}_{\mathbf{v}}\right)_{\mathrm{EQ}}$. & $\left(\mathbf{F}_{\mathrm{T}}\right)_{\mathrm{FE}}$ & $\boldsymbol{\beta}$ & $\left(\mathbf{F}_{\mathrm{T}}\right)_{\mathrm{EQ}}$. & & $\left(\mathbf{F}_{\mathrm{T}}\right)_{\mathrm{AASHTO}}$ & AASHTO Int. \\
\hline \multirow[t]{3}{*}{$\mathrm{B} 700$} & 4 & 0.7 & 12 & 10 & 14.806 & 0 & 0.0309 & 0.0613 & 1.639 & 1.659 & 0.382 & 5.115 & 0.309 & 0.380 & 0.754 & 0.674 \\
\hline & 4 & 0.7 & 13 & 10 & 16.041 & 0.767 & 0.0309 & 0.0613 & 1.752 & 1.797 & 0.377 & 5.542 & 0.309 & 0.380 & 0.754 & 0.674 \\
\hline & 4 & 0.7 & 14 & 10 & 17.276 & 1.000 & 0.0309 & 0.0613 & 1.911 & 1.936 & 0.382 & 5.969 & 0.309 & 0.380 & 0.754 & 0.674 \\
\hline \multirow[t]{3}{*}{ B700 } & 4 & 0.7 & 12 & 13 & 14.806 & 0 & 0.0309 & 0.0613 & 1.711 & 1.618 & 0.399 & 3.935 & 0.309 & 0.401 & 0.735 & 0.657 \\
\hline & 4 & 0.7 & 13 & 13 & 16.041 & 0.767 & 0.0309 & 0.0613 & 1.806 & 1.753 & 0.389 & 4.263 & 0.309 & 0.401 & 0.735 & 0.657 \\
\hline & 4 & 0.7 & 14 & 13 & 17.276 & 1.000 & 0.0309 & 0.0613 & 1.995 & 1.888 & 0.399 & 4.591 & 0.309 & 0.401 & 0.735 & 0.657 \\
\hline \multirow[t]{3}{*}{ B700 } & 4 & 0.7 & 12 & 16 & 14.806 & 0 & 0.0309 & 0.0613 & 1.580 & 1.578 & 0.369 & 3.197 & 0.309 & 0.384 & 0.719 & 0.643 \\
\hline & 4 & 0.7 & 13 & 16 & 16.041 & 0.767 & 0.0309 & 0.0613 & 1.600 & 1.710 & 0.345 & 3.464 & 0.309 & 0.384 & 0.719 & 0.643 \\
\hline & 4 & 0.7 & 14 & 16 & 17.276 & 1.000 & 0.0309 & 0.0613 & 1.880 & 1.842 & 0.376 & 3.730 & 0.309 & 0.384 & 0.719 & 0.643 \\
\hline \multirow[t]{3}{*}{ B700 } & 4 & 0.7 & 12 & 24 & 14.806 & 0 & 0.0309 & 0.0613 & 1.450 & 1.482 & 0.338 & 2.131 & 0.309 & 0.286 & 0.691 & 0.618 \\
\hline & 4 & 0.7 & 13 & 24 & 16.041 & 0.767 & 0.0309 & 0.0613 & 1.580 & 1.606 & 0.340 & 2.309 & 0.309 & 0.286 & 0.691 & 0.618 \\
\hline & 4 & 0.7 & 14 & 24 & 17.276 & 1.000 & 0.0309 & 0.0613 & 1.680 & 1.729 & 0.336 & 2.487 & 0.309 & 0.286 & 0.691 & 0.618 \\
\hline \multirow[t]{3}{*}{ B800 } & 4 & 0.7 & 12 & 20 & 14.806 & 0 & 0.0441 & 0.0810 & 1.550 & 1.529 & 0.362 & 2.657 & 0.309 & 0.339 & 0.708 & 0.633 \\
\hline & 4 & 0.7 & 13 & 20 & 16.041 & 0.767 & 0.0441 & 0.0810 & 1.670 & 1.656 & 0.360 & 2.878 & 0.309 & 0.339 & 0.708 & 0.633 \\
\hline & 4 & 0.7 & 14 & 20 & 17.276 & 1.000 & 0.0441 & 0.0810 & 1.760 & 1.784 & 0.352 & 3.100 & 0.309 & 0.339 & 0.708 & 0.633 \\
\hline \multirow[t]{3}{*}{ B800 } & 4 & 0.7 & 12 & 26 & 14.806 & 0 & 0.0441 & 0.0810 & 1.440 & 1.460 & 0.336 & 2.044 & 0.309 & 0.286 & 0.690 & 0.617 \\
\hline & 4 & 0.7 & 13 & 26 & 16.041 & 0.767 & 0.0441 & 0.0810 & 1.590 & 1.582 & 0.342 & 2.214 & 0.309 & 0.286 & 0.690 & 0.617 \\
\hline & 4 & 0.7 & 14 & 26 & 17.276 & 1.000 & 0.0441 & 0.0810 & 1.670 & 1.703 & 0.334 & 2.384 & 0.309 & 0.286 & 0.690 & 0.617 \\
\hline \multirow[t]{3}{*}{ B900 } & 4 & 0.7 & 12 & 24 & 14.806 & 0 & 0.0600 & 0.1022 & 1.450 & 1.482 & 0.338 & 2.300 & 0.309 & 0.287 & 0.700 & 0.626 \\
\hline & 4 & 0.7 & 13 & 24 & 16.041 & 0.767 & 0.0600 & 0.1022 & 1.580 & 1.606 & 0.340 & 2.492 & 0.309 & 0.287 & 0.700 & 0.626 \\
\hline & 4 & 0.7 & 14 & 24 & 17.276 & 1.000 & 0.0600 & 0.1022 & 1.680 & 1.729 & 0.336 & 2.683 & 0.309 & 0.287 & 0.700 & 0.626 \\
\hline \multirow[t]{3}{*}{ B900 } & 4 & 0.7 & 12 & 30 & 14.806 & 0 & 0.0600 & 0.1022 & 1.440 & 1.417 & 0.336 & 1.840 & 0.309 & 0.281 & 0.684 & 0.612 \\
\hline & 4 & 0.7 & 13 & 30 & 16.041 & 0.767 & 0.0600 & 0.1022 & 1.560 & 1.535 & 0.336 & 1.993 & 0.309 & 0.281 & 0.684 & 0.612 \\
\hline & 4 & 0.7 & 14 & 30 & 17.276 & 1.000 & 0.0600 & 0.1022 & 1.660 & 1.654 & 0.332 & 2.147 & 0.309 & 0.281 & 0.684 & 0.612 \\
\hline \multirow[t]{3}{*}{ B1000 } & 4 & 0.7 & 12 & 26 & 14.806 & 0 & 0.0787 & 0.1244 & 1.440 & 1.460 & 0.336 & 2.203 & 0.309 & 0.287 & 0.698 & 0.624 \\
\hline & 4 & 0.7 & 13 & 26 & 16.041 & 0.767 & 0.0787 & 0.1244 & 1.590 & 1.582 & 0.342 & 2.387 & 0.309 & 0.287 & 0.698 & 0.624 \\
\hline & 4 & 0.7 & 14 & 26 & 17.276 & 1.000 & 0.0787 & 0.1244 & 1.670 & 1.703 & 0.334 & 2.571 & 0.309 & 0.287 & 0.698 & 0.624 \\
\hline \multirow[t]{3}{*}{ B1000 } & 4 & 0.7 & 12 & 32 & 14.806 & 0 & 0.0787 & 0.1244 & 1.440 & 1.397 & 0.336 & 1.790 & 0.309 & 0.280 & 0.683 & 0.611 \\
\hline & 4 & 0.7 & 13 & 32 & 16.041 & 0.767 & 0.0787 & 0.1244 & 1.570 & 1.513 & 0.338 & 1.940 & 0.309 & 0.280 & 0.683 & 0.611 \\
\hline & 4 & 0.7 & 14 & 32 & 17.276 & 1.000 & 0.0787 & 0.1244 & 1.680 & 1.630 & 0.336 & 2.089 & 0.309 & 0.280 & 0.683 & 0.611 \\
\hline
\end{tabular}


Table A. 40: Four-Lane Bridge Shear Distribution Factors Comparison at FLS for CHBDC 2014, Alberta 2015, and AASHTO 2012

\begin{tabular}{|c|c|c|c|c|c|c|c|c|c|c|c|c|c|c|c|c|}
\hline \multicolumn{17}{|c|}{ Four Lane Bridge Shear Distribution Factors at Fatigue Limit States } \\
\hline \multicolumn{9}{|c|}{ Bridge Configuration } & \multicolumn{2}{|c|}{ CHBDC 2006} & \multicolumn{3}{|c|}{ CHBDC 2014} & \multirow{2}{*}{\begin{tabular}{|l|} 
Alberta 2015 \\
$\left(\mathbf{F}_{\mathrm{T}}\right)_{\text {Alberta }}$ \\
\end{tabular}} & \multicolumn{2}{|c|}{ AASHTO 2012} \\
\hline Girder Size & $\mathbf{n}$ & $\mathbf{R}_{\mathbf{L}}$ & $\mathbf{N}$ & $\mathbf{L}(\mathbf{m})$ & B (m) & $\mu$ & $\mathrm{I}\left(\mathbf{m}^{4}\right)$ & $\mathbf{J}\left(\mathbf{m}^{\mathbf{4}}\right)$ & $\left(\mathbf{F}_{\mathrm{v}}\right)_{\mathrm{FE}}$ & $\left(\mathbf{F}_{\mathrm{v}}\right)_{\mathrm{EQ}}$. & $\left(\mathbf{F}_{\mathrm{T}}\right)_{\mathrm{FE}}$ & $\boldsymbol{\beta}$ & $\left(\mathbf{F}_{\mathrm{T}}\right)_{\mathrm{EQ}}$ & & $\left(\mathbf{F}_{\mathrm{T}}\right)_{\text {AASHTO Ext. }}$ & $\left(\mathbf{F}_{\mathrm{T}}\right)_{\text {AASHTO Int }}$ \\
\hline \multirow[t]{3}{*}{$\mathrm{B} 700$} & 4 & 0.7 & 12 & 10 & 14.806 & 0 & 0.0309 & 0.0613 & 4.922 & 5.192 & 0.410 & 5.115 & 0.291 & 0.380 & 0.754 & 0.674 \\
\hline & 4 & 0.7 & 13 & 10 & 16.041 & 0.767 & 0.0309 & 0.0613 & 5.390 & 5.625 & 0.415 & 5.542 & 0.291 & 0.380 & 0.754 & 0.674 \\
\hline & 4 & 0.7 & 14 & 10 & 17.276 & 1.000 & 0.0309 & 0.0613 & 5.752 & 6.058 & 0.411 & 5.969 & 0.291 & 0.380 & 0.754 & 0.674 \\
\hline \multirow[t]{3}{*}{ B700 } & 4 & 0.7 & 12 & 13 & 14.806 & 0 & 0.0309 & 0.0613 & 5.033 & 4.693 & 0.419 & 3.935 & 0.291 & 0.401 & 0.735 & 0.657 \\
\hline & 4 & 0.7 & 13 & 13 & 16.041 & 0.767 & 0.0309 & 0.0613 & 5.548 & 5.084 & 0.427 & 4.263 & 0.291 & 0.401 & 0.735 & 0.657 \\
\hline & 4 & 0.7 & 14 & 13 & 17.276 & 1.000 & 0.0309 & 0.0613 & 5.872 & 5.475 & 0.419 & 4.591 & 0.291 & 0.401 & 0.735 & 0.657 \\
\hline \multirow[t]{3}{*}{ B700 } & 4 & 0.7 & 12 & 16 & 14.806 & 0 & 0.0309 & 0.0613 & 4.160 & 4.281 & 0.347 & 3.197 & 0.291 & 0.384 & 0.719 & 0.643 \\
\hline & 4 & 0.7 & 13 & 16 & 16.041 & 0.767 & 0.0309 & 0.0613 & 4.500 & 4.638 & 0.346 & 3.464 & 0.291 & 0.384 & 0.719 & 0.643 \\
\hline & 4 & 0.7 & 14 & 16 & 17.276 & 1.000 & 0.0309 & 0.0613 & 4.710 & 4.995 & 0.336 & 3.730 & 0.291 & 0.384 & 0.719 & 0.643 \\
\hline \multirow[t]{3}{*}{ B700 } & 4 & 0.7 & 12 & 24 & 14.806 & 0 & 0.0309 & 0.0613 & 3.440 & 3.469 & 0.287 & 2.131 & 0.291 & 0.286 & 0.691 & 0.618 \\
\hline & 4 & 0.7 & 13 & 24 & 16.041 & 0.767 & 0.0309 & 0.0613 & 3.540 & 3.758 & 0.272 & 2.309 & 0.291 & 0.286 & 0.691 & 0.618 \\
\hline & 4 & 0.7 & 14 & 24 & 17.276 & 1.000 & 0.0309 & 0.0613 & 3.920 & 4.048 & 0.280 & 2.487 & 0.291 & 0.286 & 0.691 & 0.618 \\
\hline \multirow[t]{3}{*}{ B800 } & 4 & 0.7 & 12 & 20 & 14.806 & 0 & 0.0441 & 0.0810 & 3.590 & 3.832 & 0.299 & 2.657 & 0.291 & 0.339 & 0.708 & 0.633 \\
\hline & 4 & 0.7 & 13 & 20 & 16.041 & 0.767 & 0.0441 & 0.0810 & 3.890 & 4.152 & 0.299 & 2.878 & 0.291 & 0.339 & 0.708 & 0.633 \\
\hline & 4 & 0.7 & 14 & 20 & 17.276 & 1.000 & 0.0441 & 0.0810 & 4.070 & 4.472 & 0.291 & 3.100 & 0.291 & 0.339 & 0.708 & 0.633 \\
\hline \multirow[t]{3}{*}{ B800 } & 4 & 0.7 & 12 & 26 & 14.806 & 0 & 0.0441 & 0.0810 & 3.310 & 3.312 & 0.276 & 2.044 & 0.291 & 0.286 & 0.690 & 0.617 \\
\hline & 4 & 0.7 & 13 & 26 & 16.041 & 0.767 & 0.0441 & 0.0810 & 3.560 & 3.588 & 0.274 & 2.214 & 0.291 & 0.286 & 0.690 & 0.617 \\
\hline & 4 & 0.7 & 14 & 26 & 17.276 & 1.000 & 0.0441 & 0.0810 & 3.770 & 3.864 & 0.269 & 2.384 & 0.291 & 0.286 & 0.690 & 0.617 \\
\hline \multirow[t]{3}{*}{ B900 } & 4 & 0.7 & 12 & 24 & 14.806 & 0 & 0.0600 & 0.1022 & 3.440 & 3.469 & 0.287 & 2.300 & 0.291 & 0.287 & 0.700 & 0.626 \\
\hline & 4 & 0.7 & 13 & 24 & 16.041 & 0.767 & 0.0600 & 0.1022 & 3.540 & 3.758 & 0.272 & 2.492 & 0.291 & 0.287 & 0.700 & 0.626 \\
\hline & 4 & 0.7 & 14 & 24 & 17.276 & 1.000 & 0.0600 & 0.1022 & 3.920 & 4.048 & 0.280 & 2.683 & 0.291 & 0.287 & 0.700 & 0.626 \\
\hline \multirow[t]{3}{*}{ B900 } & 4 & 0.7 & 12 & 30 & 14.806 & 0 & 0.0600 & 0.1022 & 3.150 & 3.037 & 0.263 & 1.840 & 0.291 & 0.281 & 0.684 & 0.612 \\
\hline & 4 & 0.7 & 13 & 30 & 16.041 & 0.767 & 0.0600 & 0.1022 & 3.330 & 3.290 & 0.256 & 1.993 & 0.291 & 0.281 & 0.684 & 0.612 \\
\hline & 4 & 0.7 & 14 & 30 & 17.276 & 1.000 & 0.0600 & 0.1022 & 3.580 & 3.544 & 0.256 & 2.147 & 0.291 & 0.281 & 0.684 & 0.612 \\
\hline \multirow[t]{3}{*}{ B1000 } & 4 & 0.7 & 12 & 26 & 14.806 & 0 & 0.0787 & 0.1244 & 3.310 & 3.312 & 0.276 & 2.203 & 0.291 & 0.287 & 0.698 & 0.624 \\
\hline & 4 & 0.7 & 13 & 26 & 16.041 & 0.767 & 0.0787 & 0.1244 & 3.560 & 3.588 & 0.274 & 2.387 & 0.291 & 0.287 & 0.698 & 0.624 \\
\hline & 4 & 0.7 & 14 & 26 & 17.276 & 1.000 & 0.0787 & 0.1244 & 3.770 & 3.864 & 0.269 & 2.571 & 0.291 & 0.287 & 0.698 & 0.624 \\
\hline \multirow[t]{3}{*}{ B1000 } & 4 & 0.7 & 12 & 32 & 14.806 & 0 & 0.0787 & 0.1244 & 3.080 & 2.916 & 0.257 & 1.790 & 0.291 & 0.280 & 0.683 & 0.611 \\
\hline & 4 & 0.7 & 13 & 32 & 16.041 & 0.767 & 0.0787 & 0.1244 & 3.360 & 3.159 & 0.258 & 1.940 & 0.291 & 0.280 & 0.683 & 0.611 \\
\hline & 4 & 0.7 & 14 & 32 & 17.276 & 1.000 & 0.0787 & 0.1244 & 3.470 & 3.402 & 0.248 & 2.089 & 0.291 & 0.280 & 0.683 & 0.611 \\
\hline
\end{tabular}


Table A. 41: Five-Lane Bridge Moment Distribution Factors Comparison at ULS for CHBDC 2014, Alberta 2015, and AASHTO 2012

\begin{tabular}{|c|c|c|c|c|c|c|c|c|c|c|c|c|c|c|c|c|}
\hline \multicolumn{17}{|c|}{ Five Lane Bridge Moment Distribution Factors at Ultimate Limit States } \\
\hline \multicolumn{9}{|c|}{ Bridge Configuration } & \multicolumn{2}{|c|}{ CHBDC 2006} & \multicolumn{3}{|c|}{ CHBDC 2014} & \multirow{2}{*}{\begin{tabular}{|l|} 
Alberta 2015 \\
$\left(\mathbf{F}_{\mathrm{T}}\right)_{\text {Alberta }}$ \\
\end{tabular}} & \multicolumn{2}{|c|}{ AASHTO 2012} \\
\hline Girder Size & $\mathbf{n}$ & $\mathbf{R}_{\mathbf{L}}$ & $\mathbf{N}$ & $\mathbf{L}(\mathbf{m})$ & $\mathbf{B}(\mathbf{m})$ & $\mu$ & $I\left(\mathbf{m}^{4}\right)$ & $\mathbf{J}\left(\mathbf{m}^{\mathbf{4}}\right)$ & $\left(\mathbf{F}_{\mathbf{v}}\right)_{\mathrm{FE}}$ & $\left(\mathbf{F}_{\mathbf{v}}\right)_{\mathbf{E Q}}$. & $\left(\mathbf{F}_{\mathrm{T}}\right)_{\mathrm{FE} .}$ & $\boldsymbol{\beta}$ & $\left(\mathbf{F}_{\mathrm{T}}\right)_{\mathrm{EQ}}$ & & $\left(\mathbf{F}_{\mathrm{T}}\right)_{\text {AASHTO E }}$ & ASHTO Int. \\
\hline \multirow[t]{3}{*}{ B700 } & 5 & 1 & 15 & 10 & 18.510 & 0.337 & 0.0309 & 0.0613 & 1.730 & 1.732 & 0.346 & 6.395 & 0.333 & 0.277 & 0.369 & 0.369 \\
\hline & 5 & 1 & 16 & 10 & 19.746 & 0.749 & 0.0309 & 0.0613 & 1.743 & 1.729 & 0.327 & 6.822 & 0.327 & 0.277 & 0.369 & 0.369 \\
\hline & 5 & 1 & 17 & 10 & 20.980 & 1.000 & 0.0309 & 0.0613 & 1.811 & 1.769 & 0.320 & 7.248 & 0.327 & 0.277 & 0.369 & 0.369 \\
\hline \multirow[t]{3}{*}{ B800 } & 5 & 1 & 15 & 20 & 18.510 & 0.337 & 0.0441 & 0.0810 & 1.344 & 1.393 & 0.269 & 3.321 & 0.273 & 0.259 & 0.363 & 0.363 \\
\hline & 5 & 1 & 16 & 20 & 19.746 & 0.749 & 0.0441 & 0.0810 & 1.367 & 1.417 & 0.256 & 3.543 & 0.262 & 0.259 & 0.368 & 0.368 \\
\hline & 5 & 1 & 17 & 20 & 20.980 & 1.000 & 0.0441 & 0.0810 & 1.407 & 1.464 & 0.248 & 3.764 & 0.257 & 0.259 & 0.369 & 0.369 \\
\hline \multirow[t]{3}{*}{ B1000 } & 5 & 1 & 15 & 32 & 18.510 & 0.337 & 0.0787 & 0.1244 & 1.201 & 1.137 & 0.240 & 2.238 & 0.257 & 0.253 & 0.338 & 0.338 \\
\hline & 5 & 1 & 16 & 32 & 19.746 & 0.749 & 0.0787 & 0.1244 & 1.216 & 1.183 & 0.228 & 2.388 & 0.245 & 0.253 & 0.341 & 0.341 \\
\hline & 5 & 1 & 17 & 32 & 20.980 & 1.000 & 0.0787 & 0.1244 & 1.250 & 1.238 & 0.221 & 2.537 & 0.239 & 0.253 & 0.344 & 0.344 \\
\hline
\end{tabular}

Table A. 42: Five-Lane Bridge Moment Distribution Factors Comparison at FLS for CHBDC 2014, Alberta 2015, and AASHTO 2012

\begin{tabular}{|c|c|c|c|c|c|c|c|c|c|c|c|c|c|c|c|c|}
\hline \multicolumn{17}{|c|}{ Five Lane Bridge Momeent Distribution Factors at Fatigue Limit States } \\
\hline \multicolumn{9}{|c|}{ Bridge Configuration } & \multicolumn{2}{|c|}{ CHBDC 2006} & \multicolumn{3}{|c|}{ CHBDC 2014} & \multirow{2}{*}{\begin{tabular}{|l|} 
Alberta 2015 \\
$\left(\mathrm{F}_{\mathrm{T}}\right)_{\text {Alberta }}$ \\
\end{tabular}} & \multicolumn{2}{|c|}{ AASHTO 2012} \\
\hline Girder Size & $\mathbf{n}$ & $\mathbf{R}_{\mathbf{L}}$ & $\mathbf{N}$ & $\mathbf{L}(\mathbf{m})$ & B (m) & $\mu$ & $I\left(\mathbf{m}^{4}\right)$ & $\mathbf{J}\left(\mathbf{m}^{4}\right)$ & $\left(\mathbf{F}_{\mathbf{v}}\right)_{\mathbf{F E}}$ & $\left(\mathbf{F}_{\mathbf{v}}\right)_{\mathbf{E Q}}$ & $\left(\mathbf{F}_{\mathrm{T}}\right)_{\mathrm{FE}}$ & $\boldsymbol{\beta}$ & $\left(\mathbf{F}_{\mathrm{T}}\right)_{\mathrm{EQ}}$ & & $\left(F_{T}\right)_{\text {AASHTO Ext. }}$ & $\left(\mathbf{F}_{\mathrm{T}}\right)_{\text {AASHTO Int. }}$ \\
\hline \multirow[t]{3}{*}{ B700 } & 5 & 1 & 15 & 10 & 18.510 & 0.337 & 0.0309 & 0.0613 & 4.320 & 4.434 & 0.288 & 6.395 & 0.431 & 0.277 & 0.369 & 0.369 \\
\hline & 5 & 1 & 16 & 10 & 19.746 & 0.749 & 0.0309 & 0.0613 & 4.315 & 4.466 & 0.270 & 6.822 & 0.477 & 0.277 & 0.369 & 0.369 \\
\hline & 5 & 1 & 17 & 10 & 20.980 & 1.000 & 0.0309 & 0.0613 & 4.598 & 4.589 & 0.270 & 7.248 & 0.553 & 0.277 & 0.369 & 0.369 \\
\hline \multirow[t]{3}{*}{ B800 } & 5 & 1 & 15 & 20 & 18.510 & 0.337 & 0.0441 & 0.0810 & 2.775 & 2.872 & 0.185 & 3.321 & 0.214 & 0.259 & 0.363 & 0.363 \\
\hline & 5 & 1 & 16 & 20 & 19.746 & 0.749 & 0.0441 & 0.0810 & 2.784 & 2.953 & 0.174 & 3.543 & 0.210 & 0.259 & 0.368 & 0.368 \\
\hline & 5 & 1 & 17 & 20 & 20.980 & 1.000 & 0.0441 & 0.0810 & 2.930 & 3.069 & 0.172 & 3.764 & 0.212 & 0.259 & 0.369 & 0.369 \\
\hline \multirow[t]{3}{*}{ B1000 } & 5 & 1 & 15 & 32 & 18.510 & 0.337 & 0.0787 & 0.1244 & 2.185 & 2.045 & 0.146 & 2.238 & 0.182 & 0.253 & 0.338 & 0.338 \\
\hline & 5 & 1 & 16 & 32 & 19.746 & 0.749 & 0.0787 & 0.1244 & 2.213 & 2.158 & 0.138 & 2.388 & 0.176 & 0.253 & 0.341 & 0.341 \\
\hline & 5 & 1 & 17 & 32 & 20.980 & 1.000 & 0.0787 & 0.1244 & 2.264 & 2.277 & 0.133 & 2.537 & 0.174 & 0.253 & 0.344 & 0.344 \\
\hline
\end{tabular}

Table A. 43: Five-Lane Bridge Shear Distribution Factors Comparison at ULS for CHBDC 2014, Alberta 2015, and AASHTO 2012

\begin{tabular}{|c|c|c|c|c|c|c|c|c|c|c|c|c|c|c|c|c|}
\hline \multicolumn{17}{|c|}{ Five Lane Bridge Shear Distribution Factors at Ultimate Limit States } \\
\hline \multicolumn{9}{|c|}{ Bridge Configuration } & \multicolumn{2}{|c|}{ CHBDC 2006} & \multicolumn{3}{|c|}{ CHBDC 2014} & Alberta 2015 & \multicolumn{2}{|c|}{ AASHTO 2012} \\
\hline Girder Size & $\mathbf{n}$ & $\mathbf{R}_{\mathbf{L}}$ & $\mathbf{N}$ & $\mathbf{L}(\mathbf{m})$ & B (m) & $\mu$ & $\mathrm{I}\left(\mathrm{m}^{4}\right)$ & $\mathbf{J}\left(\mathbf{m}^{\mathbf{4}}\right)$ & $\left(\mathbf{F}_{\mathbf{v}}\right)_{\mathrm{FE}}$. & $\left(F_{v}\right)_{E Q}$ & $\left(\mathbf{F}_{\mathrm{T}}\right)_{\mathrm{FE} .}$ & $\boldsymbol{\beta}$ & $\left(\mathbf{F}_{\mathrm{T}}\right)_{\mathrm{EQ}}$ & $\left(\mathbf{F}_{\mathrm{T}}\right)_{\text {Alberta }}$ & $\left(\mathbf{F}_{\mathrm{T}}\right)_{\text {AASHTO E }}$ & Ext. $\left(F_{T}\right)_{\text {AASHTO Int. }}$ \\
\hline \multirow[t]{3}{*}{ B700 } & 5 & 0.6 & 15 & 10 & 18.510 & 0 & 0.0309 & 0.0613 & 1.904 & 1.863 & 0.381 & 6.395 & 0.309 & 0.380 & 0.754 & 0.674 \\
\hline & 5 & 0.6 & 16 & 10 & 19.746 & 0.749 & 0.0309 & 0.0613 & 2.002 & 1.987 & 0.375 & 6.822 & 0.309 & 0.380 & 0.754 & 0.674 \\
\hline & 5 & 0.6 & 17 & 10 & 20.980 & 1.000 & 0.0309 & 0.0613 & 2.139 & 2.111 & 0.377 & 7.248 & 0.309 & 0.380 & 0.754 & 0.674 \\
\hline \multirow[t]{3}{*}{ B800 } & 5 & 0.6 & 15 & 20 & 18.510 & 0 & 0.0441 & 0.0810 & 1.565 & 1.613 & 0.313 & 3.321 & 0.309 & 0.339 & 0.708 & 0.633 \\
\hline & 5 & 0.6 & 16 & 20 & 19.746 & 0.749 & 0.0441 & 0.0810 & 1.576 & 1.721 & 0.296 & 3.543 & 0.309 & 0.339 & 0.708 & 0.633 \\
\hline & 5 & 0.6 & 17 & 20 & 20.980 & 1.000 & 0.0441 & 0.0810 & 1.761 & 1.828 & 0.311 & 3.764 & 0.309 & 0.339 & 0.708 & 0.633 \\
\hline \multirow[t]{3}{*}{ B1000 } & 5 & 0.6 & 15 & 32 & 18.51 & 0 & 0.0787 & 0.1244 & 1.447 & 1.389 & 0.289 & 2.238 & 0.309 & 0.280 & 0.683 & 0.611 \\
\hline & 5 & 0.6 & 16 & 32 & 19.746 & 0.749 & 0.0787 & 0.1244 & 1.489 & 1.482 & 0.279 & 2.388 & 0.309 & 0.280 & 0.683 & 0.611 \\
\hline & 5 & 0.6 & 17 & 32 & 20.98 & 1.000 & 0.0787 & 0.1244 & 1.651 & 1.575 & 0.291 & 2.537 & 0.309 & 0.280 & 0.683 & 0.611 \\
\hline
\end{tabular}


Table A. 44: Five-Lane Bridge Shear Distribution Factors Comparison at FLS for CHBDC 2014, Alberta 2015, and AASHTO 2012

\begin{tabular}{|c|c|c|c|c|c|c|c|c|c|c|c|c|c|c|c|c|}
\hline \multicolumn{17}{|c|}{ Five Lane Bridge Shear Distribution Factors at Fatigue Limit States } \\
\hline \multicolumn{9}{|c|}{ Bridge Configuration } & \multicolumn{2}{|c|}{ CHBDC 2006} & \multicolumn{3}{|c|}{ CHBDC 2014} & \multirow{2}{*}{\begin{tabular}{l|} 
Alberta 2015 \\
$\left(F_{T}\right)_{\text {Alberta }}$
\end{tabular}} & \multicolumn{2}{|c|}{ AASHTO 2012} \\
\hline Girder Size & $\mathbf{n}$ & $\mathbf{R}_{\mathbf{L}}$ & $\mathbf{N}$ & $\mathbf{L}(\mathbf{m})$ & $\mathbf{B}(\mathbf{m})$ & $\mu$ & $\mathrm{I}\left(\mathbf{m}^{4}\right)$ & $\mathbf{J}\left(\mathbf{m}^{4}\right)$ & $\left(\mathbf{F}_{\mathrm{v}}\right)_{\mathrm{FE}}$. & $\left(\mathbf{F}_{\mathrm{v}}\right)_{\mathrm{EQ}}$. & $\left(\mathbf{F}_{\mathrm{T}}\right)_{\mathrm{FE} .}$ & $\boldsymbol{\beta}$ & $\left(\mathbf{F}_{\mathrm{T}}\right)_{\mathrm{EQ}}$ & & $\left(\mathbf{F}_{\mathrm{T}}\right)_{\text {AASHTO Ext. }}$ & $\left(\mathbf{F}_{\mathrm{T}}\right)_{\text {AASHTO Int. }}$ \\
\hline \multirow[t]{3}{*}{ B700 } & 5 & 0.6 & 15 & 10 & 18.510 & 0 & 0.0309 & 0.0613 & 6.108 & 6.020 & 0.407 & 6.395 & 0.291 & 0.380 & 0.754 & 0.674 \\
\hline & 5 & 0.6 & 16 & 10 & 19.746 & 0.749 & 0.0309 & 0.0613 & 6.507 & 6.422 & 0.407 & 6.822 & 0.291 & 0.380 & 0.754 & 0.674 \\
\hline & 5 & 0.6 & 17 & 10 & 20.980 & 1.000 & 0.0309 & 0.0613 & 6.902 & 6.823 & 0.406 & 7.248 & 0.291 & 0.380 & 0.754 & 0.674 \\
\hline \multirow[t]{3}{*}{ B800 } & 5 & 0.6 & 15 & 20 & 18.510 & 0 & 0.0441 & 0.0810 & 4.843 & 5.008 & 0.323 & 3.321 & 0.291 & 0.339 & 0.708 & 0.633 \\
\hline & 5 & 0.6 & 16 & 20 & 19.746 & 0.749 & 0.0441 & 0.0810 & 5.136 & 5.342 & 0.321 & 3.543 & 0.291 & 0.339 & 0.708 & 0.633 \\
\hline & 5 & 0.6 & 17 & 20 & 20.980 & 1.000 & 0.0441 & 0.0810 & 5.391 & 5.676 & 0.317 & 3.764 & 0.291 & 0.339 & 0.708 & 0.633 \\
\hline \multirow[t]{3}{*}{ B1000 } & 5 & 0.6 & 15 & 32 & 18.51 & 0 & 0.0787 & 0.1244 & 4.348 & 4.167 & 0.290 & 2.238 & 0.291 & 0.280 & 0.683 & 0.611 \\
\hline & 5 & 0.6 & 16 & 32 & 19.746 & 0.749 & 0.0787 & 0.1244 & 4.609 & 4.446 & 0.288 & 2.388 & 0.291 & 0.280 & 0.683 & 0.611 \\
\hline & 5 & 0.6 & 17 & 32 & 20.98 & 1.000 & 0.0787 & 0.1244 & 4.821 & 4.724 & 0.284 & 2.537 & 0.291 & 0.280 & 0.683 & 0.611 \\
\hline
\end{tabular}

Table A. 45: Six-Lane Bridge Moment Distribution Factors Comparison at ULS for CHBDC 2014, Alberta 2015, and AASHTO 2012

\begin{tabular}{|c|c|c|c|c|c|c|c|c|c|c|c|c|c|c|c|c|}
\hline \multicolumn{17}{|c|}{ Six Lane Bridge Moment Distribution Factors at Ultimate Limit States } \\
\hline \multicolumn{9}{|c|}{ Bridge Configuration } & \multicolumn{2}{|c|}{ CHBDC 2006} & \multicolumn{3}{|c|}{ CHBDC 2014} & \multirow{2}{*}{\begin{tabular}{|l|} 
Alberta 2015 \\
$\left(F_{T}\right)_{\text {Alberta }}$ \\
\end{tabular}} & \multicolumn{2}{|c|}{ AASHTO 2012 } \\
\hline Girder Size & $\mathbf{n}$ & $\mathbf{R}_{\mathbf{L}}$ & $\mathbf{N}$ & $\mathbf{L}(\mathbf{m})$ & B (m) & $\mu$ & $\mathbf{I}\left(\mathbf{m}^{4}\right)$ & $\mathbf{J}\left(\mathbf{m}^{4}\right)$ & $\left(\mathbf{F}_{\mathrm{v}}\right)_{\mathrm{FE}}$ & $\left(\mathbf{F}_{\mathbf{v}}\right)_{\mathbf{E Q}}$. & $\left(\mathbf{F}_{\mathrm{T}}\right)_{\mathrm{FE}}$ & $\boldsymbol{\beta}$ & $\left(\mathbf{F}_{\mathrm{T}}\right)_{\mathrm{EQ}}$. & & $\left(\mathbf{F}_{\mathrm{T}}\right)_{\text {AASHTO }}$ & xt. $\left(F_{T}\right)_{\text {AASHTO Int }}$ \\
\hline \multirow[t]{3}{*}{$\mathrm{B} 700$} & 6 & 0.55 & 18 & 10 & 22.216 & 0 & 0.0309 & 0.0613 & 1.889 & 1.895 & 0.346 & 7.675 & 0.364 & 0.277 & 0.373 & 0.373 \\
\hline & 6 & 0.55 & 19 & 10 & 23.450 & 0.736 & 0.0309 & 0.0613 & 1.887 & 1.878 & 0.328 & 8.102 & 0.361 & 0.277 & 0.373 & 0.373 \\
\hline & 6 & 0.55 & 20 & 10 & 24.686 & 1.000 & 0.0309 & 0.0613 & 1.922 & 1.888 & 0.317 & 8.529 & 0.362 & 0.277 & 0.373 & 0.373 \\
\hline \multirow[t]{3}{*}{ B800 } & 6 & 0.55 & 18 & 20 & 22.216 & 0 & 0.0441 & 0.0810 & 1.450 & 1.485 & 0.266 & 3.986 & 0.282 & 0.259 & 0.373 & 0.373 \\
\hline & 6 & 0.55 & 19 & 20 & 23.450 & 0.736 & 0.0441 & 0.0810 & 1.469 & 1.508 & 0.255 & 4.208 & 0.273 & 0.259 & 0.373 & 0.373 \\
\hline & 6 & 0.55 & 20 & 20 & 24.686 & 1.000 & 0.0441 & 0.0810 & 1.506 & 1.542 & 0.248 & 4.429 & 0.268 & 0.259 & 0.373 & 0.373 \\
\hline \multirow[t]{3}{*}{ B1000 } & 6 & 0.55 & 18 & 32 & 22.216 & 0 & 0.0787 & 0.1244 & 1.253 & 1.198 & 0.230 & 2.686 & 0.261 & 0.253 & 0.345 & 0.345 \\
\hline & 6 & 0.55 & 19 & 32 & 23.45 & 0.736 & 0.0787 & 0.1244 & 1.280 & 1.256 & 0.222 & 2.835 & 0.251 & 0.253 & 0.349 & 0.349 \\
\hline & 6 & 0.55 & 20 & 32 & 24.686 & 1.000 & 0.0787 & 0.1244 & 1.317 & 1.315 & 0.217 & 2.985 & 0.245 & 0.253 & 0.352 & 0.352 \\
\hline
\end{tabular}

Table A. 46: Six-Lane Bridge Moment Distribution Factors Comparison at FLS for CHBDC 2014, Alberta 2015, and AASHTO 2012

\begin{tabular}{|c|c|c|c|c|c|c|c|c|c|c|c|c|c|c|c|c|}
\hline \multicolumn{17}{|c|}{ Six Lane Bridge Moment Distribution Factors at Fatigue Limit States } \\
\hline \multicolumn{9}{|c|}{ Bridge Configuration } & \multicolumn{2}{|c|}{ CHBDC 2006} & \multicolumn{3}{|c|}{ CHBDC 2014} & \multirow{2}{*}{\begin{tabular}{|l|} 
Alberta 2015 \\
$\left(\mathbf{F}_{\mathrm{T}}\right)_{\text {Alberta }}$ \\
\end{tabular}} & \multicolumn{2}{|c|}{ AASHTO 2012} \\
\hline Girder Size & $\mathbf{n}$ & $\mathbf{R}_{\mathbf{L}}$ & $\mathbf{N}$ & $\mathbf{L}(\mathbf{m})$ & B (m) & $\mu$ & $I\left(\mathbf{m}^{4}\right)$ & $\mathbf{J}\left(\mathbf{m}^{4}\right)$ & $\left(\mathbf{F}_{\mathrm{v}}\right)_{\mathrm{FE} .}$ & $\left(F_{v}\right)_{E Q}$. & $\left(\mathbf{F}_{\mathrm{T}}\right)_{\mathrm{FE} .}$ & $\boldsymbol{\beta}$ & $\left(\mathbf{F}_{\mathrm{T}}\right)_{\mathrm{EQ}}$. & & $\left(F_{T}\right)_{\text {AASHTO Ext. }}$ & $\left(\mathbf{F}_{\mathrm{T}}\right)_{\text {AASHTO Int }}$ \\
\hline \multirow[t]{3}{*}{$\mathrm{B} 700$} & 6 & 0.55 & 18 & 10 & 22.216 & 0 & 0.0309 & 0.0613 & 5.248 & 5.159 & 0.292 & 7.675 & 0.738 & 0.277 & 0.373 & 0.373 \\
\hline & 6 & 0.55 & 19 & 10 & 23.450 & 0.736 & 0.0309 & 0.0613 & 4.894 & 5.174 & 0.258 & 8.102 & 0.933 & 0.277 & 0.373 & 0.373 \\
\hline & 6 & 0.55 & 20 & 10 & 24.686 & 1.000 & 0.0309 & 0.0613 & 5.492 & 5.245 & 0.275 & 8.529 & 1.326 & 0.277 & 0.373 & 0.373 \\
\hline \multirow[t]{3}{*}{ B800 } & 6 & 0.55 & 18 & 20 & 22.216 & 0 & 0.0441 & 0.0810 & 3.349 & 3.383 & 0.186 & 3.986 & 0.238 & 0.259 & 0.373 & 0.373 \\
\hline & 6 & 0.55 & 19 & 20 & 23.450 & 0.736 & 0.0441 & 0.0810 & 3.295 & 3.446 & 0.173 & 4.208 & 0.238 & 0.259 & 0.373 & 0.373 \\
\hline & 6 & 0.55 & 20 & 20 & 24.686 & 1.000 & 0.0441 & 0.0810 & 3.466 & 3.532 & 0.173 & 4.429 & 0.240 & 0.259 & 0.373 & 0.373 \\
\hline \multirow[t]{3}{*}{ B1000 } & 6 & 0.55 & 18 & 32 & 22.216 & 0 & 0.0787 & 0.1244 & 2.598 & 2.426 & 0.144 & 2.686 & 0.192 & 0.253 & 0.345 & 0.345 \\
\hline & 6 & 0.55 & 19 & 32 & 23.45 & 0.736 & 0.0787 & 0.1244 & 2.561 & 2.520 & 0.135 & 2.835 & 0.188 & 0.253 & 0.349 & 0.349 \\
\hline & 6 & 0.55 & 20 & 32 & 24.686 & 1.000 & 0.0787 & 0.1244 & 2.638 & 2.621 & 0.132 & 2.985 & 0.186 & 0.253 & 0.352 & 0.352 \\
\hline
\end{tabular}


Table A. 47: Six-Lane Bridge Shear Distribution Factors Comparison at ULS for CHBDC 2014, Alberta 2015, and AASHTO 2012

\begin{tabular}{|c|c|c|c|c|c|c|c|c|c|c|c|c|c|c|c|c|}
\hline \multicolumn{17}{|c|}{ Six Lane Bridge Shear Distribution Factors at Ultimate Limit States } \\
\hline \multicolumn{9}{|c|}{ Bridge Configuration } & \multicolumn{2}{|c|}{ CHBDC 2006} & \multicolumn{3}{|c|}{\begin{tabular}{|c|} 
CHBDC 2014 \\
\end{tabular}} & \multirow{2}{*}{\begin{tabular}{|l|} 
Alberta 2015 \\
$\left(\mathbf{F}_{\mathrm{T}}\right)_{\text {Alberta }}$ \\
\end{tabular}} & \multicolumn{2}{|c|}{ AASHTO 2012} \\
\hline Girder Size & $\mathbf{n}$ & $\mathbf{R}_{\mathbf{L}}$ & $\mathbf{N}$ & $\mathbf{L}(\mathbf{m})$ & B (m) & $\mu$ & $\mathbf{I}\left(\mathbf{m}^{4}\right)$ & $\mathbf{J}\left(\mathbf{m}^{\mathbf{4}}\right)$ & $\left(\mathbf{F}_{\mathbf{v}}\right)_{\mathrm{FE} .}$ & $\left(\mathbf{F}_{\mathbf{v}}\right)_{\mathbf{E Q}}$. & $\left(\mathbf{F}_{\mathrm{T}}\right)_{\mathrm{FE} .}$ & $\beta$ & $\left(\mathbf{F}_{\mathrm{T}}\right)_{\mathrm{EQ}}$ & & $\left(F_{T}\right)_{\text {AASHTO Ext. }}\left(F_{T}\right.$ & AASHTO Int. \\
\hline \multirow[t]{3}{*}{ B700 } & 6 & 0.55 & 18 & 10 & 22.216 & 0 & 0.0309 & 0.0613 & 2.087 & 2.044 & 0.383 & 7.675 & 0.309 & 0.380 & 0.754 & 0.674 \\
\hline & 6 & 0.55 & 19 & 10 & 23.450 & 0.736 & 0.0309 & 0.0613 & 2.163 & 2.158 & 0.376 & 8.102 & 0.309 & 0.380 & 0.754 & 0.674 \\
\hline & 6 & 0.55 & 20 & 10 & 24.686 & 1.000 & 0.0309 & 0.0613 & 2.329 & 2.271 & 0.384 & 8.529 & 0.309 & 0.380 & 0.754 & 0.674 \\
\hline \multirow[t]{3}{*}{ B800 } & 6 & 0.55 & 18 & 20 & 22.216 & 0 & 0.0441 & 0.0810 & 1.714 & 1.766 & 0.314 & 3.986 & 0.309 & 0.339 & 0.708 & 0.633 \\
\hline & 6 & 0.55 & 19 & 20 & 23.450 & 0.736 & 0.0441 & 0.0810 & 1.712 & 1.864 & 0.297 & 4.208 & 0.309 & 0.339 & 0.708 & 0.633 \\
\hline & 6 & 0.55 & 20 & 20 & 24.686 & 1.000 & 0.0441 & 0.0810 & 1.906 & 1.962 & 0.314 & 4.429 & 0.309 & 0.339 & 0.708 & 0.633 \\
\hline \multirow[t]{3}{*}{ B1000 } & 6 & 0.55 & 18 & 32 & 22.216 & 0 & 0.0787 & 0.1244 & 1.586 & 1.518 & 0.291 & 2.686 & 0.309 & 0.280 & 0.683 & 0.611 \\
\hline & 6 & 0.55 & 19 & 32 & 23.45 & 0.736 & 0.0787 & 0.1244 & 1.618 & 1.603 & 0.281 & 2.835 & 0.309 & 0.280 & 0.683 & 0.611 \\
\hline & 6 & 0.55 & 20 & 32 & 24.686 & 1.000 & 0.0787 & 0.1244 & 1.764 & 1.687 & 0.291 & 2.985 & 0.309 & 0.280 & 0.683 & 0.611 \\
\hline
\end{tabular}

Table A. 48: Six-Lane Bridge Shear Distribution Factors Comparison at FLS for CHBDC 2014, Alberta 2015, and AASHTO 2012

\begin{tabular}{|c|c|c|c|c|c|c|c|c|c|c|c|c|c|c|c|c|}
\hline \multicolumn{17}{|c|}{ Six Lane Bridge Shear Distribution Factors at Fatigue Limit States } \\
\hline \multicolumn{9}{|c|}{ Bridge Configuration } & \multicolumn{2}{|c|}{ CHBDC 2006 } & \multicolumn{3}{|c|}{ CHBDC 2014} & \multirow{2}{*}{\begin{tabular}{|l|} 
Alberta 2015 \\
$\left(\mathbf{F}_{\mathrm{T}}\right)_{\text {Alberta }}$ \\
\end{tabular}} & \multicolumn{2}{|c|}{ AASHTO 2012} \\
\hline Girder Size & $\mathbf{n}$ & $\mathbf{R}_{\mathbf{L}}$ & $\mathbf{N}$ & $\mathbf{L}(\mathbf{m})$ & B (m) & $\mu$ & $I\left(\mathbf{m}^{4}\right)$ & $\mathbf{J}\left(\mathbf{m}^{4}\right)$ & $\left(\mathbf{F}_{\mathrm{v}}\right)_{\mathrm{FE} .}$ & $\left(\mathbf{F}_{\mathrm{v}}\right)_{\mathrm{EQ}}$ & $\left(\mathbf{F}_{\mathrm{T}}\right)_{\mathrm{FE}}$ & $\boldsymbol{\beta}$ & $\left(\mathbf{F}_{\mathrm{T}}\right)_{\mathrm{EQ}}$. & & $\left(\mathbf{F}_{\mathrm{T}}\right)_{\text {AASHTO Ext. }}$ & $\left(\mathbf{F}_{\mathrm{T}}\right)_{\text {AASHTO Int }}$ \\
\hline \multirow[t]{3}{*}{$\mathrm{B} 700$} & 6 & 0.55 & 18 & 10 & 22.216 & 0 & 0.0309 & 0.0613 & 7.297 & 7.192 & 0.405 & 7.675 & 0.291 & 0.380 & 0.754 & 0.674 \\
\hline & 6 & 0.55 & 19 & 10 & 23.450 & 0.736 & 0.0309 & 0.0613 & 7.823 & 7.591 & 0.412 & 8.102 & 0.291 & 0.380 & 0.754 & 0.674 \\
\hline & 6 & 0.55 & 20 & 10 & 24.686 & 1.000 & 0.0309 & 0.0613 & 7.959 & 7.991 & 0.398 & 8.529 & 0.291 & 0.380 & 0.754 & 0.674 \\
\hline \multirow[t]{3}{*}{ B800 } & 6 & 0.55 & 18 & 20 & 22.216 & 0 & 0.0441 & 0.0810 & 5.852 & 6.006 & 0.325 & 3.986 & 0.291 & 0.339 & 0.708 & 0.633 \\
\hline & 6 & 0.55 & 19 & 20 & 23.450 & 0.736 & 0.0441 & 0.0810 & 6.106 & 6.339 & 0.321 & 4.208 & 0.291 & 0.339 & 0.708 & 0.633 \\
\hline & 6 & 0.55 & 20 & 20 & 24.686 & 1.000 & 0.0441 & 0.0810 & 6.288 & 6.673 & 0.314 & 4.429 & 0.291 & 0.339 & 0.708 & 0.633 \\
\hline \multirow[t]{3}{*}{ B1000 } & 6 & 0.55 & 18 & 32 & 22.216 & 0 & 0.0787 & 0.1244 & 5.265 & 5.013 & 0.293 & 2.686 & 0.291 & 0.280 & 0.683 & 0.611 \\
\hline & 6 & 0.55 & 19 & 32 & 23.45 & 0.736 & 0.0787 & 0.1244 & 5.453 & 5.292 & 0.287 & 2.835 & 0.291 & 0.280 & 0.683 & 0.611 \\
\hline & 6 & 0.55 & 20 & 32 & 24.686 & 1.000 & 0.0787 & 0.1244 & 5.677 & 5.571 & 0.284 & 2.985 & 0.291 & 0.280 & 0.683 & 0.611 \\
\hline
\end{tabular}


APPENDIX (B): Results from Sensitivity Study 


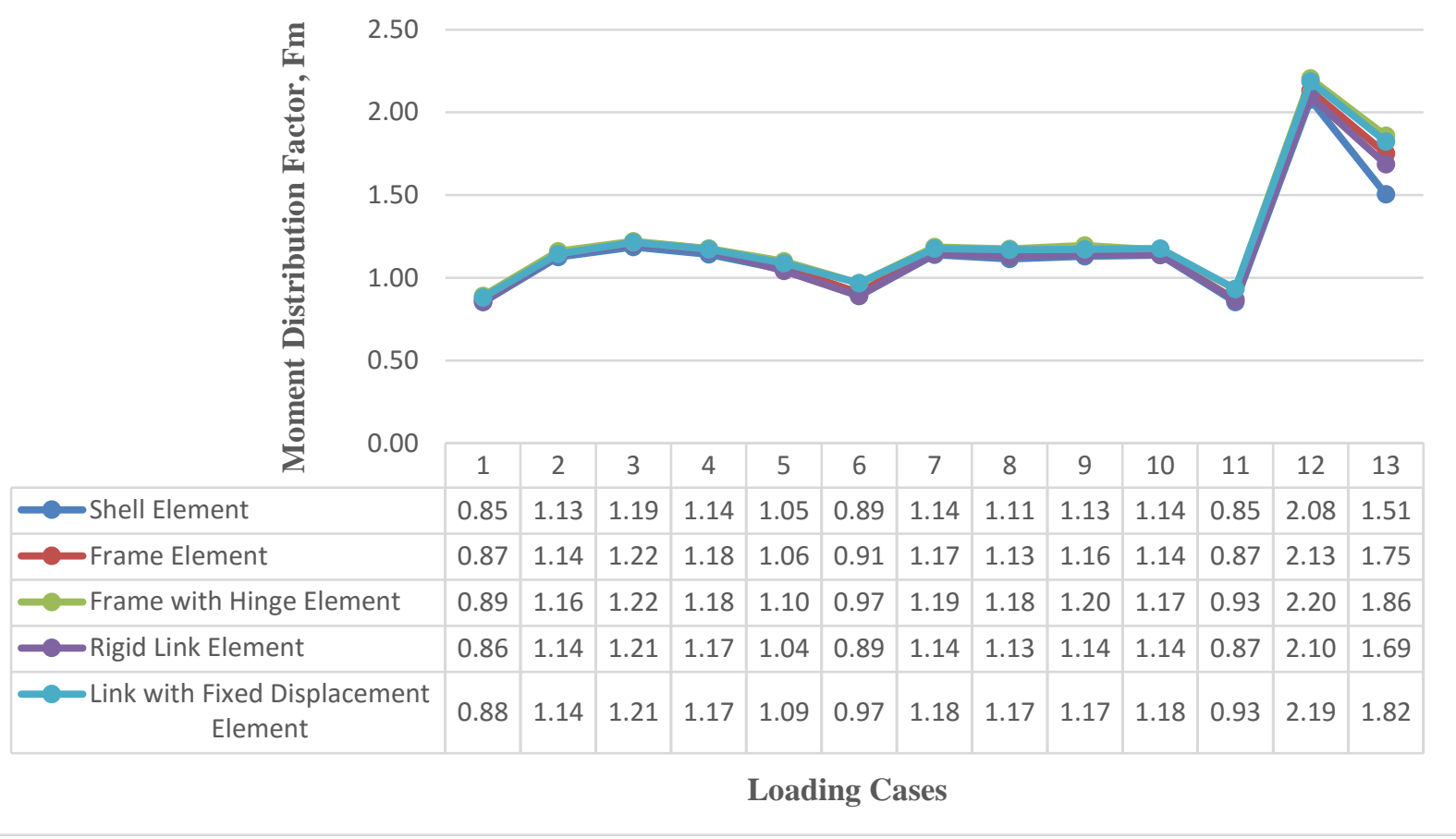

Figure B.1: Comparison between five different types of connections at top flanges for moment distribution factor

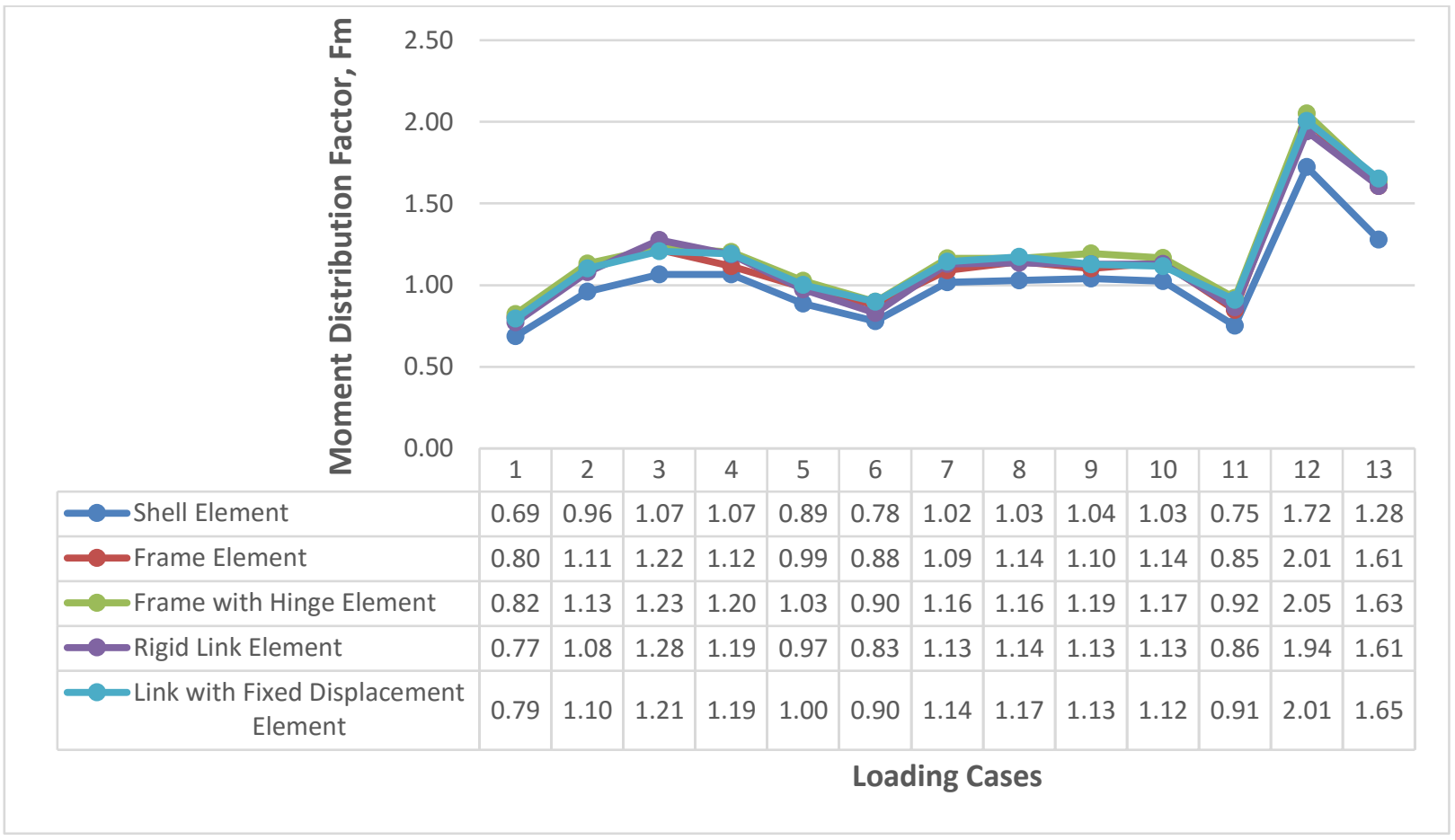

Figure B.2: Comparison between five different types of connections at top and bottom flanges for moment distribution factor 


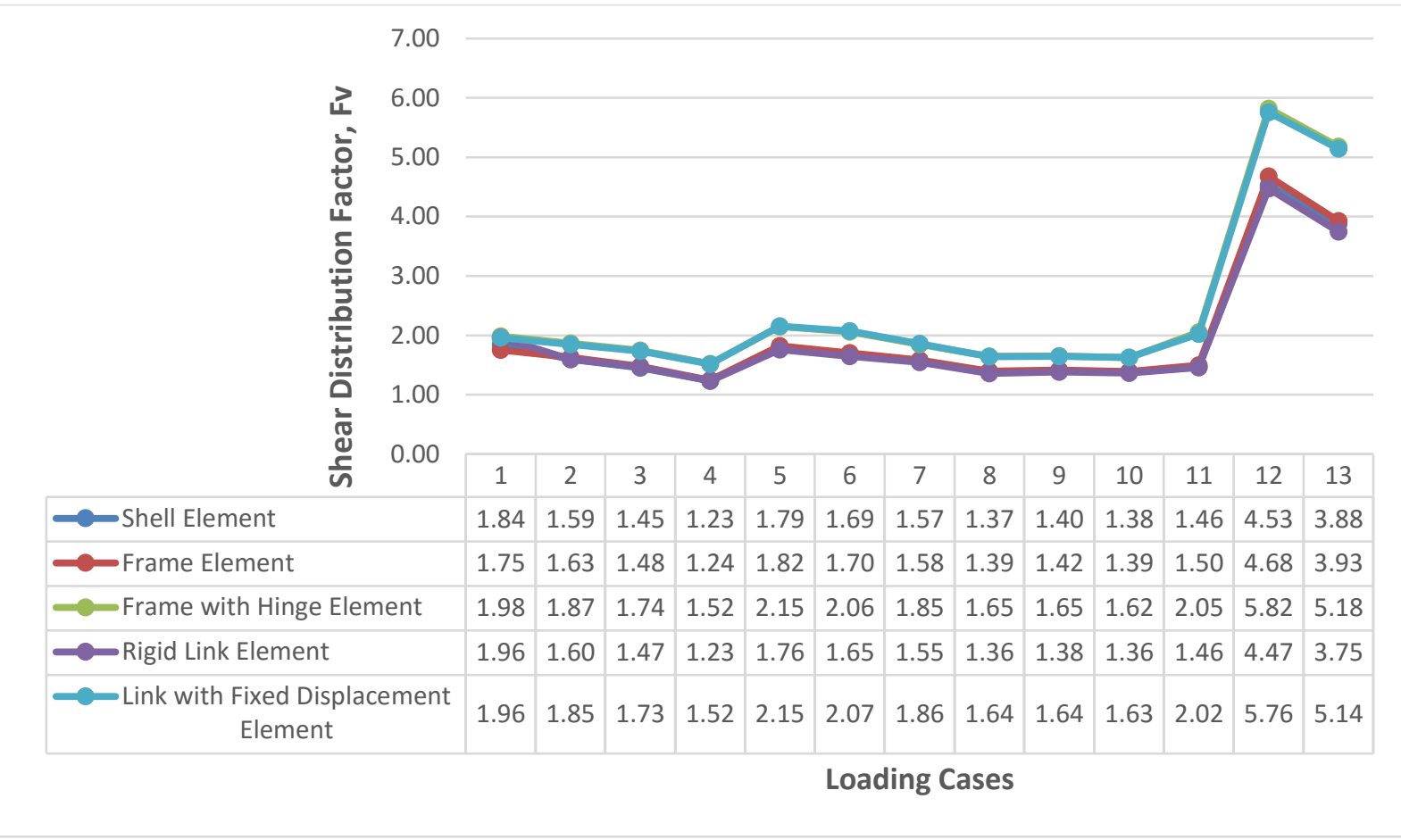

Figure B.3: Comparison between five different types of connections at top flanges for shear distribution factor

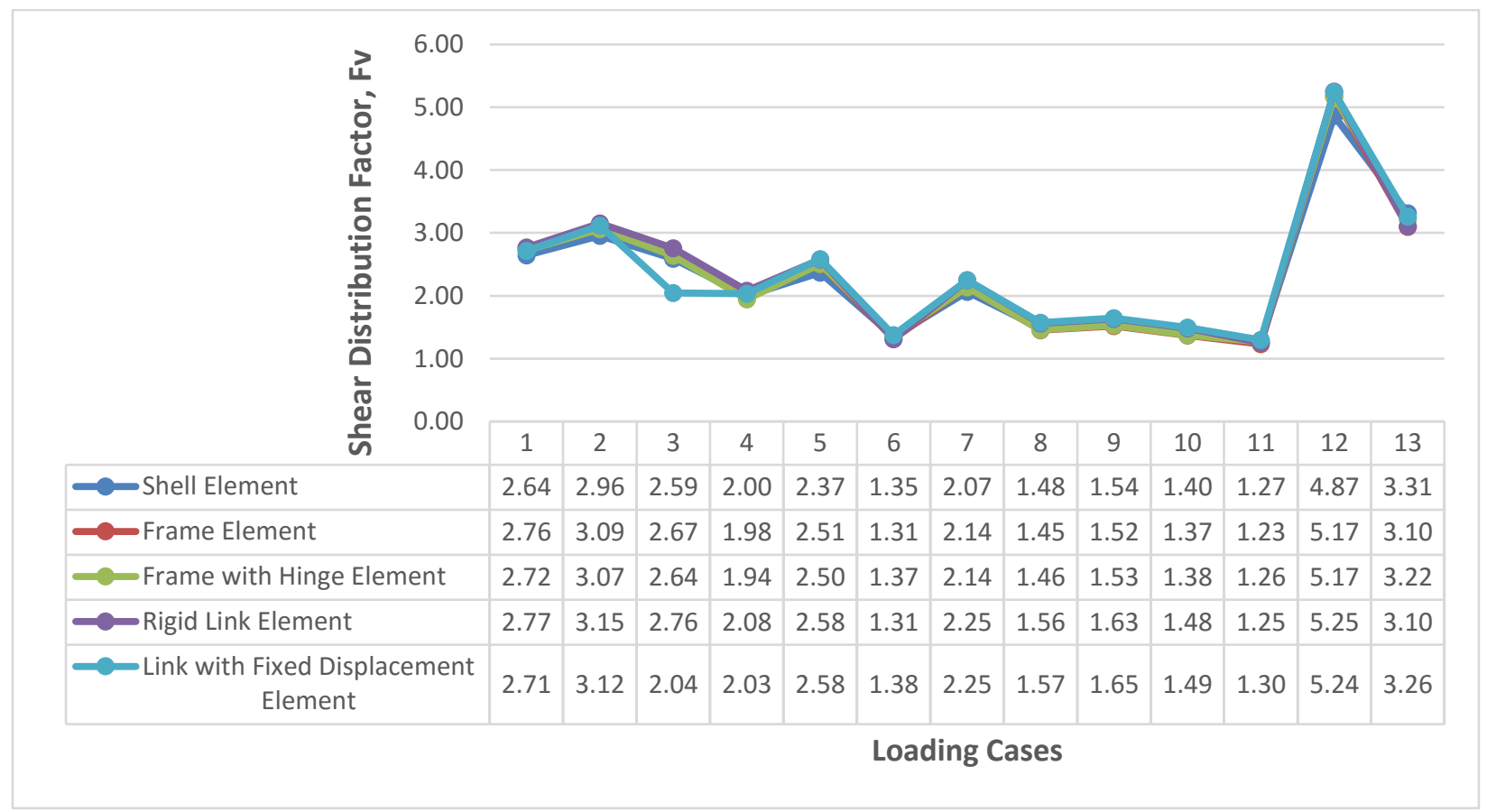

Figure B.4: Comparison between five different types of connections at top and bottom flanges for shear distribution factor 


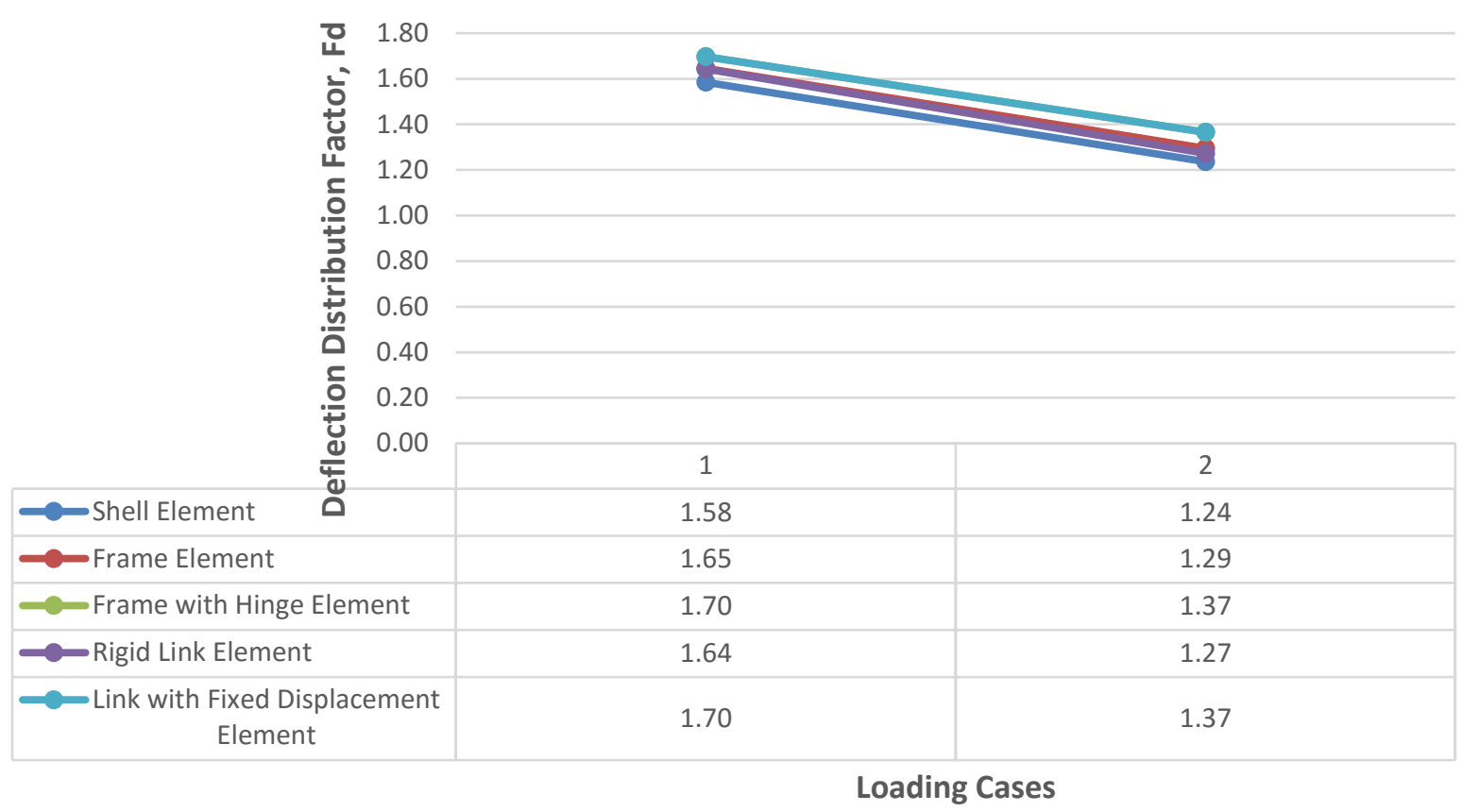

Figure B.5: Comparison between five different types of connections at top flanges for deflection distribution factor

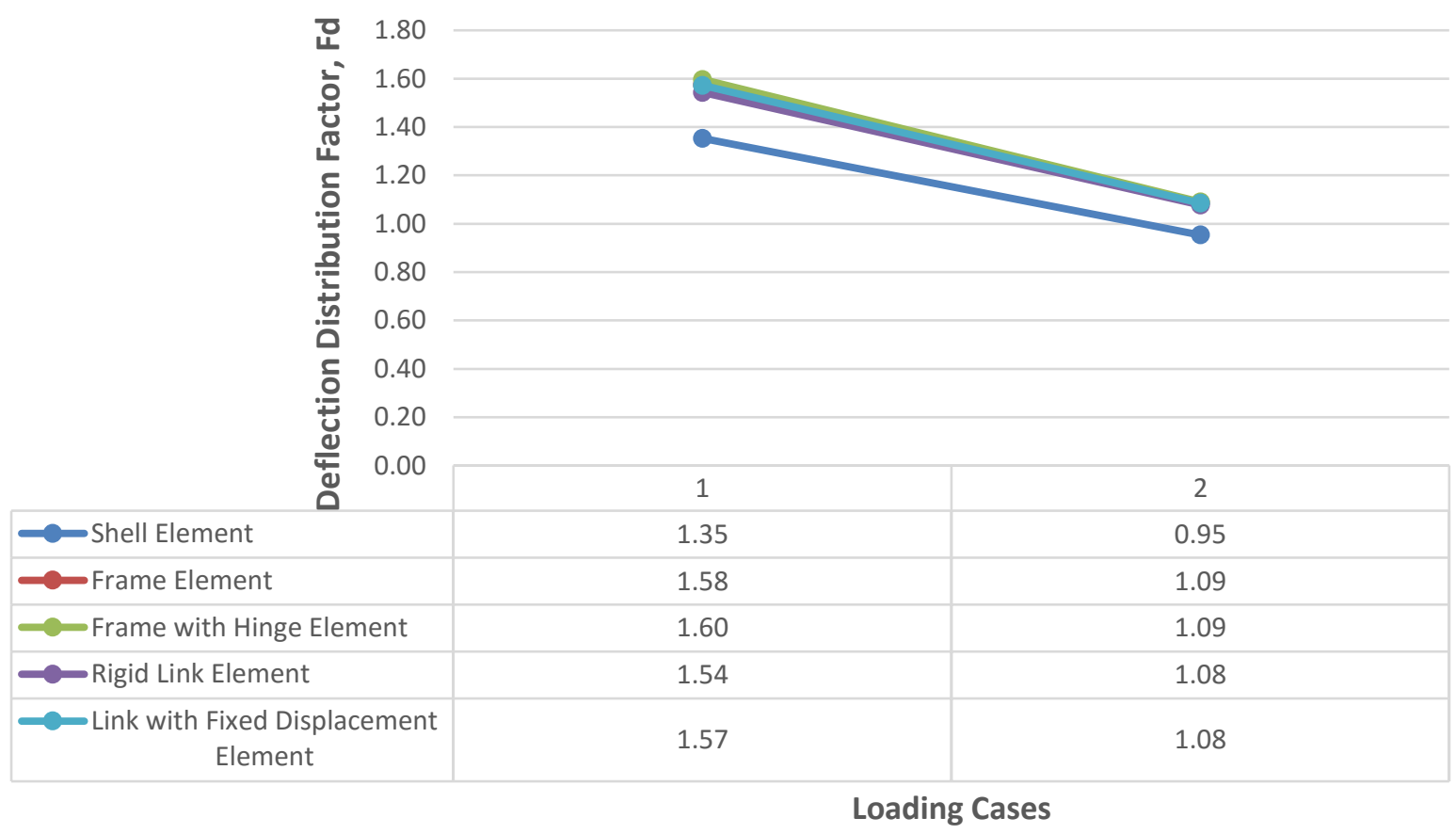

Figure B.6: Comparison between five different types of connections at top and bottom flanges for deflection distribution factor 


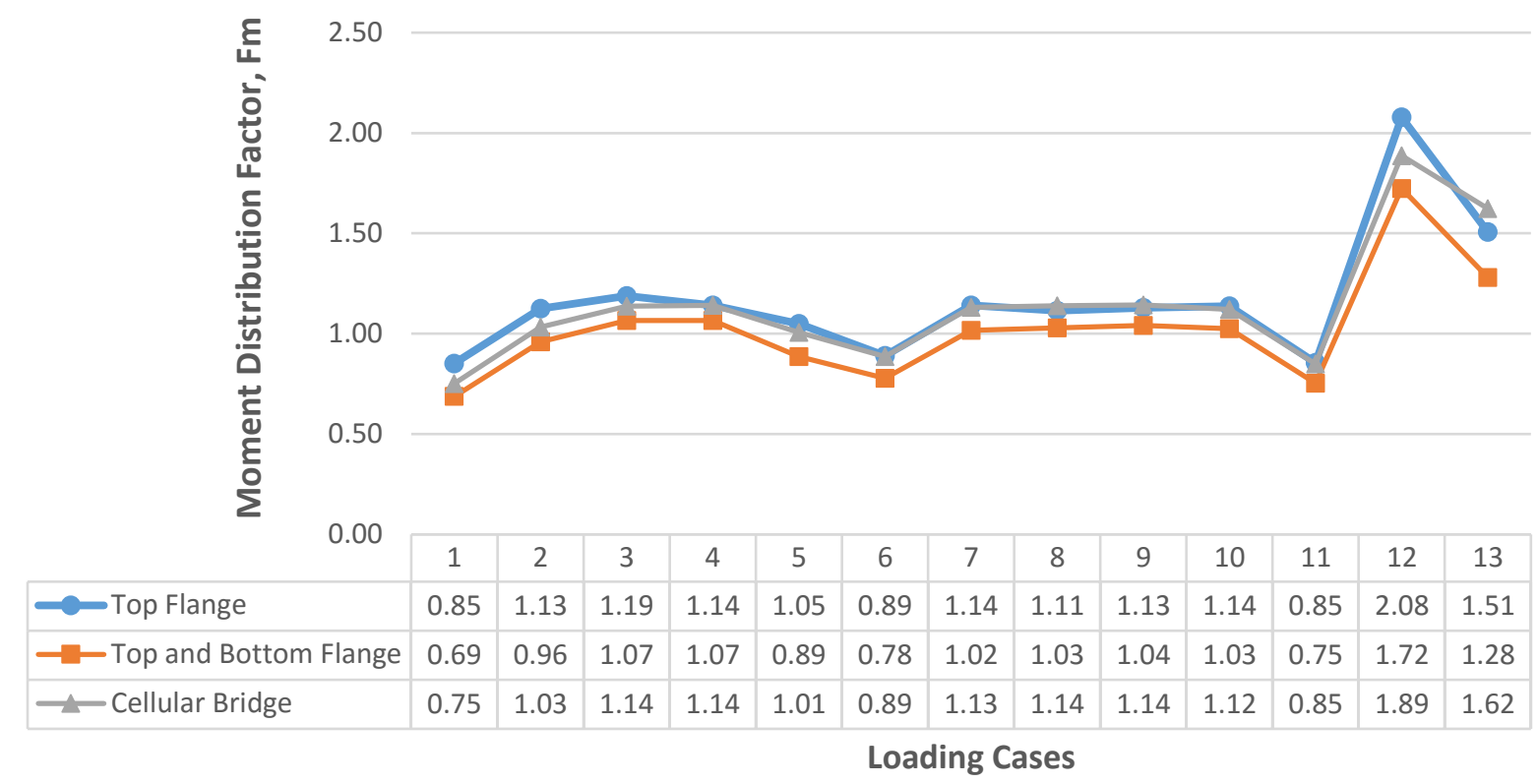

Figure B.7: Comparison between three different connection locations for moment distribution factor

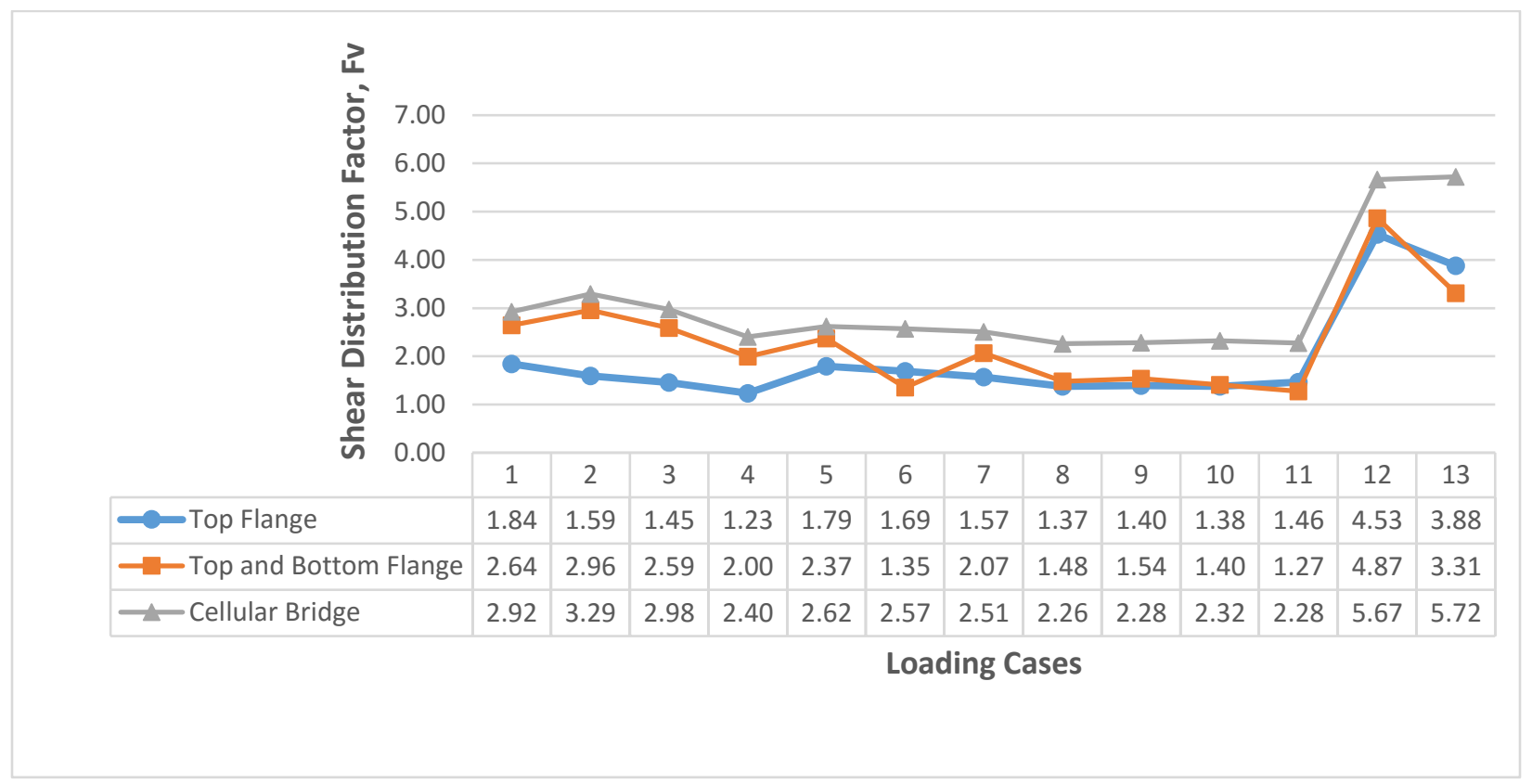

Figure B.8: Comparison between three different connection locations for shear distribution factor 


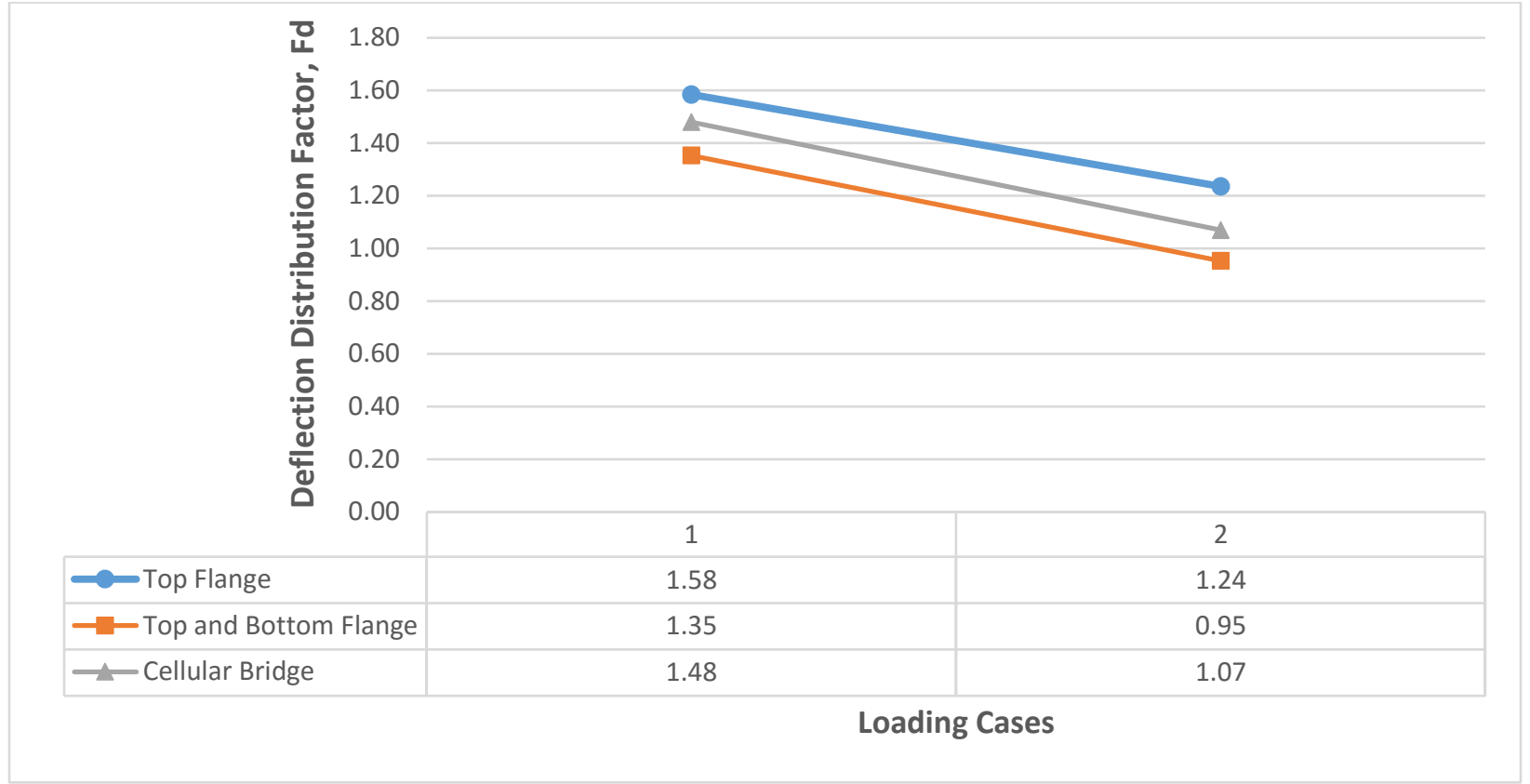

Figure B.9: Comparison between three different connection locations for deflection distribution factor 


\section{REFERENCES}

AASHTO. (1994). American Association for State Highway and Transportation Officials, AASHTO LRFD Bridge Design Specifications. First Edition, Washington, DC.

AASHTO. (1996). American Association of State Highway and Transportation Officials, Standard specifications for highway bridges. Sixteenth Edition, Washington, D.C.

AASHTO. (2004). American Association of State Highway and Transportation Officials, AASHTO LRFD Bridge Design Specifications. Second Edition, Washington, DC.

AASHTO. (2012). American Association of State Highway and Transportation Officials, AASHTO LRFD Bridge Design Specifications. Sixth Edition, Washington, DC.

Abdullah, M. A., \& Abdul-Razzak, A. (1990). Finite strip analysis of prestressed box girder. Computers and Structures, 36(5), 817-822.

Alberta Transportation, (2015). Bridge Load Evaluation Manual, V1.0, Alberta, Canada.

Androus, A. (2003). Experimental and theoretical studies of composite multiple-box girders bridges. M.Sc. thesis, Department of Civil Engineering, Ryerson University, Ontario, Canada.

Annamalai, G., and Brown, R. C. (1990). Shear transfer behavior of posttensioned grouted shearkey connections in precast concrete-framed structures. ACI Struct. J., 87(1), 53-59.

Arizumi, Y., Hamada, S., \& Oshiro, T. (1985). Static behavior of curved composite box girders. In (pp. 212-215). Tokyo, Japan: Japan Society of Civil Engineers.

Bakht, B., Cheung, M. S., and aziz, T. S. (1979). Application of Simplified Method of Calculating Longitudinal moments to the Ontario Highway Bridge Design Code. Canadian Journal of Civil Engineering, 61(1): 36-50.

Bazant, Z. P., El Nimeiri, M. (1974). Stiffness method for curved box girders at initial stress. ASCE Journal of the Structural Division, 100(10), 2071-2090.

Bakht, B., Jaeger, L. G., \& Cheung, M. S. (1983). Transverse Shear in Multibeam Bridges. Journal of Structural Engineering, 109(4), 936-949.

Bakht, B., Mufti, A. A. (2001). Load distribution in shear-connected concrete plank bridges.

Batla, F. A., Reisnour, P. H., \& Pathak, D. (1984). Finite-element program for analysis of folded plate bridge superstructures. Transportation Research Record, Second Bridge Engineering Conference, Minneapolis, MN, USA, 1, 21-27. 
Chan, M. Y. T., Cheung, M. S., Beauchamp, J. C., \& Hachem, H. M. (1990). Thermal stresses in composite box girder bridges. Third International conference on Short and Medium Span Bridges, (pp. 355-366). Toronto, Ontario, Canada.

CHBDC. (2006). Canadian Highway Bridge Design Code (CHBDC and Commentary), CAN/CSA-S6-06. Canadian Standards Association, Toronto, Ontario, Canada.

CHBDC. (2014). Canadian Highway Bridge Design Code (CHBDC and Commentary), CAN/CSA-S6-14. Canadian Standards Association, Toronto, Ontario, Canada.

Cheung, M. S., Akhras, G., \& Li, W. (1994). Combined boundary element/finite strip analysis of bridges. Journal of Structural Engineering New York, N.Y., 120(3), 716-727.

Cheung, M. S., Bakht, B., and Jaeger, L. G., (1982). Analysis of Box Girder Bridges by Grillage and Orthotropic Plate Methods. Sino-American Symposium on Bridge and Structural Engineering, Beijing, Peoples Republic of China.

Cheung, M. S., \& Chan, M. Y. T. (1978). Finite strip evaluation of effective flange width of bridge girders. Canadian Journal of Civil Engineering, 5(2), 174-185.

Cheung, M. S., Cheung, Y. K., \& Ghali, A. (1970). Analysis of slab and girder bridges by the finite strip method. Building Sciences, 5(2), 95-104.

Cheung, M. S., Li, W., \& Jaeger, L. G. (1990). Improved finite strip method for nonlinear analysis of long-span cable-stayed bridges. Canadian Journal of Civil Engineering, 17(1), 87-93.

Cheung, M. S., and Chan, M. Y. T., (1979). Program for Finite Strip Analysis. Public Works Canada, Ottawa, Canada.

Cheung, Y. L. (1985). Finite strip analysis of slab and box girder bridges. Hong Kong Engineer, 13(6), 31-41.

CSI. (2015). SAP2000 software, Integrated Finite Element Analysis and Design of Structures, version 17. Computers and Structures Inc Berkeley, California, USA.

DeFries-Skene, A., \& Scordelis, A. C. (1964). Direct stiffness solution for folded plates. ASCE Proceedings- Journal of the Structural Division, 90 (ST4, Part 1), 15-47.

El-Tawil, S. \& Okeil, A. M. (2002). Behaviour and design of composed box girder bridges. Final report submitted to Florida Department of Transportation, University of Central Florida, and Orlando, Florida. p. 90.

Evans, H. R., \& Rockey, K. C. (1975). Method of analysis for box girders based on the ordinary folded plate's theory. Bulletin of the International Association for Shell and Spatial Structures, 16(59), 3-13. 
Evans, H. R., \& Shanmugam, N. E. (1984). Simplified analysis for cellular structures. Journal of Structural Engineering, 110(3), 531-543.

Fam, A., \& Turkstra, C. (1975). A finite-element scheme for box bridge analysis. Computers and Structures, 5(2-3), 179-186.

Galuta, E. M., \& Cheung, M. S. (1995). Combined boundary element and finite-element analysis of composite box girder bridges. Computers and Structures, 57(3), 427-437.

Ghali, A., Cheung, M. S., Dilger, W. H., \& Chan, M. Y. T. (1981). Longitudinal stress over supports of concrete box girder bridges. Canadian Journal of Civil Engineering, 8(2), 155164.

Hambly, E. C., \& Pennells, E. (1975). Grillage analysis applied to cellular bridge decks. Structural Engineer, 53(7), 267-274.

Hanna, K. E. (2008). Behavior of Adjacent Precast Prestressed Concrete Box Girder Bridges. PhD diss. University of Nebraska, Lincoln, NE.

Hassan, W. (2005). Shear distribution in curved composite multiple-box girder bridges. M.Sc. thesis, Department of Civil Engineering, Ryerson University, Ontario, Canada

Hays Jr., C. O. (1984). Evaluating bridge overloads using the finite-element method. Official Proceedings - International Bridge Conference. 232-238. Pittsburgh, PA, USA.

Hrennikoff, A. (1941). Solution of problems of elasticity by framework method. American Society of Mechanical Engineers, Transactions, Journal of Applied Mechanics, 8(4), 169175.

Huckelbridge, A.A., H.H. El-Esnawi, and F. Moses, (1995). Shear Key Performance in Multibeam Box Girder Bridges. Journal of Performance of Constructed Facilities, Vol. 9, No. 4, pp. 271-285.

Huckelbridge A.A. and H.H. El-Esnawi, (1997). Evaluation of Improved Shear-Key Designs for Multi-Beam Box Girder Bridges. Final Report No. FHWA/OH/97-009, Department of Civil Engineering, Case Western Reserve University, Cleveland, Ohio.

Ishac, I. I., \& Graves Smith, T. R. (1985). Approximations for moments in box girders. Journal of Structural Engineering New York, N.Y., 111(11), 2333-2342.

Kaneko,Y., Connor, J. J., Triantafillou, T. c., and Leung, C. K. (1993a). Fracture mechanics approach for failure of concrete shear key 1: theory, J. Engrg. Mech., ASCE, 119(4), 681699. 
Kaneko, Y., Connor, J. J., Traiantafillou, T. c., and Leung, C. K. (1993b). Fracture mechanics approach for failure of concrete shear key. 11: verification. J. Engrg. Mech., ASCE, 119(4), 701-719.

Khan, W. (2010). Load distribution in adjacent precast "deck-free" concrete box girder bridges. M.A.Sc. Thesis, Faculty of Graduate Studies and Research, Ryerson University, Toronto, Ontario, Canada.

Kostem, C. N. (1984). Lateral Live Load Distribution in Prestressed Concrete Highway Bridges. Lehigh University, Pennsylvania, USA.

Lall, J., S. Alampalli, and E.F. DiCocco, (1998). Performance of Full Depth Shear Keys in Adjacent Prestressed Box Beam Bridges. PCI Journal, Vol. 43, No. 2, pp. 72-79.

Logan, D. A. (2002). A first course in the finite-element method (3rd ed.). Ontario, Canada: Ministry of Transportation Ontario, MTO.

Macioce, T.P., H.C. Rogers, R. Anderson, and D.C. Puzey, (2007). Prestressed Concrete Box Beam Bridges-Two DOTs' Experience. PCI National Concrete Bridge Conference, Proceedings, Phoenix, Ariz.

Miller, R., Shahrooz, B., Baseheart, T. M., Long, E., Jones, J., Knarr, R., \& Spraque, R. (1998). Testing of high-performance concrete single-span box girder. Transportation Research Record, (1624), 118-124.

Miller, R.A., G.M. Hlavacs, T. Long, and A. Greuel, (1999). FullScale Testing of Shear Keys for Adjacent Box Girder Bridges. PCI Journal, Vol. 44, No. 6, pp. 80-90.

Moffatt, K. R., \& Dowling, P. J. (1975). Shear lag in steel box girder bridges. Structural Engineer, 53(10), 439-448.

Mounir E., and Kassim M., (1997). Finite-Element Analysis of steel I-girder Highway Bridges, Journal of Bridge Engineering, Vol. 2, No. 3.

Newmark, N. M., Siess, C. P. and Beckham, R. R. (1948). Studies of Slab on Beam Highway Bridges. Part I: Test of Simple-Span Right I-Beam Bridges. Engrg. Experiment Station, University of Illinois, Urbana, III, Bulletin series No. 375.

OHBDC. (1991). Ontario Highway Bridge Design Code. Third edition, Ministry of Transportation Ontario, Downsview, Ontario, Canada.

Owens, G. W., Dowling, P. J., \& Hargreaves, A. C. (1982). Experimental behaviour of a composite bifurcated box girder bridge. International Conference on Short and Medium Span Bridges, 1, 357-374. 
Pre-Con Inc. (2004). Precast Prestressed Bridge Components - Technical Brochure. Brampton, Ontario, Canada.

Razaqpur, A. G., \& Li, H. (1997). Analysis of curved multicell box girder assemblages. Structural Engineering and Mechanics, 5(1), 33-49.

Razaqpur, A. G., \& Esfandiari, A. (2006). Redistribution of longitudinal moments in straight, continuous concrete slab - steel girder composite bridges. Canadian Journal of Civil Engineering, 33(4), 471-488.

Roll, F., \& Aneja, I. (1966). Model tests of box-beam highway bridges with cantilevered deck slabs. ASCE Transportation Engineering Conference.

Salmon, C.G., and Johnson, J.E. (1996). Steel Structures: Design and Behavior, Emphasizing Load and Resistance Factor Design, 4th Edition, HarperCollins College Publishers Inc., New York, N.Y

Samaan, M., Sennah, K., \& Kennedy, J. B. (2002). Distribution of wheel loads on continuous steel spread-box girder bridges. Journal of Bridge Engineering, 7(3), 175-183

Samaan, M., Kennedy, J. B., \& Sennah, K. (2007). Impact factors for curved continuous composite multiple-box girder bridges. Journal of Bridge Engineering, 12(1), 80-88.

Samaan, M., Sennah, K., \& Kennedy, J. B. (2003). Vibration of simply-supported multiple-box girder bridges. Canadian Society for Civil Engineering - 31st Annual Conference: 2003 Building our Civilization, 1266-1272. Moncton, NB, Canada.

Sargious, M. A. (1970). Principal stresses at the intermediate support of prestressed concrete continuous beams. Journal of American Concrete Institution, 67(10), 828-36

Sargious, M. A., Dilger, W. H., \& Hawk, H. (1979). Box girder bridge diaphragms with openings. ASCE Journal of the Structural Division, 105(1), 53-65.

Scordelis, A. C. (1984). Computer analysis of reinforced and prestressed concrete box girder bridges. Proceedings of the International Conference on Computer-Aided Analysis and Design of Concrete Structures, 997-1011. Split, Yugosl.

Scordelis, A. C., \& Gerasimenko, P. V. (1966). Strength of reinforced concrete folded plate models. American Society of Civil Engineers Proceedings, Journal of the Structural Division, 92(ST1), 351-363

Sennah, K. M., \& Kennedy, J. B. (1997). Free-vibration response of simply-supported composite concrete deck-steel multi-cell bridges.

Sennah, K. M., \& Kennedy, J. B. (2001). State-of-the-art in design of curved box girder bridges. Journal of Bridge Engineering, 6(3), 159-167. 
Shahawy, M, Huang, D. (2001). Analytical and Field Investigation of Lateral Load Distribution in Concrete Slab-on-Girder Bridges. ACI Structural Journal, 98 (4): 590-599.

Sisodiya, R. G., Cheung, Y. K., \& Ghali, A. (1972). New finite-elements with application to box girder bridges. Proceedings of the Institution of Civil Engineers (London).Part 1 - Design \& Construction, $\mathrm{x}$.

Sitaram, P., Swartz, S., \& Channakeshava, C. (1994). Nonlinear analysis of a reinforced concrete folded plate structure. Proceedings of the IASS-ASCE International Symposium, 857-866

Stanton, J. F., and Mattlock, A. H. (1986). Load distribution and connection design for precast stemmed multi-beam bridge superstructures. NCHRP Rep. 287, Transp. Res. Board, Washington, D.C.

Suksawang, N., \& Nassif, H. H. (2007). Development of live load distribution factor equation for girder bridges. Transportation Research Record, (2028), 9-18.

Tarhini, K. M., Mabsout, M., Harajli, M., \& Tayar, C. (1995). Finite-element modeling techniques of steel girder bridges. Proceedings of the 2nd Congress on Computing in Civil Engineering. Part 1 (of 2), 773-780. Atlanta, GA, USA

Vasseghi, A., Nateghi, F., \& Haghi, M. P. (2008). Effect of link slab on seismic response of two span straight and skew bridges. International Journal of Engineering, Transactions B: Applications, 21(3), 257-266.

Yao, L. (1990). Bridge Engineering, Edition, People's Transportation Publisher, P. R. China.

Young, D., and Huckelbridge, A. A. (1993). Effect of relative flexural/torsional characteristics upon load distribution on multi-beam prestressed concrete bridges. Final Rep., Ohio Dept. of Transp. /FHWA, Columbus, Ohio.

Yuki, T., Shimada, T., \& Hikami, Y. (1973). Studies on finite-element method for structural analysis-large deformation structure analysis program for suspension bridge and plane frame. Ishikawajima-Harima Giho/IHI Engineering Review, 6(2), 24-29.

Zhang, X., Sennah, K., \& Kennedy, J. B. (2003). Evaluation of impact factors for composite concrete-steel cellular straight bridges. Engineering Structures, 25(3), 313-321.

Zokaie, T. (2000). AASHTO-LRFD Live Load Distribution Specifications. ASCE Journal of Bridge Engineering, 5(2): 131-137.

Zokaie, T., Imbsen, R. A., and Osterkamp, T. A. (1991). Transportation Research Record, CA, 1290: 119-126. 